ESCUELA TÉCNICA SUPERIOR DE INGENIERÍA DE MONTES, FORESTAL Y DEL MEDIO NATURAL

\title{
ECOLOGÍA Y PERCEPCIÓN EN LA PLANIFICACIÓN Y EVALUACIÓN DEL PAISAJE. ÁMBITO TÉCNICO Y DE LA POBLACIÓN LOCAL
}

\section{TESIS DOCTORAL}

Alicia López Rodríguez

Ingeniera de Montes 

PROGRAMA DE DOCTORADO EN INVESTIGACIÓN FORESTAL AVANZADA

ESCUELA TÉCNICA SUPERIOR DE INGENIERÍA DE MONTES, FORESTAL Y DEL MEDIO NATURAL

\section{ECOLOGÍA Y PERCEPCIÓN EN LA PLANIFICACIÓN Y EVALUACIÓN DEL PAISAJE. ÁMBITO TÉCNICO Y DE LA POBLACIÓN LOCAL}

TESIS DOCTORAL

Alicia López Rodríguez

Ingeniera de Montes

DIRECTORES:

Rafael Escribano Bombín

Dr. en Ingeniería de Montes

Simon Bell

Dr. en Arquitectura del Paisaje 

Tribunal nombrado por el Magfco. y Excmo. Sr. Rector de la Universidad Politécnica de Madrid,

el día de de

Presidente

Vocal

Vocal

Vocal

Secretario

Suplente

Suplente

Realizado el acto de defensa y lectura de la Tesis

el día de de

EL PRESIDENTE

LOS VOCALES

EL SECRETARIO 



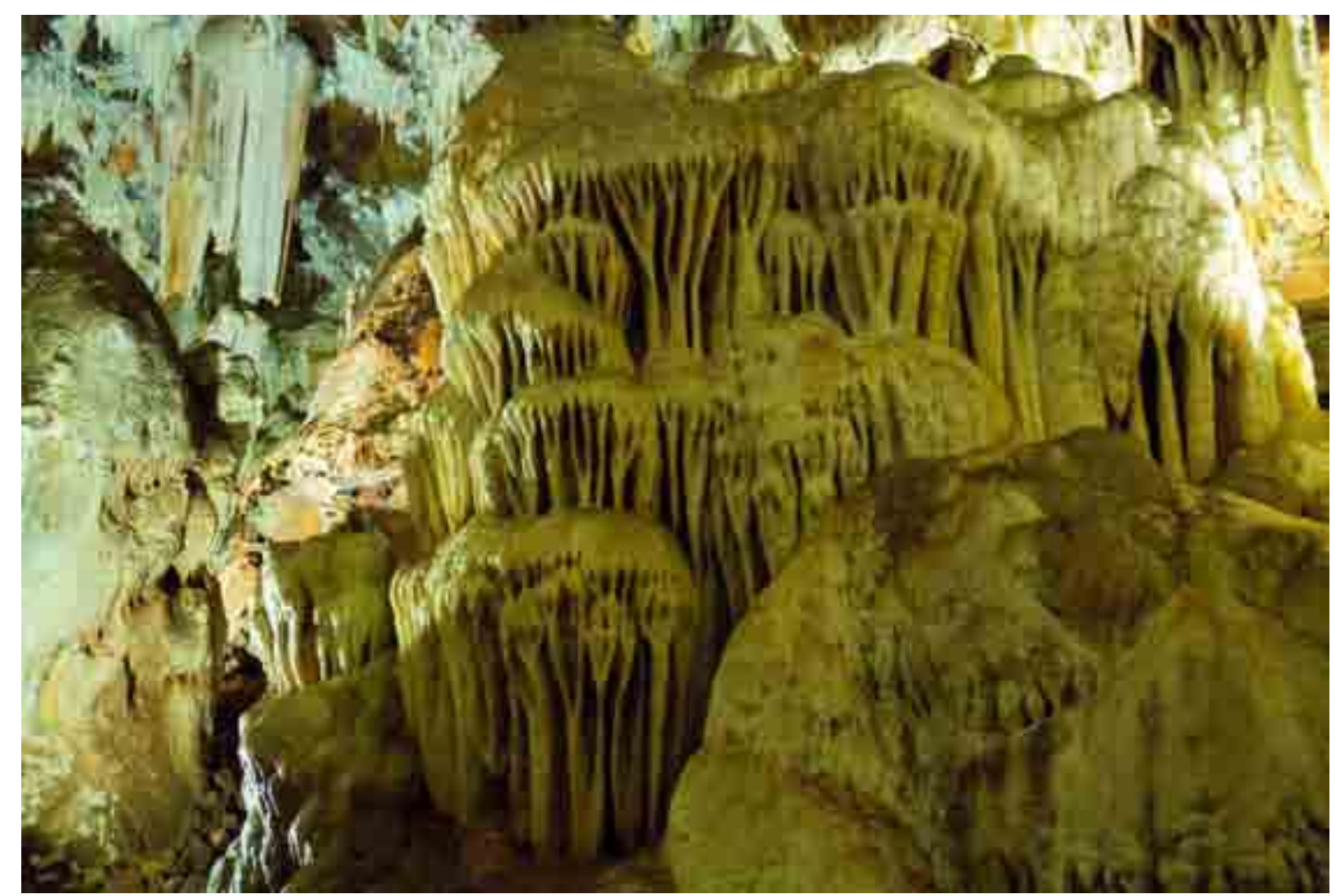

Cuevas del Águila, el "Paisaje kárstico que se esconde bajo tierra". Cerro de Romperropas o Cerro del Águila, Arenas de San Pedro (Ávila). Fotografía de Ruby Aveldaño

"Al pie de los cerros de las tortugas, más abajo de los olivares añosos cuajados de anémonas de color rojo vino, asfodelos y ciclamen rosado, donde las urracas hacían sus nidos y los arrendajos te sobresaltaban con su repentino grito bronco y desesperado, yacían las antiguas salinas venecianas, extendidas como un tablero de ajedrez. Cada cuadro, que a veces no rebasaba las dimensiones de una habitación pequeña, estaba ceñido por canales anchos de agua salobre, cenagosos y poco profundos. Su interior era una pequeña jungla de viñas, maíz, higueras, tomates de olor agrio como a chicle, sandías que parecían enormes huevos verdes de algún ave mítica, cerezos, ciruelos, albaricoqueros, nísperos, fresones y boniatos: la despensa de la isla".

Gerald Durrell sobre el paisaje mediterráneo de la isla de Corfú

- El jardín de los Dioses - 
El enfoque de esta tesis surgió de la reflexión que me produjeron dos momentos muy concretos. Un momento en la Sierra Cebollera riojana, cuando pensé si había ido allí por lo bonito o por lo ecológico. Enlacé mi pensamiento con la meditación sobre si ese hecho condicionaba en algún modo mi proceder técnico. El otro momento afloró en la Sierra Oeste madrileña, ante la visión de un cartel informativo sobre fauna de la zona, en la que aparecía el águila imperial ibérica, el sapo partero y hasta el lince ibérico (lo quemaron poco después). Me dio por pensar si llegaría a ver a esos animales en esa salida a campo, o en otras posteriores. Concluí que no era probable y me pregunté por el impacto de un cartel que muestra valores que no son notorios. Fueron esas experiencias las que me empujaron a hacer una búsqueda bibliográfica orientada, búsqueda que hasta entonces ostentaba un carácter convulsivo, casi histérico. En esos momentos estaba presente Nacho, y en los inmediatamente anteriores y posteriores, y en otros tantos en los que le abrumé con observaciones y especulaciones. Por esos y tantos otros momentos, le dedico mi agradecimiento de forma principal.

Se dice que la realización de una tesis es un proceso de aprendizaje, el coronamiento. Se dice que en el momento en que se culmina el proceso, el doctor está capacitado no sólo para descifrar las informaciones complejas, sino para ser autónomo en el aprendizaje, e incluso para poder transmitirlo de forma efectiva. La enseñanza derivada del proceso humano no se pone tan de relieve, no se evalúa en el momento de la defensa y no se coteja en el momento de la tasación de las publicaciones de impacto. Este es el espacio dentro de una tesis para poner de relieve la enseñanza que he extraído de los momentos del camino, aspecto que creo que es esencial en un doctorado, con un valor (personal) inmensamente mayor que el peso que adquiera lo publicado. Este es para mí el ámbito más críptico, cuyo aprovechamiento depende más de la calidad humana de las personas con las que te encuentras que de su calidad científica. Por eso quiero agradecer a muchos por el camino más que por el destino. A todas esas personas que tuvieron parte activa, pasiva, distraída o no intencionada en la consecución de este proceso. Yo dejo indicado en general y ya ellos que se den por aludidos y se encuadren en una de estas categorías. Al fin y al cabo, vale más que ellos se den por aludidos a que yo aluda a ellos. 
Quisiera poner de relieve, no obstante, la aportación de mi familia y amigos, esencial en todo momento. También, quiero reseñar que en ambos aspectos, el científico-técnico $y$, sobre todo, el humano, debo agradecer multitud de momentos a mis directores de tesis, Rafael Escribano y Simon Bell. También a la denominada cátedra de Planificación y Proyectos de Montes (Santi, Paz, Pedro y "becarios"), el mejor contexto para tener los mejores momentos. También destaco la aportación de todos los profesores que hicieron que en su momento surgiera mi interés, a los magníficos profesores de Ciencias Naturales de mi formación media y a los profesores de la carrera de Ingeniería de Montes, que consolidaron lo que ya intuía en la educación secundaria.

Igualmente quisiera agradecer a unas personas a las que no siempre se encuentra el momento para agradecer: a Carmen y Almudena, del equipo de secretaría de la Escuela de Montes, por haberme guiado en ese enmarañado y engorroso proceso de gestión administrativa de una tesis. La altura de los formularios necesarios para su presentación excedieron por mucho la de las conclusiones de la tesis, es evidente la necesidad del agradecimiento. 


\section{Resumen}

La compleja relación entre la dimensión ecológica del paisaje, su percepción y su interpretación estética tiene implicaciones significativas en el ámbito de la planificación y gestión paisajística. Dado que en la respuesta humana ante el paisaje media en parte la experiencia estética, la apariencia de los fenómenos ecológicos tiene efecto sobre sus actitudes. Este efecto puede derivar en decisiones que, en último término, tengan un impacto en las condiciones ecológicas y en la misma experiencia estética del paisaje. Sus repercusiones sugieren la oportunidad de considerar el condicionamiento de los factores perceptuales sobre las cualidades ecológicas de un paisaje.

Esta tesis recorre este camino y aborda la relación que se establece entre la dimensión ecológica del paisaje (dimensión funcional, parcialmente patente y en gran parte objetivable) y la dimensión relacionada con su percepción (dimensión afectiva, en gran parte subjetiva). El objetivo final es avanzar en la incorporación de la percepción del paisaje entre la información manejada en su gestión ecológica.

Para ello, en primer lugar se reúnen y relacionan las principales aproximaciones y conceptos que han surgido en torno a la relación entre ecología y percepción, enfocado fundamentalmente al caso del paisaje más natural. Esta síntesis permite dibujar el grado de desarrollo conceptual adquirido y poner de manifiesto el interés que la materia ha suscitado y suscita en la actualidad. Se realiza igualmente un diagnóstico del tratamiento que se ha otorgado a ambos aspectos en la práctica de la planificación, conservación y gestión del paisaje, que perfila la estética ecológica como el paradigma llamado a trascender y base de la propuesta metodológica.

La propuesta metodológica se compone de dos ámbitos complementarios:

Por un lado se desarrolla y valida una metodología de investigación empírica de la evaluación estética de la componente ecológica del paisaje. Dicha investigación se centra en dos de los grupos sociales con mayor relevancia en la configuración del paisaje, técnicos y población local, y es aplicada en dos contextos paisajísticos diferenciados, un paisaje de carácter forestal y fundamentalmente natural (cuenca alta del río Iregua Sierra Cebollera, La Rioja) y un paisaje agro-forestal con intervención humana más patente (Sierra Oeste, Madrid).

Por otro lado, el recorrido de la tesis culmina con la propuesta de una metodología de planificación del paisaje que pretende ampliar los factores perceptivos habitualmente considerados e incorporar la interpretación estética de la componente ecológica en la toma de decisiones. Sus premisas y resultados se contrastan en la aplicación al caso de estudio en la Sierra Oeste de Madrid. 


\section{Abstract}

The complex relationship between aesthetics and the ecological dimension of landscape may have important implications for landscape planning and management. Since human responses to the environment are shaped partially by aesthetic experiences, the appearance of ecological phenomena may influence people's attitudes and translate into decisions that can ultimately impact both the ecological function and the aesthetic experience of landscape. This relationship raises questions about the opportunity to consider the potential of perceptual factors to affect the ecological qualities of landscape.

This thesis approaches, discusses and evaluates the existing and potential relationship between these two aspects of landscape, the ecological dimension (functional, partially perceptible and mostly objective) and the dimension related to perception (affective, subjective). The ultimate objective is to contribute to the effective integration of the factors related to the perception of landscape among the variables that are normally handled in the ecological management of landscape.

For that purpose, an overview of the main approaches and concepts about the ecological-aesthetic interplay in landscape is elaborated. This synthesis of ideas allows to sharpen the conceptual development at the present and to make it clear the interest that emerged and still arises the issue. A diagnosis of the current landscape planning, conservation and management proposals is carried out, which reveals the so-called ecological aesthetic paradigm as a sound perspective and the foundation of the conceptual and methodological approach of the thesis.

The methodological development integrates two interrelated areas:

A methodology for the analysis of the aesthetic perceptions related to the ecological landscape dimension is proposed and validated. The research analyses the perceptions of two social groups that are of strategic interest because of their influence on the management of landscapes: local people and natural resource professionals. It was applied to two landscape contexts: a forested and mainly natural landscape (the upper valley of the River Iregua - Sierra Cebollera, in La Rioja), and an agro-forestry landscape with a more patent human intervention (Sierra Oeste, in Madrid,).

Finally, a methodology that expands the factors usually considered in landscape planning and incorporates the aesthetic and ecological component is proposed. The practical application of the methodology to the case of the agro-forestry landscape of Sierra Oeste (Madrid) allows to draw a critical evaluation of their assumptions and results. 


\section{ÍNDICE DE CONTENIDOS}

CAPÍTULO III.- CONCEPTOS Y ENFOQUES EN TORNO A LA

\section{III.2.- ENFOQUES PARA LA COMPRENSIÓN DE LA RELACIÓN}

III.2.1.- La percepción del paisaje desde la biología humana: paisaje como hábitat y sus implicaciones estéticas

III.2.2.- La percepción del paisaje y la cultura:

la construcción social de lo natural

III.2.3.- La percepción del paisaje y su relación con la actuación:

de la percepción, a la valoración y la acción

III.2.4.- La percepción del paisaje desde la responsabilidad del profesional:

la sensibilidad, el conocimiento y las ideas preconcebidas

III.2.5.- El valor estético y su impacto sobre la sensibilización

y la conservación de los valores naturales

III.3.- LA APRECIACIÓN DE LO NATURAL EN EL PAISAJE:

EVOLUCIÓN HISTÓRICA Y ACTUALIDAD

III.3.1.- Los inicios de la estética moderna de lo natural

III.3.2.- Nuevas ideas estéticas sobre lo natural:

lo bello, lo sublime y lo pintoresco

III.3.3.- El ideal romántico de lo natural y la influencia de los escritos naturalistas en Norteamérica

III.3.4.- Nuevas perspectivas sobre lo natural tras la dominancia de la analítica del arte 45

III.3.5.- La actualidad sobre la apreciación de lo natural: corrientes cognitivistas, no cognitivistas y "estética ecológica" 
III.4.1.- Ampliación del alcance de la estética del paisaje natural: estética ecológica_ 48

III.4.2.- Aldo Leopold: el germen de la estética ecológica___ 50

III.4.3.- González Bernáldez: Ia dualidad criptosistema-fenosistema y el desciframiento del paisaje _____ 52

III.4.4.- Allen Carlson: la estética del medio natural a través de la experiencia, el conocimiento científico y la sensibilidad__ 59

III.4.5.- Paul Gobster: estrategia hacia una estética ecológica___ 64

III.4.6.- Joan Nassauer: la "Estética del Cuidado" y la "Sostenibilidad Cultural"__ 71

III.4.7.- Stephen Sheppard: Ios paisajes forestales productivos y

la estética de la "Administración visible" 75

\section{CAPÍTULO IV.- PRÁCTICA EN EL TRATAMIENTO CONJUNTO}

IV.1.- CONSIDERACIONES SOBRE LA RELACIÓN ENTRE LA DIMENSIÓN ECOLÓGICA Y VISUAL EN EL DESARROLLO DE LA PLANIFICACIÓN DEL PAISAJE

IV.1.1.- Los inicios de la conservación y gestión del paisaje: métodos de tratamiento del paisaje como recurso visual

IV.1.2.- El carácter del paisaje y los métodos descriptivos-valorativos 87

IV.1.3.- Marco conceptual actual en la planificación europea del paisaje 88

IV.1.4.- Consideraciones sobre el tratamiento de la dimensión ecológica y percibida en la planificación del paisaje en España 90

\section{IV.2.- ENCUADRE DE LOS MODELOS DE PLANIFICACIÓN DEL PAISAJE ATENDIENDO} A SU ENFOQUE EN EL TRATAMIENTO DE LA ECOLOGÍA Y LA ESTÉTICA 108

IV.2.1.- Valores duales, ecología y estética: la estética de lo natural o de lo ecológico como un fin en sí misma 108

IV.2.2.- Valores integrados, ecología estética: enfoques basados en el aprovechamiento del éxito común o el embellecimiento de la solución ecológica

IV.2.3.- Valores interdependientes, estética ecológica: la estética como medio de mejora de lo ecológico.

IV.3.- CONCLUSIONES DE CARA A LA PROPUESTAS METODOLÓGICA QUE SE PRESENTA 
CAPÍTULO V.- ANÁLISIS DE LA PERCEPCIÓN DE LA CALIDAD ECOLÓGICA Y ESTÉTICA DEL PAISAJE. CASO DE ESTUDIO DE LA PERCEPCIÓN POR PARTE DE TÉCNICOS Y POBLACIÓN LOCAL EN UN PAISAJE FORESTAL:

V.1.- INTRODUCCIÓN 130

V.2.- ÁREA DE ESTUDIO 134

V.3.- MATERIAL Y MÉTODOS 136

V.3.1.- Marco conceptual de análisis 136

V.3.2.- Método analítico

V.4.- RESULTADOS 141

V.4.1.- Parajes seleccionados y atributos físicos que determinaron la evaluación de la calidad del paisaje

V.4.2.- Actividades y la percepción del paisaje gestionado 148

V.5.- DISCUSIÓN 152

V.5.1.- Distinta interpretación de los significados y atributos del paisaje 152

V.5.2.- La percepción del cuidado como factor determinante de la evaluación del paisaje gestionado/intervenido 154

CAPÍTULO VI.- PROPUESTA METODOLÓGICA PARA UNA PLANIFICACIÓN DEL PAISAJE QUE INCORPORE LA INTERPRETACIÓN ESTÉTICA DE LA COMPONENTE ECOLÓGICA 
V.5.1.- Encuadre metodológico 185

V.5.2.- Evaluación del paisaje en términos visuales y de apreciación escénica 186

V.5.3.- Evaluación de la interpretación de los valores ecológico-estéticos del paisaje_ 188

VI.6.- IDENTIFICACIÓN DE ÁMBITOS DE ACTUACIÓN ECOLÓGICO-ESTÉTICA Y DELINEACIÓN DE ESTRATEGIAS DE ACTUACIÓN EN EL PAISAJE 192

CAPÍTULO VII.- APLICACIÓN A UN CASO DE ESTUDIO:

PLANIFICACIÓN ECOLÓGICO-ESTÉTICA DEL PAISAJE

EN LA SIERRA OESTE DE MADRID

VII.1.- LOCALIZACIÓN, ÁREA DE PLANIFICACIÓN Y UNIDADES DE PAISAJE

VII.2.- DESCRIPCIÓN GENERAL DEL PAISAJE 203

VII.3.- EVALUACIÓN DEL ÁMBITO ECOLÓGICO 211

VII.4.- EVALUACIÓN DEL ÁMBITO DE LA APRECIACIÓN ESTÉTICA 229

VII.4.1.-Evaluación del paisaje en términos visuales y de apreciación escénica 229 VII.4.2.-Evaluación de la interpretación de los valores ecológico-estéticos del paisaje_ 231

VII.5.- IDENTIFICACIÓN DE ÁMBITOS DE ACTUACIÓN ECOLÓGICO-ESTÉTICA Y DELINEACIÓN DE ESTRATEGIAS DE ACTUACIÓN EN EL PAISAJE 
ANEXOS

\section{Anexo I}

Artículo publicado en la revista Landscape Research

Materiales adicionales: términos y mapas

Materiales empleados en las entrevistas

\section{Anexo II}

Listado de especies de fauna presentes en el área de estudio Matriz de relaciones entre las variables caracterizadoras del medio y los requerimientos de las especies de aves y resultados del análisis clúster Esquema metodológico y resultados de la evaluación de la adecuación o idoneidad de hábitat para los grupos ecológicos

Resultados de asignación de sensibilidad a los grupos ecológicos 
Tabla 1. Relación entre componentes de la percepción del paisaje según la "Teoría del procesamiento de la Información" (Kaplan y Kaplan, 1982).

Tabla 2. Algunos elementos diferenciadores entre la estética escénica y ecológica extraídos de la literatura, relacionados con las características del individuo o del propio paisaje, con la forma de interacción hombre-paisaje o con el resultado o beneficios que se derivan de la experiencia (Gobster, 1996; p. 82). 66

Tabla 3. Comparativa de las bases y características de los enfoques de planificación del paisaje dominantes en España.

Tabla 4. Características básicas de los participantes de cada grupo.

Tabla 5. Síntesis de los tipos de paisaje y características seleccionadas y comentadas por los participantes en las entrevistas.

Tabla 6. Categorías de protección para especies de fauna definidas a distintas escalas. 183

Tabla 7. Características básicas de las (sub)unidades de paisaje objetos de estudio, según se encuentran definidas en Aramburu Maqua, Escribano Bombin, Ramos Gonzalo y Rubio Maroto (2003). 200

Tabla 8. Listado de variables del medio relevantes para el análisis ecológico.

Tabla 9. Grupos de mamíferos terrestres en el área de estudio: listado de especies asociadas, breve descripción del biotopo.

Tabla 10. Listado de variables caracterizadoras de la cobertura del suelo incluidas en el análisis.

Tabla 11. Grupos de aves en el área de estudio: listado de especies asociadas, breve descripción del medio utilizado.

Tabla 12. Características de los entrevistados.

Tabla 13. Tipos de paisaje seleccionados, características comentadas por los entrevistados y frecuencia de selección: categoría Alta Calidad Ecológica

Tabla 14. Tipos de paisaje seleccionados, características comentadas por los entrevistados y frecuencia de selección: categoría Alta Calidad Estética

Tabla 15. Tipos de paisaje seleccionados, características comentadas por los entrevistados y frecuencia de selección: categoría Baja Calidad Ecológica

Tabla 16. Tipos de paisaje seleccionados, características comentadas por los entrevistados y frecuencia de selección: categoría Baja Calidad Estética 


\section{Relación de figuras}

NOTA: Las imágenes contenidas han sido realizadas por la autora de la tesis excepto en los casos que se indique otra fuente.

Figura 1. Esquema general de la estructura de la tesis. 6

Figura 2. Clasificación del paisaje en función de la combinación/integración de naturaleza y cultura (adaptado de Zonneveld, 1995, p. 8).

Figura 3. Algunos autores han observado que en numerosas partes del mundo el patrón de los paisajes culturales tiende a configurarse según un mosaico de grupos de árboles y espacios abiertos herbáceos, a la manera de los ecosistemas naturales tipo sabana africana. [...] 20

Figura 4. Brownsea Island, Dorset, England. El desvío de la vista activa la curiosidad y estimula la anticipación / Parque Nacional de Jasper, Alberta, Canadá. Los árboles en la parte baja crean una poderosa impresión de refugio, mientras que los picos en el plano lejano son vistos desde un punto una vista de prospección dominante. Ejemplos extraídos de Appleton (1984). 21

Figura 5. Relación bidireccional entre naturaleza y cultura en el paisaje. 25

Figura 6. Monte Townsed [Mount Townsed], pintado en 1863. Eugène von Guerard (1811 - 1901). Óleo sobre lienzo. National Gallery of Australia. Dramática interpretación del paisaje del Monte Townsden, el segundo pico más alto de los Alpes australianos. Vista desde la cima norte del pico Kosciusko. En primer plano se observa unas insignificantes figuras tomando datos barométricos, el científico alemán George Neumayer y su equipo, al que el artista acompañó en su expedición para determinar la altitud de la montaña.

26

Figura 7. Las cascadas del Niágara en invierno [Niagara Falls in Winter], pintado en torno a 1848. Regis Francis Gignoux (1816 - 1882). "Nuestro ego nacional se alimenta tanto de la preservación como de la conquista del espacio salvaje." Nash (1969, p.70)

Figura 8. Esquema que presenta la esencia de la relación hombre-paisaje desde el punto de vista de la percepción y las reacciones afectivas. Las acciones humanas basadas en la percepción del paisaje pueden llegar a afectar a las características ecológicas a escalas que pueden no ser percibidas directa o inmediatamente dado que se producen fuera de la "esfera perceptible" (Gobster et al., 2007, p. 963).

Figura 9. La dimensión estética de las especies es frecuentemente utilizada con fines conservacionistas. 36

Figura 10. El grévol engolado (Bonasa umbellus) es un ave de la familia de los faisanes muy conocida en Norteamérica.

Figura 11. El águila calva americana (Haliaeetus leucocephalus), es el ave más icónica en Estados Unidos, símbolo nacional por su imagen majestuosa y por representar fortaleza y libertad. 38

Figura 12. Imagen del paraíso tras la creación reflejado en la obra "El Jardín de las Delicias" de El Bosco y prototipo de jardín medieval, con formas geométricas y cerradas, y con plantación de especies de profunda simbología religiosa, buscando su relación con el ideal descrito en la Biblia, el Jardín del Edén (extraída de la obra de Hill's "The Gardener's Labyrinth, de 1586). 39

Figura 13. En tiempos medievales la percepción de la naturaleza estaba definida por las ideas cristianas. La naturaleza se imbuía de una visión trascendental, no asociada a el placer de su contemplación sino interpretada a en términos simbólicos: el mundo natural se había creado a base de una serie de símbolos edificantes que asistían al camino hacia el paraíso. [... 
Figura 14. Vue depuis la Bänisegg vers le glacier inférieur de Grindelwald [Vista del Bänisegg hacia el glaciar inferior de Grindelwald], pintado en 1778. Caspar Wolf (1735-1783). Óleo sobre lienzo, Colección privada. El artista suizo Caspar Wolf fue uno de los primeros en descubrir las cimas menos exploradas de Los Alpes como objeto artístico y de admiración

Figura 15. The hay wain [El carro de heno], pintado en 1821. John Constable (1776 - 1837). Óleo sobre lienzo, National Gallery de Londres. El pintor inglés es uno de los grandes exponentes de la pintura de paisaje, en la que frecuentemente reflejó escenas de carácter pintoresco, en la que la labor campesina sencuentra en harmonía con la naturaleza y la atmósfera general es de paz y sosiego.

Figura 16. Mañana en las montañas [Morgen im Gebirge], pintado a partir de 1823.Caspar David Friedrich (1774 - 1840). Óleo sobre lienzo (Museo Hermitage, San Petesburgo). 42

Figura 17. Aldo Leopold oteando el paisaje del Rio Gavilán (Méjico) durante una salida de caza (1937). 50

Figura 18. En palabras de José Vicente de Lucio Valle "La gran inquietud de González Bernáldez fue la búsqueda de una sintesis entre la comprensión de los procesos ecológicos subyacentes al paisaje y el entendimiento de las claves que hacen los lugares valiosos para los individuos y la sociedad. [...] 52

Figura 19. Ejemplos de correspondencia entre vegetación y topografía. "Variación del matorral de dunas estabilizadas ('naves'). Las partes altas tienen 'monte blanco' xerofítico con jaguarzo y sabinas (resto del bosque terminal). Las partes bajas presentan el 'monte negro' con brezo (Erica scoparia). [...] 54

Figura 20. Escalas de percepción del paisaje, dibujo realizado por González Bernáldez en 1984. Extraído de Montes, C., Levassor, C., Cuenca, A., y Casado, S. (Eds.) (2002), p. 131. 55

Figura 21. Ejemplo de tendencias de elección o dimensiones independientes detectadas en el análisis factorial de preferencias por paisajes forestales (grupo de universitarios, El Pardo-Casa de Campo, Madrid). La pareja de imágenes materializa la dimensión o factor "vigor, biomasa, lujurianza (sic) de la vegetación" que opone las dos imágenes del par. Tiene que ver con reacciones características frente a la vegetación natural.

Figura 22. "Representación esquemática del paisaje ideal o canónico de los ganaderos tradicionales de la Sierra de Madrid (en el centro) junto con dos aspectos desviantes de la forma canónica: una por descuido y escasez de presión (arriba) y otra por exceso de aprovechamiento (abajo). [...] 58

Figura 23. Allen Carlson, profesor de la universidad de Alberta (Canadá) fue uno de los pioneros en el campo del tratamiento filosófico de la estética ambiental, con aportaciones esenciales en relación a la ecología estética._ 59

Figura 24. El hecho de que la ausencia de madera muerta haga que el paisaje sea más escénico y resulte preferido por el público no da respaldo a dicha preferencia y no justifica que haya de retirarse del monte. [...]

Figura 25. La actividad investigadora de Gobster gravita alrededor del modo de diseñar, planificar y gestionar los paisajes para mantener relaciones mutuamente beneficiosas entre la gente y los sistemas ecológicos.

Figura 26. Geyser "OLd Faithful" en el Parque Nacional de Yellowstone. Gobster, (2008) lo cita como ejemplo de proceso que revela la belleza de los fenómenos ambientales que de otras manera quedarían fuera de la esfera perceptible humana, y que ofrece signos para poder apreciar los paisajes ecológicamente relevantes que no muestran rasgos escénicos claros. 68

Figura 27. Ejemplo de tratamiento del paisaje con un posible efecto de "museificación" del medio natural: una pasarela de madera permite la visita a la Laguna Negra en Soria y abre la panorámica a la estampa idílica del paisaje de alta montaña. [...]

Figura 28. La investigación de Joan Nassauer ha estado desde el principio basada en la innovadora idea de la "Estética del Cuidado". 
Figura 29. Creación de un patrón muy marcado de campos cultivados, diseño en el que se combina el arte y la impresión de cuidado. Extraido de (Nassauer, 1995b).

Figura 30. Diferentes diseños de un paisaje agrícola destinado a un programa de conservación, concebidos para comunicar la Estética del Cuidado. [...]

Figura 31. Además del análisis de la percepción y la estética de la sostenibilidad, Sheppard ha trabajado muy activamente en el campo de las simulaciones visuales aplicadas a la evaluación y planificación del paisaje._ 75

Figura 32. Cartel colocado en una zona de cortas por razones sanitarias en el Parque Natural de Sierra Cebollera. El objetivo de advertencia al usuario para garantizar su seguridad puede tener el efecto secundario de presentar una actividad necesaria y beneficiosa como agresiva y peligrosa. 76

Figura 33. El aspecto del monte tras un aprovechamiento forestal frecuentemente transmite una sensación de intervención drástica, descuidada o poco sensible con las condiciones del lugar. En la foto, hayedo joven tras una corta de mejora de la masa en el Parque Natural de Sierra Cebollera (La Rioja).

Figura 34. La Institución Libre de Enseñanza, abanderada por Francisco Giner de los Ríos (1839-1915) inauguró el carácter cultural y pedagógico de las excursiones naturalistas. Para los institucionistas, el "contacto purificador de la Naturaleza" permitía educar no solo la inteligencia, sino además la sensibilidad y la imaginación; ayudaba a cultivar simultáneamente las capacidades intelectuales, éticas y estéticas de la persona (Ortega Cantero, 2015). 90

Figura 35. Escribía en 1915 Constancio Bernaldo de Quirós (1873-1959), discípulo de Giner y uno de los fundadores del Club de Alpinismo Peñalara: "Antes de 1908, la Pedriza de Manzanares estaba desconocida. Nadie había ido por allá de los contados excursionistas que componían los dos o tres grupos que nos precedieron, y el que más, conocía sus crestas lejanas vistas camino de Miraflores o de Navacerrada o bien desde la cumbre de La Maliciosa o de las Guarramas. [...] 91

Figura 36. Giner de los Ríos elevó, según palabras de Ortega Cantero "lo visible a la categoría de paisaje" e inauguró en España una nueva actitud hacia la naturaleza y el paisaje, en cuya caracterización también se reconocía al hombre. [...] 92

Figura 37. En 1922, Juan Carandell escribia: "Como en muchos otros órdenes, hubo un precursor en España. iY qué precursor! Velázquez. Él comenzó a ver (en cursiva originalmente) nuestro Guadarrama. iAh, si el gran artista hubiera podido pintar ante el Pirineo o cabe la Sierra Nevada...! [...] 93

Figura 38. Genaro Pérez Villaamil (1807-1854), es el máximo exponente de la pintura romántica de los paisajes españoles. Plasmaba vistas concretas de la realidad, pero con una tendencia al alargamiento y a la desproporción que buscan la idealización de las formas, dentro de ambientes fantaseados que acentúan la atmósfera vaporosa, de ensoñación y misterio, rasgos propios del arte romántico (Zárate Martín, 1992). _ 93

Figura 39. El pintor paisajista Martín Rico (1833-1908) fue discípulo de Villaamil, del que heredó el gusto romántico en los inicios de su pintura. En sus primeras obras se aprecia la concepción panorámica, el ambiente irreal o la composición realzada de la naturaleza propia del Romanticismo. [...] 94

Figura 40. El sucesor de Villaamil en la Cátedra de Paisaje de la Real Academia de San Fernando, Carlos de Haes (18261898), abandona la composición imaginativa y desarrolla el paisaje realista en España. Bajo la influencia del cientifismo positivista, los pintores representan paisajes tomados del natural y, preocupados por el conocimiento directo y profundo de la naturaleza se lanzan a plasmar en sus cuadros los lugares que descubren los naturalistas y que estudian los geólogos. [...] 
Figura 41. El paisaje artístico y literario forjado en la época postromántica influyó poderosamente en las primeras figuras que abogaron por la conservación de los paisajes en España, como Pedro Pidal y Bernaldo de Quirós, Marqués de Villaviciosa de Asturias (1870-1941), principal impulsor político de la constitución de los Parques Nacionales y muy influido por la experiencia estadounidense al respecto. [...].

Figura 42. La excelencia de la belleza de los paisajes fue el argumento de primera línea para la creación de la figura de Parque Nacional y el uso turístico uno de sus grandes objetivos pues, como se observa en la Ley de 7 de diciembre de 1916, de Parques Nacionales de España, el favorecer el acceso al espacio se cita como fin incluso por delante del de conservación de sus valores naturales. 96

Figura 43. Los primeros espacios declarados fueron representantes de paisajes montañosos y agrestes: el Parque Nacional de la Montaña de Covadonga (creado en julio de 1918 y posteriormente ampliado en 1995, fue renombrado como Parque Nacional de los Picos de Europa) y el Parque Nacional del Valle de Ordesa o del río Ara, (declarado en agosto de 1918 y ampliado en 1982, fue renombrado como Parque Nacional de Ordesa y Monte Perdido). En las fotos, dos vistas icónicas de los Lagos de Covadonga y el Tozal del Mallo.

Figura 44. Eduardo Hernández-Pacheco (1872-1965), geólogo, geógrafo, paleontólogo y prehistoriador, miembro de la Junta Central de Parques Nacionales, director de la sección de geología del Museo Nacional de Ciencias Naturales y catedrático de la por entonces denominada Universidad Central. [...]

Figura 45. Extractos de las Guías de los Sitios Naturales de Interés Nacional publicadas en 1933 por la Comisaría de Parques Nacionales y la Protección de la Naturaleza en España bajo la dirección de Hernández-Pacheco. [...] _ 98

Figura 46. Extracto del Decreto 485/1962. Los cotos escolares eran asociaciones de alumnos dirigidas por sus maestros que, mediante una actividad con fines educativos de carácter agrícola y forestal (en ciudades fueron más del tipo industrial o artístico), pretendian ser una fuente de recursos para las mutualidades escolares de previsión, institución estrechamente ligada. [...]

Figura 47. Extracto del Inventario Nacional de Paisajes Sobresalientes confeccionado en 1975. La relación de paisajes, trabajo preliminar, atendía a dos criterios: paisajes que no estuvieran ya específicamente protegidos y paisajes con calidad paisajística derivada de los caracteres del medio físico, de los rasgos físicos de la vegetación o de importancia cultural (usos agrarios) (Instituto Nacional para la Conservación de la Naturaleza, 1977). 100

Figura 48. La perspectiva de conservación de la naturaleza en 1975 ya comenzaba a contemplar con claridad otros valores naturales además de los ligados a la belleza y la dimensión patrimonial, si bien aún lo hace desde la protección selectiva de algunos espacios destacados. 101

Figura 49. Sólo con la lectura de los principios inspiradores contenidos en la Ley 4/89 se aprecia la consolidación de la idea de la belleza del paisaje como uno de tantos valores del medio natural a proteger.

Figura 50. Las definiciones primera (la Ley 4/89) y posterior (Ley 42/2007) de Paisaje Protegido pone de manifiesto la evolución que su concepción ha experimentado.

Figura 51. La figura de "Paisaje Protegido", que protege de forma directa los aspectos paisajísticos (la dimensión paisajistica se encuentra indirectamente contemplada en otras figuras e instrumentos de gestión y planificación), ha sido escasamente aplicada en España, a excepción de casos concretos como la Comunidad Autónoma canaria o la valenciana, sin cuya aportación el catálogo español de paisajes protegidos sería muy pobre. [...] 105

Figura 52. Representación de las posibles direcciones a tomar en la decisión de actuación sobre el paisaje según Steinitz (1990).

Figura 53. Esquema de la jerarquía que componen la "estética ecológica" propuesta por Thorne y Huang (1991). 116

Figura 54. Representación del tratamiento de los corredores ecológicos propuesta por Thorne y Huang (1991) en distintos contextos paisajísticos: matriz predominantemente natural o cultivada. 
Figura 55. Esquema general del proceso de análisis e intervención en el paisaje presentado por Bell y Apostol (2008).

Figura 56. Ejemplo de mapas resultado del proceso de diseño de un paisaje forestal presentado por Bell y Apostol (2008): las condiciones de futuro deseables desde el punto de vista ecológico, el análisis de los elementos presentes en el paisaje visto desde un punto de observación preferente, y el esquema de la estrategia de diseño.

Figura 57. Cartel ubicado en el Mariposa Grove of Giant Sequoias (Parque Nacional de Yosemite, Estados Unidos). En él se ilustran los efectos ecológicos de la supresión del fuego en el bosque de secuoyas y las condiciones alcanzadas tras la aplicación de un programa de restablecimiento del papel natural del fuego por medio de quemas controladas. En él se anima al visitante a descubrir en el entorno las evidencias de fuegos recientes y pasados.

Figura 58. La serie de imágenes contenida en esta página muestra las simulaciones visuales de distintas soluciones de restauración de la morfología de un paisaje rivereño suizo, con distintos niveles de integridad ecológica o naturalidad. [...] 124

Figura 59. Imágenes extraídas de la propuesta presentada por Kristina Hill en el concurso-exposición titulado "Diseño Eco-revelador: Naturaleza Construida/Naturaleza Revelada". El diseño eco-revelador ("eco-revelatory design") se enunció en la exposición como aquel que revela e interpreta los fenómenos ecológicos. La imagen muestra el plano de los paseos arbolados y torres en una antigua zona minera, que funcionan como áreas para descubrir los procesos de regeneración ecológica que se introdujeron en la restauración. [...] 125

Figura 60. Localización y límites del área de estudio.

Figura 61. Imágenes representativas del área de estudio.

Figura 62. Esquema del modelo de 3 componentes que forman los lugares" según la Teoría del Lugar de (Canter, 1977).

Figura 63. Esquema general de la metodología de planificación del paisaje que incorpora la estética ecológica. 161

Figura 64. Esquema general del procedimiento de definición de unidades de paisaje según la metodología expuesta en Aramburu y Escribano (2014).

Figura 65. Esquema general de la evaluación ecológica del paisaje basada en la importancia para la conservación de la fauna.

Figura 66. Metodología general de formación de Grupos ecológicos de especies de fauna

Figura 67. Criterios de elección del número de grupos en un análisis clúster. 176

Figura 68. Esquema general de la metodología de Modelización de Idoneidad de Hábitat (Habitat Suitability Model, HSM) para cada Grupo ecológico de especies de fauna.

Figura 69. Esquema de integración para la obtención del índice de importancia del paisaje para la conservación de la fauna salvaje en cada punto del territorio. 182

Figura 70. Esquema del los componentes del modelo para la determinación de la calidad visual del paisaje recogido en Aramburu y Escribano (Eds.) (2014).

Figura 71. Ficha de análisis de la relación entre los valores ecológico-estéticos y la importancia para la conservación. 
Figura 72. Localización y límites del área de análisis.

Figura 73. Vistas representativas del área de estudio.

Figura 74. Áreas protegidas en la zona de estudio. 210

Figura 75. Distribución de la malla 10×10km del Inventario Español de Especies Terrestres (IEET) con respecto a la zona de estudio.

Figura 75. Dendrograma resultado del análisis clúster para las aves y definición de grupos. 221

Figura 76. Cartografía de la Importancia del paisaje para la conservación de la fauna terrestre en cada parte del territorio. 227

Figura 77. Cartografía de la Importancia del paisaje para la conservación de la fauna terrestre referenciado en las unidades de paisaje.

Figura 78. Cartografía de la calidad del paisaje en las unidades del área de estudio. 230

Figura 79. Síntesis de la evaluación ecológico-estética derivada de las entrevistas para cada (Sub)Unidad de paisaje._ 265 



\title{
CAPÍTULO I INTRODUCCIÓN
}

"La percepción de la naturaleza por parte del hombre es algo que a media vista no parece cuestionable ni ofrecer dificultad; todo el mundo, en efecto, es capaz de percibir como naturales el roquedo o ciertas formas de vegetación, es decir algunos de sus aspectos o componentes más ostensibles, que se presentan ante nosotros como aislados y con entidad propia. Mucho menos general resulta, sin embargo, la percepción de otros aspectos, como procesos e interacciones, que no son tan patentes y sólo despiertan el interés y están al alcance de estudiosos y especialistas. Si, dando un paso más avanzásemos desde determinados aspectos singulares hasta el conjunto, encontraríamos en seguida otras muchas interrogaciones ligadas a las relaciones entre el hombre y la naturaleza, que de una u

otra manera no serían sino variantes o parcelas de una pregunta mayor: ¿cabe una comprensión global de la naturaleza, del grand tout, cuando le concedemos ese atributo de totalidad o, por el contrario, es la naturaleza demasiado compleja para que podamos entenderla?."

\author{
Ángel Ramos \\ ¿POR QUÉ LA CONSERVACIÓN DE LA NATURALEZA? \\ Discurso de ingreso en Real Academia de Ciencias Exactas, Físicas y \\ Naturales \\ 28 de abril de 1993
}




\section{CAPÍTULO \\ INTRODUCCIÓN}

Esta tesis se ocupa de la relación que se establece entre la dimensión ecológica del paisaje (dimensión funcional, parcialmente patente y en gran parte objetivable) y la dimensión relacionada con su percepción (dimensión afectiva, interpretativa y estética, fundamentalmente subjetiva). Esta es una materia indudablemente compleja, polifacética y vasta, lo que convierte la tarea de analizarla y sistematizarla en un trabajo amplio en términos de investigación y sin duda inabarcable a la escala de una tesis. Esta dificultad inherente no le resta sin embargo interés, pues son numerosos los autores y las evidencias que abogan y aconsejan tener en cuenta el fenómeno subjetivo de la percepción del paisaje entre la información habitualmente manejada en la gestión ecológica del paisaje.

Dada la extensión que puede adquirir el estudio de la relación entre ecología y percepción en el paisaje, el enfoque adoptado en esta tesis orienta sus esfuerzos a contribuir al esclarecimiento de dicha relación en 4 ámbitos:

\section{Ámbito teórico y de desarrollo conceptual}

En el Capítulo III se realiza un recorrido por las principales ideas y conceptos que han surgido en torno a la relación entre ecología y percepción en el paisaje, enfocado fundamentalmente al caso del paisaje más natural.

Existen numerosas perspectivas de aproximación a la materia y contribuciones a su interpretación, que sin embargo no se han reunido y sintetizado hasta ahora en un mismo tratado, hecho que ha resultado en una dispersión de aportaciones que dificulta su estudio. En el capítulo se realiza una reunión y síntesis de ideas que permite dibujar el grado de desarrollo conceptual adquirido y poner de manifiesto el interés que la materia ha suscitado y suscita en la 
actualidad. No menos importante es su utilidad para poder perfilar las necesidades de investigación y práctica, comprensión que resulta esencial para poder orientar los posteriores análisis de la tesis.

\section{Ámbito de análisis de experiencias de tratamiento de la componente estética y ecológica en la planificación del paisaje}

En el Capítulo IV se realiza un análisis del tratamiento que se ha otorgado a ambas dimensiones, ecología y percepción/estética, en la práctica de planificación, conservación y gestión del paisaje.

Así, se realiza un recorrido histórico a través del papel jugado por la percepción del valor natural y las características ecológicas en la conservación y planificación paisajística, y el nivel de integración que tiene el tratamiento de ambas dimensiones en las propuestas actuales, con especial interés en el caso español. Dicho recorrido concluye en el diagnóstico de la situación actual, que se compone de una clasificación general de los tipos de planificación del paisaje en función de la manera de enfocar la relación entre ecología y estética. La reflexión en torno a dichos enfoques conduce a una serie de conclusiones de cara a la investigación empírica y a la propuesta metodológica que se plantea en los siguientes capítulos.

\section{Ámbito de evaluación de la percepción: investigación sobre la percepción y la estética de la dimensión ecológica del paisaje}

El Capítulo $V$ recoge una propuesta metodológica de investigación cualitativa que permite analizar y entender el fenómeno de la interpretación estética de la componente ecológica, así como la interacción que se establece entre ambos valores.

La investigación empírica llevada a cabo se concentra en el modo en que dos de los grupos con mayor relevancia en la configuración del paisaje, técnicos y población local, perciben e interpretan las características ecológicas del paisaje y le dan significado estético. Para ello, se aplica al caso de estudio de la cuenca alta del río Iregua Sierra Cebollera (La Rioja), un paisaje montañoso de carácter forestal y natural. La indagación se realiza desde un enfoque cualitativo e interpretativo, que busca más que identificar los rasgos físicos que 
desencadenan las reacciones ante el paisaje, las causas que explican que el paisaje sea evaluado de una cierta manera.

La misma metodología se aplica en el capítulo siguiente, como parte de la construcción del modelo de planificación del paisaje. En este caso, el contexto corresponde a un paisaje de tipo agroforestal con una huella humana más patente (Sierra Oeste de Madrid). Al margen de su papel en el desarrollo metodológico de planificación del paisaje que propone la tesis, los resultados derivados resultan de gran interés para el ámbito de la investigación sobre la percepción y la estética de la dimensión ecológica del paisaje.

Ámbito de desarrollo metodológico de la planificación del paisaje: propuesta metodológica para incorporar la percepción ecológicoestética en la toma de decisiones

El recorrido de la tesis culmina con una propuesta de metodología de planificación del paisaje (Capítulo VI) que es aplicada a un caso de estudio (Capítulo VII). El Capítulo VI presenta el modelo de planificación del paisaje, que incorpora la propuesta metodológica de análisis de las percepciones ecológico-estéticas desarrollada y validada en el Capítulo V. De tal manera, dicha metodología de planificación ecológico-estética del paisaje amplían los factores perceptivos considerados y se incorpora la manera en la que el fenómeno social de la apreciación estética del paisaje puede afectar a su valoración en términos ecológicos y finalmente a sus condiciones y funcionamiento.

La aplicación a un caso de estudio se presenta en el Capítulo VII, en el que se pone en práctica la metodología propuesta en un paisaje de carácter agro-forestal (Sierra Oeste de Madrid).

A efectos de facilitar la comprensión de la organización y línea argumental de la tesis se presenta un esquema general de su estructura (Figura 1). 


\section{Capitulo III}

AMBITO TEORICO Y DE DESARROLLO CONCEPTUAL

Reunichy simtes is de las principales beas y coniceptos on

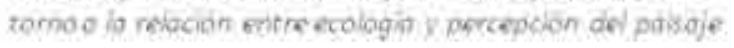

\section{Capitulo IV}

AMBITO DE ANALISIS DE EXPERIENCIAS DE TRATAMIENTO DE LA COMPONENIE ESTEITCA Y ECOLOGICA ENLA PLANIFICACIÓN DEL PAISAIE

Diagrostico del tratamiento que is ha otorgads a ambis dirnensiories, acologia y percepciónlestética en la practica de planificación conitrvacion y gestidri del puisaje.

Necesidades de investigacion y practica:colxclusiones de cara a la inestugación emipinca y a la propeir ta inetodologica que te plantea: ENFOOUEDE IA :ESTETICAETOLOGHA-

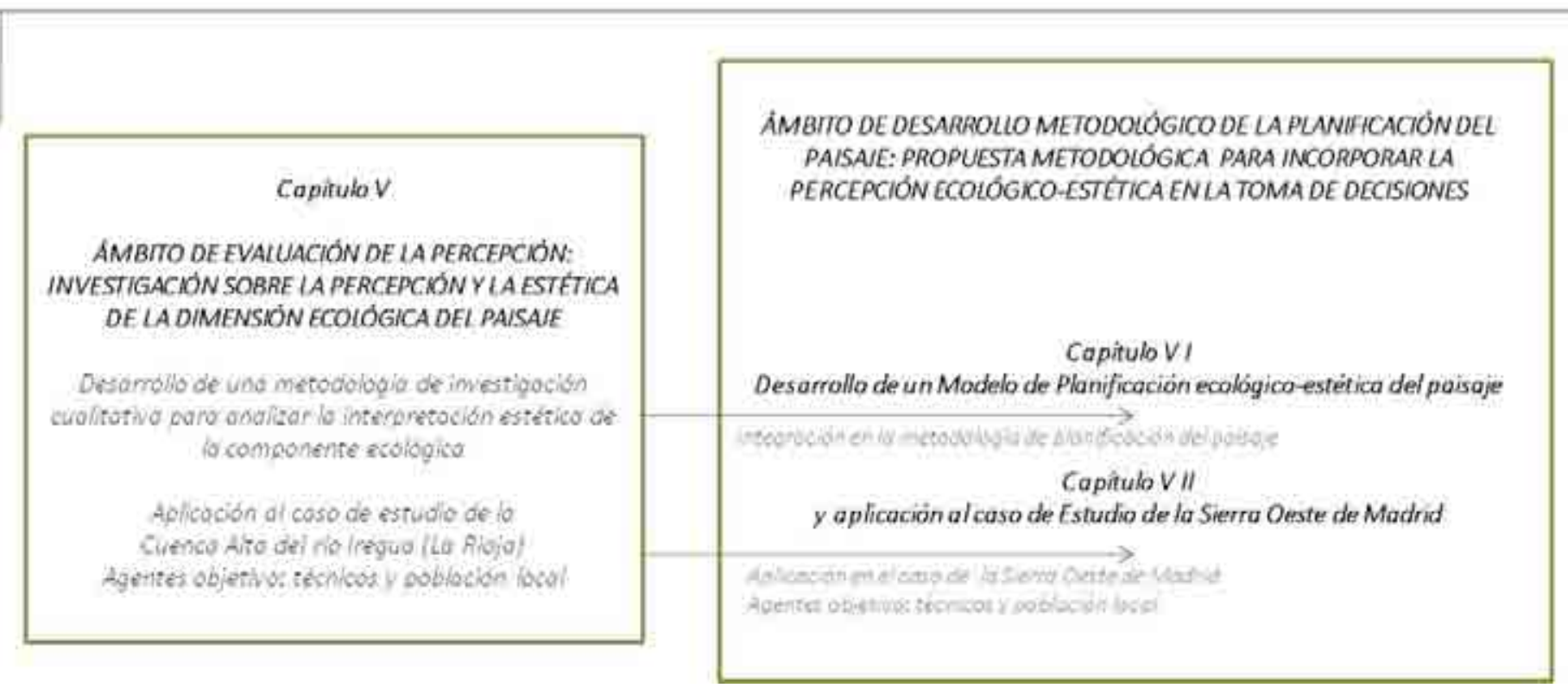

Figura 1. Esquema general de la estructura de la tesis. 
CAPÍTULO II

OBJETIVOS 


\section{CAPÍTULO OBJETIVOS}

- Reunir y sintetizar las principales ideas, conceptos y propuestas de actuación que han surgido en torno a la relación entre ecología y percepción en el paisaje más natural, para perfilar el grado de desarrollo conceptual y práctico adquirido.

- Desarrollar una metodología de análisis cualitativo de la interpretación estética y la valoración que se hace de la dimensión ecológica del paisaje, y verificar su validez.

- Ampliar el conocimiento existente sobre la evaluación del paisaje en clave ecológica y estética que hacen dos grupos sociales: los técnicos gestores y la población local.

- Desarrollar una metodología de planificación del paisaje que integre de manera efectiva el efecto sobre el paisaje de la interpretación estética de la componente ecológica. 


\section{CAPÍTULO III}

CONCEPTOS Y ENFOQUES EN

TORNO A LA RELACIÓN ENTRE

LO ECOLÓGICO Y LO

PERCIBIDO EN EL PAISAJE 
CAPÍTULO III.- CONCEPTOS Y ENFOQUES EN TORNO A LA

III.1.1.- Lo natural y el paisaje 13

III.1.2.- La percepción del medio, el paisaje y la estética 16

III.2.- ENFOQUES PARA LA COMPRENSIÓN DE LA RELACIÓN DE LO ECOLÓGICO Y LO PERCIBIDO EN EL PAISAJE

III.2.1.- La percepción del paisaje desde la biología humana: paisaje como hábitat y sus implicaciones estéticas

III.2.2.- La percepción del paisaje y la cultura:

la construcción social de lo natural

III.2.3.- La percepción del paisaje y su relación con la actuación: de la percepción, a la valoración y la acción

III.2.4.- La percepción del paisaje desde la responsabilidad del profesional: la sensibilidad, el conocimiento y las ideas preconcebidas 32

III.2.5.- El valor estético y su impacto sobre la sensibilización y la conservación de los valores naturales 35 


\section{CAPÍTULO}

\section{CONCEPTOS Y ENFOQUES EN TORNO A LA RELACIÓN ENTRE LO ECOLÓGICO Y LO PERCIBIDO EN EL PAISAJE}

\section{III.1. - CONCEPTOS PREVIOS}

La percepción y evaluación de la componente natural del paisaje o de paisajes con alto grado de naturalidad presenta una serie de particularidades que las singularizan y que se irán desgranando en los apartados que siguen. Como punto de partida, es necesario definir una serie de conceptos.

\section{III.1.1. Lo natural y el paisaje}

El término naturalidad, como veremos, se ha utilizado en numerosos estudios de análisis del paisaje y es objeto frecuente de reflexión estética. Es, sin embargo, un concepto difícil de definir: se suele tener una idea intuitiva de lo que es natural, pero surgen dificultades a la hora de precisar su esencia. En general, se acepta que lo natural es lo contrario a lo artificial, entendido como lo que proviene de la manifestación de la actividad humana. Así pues, lo natural, en sentido estricto, es aquello que se originó y se desarrolla sin intervención del hombre.

Esta distinción entre lo antrópico y lo natural resulta un constructo típico del mundo occidental, símbolo revelador de la separación de su medio. La diferenciación, sin embargo, no es observada en otras culturas más primarias, con una relación con el medio más estrecha y dependiente, en las que ni siquiera existe la palabra o el concepto naturaleza (Bourassa, 1991). Este alejamiento se ha producido en gran medida por el hecho de que éste ha construido un "hábitat" propio. 
Efectivamente, el hombre ha llegado a tener tal poder de control y modificación de su medio que se ha posicionado en un nivel superior a éste (López Lillo y Ramos, 2010). Hoy en día, el ser humano incluso tendría capacidad para dictaminar sobre cómo quiere evolucionar como especie en el futuro. Sin embargo, la causa esencial de la separación de lo humano y su medio natural no es el control sobre este, pues esta es fundamentalmente consecuencia de la dimensión que singulariza de una manera radical al hombre, el poder de raciocinio. La capacidad de usar la razón para conocer y juzgar, aunque producto de la evolución, aparta al ser humano de lo natural, pues le lleva a entender su papel en el sistema, así como decidir y actuar por sí mismo, es decir, de manera más o menos independiente a las reglas de lo natural. Dado que el hombre tiene consciencia de sí mismo y de sus creaciones, la diferenciación entre lo cultural y lo natural tiene un porqué.

Por otro lado, la noción estricta de lo natural (aquello que se origina y desarrolla sin influencia humana, lo contrario a lo artificial) lleva a no poder reconocer la existencia de la naturalidad en la actualidad. La misma civilización ha extinguido lo natural hace tiempo (Parsons, 2008). En el caso de un espacio tan históricamente intervenido como el europeo, los llamados sistemas naturales cuya conservación se pretende son en realidad ecosistemas naturales humanizados en mayor o menor grado, e incluso debidos a su acción.

Así pues, si no existiera lo natural en sentido estricto, el paisaje natural tampoco podría ser. "Paisaje natural" puede llegar a ser un término contradictorio, pues en la esencia del concepto paisaje aparece siempre lo natural junto con lo humano. Es el hombre el que hace el paisaje y sin él, sin su acción o su percepción, no existiría, estaríamos hablando de otra cosa. Sin embargo ¿no resulta demasiado rígida esta interpretación? Parsons (2008) expone que aunque no existen ya sitios que hayan escapado a la modificación humana, la negación del concepto de lo natural supone una reacción desmesurada a este hecho. El autor recoge la definición del filósofo inglés John Stuart Mill (1806 -1873) según la cual lo natural es aquello que ocurre al margen de la acción humana, o al margen de su intervención deliberada (Mill, 1874), algo que sin duda existe. Aunque muchos procesos se deben a nuestra presencia, otros muchos no (circulación de la atmósfera, tormentas, mareas, leyes

López Lillo, A. y Ramos, A. (2010). Valoración del paisaje natural. Madrid: ABADA.
Parsons, G. (2008). Aesthetics \& Nature. Londres, UK: Continuum.
Mill, J. S. (1874). Nature, the utility of religion, and Theism (2 2 Ed.). Londres: Longmans, Green, Reader and Dyer. 
Consejo de Europa (2000). Convenio Europeo del Paisaje (ETS No.176). Florencia: Consejo de

Europa.

Zonneveld, I. S. (1995). Land ecology: an introduction to landscape ecology as a base for land evaluation, land management and conservation. Amsterdam: SPB Academic Publishing. termodinámicas, crecimiento de las plantas, comportamientos instintivos de la fauna, adaptaciones a las condiciones del medio, etc.). Según esta concepción, existirían muchos elementos y fenómenos naturales $y$, consecuentemente, el paisaje natural existiría en los espacios en los que la carga natural sobrepasara ampliamente a la artificial. Además, abandonar la noción de lo natural sería para el autor desafortunado, pues nos privaría de poder usar un concepto extremadamente útil. ¿Cómo diferenciar entre la belleza de una montaña o un pájaro y la belleza de una catedral? El hecho de adjetivar la palabra paisaje puede llegar a ser orientador en torno a la característica particular tratada del paisaje.

Con estas premisas, surge la perspectiva de gradiente asociado a la tasa de intervención humana como el concepto fundamental para entender y referirse al paisaje natural. El paisaje es una combinación de naturaleza y cultura en la que existe todo el rango de situaciones intermedias. Dicha combinación es un aspecto fundamental de la definición del Convenio Europeo del Paisaje (Consejo de Europa, 2000). Las áreas quedan así definidas sin referir lo absoluto, sino con respecto a su posición en el gradiente naturaleza-cultura, desde un paisaje calificado como de máxima naturalidad a otro de máxima artificialidad (Figura 2). El paisaje natural denotaría un predominio de la composición de elementos y la acción de fenómenos no antrópicos, frente al paisaje artificial o humanizado, en el que predominaría la intervención humana.

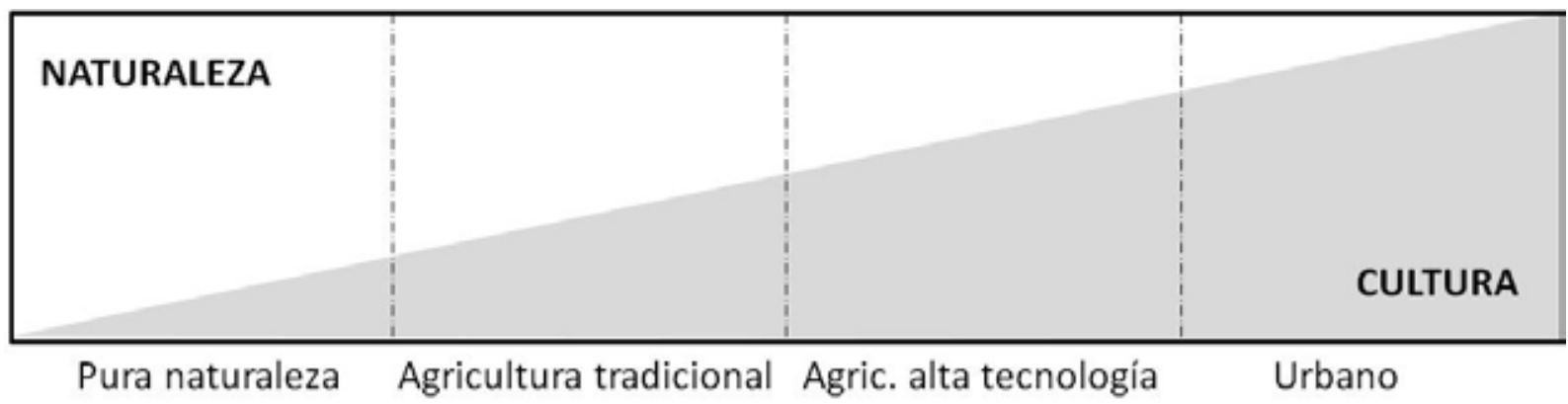

Figura 2. Clasificación del paisaje en función de la combinación/integración de naturaleza y cultura (adaptado de Zonneveld, 1995, p. 8).

En este punto, hay que detallar que el paisaje natural difiere del prístino y engloba al salvaje. El paisaje prístino, primigenio, no admite ningún tipo de influencia humana. Lo prístino solo existió antes que el 
hombre o en los espacios en los que éste no llegó a habitar (el paisaje prístino es el término verdaderamente contradictorio). El paisaje salvaje sería aquel que no está domesticado y se suele aplicar a terrenos agrestes y ásperos, que siguen su propio curso dominados por las fuerzas naturales, a pesar de los intentos del hombre por guiarlo. El paisaje de alta montaña, por ejemplo, no sería prístino, pues ha sido habitado y modificado por el hombre, pero sí podría ser Ilamado natural, pues está compuesto fundamentalmente por materia no producida por el hombre y el equilibrio de fuerzas que marca su desarrollo se inclina claramente hacia el lado de la naturaleza (está sujeto a condiciones climáticas extremas incontrolables para el hombre, a un proceso erosivo imparable, a fenómenos violentos difícilmente atenuables...). De hecho en muchos casos se trata del caso particular de un paisaje natural salvaje por el escaso control ejercido por el hombre. El paisaje de ciertas zonas protegidas por sus valores ecológicos podría calificarse de natural en la medida en que, aunque reciba una gestión esmerada, se compone de una materia y unos procesos que no han sido generados por el hombre y que difícilmente pueden ser recreados.

En conclusión, en lo natural el hombre interviene, pero no se debe a su presencia. Es por este motivo que en la presente tesis se refieren este tipo de paisajes como predominantemente naturales, paisajes más naturales, paisajes de carácter natural y también, conscientemente, de paisaje natural, aún a riesgo de incurrir en una inexactitud teórica, que no incoherencia.

\section{III.1.2. La percepción del medio, el paisaje y la estética}

El término estética fue definido en el siglo XVIII por el filósofo alemán Baumgarten para designar la rama de la filosofía que estudiaba lo que denominó cognición sensible ("the science of sensible cognition"). (citado en Bell, 2012). El término estética también se asocia al placer de la percepción. Por ejemplo, Tuan definió la experiencia estética como sobretodo un asunto del placer de los sentidos, "instruidos" en grado variable por la mente (Tuan, 1989). La estética tiene que ver pues tanto con el conocimiento que se adquiere a través de la percepción, como con el placer que se obtiene de este proceso.

Bell, S. (2012). Landscape. Pattern, Perception and Process (2a ed.). Nueva York, NY: Routledge.

Tuan, Y. F. (1989). Surface Phenomena and Aesthetic Experience. Annals of the Association of American Geographers, 79, 233-241. 
Carlson, A. (2009) The Development and Nature of Environmental Aesthetics. En A Carlson, Nature and Landscape: An Introduction to Environmenta Aesthetics (pp. 1-21). Nueva York, NY: Columbia University Press.

Gobster, P. H. (1995) Aldo Leopold's ecological esthetic: integrating esthetic and biodiversity values. Journal of Forestry, 6-10

Tuan, Y. F. (1974)

Topophilia: A Study of Environmental Perception Attitudes and Values. Nueva Jersey, NY: Prentice-Hall.

Bell, S. (2012) Landscape. Pattern, Perception and Process ( 2 e ed.). Nueva York, NY: Routledge.

Escribano, R. y Aramburu, M. P. (2000). El paisaje: diversidad de enfoques. Boletín de la Rea Sociedad Española de Historia Natural, 96, 89-97.

Aramburu, M. P. y Escribano, R.

(Eds.) (2014). Guía para la elaboración de estudios del medio físico. Contenido y metodología (4a ed.). Madrid: Fundación Conde del Valle de Salazar Ministerio de Agricultura, Alimentación y Medio Ambiente.

González Bernáldez, F. (1981). Ecología y Paisaje. Madrid: Blume.

Bourassa, S. C. (1991) The aesthetics of landscape. Londres: Belhaven Press.
Tradicionalmente, el placer estético se ha asimilado con la apreciación artística y la belleza, y por tanto se ha asociado fundamentalmente con el arte (Carlson, 2009; Gobster, 1995). Ahora bien, en el caso de la estética del medio, este significado dominante ha de ser matizado para recoger todo lo que significa la estética de algo que nos rodea y de lo que formamos parte, un bien común y construido por todos, con el cual nos relacionamos constantemente, al cual pertenecemos y en el cual podemos influir, hecho que lo diferencia radicalmente de la estética relacionada con el arte (Tuan, 1974). Así pues, si se trata de nuestra relación con el medio que nos rodea, resulta que la percepción se encuentra en la base de la forma con la que lo entendemos y que la manifestación externa del territorio es automáticamente objeto de interpretación. Todo lo que nos rodea muestra una dimensión estética pues tiene un efecto directo e inmediato en nuestra percepción sensorial, contribuye a nuestro conocimiento del medio y nos lleva a una reacción. La estética del medio se puede entender por tanto como lo percibido por nuestros sentidos y nuestras reacciones ante esas percepciones (Bell, 2012).

El término paisaje ha sido empleado a lo largo de la historia con muy diversos significados, pero ante todo y en todos los casos el paisaje es manifestación externa (Escribano y Aramburu, 2000). Como tal, el paisaje se vuelve fuente de información y placer, y se hace objeto de interpretación: el hombre establece su relación con el paisaje como receptor de información y lo analiza científicamente o lo experimenta emocionalmente, siempre condicionado por su capacidad física de percepción (González Bernáldez, 1981; Aramburu y Escribano (Eds.), 2014). Del acto de percibir e interpretar el paisaje surgen distintas sensaciones de placer o rechazo, de sentimiento de belleza o fealdad, o de coherencia o desorientación, que nos lleva a apreciarlo en mayor o menor medida. La calidad estética dependerá del signo e intensidad de estas reacciones. Tal y como denota Bourassa (1991), el paisaje como objeto estético sería diferente al paisaje en términos generales, y la estética del paisaje no es necesariamente lo mismo que la estética de otro objeto. Inicialmente, la cuestión de la estética del paisaje puede ser definida como lo que nos gusta o disgusta del paisaje y el paisaje puede ser reducido a una mera escena con propiedades artísticas, pero estas serían unas concepciones limitadas. 


\section{II.2. ENFOQUES PARA LA COMPRENSIÓN DE LA RELACIÓN DE LO ECOLÓGICO Y LO PERCIBIDO EN EL PAISAJE}

La percepción y la relación que el hombre establece con lo natural y su funcionamiento ecológico posee numerosas ramificaciones. En los siguientes apartados se tratan diversos aspectos de esta experiencia desde distintos puntos de vista o dimensiones: desde el sustrato biológico del ser humano, desde el sustrato cultural, desde la dualidad perceptor-actor del hombre ante el paisaje, desde el sustrato profesional y desde su utilidad para la sensibilización social y las acciones de conservación.

III.2.1. La percepción del paisaje desde la biología humana: paisaje como hábitat y sus implicaciones estéticas

En la década de los años 80 del siglo XX florecieron las llamadas teorías evolutivas o biológicas, que explicaban la relación estética del hombre con el paisaje basándose en la componente biológica del ser humano y considerando el paisaje como hábitat. Así, no sólo se trata de entender las reacciones del hombre ante el medio natural como objeto independiente a él, o a través de su intelecto o emociones, sino que estas teorías desvelan que parte de la apreciación estética del hombre tiene su base en el instinto, como un organismo más que busca el uso del medio en términos de supervivencia. Las teorías evolutivas o biológicas explican la existencia de un cierto sustrato común en las preferencias ante el paisaje que han de entenderse desde un punto de vista atávico y una escala temporal amplia, aquella que incorpora la evolución del ser humano como especie. Su base argumental se puede sintetizar en la siguiente frase:

"Las preferencias [ante el paisaje] tienen una función adaptativa, esto es, son un apoyo para la supervivencia del individuo" (Kaplan y Kaplan, 1982, p. 12). 
Wilson, E. O. (1993). Biophilia and the Conservation Ethic. En S. Kellert y E. O. Wilson (Eds.), The Biophilia Hypothesis (pp. 31-40). Washington, DC: Shearwater Books.

Bourassa, S. C. (1991) The aesthetics of landscape. Londres, UK: Belhaven Press.
Las especies animales son sensibles a la calidad de su hábitat por medio de un proceso de reconocimiento de su configuración y detección de los elementos y características clave que les provean de las mejores condiciones para desarrollar sus ciclos vitales. Este proceso, que en buena parte se lleva a cabo mediante la percepción sensorial del medio, siempre está presente en las decisiones de uso del entorno de todas las especies y su fin siempre es la optimización de recursos que maximice las posibilidades de supervivencia. Del mismo modo, el ser humano también realiza una evaluación del paisaje desde el punto de vista de las condiciones del hábitat, hoy en día de forma dominante en el ámbito de lo inconsciente, pero con resultados probados en el consciente. El hombre ha evolucionado durante varios cientos de miles de años en contacto directo e íntimo con la naturaleza, en total dependencia de esta. En comparación, el tiempo que se lleva viviendo en entornos más tecnológicos y con la sensación de control sobre el medio es mínimo. Este hecho ha dejado inscrito en su comportamiento una serie de rasgos con trascendencia en la relación estética con el medio.

"...la historia de la humanidad no comenzó hace ocho o diez mil años con la invención de la agricultura y los pueblos. Se inició hace cientos de miles de años con el origen del género Homo. Durante más del 99\% de su historia, el ser humano ha vivido en bandas de recolectores-cazadores en relación total e íntima con otros organismos. Durante este periodo de historia profunda, y aun anteriormente, en tiempos de los paleohomínidos, dependía de un conocimiento aprendido y preciso de los aspectos cruciales de la historia natural."

(Wilson, 1993; p. 32).

Las teorías evolutivas o biológicas de preferencias del paisaje defienden que parte de nuestras preferencias se encuentran determinadas por la evolución adaptativa común como especie y que el proceso perceptual y valorativo ante el paisaje se relaciona de esta manera con nuestros instintos y búsqueda de satisfacción de necesidades básicas. Son por tanto aproximaciones que enlazan con los factores biológicos del proceso mental implicado en la experiencia estética del paisaje (Bourassa, 1991), y por tanto con las experiencias que todos los hombres comparten de manera innata. Si el paisaje se interpreta en términos de cómo refleja su aptitud para la supervivencia humana, ha de reconocerse la existencia de un conjunto de características que son interpretadas como positivas o negativas por todos los humanos, aquellas que satisfacen las 
necesidades biológicas comunes y su progreso como especie. Igualmente, habría que reconocer que se tiende a preferir aquellos paisajes para los que estamos mejor adaptados.

A lo largo de los años se han desarrollado diversas aproximaciones que explican la existencia de ese sustrato interpretativo común. Estas pueden dividirse en teorías que tratan la configuración del paisaje y las que tratan su contenido (González Bernáldez, 1985).

\section{Teorías sobre la configuración del paisaje}

La "Teoría de la sabana" ("Savannah Theory") de Orians (1980; 1986) establece que nuestras preferencias por el hábitat se formaron en la sabana africana, ambiente en el que inicialmente el linaje humano desarrolló su habilidad para buscar y utilizar la información ambiental de manera sensata y con garantías, y en el que desplegó su capacidad de análisis del medio. Este punto de vista considera las respuestas humanas ante el paisaje desde una perspectiva de resolución de problemas adaptativos: nuestro cerebro es un órgano evolucionado y específicamente diseñado para analizar y responder adecuadamente a las oportunidades y limitaciones existentes en nuestro ambiente ancestral y, aún tras milenios de evolución y reorganización del medio, estas respuestas están vigentes (Orians, 1986). Esta teoría explicaría la tendencia observada a preferir paisajes semiabiertos, con una estructura similar a la sabana (Figura 3).

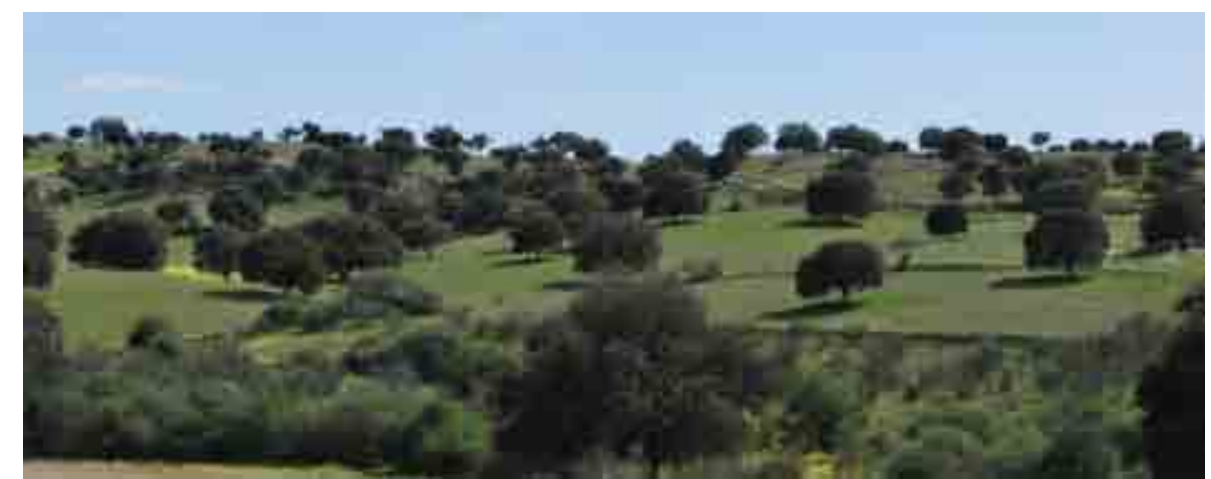

Orians, G. H. (1980).

Habitat selection: general theory and applications to human behavior. En J. S. Lockard (Ed.), The Evolution of Human Social Behaviour (pp. 44-66). Nueva York, NY: Elsevier.

Orians, G. H. (1986)

An Ecological and Evolutionary Approach to Landscape Aesthetics. En E. C. PenningRowsell y D. Lowenthal (Eds.), Landscape Meanings and Values (pp. 3-25). Londres, UK: Allen and Unwing.
Hunziker, M., Buchecker, M., y Hartig, T. (2007). Space and Place - Two aspects of the human-landscape relationship. En F. Kienast, O. Wildi y S. Ghosh (Eds.), A Changing World. Challenges for Landscape Research (pp. 47-62). Dordrecht: Springer.

Figura 3. Algunos autores han observado que en numerosas partes del mundo el patrón de los paisajes culturales tiende a configurarse según un mosaico de grupos de árboles y espacios abiertos herbáceos, a la manera de los ecosistemas naturales tipo sabana africana. La investigación empírica sobre preferencias ante el paisaje ha revelado que este tipo de paisaje suele estar entre los predilectos (Hunziker, Buchecker y Hartig, 2007). En la foto, dehesa de encinas en la Sierra Oeste de Madrid. 
Appleton, J. (1975)

The Experience of Landscape. Londres, UK: Wiley and Sons.

La "Teoría de la prospección y refugio" ("Prospect-Refuge Theory ") de Appleton (1975) considera las oportunidades para recabar información y la seguridad con la que se puede realizar la evaluación del medio como la clave en el entendimiento de la relación biológica humana con el entorno (especialmente en la exploración y evaluación de los paisajes que no son familiares al observador). Teniendo como base común nuestro pasado compartido como cazadores y recolectores, la experiencia estética humana se relaciona con los elementos que simbolizan las posiciones desde las cuales "ver sin ser vistos", es decir, el ser humano prefiere paisajes que le permiten mantenerse escondido al mismo tiempo que puede inspeccionar el entorno (Appleton, 1975) (Figura 4).
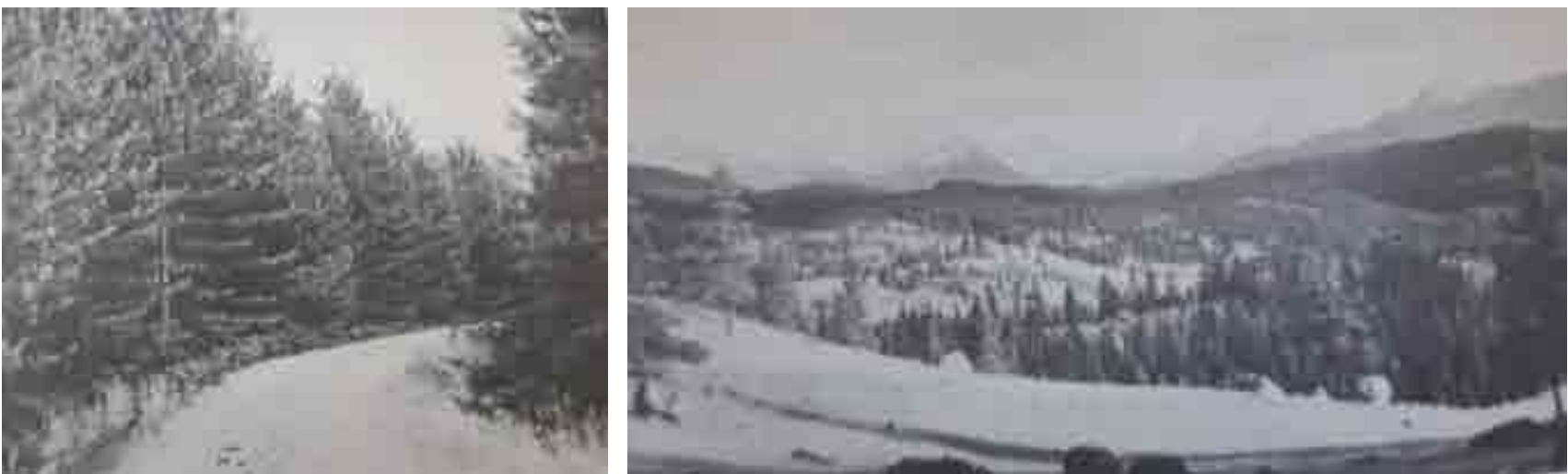

Appleton, J. (1984) Prospects and Refuges Re-Visited. Landscape Journal, 3(2), 91-103.

Kaplan, S. y Kaplan, R. (1982)

Cognition and environment Functioning in an Uncertain World Nueva York, NY: Praeger.
Figura 4. Brownsea Island, Dorset, England. El desvío de la vista activa la curiosidad y estimula la anticipación / Parque Nacional de Jasper, Alberta, Canadá. Los árboles en la parte baja crean una poderosa impresión de refugio, mientras que los picos en el plano lejano son vistos desde un punto una vista de prospección dominante. Ejemplos extraídos de Appleton (1984).
La "Teoría del procesamiento de la información" ("Information Processing Theory") (Kaplan y Kaplan, 1982) juzga al hombre como un organismo que gestiona información, proceso que, entre otras, también tienen una lectura biológica por su papel esencial en cuanto a supervivencia y adaptación. Así, se detectan dos fines fundamentales y omnipresentes en la percepción humana del entorno: la necesidad de dar sentido a lo que se percibe y la implicación en el mismo entorno. Ambas necesidades son analizadas de dos maneras diferentes: por un lado estaría la percepción de la escena (visual array), el patrón bidimensional, análogo a la percepción de una fotografía; por otro lado se produciría la percepción tridimensional del patrón, o el espacio que se despliega y en el cual el observador se desenvuelve. Por tanto, el que observa no sólo recibe las cualidades 
bidimensionales de una escena, sino que también, y de manera automática, se adivina a sí mismo inserto en la misma y pronostica su funcionamiento dentro de ella. El espacio de percepción y acción están así íntima e ineludiblemente ligados, y las propiedades en cuanto a coherencia, legibilidad, diversidad y misterio del paisaje tienen un efecto directo en el observador (Tabla 1).

Tabla 1. Relación entre componentes de la percepción del paisaje según la "Teoría del procesamiento de la Información" (Kaplan y Kaplan, 1982).

\begin{tabular}{|l|c|c|}
\hline & Entendimiento & Exploración \\
\hline Esfuerzo de percepción de los aspectos inmediatos de una escena & COHERENCIA & $\begin{array}{c}\text { DIVERSIDAD O } \\
\text { COMPLEJIDAD }\end{array}$ \\
\hline Esfuerzo de percepción en los aspectos futuros de una escena & LEGIBILIDAD & MISTERIO \\
\hline
\end{tabular}

\section{Teorías sobre contenido del paisaje}

Edward O. Wilson, entomólogo estadounidense, planteó en los años 80 la "Hipótesis de la Biofilia" ("Biophilia Hypothesis"), que asevera que existe una necesidad inherente a la esencia humana de asociarse con la materia viva y los procesos biológicos (Wilson, 1984). Según ésta, los humanos evolucionaron como seres totalmente insertados en la naturaleza, y como tales, todavía tienen inscrita en su genotipo esa afinidad con el medio natural. Dicha afinidad no sólo se explica en términos de dependencia de lo natural para la supervivencia, sino que el contacto con lo vivo ha tenido y tiene una influencia en el desarrollo emocional, cognitivo, estético y espiritual del ser humano (Kellert, 1993).

La "Hipótesis de la Biofilia" explica la significación cultural del contacto con lo natural a través de lo que denomina la evolución biocultural o coevolución gen-cultura. Es decir, ciertos valores y conductas se deben a una evolución en la que lo cultural se elaboró bajo la influencia de predisposiciones a aprender adquiridas por procesos naturales, por medio de la selección natural de genes responsables de estas predisposiciones. De manera más sencilla, un cierto genotipo presenta un comportamiento más probable, esta conducta más frecuente le lleva a un mayor éxito de supervivencia y reproducción, el genotipo consecuentemente se propaga dentro de la población y así la conducta se generaliza en la especie (Lumsden y Wilson, 1981).
Wilson, E. O. (1984).

Biophilia: The human bond with other species. Cambridge, MA: Harvard University Press.

Kellert, S. R. (1993). The Biological Basis for Human Values of Nature. En S.R. Kellert y E.D. Wilson (Eds.), The biophilia hypothesis (pp. 42-69). Washington, DC: Island Press.

Lumsden, C. J. y Wilson, E. O. (1981).Genes, mind, and culture. Cambridge, MA: Harvard University Press. 
Estas conductas se convirtieron en ventajas evolutivas que se tradujeron en actitudes y valores hacia lo natural. Cuando los humanos se apartaron del medio natural, no sustituyeron las reglas de aprendizaje basadas en la "biofilia" por las de adaptación a los artefactos, sino que éstas persisten, atrofiadas y manifestándose de manera irregular.

Kellert, S. R. (1993). The Biological Basis for Human Values of Nature. En S.R. Kellert y E.D. Wilson (Eds.), The biophilia hypothesis (pp. 42-69) Washington, DC: Island Press.
Kellert (1993) formalizó las diferentes expresiones de la afinidad del humano por lo natural como tipos de visiones-actitudes ante la naturaleza y explicó su base evolutiva. Estas distintas visiones se basan en los resultados de sus investigaciones empíricas sobre las percepciones del público. Estas son: utilitaria, naturalista, científicoecologista, estética, simbólica, humanista, moralista, dominadora y negativista. Aunque todas son interesantes para explicar la base evolutiva del fenómeno de relación del hombre con el paisaje natural, nos centraremos en las más directamente asociadas a la relación entre la percepción del paisaje y su componente ecológica: las visiones-actitudes estética, naturalista y científico-ecologista.

Respecto a la belleza de lo físico de la naturaleza, Kellert reconoce que sus conexiones con lo biológico no son evidentes, aunque resulta uno de los más poderoso atractivos para el humano. Como se ha apuntado anteriormente, la diferente respuesta estética ante diversos paisajes y especies animales puede responder a un reconocimiento intuitivo de su potencial para ofrecer comida y seguridad, de su compatibilidad con la vida. Por otro lado, el valor adaptativo de una sensibilidad estética puede relacionarse con los sentimientos derivados de tranquilidad o de paz mental y sus consecuencias en el bienestar psicológico.

La visión naturalista se relaciona con la satisfacción que se obtiene del contacto directo con la naturaleza y de la fascinación ante su diversidad y complejidad. Esta satisfacción en la fascinación por lo oculto lleva al ser humano a querer conocer más sobre lo ignorado de la naturaleza y esa búsqueda lleva a más misterios, que a su vez empujan a una mayor curiosidad. El placer por indagar e inspeccionar se tradujo en un mejor conocimiento del medio, lo que llevó a ciertos individuos a una posición ventajosa. 
La perspectiva científico-ecologista resulta fascinante igualmente, pero se basa en mecanismos más sistemáticos y racionales, y características menos evidentes: el reconocimiento intuitivo del observador atento de la interconexión de procesos y estructura, la indagación empírica ordenada y sistemática, el análisis detallado, resultó en un mejor aprovechamiento de las complejidades del medio.

Muchas de las observaciones indicadas han sido corroboradas por la investigación empírica. González Bernáldez hizo un excelente repaso del estado de conocimiento en el momento basado en los resultados obtenidos por numerosos estudios de psicología de la percepción y en sus propias investigaciones (González Bernáldez, 1985).

González Bernáldez, F. (1985). Invitación a la ecología humana. La adaptación afectiva al entorno. Madrid: Tecnos S. A.

Las teorías evolutivas o del hábitat, por ejemplo, explicarían al menos parte de las preferencias ante los paisajes semiabiertos en comparación con los paisajes completamente abiertos o cerrados, quizá porque ofrezcan una combinación óptima entre coherencia y misterio o por proveer de refugios desde los cuales explorar el paisaje en condiciones de seguridad. Por otra parte, la presencia de vegetación o agua superficial, elementos esenciales para cubrir las necesidades biológicas de los organismos, se consideran como esenciales en la predilección experimentada por determinados paisajes naturales.

Esto no quiere decir que la experiencia del paisaje se explique enteramente desde la perspectiva biológica, dado que el factor de aprendizaje modifica esta experiencia, en algunos contextos de manera determinante. Pero se evidencia que existe una interrelación de las fuerzas innatas y aprendidas en la experiencia del paisaje y que las preferencias se forman sobre la base evolutiva y genética, sobre la que actúan las influencias culturales y personales. 


\section{III.2.2. La percepción del paisaje y la cultura: la construcción social de lo natural}

A la hora de analizar cómo el componente natural del paisaje se relaciona con la cultura se ha de tratar tanto la manera en que la cultura determina la interpretación del paisaje natural, como la manera en la que el paisaje natural impacta y modela ciertos aspectos sociales y culturales (Figura 5).

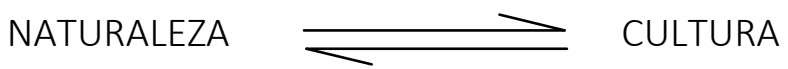

Figura 5. Relación bidireccional entre naturaleza y cultura en el paisaje.

Aramburu, M. P. y Escribano, R.

(Eds.) (2014). Guía para la elaboración de estudios del medio físico. Contenido y metodología

(4a ed.). Madrid: Fundación

Conde del Valle de Salazar;

Ministerio de Agricultura, Alimentación y Medio Ambiente.

Gobster, P. H. (1994). The aesthetic experience of sustainable forest ecosystems. En W. W. Covington y L. F. De Bano (Eds.), Sustainable Ecological Systems: Implementing an Ecological Approach to Land Management (pp. 246-255) (General Technical Report RM247). Fort Collins, CO: USDA Forest Service, Rocky Mountain Forest and Range Experiment Station

Rees, R. (1975). The Scenery Cult: Changing Landscape Tastes over Three Centuries. Landscape, 19(3), 39-47.

\section{Construcción socio-cultural de lo natural}

El hombre no es neutral ante lo que mira, en realidad ve desde la memoria personal y colectiva (Aramburu y Escribano (Eds.), 2014). Por tanto, la interpretación de lo visto en el paisaje más natural se lleva a cabo siempre sobre la base de unos antecedentes sociales e individuales, de un contexto creado por la historia y la cultura, además de un desarrollo biológico común como se ha visto. De tal manera, nuestras concepciones en torno a lo natural se inscriben en un ámbito "socio-construccionista", es decir, la cultura aporta inevitablemente sentidos a lo natural.

Esta interpretación de lo natural desde lo cultural resulta ser sustancial a la hora de tratar la planificación y gestión del paisaje, pues define en gran medida la naturaleza de la experiencia estética que establecemos en los paisajes naturales. A este respecto, Gobster (1994), recogiendo el análisis de Rees (1975), observa que en las preferencias actuales por el paisaje más natural se esconden condicionamientos derivados de la pintura, literatura y teoría estética de los siglos XVII y XVIII (ver Apartados III.4.5 y IV.1.4). Así, la naturaleza reflejada en aquella época en los paisajes pintados, descritos en la literatura y por los viajeros, y diseñado en los jardines, hizo surgir una estética que gustaba de las vistas panorámicas de 
paisajes montañosos llenos de dramatismo y rasgos monumentales, o de paisajes pastorales ordenados pero exuberantes que mostraban una perfecta armonía entre hombre y naturaleza, que adaptaba las características y composición de la naturaleza para realzar su belleza bajo el signo de cualidades formales (equilibrio, proporción, simetría, unidad, fuerte impresión, variedad en la línea, color, forma, textura...). La naturaleza mostrada era estilizada y el paisaje natural lo era en realidad sólo en su carácter (Figura 6). Este hecho derivó en un gusto por la "estética escénica" como modo dominante de apreciación del paisaje, centrada en una naturaleza idealizada, en sus rasgos espectaculares y en una percepción preferentemente visual y estática que tolera con dificultad los cambios en aquello que contempla. Este tipo de estética de lo natural se ha ido perpetuando de forma larvada en la cultura occidental y formó la base a partir de la cual se desarrollaron inicialmente los programas de gestión del recurso visual paisajístico en Norteamérica (ver Apartado IV.1.1.).

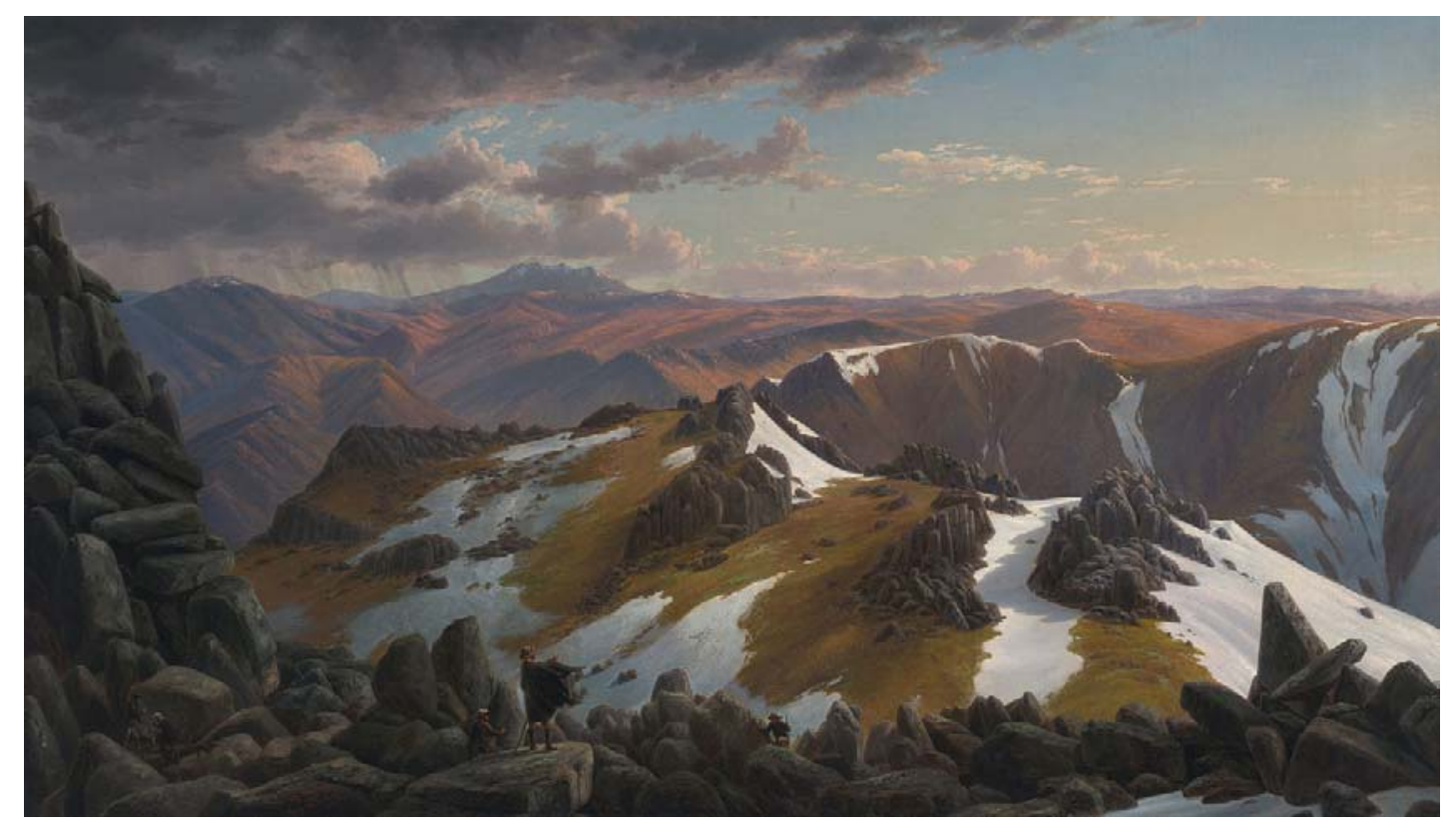

Figura 6. Monte Townsed [Mount Townsed], pintado en 1863.

Eugène von Guerard (1811 - 1901)

Óleo sobre lienzo. National Gallery of Australia.

Dramática interpretación del paisaje del Monte Townsden, el segundo pico más alto de los Alpes australianos. Vista desde la cima norte del pico Kosciusko. En primer plano se observa unas insignificantes figuras tomando datos barométricos, el científico alemán George Neumayer y su equipo, al que el artista acompañó en su expedición para determinar la altitud de la montaña. 
Williams, D. R. (2000). Personal and Social Meanings of Wilderness: Constructing and Contesting Places in a Global Village. En A. E. Watson, G. H. Aplet y J. C. Hendee (Eds.),

Personal, societal, and ecological values of wilderness:

Sixth World Wilderness

Congress proceedings on research, management, and allocation, Volume II (pp. 77-

82). Ogden, UT: U.S.

Department of Agriculture, Forest Service, Rocky Mountain Research Station

Williams, D. R. y Kaltellbom, B. P. (1999). Leisure places and modernity: The use and meaning of recreational cottages in Norway and the USA. En D. Crouch (Ed.), Leisure practices and geographic knowledge (pp. 214-230).

Londres: Routledge.

Nash, R. (1969).

The cultural significance of the American wilderness. En J. McCloskey M. y J.P. Gilligan (Eds.), Wilderness and the quality of life (pp. 66-73). San Francisco, CA: Sierra Club.

\section{Incidencia de los paisajes naturales en lo cultural}

Williams (2000) establece tres niveles en los cuales lo natural y lo salvaje contribuyen a la formación de la identidad del ser humano: nivel individual, nivel de grupo cultural y nivel de especie.

Un primer nivel correspondería a la identidad individual. Sobre todo en el mundo occidental, el contacto con la naturaleza ofrece la oportunidad de la "individualización", de la afirmación del "ser personal". El espacio natural, desvinculado en mayor o menor medida de la artificialidad humana, es un ámbito en el que cada uno puede forjar libremente su personalidad, su singularidad y su propio patrón de satisfacción, de afirmar creencias esenciales sobre cómo se es como individuo y cómo se ha de comportar en consecuencia.

Un segundo nivel concordaría con el "ser colectivo" o la identidad como grupo cultural. Lo natural puede definir en buena medida la identidad nacional o de una cultura concreta. Williams expone el ejemplo de la importancia de los espacios salvajes como símbolo del legado cultural en América del Norte y la aportación de la conquista y preservación de los espacios salvajes en su ideología (Figura 7). También expone la manera en la que el contacto con el mundo natural forma parte importante de la cultura escandinava (Williams y Kaltenborn, 1999).

Figura 7. Las cascadas del Niágara en invierno [Niagara Falls in Winter], pintado en torno a 1848 Regis Francis Gignoux (1816 - 1882)

"Nuestro ego nacional se alimenta tanto de la preservación como de la conquista del espacio salvaje." Nash (1969, p.70).

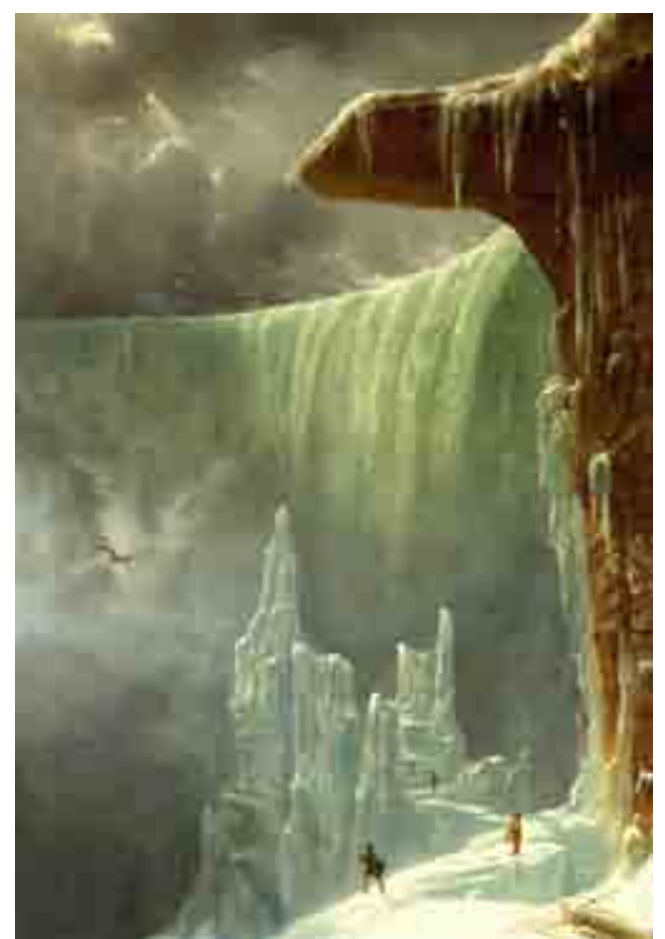


El tercer nivel se relaciona con la aportación del contacto con lo natural para el hombre como especie. Lo natural ofrece al hombre la oportunidad de reafirmarse como "ser biológico", determinar su lugar en el sistema ecológico del mundo, de descubrir y ratificar qué es y qué papel tiene como especie.

De tal manera, vemos las vías a través de las cuales no sólo lo natural se ve desde lo cultural, sino cómo lo cultural es visto desde el impacto que tiene lo natural sobre él.

\section{III.2.3. La percepción del paisaje y su relación con la actuación: de la percepción, a la valoración y la acción}

Los mecanismos por los que se regula la relación hombre-paisaje se pueden resumir en que el paisaje actúa como efecto y afectado a la vez a través de un proceso de percepción-cognición-valoraciónacción. El resultado de las acciones en el territorio tiene un impacto directo o indirecto en la función ecológica subyacente que sostienen el paisaje y, a su vez, un efecto directo y frecuentemente inmediato en el hombre a través del paisaje percibido (Ramos y Mantilla, 1976; Ramos y Pinedo, 1989). Se establece así una relación recíproca (transaccional) de la que se derivan importantes implicaciones.

El ser humano se relaciona con su medio a través de la percepción y la experiencia estética; y esto determina su valoración de una manera decisiva: la gente tiende a interpretar y juzgar aquello que ve en función de qué ve, y aquello que ve es lo que en última instancia considera cambiar o preservar (Bell, 2012). Gobster, Nassauer, Daniel y Fry (2007) presentan tres razones por las que la consideración estética se relaciona con los cambios en el paisaje:

- la estética del paisaje provee de una unión crucial entre el ser humano y los procesos ecológicos.

- la experiencia estética puede llegar a dirigir el cambio del paisaje.

- la atención sobre la calidad ecológica puede producirse a partir de la percepción del valor estético del paisaje.

Ramos, A. y Mantilla, P. (1976). Natural landscapes in Spain. II. Ideas and real concern for landscape planning. Landscape Planning, 3, 25-33.

Ramos, A. y Pinedo, A. (1989). Modelos numéricos en evaluación del paisaje y E.I.A. Arbor, 518-519, 179-189.

Bell, S. (2012). Landscape. Pattern, Perception and Process (2a ed.). Nueva York, NY: Routledge.

Gobster, P. H., Nassauer, J. I., Daniel, T. C., y Fry, G. (2007). The shared landscape: what does aesthetics have to do with ecology? Landscape Ecology, 22(7), 959-972. 
Nassauer, J. I. (1995a). Culture and changing landscape structure. Landscape Ecology, 10(4), 229-237.

Sheppard, S. R. J., Harshaw, H. W., y Mc Bride, J. R. (2001). Priorities for Reconciling Sustainability and Aesthetics in Forest Landscape Management. En S. R. J. Sheppard y H. W. Harshaw (Eds.), Forests and Landscapes: Linking Ecology, Sustainability and Aesthetics (pp. 263-288). Nueva York, NY: CABI Publishing - IUFRO.

Daniel, T. C. (2001). Whither scenic beauty? Visual landscape quality assessment in the 21st century. Landscape and Urban Planning, 54(1-4), 267-281.

Gobster, P. H. (1999). An ecological aesthetic for forest landscape management. Landscape Journal, 18(1), 54-64

Hull, R. B., Ashton, S. F., Visser, R. M., y Monroe, M. C. (2011). Forest Management in the Interface: Practicing Visible Cues-to-Care. Journal of Forestry, 177, 1-4.

Nassauer, J. I. (1992). The appearance of ecological systems as a matter of policy. Landscape Ecology, 6(4), 239-
Nassauer (1995a), entre otros muchos (ver Apartado III.4), aboga por una perspectiva de tratamiento ecológico del paisaje que atienda de manera más decidida al comportamiento humano, dado que el hombre construye y gestiona el paisaje, y también lo observa y toma decisiones basándose en lo visto, en lo conocido y en lo sentido.

\footnotetext{
"La cultura no sólo asiste en la comprensión de la estructura del paisaje, sino que también sugiere el enorme rango de posibilidades de acción y construcción en el paisaje, incluidos aquellos paisajes que aún no existen pero que pueden ser diseñados para promover la función ecológica."

Nassauer (1995a), p. 230.
}

Sin embargo, la naturaleza del vínculo entre las condiciones ecológicas y su consideración social es una cuestión que no ha sido aun suficientemente dilucidada: si bien se asume que los paisajes de alta calidad ecológica tienden a ser más atractivos que los degradados, existen una serie de casos intermedios en los que la relación no es ni directa ni evidente, por lo que el análisis de este asunto se enfrenta con una considerable incertidumbre (Sheppard, Harshaw, y Mc Bride, 2001). A continuación se exponen los factores más importantes que condicionan esta relación.

\section{Correspondencia con las representaciones culturales de un paisaje ecológicamente valorable}

En esta relación, la componente ecológica objetivable se enfrenta con la componente subjetiva de la apreciación humana del paisaje. Así, se ha observado que la correspondencia positiva entre alta calidad estética y ecológica suele ocurrir bajo determinadas condiciones, esto es, en los casos en los que el aspecto de los paisajes saludables y sostenibles se ajusta a ciertas preferencias determinadas biológica o culturalmente (Daniel, 2001). El conflicto surge cuando la representación cultural de lo ecológico no corresponde con la realidad. Por ejemplo, Gobster (1999) o Hull, Ashton, Visser y Monroe (2011) ponen de relieve que el arraigo de la estética del paisaje basada en una idealización de la escena natural tiene el efecto final de priorizar la conservación de determinadas zonas en detrimento de otras con valores visuales menos claros pero con importantes funciones ecológicas. Gobster (1999), Nassauer (1992), Parsons 
(1995), Steinitz (1990) o Thayer (1989) han señalado también numerosos casos de patrones de relación inversa, en los que surgen conflictos entre la sostenibilidad ecológica y las reacciones ante el paisaje. Se pueden citar, centrando la atención en el paisaje forestal, el caso insistentemente mencionado de la madera muerta o el ejemplo paradigmático de los incendios forestales (ver Apartado III.4.5.)

\section{Notoriedad de la componente ecológica}

Por otra parte, la lectura del paisaje no siempre es fácil ni inmediata, algunos fenómenos y valores se muestran conspicuos mientras que otros permanecen sin desvelar, especialmente algunos procesos ecológicos que son invisibles para el ojo humano y actúan como poderosas fuerzas de dinámica del paisaje. Adicionalmente, la tecnificación y el progresivo carácter urbano de la sociedad occidental hace que cada vez se sea menos capaz de ver y entender las condiciones y mecanismos naturales (López Lillo y Ramos, 2010), volviendo los procesos que pasan más desapercibidos aún menos patentes, lo que conduce a una crisis en el significado del paisaje, pues este se vuelve cada vez menos interpretable (Thayer, 1998).

\section{Escala espacial en la que se perciben los fenómenos ecológicos}

A este respecto, Gobster (1999) establece la escala a la cual los humanos perciben el paisaje, lo que denomina la "esfera perceptible" ("perceptible realm"), como el ámbito decisivo, pues es la escala en la cual el hombre interactúa con los ecosistemas e intencionadamente introduce cambios. El modelo por el cual se establece una relación entre la percepción de la ecología en el paisaje y su resultado estético fue descrita de forma más completa posteriormente por Gobster et al. (2007) (Figura 8).
Parsons, R. (1995). Conflict between ecological sustainability and environmental aesthetics: Conundrum, canärd or curiosity. Landscape and Urban Planning, 32, 227-244.

Steinitz, C. (1990). Toward a sustainable landscape with high visual preference and high ecological integrity: the loop road in Acadia National Park, U.S.A. Landscape and Urban Planning, 19(3), 213-250.

Thayer, R. L. (1989).

The experience of sustainable landscapes. Landscape Journal, 8(2), 101-110

López Lillo, A. y Ramos, A. (2010). Valoración del paisaje natural. Madrid: ABADA

Thayer, R. L. (1998). Landscape as an Ecologically Revealing Language [Special Issue: Exhibit Catalog. Eco-Revelatory Design: Nature Contructed/Nature Revealed]. Landscape Journal, Special Issue, 118-129.

Gobster, P. H. (1999).

An ecological aesthetic for forest landscape management.

Landscape Journal, 18(1), 54-64

Gobster, P. H., Nassauer, J. I., Daniel, T. C., y Fry, G. (2007). The shared landscape: what does aesthetics have to do with ecology? Landscape Ecology, 22(7), 959-972 


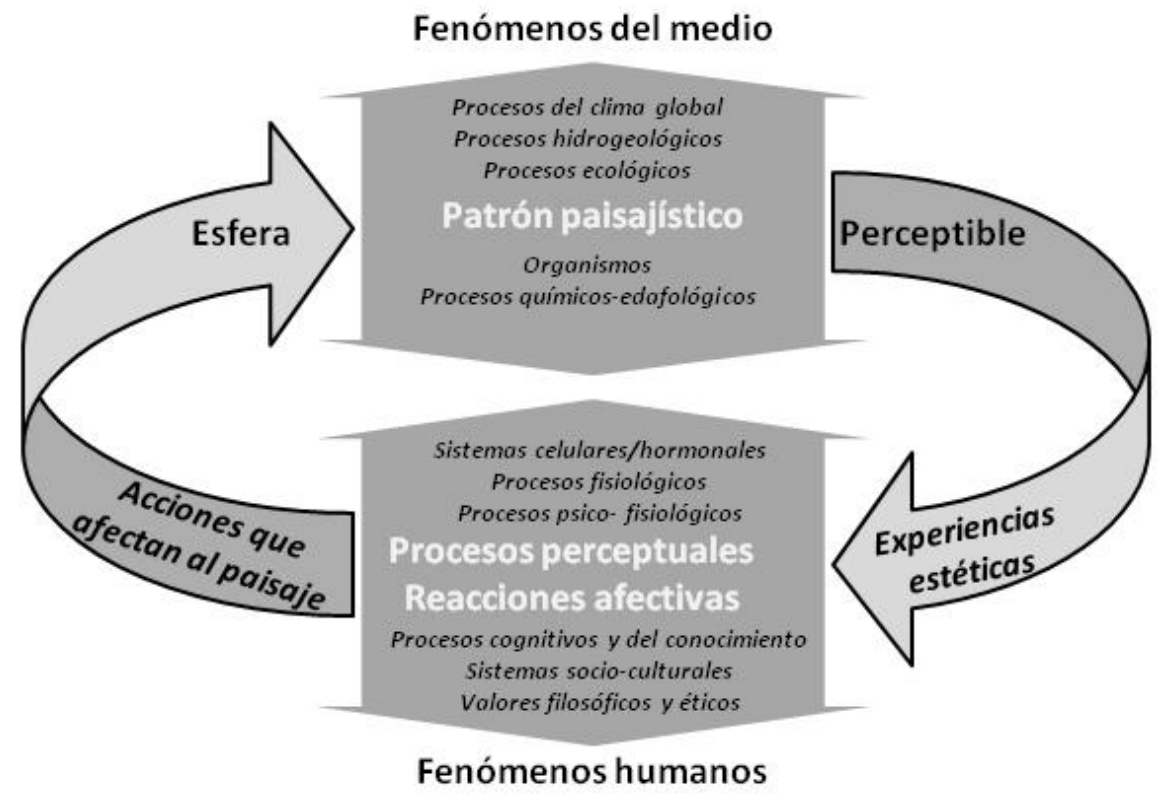

Figura 8. Esquema que presenta la esencia de la relación hombre-paisaje desde el punto de vista de la percepción y las reacciones afectivas. Las acciones humanas basadas en la percepción del paisaje pueden llegar a afectar a las características ecológicas a escalas que pueden no ser percibidas directa o inmediatamente dado que se producen fuera de la "esfera perceptible" (Gobster et al., 2007, p. 963).

Kimmins, J. P. (2001). Visible and Non-Visible Indicators of Forest Sustainability. En S. R. J.

Sheppard y H. W. Harshaw (Eds.), Forests and Landscapes: Linking Ecology, Sustainability and Aesthetics (pp. 43-56). Nueva York, NY: CABI Publishing - IUFRO.
Sheppard, S. R. J., Harshaw, H. W., y Mc Bride, J. R. (2001) Priorities for Reconciling Sustainability and Aesthetics in Forest Landscape Management. En S. R. J. Sheppard y H. W. Harshaw (Eds.), Forests and Landscapes: Linking Ecology, Sustainability and Aesthetics (pp. 263-288). Nueva York, NY: CABI Publishing - IUFRO.
A este respecto, Kimmins (2001) indica, para el caso particular de los paisajes forestales pero generalizable a otro tipo de paisajes, que se cuenta con muy pocos indicadores biofísicos visibles, si acaso existe alguno, que a escala de parcela puedan ser usados para juzgar la sostenibilidad ecológica (particularmente cierto en el caso de ojos "poco entrenados"). La gama de indicadores se amplía si nos trasladamos a la escala de paisaje, donde aparece el denominado "mosaico cambiante de condiciones ecológicas" ("shifting mosaic of ecosystem conditions"): diversas edades de la masa forestal en diferentes condiciones de desarrollo en un contexto regional. No obstante, el juicio puede llegar a ser incompleto, precisamente porque muchos factores ecológicos importantes no son reconocidos en la escala temporal de la vida de una persona.

\section{Escala temporal}

Se podría especular, tal y como propone Sheppard et al. (2001), que los paisajes insostenibles acaban perdiendo su valor estético y que los sostenibles, al mediar tiempo suficiente, se tornan visualmente atractivos. En este punto, la importancia de la escala temporal, tan reconocida en el ámbito de la ciencia ecológica de los paisajes, se 
revela como fundamental también en la consideración social de la sostenibilidad y el cambio paisajístico. Kimmins (1997) representa esta relación entre el cambio en el paisaje y el juicio de la gente bajo lo que denomina el "Principio de Peter Pan" ("Peter Pan principle"): la relativa corta duración de una vida humana en relación con la escala temporal de cambio de los ecosistemas, combinado con la generalizada poca experiencia ante el cambio natural del paisaje y ciertas convenciones sociales, incitan al público a pensar que cualquier cambio en el medio natural es malo, sea antropogénico o basado en las reglas del funcionamiento natural. Y sin embargo, el cambio no solo es inherente al paisaje y esencial en su correcto funcionamiento ecológico, sino que es inevitable. En este sentido, Bell (2012) observa que nuestra percepción del cambio es dependiente de la frecuencia, escala e intensidad del mismo: nuestras reacciones son negativas si el paisaje se modifica de forma catastrófica (ejemplo antes citado de un gran incendio forestal), hecho que ocurre con poca frecuencia, mientras que los pequeños cambios continuos son fácilmente asumidos e incluso pasan completamente desapercibidos.

\section{III.2.4. La percepción del paisaje desde la}

responsabilidad del profesional: la sensibilidad, el conocimiento y las ideas preconcebidas

Son muchas las líneas escritas y los estudios empíricos dedicados al análisis de la relación estética que establece con el paisaje el denominado "gran público" y cómo tratar estas de manera que se produzca una mejora en la calidad de vida en paralelo a una mejora en la calidad del paisaje (para una revisión, ver por ejemplo, Fry, Tveit, Ode, y Velarde, 2009; García-Abril, Núñez, Grande, Velarde, MartínezObispo, y Rodríguez-Solano, 2013; Ribe, 1989). No resultan tan frecuentes, sin embargo, los destinados a analizar la apreciación estética de la población local o del profesional, y cómo esta decanta unas determinadas actuaciones o propuestas en el paisaje.

Respecto a este análisis, a priori una variable clave a tener en cuenta sería la mayor comprensión por parte del profesional formado en ciencias naturales-ambientales sobre la esencia y funcionamiento de

Fry, G., Tveit, M. S., Ode, $\AA .$, y
Velarde, M. D. (2009). The
ecology of visual landscapes:
Exploring the conceptual
common ground of visual and
ecological landscape indicators.
Ecological Indicators, 9(5), 933947.

García-Abril, A., Núñez, M. V., Grande, M. A., Velarde, D., Martínez-Obispo, P., y Rodríguez-Solano, R. (2013). Landscape indicators for Sustainable Forest Management. En E. Martinez-Falero, S. MartinFernandez, y A. D. García-Abril (Eds.), Quantitative Techniques in Participatory Forest Management (pp. 263-366). Boca Ratón, NW: CRC Press, Taylor \& Francis Group.

Ribe, R. G. (1989). The aesthetics of forestry: What has empirical preference research taught us? Environmental Management, 13(1), 55-74. 
Meinig, D. W. (1979). The beholding eye: Ten versions of the same scene. En D. W. Meinig y J. B. Jackson (Eds.), The interpretation of ordinary landscapes: Geographical Essays (pp. 1-9). Nueva York, NY: Oxford University Press

Botkin, D. B. (2001) An Ecologist's Ideas About Landscape Beauty: Beauty in Art and Scenery as Influenced by Science and Ideology. En S. R. J.

Sheppard y H. W. Harshaw (Eds.), Forests and Landscapes: Linking Ecology, Sustainability and Aesthetics (pp. 111-123). Nueva York, NY: CABI Publishing -IUFRO

Hagan, J. M. (1996). Clearcutting in Maine: would somebody please ask the right question? Maine Policy Review, 5(2), 7-19. los sistemas naturales. Sin embargo, al igual que la opinión del público se fundamenta en aspectos biológicos, socio-culturales e individuales, las decisiones del profesional obviamente no siempre se fundamentan sólo en la lógica científico-técnica. Cualquier profesional relacionado con el tratamiento del paisaje más natural parte de una alta sensibilización sobre la conservación ecológica y un cierto grado de sensibilidad ante la belleza de lo natural en el paisaje, así como un conocimiento experto fundamentado en la razón, unas influencias del contexto social en el que se encuentra y también unas ideas preconcebidas sobre la aportación de lo natural a la estética del paisaje (recordemos por ejemplo las nueve interpretaciones distintas de varios profesionales que Meinig (1979) expuso en su artículo The beholding eye: Ten versions of the same scene). Dado que el profesional resulta una parte importante implicada en el proceso de toma de decisiones que afectan al paisaje, en este punto cabría preguntarse si sus preferencias estéticas influyen de alguna manera en sus decisiones. Esta afirmación presenta implicaciones claras en muchos aspectos de la planificación, gestión y diseño del paisaje.

Se han expuesto algunos casos y ámbitos en los que en la práctica profesional se han filtrado consideraciones y efectos secundarios ajenos a la lógica científica pura. Por ejemplo, Botkin (2001) plantea este hecho mediante el ejemplo de lo escrito por el ecólogo John M. Hagan, que reflexionó sobre cómo la visión de unas parcelas sujetas a cortas a hecho le consternó de tal manera que concluyó que su inventario de aves no habría de tener en cuenta estos espacios pues "nada podría crecer en lo que vio, al menos por muchos años" (Hagan, 1996, p. 8). Las observaciones sistemáticas de sus investigaciones posteriormente contradijeron su juicio inicial.

\footnotetext{
"En medio de la zona cortada a hecho mi sentido de la vista estaba agredida. Apenas podía concentrarme en lo que el forestal me decía. Curiosamente, en cambio, los tocones recién cortados despedían al aire los compuestos aromáticos del abeto, llenándolo del aroma de Navidad y tiempos felices. La incongruencia de esas señales sensoriales era apabullante. Aquí y allá podía percatarme de lo poderosa y paradójica que puede ser una corta a hecho. [...] Menos de un mes después, durante la primera serie de trabajo de campo en 1992, mi equipo y yo nos dimos cuenta de que los claros cortados y la regeneración consiguiente de matorrales estaban llenos de aves. Muchos de ellos de importancia para la conservación [...] Las parcelas cortadas a hecho no eran el desierto biológico que me imaginaba. [...] Pero las noticias no eran todas buenas. Si bien las cortas a hecho no eran desiertos biológicos, fueron creadas a expensas del bosque maduro. Otra cohorte de especies de aves utiliza el bosque maduro, muchas de ellas igualmente protegidas a nivel nacional. Esta fue la segunda manifestación de la paradoja de las cortas a hecho. Dependiendo de las especies, las cortas pueden ser tanto "buenas" como "malas" (Hagan, 1996, p. 8-9).
} 
Otro caso es el expuesto Thorne y Huang (1991), que apuntaban cómo la ciencia de la ecología del paisaje tardó en desarrollarse en Norteamérica con respecto al avance que mostraba en Europa. Estas diferencias se debían fundamentalmente al desarrollo en Norteamérica de ciudades con menor densidad de población, a la gestión del territorio menos intensiva y a un esfuerzo planificador hasta ese momento menos significativo. Pero también refieren que los ecologistas norteamericanos se mantuvieron fascinados por la naturaleza "inexplotada" de su continente y mantuvieron su desarrollo profesional al margen del ámbito de la planificación y el diseño de ámbitos más intervenidos, retrasando así la emergencia de la nueva disciplina y apartando la influencia humana como objeto de su actividad. Kovacs, Leroy, Fischer y Lubarsky (2006) subrayan también que hasta hace poco el interés de los profesionales estuvo apenas enfocado a zonas urbanas, periurbanas, industriales o degradadas, debido al sesgo en la elección de áreas de estudio de la ciencia ecológica hacia zonas naturales atractivas y el deseo de comprender el funcionamiento de las áreas poco perturbadas.

En el ámbito nacional, Gómez Mendoza (2002) indica cómo los profesionales forestales han mostrado una tendencia a identificar el bosque maduro como ideal de sistema forestal y finalmente como ideal estético, privilegiando este estado frente al monte bajo o los pastizales. Según la autora, los forestales españoles de finales del siglo XIX y primer tercio del XX poseían una sensibilidad estética clara que se dejaba seducir por las masas arboladas y que se complacía en el análisis del detalle y la riqueza de sus elementos. Atribuye a figuras como Agustín Pascual (1818-1884) una preferencia marcada por el monte arbolado o a Ximénez de Embún (1882-1954) una cierta obsesión por la ordenación basada en el monte alto, representativa de la profesión en general, e influida por los preceptos de la selvicultura germánica. Todas estas consideraciones tuvieron un reflejo en la configuración del paisaje, pues la ciencia y técnica forestal ha sido y es uno de sus modificadores más relevantes. Cabría preguntarse hasta qué punto este pensamiento y proceder se ha transmitido a la sociedad actual, que efectivamente tiende a valorar más la estética asociada al sistema arbolado (García-Abril et al., 2013).

Thorne, J. F. y Huang, C.-S. (1991). Toward a landscape ecological aesthetic: methodologies for designers and planners [Special Issue: Landscape Ecology]. Landscape and Urban Planning, 21(1-2), 61-79.

Kovacs, Z. I., Leroy, C. J., Fischer D. G., y Lubarsky, S. (2006) How do Aesthetics Affect our Ecology? Journal of Ecological Anthropology, 10, 61-65.

Gómez Mendoza, J. (2002). Paisajes forestales e ingeniería de montes. En F. Zoido Naranjo (Ed.), Paisaje y ordenación del territorio (pp. 237-254). Sevilla: Junta de Andalucía y Fundación Duques de Soria

García-Abril, A., Núñez, M. V., Grande, M. A., Velarde, D., Martínez-Obispo, P., y Rodríguez-Solano, R. (2013). Landscape indicators for Sustainable Forest Management. En E. Martinez-Falero, S. MartinFernandez, y A. D. García-Abril (Eds.), Quantitative Techniques in Participatory Forest Management (pp. 263-366). Boca Ratón, NW: CRC Press, Taylor \& Francis Group 
III.2.5. El valor estético y su impacto sobre la sensibilización y la conservación de los valores naturales

\section{El dilema ante la conservación de la estética de lo natural}

Parsons, G. 2008 Aesthetics \& Nature. Londres, UK: Continuum.
Parsons (2008) llama la atención sobre el hecho de que frecuentemente se recurre al valor estético con el fin de proteger los valores de la naturaleza y concluye que este argumento puede llegar a ser perverso y que la conexión entre ética y estética conduce a un dilema: o bien el argumento para conservar lo natural se basa en el puro valor estético de su apariencia, o bien se conecta la estética de lo natural con lo ético.

Si la estética de lo natural se pone sobre la mesa como argumento para la conservación (merece la pena conservar un paisaje natural pues es bello), invariablemente ese valor se tiene que evaluar en relación con el valor estético de la alternativa a lo natural. De tal manera, el argumento estético pasa a estar supeditado a una comparativa de valores. Esto es, si los beneficios prácticos o el valor estético del desarrollo artificial que se haga en detrimento de la estética de lo natural se juzgan mayores que esta, entonces el argumento de conservar lo natural en razón de su estética se vuelve débil. El argumento sólo sería útil en los casos más claros de superioridad de la estética natural, es decir, en los casos en los que la naturaleza muestre un atractivo extraordinario. Ahora bien, frecuentemente la pérdida de calidad estética ocurre en los espacios en que esta no es un valor distintivo, singular o sobresaliente (González Alonso, 2010). Por el contrario, si la estética se carga de consideraciones éticas (lo natural merece ser conservado por sí mismo, tiene un valor superior a lo artificial y posee unas cualidades estéticas que remiten a ese valor), el argumento se vuelve fuerte por sí mismo, pero sólo para aquellas personas que efectivamente se apoyen en la ética. Así, el valor estético pasa a ser un argumento supeditado al argumento moral. Nos encontramos por tanto ante una argumentación que en la práctica frecuentemente resulta en que la conservación o no de un espacio considera el argumento de su estética como no decisivo. 
Ahora bien, enfoquemos el argumento estético desde el punto de vista de su "capacidad retórica", esto es, de su potencial para disuadir sobre la bondad de un objetivo. En este ámbito la utilidad de la estética para la conservación se vuelve más provechosa. La "elocuencia de lo estético" (su capacidad para transmitir un mensaje de manera eficaz) reside en que es tangible, es fácilmente perceptible. Así se erige como un medio efectivo y cautivador para promocionar y respaldar la gestión sensible con la base ecológica. Tal y como expuso Callicott (1983), la estética del paisaje complementa a la ética dado que es un acercamiento más seductor y menos oneroso para promover las conductas favorables a la conservación.

Callicott, J. B. (1983).

The Land Aesthetic [Special Issue: A Cumulative Index to the First Seven Years of Environmental Review]. Environmental Review, 7 (4), 345-358.

A este respecto, resulta especialmente revelador el ejemplo de la influencia que el aspecto que ciertas especies protegidas tiene en su propia conservación, algo que ciertamente ocurre (Figura 9). La conservación de las especies emblemáticas, estéticamente atractivas por su belleza, o imagen de fuerza, nobleza y elegancia, es uno de los ejemplos más evidentes de las repercusiones de las consideraciones estéticas en la gestión de los valores ecológicos.
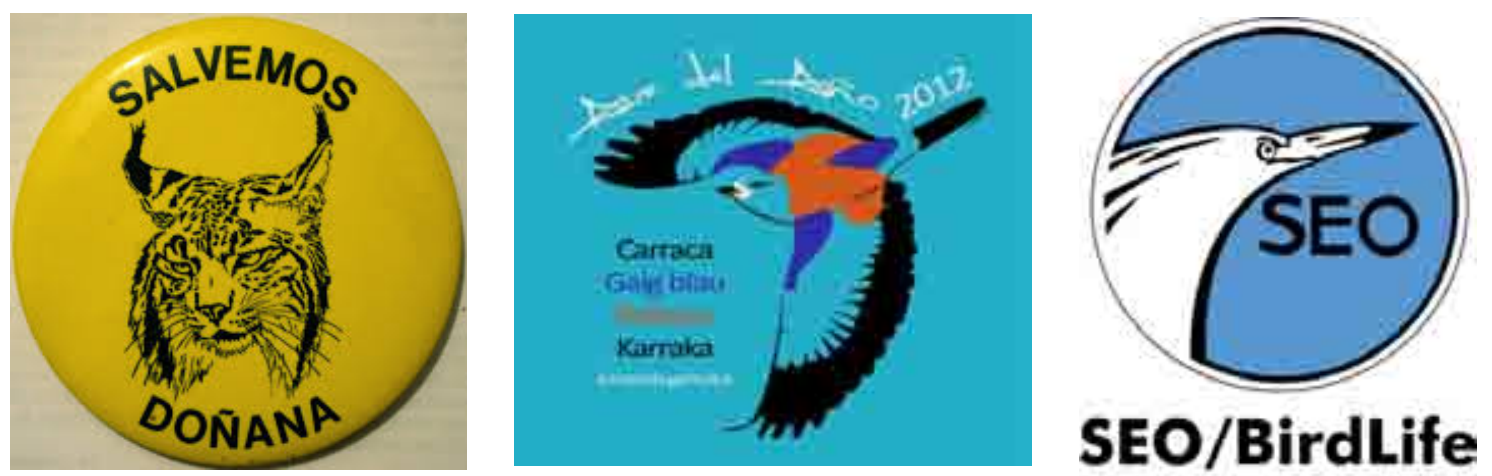

Figura 9. La dimensión estética de las especies es frecuentemente utilizada con fines conservacionistas. FUENTE IMAGEN: wWw.salvemosdoñana.org y www.seo.org.

Esta característica de las especies carismáticas fue designada por Callicott (1983), parafraseando a Aldo Leopold (1949) (ver Capítulo III.4.2), como "las especies indicadoras estéticas" ("aesthetic indicator species"), aquellas que dotan al paisaje de la marca que le da esencia, Leopold, A. (1949). A Sand County Almanac with Sketches Here and There. Nueva York, NY: que anima al paisaje y que le aporta una emoción de carácter estético ("the hallmark, the imprimatur, [...] the aesthetic exictement", p. 352). 
Estas especies, sean o no vistas u oídas, ilustran la salud del ecosistema y dotan al paisaje de significados simbólicos profundos (Figura 10).

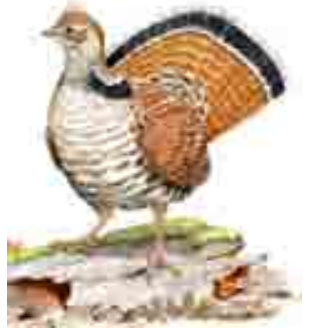

Figura 10. El grévol engolado (Bonasa umbellus) es un ave de la familia de los faisanes muy conocida en Norteamérica.

FUENTE IMAGEN: https://www.massaudubon.org

"Todo el mundo sabe, por ejemplo, que el paisaje otoñal de los bosques norteños es el terreno, más el arce rojo, más el grévol engolado. En términos de ecosistema el grévol representa tan solo una millonésima parte de la masa o la energía de un acre. Ahora bien, sustrae el grévol y todo está muerto. Una enorme cantidad de fuerza motriz se habría perdido." (Leopold, 1949, p. 137).

Kellert, S. R. (1985).

Social and Perceptual Factors in Endangered Species

Management. The Journal of Wildlife Management, 49(2), 528.

Tindall, D. B. (2001). Why do you think that hillside is ugly? A sociological perspective on aesthetic values and public attitudes about forest. En S. R. J. Sheppard y H. W. Harshaw (Eds.), Forests and Landscapes: Linking

Ecology, Sustainability and Aesthetics (pp. 57-70). Nueva York, NY: CABI Publishing - IUFRO.

Snow, D. A. y Benford, R. D. (1988). Ideology, frame resonance, and participant mobilization. En B. Klandermans, H. Kriesi y S. Tarrow (Eds.), From Structure to Action (pp. 197-218).

Greenwich: JAI Press.

Snow, D. A., Rochford, E. B., Worden, S. K., y Benford, R. D.

(1986). Frame Alignment Processes, Micromobilization, and Movement Participation. American Sociological Review, 51, 464-481.
Por ejemplo, Kellert (1985) ofrece los datos que muestran que una mayoría de público estaría a favor de apoyar los programas de conservación del águila calva americana (Haliaeetus leucocephalus) (Figura 11), frente a una minoría que apoyaría la conservación de una araña en peligro de extinción. El carisma de las especies más bellas y populares, tales como los grandes vertebrados, ha sido frecuentemente utilizado por los técnicos como forma de atraer financiación para los propósitos conservacionistas.

Tindall (2001) contextualiza este fenómeno en la estrategia de la "frame alignment" y "frame resonance" (Snow y Benford, 1988; Snow, Rochford, Worden y Benford, 1986). En la construcción y comunicación de un mensaje a la sociedad, el primer proceso explica la búsqueda de una vinculación entre las interpretaciones del público y las organizaciones activistas, de manera que los intereses, valores y creencias de los individuos aparezcan como congruentes y complementarios con las actividades, fines e ideología de las organizaciones que pretenden movilizarlos. El segundo fenómeno explica que los mensajes que están formulados de tal manera que se reflejen en ciertos aspectos de la cultura dominante, o que produzcan una reacción basada en la experiencia predominante del público, se amplifican, tienen mayor eco en la sociedad y por tanto mayores 
posibilidades de tener éxito. El modo de comunicación es importante, pues el humano es un ser muy visual.

Respecto a la repercusión de la utilización de la estética de las especies en términos puramente ecológicos, algunos estudios han puesto de relieve sus beneficios, aunque existe un escepticismo general sobre su eficacia a largo plazo y sus posibles efectos perversos (Sergio, Newton, Marchesi, y Pedrini, 2006).

Sergio, F., Newton, I., Marchesi, L., y Pedrini, P. (2006). Ecologically justified charisma: preservation of top predators delivers biodiversity conservation. Journal of Applied Ecology, 43(6), 1049-1055.
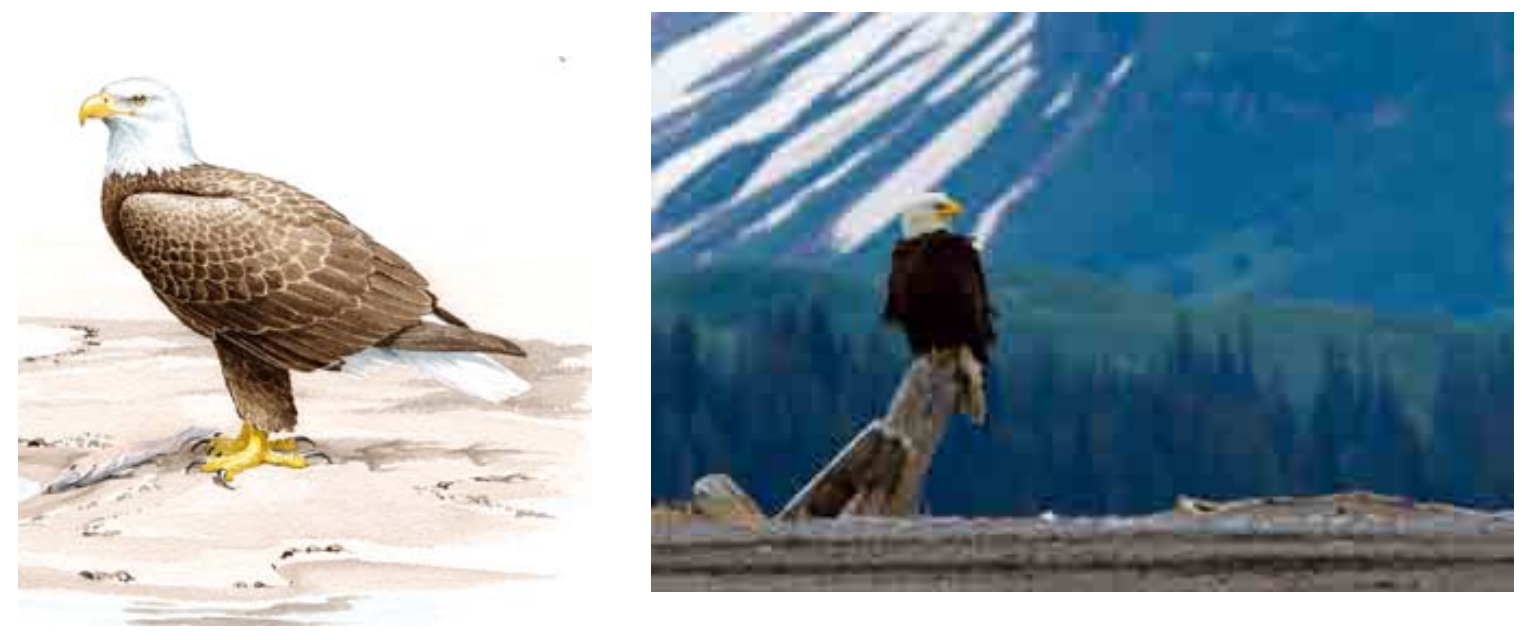

Figura 11. El águila calva americana (Haliaeetus leucocephalus), es el ave más icónica en Estados Unidos, símbolo nacional por su imagen majestuosa y por representar fortaleza y libertad. FUENTE IMÁGENES: https://www.massaudubon.org y https://www.yoopit.com/ 


\section{III.3. LA APRECIACIÓN DE LO NATURAL EN EL PAISAJE: EVOLUCIÓN HISTÓRICA Y ACTUALIDAD}

Carlson, A. (2009). The Development and Nature of Environmental Aesthetics. En A Carlson, Nature and Landscape: An Introduction to Environmental Aesthetics (pp. 1-21). Nueva York, NY: Columbia University

Press.

Lothian, A. (1999). Landscape and the philosophy of aesthetics: is landscape quality inherent in the landscape or in

the eye of the beholder? Landscape and Urban Planning, 44(4), 177-198.

Porteous, J. D. (1996). Environmental Aesthetics: Ideas, Politics and Planning. Londres y Nueva York, NY: Routledge.

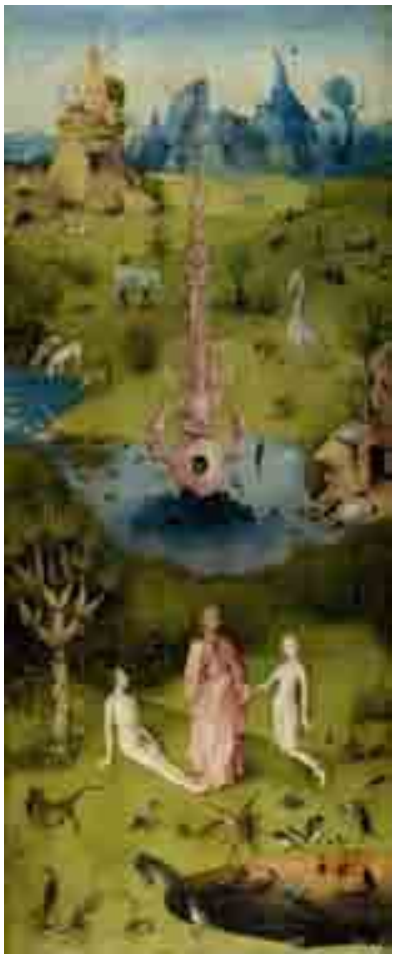

La estética de lo natural ha formado parte de los temas de reflexión desde épocas muy tempranas. Para entender las raíces de la estética asociada a lo natural y su evolución hasta la concepción actual resulta útil seguir el hilo conductor que ofrece la revisión de Carlson (2009).

\section{III.3.1. Los inicios de la estética moderna de lo natural}

Las raíces de la estética de lo natural actual se encuentran en los desarrollos filosóficos modernos sobre estética del siglo XVIII y XIX. Hasta ese momento, la concepción clásica se había limitado a la consideración de la belleza desde un punto de vista objetivista, limitada al ideal de belleza de la proporción, la simetría o la unidad en la variedad. La estética renacentista de lo natural adoptó esta concepción en sus ideas y se reflejó en la regularidad y proporción con la que se entendía la esencia de la belleza. Por su parte, la estética enunciada por los filósofos cristianos de la Edad Media concebía la belleza de la naturaleza como el reflejo físico del orden, armonía y regularidad de su Creador (Lothian, 1999), al mismo tiempo que para la gente del medievo la naturaleza más allá de sus pueblos y campos era perturbadora, inmensa y terrible (Porteus, 1996) (Figura 12 y 13).

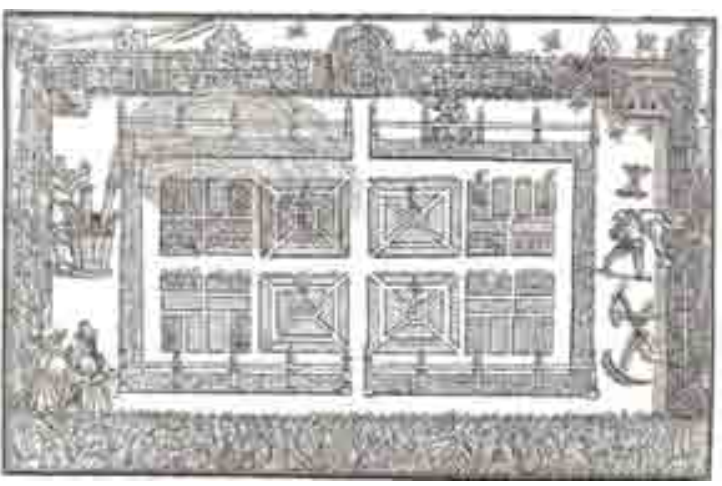

Figura 12. Imagen del paraíso tras la creación reflejado en la obra "El Jardín de las Delicias" de El Bosco y prototipo de jardín medieval, con formas geométricas y cerradas, y con plantación de especies de profunda simbología religiosa, buscando su relación con el ideal descrito en la Biblia, el Jardín del Edén ( extraída de la obra de Hill's "The Gardener's Labyrinth", de 1586). 


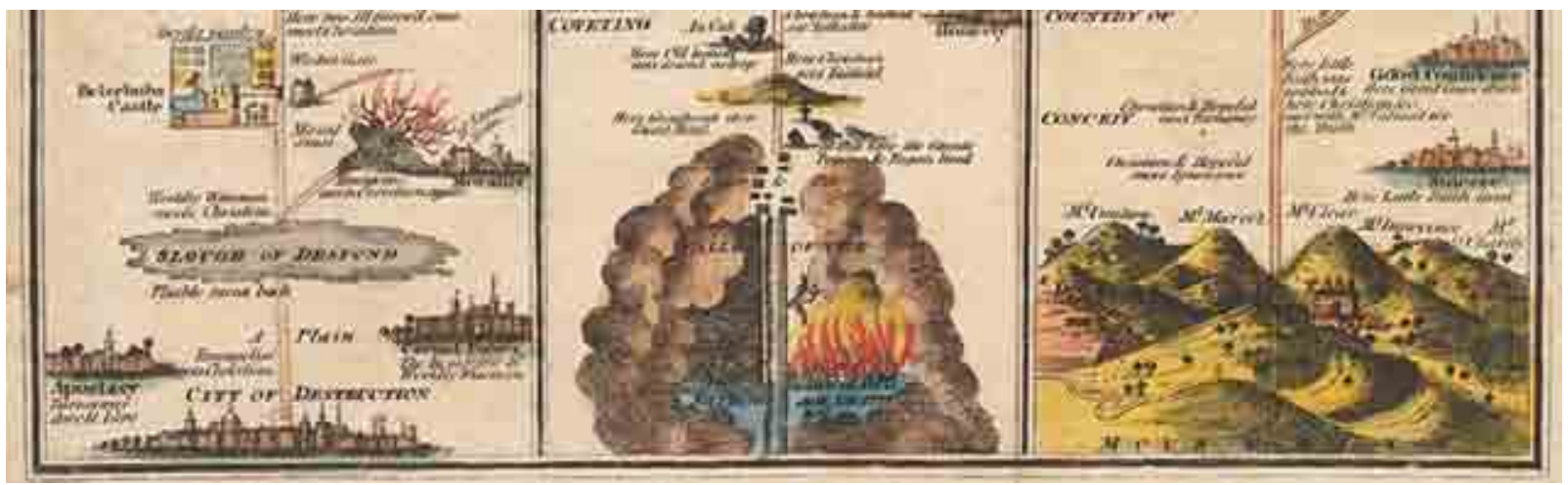

Figura 13. En tiempos medievales la percepción de la naturaleza estaba definida por las ideas cristianas. La naturaleza se imbuía de una visión trascendental, no asociada al placer de su contemplación sino interpretada en términos simbólicos: el mundo natural se había creado a base de una serie de símbolos edificantes que asistían al camino hacia el paraíso. Tal y como observa Porteous (1996) "En la obra de Bunyan 'El progreso del Peregrino' no encontramos humedales o valles boscosos, sino el Cenagal de la Infelicidad o los Valles de la Sombra de la Muerte" (p.52).

Es en los siglos XVIII y XIX cuando se produce un gran cambio en la apreciación de lo natural, se inaugura el subjetivismo y se adopta lo natural como el objeto ejemplar y preferente de la experiencia estética (Figura 14). El paisaje natural dejó de ser valorado desde la perspectiva exclusiva de las normas clásicas de proporción y simetría, al mismo tiempo que dejaba de inspirar la amenaza de lo salvaje, para comenzar a ser admirado por la fuerza y grandiosidad con que se desplegaba. A este cambio de apreciación contribuyeron los avances en las ciencias naturales y los viajes ilustrados, que supusieron o fueron consecuencia de un cambio de actitud hacia la naturaleza: una expedición por Los Alpes pasó de ser una experiencia no deseable, llena de peligros e incertidumbres, a un viaje que permitiera apreciar la grandeza de la naturaleza salvaje y su belleza (Botkin, 2001; Ortega Cantero, 2014; Parsons, 2008).

Porteous, J. D. (1996). Environmental Aesthetics: Ideas, Politics and Planning. Londres y Nueva York, NY: Routledge. Botkin, D. B. (2001).
An Ecologist's Ideas About
Landscape Beauty: Beauty in Art
and Scenery as Influenced by
Science and Ideology. En S. R. J.
Sheppard y H. W. Harshaw (Eds.),
Forests and Landscapes: Linking
Ecology, Sustainability and
Aesthetics (pp. 111-123). Nueva
York, NY: CABI Publishing -IUFRO.
Ortega Cantero, N. (2014).
Montañismo y valoración del
paisaje: la Real Sociedad Española
de Alpinismo Peñalara (1913-
1936). Ería, 95, 253-279.
Parsons, G. (2008). Aesthetics \&
Nature. Londres, UK: Continuum.

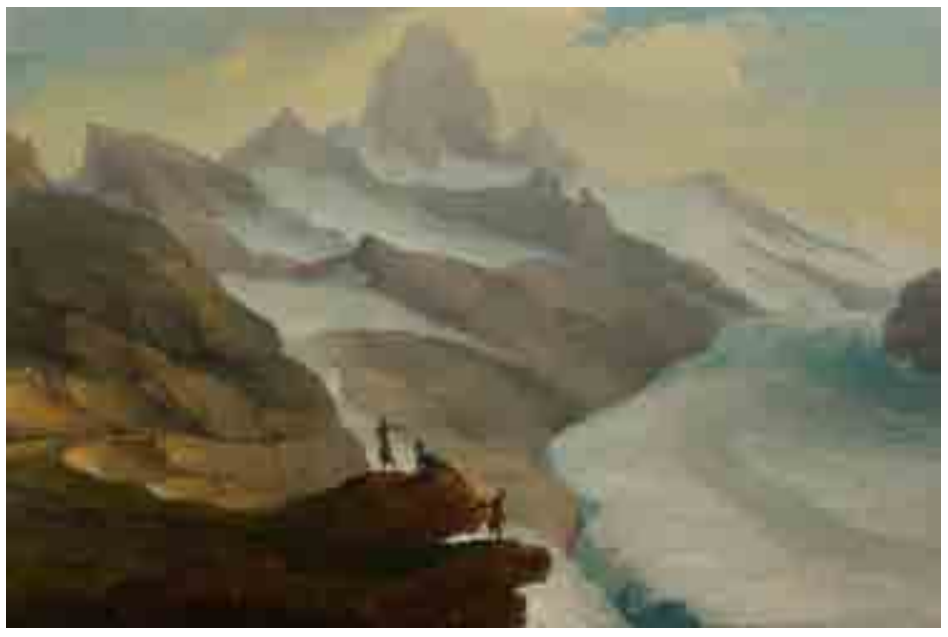

Figura 14.

Vue depuis la Bänisegg vers le glacier inférieur de Grindelwald

[Vista del Bänisegg hacia el glaciar inferior de Grindelwald], pintado en 1778.

Caspar Wolf (1735-1783)

Óleo sobre lienzo, Colección privada

El artista suizo Caspar Wolf fue uno de los primeros en descubrir las cimas menos exploradas de Los Alpes como objeto artístico y de admiración. 
Kant, E. (2003). Crítica del juicio seguida de las observaciones sobre el asentimiento de lo bello y lo sublime. (A. García Moreno y J. Ruvira (Trad.)). Madrid: Nueva Biblioteca Filosófica (Trabajo original publicado en 1790)

Burke, E. (1757). A Philosophical Inquiry Into The Origin of Our Ideas of The Sublime And Beautiful. Londres, UK: Dodsley

Gilpin, W. (1789). Observations on several parts of England, particularly the mountains and lakes of Cumberland and Westmoreland: relative chiefly to picturesque beauty. Londres, UK: Blamire, R.

\section{III.3.2. Nuevas ideas estéticas sobre lo natural: lo bello, lo sublime y lo pintoresco}

En 1790, tras desarrollos conceptuales previos, el filósofo alemán Immanuel Kant (1724-1804) enunció su influyente formulación sobre cómo se juzga la belleza en el mundo natural (y en el arte) en su obra Crítica del Juicio (Kant, 2003). La teoría del "desinterés estético" de Kant entiende la experiencia estética como un estadio que no se basa en conceptualizaciones o explicaciones lógicas ni aspira a ellas, sino que se sustenta en intuiciones y sensaciones y se sumerge en el placer. Por entonces, surgieron también conceptos estéticos de lo natural que se alejaban del ideal clásico. El filósofo irlandés Edmun Burke (1729-1797) y el mismo Kant introdujeron y elaboraron los conceptos de lo bello y lo sublime (Burke, 1757; Kant, 2003), y el escritor, artista y arquitecto del paisaje William Gilpin (1724-1804) desarrolló el concepto de lo pintoresco (Gilpin, 1789) (Figura 15). Estas tres concepciones tratan los estados diversos y en ocasiones opuestos con los que se muestra la naturaleza.

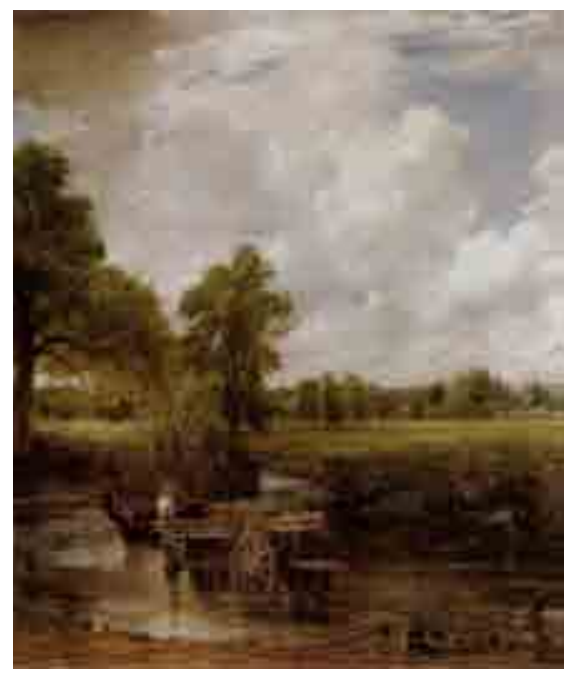

Figura 15. The hay wain [El carro de heno], pintado en 1821. John Constable (1776 - 1837) Óleo sobre lienzo, National Gallery de Londres. El pintor inglés es uno de los grandes exponentes de la pintura de paisaje, en la que frecuentemente reflejó escenas de carácter pintoresco, en la que la labor campesina s encuentra en harmonía con la naturaleza y la atmósfera general es de paz y sosiego.

Lo bello se encontraría en los paisajes cultivados europeos o en los jardines. Lo sublime lleva a una experiencia placentera cuando los paisajes que muestran la dimensión más amenazadora y aterradora de la naturaleza se contemplan desde el "desinterés". La diferencia 
fundamental entre lo bello y lo sublime es resumido por Bell (2012) "ante lo bello podemos entender la escena completa y encontrarla agradable y generar afecto. Ante lo sublime, dado que no podemos entender el paisaje por su complejidad y fuerza, nos surge un sentimiento de miedo que puede no ser agradable, pero sí inspirador y muy estimulante [siempre que el peligro real no exista]. Los paisajes que muestran unidad en la diversidad, cierto grado de orden, de sentido del lugar y cuyo patrón espacial es comprensible son los que provocan la experiencia de lo bello, algo que puede surgir frecuentemente. La experiencia de lo sublime sin embargo ocurre en contadas ocasiones, ante paisajes de gran escala y complejidad, ante los que el humano se siente pequeño e indefenso" (p.76). Lo pintoresco fue caracterizado por Gilpin (1789): "Las diferencias pueden ser sintetizadas de la siguiente manera: lo experimentado como bello tiende a ser pequeño y calmado, pero sutilmente variado, delicado y ajustado en su color; mientras que lo experimentado como sublime, contrariamente, es poderoso, vasto, intenso, aterrador e indefinido. Lo pintoresco se encuentra entre ambas experiencias, lo bello y lo sublime, y es complejo e inusual, variado e irregular, rico y lleno de fuerza, y enérgicamente vibrante." (p. ix).

En esta época lo pintoresco empieza a influir en el ideal de los turistas ingleses, que buscaron la escena pintoresca en el Lake District, las Highlands escocesas o en Los Alpes suizos. Igualmente, fue un modelo dominante en la apreciación popular de lo natural durante los siglos siguientes. De tal manera, la experiencia estética que emana de lo pintoresco caracteriza hoy día buena parte del denominado "turismo de postal".

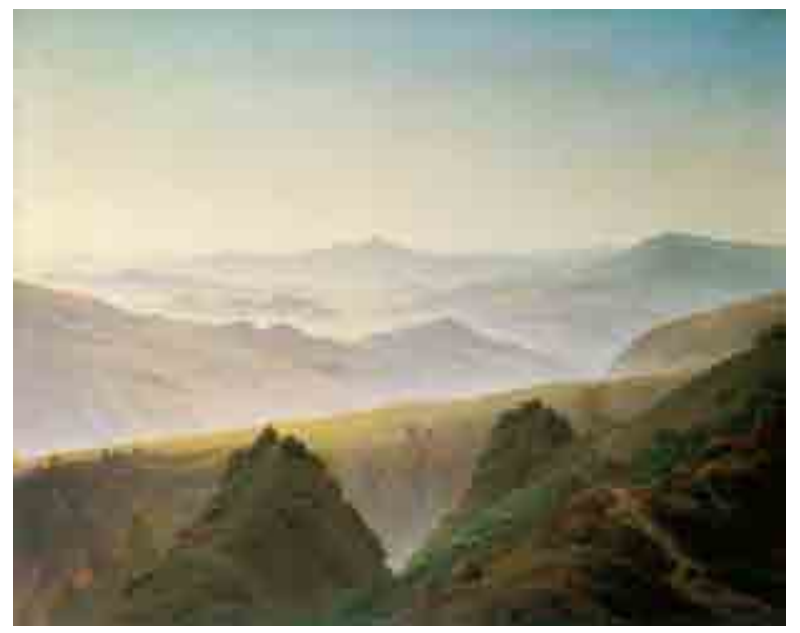

Figura 16.

Mañana en las montañas [Morgen im Gebirge], pintado a partir de 1823.

Caspar David Friedrich (1774 - 1840)

Óleo sobre lienzo

(Museo Hermitage, San Petesburgo)

Bell, S. (2012).
Landscape. Pattern, Perception and Process (2a Ed.). Nueva York, NY: Routledge.

Gilpin, W. (1789). Observations on several parts of England, particularly the mountains and lakes of Cumberland and Westmoreland: relative chiefly to picturesque beauty. Londres, UK: Blamire, R. 


\section{II.3.3. El ideal romántico de lo natural y la influencia de los escritos naturalistas en Norteamérica}

En el siglo XIX se aparca lo natural como objeto estético para el pensamiento filosófico europeo, que cede su sitio al arte tras su posicionamiento por Hegel como la más alta expresión del espíritu: la libertad, lo único verdadero. Sólo algunos filósofos y pensadores del movimiento romántico profundizaron en la estética de lo natural en Europa, aunque con gran resonancia en la concepción del paisaje del siglo XX.

"CYRIL. ¿La Naturaleza deriva del pintor paisajista y adquiere sus efectos del mismo?

VIVIAN. En efecto. ¿De dónde, si no es de los impresionistas, hemos obtenido esas maravillosas nieblas cobrizas que se deslizan por nuestras calles, empañando las farolas de gas y tornando las casas en sombras monstruosas? ¿A quién, si no es a ellos y a sus maestros, debemos las encantadoras neblinas plateadas que se ciernen sobre nuestro río y que adoptan formas evanescentes de puentes y barcazas oscilantes? El cambio extraordinario que se ha producido en el clima de Londres durante los últimos diez años se debe enteramente a una particular escuela de arte. Sonríes. Considera el asunto desde un punto de vista científico o metafísico y descubrirás que estoy en lo cierto. ¿Qué es la Naturaleza? La naturaleza no es esa gran madre que nos ha parido. Ella es nuestra creación. Es en nuestro cerebro donde cobra vida. Las cosas son porque nosotros las vemos, y lo que vemos, y cómo lo vemos, depende de las artes que nos han influido. Mirar las cosas no es igual que verlas. Uno no ve las cosas hasta que no ve su belleza. Entonces, y solo entonces, cobra existencia. Ahora la gente ve las nieblas, no porque existan nieblas, sino porque los poetas y pintores nos has enseñado el misterioso encanto de esos efectos."

Wilde, 0. 2008. The Decay of Lying - An Observation. Richmond, UK: Alma Books (publicado por primera vez en 1891).
Extracto del ensayo "La decadencia de la mentira" (The Decay of Lying), presentado en forma de diálogo socrático por Oscar Wilde en 1891, en el que reflexiona sobre lo natural y el arte.

El movimiento romántico adoptó y difundió los conceptos de lo bello y lo sublime, y ligó lo estético más con la poesía que con la filosofía y el amor por la naturaleza: el íntimo contacto emocional con ella abarcó una visión muy lírica y una apreciación encendida de su belleza. Autores como Rousseau (1712-1778), Goethe (1749-1832) o Wordsworth (1770-1950) han condicionado en gran medida una 
imagen del paisaje natural que se ha sedimentado en la apreciación de este por la sociedad actual (Lothian, 1999). Los paisajes representados en pinturas y escritos resultaban interpretaciones del carácter natural con una composición cuidadosa, diseñadas bajo las directrices del formalismo, en las que lo dramático era privilegiado frente a lo mundano y el carácter salvaje era frecuentemente suavizado (Parsons y Daniel, 2002). Dichos ideales tuvieron por ejemplo mucho peso en la declaración de Parques Nacionales y en el diseño de parques y jardines y, según muchos autores promovieron una visión formal en la estética de lo natural (Gobster, 1995; Rees, 1975).

"Sabido es lo que yo llamo un bello paisaje. En absoluto una zona llana, por bonita que sea me lo parece: necesito torrentes, rocas, bosques sombríos, montañas, caminos abruptos para subir y bajar, precipicios a ambos lados" Jean-JacquesRousseau, en Gómez Mendoza (2002), p. 238.

Al contrario que en Europa, en esta época en Norteamérica floreció una forma de apreciación estética del mundo natural que surgió tras la estela de los escritos naturalistas. El contacto íntimo con la naturaleza que describe Thoreau (1817-1862) en sus ensayos, las observaciones conservacionistas/preservacionistas de Marsh (18011882) o el "positivismo estético" de Muir (1838-1914) influyeron notablemente en la estética de lo natural desarrollada en la sociedad estadounidense. Esta apreciación se desmarca del ideal de lo pintoresco, que encuentra interés y deleite en la presencia humana en equilibrio con lo natural. El positivismo estético halla la Naturaleza intocada como esencialmente bella, y dicha belleza se oscurece cuanto más evidente es la marca humana en el paisaje.

"El hombre también está realizando cambios de calado. Este gran modificador, mitad animal, mitad ángel, se está multiplicando y extendiendo rápidamente, llenando los mares y lagos con barcos, la tierra con cabañas, hoteles, catedrales y tiendas y casas urbanas apiñadas, de tal manera que, según parece, vamos a tener que ir más lejos que Nansen [explorador noruego del Polo Norte] para hallar una buena y profunda soledad. Nada en el paisaje de la Naturaleza es feo en la medida en que es salvaje; y podemos decir sin temor que la mayoría va a seguir siendo salvaje, en particular el mar y el cielo, el caudal de luz de las estrellas y el corazón de la tierra, caliente e insondable, infinitamente bello aunque sólo sea vagamente visible a través de los ojos de la imaginación. Los geiseres también, escupiendo agua desde el caliente inframundo; los inmutables y duraderos glaciares en las montañas, que deben obediencia únicamente al sol; los domos de Yosemite y la tremenda
Lothian, A. (1999)

Landscape and the philosophy of aesthetics: is landscape quality inherent in the landscape or in the eye of the beholder? Landscape and Urban Planning, 44(4), $177-$ 198.

Parsons, R. y Daniel, T. C. (2002). Good looking: in defense of scenic landscape aesthetics. Landscape and Urban Planning, 60(1), 43-56.

Gobster, P. H. (1995).

Aldo Leopold's ecological esthetic: integrating esthetic and biodiversity values. Journal of Forestry, 6-10.

Rees, R. (1975). The Scenery Cult: Changing Landscape Tastes over Three Centuries. Landscape, 19(3), 39-47.

Gómez Mendoza, J. (2002). Paisajes forestales e ingeniería de montes. En F. Zoido Naranjo (Ed.), Paisaje y ordenación del territorio (pp. 237-254). Sevilla: Junta de Andalucía y Fundación Duques de Soria.

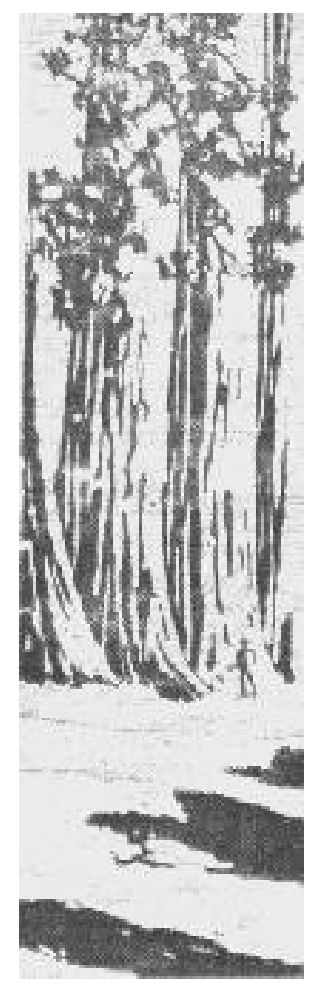


Muir, J. (1901)

Our National Parks. Boston y Nueva York, NY: Houghton, Mifflin, and Co.

Wood, D. (1988) Unnatural illusions: some words about visual resource management. Landscape Journal, 192-205. magnificencia de los cañones rocosos y de las montañas en general permanecerán salvajes, porque el hombre apenas puede cambiarlos o dañarlos, no más de lo que pueden las mariposas que los merodean. Pero las belleza externa del continente está falleciendo, especialmente las que encierra el mundo vegetal, la más destructible y la más cautivadora de todas." (Muir, 1901; pp. 4-5)

"John Muir no recorrió las cimas del país por las vistas; partió no 'como una mero deporte o excursión de entretenimiento, sino para encontrar la ley que gobierna la relación de subsistencia entre la raza humana y la Naturaleza'."

(Wood, 1988; p. 195).

\section{III.3.4. Nuevas perspectivas sobre lo natural tras la dominancia de la analítica del arte}

En buena parte del siglo XX la disciplina estética de lo natural estuvo completamente dominada por la "analítica del arte". Este enfoque en lo artístico se ramificó en dos corrientes: aquella que simplemente negaba la experiencia estética en lo natural (pues no resultaba del logro del intelecto), y aquella que consideraba lo natural desde la perspectiva única de sus cualidades artísticas y formales (reforzando la idea de lo pintoresco). En esta etapa, sólo resaltan casos excepcionales en el tratamiento filosófico del paisaje natural, como el hispano-estadounidense George Santayana (1863-1952) o el estadounidense John Dewey (1859-1952).

"El paisaje natural es un objeto indeterminado, casi siempre contiene suficiente diversidad como para dar al ojo una gran libertad para seleccionar, resaltar y agrupar sus elementos, y es además rico en sugestiones y en estímulos emocionales vagos. Un paisaje debe ser estructurado y organizado para ser visto y debe ser interpretado a través de la moral para ser apreciado [...] Cuando aprendemos a apercibirlo; cuando nos aficionamos a rastrear sus líneas y sus escenas; cuando, sobre todo, las influencias más sutiles de los lugares se transmutan en nuestra mente en la expresividad de dichos lugares, y son poetizados por medio de nuestras ensoñaciones y, por medio de nuestra fantasía, descubren múltiples indicios de un país de hadas de vida dichosa y de una vaga aventura, entonces sentimos que el paisaje es bello. Los bosques, los campos, todas las escenas silvestres o rurales, están entonces llenas de compañía y entretenimiento." (Santayana, 1961 (publicado por primera vez en 1896), p. 99). 
En el último tercio del siglo XX, sin embargo, se rearma la importancia de lo natural en la estética como respuesta al impulso de la concienciación ambiental y su resonancia en el mundo académico a partir de los años 60. Así, se reivindica la importancia de la apreciación estética de la naturaleza como tal, como naturaleza, y se argumenta insistentemente que los modelos orientados al arte no alcanzan una verdadera y apropiada apreciación de lo natural, sino que distorsionan su verdadero carácter.

La ética ambiental fue tomando cuerpo también en esta época y las críticas dirigidas a una estética demasiado centrada en lo formal y lo escénico comenzaron a aparecer. Carlson (2009) llama la atención sobre el ensayo de Ronald Hepburn de 1966 "Estética contemporánea y el olvido de la belleza de lo natural" ("Contemporary Aesthetics and the Neglect of Natural Beauty") como uno de los hitos que inauguró la estética ambiental y del paisaje ordinario. Hepburn Ilamó la atención sobre la existencia de la experiencia estética más allá del arte e hizo una clara distinción entre la estética trivial y superficial, y la estética profunda que ha de caracterizar la relación con lo natural.

III.3.5. La actualidad sobre la apreciación de lo natural: corrientes cognitivistas, no cognitivistas y "estética ecológica"

Carlson (2009) observa la existencia en la actualidad de dos corrientes en la estética ambiental que explican de diverso modo la apreciación de lo natural: la cognitiva y la no cognitiva.

Para las corrientes cognitivas, si bien la apreciación estética puede tener un componente artístico o formal, el conocimiento sobre la naturaleza del objeto de apreciación es esencial en el proceso. Según el tipo de recurso cognitivo que se trate con preferencia, distingue entre el cognitivismo científico o el de las tradiciones históricoculturales, es decir, la apreciación estética de las cualidades del mundo natural apoyada por conocimientos sobre la historia y ciencias naturales o por las prácticas, costumbres, folclore o mitos locales 0 regionales. Por otro lado, la corriente no-cognitivista defiende que los

The Development and Nature of Environmental Aesthetics. En A. Carlson (ed.), Nature and Landscape: An Introduction to Environmental Aesthetics (pp. 121). Nueva York, NY: Columbia University Press.

Hepburn, R. (1966).

Contemporary Aesthetics and the Neglect of Natural Beauty. En B. Williams y A. Montefiore (Eds.), British Analytical Phylosophy (pp. 285-310). Londres, UK: Routledge \& Kegan Paul. 
Berleant, A. (1992) The Aesthetics of Environment. Filadelfia, PA: Temple University

Carroll, N. (1993) On Being Moved by Nature: Between Religion and Natura History. En S. Kernall y I. Gaske (Eds.), Landscape, Natural Beauty and the Arts (pp. 89-107). Cambridge, UK: Cambridge University Press

Carlson, A. (1993) On the theoretical vacuum in landscape assessment. Landscape Journal, 12(1), 51-56

Saito, Y. (1998) The aesthetics of unscenic nature. The Journal of Aesthetics and Art Criticism, 56(2), 101-111. factores con mayor peso en la experiencia estética del paisaje son aquellos que no tienen tanto que ver con lo intelectual, sino con la experiencia emocional del paisaje. En esta corriente se encuadran por ejemplo la "estética de la implicación" ("Aesthetics of Engagement") de Berleant (1992), que defiende la importancia de la experiencia participativa y del contacto íntimo con el paisaje; o el "modelo del despertar" ("Arousal model") de Carroll (1993), que implica que podemos apreciar la naturaleza simplemente abriéndonos a ella y dejando que nos estimule emocionalmente.

En general, actualmente se reconoce que no existe razón que niegue que todas estas dimensiones cuentan en la experiencia estética del paisaje natural y que ninguna debería excluirse. El interés se funda hoy en día más en lo que debería ser que en lo que es, es decir, más allá de la retórica sobre la esencia de la estética de lo natural, lo trascendental es la legitimidad de la experiencia, esto es, qué tipo de experiencia sería deseable por la conveniencia de sus consecuencias para la conservación y mejora de lo natural. Así, el debate actual hace hincapié en el aspecto ético de la estética del paisaje y sus resultados sobre el funcionamiento ecológico (Carlson, 1993; Saito, 1998).

La denominada "estética ecológica" surge como una corriente que recorre esta vía, recoge la preocupación ante la manera en la que la apreciación dominante de lo natural puede afectar al funcionamiento ecológico del paisaje y se funda sobre una estrategia que se sirve de la estética del paisaje natural para dirigir la evolución del mismo. En el Apartado III.4 - Contribuciones a la estética ecológica - se ofrece una revisión amplia de sus postulados. 


\section{III.4. CONTRIBUCIONES A LA ESTÉTICA ECOLÓGICA}

\section{I.4.1. Ampliación del alcance de la estética del paisaje natural: estética ecológica}

Como reacción a la estética escénica que en mayor o menor grado ha dominado la conceptualización y el proceder del tratamiento paisajístico (Gobster, 1994), algunos planificadores, diseñadores, filósofos y sociólogos ambientalistas han defendido desde los años 80 del siglo XX la necesidad de ampliar el alcance y posibilidades de la estética del paisaje para incorporar de forma efectiva ideas o mensajes sobre los procesos ecológicos (Fry et al., 2009; Gobster et al., 2007). De la estela de esta preocupación surgió entonces la denominada "estética ecológica", que propugna que un medio clave para alcanzar una óptima gestión ecológica del paisaje consiste en servirse de la experiencia estética y sus efectos sobre la sociedad. Trata así la manera en la que la apreciación dominante del paisaje puede afectar a su funcionamiento ecológico y se funda sobre la base de una estrategia de potenciación mutua de ambos aspectos.

Una de las principales aportaciones de la estética ecológica ha sido hasta el momento el poner de relieve los conflictos generados entre la función ecológica y la imagen percibida y abrir el debate sobre cómo estos pueden ser resueltos. Sin embargo, el salto hacia la práctica se encuentra aún en estados primigenios. Se reconoce que existen muchas medidas de gestión con efecto positivo tanto en el plano visual como en el ecológico, pero es precisamente en las áreas en las que la relación no es compatible en la que la estética ecológica pretende actuar.

Dentro de la línea de la estética ecológica, pueden distinguirse dos formas de abordar estas incompatibilidades, cuya diferencia radica en la parte del binomio hombre-paisaje sobre la que se pretende actuar (Gobster et al., 2007):
Gobster, P. H. (1994).

The aesthetic experience of sustainable forest ecosystems. En W. W. Covington y L. F. De Bano (Coords.) Sustainable Ecological Systems:

Implementing an Ecological Approach to Land Management, pp. 246-255 (General Technical Report RM247). Fort Collins, CO USDA Forest Service, Rocky Mountain Forest and Range Experiment Station.

Fry, G., Tveit, M. S., Ode, Å., y Velarde, M. D. (2009). The ecology of visual landscapes: Exploring the conceptual common ground of visual and ecological landscape indicators Ecological Indicators, 9(5), 933947.

Gobster, P. H., Nassauer, J. I., Daniel, T. C., y Fry, G. (2007) The shared landscape: what does aesthetics have to do with ecology? Landscape Ecology, 22(7), 959-972. 
- Influir sobre la forma en la que la gente interpreta los valores ecológicos en el paisaje. A través de la mejora de la comprensión, un mayor contacto con los procesos ecológicos, y de una mayor y mejor exposición de sus características, el público podría llegar a una experiencia de mayor calado ante el paisaje y llegar a realizar una valoración más consecuente con la realidad y conveniencia ecológica de las actuaciones.

- Creación de formas de paisaje mediante el diseño que den cabida a la dimensión ecológica de tal manera que se establezca una correspondencia entre los valores funcionales, lo percibido y lo esperado.

Los principales valedores de la línea argumental de la estética ecológica fueron desarrollando su visión hasta que en torno al año 2005 comenzaron a contrastar ideas ${ }^{1}$ y a recoger su cuerpo teórico formal con la intención de inicio de construcción de un paradigma de tratamiento del paisaje (Gobster et al., 2007). La forma en que se trata la unión entre la experiencia estética y el funcionamiento ecológico se ha desarrollado de forma diferente según cada autor (mostrando igualmente coincidencias), asunto que enraíza en diferencias conceptuales o de trayectoria profesional que resultan en estrategias diversas. En los epígrafes siguientes se realiza una revisión de las particularidades expuestas por autores ligados directa o indirectamente a los postulados de la estética ecológica y que ayudan a construir una imagen completa del nuevo paradigma.

\footnotetext{
${ }^{1}$ Gobster (2008) cita la conferencia "Our shared landscape" como el punto de inicio del debate y la colaboración en este sentido.
} 


\section{III.4.2. Aldo Leopold: el germen de la estética ecológica}

El modelo de interpretación del paisaje propuesto por la estética ecológica bebe directamente del legado del forestal y ambientalista estadounidense Aldo Leopold (1887-1948) (Figura 17) y sus escritos recopilados en su conocido A Sand County Almanac (Leopold, 1949) y The River of the Mother of God: and other Essays by Aldo Leopold (Callicott y Flader, 1992).

Leopold, A. (1949). A Sand County Almanac with Sketches Here and There. Nueva York, NY: Oxford University Press.

Callicott, J. B. y Flader, S. L. (1992) The River of the Mother of God: and other Essays by Aldo Leopold. Madison, WI: University of Wisconsin Press.

Figura 17. Aldo Leopold oteando el paisaje del Rio Gavilán (Méjico) durante una salida de caza (1937).

Fuente Fotografía: Starker Leopold/Aldo Leopold Foundation.

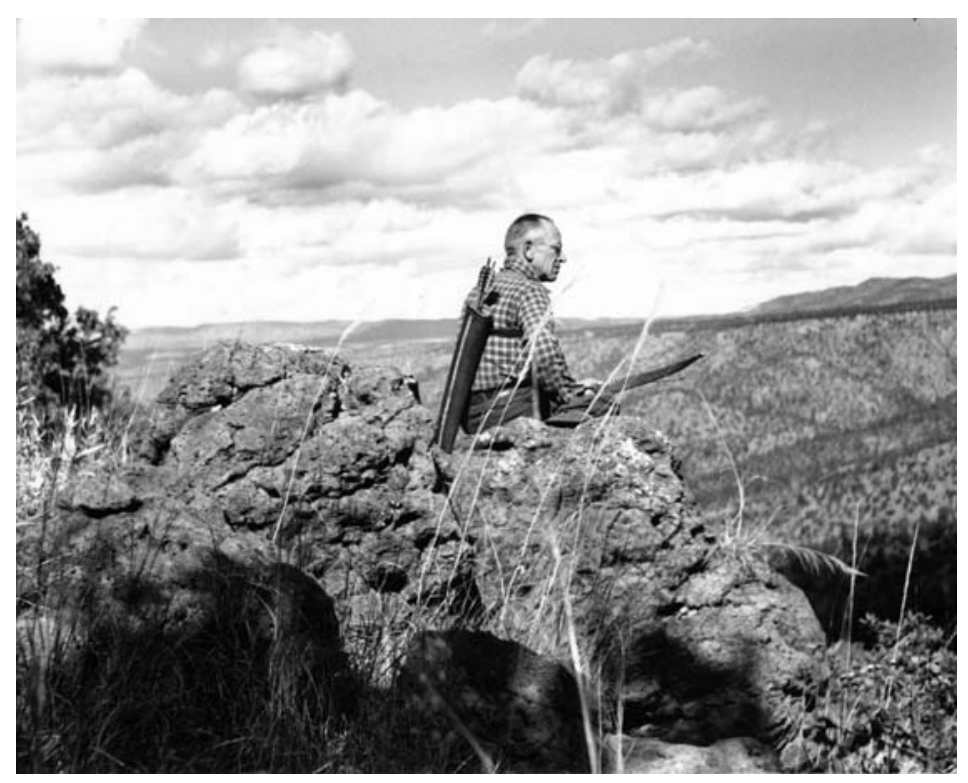

Aunque Leopold es fundamentalmente reconocido como un referente en el surgimiento del movimiento conservacionista y ambientalista gracias a su pensamiento sintetizado en su ensayo The Land Ethic (Leopold, 1949), dispersa en sus numerosos escritos se destila una "estética de la tierra" ("land aesthetic") igualmente original y revolucionaria, aunque, al contrario que la "ética de la tierra" (término acuñado por el mismo Leopold) ésta no se encuentre etiquetada como tal. En palabras de J. Baird Callicott, uno de los autores que más ha reflexionado en torno a los escritos de Leopold, la estética de la tierra que se destila en A Sand County Almanac es la primera estética natural en la literatura occidental, genuina y autónoma (no supeditada a la estética del artefacto), desde la aportación de Kant (Callicott, 1983; p. 353).

Callicott, J. B. (1983). The Land Aesthetic [Special Issue: A Cumulative Index to the First Seven Years of Environmental Review]. Environmental Review, 7 (4), 345-358. 
Leopold, A. (1949). A Sand County Almanac with Sketches Here and There. Nueva York, NY: Oxford University Press.

Callicott, J. B. (1983). The Land Aesthetic [Special Issue: A Cumulative Index to the First Seven Years of Environmental Review]. Environmental Review, 7 (4), 345-358

Callicott, J. B. y Flader, S. L. (1992). The River of the Mother of God: and other Essays by Aldo Leopold. Madison, WI: University of Wisconsin Press.
El pensamiento de Leopold descansa en la consideración de lo bello siempre a través de la lente de la integridad ecológica y en la apreciación estética basada en la experiencia y el reconocimiento de la evolución natural y la ecología, que conducen a un gusto refinado y profundo a través del conocimiento. Así se puede llegar a una apreciación de la belleza del entorno más intensa, al estar bañada por el significado de lo que se ve. El pensamiento de Leopold se sintetiza en su sentencia más citada:

\footnotetext{
"Algo está bien cuando tiende a preservar la integridad, estabilidad y belleza de la comunidad biótica. Está mal cuando tiende a lo contrario" (Leopold, 1949; p. 224).
}

Leopold no ensalza el carácter salvaje o natural del paisaje, sino más bien el conocimiento de sus funciones, sus mecanismos, sus relaciones... incluyendo al hombre. La estética de Leopold no favorece unas comunidades naturales frente a otras, pues los paisajes menos bellos no tienen por qué ser los menos interesantes en términos estéticos. La "estética de la tierra" incluye todos los sentidos y se ocupa de todos los elementos. No excluye la experiencia escénica o la experiencia sin conocimiento, sino que aboga por considerar que el conocimiento en historia natural y ecología aportan profundidad y amplitud a la apreciación estética. Cualquier forma de conocimiento "penetra" en la superficie ofrecida por la experiencia sensorial directa y aporta sustancia a la escena (Callicott, 1983, p. 348).

"En la revolucionaria estética de la tierra de Leopold todos los sentidos, no sólo la vista, median a través de un gusto refinado por los objetos naturales, una experiencia estética que es igualmente cerebral y perceptual"

(Callicott y Flader, 1992; p. 9)

Pero no se podría encuadrar la estética de Leopold como puramente cognitivista, pues contiene suficientes recursos relativos al carácter poético y a la imaginación como para extender la estética más allá del conocimiento científico. Por ejemplo, al contrastar la visión de unas praderas que la estética superficial podría encontrar tediosa, Leopold no se refiere a un conocimiento ecológico o a valores presentes, sino que recurre a la imaginación y a la historia antropológica para aportar valores al contexto natural actual. Igualmente se refiere al contacto directo con la Naturaleza, al tipo de relación íntima que se impone por la dependencia y el acercamiento profundo y frecuente. 


\section{III.4.3. González Bernáldez: la dualidad criptosistema- fenosistema y el desciframiento del paisaje}

Fernando González Bernáldez (1933-1992) fue un reconocido ecólogo español que realizó interesantes aportaciones en el campo de la percepción del paisaje (Figura 18). Su concepción resulta relevante en cuanto que adopta una perspectiva unificadora basada en el punto de vista de la información que ofrece el paisaje. De tal manera, interconecta los procesos ecológicos con los resultados visuales, muestra una visión completa (biológica, estética y antropológicacultural) de la relación hombre-paisaje y se apoya siempre en la necesidad de comprender e interpretar los paisajes, todo ello encaminado a la búsqueda de mecanismos para conservar los paisajes de forma estable y duradera.
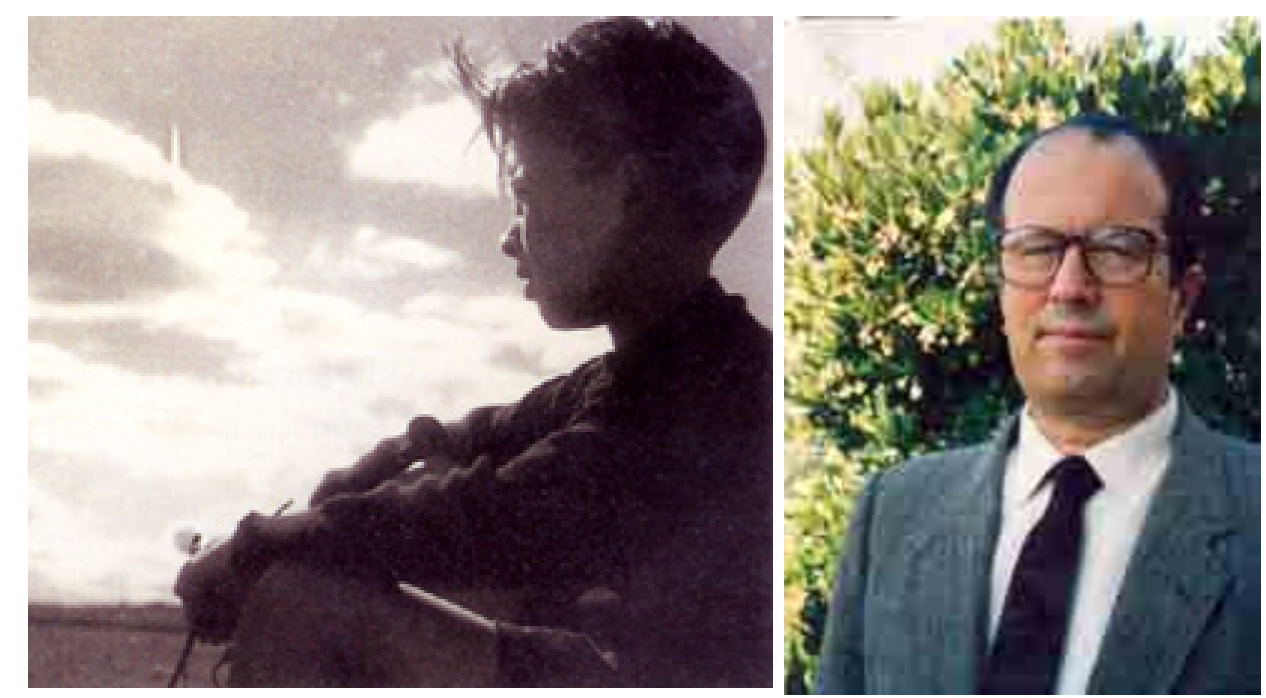

Figura 18. En palabras de José Vicente de Lucio Valle "La gran inquietud de González Bernáldez fue la búsqueda de una síntesis entre la comprensión de los procesos ecológicos subyacentes al paisaje y el entendimiento de las claves que hacen los lugares valiosos para los individuos y la sociedad. La expresión 'desciframiento del paisaje' utilizada habitualmente en escritos y conferencias proporciona un titular para dicha tarea" (Lucio del Valle, 2002, p. 127).

Fuente fotografías: Libro homenaje a González Bernáldez (Montes, Levassor, Cuenca, y Casado (Eds.), 2002).

Lucio del Valle, J.V. (2002).

Paisaje y ecología del paisaje. En C. Montes, C. Levassor, A. Cuenca, y S. Casado, (Eds.), Figura con paisajes. Homenaje a Fernando González Bernáldez. Madrid: Fundación Interuniversitaria Fernando González Bernáldez. 
González Bernáldez, F. (1981) Ecología y Paisaje. Madrid: Blume.

\section{El paisaje interpretado desde la perspectiva dual criptosistema- fenosistema}

En palabras de González Bernáldez el paisaje es "la información que el hombre recibe de su entorno ecológico". Este autor señala la existencia de dos componentes en la realidad territorial: un sistema de relaciones subyacentes, presentes pero no observables de forma directa ("criptosistema") y el sistema aparente ("fenosistema"), la parte fácilmente perceptible de esas relaciones ocultas, cuyo funcionamiento explicaría la copresencia y coherencia de los elementos percibidos (González Bernáldez, 1981).

La importancia del fenosistema reside en su papel como fuente de información sobre la realidad espacial, que es posible asimilar e interpretar, al menos en parte. El paisaje hace patente, revela, exhibe. El paisaje es, en fin, la manifestación sintética de las circunstancias que concurren en el territorio. La idea que subyace es la de que una función básica y primigenia del paisaje es la de provisión constante de indicativos y la actitud del hombre ha de ser la de indagación.

\section{El desciframiento del paisaje}

González Bernáldez, F. (1988). El paisaje natural. En J.R MartínezRodríguez (Coord.), Elementos básicos para Educación ambiental (pp. 97-112). Madrid: Ayuntamiento de Madrid
"Si el paisaje es la manifestación visible de todo un sistema ecológico subyacente, es lógico que a partir de ciertos signos o características fácilmente observables podamos inducir características más escondidas, latentes, ocultas del sistema" (González Bernáldez, 1988; p.102)

De este modo resumía González Bernáldez la oportunidad que ofrecía el paisaje para informar sobre su propio funcionamiento ecológico. Esta capacidad de transmisión del paisaje constituye la idea central sobre la que apoyó la tarea de desciframiento del paisaje, es decir, el paso del fenosistema al criptosistema (González Bernáldez, 1981).

\footnotetext{
"Un naturalista atento al medio que frecuenta puede establecer gran cantidad de relaciones entre los organismos presentes, las formas del terreno y las características escondidas del medio. Puede llevar a cabo asi una interpretación del entorno relacionando los aspectos manifiestos con los menos visibles del sistema. Si este modo de interpretar el entorno se actualiza, incorporando los nuevos resultados de investigaciones ecológicas, ecofisiológicas, hidrológicas, etc...constituye una importante posibilidad de vigilar y conocer cambios en el sistema [...]"
} 
A través del uso de indicadores (bioindicadores) el autor proponía una herramienta para informar sobre el estado de los paisajes con importantes potencialidades en la práctica del análisis ambiental y la conservación. En primer lugar el desciframiento del paisaje ofrece un complemento útil para la investigación y análisis ambiental a través de la instrumentación, pues resulta un medio rápido (y barato) que lleva a inferir propiedades más ocultas del entorno, para entender su funcionamiento y fisiología en términos ecológicos. No sólo eso, sino que González Bernáldez también posiciona el carácter sintético del fenosistema como característica clave para alcanzar una verdadera interdisciplinariedad en su estudio, que no aglutine sino que integre temas y perspectivas a través de una interpretación centrada en el resultado final del paisaje (Figura 19 y 20).

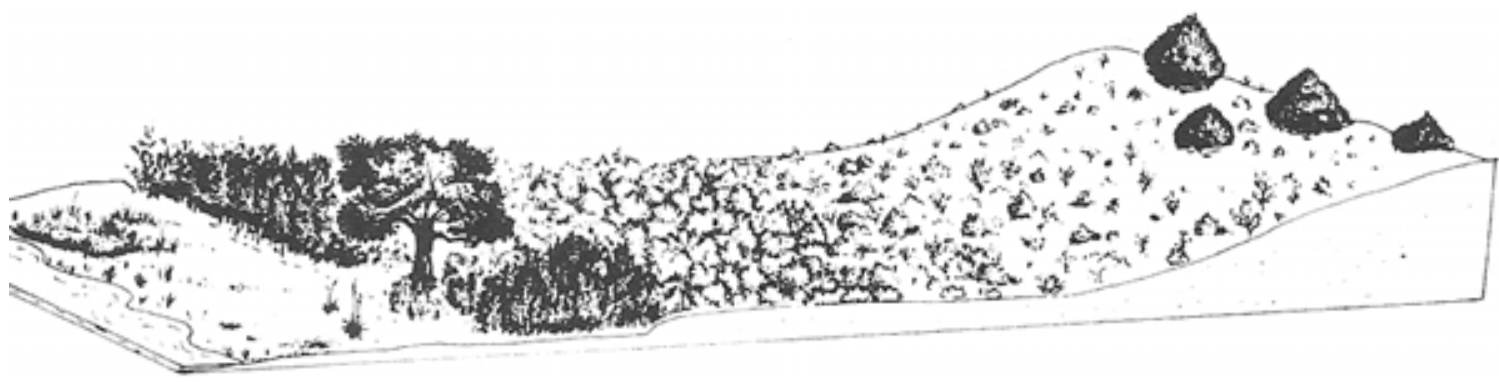

Figura 19. Ejemplos de correspondencia entre vegetación y topografía. "Variación del matorral de dunas estabilizadas ('naves'). Las partes altas tienen 'monte blanco' xerofitico con jaguarzo y sabinas (resto del bosque terminal). Las partes bajas presentan el 'monte negro' con brezo (Erica scoparia). Algún alcornoque aislado representa vestigios del bosque terminal". Figura y texto extraído de González Bernáldez (1981), p. 82.

"Para entender correctamente la naturaleza de ese recurso [refiriéndose a 'paisaje percepción'] y para poder gestionarlo adecuadamente es necesario sin embargo conocer los sistemas que lo soportan o mantienen, es decir, también el criptosistema o parte menos accesible a la observación y por lo tanto no incluida en el concepto vulgar de paisaje. Por ejemplo: Los multicolores brezales de tipo oceánico con Calluna y especies de Erica y Ulex como en la Reserva Biológica de Doñana [...], además de su valor científico y de conservación del patrimonio genético, posee un valor estético. Sin embargo, por (sic) preocuparnos de la conservación de los valores estéticos que se representan en esos lugares, es necesario que investiguemos

lo mejor posible los aspectos del criptosistema o procesos menos manifiestos, pero necesarios para entender el mantenimiento del estado actual del sistema y sus atributos. Así, los efectos de perforación y extracción de agua en determinadas cantidades y tiempos en la vecindad de esas zonas debe ser valorada en sus efectos sobre el descenso del límite superior de la capa saturada del agua subterránea. Así puede decirse si va a afectar a la vegetación provocando un cambio por ejemplo hacia matorrales de jaguarzo (como de hecho ocurre en el Parque Nacional de Doñana) [...].Por lo tanto, el paisajista debe conocer no sólo los aspectos "paisaje percepción" sino también los de "paisaje ecosistema" o al menos principios y fundamentos suficientes que le permitan una comunicación adecuada con otros especialistas." Texto extraído de González Bernáldez (1988), p.100. 


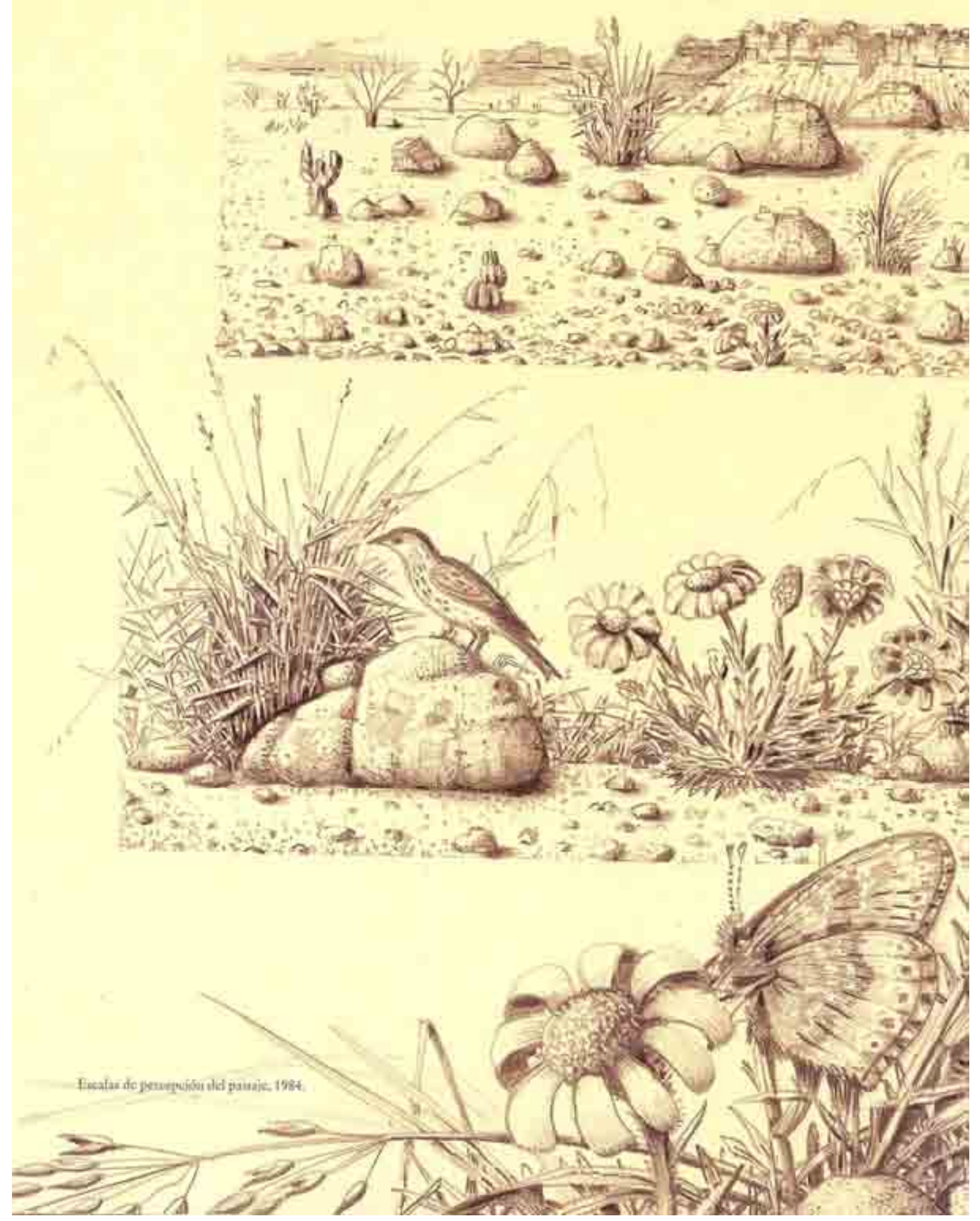




\section{Percepción subjetiva y relación con la gestión del paisaje}

El interés del paisaje en su acepción como medio percibido conduce a Bernáldez a poner de manifiesto la dimensión subjetiva que posee y a estudiar sus características desde dos puntos de vista (González Bernaldez, 1988):

- El de su dimensión como recurso escénico que es necesario gestionar para su conservación y utilización.

González Bernáldez, F. (1988). El paisaje natural. En J.R MartínezRodríguez (Coord.), Elementos básicos para Educación ambiental (pp. 97-112). Madrid:

Ayuntamiento de Madrid.

- El de concepto "bisagra" que une los componentes ecológicofisiológico y antropológico-cultural.

En cuanto al primer punto de vista, son reconocidos los trabajos llevados a cabo sobre el estudio de preferencias ante el paisaje (fundamentalmente natural) que, unido a otras variadas aportaciones al campo de la estética experimental del paisaje (Figura 21), aportaron luz a la comprensión de los factores del medio que desencadenan las reacciones estéticas del público ante el paisaje (para una revisión completa, ver González-Bernáldez, 2011).

González Bernáldez, F. (2011). Invitación a la ecología humana. La adaptación afectiva al entorno. Madrid: Fundación Fernando González Bernáldez y Red Eléctrica de España (publicación original en 1985).
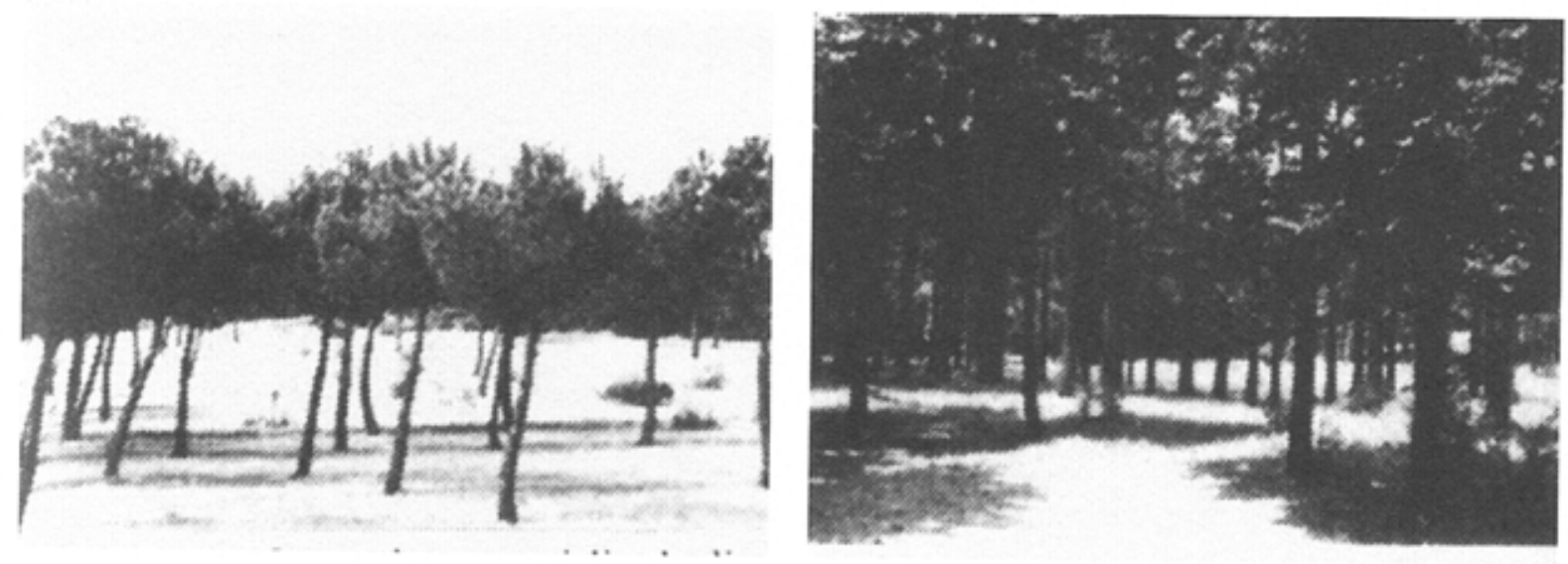

Figura 21. Ejemplo de tendencias de elección o dimensiones independientes detectadas en el análisis factorial de preferencias por paisajes forestales (grupo de universitarios, El Pardo-Casa de Campo, Madrid). La pareja de imágenes materializa la dimensión o factor "vigor, biomasa, lujurianza (sic) de la vegetación" que opone las dos imágenes del par. Tiene que ver con reacciones características frente a la vegetación natural.

Figura y texto extraídos de González-Bernáldez (2011), p.19-20. 
González Bernáldez, F., Ruiz,

M., y Ruiz Sanz, J. P.

(1985).La percepción del paisaje por los protagonistas de su creación y mantenimiento. Pirineos $125,5-29$.

Ruiz, J. P. y González-

Bernáldez, F. (1983). Landscape perception by its traditional users: the ideal

landscape of Madrid livestock raisers. Landscape Planning, 9(3-4), 279-297.

González Bernáldez, F. (1981). Ecología y Paisaje. Madrid: Blume.

Igualmente interesante resulta para la perspectiva de esta tesis el segundo punto de vista que desarrolló González Bernáldez, por su capacidad para servir de puente entre científicos, gestores y modificadores directos del paisaje. Nos referimos a su indagación sobre las reglas culturales para la valoración del entorno natural que puso de manifiesto en su análisis de las preferencias estéticas de los protagonistas de su creación y mantenimiento, en concreto el caso de los ganaderos tradicionales del norte de Madrid (González Bernáldez, Ruiz, y Ruiz Sanz, 1985; Ruiz y González-Bernáldez, 1983). De tal manera, se pone de manifiesto cómo la percepción del paisaje por la población rural (Figura 22) se basa en características funcionales, de utilización y gestión, que se confunden o superponen generalmente con la consideración en términos de bonito/feo (o bien estas no tienen sentido si son desligadas de las características de una buena o mala gestión) (González Bernáldez, 1981).

Estas indagaciones tienen una relevancia importante y aun insuficientemente explorada pues, en primer lugar, ponen el foco en la estética de un usuario importante del paisaje por su papel como modelador (ante el imperante interés actual del público general y los fines recreativos). Por otro lado, permite entender mejor la relación que se establece entre hombre y paisaje en los importantes sistemas productivos que se apoyan en la dinámica ecológica.

"Solo una ínfima parte de nuestro paisaje es el resultado de un 'paisajismo voluntario', realizado de forma intencionada y consciente para la promoción de características estéticas visuales. La inmensa mayor parte del paisaje 'natural' es el producto de una interacción hombre-naturaleza donde se persiguen finalidades productivas" (González-Bernáldez, 1981, p. 81) 

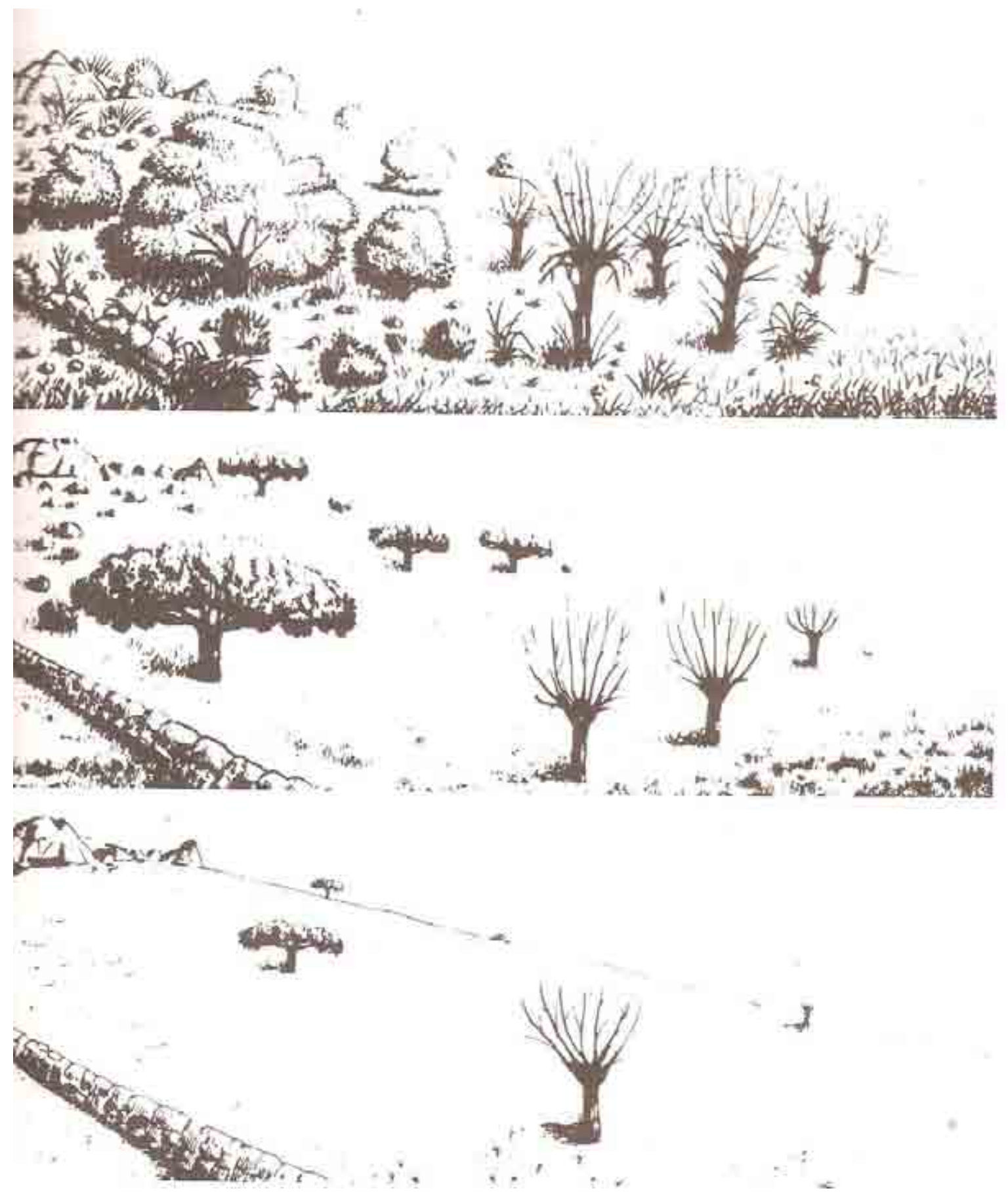

Figura 22. "Representación esquemática del paisaje ideal o canónico de los ganaderos tradicionales de la Sierra de Madrid (en el centro) junto con dos aspectos desviantes de la forma canónica: una por descuido y escasez de presión (arriba) y otra por exceso de aprovechamiento (abajo). La "lectura" del paisaje por parte de sus usuarios tradicionales incluye la interpretación de símbolos tanto de la potencialidad inherente del entorno como de los resultados de los esfuerzos de gestión (según Ruiz y González-Bernáldez, 1983)". Figura y texto extraídos de González Bernáldez (2011), p.83.
González Bernáldez, F. (2011). Invitación a la ecología humana. La adaptación afectiva al entorno. Madrid: Fundación Fernando González Bernáldez y Red Eléctrica de España (publicación original en 1985) 


\section{III.4.4. Allen Carlson: la estética del medio natural a través de la experiencia, el conocimiento científico y la sensibilidad}

Carlson, A. (1979) Appreciation and the natura environment. The Journal of Aesthetics and Art Criticism, $37(3), 267-275$

\section{Crítica a la estética de lo escénico - formal y defensa de la apreciación desde el conocimiento}

Allen Carlson (1949-), filósofo especializado en la estética ambiental (Figura 23), denuncia como el formalismo y lo escénico, que tienen más que ver con el arte, no conducen a una evaluación estética consecuente para el caso del paisaje natural y resulta en un juicio banal y carente de relevancia. El autor no niega que las características formales supongan un valor añadido, sino que defiende que el análisis de las características del paisaje natural realizado exclusivamente en dichos términos resulta en una evaluación limitada del paisaje, no responde a la esencia del objeto de apreciación y soslaya cualidades importantes que le son propias (Carlson, 1979).

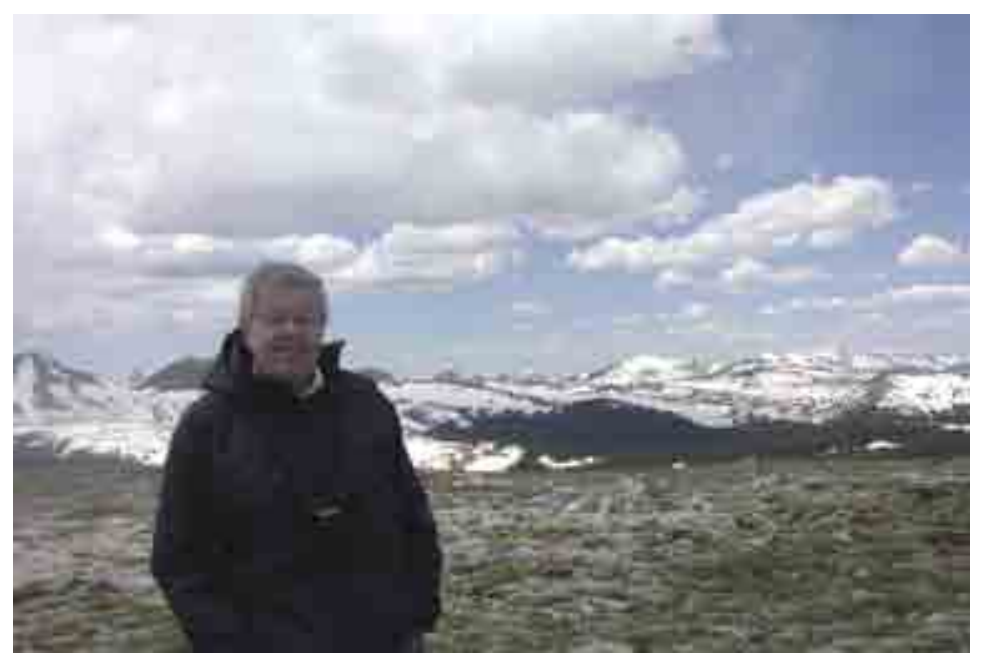

"...para apreciar y valorar la calidad estética del medio debemos apreciar y valorar cualidades como la gracilidad del antílope, la delicadeza de una flor, la austeridad de un paisaje desierto, la serenidad de una silenciosa pradera o la amenaza que encierra un cielo antes de la tormenta. De hecho, el omitir estas cualidades de possibility of quantifying scenic beauty. Landscape Planning, 4, 131-172.
Figura 23. Allen Carlson, profesor de la universidad de Alberta (Canadá) fue uno de los pioneros en el campo del tratamiento filosófico de la estética ambiental, con aportaciones esenciales en relación a la ecología estética. Fuente fotografía:

https://allencarlson.com/ nuestra apreciación estética del medio natural la reduce hasta tal punto que a duras penas puede ser reconocida incluso como una apreciación estética, y evaluar un paisaje sin esa aportación significa evaluarlo de una manera excesivamente trivial y superficial." (Carlson, 1977, p. 158) 
En contraposición a estas formas de evaluación dominantes, Carlson aboga por una apreciación del medio natural según su esencia, esto es, el medio como lo que nos rodea y en calidad de natural, es decir, alejado del artefacto humano ${ }^{2}$. Carlson reconoce que una apreciación estética profunda del paisaje natural ha de referenciarse siempre bajo la influencia del conocimiento de las leyes naturales y su evolución. El autor relega los atributos formales y escénicos a un segundo plano y posiciona las cualidades no formales y la comprensión científica del paisaje en la primera línea. Se posiciona así en la corriente cognitivista-científica de la relación hombre-paisaje.

Consecuentemente, Allen Carlson aboga por que las preferencias han de estar basadas no sólo en el aspecto del paisaje, sino también en su capacidad de expresar su sostenibilidad a la luz de nuestro conocimiento (o creencias) y nuestro juicio sobre por qué los paisajes se muestran de la manera en que se muestran. El asunto central sería pues analizar qué se conoce de los paisajes, cómo se puede llegar a conocerlos en profundidad y en qué grado y cómo expresan dichos paisajes esas cualidades. Al margen de que los paisajes sostenibles (y por tanto los que presentan un correcto funcionamiento ecológico) puedan o no tener una apariencia reconocible, para Carlson puede establecerse un reconocimiento de sus cualidades basadas en otras fuentes a parte de su propia apariencia, y este conocimiento acaba determinando nuestra apreciación.

\section{La figura del crítico ambiental}

Siguiendo esta línea, Carlson (como otros muchos autores) duda de la validez de las llamadas metodologías de evaluación de preferencias (escénicas) ante el paisaje basadas en el uso de fotografías, argumentando que éstas en realidad no analizan la verdadera calidad estética del paisaje, sino simplemente las preferencias del público, y

\footnotetext{
${ }^{2}$ El hecho de que sea natural remite a que no es una creación del hombre (o no es únicamente antrópica). Por tanto nuestra apreciación estética no deriva de nuestra implicación en su creación, sino de nuestro conocimiento derivado del descubrimiento por medio de la experiencia, el sentido común y el saber científico. Este mecanismo es crucial para transformar la mezcla de sensaciones en bruto que recibimos en una experiencia reconocible, armónica y llena de sentido. Esta competencia es la que nos guía en la forma de apreciar distintos contextos naturales y de tal manera apreciar por las cualidades que le pertenecen a una pradera o el interior de un bosque.
} 
Carlson, A. (1977). On the possibility of quantifying scenic beauty. Landscape Planning, 4, 131-172.

Carlson, A. (1979) Appreciation and the natura environment. The Journal of Aesthetics and Art Criticism, 37(3), 267-275 que lo hacen desde la perspectiva dominante de lo visual. De este modo, estima que estos métodos dejan de detectar numerosos valores no relacionados con la visión bidimensional de una fotografía, y supeditan la evaluación a lo que denomina el "mínimo común denominador" ("lowest common denominator"), es decir, detectan los valores más obvios y desdibujan los más sutiles, que pueden llegar a ser transcendentales (Carlson, 1977).

"[el modelo escénico] requiere la reducción del medio[paisaje natural]a una escena o una vista. Sin embargo, lo que debe tenerse en cuenta es que el medio no es una escena, ni una representación, no es estático, ni bidimensional. La clave es que este modelo requiere la apreciación del medio no como lo que es y con las cualidades que le son propias, sino más bien como algo que no es y con cualidades que no posee. El modelo es por tanto inadecuado a la verdadera esencia del objeto de apreciación" (Carlson, 1979; p. 271)

No es que Carlson niegue la importancia de la consulta al gran público o cierta utilidad de estas metodologías, sino que encuentra esencial el que sean complementadas. Este complemento vendría no sólo dado por la incorporación de dimensiones estéticas complementarias a las formales, sino que también resultaría pertinente identificar a los expertos capaces de llevar a cabo una evaluación estética del paisaje natural relevante, pues han de tomar parte importante en el proceso de evaluación y conservación.

Esta última observación se fundamenta en su defensa de las competencias del denominado "crítico del medio ambiente" ("environmental critic"), un experto que actuaría como garante de la incorporación de los valores menos obvios a la evaluación del paisaje. Este crítico ambiental habría de combinar el conocimiento científiconaturalista y la sensibilidad suficiente ante los aspectos perceptuales y emocionales contenidos en el paisaje natural para realizar un juicio de la calidad estética del medio completo, pues la sensibilidad conduce exclusivamente a una apreciación limitada de un diseño agradable para los sentidos, y la aplicación de solo el conocimiento conduce a apreciarlo únicamente por sus cualidades científicas o intelectuales.

"... del mismo modo que la apreciación seria y apropiada del arte requiere un conocimiento en historia y crítica artística, la apreciación estética de la naturaleza requiere conocimientos en historia natural"

(Carlson, 1979; p. 273) 
Carlson ejemplifica la conveniencia de la actuación del crítico ambiental por medio de una analogía con la evaluación de la calidad del arte: si por la razón que fuere se tuviera que hacer una selección de las obras de arte más valiosas de una colección, previsiblemente entenderíamos como poco apropiado basar esta selección únicamente en las preferencias de una muestra representativa del público. Con este proceder sería probable que pasaran desapercibidos los aspectos más difíciles de entender por el público que no ha desarrollado la sensibilidad, conocimientos o la experiencia para detectarlos. Al contrario, recurriríamos también a la evaluación de los críticos de arte que reconocieran la calidad estética de las obras al margen de las preferencias generalizadas en la sociedad. De tal manera, movimientos como el arte abstracto u obras con un papel determinante en el desarrollo histórico del arte formarían parte de esta colección seleccionada.

Aldo Leopold encarnaba para Carlson las cualidades a reunir por el crítico ambiental. Sin embargo, el autor reflexionaba a finales de los años 70 del siglo XX sobre la necesidad de ese tipo de experto $y$ concluía que la mayoría de las veces no era buscado, lo cual revelaba que no se había desarrollado en la sociedad el reconocimiento de esta figura (y hoy en día aún puede decirse lo mismo). Para Carlson, en el tratamiento del paisaje, se ha transitado desde una dominancia del criterio del experto hacia una dominancia del criterio del público.

Teoría explicativa y justificativa: lo que es, por qué lo es y cómo debería ser

En su análisis del proceder en la evaluación del paisaje percibido, Carlson (1993) divide las experiencias de desarrollo teórico y evaluación por su carácter explicativo (identifican los fenómenos, explican sus causas, y predicen las reacciones) o justificativo

Carlson, A. (1993). On the theoretical vacuum in landscape assessment. Landscape Journal, 12(1), 51-56. (argumentan sobre la conveniencia de que los fenómenos sean de una cierta manera). 
Así, conocer qué paisajes son preferidos o apreciados e identificar las características que contribuyen a ello sería un paso que actualmente ha experimentado bastante desarrollo. Conocer por qué dichos paisajes son apreciados sería un segundo paso que aún es necesario desarrollar con mayor interés y profundidad. Carlson llama la atención sobre la falta de desarrollo de un paso más: esclarecer (justificar) por qué un paisaje debería ser preferible (Figura 24 y 33).

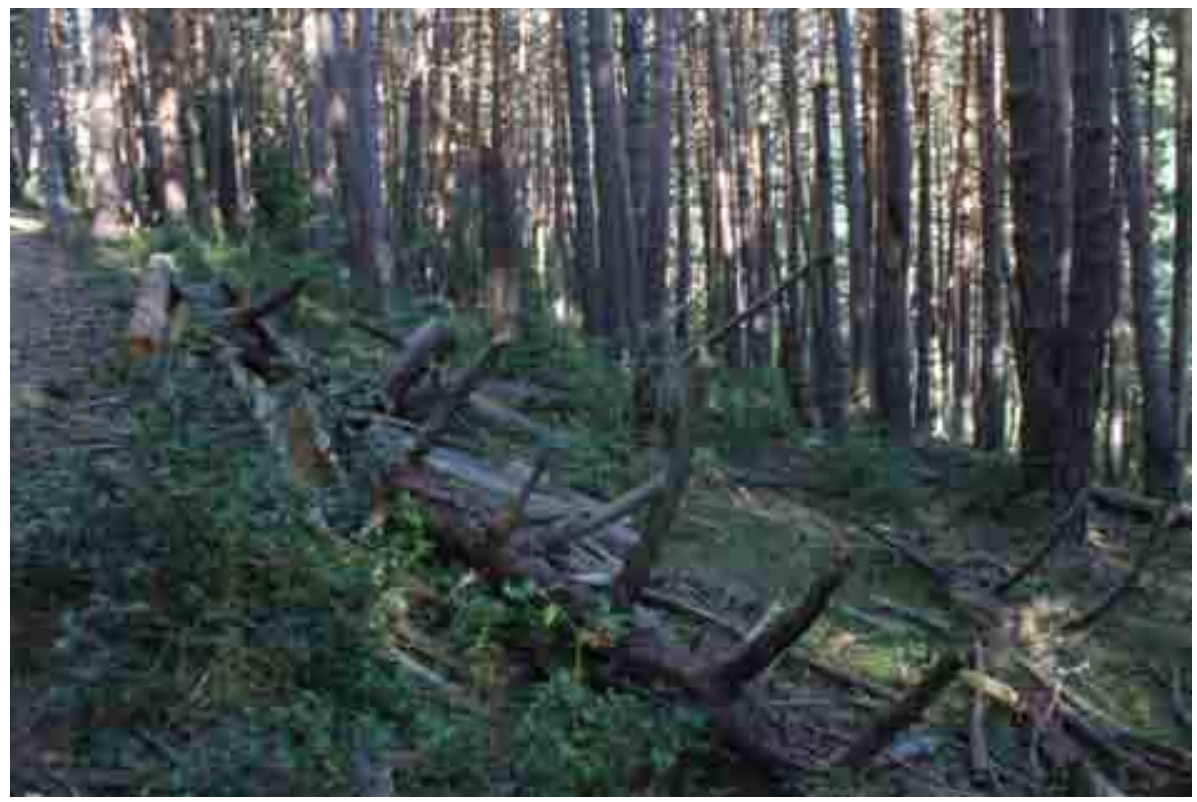

Figura 24. El hecho de que la ausencia de madera muerta haga que el paisaje sea más escénico y resulte preferido por el público no da respaldo a dicha preferencia y no justifica que haya de retirarse del monte. Un aspecto que merecería mayor examen y reflexión correspondería a la cuestión del origen de la presencia de madera muerta: natural o provocado por las actividades forestales. Fotografía tomada en 2015 en el Parque Natural de Sierra Cebollera, La Rioja.

La exploración y desarrollo de la teoría justificativa no tiene como cometido el constatar un hecho, sino el probar las conclusiones como válidas, razonables y sobre todo defendibles. No persigue marcar lo que es deseado, sino marcar lo que es deseable. Esto es esencial, pues evidencian las razones por las que los paisajes habrían de ser de cierto modo y la importancia de este hecho, por ejemplo en términos de bienestar humano. Los resultados de este tipo de teorías tienen por tanto una traducción directa en el ámbito de la planificación y el diseño, además de en la educación para la apreciación de paisajes. 


\section{II.4.5. Paul Gobster: estrategia hacia una estética ecológica}

Paul H. Gobster, investigador social y arquitecto del paisaje estadounidense (Figura 25), se ha ocupado principalmente del papel que tiene la relación entre estética y ecología en el paisaje desde el punto de vista de la conservación (sobre todo en paisajes forestales) y desde la perspectiva de su uso y disfrute social (fundamentalmente en términos recreativos) en los contextos más naturales ${ }^{3}$.

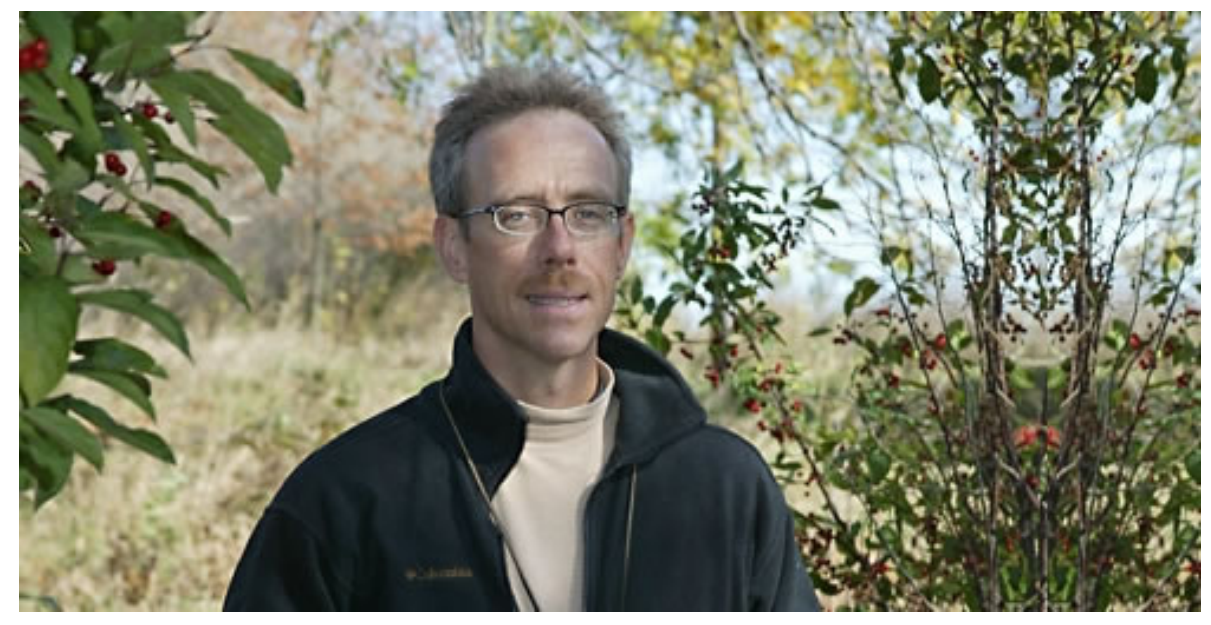

Figura 25. La actividad investigadora de Gobster gravita alrededor del modo de diseñar, planificar y gestionar los paisajes para mantener relaciones mutuamente beneficiosas entre la gente y los sistemas ecológicos.

Fuente fotografía: www.nrs.fs.fed.us

\section{Conflictos entre la "estética escénica" y la "estética ecológica"}

En la pura línea de la estética ecológica, Gobster ha sido uno de los primeros y más activos autores en defender que el placer ante el paisaje deriva en su forma más completa del hecho de ser conscientes de que lo que se está viendo es ecológicamente conveniente. De esta manera la experiencia del paisaje puede promover preferencias y

\footnotetext{
${ }^{3}$ Destacan también sus investigaciones experimentales y desarrollo teórico en zonas verdes urbanas.
} 
Gobster, P. H. (1994)

The aesthetic experience of sustainable forest ecosystems. En W. W. Covington y L. F. De Bano

(Eds.), Sustainable Ecological Systems: Implementing an Ecological Approach to Land Management (pp. 246-255)

(General Technical Report RM247). Fort Collins, CO: USDA Forest Service, Rocky Mountain Forest and Range Experimen Station

Gobster, P. H. (1995) Aldo Leopold's ecological esthetic integrating esthetic and biodiversity values. Journal of Forestry, 6-10.

Gobster, P. H. (1996) Forest aesthetics, biodiversity and the perceive appropriateness of ecosystem management practices. En M. W. Brunson, L. E. Kruger, C. B. Tyler y S. A. Schroeder (Eds.), Defining Social Acceptability of Forests and Forestry Practices: a workshop proceedings (pp.77-97). Kelso Washington Seattle, WA: U.S Department of Agriculture, Forest Service, Pacific Northwest Research Station.

Gobster, P. H. (1999). An ecological aesthetic for fores landscape management. Landscape Journal, 18(1), 54-64. actitudes que amplíen la perspectiva basada en la belleza y apoyen la función ecológica de manera más sólida (Gobster, 1994, 1995, 1999).

Gobster (1995) argumenta que nuestras preferencias ante el paisaje siguen la línea de la estética escénica por razones histórico-culturales (ver Apartado III.2.2 y IV.1.4). Consecuentemente el público occidental muestra unos estándares estéticos ante el paisaje más natural que el autor califica como superficiales y que pueden conducir a conflictos en aquellos casos en que ambas consideraciones, la ecológica y la escénica se confrontan.

Estos conflictos surgen por ejemplo, y para el caso particular de los paisajes forestales, ante la visión de árboles muertos y madera caída en el suelo (sea de forma natural o como consecuencia de las cortas) que conduce muchas veces a retirar un material que cumple una función ecológica reconocida y relevante (Figura 24 y 25). Por otro lado, se considera probada la preferencia por los bosques maduros y árboles añosos y en general los modelos de preferencias establecen una relación directa de la madurez forestal con la calidad estética. Sin embargo, se da la ironía de que una de las características que poseen estos bosques maduros y que los hace ecológicamente valiosos es precisamente la presencia de madera muerta. Otro ejemplo sería el caso de los resultados visuales de algunas actuaciones selvícolas, que chocan con la estética de lo no intervenido en los paisajes naturales. Sin embargo, al mismo tiempo los bosques con mínima o nula gestión muestran precisamente una mayor cantidad de madera muerta y un estrato arbustivo más denso, características que suelen provocar reacciones adversas en el público. Además, son numerosos los estudios que han confrontado el impacto ecológico del tamaño, forma y distribución de las áreas de corta (en términos por ejemplo de perturbación y fragmentación, pero también como medio para aportar diversidad de condiciones al paisaje forestal) con las preferencias del público ante distintos escenarios: áreas cortadas más pequeñas y numerosas frente a pocas áreas cortadas pero de gran extensión. Por último, cabe citar el caso de los incendios forestales, esenciales en la dinámica ecológica del monte mediterráneo (incluso se prescriben quemas controladas) pero con una consideración social de su apariencia muy negativa (Gobster, 1996; 1999). 
Gobster ha puesto de relieve la diferente naturaleza de la experiencia estética entre ambas formas, la escénica y la ecológica, que se sintetiza en la Tabla 2.

Tabla 2. Algunos elementos diferenciadores entre la estética escénica y ecológica extraídos de la literatura, relacionados con las características del individuo o del propio paisaje, con la forma de interacción hombre-paisaje o con el resultado o beneficios que se derivan de la experiencia (Gobster, 1996; p. 82).

Estética escénica

\section{Elementos relacionados con el individuo}

Perceptual, inmediata, afectiva/emocional

Limitada a lo visual

Gusto popular, "mínimo común denominador"

Visión del mundo homocéntrica
Cognitiva, basada en el conocimiento, "un gusto refinado", además de afectiva

Todos los sentidos están implicados - vista, oído, olfato, tacto, gusto, al igual que el movimiento/exploración

Elitista?

Visión del mundo biocéntrica, "humanismo ecológico" ético

\begin{tabular}{cc}
\hline \multicolumn{2}{c}{ Elementos relacionados con el paisaje } \\
\hline $\begin{array}{c}\text { Estático, inanimado, inmutable } \\
\text { Elementos formales, pastoral, pintoresco }\end{array}$ & Multimodal, ambiente \\
Dramático & Linámico, vivo, cambiante \\
Naturalístico & Sutil \\
Literal & Natural \\
Delimitado, enmarcado, lugares específicos & Simbólico, significados profundos \\
Composición de la vista & Ilimitado, bosque en su totalidad \\
Organizado, prístino & indacto \\
\end{tabular}

\section{Elementos relacionados con la interacción}

Pasiva, orientada al objeto de contemplación, respuesta al estímulo

Aceptada como algo dado
Activa, participativa, experimental

Invoca diálogo

\begin{tabular}{cc}
\hline \multicolumn{2}{c}{ Elementos relacionados con el efecto y resultados } \\
\hline Placer & Entendimeinto y placer \\
Observación & $\begin{array}{c}\text { Acción e implicación } \\
\text { Corto plazo, sujeto a cambios en el estado de } \\
\text { ánimo }\end{array}$ \\
Mantiene el status quo & $\begin{array}{r}\text { Perdurable, restaurador, valores profundos, unidad, } \\
\text { identidad, sentido del lugar } \\
\text { Cataliza el cambio interno y externo }\end{array}$ \\
\hline
\end{tabular}

Gobster, P. H. (1996). Forest aesthetics, biodiversity, and the perceived appropriateness of ecosystem management practices. En M. W. Brunson, L. E. Kruger, C. B. Tyler y S. A. Schroeder (Eds.), Defining Social Acceptability of Forests and Forestry Practices: a workshop proceedings (pp.77-97). Kelso, Washington Seattle, WA: U.S. Department of Agriculture, Forest Service, Pacific Northwest Research Station. 
Gobster, P. H. (1994). The aesthetic experience of sustainable forest ecosystems. En W. W. Covington y L. F. De Bano (Eds.), Sustainable Ecological Systems: Implementing an Ecological Approach to Land Management (pp. 246-255) (General Technical Report RM247). Fort Collins, CO: USDA Forest Service, Rocky Mountain Forest and Range Experiment Station

\section{Acciones para la puesta en práctica de una estética ecológica}

Gobster (1994) definió una estrategia para alcanzar esta forma de experiencia estética a través de distintos ámbitos de actuación, con relevancia ara la propuesta metodológica expuesta en esta tesis:

- Ámbito de la planificación del paisaje y desarrollo de programas de actuación.

- Ámbito de la gestión sobre el terreno.

- Ámbito de la investigación y el desarrollo teórico.

Respecto a las acciones en el primer campo, el autor identifica como un asunto crítico el ampliar las prácticas de evaluación en la planificación paisaje desde la consideración puramente visual (caso actual en la mayoría de experiencias, ver Capítulo IV), a la práctica que incorpore los principios de la sostenibilidad ecológica en la percepción del paisaje. Para ello, recomienda hacer un mayor esfuerzo para contextualizar los ámbitos en los que se pueda aplicar una determinada estrategia de gestión de los aspectos perceptuales, dado que no es lo mismo evaluar las acciones en paisajes "funcionales", en los dedicados primordialmente al uso recreativo o a los reservados a la gestión y conservación ecológica. Igualmente, la planificación del uso recreativo debería introducir mayores oportunidades para que el público pudiera experimentar e interpretar la dimensión ecológica en la estética del paisaje (Figura 26).

Respecto a las acciones sobre el terreno, propone crear diseños que muestren de manera más clara la impresión que provocan los paisajes sostenibles y también hacer manifiestas las acciones de gestión tendentes a alcanzarlos, para ofrecer al público una "experiencia más conspicua de la calidad de estos paisajes" y avanzar hacia el objetivo de que la estética ecológica sea entendida y apreciada por el público. 


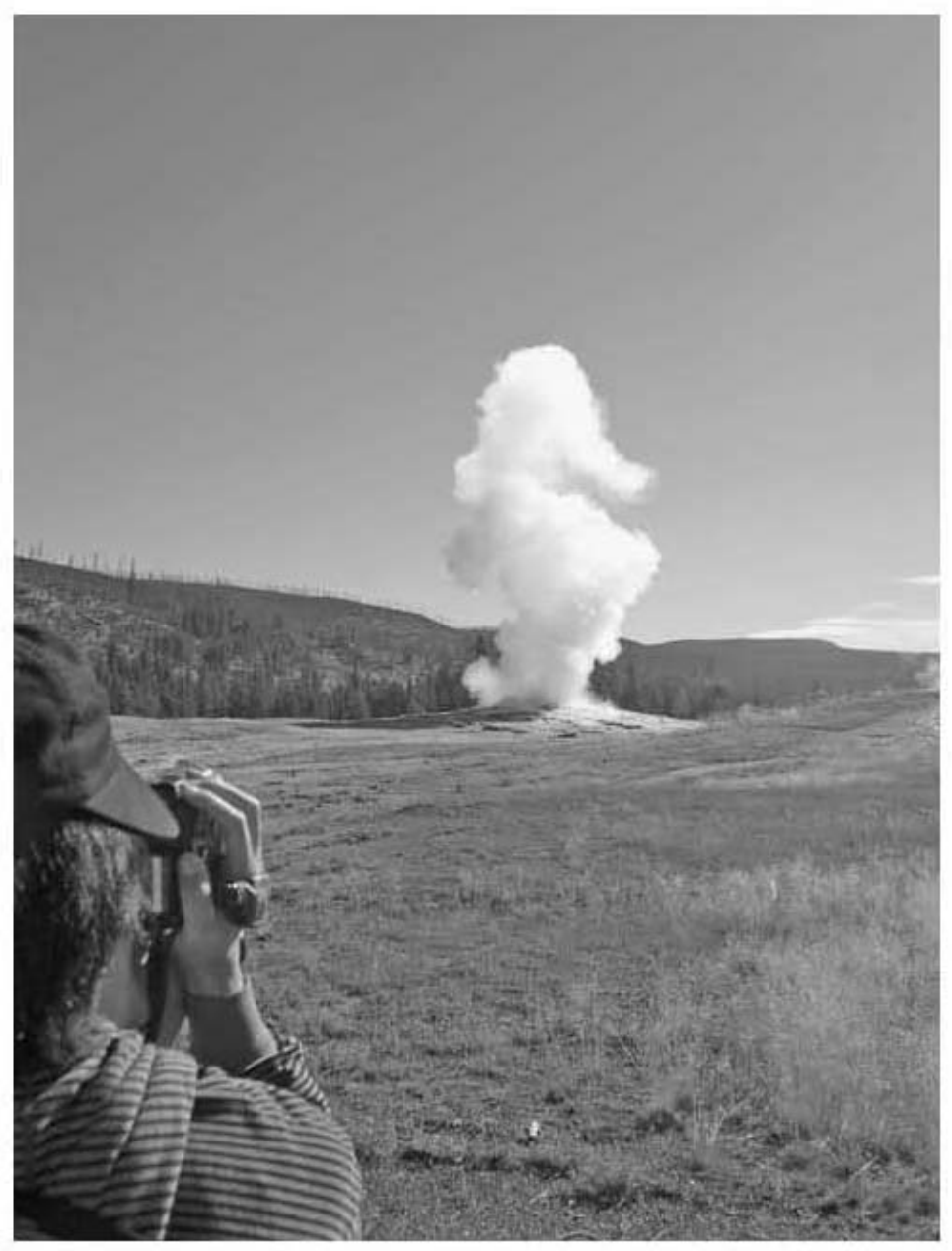

Figura 26 - Geyser "OLd Faithful" en el Parque Nacional de Yellowstone. Gobster, (2008) lo cita como ejemplo de proceso que revela la belleza de los fenómenos ambientales que de otras manera quedarían fuera de la esfera perceptible humana, y que ofrece signos para poder apreciar los paisajes ecológicamente relevantes que no muestran rasgos escénicos claros. Fuente de la fotografía: Extraída de Gobster, 2008.

Gobster, P. H. (2008).

Yellowstone Hotspot Reflections on Scenic Beauty, Ecology, and the Aesthetic Experience of Landscape. Landscape Journal, 27, $2-8$.

Al margen de las intervenciones sobre el terreno, indica como un asunto esencial el actuar sobre la otra parte de la relación ser humano-paisaje, más concretamente sobre el público usuario. Así, Gobster propone el uso de información que ayude a interpretar los aspectos menos patentes del funcionamiento ecológico de los paisajes (en cartelería, trípticos y visitas guiadas...), así como proveer a los usuarios de oportunidades para experimentar por ellos mismos la verdadera esencia de los procesos ecológicos y promover así una apreciación de la verdadera "belleza ecológica". 
En el plano de la investigación y desarrollo teórico, Gobster igualmente hace hincapié en ambos componentes del binomio ser humano-paisaje. Así, propone ampliar las indagaciones sobre los atributos que influyen o desencadenan la reacción estética ecológica. Es decir, no tanto identificar los rasgos que provocan una preferencia escénica en el público, sino indagar sobre las reacciones ante determinadas prácticas de gestión (quemas prescritas, mantenimiento de madera muerta en el monte, la configuración de cortas que minimizan los efectos de la fragmentación, etc.) o la manera en que los atributos relacionados con la estructura y función ecológica de los ecosistemas provocan una respuesta estética relevante (por ejemplo cómo se perciben las dinámicas de cambio de los ecosistemas). Por otro lado, incide en la conveniencia de ampliar el rango de técnicas para investigar las reacciones del público, aumentando la aplicación de métodos del tipo "experiencial" en los que el usuario se encuentra inmerso en el paisaje real (paseos, elaboración de diarios de experiencias, descripciones, observación directa...) frente al tradicional uso de fotografías seleccionadas como representantes de los paisajes a evaluar. Por último, recoge la teoría justificativa de Carlson (ver Aparatado III.4.4) como medio para construir la teoría sobre percepción del paisaje que integre la estética ecológica y fundamente una manera mejorada de evaluar, planificar y diseñar el paisaje. En esta línea, marca la estética basada en la "ética de la tierra" de Leopold como el camino para aproximarse a ese objetivo.

\section{La importancia de experimentar la dimensión ecológica del paisaje}

Gobster, P. H. (2007). Urban Park Restoration and the "Museumification" of Nature. Nature and Culture, 2(2), 95-114.
La promoción de experiencias con la verdadera naturaleza se encuentra en la base de los principios que Gobster entiende que se debería promover de forma más decidida para poder avanzar hacia la consecución de la estética ecológica. A este respecto, resulta muy interesante su reflexión sobre cómo se habilitan las zonas verdes urbanas y qué tipo de experiencia provoca, pues son los ámbitos en los que gran parte de la experiencia natural ocurre para un sector significativo de la población. Dicha reflexión puede también ser aplicada para el caso de ciertas áreas con una componente natural marcada. Se trata del denominado efecto de "museificación" ("museification") de la naturaleza (Gobster, 2007). 
"El efecto de "museificación" es un proceso mediante el cual los lugares o componentes del mundo de cada día son tratados de tal manera que empuja a la gente a pensar y actuar hacia ellos como si se encontraran en un museo. La "museificación" puede ser accidental o intencionada [...] y el resultado final es un cambio de significados, comportamientos y experiencias que la gente tiene en relación a ese lugar o componente" (Gobster, 2007; p.100)

Así por ejemplo, itinerarios muy marcados, con barreras que impiden el paso a muchos espacios que sólo se pueden contemplar como una sucesión de vistas, o con especies etiquetadas como si fueran una colección botánica y no un ecosistema, ofrece un tipo de visita similar al de una galería de arte, en la que los cuadros se disponen en línea colgados en la pared. Igualmente las restricciones de uso en aras de una mejor conservación de sus valores ecológicos pueden provocar involuntariamente un efecto secundario negativo al coartar el disfrute activo de la naturaleza. De tal manera, el público no experimenta todo el rango de interacciones que pueden establecer con la naturaleza, esta es tratada como un objeto de museo ante la cual el visitante se aparta y adopta una actitud distante que lo aleja de la experiencia trascendente que podría haber practicado (Figura 27). Este hecho puede desembocar en una falta de capacidad de reconocimiento y disfrute de las características propias y verdadera belleza de lo natural.

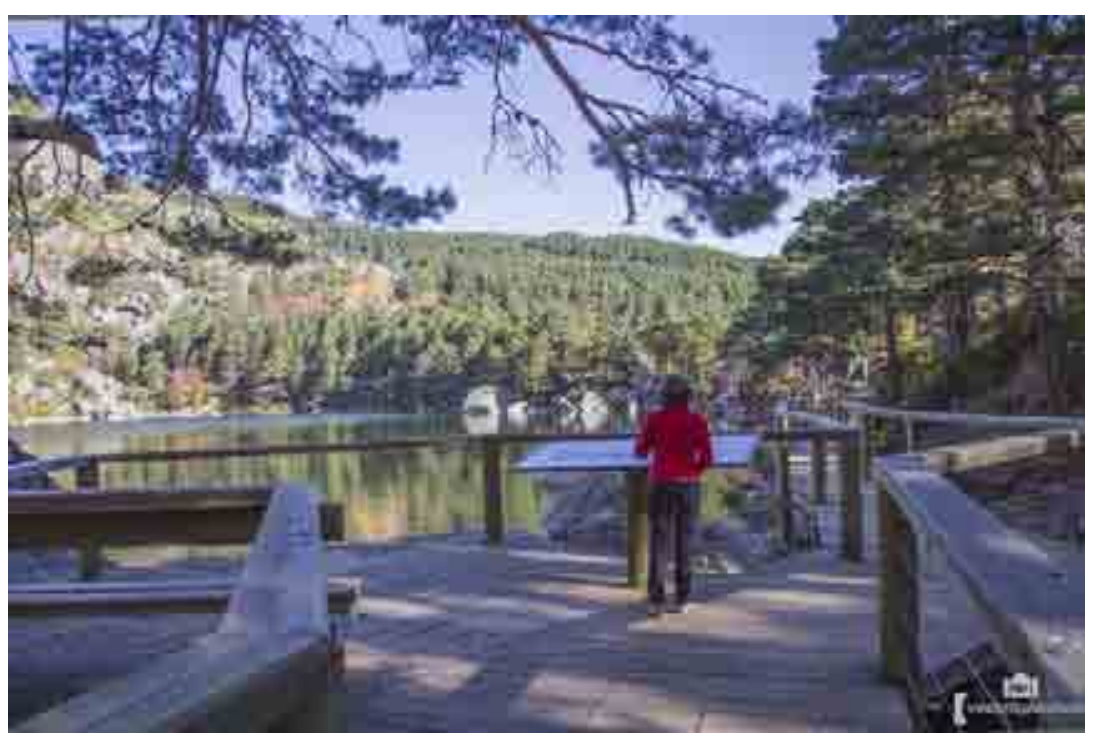

Figura 27. Ejemplo de tratamiento del paisaje con un posible efecto de "museificación" del medio natural: una pasarela de madera permite la visita a la Laguna Negra en Soria y abre la panorámica a la estampa idílica del paisaje de alta montaña. La pasarela es necesaria por motivos de protección del espacio, pero fomenta por otro lado una experiencia puramente escénica y pasiva del medio. Fuente fotografía: www.tortajadanieto.com

Gobster, P. H. (2007).

Urban Park Restoration and the "Museumification" of Nature. Nature and Culture, 2(2), 95-114. 


\section{II.4.6. Joan Nassauer: la "Estética del Cuidado" y la "Sostenibilidad Cultural"}

Joan Nassauer (1952-), arquitecta del paisaje estadounidense (Figura 28), basa su propuesta de tratamiento del paisaje en el concepto del "cuidado" ("care"), es decir, en la impresión de que el paisaje merece consideración dado que "alguien" le dedica un mantenimiento y protección activos.

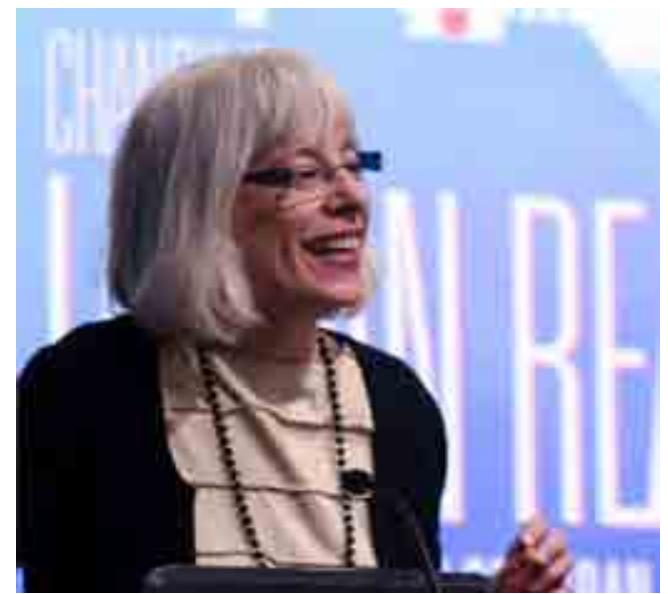

Figura 28. La investigación de Joan Nassauer ha estado desde el principio basada en la innovadora idea de la "Estética del Cuidado".

FUENTE DE LA FOTOGRAFÍA: http://www.joan-nassauer.com
Nassauer, J. I. (1988). The aesthetics of horticulture: neatness as a form of care. HortScience, 23(6), 973-977

Nassauer, J. I. (1995a). Culture and changing

landscape structure. Landscape Ecology, 10(4), 229-237.

Nassauer, J. I. (1997). Cultural

Sustainability: Aligning aesthetics and Ecology. En J. I.

Nassauer (Ed.), Placing nature: culture and landscape ecology (pp. 65-83). Washington, DC: Island Press.

Nassauer, J. I. (2011). Care and stewardship: From home to planet. Landscape and Urban Planning, 100, 321-323.
El potencial estético del cuidado en el paisaje reside precisamente en que este es fácilmente perceptible y provoca una respuesta inmediata fundada en una interpretación cultural común: denota la intención deliberada de alguien que persigue que el paisaje sea de una determinada manera, lo cual sugiere que dicho paisaje está siendo gestionado hacia un fin bienintencionado (Nassauer, 1988). La "Estética del Cuidado" ("Aesthetic of Care"), teoría enunciada por Nassauer, sería por tanto aquella que refleja la preocupación por el paisaje, de su mantenimiento activo y esmerado, a través de una apariencia fácilmente entendible por una gran mayoría de gente (Nassauer, 1995a, 1997).

"El cuidado puede ser un concepto poderoso a la hora de promover la sostenibilidad en el paisaje pues nos es notorio a nosotros y a otros, es una norma cultural profunda y generalizada, puede evocar una respuesta estética y además es una forma de intervención" (Nassauer, 2011; p. 321) 
Nassauer elaboró esta teoría, que ha tenido una importante acogida en el ámbito del análisis y diseño del paisaje, a partir de sus estudios sobre la percepción local del paisaje en medios rurales. En los paisajes agrícolas del medio oeste estadounidense (como Minnesota o Illinois) las diferentes formas de cuidado del paisaje y la noción de pulcritud estaban presentes de forma significativa en las preferencias de la población local (Nassauer, 1988). Dichos espacios (Figura 29), junto con los paisajes del día a día, son los ámbitos en los que la estética del cuidado funcionaría de forma más efectiva, dado que la teoría subraya la intervención del hombre en el paisaje, siempre que esta sea adecuada (Gobster et al., 2007). Sin embargo, y aunque parezca contradictorio, su utilidad también se extiende a los paisajes más naturales.

Nassauer, J. I. (1988)

The aesthetics of horticulture: neatness as a form of care. HortScience, 23(6), 973-977.

Gobster, P. H., Nassauer, J. I., Daniel, T. C., y Fry, G. (2007) The shared landscape: what does aesthetics have to do with ecology? Landscape Ecology, 22(7), 959-972.

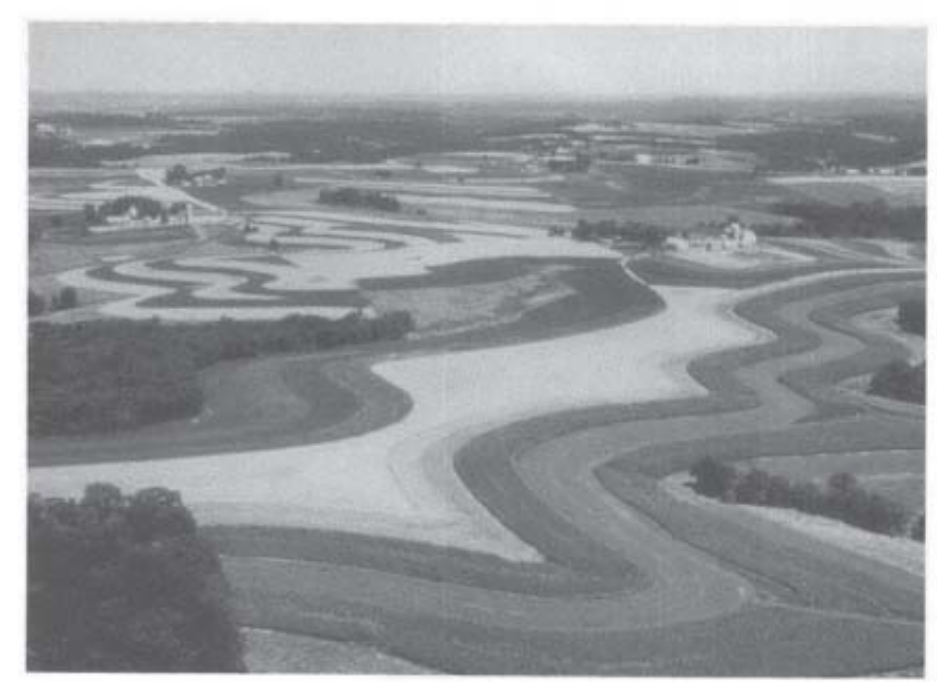

Figura 29. Creación de un patrón muy marcado de campos cultivados, diseño en el que se combina el arte y la impresión de cuidado. Extraído de (Nassauer, 1995b).
En el plano más simbólico, nos encontramos con que el hecho de que un espacio más o menos natural tenga una figura de protección puede ser interpretada como un tipo de cuidado. Incluso la misma naturalidad que muestra el paisaje en estos espacios es un signo de intervención adecuada fundamentada en una decisión deliberada de no intervención (Nassauer, 2011). Pero el hecho que perfila la estética del cuidado como relevante en el paisaje más natural es que este exhibe en mayor o menor medida evidencias de la intervención humana, por lo que también estaría sujeto al escrutinio público en clave del cuidado que se le dedica. Ahora bien, es necesario tener claro que en este caso el cuidado percibido indicaría al observador las
Nassauer, J. I. (2011). Care and stewardship: From home to planet. Landscape and Urban Planning, 100, 321-323. 
Nassauer, J. I. (1995b) Messy Ecosystems, Orderly Frames. Landscape Journal, $14(2), 161-170$

Nassauer, J. I. (1997) Cultural Sustainability: Alignin aesthetics and Ecology. En J. I. Nassauer (Ed.), Placing nature: culture and landscape ecolog (pp. 65-83). Washington, DC Island Press.

Nassauer, J. I. (1995a). Culture and changing landscape structure. Landscape Ecology, 10(4), 229-237.

Nassauer, J. I. (1992) The appearance of ecologica systems as a matter of policy. Landscape Ecology, 6(4), 239- condiciones de gestión del paisaje más que las condiciones ecológicas de los ecosistemas (Nassauer, 1995b).

La Estética del Cuidado se erige así en una interesante herramienta para garantizar la sostenibilidad y mostrar la conveniencia de las actuaciones gestoras en lo relativo al funcionamiento ecológico del paisaje. Esta utilidad se funda en la denominada "Sostenibilidad Cultural" ("Cultural Sustainability"), que enraíza en la reflexión de que la permanencia de los paisajes saludables depende de la atención que reciban por parte del hombre. Es decir, los paisajes con buenas condiciones ecológicas que adicionalmente disfruten de la aprobación social tienen más probabilidad de recibir un cuidado apropiado y sostenido en el tiempo (Nassauer, 1997). Dado que lo que aparenta ser apropiado no siempre lo es en términos ambientales o ecológicos $y$, a la inversa, lo que se muestra como inadecuado puede ser en realidad conveniente, es necesario apoyarse en un lenguaje más reconocible que se alinee con la verdadera esencia de lo percibido (Nassauer, 1997).

"Esto lleva a la cuestión de cómo crear formas del paisaje que acomoden la función ecológica para que sea consistente con los valores que son culturalmente esperados" (Nassauer, 1995a; p. 235)

Dicho lenguaje se ha de basar, según la teoría, en la conexión que surge de la interpretación cultural del paisaje, por lo que defiende que "la gestión y diseño deberían usar el lenguaje cultural común de la estética del paisaje para mostrar la función ecológica" (Nassauer, 1992). La traducción de estas consideraciones en términos de diseño del paisaje se fundamenta en la búsqueda en cada caso de los "Indicios del Cuidado" ("Cues to Care"), elementos físicos en el paisaje que conectan las funciones ecológicas con los valores que son culturalmente reconocibles y con la experiencia estética, de tal manera que la ecología no visible se proyecta, se evidencia y se refuerza a los ojos del observador (Nassauer, 1995b) (Figura 30). 

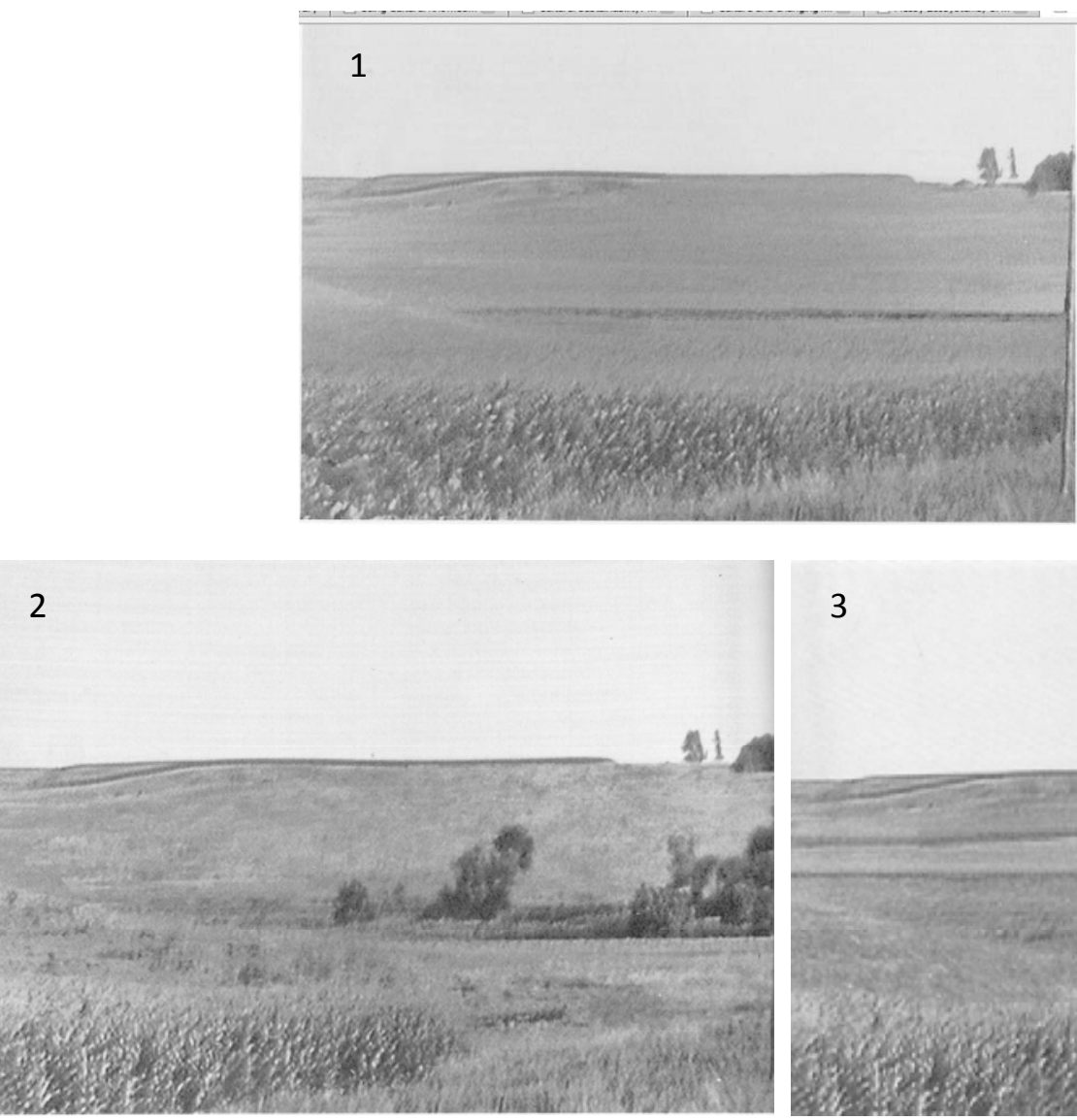

\section{3}
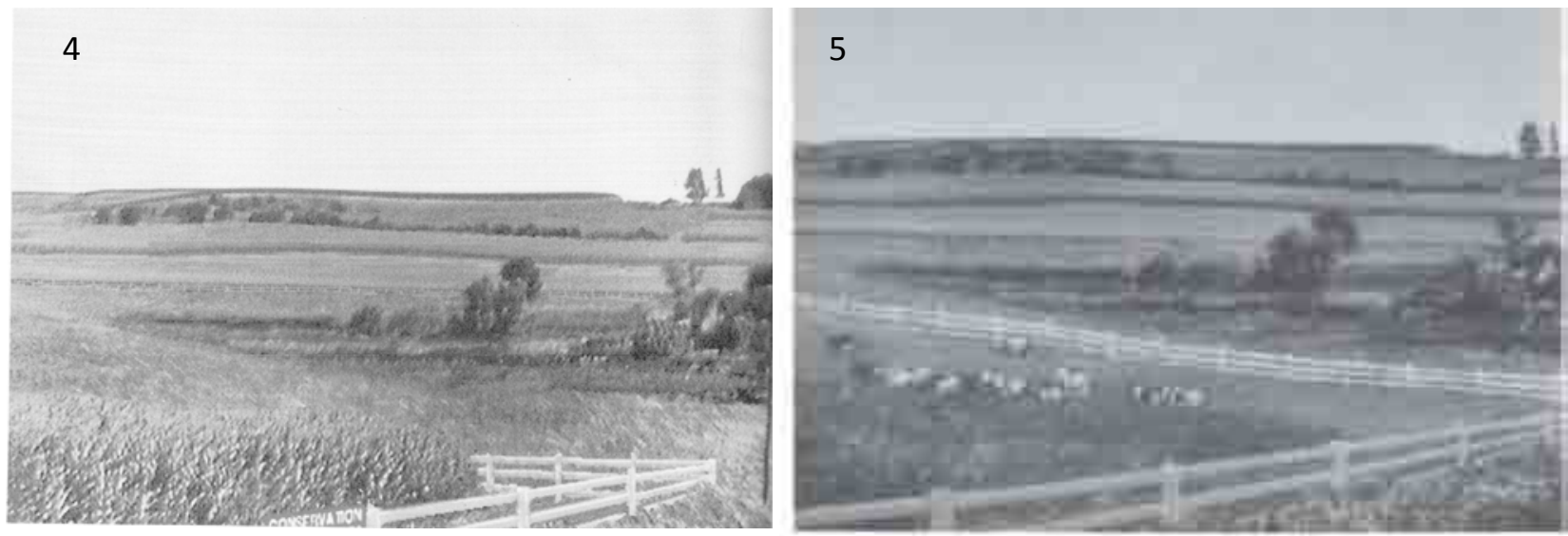

Figura 30. Diferentes diseños de un paisaje agrícola destinado a un programa de conservación, concebidos para comunicar la Estética del Cuidado:

1.- Imagen correspondiente con una gestión orientada a la máxima producción de maíz.

2.- El campo está sembrado con una mezcla de especies agrícolas recomendadas por sus beneficios ecológicos.

3.- La tercera imagen integra elementos vernáculos que resultan atractivos para la población local y transmiten el mensaje de paisaje mantenido y cuidado: lindes vegetadas recortadas, pastos aprovechados, parcelas cosechadas.

4.- La cuarta imagen muestra otra alternativa para acomodar ambos objetivos, el de conservación y el estético (vallado y panel informativo como signos inequívocos de la intención conservadora).

5.- La imagen transmite mantenimiento y cuidado del paisaje por medio de la actividad ganadera local. 


\section{III.4.7. Stephen Sheppard: los paisajes forestales productivos y la estética de la "Administración visible"}

Stephen R. J. Sheppard (Figura 31), perteneciente al Departamento de Recursos Forestales y Planificación Física de la Universidad de la Columbia Británica (Canadá), propone una teoría complementaria a la de la Estética del Cuidado para el caso particular de los paisajes forestales sujetos a aprovechamientos comerciales, que pudiera dar respuesta a las reacciones adversas ante los trabajos forestales.

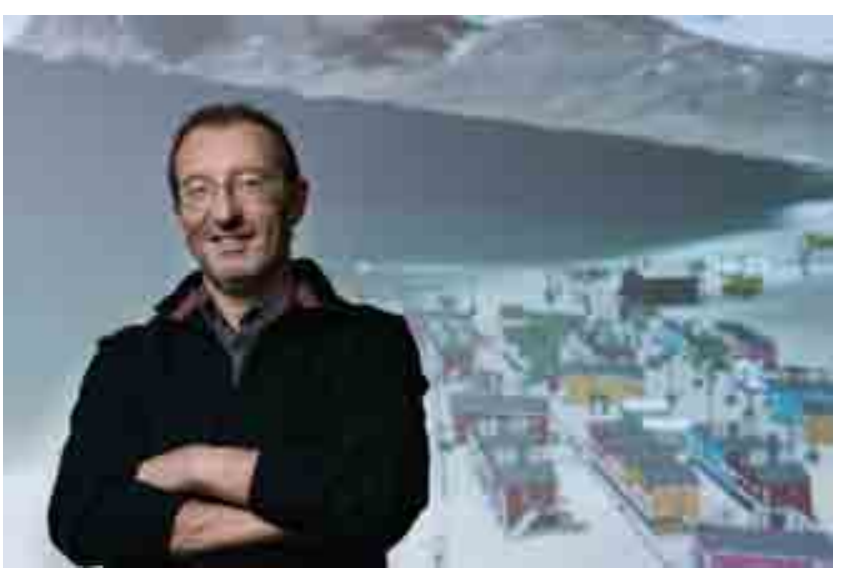

Figura 31. Además del análisis de la percepción y la estética de la sostenibilidad, Sheppard ha trabajado muy activamente en el campo de las simulaciones visuales aplicadas a la evaluación y planificación del paisaje.

Fuente fotografia: www.ubc.ca
Sheppard, S. R. J. (2001) Beyond Visual Resource Management : Emerging Theories of an Ecological Aesthetic and Visible Stewardship. En S. R. J. Sheppard y H. W. Harshaw

(Eds.), Forests and Landscapes: Linking Ecology, Sustainablility, and Aesthetics (pp. 149-173). Nueva York, NY: CABI Publishing - IUFRO.
Sheppard (2001) pone de relieve las razones por las que en este tipo de contextos los postulados de las denominadas "Estética del Cuidado" ("Aesthetic of Care") o la Estética Ecológica ("Ecological Aesthetic") tendrían resultados limitados en la práctica. En primer lugar, el autor duda (éticamente) sobre la conveniencia de asentar en la sociedad una estética basada en unas condiciones ecológicas en torno a cuya sostenibilidad aún no existe un conocimiento testado. Por otro lado, estas teorías no toman en cuenta el hecho de que las reacciones instintivas o emocionales ante el paisaje son tremendamente resistentes a los intentos de cambio o adaptación a una determinada estética. Así, aquellas preferencias derivadas de la propia biología y evolución humana, o el apego de las personas al 
entorno al que se sienten emocionalmente vinculadas y otras motivaciones "egoístas", pueden impedir la generalización de una forma de apreciar el paisaje deseable. Adicionalmente, los trabajos forestales son un tipo de intervención que, en ocasiones, provoca un nivel de perturbación drástico en paisajes en los que culturalmente se espera percibir naturalidad, tranquilidad y poco cambio (Figura 32).

Figura 32. Cartel colocado en una zona de cortas por razones sanitarias en el Parque Natural de Sierra Cebollera. El objetivo de advertencia al usuario para garantizar su seguridad puede tener el efecto secundario de presentar una actividad necesaria y beneficiosa como agresiva y peligrosa.

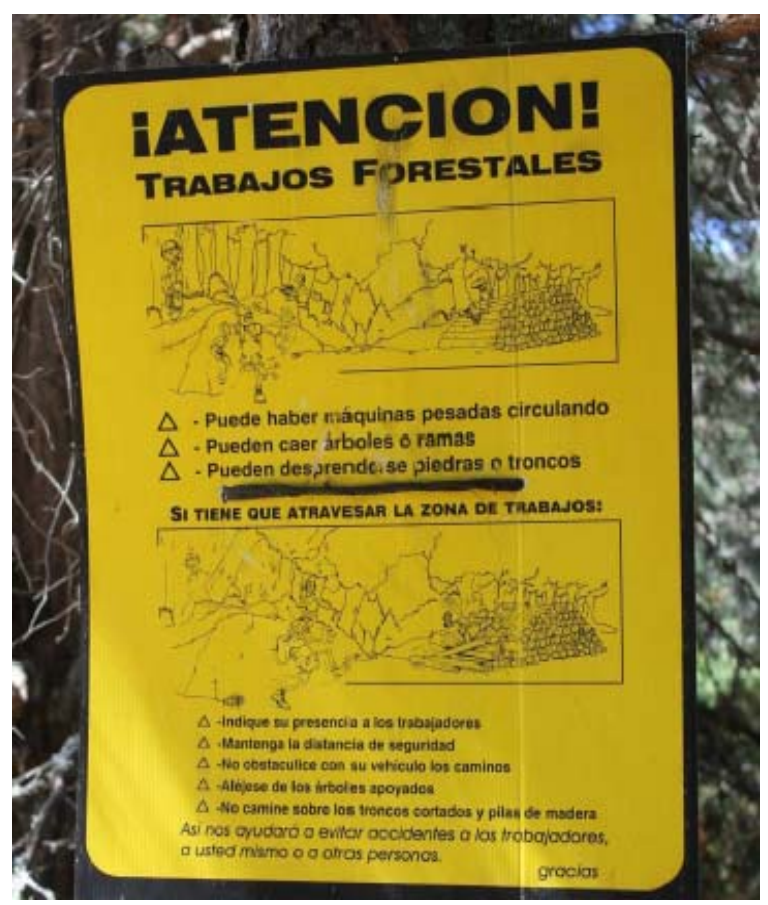

El tiempo necesario para la restauración del paisaje perturbado es contemplado como otra pega, dado que este puede simplemente ser demasiado largo para la escala de una vida humana: la diferencia entre la escala temporal ecológica y la humana hace que la "promesas" de futuras condiciones deseables por el público derivadas de configuraciones poco atractivas pero esenciales en el proceso ecológico, si bien transitorias, no supongan demasiado consuelo para el público.

"Un propietario puede pensar 'Sé que debería hacer quemas en mi parcela forestal, pero quiero extraer la madera' o 'Quiero preservar las vistas para mi disfrute en mi jubilación"' (Sheppard, 2001; p. 159)

Además, en estos entornos es difícil (y resulta menos atractivo para el Sheppard, S. R. J. (2001). Beyond Visual Resource Management : Emerging Theories of an Ecological Aesthetic and Visible Stewardship. En S. R. J. Sheppard y H. W. Harshaw (Eds.), Forests and Landscapes: Linking Ecology, Sustainablility, and Aesthetics (pp. 149-173). Nueva York, público) evidenciar las relaciones ecológicas que se desarrollan y los beneficios a largo plazo. Por último, resulta especialmente difícil transmitir la Estética Ecológica en los paisajes sujetos a aprovechamiento forestal, una actividad que en muchas ocasiones 
provoca recelos asentados en el subconsciente colectivo y en la desconfianza ante la honestidad de la práctica.

¿Qué ocurriría por tanto en aquellas zonas en las que dichas teorías no son tan efectivas? Para estos casos Sheppard aboga por la denominada "Administración o Gobernanza Visible" ("Visible Stewardship"), que vendría a aliarse y complementar los efectos de la Estética Escénica o la Estética del Cuidado en espacios forestales productivos. La estética basada en la Administración Visible se fundamenta en la no ocultación de las prácticas forestales sino al revés: en paisajes modificados para atender las necesidades de materias primas forestales el público acepta con más facilidad su aspecto si reconoce que estos son la evidencia de una intención de gestión sostenible y si percibe que alguien detrás se ocupa de que en sus planteamientos siempre estén presentes el respeto por la naturaleza y por el sitio. La gestión forestal correcta y bienintencionada por tanto no tendría por qué ser ocultada, sino que habría de ser evidenciada y explicada. Se trata pues de una teoría que incide en la dimensión simbólica del cambio que opera la gestión forestal en el medio, que actúa sobre la interpretación ética que el público hace del proceso de intervención más que del resultado visual

Tindall, D. B. (2001). Why do you think that hillside is ugly? A sociological perspective on aesthetic values and public attitudes about forest. En S. R. J. Sheppard y H. W. Harshaw (Eds.), Forests and Landscapes: Linking Ecology, Sustainability and Aesthetics (pp. 57-70). Nueva York, NY: CABI Publishing - IUFRO.

Hull, R. B., Robertson, D. P., Buhyoff, G. J., y Kendra, A. (2000). What are we hiding behind the visual buffer strip? Forest aesthetics reconsidered. Journal of Forestry, 98(7), 34-38. final. Este proceso estaría detrás, por ejemplo, de la divergencia descrita por Tindall (2001) en la aparente coincidencia entre un activista de una organización medioambiental y un contratista para aprovechamiento de madera en la valoración negativa de los corredores escénicos que ocultan o integran las parcelas forestales cortadas a hecho. Mientras el primero argumentó que su crítica se fundaba en el hecho de que los corredores escénicos servían para ocultar las malas prácticas forestales, el segundo argumentó que se sentía orgulloso de hacer aprovechamientos forestales y que la práctica deshonesta era precisamente el hacer los corredores, pues equivalía a asumir que se pretende ocultar las cortas a hecho porque se está avergonzado de esa práctica.

Estas consideraciones también han sido puestas de relieve por autores como Hull, Robertson, Buhyoff y Kendra (2000), que defienden la conveniencia de lo que se podría denominar "Estética del esmero" ("Tended Aesthetic"), una estética que además de subrayar los procesos ecológicos y los bienes y servicios derivados, dirige la atención hacia la calidad de la gestión forestal que se lleva a cabo. 


\footnotetext{
"la estética de la masa forestal ofrece una fachada que refleja la ética de la práctica forestal, y por tanto esta no debería mostrarse de forma falsa o hipócrita a los ciudadanos escépticos. La política de tratamiento estético del paisaje debería ser socialmente aceptable, apropiada ecológicamente, fácil de captar y comprender y económicamente factible"

(Hull et al., 2000; p. 38)
}

Hull, R. B., Robertson, D. P. Buhyoff, G. J., y Kendra, A. (2000). What are we hiding behind the visual buffer strip? Forest aesthetics reconsidered. Journal of Forestry, 98(7), 34-38.

Los autores consideran la visibilidad y el potencial comunicativo de los paisajes forestales gestionados como una oportunidad para el público que se ve capacitado para de alguna manera "auditar" los propósitos y consecuencias de la intervención forestal y así poder generar la confianza necesaria en las acciones. Esta estética se caracteriza por tanto por una imagen de cuidado esmerado, implicación y responsabilidad por parte del gestor. La evidencia de la gestión es por tanto considerada positivamente, puesto que se entiende que esta puede tener un efecto de mejora en los procesos ecológicos.

Sheppard aboga por hacer patente que los aprovechamientos se realizan de forma responsable y bienintencionada mostrando de forma más evidente que es fruto de una planificación y ejecución meditada, sensible con los aspectos ambientales del sitio concreto, que existe una preocupación sobre la evolución del ecosistema y que los cálculos no terminan en la corta, sino que se ocupan de una sucesión de turnos que aseguren la salud ecológica de la masa forestal y unos beneficios sostenidos para la comunidad local y la sociedad en general. De tal manera, la fase final del proceso dejaría de parecer tan drástica e insensible. Apunta además algunas acciones prácticas que reforzarían esta imagen más allá de la colocación de carteles informativos, como la presencia más visible y frecuente de un representante del organismo o empresa gestora que se asocie con una figura reconocible con mayor vinculación y presencia física en la zona, la involucración de la gente local en el proceso de decisión sobre la gestión de tal manera que se genere un intercambio de impresiones y se acreciente la confianza, o un programa de seguimiento estable y a largo plazo que ponga de relieve los beneficios de tal gestión.

La propuesta surge ante los grandes aprovechamientos que se dan en Norteamérica, un tipo de prácticas que tiene pocos equivalentes en Europa (fundamentalmente en Escandinavia). En el caso de España, este tipo de conflictos se darían en las regiones con selvicultura más intensiva, tales como Galicia, País Vasco, Cantabria, Asturias o algunas 
zonas de Castilla y León. Sin embargo, puede tener también trascendencia en paisajes en los que se practica una selvicultura a menor escala y con menor intensidad (cortas progresivas o entresaca), o incluso en las intervenciones selvícolas necesarias en áreas protegidas (Figura 33). En estos espacios es igualmente necesario hacer ver por parte de los servicios forestales la intención de actuar con sensibilidad ecológica.

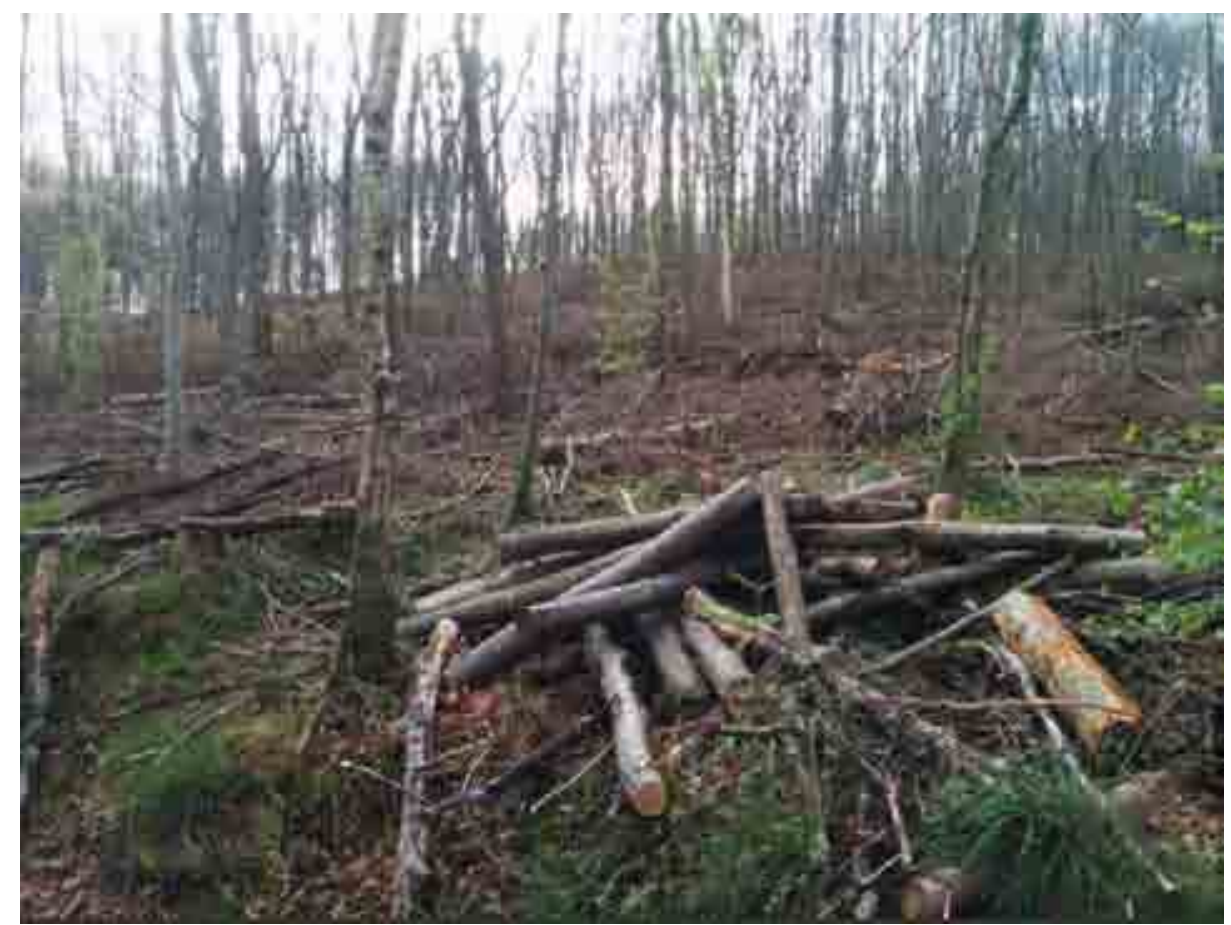

Figura 33. El aspecto del monte tras un aprovechamiento forestal frecuentemente transmite una sensación de intervención drástica, descuidada o poco sensible con las condiciones del lugar. En la foto, hayedo joven tras una corta de mejora de la masa en el Parque Natural de Sierra Cebollera (La Rioja). 
CAPÍTULO III. CONCEPTOS Y ENFOQUES EN TORNO A LA RELACIÓN ENTRE LO ECOLÓGICO Y

LO PERCIBIDO EN EL PAISAJE 


\section{CAPÍTULO IV}

\section{PRÁCTICA EN EL \\ TRATAMIENTO CONJUNTO DE LO ECOLÓGICO Y LO PERCIBIDO EN EL PAISAJE}

\section{CAPÍTULO IV.- PRÁCTICA EN EL TRATAMIENTO CONJUNTO

IV.1.- CONSIDERACIONES SOBRE LA RELACIÓN ENTRE LA DIMENSIÓN ECOLÓGICA Y VISUAL EN EL DESARROLLO DE LA PLANIFICACIÓN DEL PAISAJE

IV.1.1. Los inicios de la conservación y gestión del paisaje: métodos de tratamiento del paisaje como recurso visual

IV.1.2. El carácter del paisaje y los métodos descriptivos-valorativos

IV.1.3. Marco conceptual actual en la planificación europea del paisaje

IV.1.4. Consideraciones sobre el tratamiento de la dimensión ecológica y percibida en la planificación del paisaje en España

IV.2.- ENCUADRE DE LOS MODELOS DE PLANIFICACIÓN DEL PAISAJE ATENDIENDO A SU ENFOQUE EN EL TRATAMIENTO DE LA ECOLOGÍA Y LA ESTÉTICA 108

IV.2.1. Valores duales, ecología y estética:

la estética de lo natural o de lo ecológico como un fin en sí misma

IV.2.2. Valores integrados, ecología estética:

enfoques basados en el aprovechamiento del éxito común o el

embellecimiento de la solución ecológica

IV.2.3. Valores interdependientes, estética ecológica:

la estética como medio de mejora de lo ecológico

IV.3.- CONCLUSIONES DE CARA A LA PROPUESTAS METODOLÓGICA

QUE SE PRESENTA 


\section{CAPÍTULO \\ PRÁCTICA EN EL TRATAMIENTO \\ CONJUNTO DE LO ECOLÓGICO Y LO \\ PERCIBIDO EN EL PAISAJE}

En la revisión que se presenta, se busca subrayar el papel que ha jugado la consideración de la percepción y la apreciación estética de los valores naturales del paisaje en la protección de dichos valores y en la gestión paisajística. Esto se ha llevado a cabo desde una perspectiva histórica de su función en la planificación en distintos contextos paisajístico. Desde esta perspectiva histórica, se constata que el valor depositado en los servicios del medio más natural ha posibilitado la generación de la toma de conciencia paisajística, y la belleza del paisaje más natural (o pérdida de esta) muchas veces ha actuado como facilitador del proceso de protección de sus valores. El desarrollo de la conciencia paisajística ha corrido desde el principio en paralelo a la conciencia ambiental y no en pocas ocasiones esta última ha sido el germen de la primera. 


\section{IV.1. CONSIDERACIONES SOBRE LA RELACIÓN ENTRE LA DIMENSIÓN ECOLÓGICA Y PERCEPTUAL EN EL DESARROLLO DE LA PLANIFICACIÓN DEL PAISAJE}

Zube, E. H., Sell, J. L., y Taylor J. G. (1982). Landscape

Perception: Research, Application and Theory. Landscape Planning, 9, 1-33.

Litton, R. B. (1972). Aesthetic Dimensions of the Landscape. En V. Krutilia, Natural environments (pp. 262-291). Washington, D.C.: Resources for the Future.

Botkin, D. B. (2001b) No Man's Garden. Thoreau and a new vision for civilization and nature. Washington, D.C.: Island Press \& Shearwater Books.
IV.1.1. Los inicios de la conservación y gestión del paisaje: métodos de tratamiento del paisaje como recurso visual

La consideración y gestión como recurso de los aspectos visuales del paisaje adquirió especial fuerza tanto en el ámbito norteamericano como en el británico en los años 60 del siglo XX. En ambos casos, la nueva perspectiva se desarrolló animada por una fuerza común: la inquietud ante la constatación de que no todo el rango de valores depositados en el medio más natural estaban siendo detectados y adecuadamente gestionados. Los valores asociados al paisaje visual fueron entendidos entonces como servicios que hasta el momento habían permanecido al margen del proceder gestor y que habrían de ser incorporados para alcanzar un cambio de política (Zube, Sell, y Taylor, 1982). Esta toma de conciencia surgió de lo social para a continuación repercutir en lo político y el proceder técnico, e inicialmente precipitó en el ámbito de la gestión del paisaje forestal en terrenos de titularidad pública (Litton, 1972).

\section{Contexto norteamericano}

En los años del "despertar ambiental" la reflexión interna se fue fraguando en el contexto norteamericano gracias a los escritos y proyectos de autores como Thoreau o Marsh (Botkin, 2001b). La toma de conciencia estalló finalmente en la sociedad civil al mismo tiempo que el desarrollo económico permitió al ciudadano medio explorar 
más espacios naturales y lo confrontó con las actividades que paralelamente operaban grandes impactos negativos en el paisaje. Este proceso tuvo lugar preferentemente en el ámbito forestal: la política productivista que respondía al fenómeno de incremento de la demanda de madera durante y tras las Guerras Mundiales (política del "cut and run") alimentaron la contestación social (Bell y Apostol, 2008; Ribe, Armstrong y Gobster, 2002).

En este caldo de cultivo surgieron en el ámbito americano los primeros "Sistemas de Gestión Visual del Paisaje" (VMS, siglas en inglés de Visual Management Systems), de los que el U.S. Forest Service (USFS) fue uno de las precursores (Priestley, 1983; Smardon, Palmer, y Felleman (Eds.), 1.986). Estos sistemas se desarrollaron como medio para salvaguardar apropiadamente la calidad del medio visual, respondiendo al requisito legal establecido por la National Environmental Policy Act of 1969 (NEPA) y por la National Forest Management Act of 1976 (NFPA). El enfoque emanó así de la evaluación de impactos ambientales y pretendía posicionar el aspecto visual en igualdad de condiciones ante otros recursos básicos del territorio. Los distintos organismos públicos fueron desarrollando y poniendo a disposición de los gestores de los espacios públicos manuales que recogían metodologías dirigidas a prever, minimizar y corregir los cambios visuales negativos. Dichos sistemas fueron pronto recogidos y adoptados por otros países (ver resumen en Taylor, Zube y Sell (1987)).

A partir de ese momento, y como respuesta a la necesidad de conocer mejor la respuesta de los observadores ante el estímulo visual del paisaje, los estudios científicos experimentales de evaluación de preferencias se multiplicaron. En aquellos años, estos estudios se centraban en la estética escénica considerada por el público general (los llamados outsiders). Con el tiempo, los métodos empezaron a mostrar mayor sensibilidad hacia la concertación de las expectativas del público local (ver revisiones en Dakin, 2003; Zube et al., 1982).

Estos sistemas de gestión del recurso visual del paisaje nacieron con la vocación de minimizar los impactos exclusivamente visuales (fundamentalmente derivados del aprovechamiento de los recursos forestales), con la pretensión de posicionar el efecto visual en su justa medida ante otro tipo de valores o intereses, y decantar el aspecto
Bell, S. y Apostol, D. (2008) Designing Sustainable Forest Landscapes. Londres, UK, Nueva York, NY: Taylor \& Francis.

Ribe, R. G., Armstrong, E. T., Y Gobster, P. H. (2002). Scenic Vistas and the Changing Policy Landscape: Visualizing and Testing the Role of Visual Resources in Ecosystem Management. Landscape Journal, 21(1), 42-66.

Priestley, T. (1983). The Field of Visual Analysis and Resource Management : A Bibliographic Analysis and Perspective. Landscape Journal, 2(1), 52-59.

Smardon, R.C., Palmer, J.E., y Felleman, J.P. (Eds.) (1986). Foundations for Visual Projects Analysis. Nueva York, NY: John Wiley \& Sons.

National Environmental Policy Act of 1969 (NEPA). Public Law 91-190, 1 de enero de 1970, pp. 852-856.

National Forest Management Act of 1976 (NFMA). Public Law 94-588, 22 de octubre de 1976, pp. 2949-2963.

Taylor, J. G., Zube, E. H., y Sell, J. L. (1987). Landscape assessment and perception

research methods. En R. Bechtel, R. Marans, y W. Michelson (Eds.), Methods in Environment Behavior Research (pp. 363-393). Nueva York, NY: Van Nostrand Reinhold.

\section{Dakin, S. (2003).}

There's more to landscape than meets the eye: towards inclusive landscape assessment in resource and environmental management. The Canadian Geographer/Le Géographe Canadien, 47(2), 185-200.

Zube, E. H., Sell, J. L., y Taylor, J. G. (1982). Landscape

Perception: Research, Application and Theory Landscape Planning, 9, 1-33. 
Wood, D. (1988). Unnatural illusions: some words about visual resource management. Landscape Journal, 192-205.

Sheppard. (2001). Beyond Visual Resource Management : Emerging Theories of an Ecological Aesthetic and Visible Stewardship. En S. R. J. Sheppard y H. W. Harshaw

(Eds.), Forests and Landscapes: Linking Ecology, Sustainablility, and Aesthetics (pp. 149-173). Nueva York, NY: CABI Publishing - IUFRO.

Daniel, T. C. (1990). Measuring the quality of the human environment: a phsychophysical approach. American Psychologist, 45, 633-637.

Zube, E. H., Sell, J. L., y Taylor,

J. G. (1982). Landscape

Perception: Research,

Application and Theory. Landscape Planning, 9, 1-33.

Brown, T. (1994). Conceptualizing smoothness and density as landscape elements in visual resource management. Landscape and Urban Planning, 30(1-2), 49-

visual del paisaje en el espacio normativo y gestor. En este sentido, es indudable que fueron exitosos. Aún así, y tras contar con suficientes experiencias prácticas contrastables, numerosos autores han expuesto dudas sobre su conveniencia. Las críticas se centran en cuatro aspectos:

- Enfoque excesivamente escénico y enmascarador de la realidad. Algunos autores reprueban la misma ética de los métodos. Así, Wood (1988) cuestiona el afán enmascarador por el que se rigen (lo que denomina "out of sight, out of mind"), que impide al público enfrentarse y reflexionar sobre el nivel de impacto que soporta el paisaje. El autor arguye además que sus preceptos tienden a reducir el paisaje a una mera escenografía en la que la percepción visual neutraliza otros aspectos no visibles pero igualmente importantes.

- Perspectiva excesivamente centrada en el resultado visual. Su desmesurado apoyo en la dimensión exclusivamente visual podría conducir a una gestión poco sensible con los agentes generadores que sostienen el resultado visual (Sheppard, 2001).

- Excesivo apoyo en el criterio experto. El ámbito de la psicología ambiental ha sido especialmente crítico con la escasa incorporación de la experiencia más subjetiva del observador. Así, se han reconocido como métodos útiles y prácticos que sin embargo no muestran una fiabilidad elevada (Daniel, 1990; Zube et al., 1982) o escasa validez al no incorporar la compleja y subjetiva dimensión de la experiencia del público, que efectivamente es el usuario final del paisaje (Dakin, 2003).

- Evaluación muy sensible a valores extremos que diferencia poco los valores intermedios. Brown (1994), por ejemplo, plantea dudas sobre la capacidad de estos métodos para marcar diferencias en el valor de determinados paisajes que no muestren rasgos espectaculares o una degradación patente (los denominados paisajes intermedios), espacios con gran riesgo de cambio y cuyos valores son pobremente detectados y por tanto inadecuadamente gestionados. 
Como se puede observar, todas estas consideraciones admiten la conveniencia de integrar el análisis visual del paisaje en el proceder gestor, pero ponen de relieve los efectos perversos a los que puede conducir un excesivo interés en el mismo. Uno de los más importantes se refiere al impacto que las directrices visuales pueden tener sobre el funcionamiento ecológico del paisaje: ¿puede la protección de paisajes escénicos y/o ubicados en las zonas más expuestas al escrutinio público favorecer que las intervenciones e implantación de actividades se trasladen a zonas menos expuestas o con valores escénicos menos claros, pero con importancia ecológica? Esta cuestión ha conducido a un debate más complejo en el que se presenta una relación triangular entre objetivos productivos, ecológicos y estéticos.

El germen de esta preocupación coincidió con un cambio en la perspectiva de gestión ecológica, que experimentó una transición hacia un tratamiento de los recursos naturales alejado de los principios clásicos, que considerara el monte como un ecosistema y desde la perspectiva de una escala amplia. Se inauguró así la actuación inspirada en los principios de la New Forestry y la Ecosystem Management (Velarde Catolfi-Salvoni, 1997). Los sistemas de gestión visual gravitaron entonces hacia una mayor relación entre la gestión ecológica y visual, incorporando las unidades ecológicas y ciertas reglas derivadas de estos métodos (USDA Forest Service, 1995), aunque sin llegar a armonizar sus fundamentos (Sheppard, 2001). La investigación sobre preferencias también reaccionó ante estas dudas y surgieron los estudios experimentales en los que se contrastaban las preferencias puramente visuales o estéticas con los preceptos de la gestión ecológica del paisaje (ver por ejemplo Ribe, 1999; Ribe et al., 2002; Ribe y Matteson, 2002).

Estos métodos, a día de hoy, siguen aplicándose en el contexto en que surgieron.

\section{Contexto europeo}

Paralelamente al proceso acaecido en Norteamérica, en Europa uno de los países en los que antes se inició el tratamiento visual del paisaje fue el Reino Unido a través de los organismos a cargo de la gestión de

Velarde Catolfi-Salvoni, M. D (1997). La Consideración del Paisaje en la Gestión Forestal. análisis de tendencias y propuesta de líneas de actuación (Tesis doctoral no publicada). E.T.S. Ingenieros de Montes - Universidad Politécnica de Madrid, Madrid.

USDA Forest Service (1995). Landscape aesthetics. A handbook for Scenery Management (Agriculture Handbook No. 701). Washington, D.C.: U.S. Dept. of Agriculture, Forest Service.

Sheppard. (2001).

Beyond Visual Resource Management : Emerging Theories of an Ecological Aesthetic and Visible Stewardship. En S. R. J. Sheppard y H. W. Harshaw (Eds.), Forests and

Landscapes: Linking Ecology, Sustainablility, and Aesthetics (pp. 149-173). Nueva York: CABI Publishing - IUFRO.

Ribe, R. G. (1999).

Regeneration harvests versus clearcuts: public views of the acceptability and aesthetics of Northwest Forest Plan harvests. Northwest Science, 73 (Special Issue), 102-117.

Ribe, R. G., Armstrong, E. T., Y Gobster, P. H. (2002). Scenic Vistas and the Changing Policy Landscape: Visualizing and Testing the Role of Visual Resources in Ecosystem Management. Landscape Journal, 21(1), 42-66.

Ribe, R. G. y Matteson, M. (2002). Views of Old Forestry and New Among Reference Groups in the Pacific Northwest. Western Journal of Applied Forestry, 17(4), 173182. 
Lucas, O. W. R. (1991). The design of Forest Landscapes. Oxford, UK: Oxford University Press.

Bell, S. (1993). Elements of visual Design in the landscape (1 1 ed. e. . Londres, UK: Spon Press.

los espacios públicos forestales. En este país, en los años 60 del siglo $X X$, las críticas que se suscitaron ante el resultado visual de las repoblaciones intensivas de coníferas, ejecutadas bajo el signo de la urgencia y del mínimo coste para crear rápidamente una reserva estratégica de madera tras la Primera Guerra Mundial, estimuló a la Forestry Commission hacia el desarrollo de un nuevo sistema de diseño del paisaje. La Forestry Commission contrató a la arquitecta del paisaje Sylvia Crowe como consultora, y nuevos conceptos visuales y una filosofía tendente a la consecución de una apariencia del medio forestal más natural, diversa y ligada a la comprensión del paisaje subyacente fueron entonces desarrollados. El sistema progresó posteriormente con las aportaciones de otros arquitectos paisajistas y fue arraigando en la práctica y política forestal británica, por medio de la producción de cuadernillos para el gestor o la integración en procesos como el de "Reestructuración" ("Restructuration"), proceso este último que permitió un cierto grado de integración de los aspectos ambientales y visuales (Lucas, 1991; Bell, 1993).

Sin embargo, en Europa se comenzó a fraguar una perspectiva distinta de comprensión del valor del paisaje, sin duda posible por las particularidades culturales y poso histórico del paisaje europeo. Dicha perspectiva derivó en una evaluación y gestión del paisaje diferente con respeto a los métodos centrados en el paisaje como recurso visual, anteriormente expuestos.

\section{IV.1.2. El Carácter del paisaje y los métodos descriptivos-valorativos}

A partir de los años 70 del siglo XX en el Reino Unido el desarrollo de los estudios de paisaje siguió un camino diferenciado con respecto al de otros países. El establecimiento de agencias gubernamentales de carácter nacional diferenciadas de las de conservación de la naturaleza (Countryside Commmission for Scotland, England and Wales), y con responsabilidad en la conservación de paisajes, trajo como consecuencia una atención especial a los aspectos culturales y sociales y una perspectiva integral en el acercamiento al paisaje (Encinas, 2000). En el seno de estas agencias se desarrolló en la década de los 80-90 del siglo XX el concepto de carácter del paisaje y 
los procesos descriptivos-valorativos, base que ha cimentado buena parte del proceder en materia de paisaje y el actual marco conceptual en Europa (Swanwick, 2009; Wascher, 2005)

Los inicios de la protección y gestión del paisaje europeo enraízan en la conciencia y legislación ambiental, al igual que en el caso estadounidense. Sin embargo, la dimensión patrimonial-cultural del paisaje ha sido igualmente sólida por las particularidades históricas e identitarias tan intensas que acaudalan los paisajes europeos. La preservación de los valores naturales manifestados en el paisaje bañó desde el inicio el proceder gestor y legislativo, pero el carácter patrimonial del paisaje, el reconocimiento de la identidad de cada territorio en su manifestación paisajística y el sentimiento de pertenencia colectiva se ha entrelazado desde el inicio hasta llegar a la actual perspectiva europea del paisaje (Gómez Mendoza, 2008, 2013).

El carácter del paisaje se define como el patrón de elementos distintivo, reconocible y consistente que hace un paisaje diferente de otro, y no tanto mejor o peor (Swanwick y Land Use Consultants, 2002). El proceso de definición del carácter del paisaje se considera un proceso fundamentalmente objetivo de identificación de su esencia. Dicho proceso se independiza claramente del proceso posterior en el que se emiten juicios basados en el conocimiento del carácter del paisaje para orientar la toma de decisiones en determinados procesos (planificación, programas de mejora del paisaje, evaluaciones de impacto ambiental, etc.). De tal manera, la definición del carácter es el paso fundamental en los denominados métodos descriptivos-valorativos, diferentes en su concepción con respecto a los métodos americanos anteriormente expuestos, que se fundamentan en una asignación directa de valor visual (que no integral) de un paisaje con respecto a otro basada en la evaluación de una serie de componentes desagregados.

\section{IV.1.3. Marco conceptual actual en la planificación europea del paisaje}

La evaluación del carácter y el tratamiento patrimonial del paisaje cristalizaron en la declaración del Convenio Europeo del Paisaje
Swanwick, C. (2009).

L'avaluació del caràcter del paisatge al Regne Unit. En J. Nogué, L. Puigbert y $G$. Bretcha (Eds.), Ordenació $i$ gestió del paisatge a Europa (pp. 130-151). Olot: Observatori del Paisatge.

Wascher, D. M. (Ed.) (2005). European Landscape Character Areas - Typologies, Cartography and Indicators for the Assessment of Sustainable Landscapes. Final Project Report as deliverable from the EU's Accompanying Measure project European Landscape Character Assessment Initiative (ELCAI), funded under the 5th Framework Programme on Energy, Environment and Sustainable Development (Alterra Report No. 1254). Wageningen: Landscape Europe, ELCAI.

Gómez Mendoza, J. (2008). La mirada del geógrafo sobre el paisaje: del conocimiento a la gestión. En J. Maderuelo, Paisaje y Territorio (pp. 1156). Madrid: Fundación Beulas, CDAN (Centro de Arte y Naturaleza), Abada Editores.

Gómez Mendoza, J. (2013). Del patrimonio paisaje a los paisajes del patrimonio. Documents D'anàlisi Geogràfica, 59(1), 5-20.

Swanwick, C. y Land Use Consultants. (2002). Landscape Character Assessment: Guidance for England and Scotland (Vol. 1). The Countryside Agency Scottish Natural Heritage. 
Consejo de Europa (2000). Convenio Europeo del Paisaje

(ETS No.176). Florencia: Consejo de Europa.

Cortina, A. y Queralt, A. (Coords) (2007). Convenio Europeo del Paisaje. Textosy comentarios. Madrid: Ministerio de Medio Ambiente.

Gómez Zotano, J. y Riesco Chueca, P. (Coords) (2010). Marco conceptual y metodológico para los paisajes españoles. Aplicación a tres escalas espaciales. Sevilla: Junta de Andalucía. Consejería de Obras Públicas y Vivienda Centro de Estudios Paisaje y Territorio.

Wascher, D. M. (Ed.) (2005) European Landscape Character Areas - Typologies, Cartography and Indicators for the Assessment of Sustainable Landscapes. Final Project Report as deliverable from the EU's Accompanying Measure project European Landscape Character Assessment Initiative (ELCAI), funded under the 5th Framework Programme on Energy, Environment and Sustainable Development (Alterra Report No. 1254) Wageningen: Landscape Europe, ELCAI

Antrop, M. (2005) Why landscapes of the past are important for the future. Landscape and Urban Planning, 70, 21-34.

Tarroja, À. (2006). Un concepto de paisaje para la gestión sostenible de territorio. En R. Mata Olmo y A. Tarroja (Eds.), El paisaje y la gestión del territorio. Criterios paisajísticos en la ordenación del territorio y el urbanismo (pp.41-50). Barcelona: Diputació de Barcelona / CUIMP.
(Consejo de Europa, 2000), que surgió tras varios avances normativos que no eran sino reflejo de la progresiva toma de conciencia sobre los problemas ambientales y la necesidad de un desarrollo territorial equilibrado (Cortina y Queralt, 2007). El Convenio ha supuesto un poderoso estímulo para la reflexión metodológica, además de para la acción y avance planificador y gestor (Gómez Zotano y Riesco Chueca, 2010). Ya sólo atendiendo a la definición que hace de paisaje establece tres rasgos fundamentales que son de importancia para el tema tratado: "cualquier parte del territorio tal como la percibe la población, cuyo carácter sea el resultado de la acción y la interacción de factores naturales y/o humanos".

En primer lugar, abandona el tratamiento exclusivo del paisaje excepcional: en todos los paisajes han de ser reconocidos valores, asunción directamente enraizada en el concepto de carácter del paisaje. En segundo lugar, coloca la acción y percepción de la gente en una posición privilegiada, por lo que un tratamiento únicamente desde el punto de vista experto resultaría deficiente. Por último, posiciona al mismo nivel tanto el funcionamiento ecológico como el uso antrópico del espacio y especifica la naturaleza cambiante del paisaje, al evidenciar su naturaleza de interacción dinámica. De tal manera, instaura un marco orientador en el que la dicotomía entre los aspectos naturales y culturales y el carácter estático del paisaje se supera, perspectiva igualmente asumida por la disciplina de la ecología del paisaje en Europa, cuyo desarrollo conceptual sirve como una de sus influencias (Wascher, 2005).

En el primer punto es quizá donde se da la mayor innovación con respecto a normas anteriores (Antrop, 2005). En contraposición con la filosofía de los métodos americanos, que premiaban la singularidad, excepcionalidad y mínima disrupción humana en el paisaje, el Convenio no sólo posiciona como objeto de atención paisajística a todos los paisajes, sino que dirige la atención a los cotidianos e incluso a los degradados. Responde así al contexto paradójico en el que surge: la época en el que existe mayor interés del público general (y experto) sobre la materia del paisaje y mayor reivindicación de su calidad como un derecho, coincide con la época en la que la pérdida de su integridad y valores es más patente (Tarroja, 2006). El enfoque consecuentemente no puede ser el de lo excepcional, sino el de lo más susceptible a la degradación. 


\section{IV.1.4. Consideraciones sobre el tratamiento de la dimensión ecológica y percibida en la planificación del paisaje en España}

\section{Inicios del tratamiento del paisaje en España: los valores paisajísticos y naturales entretejidos}

El interés sobre la protección de paisajes en España tiene una historia ya centenaria. Sus orígenes aparecen vinculados a los naturalistas del siglo XIX reunidos en torno a la universidad, las sociedades científicas, las instituciones científico-pedagógicas y las sociedades excursionistas (Martínez de Pisón, 1998; Ortega Cantero, 2003) (Figura 34). La valoración de los paisajes se ligó entonces al sentimiento romántico de admiración de las maravillas de la naturaleza, al regionalismo que reinaba en la época, y también al descubrimiento científico (Sanz Herráiz, 2008) (Figura 35 y 36). La importancia de la base pictórica, estética y nacionalista de la época es esencial para entender la gestación de las primeras normas que apelan al paisaje en España (López Silvestre y Zusman, 2008) (Figura 37, 38, 39 y 40).

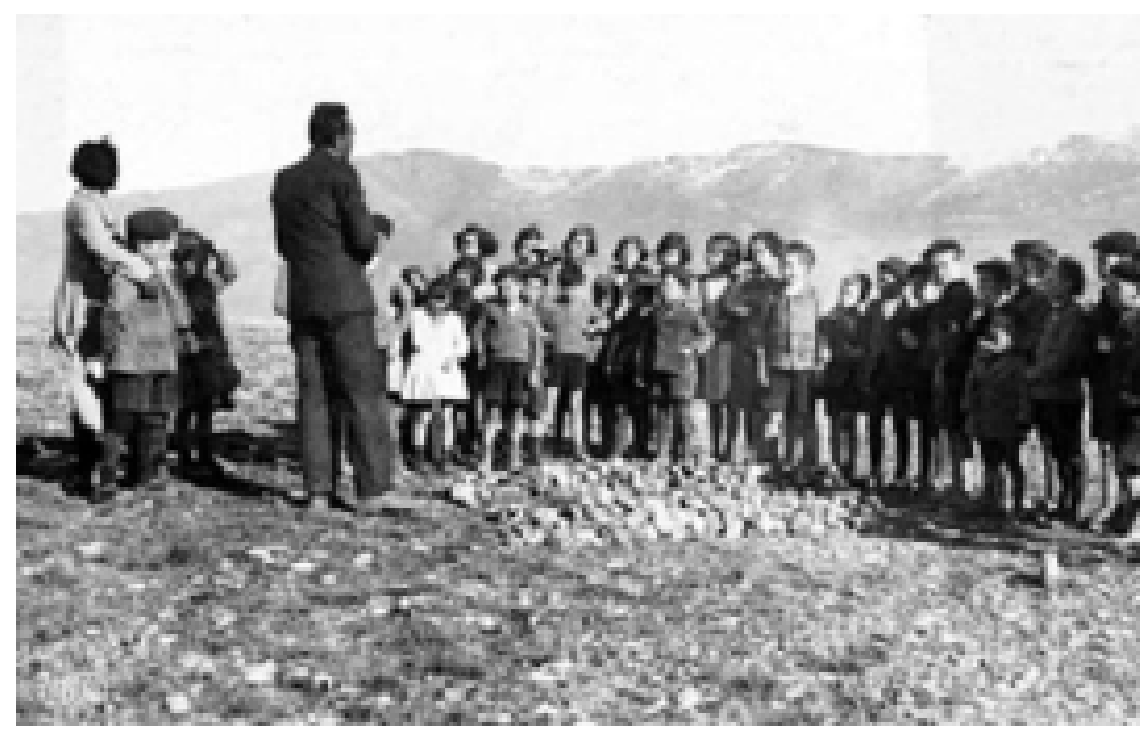

Figura 34. La Institución Libre de Enseñanza, abanderada por Francisco Giner de los Ríos (1839-1915) inauguró el carácter cultural y pedagógico de las excursiones naturalistas. Para los institucionistas, el "contacto purificador de la Naturaleza" permitía educar no solo la inteligencia, sino además la sensibilidad y la imaginación; ayudaba a cultivar simultáneamente las capacidades intelectuales, éticas y estéticas de la persona (Ortega Cantero, 2015)

Fuente fotografía: "Los pioneros de la indómita Sierra de Guadarrama" (www.elguadarramista.com).

Martínez de Pisón, E. (1998). Imagen del paisaje. La generación del 98 y Ortega y Gasset. Madrid: Caja de Madrid, Obra social.

Ortega Cantero, N. (2003). La imagen literaria del paisaje de España. En R. Mata Olmos y C. Sanz Herráiz (Eds.), Atlas de los Paisajes de España (pp. 2952). Madrid: Ministerio de Medio Ambiente.

Sanz Herráiz, C. (2008). Los científicos de la Tierra y la evolución de los estudios sobre el paisaje en España. En F. Mateu Bellés y M. Nieto Salvatierra (Eds.), Retorno al paisaje. El saber filosófico, cultural y cientifico del paisaje en España (pp. 389-474). Valencia: EVREN.

López Silvestre, F. y Zusman, P. (2008). Las normas sobre el paisaje como mirada de época. Del proteccionismo esteticista al derecho universal en España y Argentina. Quintana, 7, 137-155.

Ortega Cantero, N. (2015). Francisco Giner y el descubrimiento moderno del paisaje de España. Anales, 27, 23-44. 


\section{POESIA DE MONTAÑA}
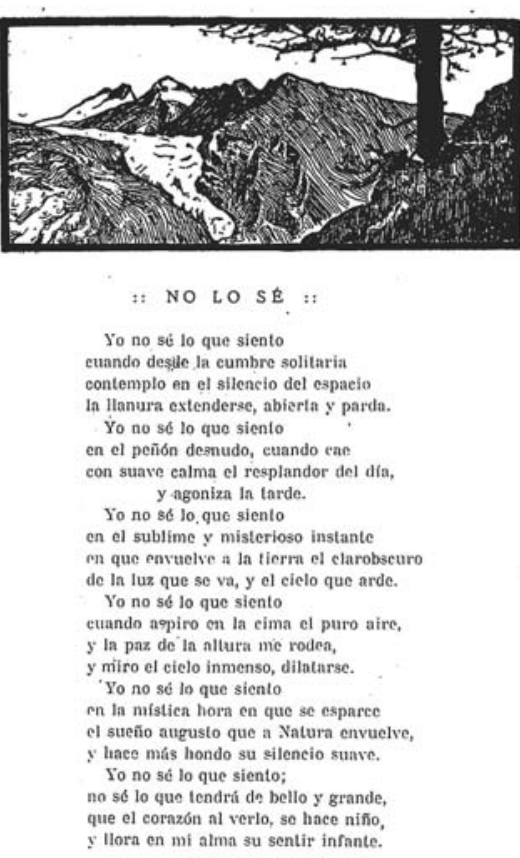

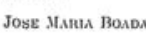

\section{OCUMENTOS}

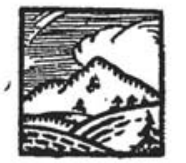

\section{$\therefore \quad$ LA FAUNA DE NUESTRAS MONTAÑAS}

" Mariposas DE ALtURA "

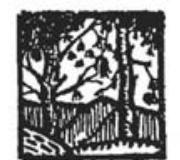

T o me ciega el cariño patriótico, 1 no. Aunque dejáramos a un lado la bellísima Grarllsia isabellx, orgullo legítimo de nuestro Guadarrama, a quien

gantísima Isabelina, vivía también en Francia se sịntió transportado de júbilo, nombre menos refulgente y magnífico con nadie osará dispular la soberanía de la hermosura en el mundo de las mariposas curopeas, ninguna nación del viejo conlinents purde compelir con Espaก̃a en el terreno do las bellezas mariposeras de montaña. Por supuesto que on tre las de llanura tampoco hay en Furopa quien la gane, pero hablamos de las montañeras. Sólo con pensar Sólo con pensar
Oberthur, el gran lepidoplerista fruncés que acaba de morir, que la Gracllsia isabellæ, nuestra arro-

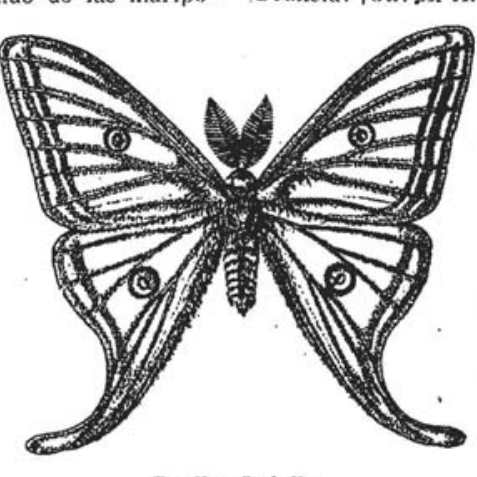

Graellsin Isabellex.

(Dib.S. Martinez.) o de Triunfo se hrbría estremecido si se hubieran confirmado las sospechas de Oberthur, de Cleu y de Powell; pero no: por- ahora nuestra isabclla, la rutilante esmeralda rayada do rojo ardiente, continúa siendo de propiedad exclusiva do las monlañas casteJlanas y aragonesas. Los pinares del Gundarrama, donde fué descubierta por don Mariano Graells, en 1849 y los montos de la sicrra aragonesa

Bernaldo de Quirós, C.

(1915). Cómo fue

descubierta y explorada la

Pedriza de Manzanares.

Peñalara, 21, 129-134.

Mollá Ruiz-Gómez, M.

(2009). "El Grupo de los

alemanes" y el paisaje de la

Sierra de Guadarrama.

Boletín de la Asociación de Geógrafos Españoles, 51

Ortega Cantero, N. (2014). Montañismo y valoración

del paisaje: la Real

Sociedad Española de Alpinismo Peñalara (1913 1936). Ería, 95, 253-279.

Boada, J. M. (1929). Poesía de Montaña: "No lo sé".

Peñalara, 184, 102.

Fernández OSA, A. (1929).

La fauna de nuestras montañas. Mariposas de altura. Peñalara, 181, 1-4.
Figura 35. Escribía en 1915 Constancio Bernaldo de Quirós (1873-1959), discípulo de Giner y uno de los fundadores del Club de Alpinismo Peñalara: "Antes de 1908, la Pedriza de Manzanares estaba desconocida. Nadie había ido por allá de los contados excursionistas que componían los dos o tres grupos que nos precedieron, y el que más, conocía sus crestas lejanas vistas camino de Miraflores o de Navacerrada o bien desde la cumbre de La Maliciosa o de las Guarramas. Tan sólo don Casiano del Prado había hablado de esta región en su clásica Memoria geológica de la Provincia de Madrid (1864), y quizá también el novelista Pérez Escrich, a quien sus aficiones cinegéticas llevaron a recorrer nuestros montes bravos." (Bernaldo de Quirós, 1915, p. 129).

A finales del siglo XIX se inicia la valoración moderna de la montaña que, de un espacio desconocido e incluso temido por ser un entorno arriesgado, pasa a ser el objeto de interés científico, de exploración y de contemplación en parte gracias a la labor de la Institución Libre de Enseñanza, la Real Sociedad Española de Historia Natural o el Museo Nacional de Ciencias Naturales (Mollá Ruiz-Gómez, 2009). El 16 de octubre de 1913 se constituyó la sociedad "Peñalara, Los doce amigos", cuyo objetivo era ampliar y difundir el conocimiento de las cordilleras españolas y el fomento y desarrollo de la afición a la montaña. La sociedad construyó refugios, promovió las federaciones y grupos de montañismo y, en 1930, los Sitios Naturales de Interés Nacional, precedente de los espacios naturales protegidos (Ortega Cantero, 2014). Desde su constitución edita la revista ilustrada de alpinismo "Peñalara", cuyos escritos glosaban observaciones de carácter científico, con poesía y descripciones exaltadas de recorridos y paisajes.

En la imagen, extractos de la Revista: poesía dedicada a la montaña por José María Boada, componente del Grupo de Alta Montaña del Club Peñalara y artículo de descripción de lepidópteros publicado por Ambrosio Fernández OSA, entomólogo de primera fila. 
Aun reduciendo el paisaje á una perspectiva y su percepción á la mera contemplación visual, es incalculable el mundo de factores que intervienen para constituirla; tantos como fuerzas, seres $\mathrm{J}$ productos despliega la Naturaleza ante nuestros ojos: la tierra y el agua en sus formas; el mundo vegetal con sus tipos, figuras y colores; la atmósfera con sus celajes; el hombre con sus obras; los animales y hasta el cielo con sus astros y con el juego de tintas, luces y sombras que matizan diversamente el cuadro á cada hora del día y de la noche. Ahora bien, de todos estos elementos, hay uno en el que tal vez no siempre se-repara bastante: el suelo. Sin duda que no hay quien desconozca el papel, por ejemplo, de las grandes montañas en el paisaje ó el del contraste entre el mar y la costa; pero á esto se reduce casi todo. Vischer mismo, que en su Estética.tan extraordinaria amplitud concede al estudio de la belleza en este orden, descuida, sin embargo,- - cosa explicable por sus ideas-muchos puntos.

El suelo, la costra sólida del planeta, como elemento de paisaje, prescindiendo de las corrientes de agua y de la vegetación, ofrece por sí sólo datos suficientes para constituir una que podría llamarse cestética geológicas. El primero de éstos es la naturaleza de los materiales que lo forman. Asi, por ejemplo, hay paisaje granítico, basáltico, de aluvión, etc. Todo el mundo, v. g., distingue el pintoresco dentellado con que se recortan sobre el azul del cielo las Pedrizas del Manzanares, en la vecina sierra Carpetana, y el suave modelado de los cerros que rodean á Madrid. Aquellas son de granito; éstos de diluvio cuaternario. El granito, por su composición y estructura, presenta una cierta resistencia, así en cantidad como en dirección, á loś agentes atmosféricos; merced á lo cual, no se deja destruir sino en un cierto sentido, de donde nacen á su vez ciertas formas. Doquiera que aflora al descubierto, el agua, al resbalar sobre sus masas, las redondea, produciendo, en las pequeñas, esas superficies ásperas, rugosas, cubiertas de liquenes, que interrumpen la continuidad de la tierra vegetal, y en los grandes cantos, la configuración peculiar de las epiedras caballeras", monolitos á veces enormes y : que en ocasiones oscilan como otros tantos monumentos megalíticos naturales; hasta que, la radiación del calor, que las dilató durante el día, las contrae por la noche, las hiende, las raja en mil grietas, que luego, al hincharse dentro de ellas el hielo, estallan, desprendiendo gigantescas esquirlas, y éstas, apiladas unas sobre otras, forman ese agudo dentellado de las cimas graníticas de nuestra cordillera; dentellado, sobre todo visible allí donde se entrelazan dos tipos de granito: uno más resistente, otro más quebradizo y más blando.

Figura 36. Giner de los Ríos elevó, según palabras de Ortega Cantero "lo visible a la categoría de paisaje" e inauguró en España una nueva actitud hacia la naturaleza y el paisaje, en cuya caracterización también se reconocía al hombre. Bajo el halo humboldiano, Giner superó los límites estéticos de las imágenes románticas del paisaje en España y propuso un modo de entenderlo más amplio y complejo, que aunaba su explicación, su comprensión y la mirada emocional o artística que conecta los rasgos naturales con las notas estéticas (Ortega Cantero, 2015). En la imagen, extracto del artículo de Giner que reeditó la revista Peñalara tras su fallecimiento (Giner de los Ríos, 1915, p.37-38).

Ortega Cantero, N. (2015) Francisco Giner y el descubrimiento moderno del paisaje de España. Anales, 27, 23-44

Giner de los Ríos, F. (1915). Paisaje. Peñalara, 15, 36-44 (publicado originalmente en 1886). 
El príncipe Baltasar Carlos, cazador, pintado entre.1635

1636.

Diego Rodríguez de Silva y

Velázquez (1599-1660)

Óleo sobre lienzo, 191×103 cm

(Madrid, Museo del Prado)

Carandell, J. (1922). Velázquez y la Pedriza de Manzanares. Peñalara, 100, 71-73.

Manada de toros junto a un río, al pie de un castillo, pintado en 1837

Genaro Pérez Villaamil

(1807-1854)

Óleo sobre lienzo, 91×115 cm

(Madrid, Museo del Prado)

Zárate Martín, A. (1992).

Pintura de paisaje e imagen de España: un instrumento de análisis geográfico.Espacio,

Tiempo y Forma, Serie VI,

Geografía, 5, 41-66.

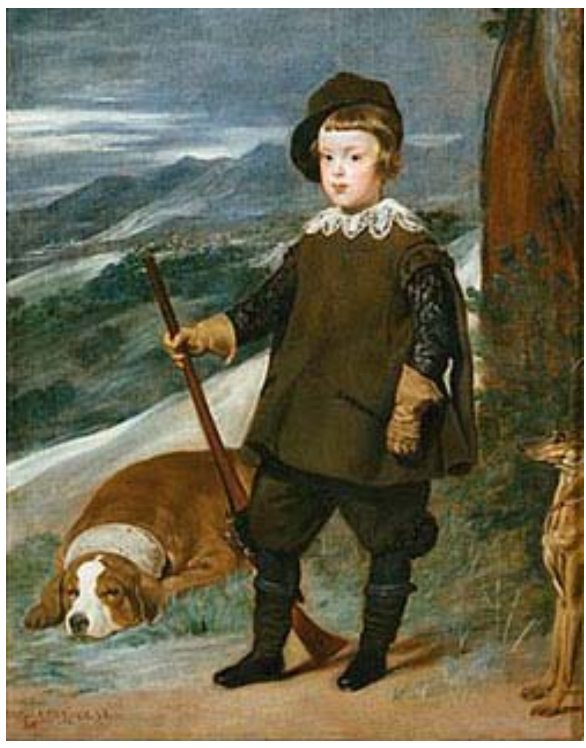

Figura 37. En 1922, Juan Carandell escribía: "Como en muchos otros órdenes, hubo un precursor en España. iY qué precursor! Velázquez. Él comenzó a ver (en cursiva originalmente) nuestro Guadarrama. iAh, si el gran artista hubiera podido pintar ante el Pirineo o cabe la Sierra Nevada...! Claro está que la concepción estética velazqueña había de responder, de por fuerza (en parte, eso si), al ambiente de la época en el arte pictórico, y que, por tanto, el objeto central en sus lienzos es la figura humana, como si el fondo geográfico, el paisaje, estuviese mentalmente desenfocado de aquélla a consecuencia de un prurito de indiferencia ante la perspectiva; producto de un antropocentrismo." (Carandell, 1922, p. 71).

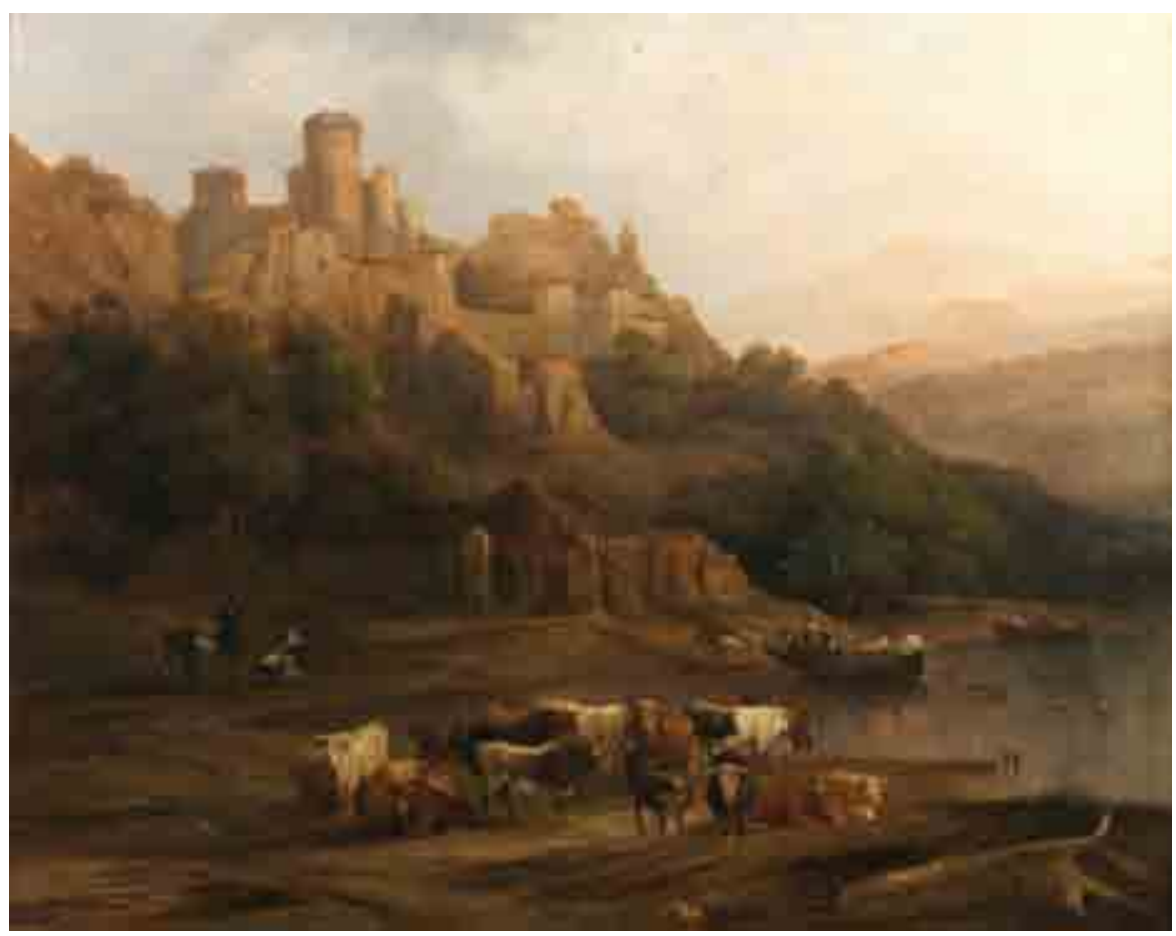

Figura 38. Genaro Pérez Villaamil (1807-1854), es el máximo exponente de la pintura romántica de los paisajes españoles. Plasmaba vistas concretas de la realidad, pero con una tendencia al alargamiento y a la desproporción que buscan la idealización de las formas, dentro de ambientes fantaseados que acentúan la atmósfera vaporosa, de ensoñación y misterio, rasgos propios del arte romántico (Zárate Martín, 1992).

"A través de la obra de arte, el pintor proyecta una concepción del territorio, la suya, que influye sobre la mente del espectador, modifica su observación y en consecuencia condiciona su conducta en mayor o menor grado. Recordando las palabras de P. Klee: "el arte no restituye lo visible, lo hace visible», podemos decir que la pintura enseña a ver el mundo, crea imágenes mentales que cambian la realidad, y orienta la acción." (Zárate Martín, 1992) 


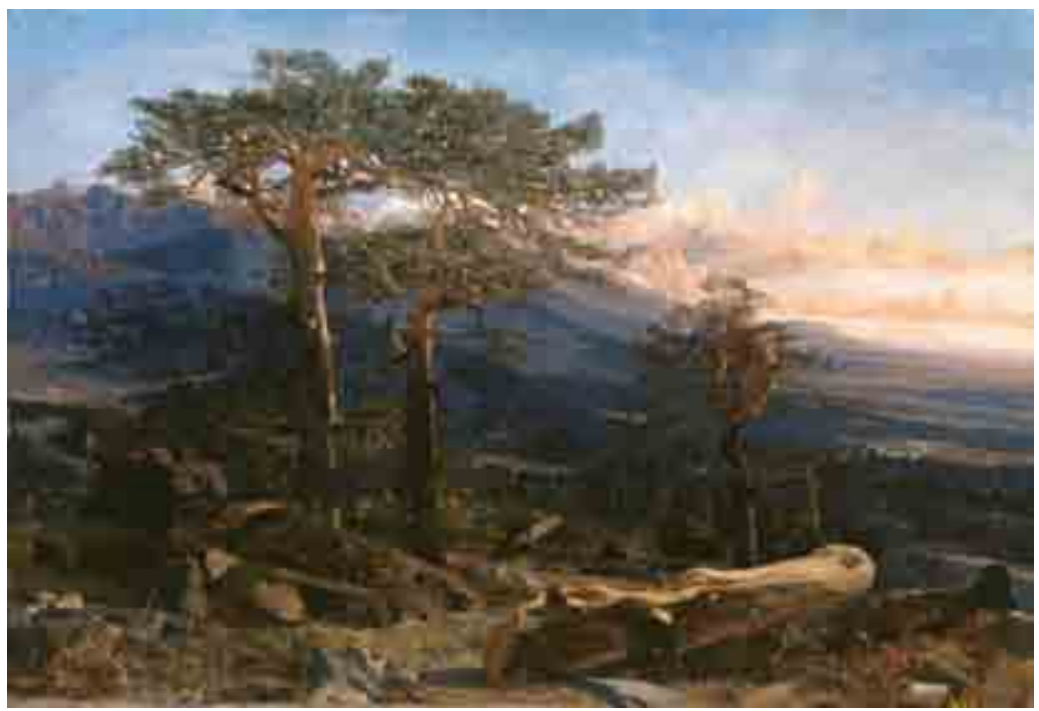

Un paisaje del Guadarrama, pintado en 1858.

Martín Rico y Ortega (1833-1908). Óleo sobre lienzo, 69 × 100 cm (Madrid, Museo Nacional del Prado)

Figura 39. El pintor paisajista Martín Rico (1833-1908) fue discípulo de Villaamil, del que heredó el gusto romántico en los inicios de su pintura. En sus primeras obras se aprecia la concepción panorámica, el ambiente irreal o la composición realzada de la naturaleza propia del Romanticismo. Su estilo sin embargo evolucionó hacia el realismo y, más tarde, hacia el impresionismo. Su búsqueda del natural lo llevó en primera instancia a representar los sistemas montañosos españoles, en especial la sierra de Guadarrama, con la que entabló una intensa relación artística y personal, pues el artista nació y vivió sus primeros años en El Escorial. En su obra "Un paisaje del Guadarrama", pintada directamente del natural, la atmósfera romántica, con elementos típicos de la corriente como el declive gradual de los perfiles de las montañas, nubes fascinantes, el tronco cortado en primer término que actúa como un "naturaleza muerta", conviven con rasgos realistas, como la representación de detalles en las hierbas, matorrales y rocas del primer plano o la atención a las cualidades de los árboles representados, en los que aparecen ramas cortadas, en referencia a la actividad maderera desarrollada en la sierra.

La Canal de Mancorbo en los Picos de Europa, pintado en 1876 Carlos de Haes (1826-1898) Óleo sobre lienzo, $168 \times 123 \mathrm{~cm}$. (Madrid, Museo Nacional del Prado).

Figura 40. El sucesor de Villaamil en la Cátedra de Paisaje de la Real Academia de San Fernando, Carlos de Haes (1826-1898), abandona la composición imaginativa y desarrolla el paisaje realista en España. Bajo la influencia del cientifismo positivista, los pintores representan paisajes tomados del natural y, preocupados por el conocimiento directo y profundo de la naturaleza se lanzan a plasmar en sus cuadros los lugares que descubren los naturalistas y que estudian los geólogos. No están

exentos sin embargo de la herencia romántica. Tal y como observa Zárate Martín (1992) "Háes prefiere los paisajes montañosos del Norte, sobre todo de los Picos de Europa, envueltos en vaporosidad, donde la

naturaleza se muestra con una dimensión misteriosa, gigantesca y sombría que se sitúa por encima del hombre, y cuando pinta la meseta castellana, lo hace a través de rincones arbolados de la Sierra. madrileña y de parajes húmedos de las orillas del Manzanares, que constituyen lo menos característicos de ella" (p. 50)

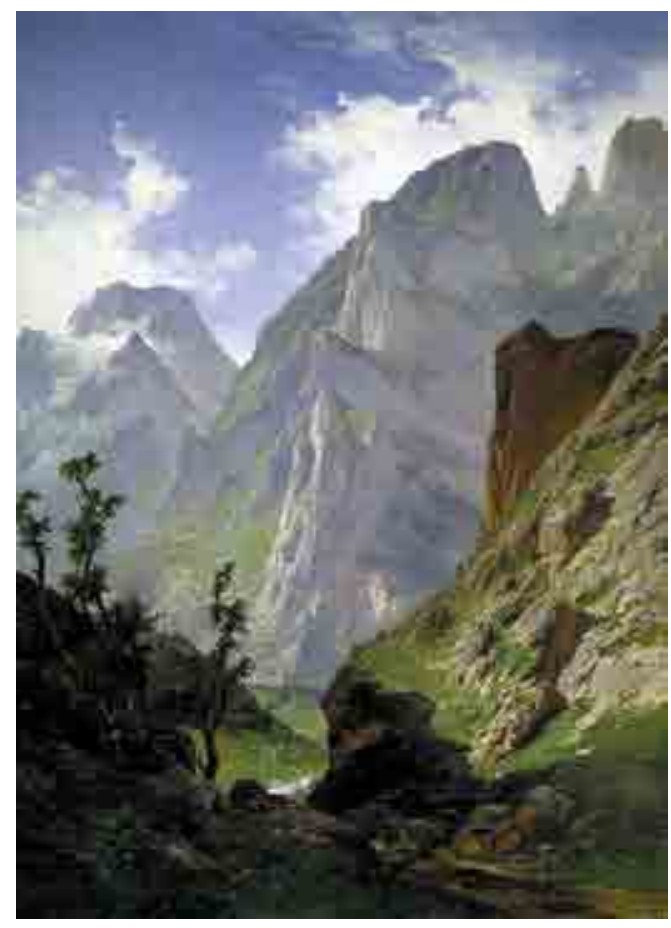


Ley de 7 de diciembre de 1916, de Parques Nacionales de España. Gaceta de Madrid, núm. 343 de 8 de diciembre de 1916, p. 575

López Silvestre, F. y Zusman, P. (2008). Las normas sobre el paisaje como mirada de época. Del proteccionismo esteticista al derecho universal en España y Argentina. Quintana, 7, 137-155.

Mata Olmo, R. (2000). Los orígenes de la conservación de la naturaleza en España. En E. Martínez de Pisón (Ed.) Estudios Sobre El Paisaje (pp.

259-280). Madrid: Fundación Duques de Soria - Ediciones de la UAM.

El término paisaje aparece por primera vez en el ordenamiento jurídico español con la promulgación de la Ley de 7 de diciembre de 1916, de Parques Nacionales de España, una de las primeras normativas españolas de conservación y en la que la protección se ve claramente relacionada con las cualidades patrimoniales y estéticas del paisaje (López Silvestre y Zusman, 2008). Dicha protección presentó una clara inclinación hacia los espacios forestales poco modificados por el hombre (agrestes), sobre los que ciertamente se pretendía la preservación (que no conservación) del paisaje más natural, en su calidad de intocado y excelente, siempre desde un punto de vista impregnado por la apreciación de lo pintoresco (Mata Olmo, 2000). Así, resulta que a principios del siglo XX la consideración de la belleza, simbolismo e historia de los paisaje excepcionales guió en España la preservación de sus valores naturales más que los valores naturales en sí mismos (Figura 41, 42 y 43).

No, Sres. Senadores; ¿cómo voy a pretender ilustraros respecto á cosas que tenéis tan sabidas? ¿Cómo voy á pretender convenceros, si lo estáis más que yo, de que asi como para proteger Er Arte tiene el Estado la declaracion de Monumentos Nacionales, para proteger La Naturalsza debiera trner la declaración de Parques Nacionales?

... Un castillo, una torre, una muralla, un templo, un edificio, se declara Monumento Nacional para salvarlo de la destrucción. ¿Y por qué un monte, excepcionalmente pintoresco, con sus tocas de nieve, sus bosques seculares, su fauna nacional y sus valles paradisiacos, no ha de ser declarado Parque Nacional para salvarlo de la ruina?... ¿ No hay Santuarios para el Arte? ¿Por qué no ha de haber Santuarios para la Naturaleza, para la Madre Naturaleza?
Yosemita es el parque más hermoso de los Estados Unidos en la Sierra Nevada de California. E! Yellowstone fué el valle que se elevó, pues está á 2.400 metros de altura sobre el nivel del mar; el Yosemita, en cambio, fué el valle que se hundió, pues está rodeado de paredes verticales de $900 \AA 1.000$ metros de altura. Sus cascadas, son las más altas del mundo; sus árboles, los más grandes: la célebre "sequoia gigantesca", que arranca derecha en competencia con los montes jara escalar el cielo, y sus lagos, los que con mayor perfección reflejan la composición entera del paisaje.

Yosemita, en el lenguaje de los indios, de los pieles rojas, quiere decir "el gran oso gris", y grande fué el que nos encontramos mi hijo y yo cuando bajábamos del "punto de la inspiración” y habíamos atravesado el "punto del artista». "Punto de la inspiraciónn, llaman los americanos, aquel en que el paisaje nos sorprende, nos suspende, nos inspira. "Punto del artista", aquel, ya rebuscado, desde el cual el paisaje resulta más hermoso. Al salir del punto del artista, nos encontramos con el oso magnífico, corpulento, plantado en medio del camino, que se perdió tranquilamente en la espesura.

Figura 41. El paisaje artístico y literario forjado en la época postromántica influyó poderosamente en las primeras figuras que abogaron por la conservación de los paisajes en España, como Pedro Pidal y Bernaldo de Quirós, Marqués de Villaviciosa de Asturias (1870-1941), principal impulsor político de la constitución de los Parques Nacionales y muy influido por la experiencia

estadounidense al respecto. Sus escritos y discursos están forjados por un lenguaje propio del arte (que bebe de la estética decimonónica), y con un exaltado carácter sacralizador y nacionalista. Los textos mostrados forman parte de su intervención en el Senado el 14 de junio de 1916, considerado como antecedente de la aprobación de la Ley de Parques Nacionales de 7 de diciembre de 1916 (López Silvestre y Zusman, 2008). 
Figura 42. La excelencia de la belleza de los paisajes fue el argumento de primera línea para la creación de la figura de Parque Nacional y el uso turístico uno de sus grandes objetivos pues, como se observa en la Ley de 7 de diciembre de 1916, de Parques Nacionales de España, el favorecer el acceso al espacio se cita como fin incluso por delante del de conservación de sus valores naturales.
D.n ALPONSO XIII, por la gracia de Dlos y la Constitución, REx de Españo;

A todos los que presento vieren $\mathbf{y}$ entendieran, sabed: que las Cortes han deoretado y $\mathrm{N} 63$ sancionado lo siguiente:

Artículo $10^{\circ}$ Se crean en España los Parques Nacionales.

Art. 2. ${ }^{\circ}$ Son Parques Nacionales, para los efectos de esta Ley, aquelios sitios 6 parajes exsepcionalmente pintorescos,. forestales 6 agrestes del territorio nacional, que el Estado consagra, declarándo. res tales, con el exclusivo objeto de favorecer su acceso por vís de comunica. cíon adecuadas, $y$ de respetar $y$ hacer que se respete la belleza natural de sus paisajes, la riqueza de su fauna y de su flora y las particularidares geológicas 6 hidrologicas que encierren, evitando de este modo con la mayor eflcacia todo acto de destrucción, deterioro 6 desfgurací́n por la mano del hombre.
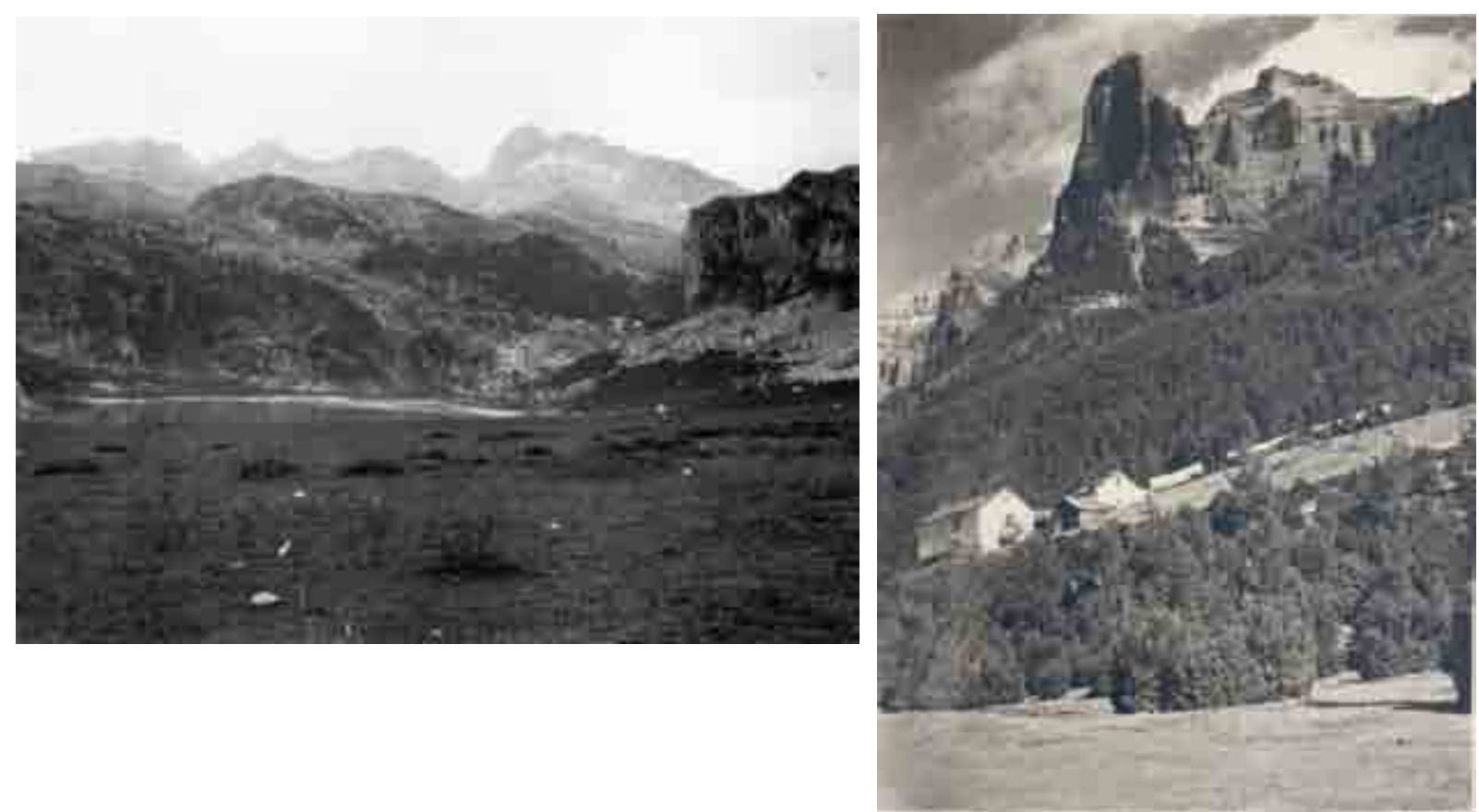

Figura 43. Los primeros espacios declarados fueron representantes de paisajes montañosos y agrestes: el Parque Nacional de la Montaña de Covadonga (creado en julio de 1918 y posteriormente ampliado en 1995, fue renombrado como Parque Nacional de los Picos de Europa) y el Parque Nacional del Valle de Ordesa o del río Ara, (declarado en agosto de 1918 y ampliado en 1982, fue renombrado como Parque Nacional de Ordesa y Monte Perdido). En las fotos, dos vistas icónicas de los Lagos de Covadonga y el Tozal del Mallo.

Fuente fotografías: Ministerio de Agricultura, Pesca y Alimentación, España. 
Real Orden de 15 de julio de

1927, de Sitios y Monumentos Naturales de Interés Nacional. Gaceta de Madrid, núm. 203 de 22 de julio de 1927, p. 451

López Silvestre, F. y Zusman, P. (2008). Las normas sobre el paisaje como mirada de época. Del proteccionismo esteticista al derecho universal en España y Argentina. Quintana, 7, 137-

La influencia del arte romántico se dejó notar durante muchas décadas después en la normativa de conservación. Una vez creada la figura de Parque Nacional y declarados como tales los primeros espacios naturales, a lo largo del primer tercio del siglo XX se fue ahondando en la política de protección de la naturaleza ligada a los valores del paisaje con el establecimiento de figuras de protección como los Sitios y Monumentos Naturales de Interés Nacional en virtud de la Real Orden de 15 de julio de 1927. Estas figuras, como claramente recoge la exposición de motivos de la ley, se declaran como complemento de los Parques Nacionales. Su promulgación se produjo bajo la dirección de Eduardo Hernández Pacheco (18721965). Aunque mantenían como argumento de protección lo extremo de su belleza y carácter pintoresco, la influencia de Hernández Pacheco se deja notar en un cierto desvío desde el conservacionismo esteticista tendente a privilegiar la postal alpina intocada, hacia un mayor reconocimiento de la interacción entre naturaleza y hombre, de la realidad geográfica y social, con una sensibilidad más ecológica y una búsqueda de lo regionalmente "representativo". Así, junto con la exaltación de la belleza y peculiaridades del mundo natural, aparecen apuntes sobre geología, climatología, ganadería y cultivos o cultura tradicional (López Silvestre y Zusman, 2008) (Figura 44 y 45).

Sánchez Vigil, L. M., Salvador Benítez, A., y Olivera Zaldua, M. (Ed.) (2017). Portugal Inédito. Fotografías de Eduardo HernándezPacheco. Madrid: Facultad de Ciencias de la Documentación. Universidad Complutense de Madrid

Fuente fotografías: Biblioteca Histórica de la Universidad Complutense de Madrid
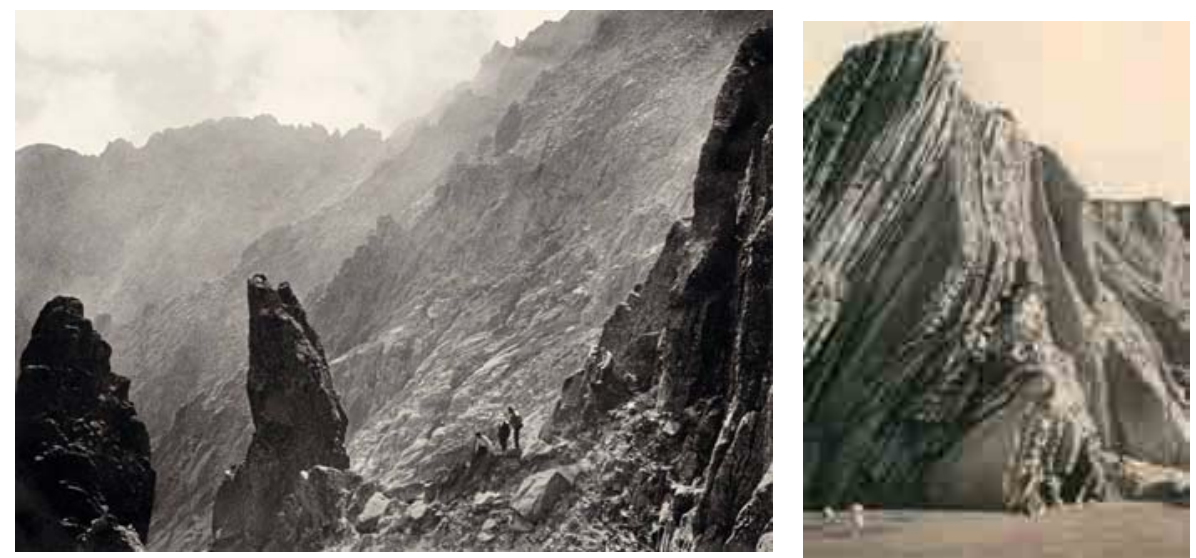

Figura 44. Eduardo Hernández-Pacheco (1872-1965), geólogo, geógrafo, paleontólogo y prehistoriador, miembro de la Junta Central de Parques Nacionales, director de la sección de geología del Museo Nacional de Ciencias Naturales y catedrático de la por entonces denominada Universidad Central. Fue un eminente científico que utilizó las fotografías de campo en sus indagaciones y como apoyo visual para sus clases y disertaciones públicas. En ellas se evidencia su sensibilidad estética sobre el paisaje, con "una cuidada composición, una esmerada elección del punto de vista y la atención puesta en la luz", como señala Cristina Zelich, comisaria de la exposición "Elementos del Paisaje. Fotografías 1907-1950" (Museo Extremeño e Iberoamericano de Arte Contemporáneo (MEIAC)) (Sánchez Vigil, Salvador Benítez, y Olivera Zaldua, 2017) 
Con las bellezas de la Naturaleza se trata de hacer lo que en todos los países cultos se ha hecho con los monumentos importantes del arte y con los monumentos arqueoĺgicos de gran relieve: evitar su destrucción y protegerlos por el Estado. Hace tres cuartos de siglo, todos sabemos que las esplén. didas habitaciones de las torres de la Alhambra de Granada eran asilo de gitanos. Hace veinticinco años el circo y teatro romanos de la ciudad de Mérida eran unas ruinas abandonadas y se sembraban de forraje. Hoy son edificios consolidados y cuidados con esmero. Algo análogo a esto es lo que se trata hacer con aquellos parajes en donde la Naturaleza se muestra con característica más extraordinaria y con belleza más exuberante. Hay que evitar la destrucción y la transformación de aquellos parajes naturales de excepcional belleza, y hay que evitar también la desaparición de los animales salvajes bellos, que son el ornamento de los lugares agrestes y selváticos y de los roquedos y luminosas crestas montañosas.

Son los bellos paisajes, ornato de la Tierra, lo que se trata de proteger, como asilos de tranquilidad y de paz en este turbulento y angustioso vivir de los tiempos modernos; pero no como lugares reservados a uno solo, a unos privilegiados, sino como lugares abiertos a todos los ciudadanos. Por esto debe ser el Estado el que cuide de ellos y el que los proteja y el que los tenga a disposición de todos.

A pesar del creciente desarrollo de los cultivos y de la industria, aún quedan, en el ámbito nacional, algunos parajes agrestes y bellos que son residuos de las selvas primitivas de la Naturaleza espléndida y salvaje de las épocas prehistóricas, porque a ellos aún no llegaron las vías modernas de comunicación, y con ellas la desforestación egoísta y despiada, o porque su suelo rocoso, abrupto y pobre, fué desdeñado por la Agricultura, y, si acaso, sostiene una mísera ganadería.

Figura 45. Extractos de las Guías de los Sitios Naturales de Interés Nacional publicadas en 1933 por la Comisaría de Parques Nacionales y la Protección de la Naturaleza en España bajo la dirección de Hernández-Pacheco. Sobre estas líneas, extracto perteneciente al capítulo Características de los parajes de Naturaleza protegida por el Estado, en el que se exponen los fines que se buscaban con la protección. En la página siguiente, extracto del capítulo Los Sitios Naturales de Interés Nacional, en el que se aprecia la consideración de la componente humana en el paisaje.

Hernández Pacheco, E. (Dir.) (1933). Guías de los Sitios Naturales de Interés Nacional (número 3). La Comisaría de Parques Nacionales y la Protección de la Naturaleza en España. Madrid: Ministerio de Agricultura. Comisaría de Parques Nacionales. 
Io. Sierra de Espuña.-También en la provincia de Murcia, cerca de Alhama y de Totana. Constituye una bella montaña de formas abruptas en sus cumbres, de pintorescos y escarpados roquedos. Desde la cumbre, fácilmente accesible, se disfruta extenso panorama hacia la Cordillera Bética,

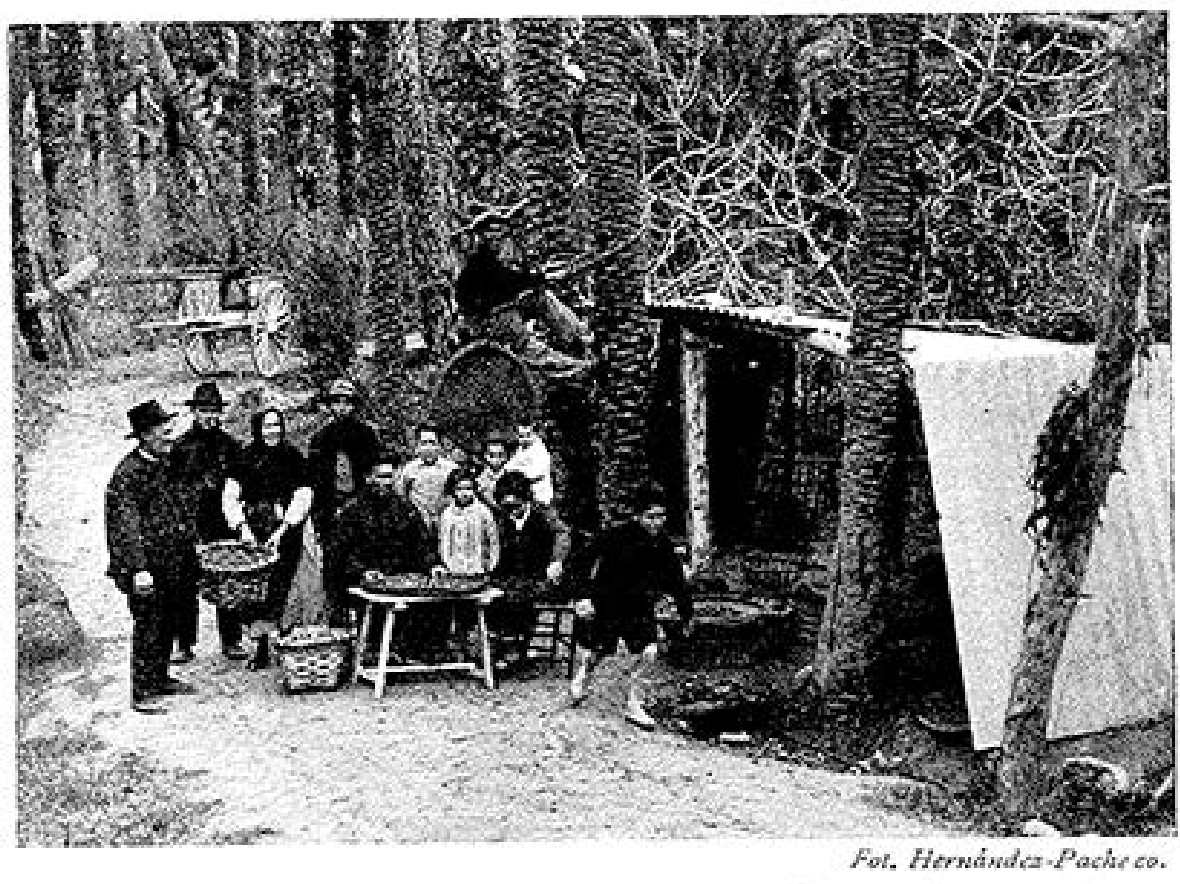

Palmar de Elche (Murcia), protegido por el Estado: Recolección de dátiles en el palmar.

hacia el Mediterráneo, que se divisa en la lejanía y hacia los otros rumbos. Extensos pinares excelentemente cuidados rodean las zonas rocosas de las cumbres. Una red de caminos perfectamente establecidos y bien cuidados permite recorrer en carruaje los diversos lugares del Sitio Natural. Una hospedería en uno de los parajes más amenos facilita la estancia en estos pinares, cuya frondosidad hace contraste con las secas y áridas montañas de esta parte del Sureste de la Península. 
Tras un periodo en el que la política de protección se desdibujó (guerra civil y primeros años de posguerra), el período franquista (Figura 46 y 47) apenas añadió cambios a la perspectiva de protección selectiva del paisaje natural primigenio y excepcionalmente bello. E desarrollo reglamentario de la Ley de Montes de 1957, por medio del Decreto 485/1962, recoge todo lo referente a Parques Nacionales y a las figuras de Sitios y Monumentos Naturales de Interés Nacional sin mayor modificación. Esta época se encuentra inmersa en la equivalencia entre paisaje y espacio natural protegido (Mulero Mendigorri, 2013).
Decreto 485/1962, de 22 de febrero, por que se aprueba el Reglamento de Montes. Boletín Oficial del Estado núm. 61 de 12 de marzo de 1962, p. 3399 a 3417

Mulero Mendigorri, A. (2013) Significado y tratamiento del paisaje en las políticas de protección de espacios naturales en España. Boletín de La Asociación de Geógrafos Españoles, 62, 129-14.

\section{CAPITULO III}

\section{Repoblaciones en beneficio de Cotos Escolares, Frente de} Juventudes y Hermandades

Art. 328. Sin perjuicio de su función pedagógica ni menos cabo del vínculo económico de índole local que establecen. se cuidará que estos Cotos Forestales sirvan para embellecer y realzar puntos notables del paisaje o que posean interés histórico. rélígioso o turístico, $y$, en genéral, que todas las repoblaciones de este tipo despierten y estimulen en el orden cultura $\nabla$ afectivo del pueblo su adhesión a la politica forestal

Figura 46. Extracto del Decreto 485/1962. Los cotos escolares eran asociaciones de alumnos dirigidas por sus maestros que, mediante una actividad con fines educativos de carácter agrícola y forestal (en ciudades fueron más del tipo industrial o artístico), pretendían ser una fuente de recursos para las mutualidades escolares de previsión, institución estrechamente ligada. El coto escolar estuvo ligado a la escuela española durante la mayor parte del siglo XX y posibilitaba trasladar al alumnado al medio natural para su observación, para despertar su interés por el estudio del mismo, por su conservación y respeto.

\section{MADRID}

1. Nombra: Las Cabreras, Cerro de San Esteban y Pantano de San Juan.

2. Tipo de paisaje: Valle cubierto por el pantano y laderas pobladas por pinos: formaciones rocosas con vista al pantano.

3. Localización: Término municipal: San Martín de Valdeiglesias.

4. Tamaño: 3.200 Has.

5. Rasgos distintivos: Contraste entre la vegetación y las aguas del Pantano de San Juan. Deportes acuáticos.

Figura 47. Extracto del Inventario Nacional de Paisajes Sobresalientes confeccionado en 1975. La relación de paisajes, trabajo preliminar, atendía a dos criterios: paisajes que no estuvieran ya especificamente protegidos y paisajes con calidad paisajística derivada de los caracteres del medio físico, de los rasgos físicos de la vegetación o de importancia cultural (usos agrarios) (Instituto Nacional para la Conservación de la Naturaleza, 1977).
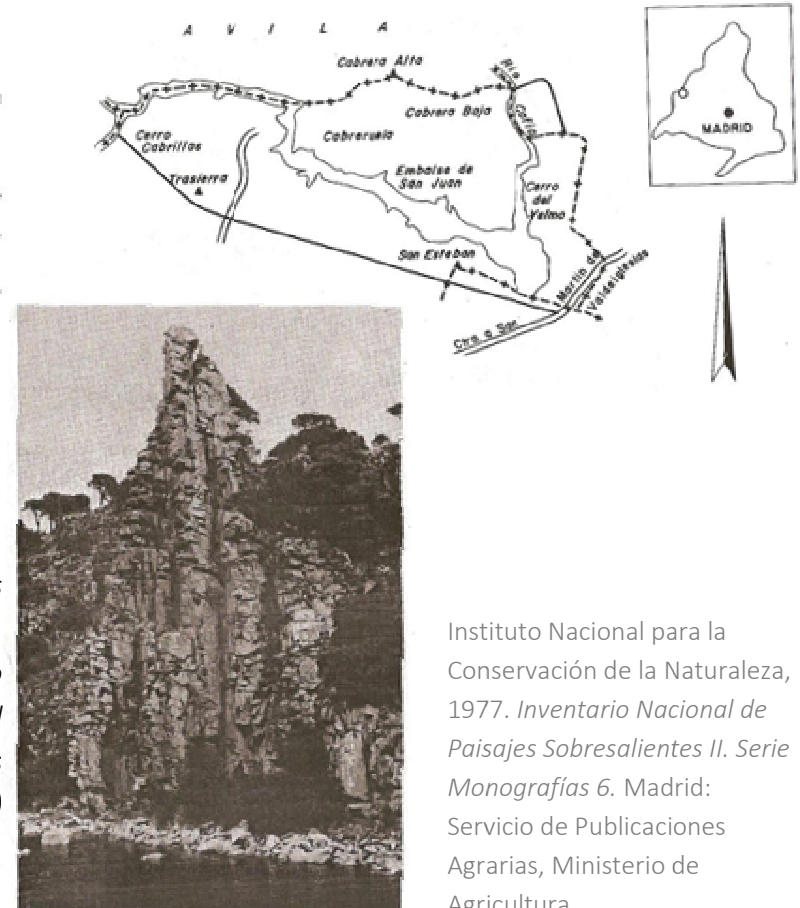

Instituto Nacional para la Conservación de la Naturaleza, 1977. Inventario Nacional de Paisajes Sobresalientes II. Serie Monografías 6. Madrid: Servicio de Publicaciones Agrarias, Ministerio de Agricultura. 
Ley 15/1975, de 2 de mayo, de espacios naturales protegidos. Boletín Oficial del Estado núm. 107 de 5 de mayo de 1975, pp. 9419 a 9421.

La Ley 15/1975, de 2 de mayo, de espacios naturales protegidos, sin embargo, comienza a definir la figura de Parque Nacional con un matiz diferente, pues sigue privilegiando la naturaleza primigenia y el valor destacado, pero la belleza pierde preeminencia y se equilibra con el interés cultural, educativo o recreativo (Figura 48). En virtud de dicha Ley se abre el abanico de posibilidades de conservación de espacios y se comienza a desligar esta de lo intocado, de lo excepcional y de lo puramente bello: las Reservas Integrales de Interés Científico (con clara vocación de conservación de valores ecológicos y fines investigadores), los Parques Naturales (en los que se reconocen los valores naturales destacados pero que da entrada a la posibilidad del aprovechamiento ordenado de los recursos) y los Parajes Naturales de Interés Nacional (sitios de ámbito reducido en el que los valores estéticos están presentes).

\section{6}

LEY 15/j975. de 2 de meyo de espactos natu. rales protegiuns

Dentro de la politica general de conservarión de la Natura. lez: debe ocupar lugur preferente la protección selectiva de ariatllos espacios nalurales que por sus caracleristjcas generaies o especificas scan merecentoras de una ciaśficacion espocial. Esta calif́ceación deberá concretarse en una declararion formal que expecifique para cara lugar jos valores o peculiaridades guo la han detcrminato y los objetivos de todo orden que se prefentan R'chazar.

Articul turectu. Parques Nacionates.

Uno. Sun Parques Nacionales los espacios naturales de, refativa extensiun quo se dectaren por loy como tales por la existen ia en los mismos de erosistemas primigenios quo no hayan sido sustancialmento alterados por la penetración, explotación 5 ccupación humana $y$ donde las especies vegetales $y$ animeales, ast cumo los lugares $y$ las formaciones geomorfologicas, tersan un testacudo interes culturad, educativo o recrea1urs o uc los que exjetan paisajes naturales de gran belleza.

Figura 48. La perspectiva de conservación de la naturaleza en 1975 ya comenzaba a contemplar con claridad otros valores naturales además de los ligados a la belleza y la dimensión patrimonial, si bien aún lo hace desde la protección selectiva de algunos espacios destacados. 
A partir de este momento, sucesivas leyes fueron facilitando que la filosofía virase desde la protección del espacio natural bello, con una dimensión patrimonial clara, a una protección centrada en los aspectos más biológicos (Frolova, Menor Toribio y Cancer Pomar, 2003; López Silvestre y Zusman, 2008). En la Ley 4/89, de Conservación de los Espacios Naturales y de la Flora y Fauna Silvestres ya se advierte ese viraje hacia la protección de la dimensión ecológica del medio (Figura 49).

\section{Frolova, M., Menor Toribio, J., Y Cancer Pomar, L. (2003). El paisaje en las políticas públicas de Francia y España: desde la protección del monumento a la gestión del espacio. Estudios Geográficos, 253, 605-622.}

López Silvestre, F. y Zusman, P. (2008). Las normas sobre el paisaje como mirada de época. Del proteccionismo esteticista al derecho universal en España y Argentina. Quintana, 7, 137-155. Ley 4/1989, de 27 de marzo, de Conservación de los Espacios Naturales y de la Flora y Fauna Silvestres. Boletín Oficial del Estado núm. 74, de 28 de marzo de 1989, páginas 8262 a 8269 . mejora de los recursos naturales y, en particular, las relativas a los espacios naturales y a la flora y fauna silvestres.

\section{Articulo 2.}

1. Son principios inspiradores de la presente Ley los siguientes:

a) El mantenimiento de los procesos ecológicos esenciales y de los sistemas vitales básicos.

b) La preservación de la diversidad genética.

c) La utilización ordenada de los recursos, garantizando el aprovethamiento sostenido de las especies y de los ecosistemas, su restauración y mejora.

d) La preservación de la variedad, singularidad y belleza de los *cosistemas naturales y del paisaje.

Figura 49. Sólo con la lectura de los principios inspiradores contenidos en la Ley 4/89 se aprecia la consolidación de la idea de la belleza del paisaje como uno de tantos valores del medio natural a proteger.

La Ley 4/89 inaugura el tratamiento del paisaje no desde la perspectiva de argumento que sostiene la salvaguarda del espacio natural, sino como una de las riquezas que ostenta el medio natural y cuya protección es asegurada por la conservación de éste y no al revés. La protección jurídica del paisaje en España es desde entonces un cometido preferentemente ligado a las leyes de protección del medio ambiente (Hervás Más, 2009). Se deriva de dicha ley la existencia de medidas con incidencia directa e indirecta en la protección del paisaje que ilustran el cambio de enfoque (Mulero Mendigorri, 2013). Por un lado, la inclusión de la preservación del

Hervás Más, J. (2009). Ordenación del Territorio, Urbanismo y

Protección del Paisaje. Barcelona: Editorial Bosch.

Mulero Mendigorri, A. (2013) Significado y tratamiento del paisaje en las políticas de protección de espacios naturales en España. Boletín de La Asociación de Geógrafos Españoles, 62, 12 
paisaje como uno de los cuatro principios básicos inspiradores de la ley y el establecimiento del Plan de Ordenación de los Recursos Naturales como instrumento fundamental de gestión de los espacios protegidos define un tratamiento del paisaje como uno de tantos valores a los que prestar atención. La inclusión de la figura de Paisaje Protegido entre las reconocidas a nivel estatal (siguiendo los estándares internacionalmente reconocidos) constituye según Mulero un salto jurídico de calado, por cuanto vino a reconocer de forma explícita que es necesario proteger determinados paisajes, y que ello debe hacerse en el marco de la legislación medioambiental. Ahora bien, también simbolizó la polarización entre la perspectiva ecológica y la estética.

Ley 42/2007, de 13 de diciembre, del Patrimonio Natural y de la Biodiversidad. Boletín Oficial del Estado núm. 299, de 14 de diciembre de 2007 , pp. 51275 a 51327
Si bien en la definición de Paisaje Protegido que hace la Ley 4/89 sólo se hace referencia a sus valores estéticos y culturales, aún exclusivamente buscados en el medio más natural, la Ley 42/2007, de 13 de diciembre, del Patrimonio Natural y de la Biodiversidad, hace referencia al Convenio Europeo del Paisaje y refleja la idea imperante de paisaje como ámbito más allá de lo extraordinario y fruto de la interacción entre hombre y medio natural (Figura 50).

\section{Articulo 17}

Los Paisajes Protegidos son aquellos lugares concretos del medio natural que, por sus valores estéticos y culturales, sean merecedores de una protección especial.

Artículo 35. Los Paisajes Protegidos.

1. Paisajes Protegidos son partes del territorio que las Administraciones competentes, a través del planeamiento aplicable, por sus valores naturales, estéticos y culturales, y de acuerdo con el Convenio del paisaje del Consejo de Europa, consideren merecedores de una protección especial.

2. Los objetivos principales de la gestión de los Paisajes Protegidos son los siguientes:

a) La conservación de los valores singulares que los caracterizan.

b) La preservación de la interacción armoniosa entre la naturaleza y la cultura en una zona determinada.

3. En los Paisajes Protegidos se procurará el mantenimiento de las prácticas de carácter tradicional que contribuyan a la preservación de sus valores y recursos naturales.

Figura 50. Las definiciones primera (la Ley 4/89) y posterior (Ley 42/2007) de Paisaje Protegido pone de manifiesto la evolución que su concepción ha experimentado.

En las últimas décadas se asiste a la emergencia de legislación específica de protección y gestión del paisaje, como se verá en el siguiente apartado. 


\section{Actualidad de la planificación del paisaje en España y su tratamiento a través de la componente ecológica y perceptiva}

El último gran respaldo legislativo a la protección del paisaje ha sido la entrada en vigor en España del Convenio Europeo del Paisaje a partir de 2008. Sin embargo, la firma del Convenio no inauguró la práctica española de ordenación y gestión del paisaje, pues anteriormente ya se habían desarrollado algunos trabajos de caracterización y valoración (Gómez Zotano y Riesco Chueca, 2010). A escala nacional, el Atlas de los Paisajes de España (Mata Olmo y Sanz Herráiz (Dir.), 2004) se alinea con la aplicación del Convenio Europeo del Paisaje para la identificación y caracterización el conjunto de paisajes del territorio español y constituye un marco general para los estudios y políticas de carácter regional o local, más detallados. La filosofía es eminentemente clasificadora y descriptiva sobre la base de la identificación del carácter de los distintos paisajes.

Pero es a nivel autonómico, escala en la que actualmente residen las competencias en la protección del espacio natural y el paisaje, donde más esfuerzos se han realizado, especialmente tras la ratificación del Convenio Europeo del Paisaje. Los estudios a nivel regional han avanzado según la estela marcada por el Convenio, si bien muestran, al igual que lo que ocurre a escala continental, diferencias en cuanto a los enfoques, métodos y alcance normativo del tratamiento del paisaje (Zoido Naranjo, 2012). La radiografía de la situación del paisaje en las distintas comunidades autónomas elaborada por el Observatorio de la Sostenibilidad en España contienen una serie de conclusiones que ayudan a trazar la imagen actual de tratamiento del paisaje (OSE, 2009).

A este nivel operativo, el autonómico, el paisaje ha ido siendo progresivamente considerado como un recurso natural y cultural, aunque el informe subraya que todavía en algunas comunidades se identifica con lo natural $y$, en algunos otros casos, con lo estrictamente cultural. Uno de los puntos en común deriva precisamente de la inercia de la consideración del paisaje emanada de las normas de conservación de la naturaleza, germen como ya se ha indicado de la incorporación del paisaje como valor asociado a los

Gómez Zotano, J. y Riesco Chueca, P. (Coord. . (2010). Marco conceptual y metodológico para los paisajes españoles. Aplicación a tres escalas espaciales. Sevilla: Junta de Andalucía. Consejería de Obras Públicas y Vivienda - Centro de Estudios Paisaje y Territorio.

Mata Olmo, R. y Sanz Herráiz, C. (Dir.) (2004). Atlas del Paisaje de España. Madrid: Ministerio de Medio Ambiente.

Zoido Naranjo, F. (2012). El paisaje: un concepto útil para relacionar estética, ética y política. Scripta Nova. Revista Electrónica de Geografía y Ciencias Sociales [on line], 16 (407). Recuperado de: http://www.ub.edu/geocrit/s $n / s n-407 . h t m$

Observatorio de la Sostenibilidad en España (2009). Patrimonio Natural, Cultural y Paisajístico.

Madrid: Observatorio de la Sostenibilidad en España, Ministerio de Medio Ambiente y Medio Rural y Marino, Fundación Biodiversidad, Fundación General de la Universidad de Alcalá. 
Ley 4/1989, de 27 de marzo de Conservación de los

Espacios Naturales y de la Flora y Fauna Silvestres. Boletín Oficial del Estado núm. 74 , de 28 de marzo de 1989, pp. 8262 a 8269 .

Mulero Mendigorri, A. (2013).

Significado y tratamiento del

paisaje en las políticas de

protección de espacios

naturales en España. Boletín de La Asociación de Geógrafos Españoles, 62, 12 espacios más naturales. Por un lado, se constata el valor paisajístico como una cualidad propia de las distintitas figuras de protección derivadas de la Ley estatal 4/89 de Conservación de los Espacios Naturales Protegidos y de la Fauna y Flora Silvestres. Por otro lado, la dimensión paisajística se concreta de forma específica en una mayor o menor aplicación de la figura de "Paisaje Protegido", figura adoptada en virtud de la misma Ley estatal pero escasamente aplicada (Figura 51).

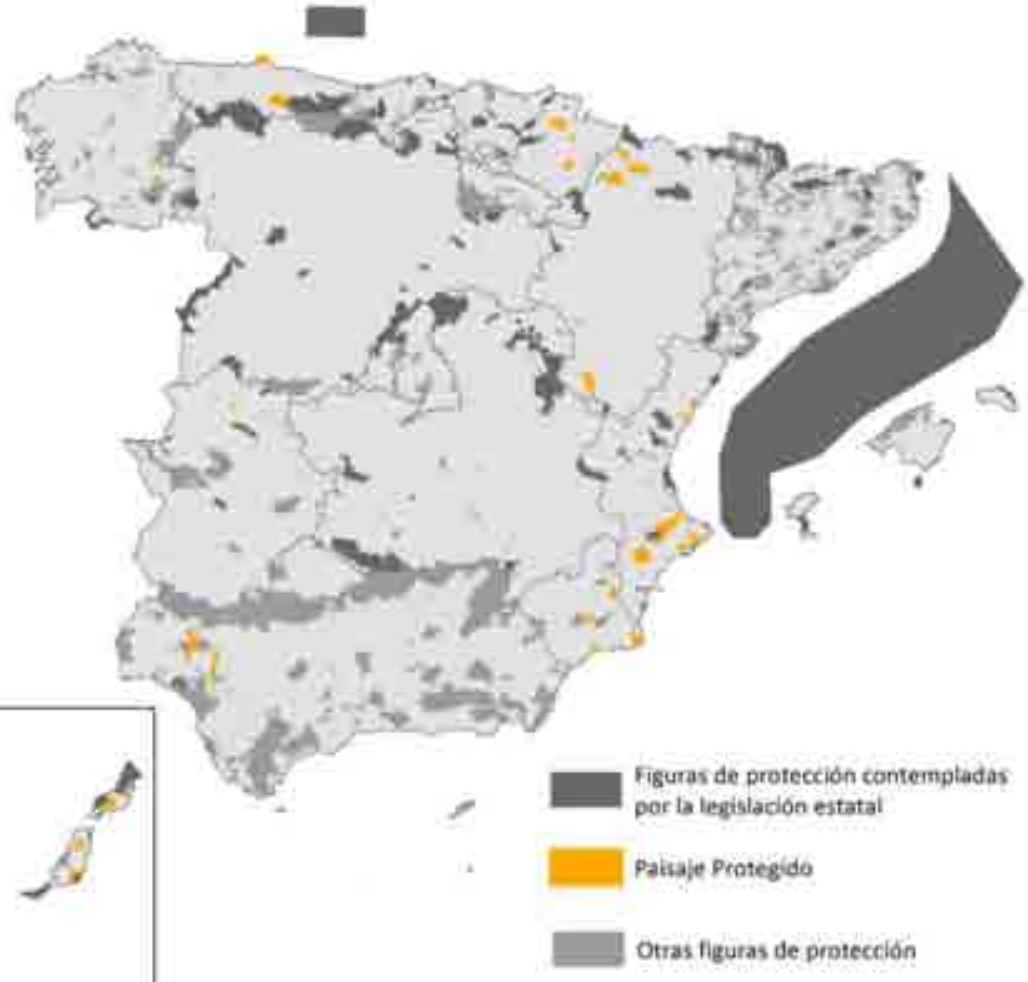

Fuente de los datos: Elaborado a partir de los datos actualizados a junio de 2018 del (C) Ministerio para la Transición Ecológica (MITECO).

Figura 51. La figura de "Paisaje Protegido", que protege de forma directa los aspectos paisajísticos (la dimensión paisajística se encuentra indirectamente contemplada en otras figuras e instrumentos de gestión y planificación), ha sido escasamente aplicada en España, a excepción de casos concretos como la Comunidad Autónoma canaria o la valenciana, sin cuya aportación el catálogo español de paisajes protegidos sería muy pobre. Existen en la actualidad, 57 espacios declarados como Paisaje Protegido (164.184,7 ha), ubicados en 10 comunidades autónomas. Resulta la categoría protectora menos aplicada en el contexto nacional. Tal y como observa Mulero Mendigorri (2013), la figura se ha aplicado conforme a criterios muy heterogéneos, patentes tanto en la selección como en la gestión de los espacios designados, quizá debido a la imprecisión de su definición legal. El autor se pregunta si resulta coherente la existencia de una figura como la de Paisaje Protegido en el mapa de protección de espacios español y si ésta debiera regularse a través de la legislación específica de conservación del medio natural dado que, entre otras, las directrices emanadas del Convenio Europeo del Paisaje establecen criterios variados y complejos para la definición y selección de los paisajes representativos, que sobrepasan claramente las competencias y los objetivos de los organismos medioambientales. 
La mayor diversidad de enfoques acontece en el tratamiento del paisaje desde el punto de vista comprensivo del territorio. En primer lugar, hay que indicar que dependiendo de la comunidad autónoma, la materia paisaje se trata bien como elemento central de intervención o de manera colateral o coyuntural. Es decir, en algunas comunidades, caso de Cataluña, Galicia, País Vasco o Valencia, por ejemplo, se realiza un tratamiento específico del paisaje, con la formulación de leyes e implantación de organismos y/o instrumentos de planificación en los que el paisaje es el objeto de atención exclusivo. En otras, la mayoría, el tratamiento del paisaje está integrado dentro del marco jurídico y procedimental de la planificación/ordenación territorial, como materia imbricada en las estrategias, directrices y planes territoriales. Sea como fuere, estas acciones han cristalizado en la producción de inventarios, caracterizaciones y evaluaciones del paisaje a escalas medias (nivel regional o subregional, escala 1:50.000 o 1:25.000), orientados a la práctica de la planificación del paisaje como preludio de actuaciones más específicas o intervenciones a escala de mayor detalle. A este respecto, el informe del Observatorio de la Sostenibilidad en España refleja cómo las perspectivas varían a grandes rasgos en el mayor énfasis en los aspectos visuales, o en la integración de aspectos más morfológicos-funcionales. Igualmente, los métodos de valoración oscilan entre los más clásicos, de tipo numérico o evaluación cualitativa de las componentes desagregadas, a los que pretenden la valoración del carácter. Finalmente, existe una consideración desigual del papel de la percepción y comprensión del paisaje por parte del público, partiendo desde la mera consulta a través de una encuesta, pasando por la participación pública realizada en un momento puntual, hasta un verdadero proceso de participación pública, en el que los agentes están implicados en todo el ciclo, desde la fase de la identificación, planificación, intervención e impacto.

Si se trata pues de sintetizar la filosofía que anima el actual mapa español de planificación del paisaje, y centrándonos en los resultados de identificación y valoración del paisaje a escala regional-subregional, cabe diferenciar en conclusión dos visiones prácticas que hoy por hoy coexisten y aportan riqueza a la imagen final:

Ley $8 / 2005$, de 8 de junio, de Protección, Gestión y Ordenación del Paisaje.de la Comunidad Autónoma de Cataluña Diari Oficial de la Generalitat de Catalunya, núm. 4407, de 8 de junio de 2005

Ley $7 / 2008$, de 7 de julio, de protección del paisaje de Galicia. Diario Oficial de Galicia, núm. 139, de 18 de julio de 2008

Decreto 90/2014, de 3 de junio, sobre protección, gestión y ordenación del paisaje en la ordenación del territorio de la Comunidad Autónoma del País Vasco.

Euskal Herriko Agintaritzaren Aldizkaria (Boletín Oficial del País Vasco), núm. 112 de 16 de junio de 2014

Ley 5/2014, de 25 de julio, de Ordenación del Territorio, Urbanismo y Paisaje, de la Comunitat Valenciana. Diari Oficial de la Generalitat Valenciana núm. 7329, de 31 de juliode 2014. 
- Enfoque que se fundamenta en la evaluación del carácter del paisaje, con una visión integral del paisaje en la línea de los métodos descriptivos-valorativos originados en el contexto inglés.

- Enfoque que parte de la evaluación del binomio de calidad-fragilidad visual para integrar el recurso visual con otras variables, derivada de los métodos americanos.

La Tabla 3 recoge los aspectos definitorios de cada enfoque, tomando como ejemplo dos experiencias representativas y bajo el signo del peso que asignan a la componente ecológica y su nivel de integración de esta con la componente perceptiva.

Tabla 3. Comparativa de las bases y características de los enfoques de planificación del paisaje dominantes en España.

Nogué, J., Sala, P., y Grau, J. (2016). Els catàlegs de paisatge de Catalunya. metodologia. Olot/Barcelona: Observatorio del Paisatge de Catalunya/ATLL.

Aramburu Maqua, M. P., Escribano Bombín, R., Ramos Gonzalo, L., y Rubio Maroto,

R. (2003). Cartografía del Paisaje de la Comunidad de Madrid. Madrid: Comunidad Autonoma Madrid. Dirección General de Promoción y Disciplina Ambiental.

\begin{tabular}{|l|l|}
\hline \multicolumn{1}{|c|}{ Enfoque carácter del paisaje } & \multicolumn{1}{|c|}{ Enfoque paisaje como recurso visual } \\
\hline $\begin{array}{l}\text { En la línea del Convenio Europeo del Paisaje } \\
\text { El objeto central es el Carácter del paisaje }\end{array}$ & $\begin{array}{l}\text { En la línea de los métodos americanos } \\
\text { El objeto central es el valor del paisaje como } \\
\text { recurso visual }\end{array}$ \\
\hline $\begin{array}{l}\text { Enfoque cualitativo y con filosofía objetiva- } \\
\text { subjetiva }\end{array}$ & $\begin{array}{l}\text { Enfoque cuantitativo-cualitativo con filosofía } \\
\text { objetiva }\end{array}$ \\
\hline $\begin{array}{l}\text { Análisis integral: paisaje como elemento } \\
\text { complejo, síntesis y expresión del conjunto del } \\
\text { medio (enfoque multidimensional) }\end{array}$ & $\begin{array}{l}\text { Análisis parcial: paisaje visual como un } \\
\text { elemento más, en paralelo con otras } \\
\text { características(enfoque unidimensional) }\end{array}$ \\
\hline $\begin{array}{l}\text { Unidades de paisaje definidas por su carácter, } \\
\text { resultado de la combinación de elementos que } \\
\text { estructuran el medio, dinámicas, percepciones } \\
\text { y relaciones entre población y su paisaje }\end{array}$ & $\begin{array}{l}\text { Unidades visuales de paisaje: espacios } \\
\text { visualmente autocontenidos, en las que la } \\
\text { incidencia de una actividad repercuta en } \\
\text { toda la unidad }\end{array}$ \\
\hline $\begin{array}{l}\text { Metodología descriptiva (carácter del } \\
\text { paisaje)+valorativa }\end{array}$ & $\begin{array}{l}\text { Metodología de evaluación por } \\
\text { desagregación de componentes, } \\
\text { comparación de valor de unos paisajes con } \\
\text { otros y combinación de niveles de } \\
\text { calidad+fragilidad }\end{array}$ \\
\hline $\begin{array}{l}\text { Inclusión de valores naturales, culturales, } \\
\text { históricos, perceptuales, simbólicos }\end{array}$ & $\begin{array}{l}\text { Valores visuales para integración de usos y } \\
\text { actividades }\end{array}$ \\
\hline $\begin{array}{l}\text { Procesos participativos de concertación y } \\
\text { sensibilización }\end{array}$ & $\begin{array}{l}\text { Participación del público mediante consulta } \\
\text { Ejemplo representativo: } \\
\text { (Obserlogos del Paisaje de Cataluña } \\
\text { (Nogué, Sala y Grau, 2016) }\end{array}$ \\
\hline
\end{tabular}




\section{IV.2. ENCUADRE DE LOS MODELOS DE PLANIFICACIÓN DEL PAISAJE ATENDIENDO A SU ENFOQUE EN EL TRATAMIENTO DE LA ECOLOGÍA Y LA ESTÉTICA}

Cuando se aborda, desde el punto de vista de sus componentes ecológicas y perceptivas, la cuestión de la evaluación y planificación del paisaje (y de su gestión y las intervenciones en él, su diseño), cabe preguntarse primeramente desde qué perspectiva se lleva a cabo la tarea. Este aspecto resulta esencial, pues el punto de vista desde el cual se entiende la ecología, la estética y la relación entre ambas baña por completo la finalidad del tratamiento del paisaje y aquilata sus resultados. Ese ejercicio ineludible de puesta en contexto se puede acometer clarificando el grado $y$, sobre todo, la naturaleza de la relación entre ambos valores en el paisaje. De tal manera, se presenta un encuadre genérico de los modelos de planificación del paisaje desde el punto de vista de su tratamiento de la componente ecológica y estética, con el ánimo de definir los límites en los que se mueve cada uno, los matices diferenciadores y las repercusiones sobre el paisaje que pueden llegar a tener.

IV.2.1. Valores duales, ecología y estética: la estética de lo natural o de lo ecológico como un fin en sí misma

Ciertas aproximaciones a la planificación del paisaje no se centran en la correspondencia entre lo ecológico y lo estético, sino que soslayan dicha relación y tratan ambos aspectos de forma separada. La perspectiva de estas propuestas es la del tratamiento de ambas dimensiones como valores duales, más o menos objetivables, que concurren en el paisaje. Por un lado, el valor ecológico es analizado y evaluado de forma independiente, como uno de los distintos aspectos 
González Bernáldez, F. (1981). Ecología y Paisaje. Madrid: Blume. que es necesario diagnosticar en el proceso de planificación u ordenación del territorio. Por otro lado, la dimensión perceptiva o estética es igualmente tratada de forma individual. Por ende, la percepción o la estética de lo natural es tratada desde el punto de vista exclusivamente visual o escénico, sin explorar u ocuparse de su conexión con lo ecológico, que sería la dinámica interna que anima esa imagen y la hace perdurar y evolucionar (utilizando el concepto de González Bernáldez (1981), estas metodologías se ocupan del fenosistema, pero no de su conexión con el criptosistema). La estética del paisaje más natural acaba convirtiéndose pues en un fin en sí misma, es tratada en términos de resultado, de forma.

Este sería el caso de la mayoría de la práctica en planificación territorial o del paisaje, modelos en los que desde luego se reconocen los valores estéticos asociados al paisaje natural ( $y$ en el menos natural), pero estos son tratados como un valor más a manejar entre otros tantos, entre ellos, precisamente, el valor natural o ecológico. Esto es así, por supuesto, debido al fin que persiguen estos modelos, que no es el de tratamiento específico de la relación entre lo ecológico y lo percibido o estético, sino una ordenación comprensiva del paisaje o un tratamiento en términos puramente visuales. En este sentido, resultan metodologías efectivas y valorables.

Si atendemos exclusivamente al contexto español de la planificación del paisaje, ambas corrientes de tratamiento del paisaje que se han identificado anteriormente, tanto la que trata el paisaje desde el punto de vista de un recurso visual (derivada de los métodos americanos), como la que se fundamenta una visión integral del paisaje y en la evaluación del carácter (en la línea de los métodos descriptivos-valorativos), realizan un tratamiento de lo ecológico y lo perceptivo/estético desde este punto de vista. A continuación se describe brevemente sus bases conceptuales a través de un ejemplo representativo. 
Dentro de los métodos que plantean un análisis enfocado al paisaje como recurso visual se podría tomar como ejemplo la metodología aplicada en comunidades autónomas españolas como Madrid (Aramburu Maqua et al., 2003), aplicado también en La Rioja (Aramburu Maqua, Escribano Bombín, López Hernández, y Sánchez Ramos, 2004) o, más recientemente, en Aragón (Ibarra, P. y Escribano, R. (Coord.), 2009). Esta metodología enfoca su análisis hacia los aspectos puramente visuales del paisaje, con la pretensión de objetivar lo más posible su valoración, de manera que se considere por derecho propio entre los aspectos ambientales que condicionan la toma de decisiones (Aramburu Maqua et al., 2003; p.16 y 17). Sus bases conceptuales enraízan en la identificación de la capacidad del paisaje para adaptarse, sin perder su esencia visual, a los cambios que se producen o se inducen en él. Así, la clasificación del paisaje se realiza definiendo unidades que presentan una respuesta visual suficientemente homogénea frente a actuaciones. La evaluación de cada una de estas unidades se realiza mediante la desagregación de componentes y su interpretación en términos de calidad y fragilidad visual del paisaje. La calidad, es entendida a través de las características visuales que según cada caso pueden alcanzar mérito o valor para ser conservadas (Cifuentes, 1976), y la fragilidad como la susceptibilidad de un paisaje al cambio cuando se desarrolla un uso sobre él.

Mientras que la evaluación de la fragilidad es un asunto relacionado fundamentalmente con el grado de visibilidad y la capacidad de ocultación de cambios del paisaje, la difícil objetivación de la calidad se sustancia a través fundamentalmente del grado de naturalidad (percibida) y del atractivo de la componente natural en término escénicos (estructura, línea, color, variedad...), además de tener en cuenta las actividades humanas con un claro valor tradicional o patrimonial. De tal manera, se evalúan los aspectos formales de la base biofísica y se detrae calidad a partir del grado de artificialidad presente. Se podría matizar por tanto que estos métodos fundamentan su evaluación en una mayor naturalidad percibida, y la relacionan con un mayor interés y atractivo del paisaje, por lo que éste estará garantizado si se lleva a cabo una gestión ambiental de los paisajes adecuada. Daniel y Vining (1983) clasifican este tipo de metodologías dentro del "enfoque experto de tradición ecológica", es
Aramburu Maqua, M. P., Escribano Bombín, R., Ramos Gonzalo, L., y Rubio Maroto, R. (2003). Cartografía del Paisaje de la Comunidad de Madrid. Madrid: Consejería de Medio Ambiente de la Comunidad de Madrid. Madrid: Dirección General de Promoción y Disciplina Ambiental - Consejería de Medio Ambiente - Comunidad de Madrid.

Aramburu Maqua, M. P., Escribano Bombín, R., López Hernández, R. y Sánchez Ramos, P. (2004). Estudio y Cartografía del Paisaje de la Comunidad Autónoma de La Rioja. Logroño: Consejería de Turismo, Medio Ambiente y Política Territorial, Gobierno de La Rioja (publicación electrónica).

barra, P. y Escribano, R. (Coord.) (2009). Mapas de Paisaje de las Comarcas de La Jacetania, Alto Gallego, Matarraña/Matarranya, Maestrazgo, GúdarLavalambre, La Sierra de Albarracín y Los Monegros. Zaragoza: Departamento de Política Territorial, Justicia e Interior, Gobierno de Aragón.

Cifuentes, P. (1976). La calidad visual de unidades territoriales. Aplicación al Valle del Tiétar (Tesis doctoral no publicada). E.T.S. Ingenieros de Montes Universidad Politécnica de Madrid, Madrid.

Daniel, T. C. y Vining, J. (1983) Methodological Issues in the Assessment of Landscape Quality. En I. Altman y J. F. Wohlwill (Eds.), Behavior and the Natural Environment (pp. 39-84). Nueva York, NY: Springer US. 
decir, una corriente que se basa en la medición y evaluación de la dimensión física del paisaje llevada a cabo por expertos que derivan de la tradición intelectual de la ecología y la gestión de recursos, sustrato disciplinar que frecuentemente lleva a fundamentar la evaluación precisamente en la estética de la naturalidad percibida.

Esta manera de evaluar el paisaje no escapa a las clásicas críticas a los métodos de gestión de los recursos visuales del paisaje (ver Apartado IV.1.1), entre ellos, la perspectiva excesivamente centrada en el resultado visual y poco sensible a los agentes generadores que lo sostienen (entre ellos, los ecológicos). El hecho de que frecuentemente la evaluación se realice a través de un grupo de expertos que representan las preferencias de la sociedad, hace que la evaluación se base en lo que Carlson (1977) enunció como las

Carlson, A. (1977). On the possibility of quantifying scenic beauty. Landscape Planning, 4, 131-172. preferencias por el paisaje natural del "mínimo común denominador" ("lowest common denominator"), esto es, la identificación de las dimensiones de las preferencias más obvias y estereotipadas, aquellas que comparten la mayoría y son menos sutiles (ver Apartado III.4.4). 
Entre los métodos descriptivos-valorativos basados en el carácter del paisaje podríamos ejemplificar el caso de los Catálogos del Paisaje en Cataluña. La Ley 8/2005 de Cataluña es el marco legislativo de protección, gestión y ordenación del paisaje en esta Comunidad Autónoma, que se instrumentaliza a través del Observatorio del Paisaje en la generación de los Catálogos y Directrices de paisaje, concebidos como soporte en la planificación territorial (Nogué, 2011). El Observatorio del Paisaje, con el fin de dotar de la homogeneidad necesaria al tratamiento de cada comarca estudiada, esbozó un marco conceptual, metodológico y procedimental en el documento director Prototipo de Catálogo del Paisaje que da homogeneidad al resultado en todas las comarcas (Nogué, Sala, y Grau, 2016).

La perspectiva de análisis bebe de los procedimientos de la evaluación del carácter del paisaje ("Landscape Character Assessment"). Se basa por tanto en la definición de unidades de carácter distintivo, en las que se identifican los valores y dinámicas propias, definidos desde una perspectiva cualitativa y huyendo de una jerarquización de los mismos. Esta evaluación formará la base para la definición de objetivos de calidad paisajística y propuestas de actuación. La lógica de la evaluación parte de un enfoque multidimensional, que se traduce en la identificación de múltiples valores (naturales, históricos, de uso social, estéticos, productivos y simbólicos), que son analizados de manera separada. Dichos valores encuentra fundamento en la percepción de la población, recogida a través de un significativo esfuerzo de participación pública a través de cuestionarios, consultas y sesiones de trabajo. De tal manera, la evaluación se concreta el diagnóstico de los puntos fuertes y débiles del paisaje a través de un análisis DAFO.

En el caso de los valores naturales y ecológicos, estos son definidos como aquellos "factores o elementos que determinan la calidad del medio natural" (Nogué, Sala, y Grau, 2016, p. 44) y son identificados y evaluados, como se ha indicado, de forma paralela al resto. Las directrices que orientan en su identificación en el territorio delimitan 3 ámbitos: los espacios reconocidos legalmente, los espacios que se distingan por el especial interés de sus factores naturales y ecológicos en razón de su singularidad, representatividad, etc. y, por último, el ámbito más funcional y que entronca parcialmente con la ecología del

Ley $8 / 2005$, de 8 de junio, de Protección, Gestión y Ordenación del Paisaje.de la Comunidad Autónoma de Cataluña Diario Oficial de la Generalitat de Catalunya, núm. 4407, de 8 de junio de 2005.

Nogué, J. (2011). El paisaje en la ordenación del territorio. La experiencia del Observatorio del Paisaje de Cataluña. Estudios Geográficos, 71(269), 415448.

Nogué, J., Sala, P., y Grau, J. (2016). Els catàlegs de paisatge de Catalunya. metodologia. Olot/Barcelona: Observatorio del Paisatge de Catalunya/ATLL. 
paisaje, los espacios que provean conectividad ecológica entre espacios naturales.

Los valores estéticos se definen en el documento director a partir de la capacidad que posee un paisaje de transmitir un determinado sentimiento de belleza (Nogué, Sala, y Grau, 2016, p. 43). Para concretar esta línea, se explica que estos valores no se relacionan sólo con los aspectos formales intrínsecos del paisaje (textura, color, contraste...), sino sobre todo con la base cultural adquirida que asocia la apreciación de la belleza a determinados patrones o modelos. De tal manera, se establece la perspectiva "socio-construccionista" como el enfoque de análisis de la estética del paisaje (ver Apartado III.2.2). 


\section{IV.2.2. Valores integrados, ecología estética: enfoques basados en el aprovechamiento del éxito común o el embellecimiento de la solución ecológica}

Ciertas perspectivas hacen un tratamiento de la ecología y la estética como valores que no sólo han de ser igualmente tenidos en cuenta, sino que han de ser integrados de manera activa. Estos enfoques no solo tratan la belleza del paisaje natural por sí misma, ni buscan el efecto puramente retórico de una imagen sostenible o ecológica, sino que entienden ambos aspectos como fenómenos que es necesario compatibilizar o cuya suma es necesario optimizar de forma conjunta. La estrategia de tratamiento del paisaje estaría basada en lo que se podría denominar el "aprovechamiento del éxito común", es decir, el aprovechamiento de las oportunidades que ofrece una ecología que es apreciada desde el punto de vista de su belleza, la promoción de los felices casos de coincidencia de valores que inducen una mejora del paisaje por medio de la obtención de un beneficio común. O bien el intento de mejora de casos de conflicto, de compatibilización de valores, pero siempre basado en la búsqueda de un resultado ecológico que sea reconocido estéticamente. Dependiendo de la relevancia que se dé a cada uno de los valores, el signo de la compatibilización cambia: o bien se "embellece" una actuación que cumple primeramente con todos los objetivos ecológicos, o bien se buscan componentes más adecuados ecológicamente a un diseño estéticamente atractivo.

Los autores que han aplicado esta perspectiva suelen etiquetarla bajo el término inglés "ecological aesthetic", cuya traducción al español es la de "estética ecológica". Sin embargo, entendemos que el término traducido más apropiado sería el de "ecología estética", pues en general se trata de evaluar una situación o ajustar un resultado según los cánones escénicos o preferencias vigentes, hacer que la solución ecológica tenga una apariencia apreciada en términos estéticos. Ejemplos de esta perspectiva se encuentran en propuestas que específicamente buscan conjugar ambos aspectos como la de Steinitz (1990), Thorne y Huang (1991) o Bell y Apostol (2008). Todos estos modelos tratan el paisaje desde la óptica escénica.

Steinitz, C. (1990). Toward a sustainable landscape with high visual preference and high ecological integrity: the loop road in Acadia National Park, U.S.A. Landscape and Urban Planning, 19(3), 213250.

Thorne, J. F. y Huang, C.-S. (1991). Toward a landscape ecological aesthetic: methodologies for designers and planners [Special Issue: Landscape Ecology]. Landscape and Urban Planning, 21(1-2), 61-79. Bell, S. y Apostol, D. (2008). Designing Sustainable Forest Landscapes. Londres, UK, Nueva York, NY: Taylor \& Francis. 
Steinitz, C. (1990). Toward a sustainable landscape with high visual preference and high ecological integrity: the loop road in Acadia Nationa Park, U.S.A. Landscape and Urban Planning, 19(3), 213250.
Steinitz (1990) presentó una metodología en el que se buscaba la consecución de un paisaje sostenible con alta integridad ecológica y por el que se generara una alta preferencia. El contexto paisajístico en el que se genera dicha metodología condiciona absolutamente el enfoque adoptado, pues se trata del Parque Nacional de Acadia y Mt Desert Island (Maine, E.E.U.U.), un contexto denominado por el propio autor como "paisaje de destino turístico" ("destination landscape"). Se trata de un paisaje en el que desde luego la conservación ecológica es esencial, dado que es un espacio protegido por sus valores naturales, y en el que el público es considerado desde el punto de vista de "cliente" o consumidor, es decir, se asume que el visitante alberga una idea preestablecida del paisaje que espera encontrarse y a la que en la medida de lo posible hay que responder.

Ambas dimensiones son estudiadas mediante modelos independientes que son posteriormente comparados. Así, la aproximación a la estética del paisaje se hace a través de un modelo predictivo de preferencia visual basado en la escénica, en el que se busca determinar los factores que más poderosamente influyen en el patrón de apreciación del paisaje natural en términos de belleza (relieve quebrado, vegetación diversa, presencia de agua, sensación de misterio, presencia de instalaciones turísticas, ausencia de desarrollos antrópicos, vistas panorámicas). La evaluación ecológica se basa en la aplicación de un modelo de adecuación del hábitat (Habitat Suitability Assessement), que estime la capacidad de los elementos del paisaje para proveer de hábitat potencial a las especies de fauna seleccionadas como indicadoras. De la comparación en cada parte del territorio de ambos modelos surgen los niveles de congruencia entre ambas dimensiones y la definición de la estrategia de planificación (Figura 52), que variará desde una política de conservación a acciones más agresivas, cuya dirección y efectos habrá de ser concretada.
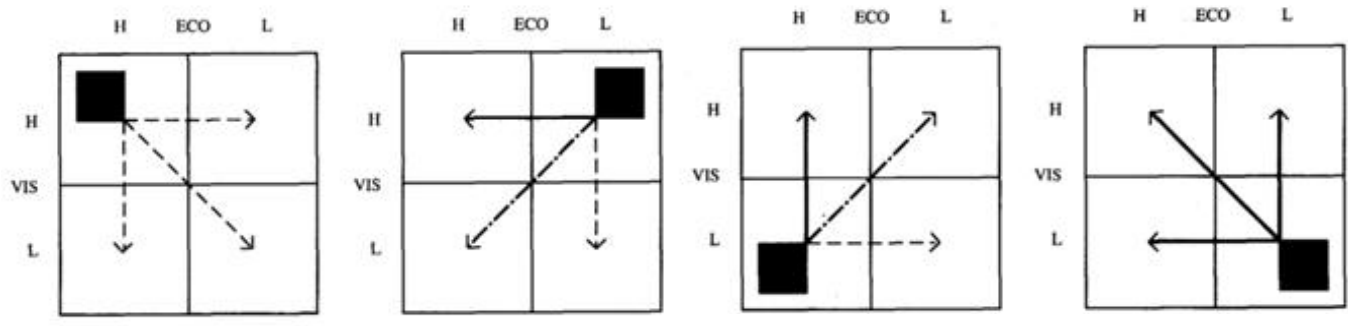

Figura 52. Representación de las posibles direcciones a tomar en la decisión de actuación sobre el paisaje según Steinitz (1990).

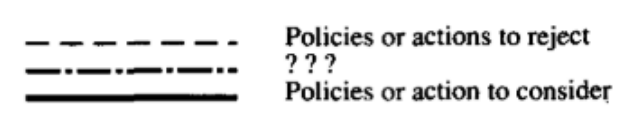


Thorne y Huang (1991) ofrecen un marco teórico de tratamiento ecológico y estético del paisaje más generalista y aplicable a distintos contextos territoriales. La lógica que encierra la propuesta se podría sintetizar en la definición de la ecología estética del paisaje que enuncian "unión de la integridad ecológica en el paisaje y su atractivo estético" (p. 62). La unión es entendida como el campo en común entre las dos consideraciones, es decir, la propuesta de Thorne y Huang se dirige a detectar aquellos supuestos en los que se encuentran beneficios tanto para la ecología como para la estética del paisaje, situaciones o propuestas en las que ambas perspectivas ven cumplidas sus expectativas de una manera $u$ otra.

Los autores definen primeramente los ámbitos importantes para la consecución de esa unión (Figura 53), para más adelante proveer de ciertas soluciones que caminen en este sentido.
Thorne, J. F. y Huang, C.-S. (1991). Toward a landscape ecological aesthetic: methodologies for designers and planners [Special Issue: Landscape Ecology]. Landscape and Urban Planning, 21(1-2), 61-79

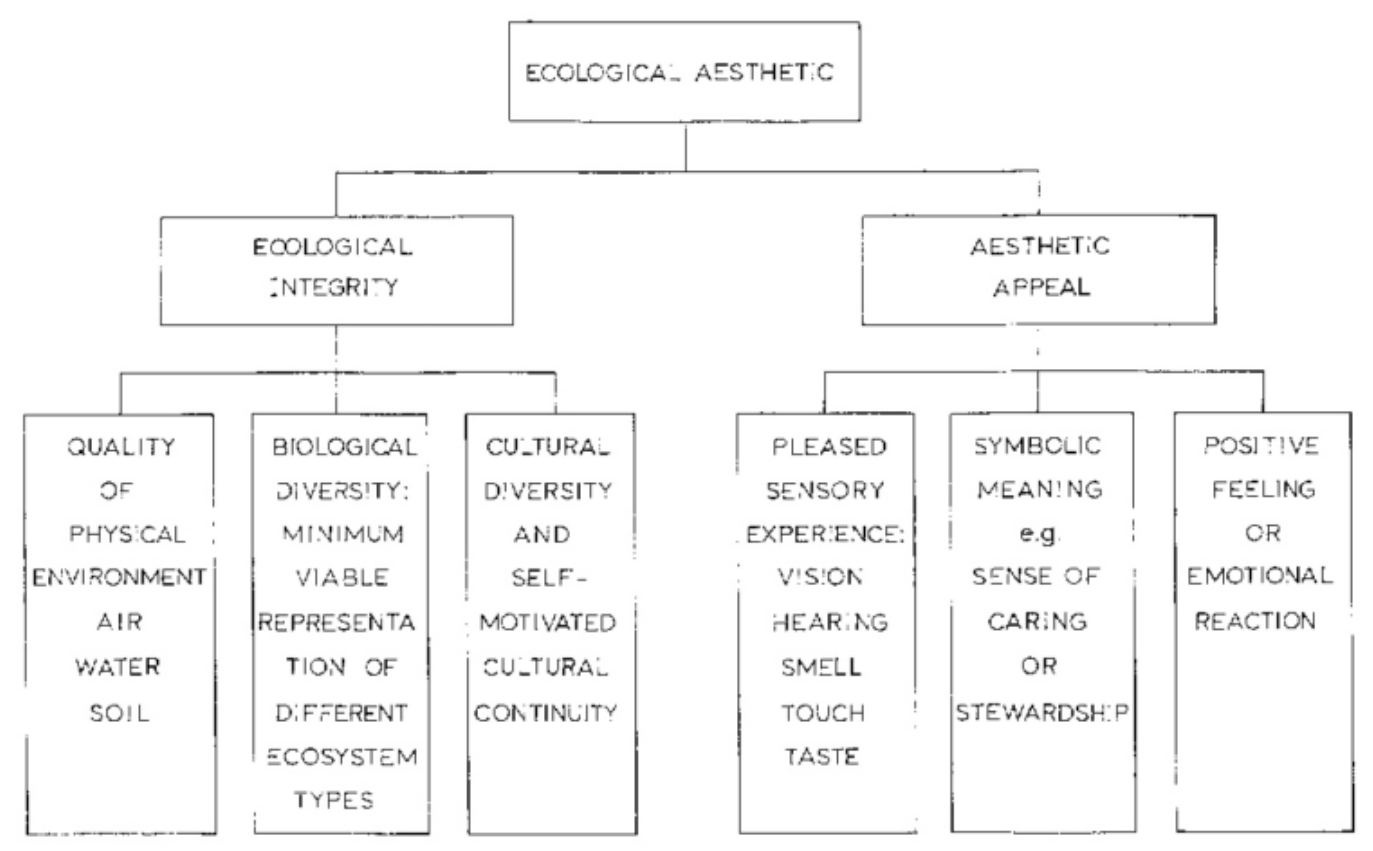

Figura 53. Esquema de la jerarquía que componen la "estética ecológica" propuesta por Thorne y Huang (1991).

De tal manera, una propuesta debería responder afirmativamente a las siguientes preguntas: 
- ¿El concepto de diseño tiene un efecto neutro o positivo en la calidad del aire, agua y suelo?

- ¿Se mejora la representación de tipos de ecosistemas diferentes mediante la mejora de la conectividad, la creación de nuevos espacios verdes de carácter autóctono o la mejora de hábitat?

- ¿Asegura la representación mínima viable de todos los grupos culturales de tal manera que se promueva la continuidad cultural autosostenida?

- ¿Satisface los criterios de atractivo visual?

De hecho, los mismos autores destacan que, al estudiar la configuración espacial y la dinámica de ciertas soluciones a escala de planificación del paisaje, se pueden encontrar muchas coincidencias entre la integridad ecológica y el atractivo estético. Algunos ejemplos de su propuesta permiten darse cuenta del fondo de esta aseveración: la alternancia de espacios naturales con zonas con una intensidad de uso humana mayor crea un ritmo visual atractivo; la conservación de cumbres y fondos de valle vegetados y con suficiente variedad de estados sucesionales ofrece una interesante complejidad visual, mientras que la funcionalidad ecológica puede conseguirse con corredores riparios; la presencia de zonas más abiertas en una orilla ofrece la oportunidad de contemplar la vegetación autóctona desarrollada y bien conservada de la otra orilla en un paisaje ribereño (Figura 54).
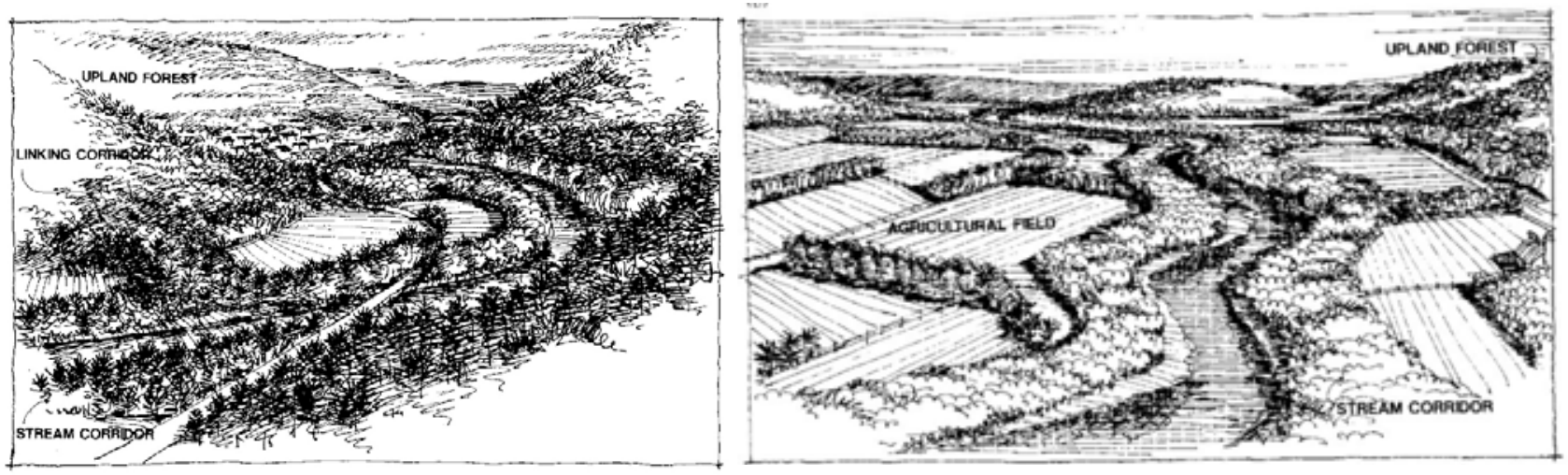

Figura 54. Representación del tratamiento de los corredores ecológicos propuesta por Thorne y Huang (1991) en distintos contextos paisajísticos: matriz predominantemente natural o cultivada. 
En el modelo de diseño de paisajes forestales sostenibles de Bell y Apostol (2008) se define un proceso de intervención deliberada en el patrón de los paisaje forestales de tal manera que se atiendan múltiples objetivos, pero sobre la base de la integración de los aspectos ecológicos y estéticos (Figura 55). En la propuesta, la ecología del paisaje establece la base sobre la que se apoya el análisis y diseño del paisaje forestal en términos fundamentalmente visuales y a través de un proceso reiterativo. Así, primeramente el análisis ecológico asiste para definir lo que denominan las "condiciones de futuro deseables" ("desired future conditions"), es decir un "paisaje ecológico ideal" que es utilizado como base para acomodar la estrategia de diseño que atiende a los criterios estéticos, que en la propuesta son del tipo visual y formal. De tal manera, se procede a un reajuste del diseño propuesto hasta que se alcanza la solución de compromiso, en la cual se asegure la suficiente adecuación ecológica mientras que se maximicen los beneficios en el plano estético, además de otros como el social, económico, operativo, etc (Figura 56).

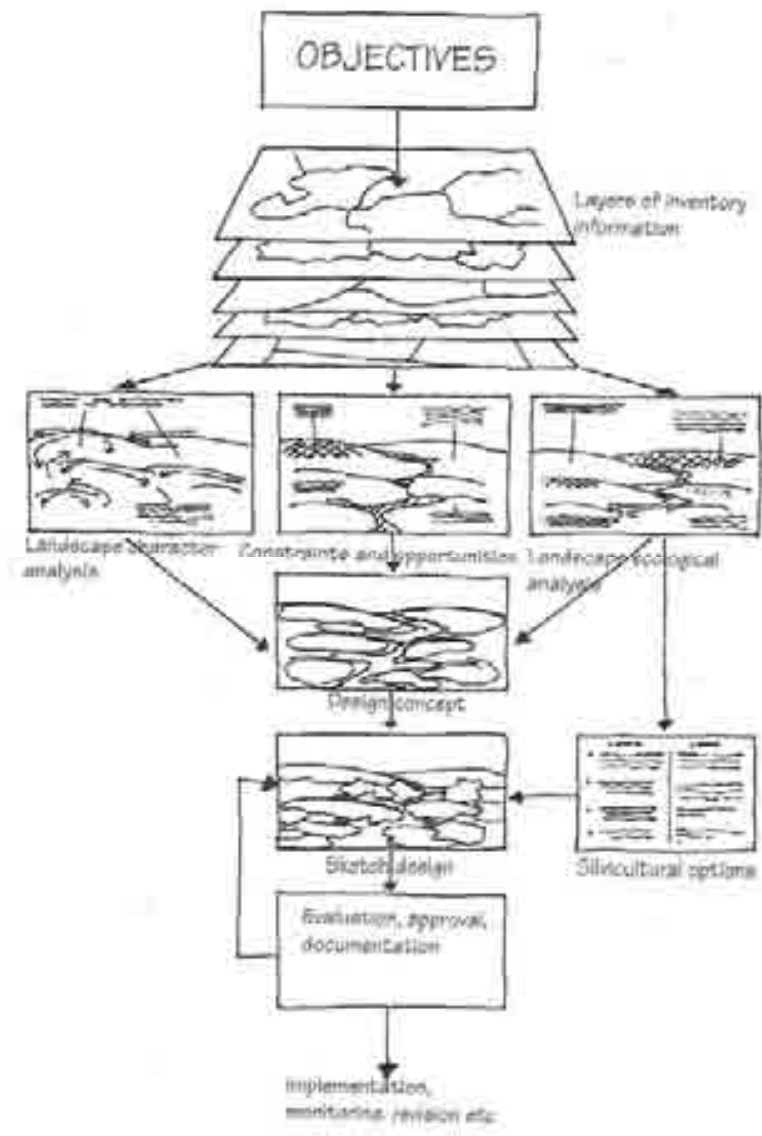

Figura 55. Esquema general del proceso de análisis e intervención en el paisaje presentado por Bell y Apostol (2008).
Bell, S. y Apostol, D. (2008).

Designing Sustainable

Forest Landscapes. Londres, UK, Nueva York, NY: Taylor \& Francis. 

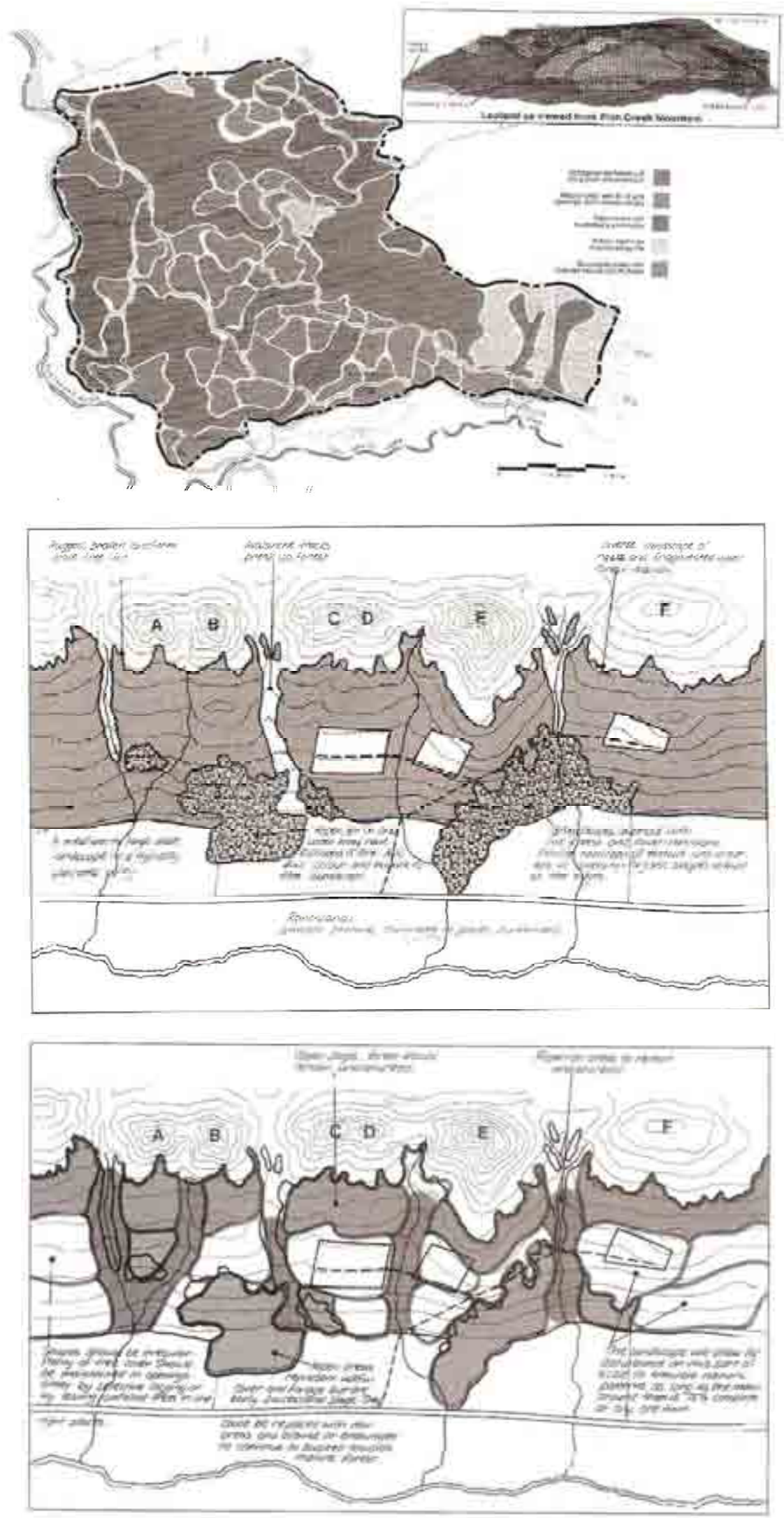

Figura 56. Ejemplo de mapas resultado del proceso de diseño de un paisaje forestal presentado por Bell y Apostol (2008): las condiciones de futuro deseables desde el punto de vista ecológico, el análisis de los elementos presentes en el paisaje visto desde un punto de observación preferente, y el esquema de la estrategia de diseño. 
Tal y como se aprecia en la breve descripción de estos modelos que combinan la dimensión ecológica y estética expuesta, la lógica que subyace es la de conjunción de valores en busca de una solución de compromiso, la búsqueda del equilibrio óptimo entre funcionamiento ecológico y efecto estético. Cabría sin embargo preguntarse como resuelven estas perspectivas los casos de discordancia irreconciliable entre valores, es decir, ¿qué hacer cuando el resultado de unas condiciones ecológicas o un diseño del paisaje no producen un efecto estético positivo según los estándares estéticos imperantes que se manejan? Esta cuestión es tratada por la perspectiva explicada en el siguiente apartado. 
IV.2.3. Valores interdependientes, estética ecológica: la estética como medio de mejora de lo ecológico

Las anteriores perspectivas basan su quehacer en el tratamiento del resultado en las dos dimensiones, la ecológica y la estética, que es necesario compatibilizar para que sea aceptable. Existe sin embargo un peldaño más en la concepción de la relación entre ambos valores. Se trata de la perspectiva que entiende dichas dimensiones como interdependientes, de tal manera que las concibe como ligadas de tal forma que la interpretación de lo ecológico no puede entenderse de forma completa sin la participación de lo estético, y viceversa. Aún más, y más relevante en el ámbito de lo práctico, considera la estética como un factor de oportunidad del que el gestor puede servirse, que puede ayudar no sólo a hacer más aceptable un paisaje, sino a mostrar la función de la ecología, su adecuación, su conveniencia y la belleza que encierra. Esta perspectiva entroncaría con lo que Carlson (1993) denominó teoría justificativa, es decir, un modo de tratar el paisaje que atiende más a lo deseable que a lo deseado.

En este caso sí se podría hablar con de una verdadera "estética ecológica", es decir, la apreciación del paisaje que encuentra el atractivo en lo ecológico. El matiz que dirime la diferencia entre el aparente trabalenguas de la ecología estética y la estética ecológica es que la primera parte del gusto estético actual y lo aprovecha, mientras que la segunda pretende que lo ecológico adquiera ese sentido de belleza que puede no tener en un principio. La estética ecológica pretende en último término hacer evolucionar la estética de la sociedad, procura revelar o desvelar el atractivo que encierra lo ecológico de tal manera que llegue a ser apreciada.

Un ejemplo que aporta luz sobre el matiz distintivo de la ecología estética es el de los efectos que produjeron los grandes incendios forestales que sufrió el Parque Nacional de Yellowstone (Estados Unidos). En el verano de 1988 una serie de incendios catastróficos afectaron a prácticamente un tercio de la superficie del emblemático Parque Nacional, uno de los grandes iconos norteamericanos de belleza del mundo natural. El evento, que en un principio fue considerado una catástrofe de magnitud inmensa, tanto por la pérdida de valores naturales como estéticos, supuso sin embargo el 
principio de una nueva gestión del fuego, que evolucionó desde la Gobster, P. H. (1996). perspectiva de la política de supresión total al reconocimiento de su conveniencia y a la gestión integradora del fuego mediante la prescripción de quemas controladas (Figura 57). En el plano estético se produjo un efecto quizá aún más sorprendente, ya que los terrenos afectados comenzaron a recibir a gran cantidad de visitantes fascinados por la percepción del proceso de recuperación del ecosistema, público atraído por la fuerza y vitalidad que mostraba, atraídos precisamente por la dinámica ecológica que se revelaba ante ellos, patente ante sus ojos. A este fenómeno contribuyeron las campañas de educación y los escritos que mostraron los beneficios y el atractivo resultante tras el efecto del fuego (Gobster, 1996).

Forest aesthetics,

biodiversity, and the

perceived appropriateness of ecosystem management practices. En M. W. Brunson, L. E. Kruger, C. B. Tyler y S. A. Schroeder (Eds), Defining Social Acceptability of Forests and Forestly Practices: a workshop proceedings, June 23-25, 1992 (pp.77-97). Kelso, Washington Seattle, WA: U.S. Department of Agriculture, Forest Service, Pacific Northwest Research Station.

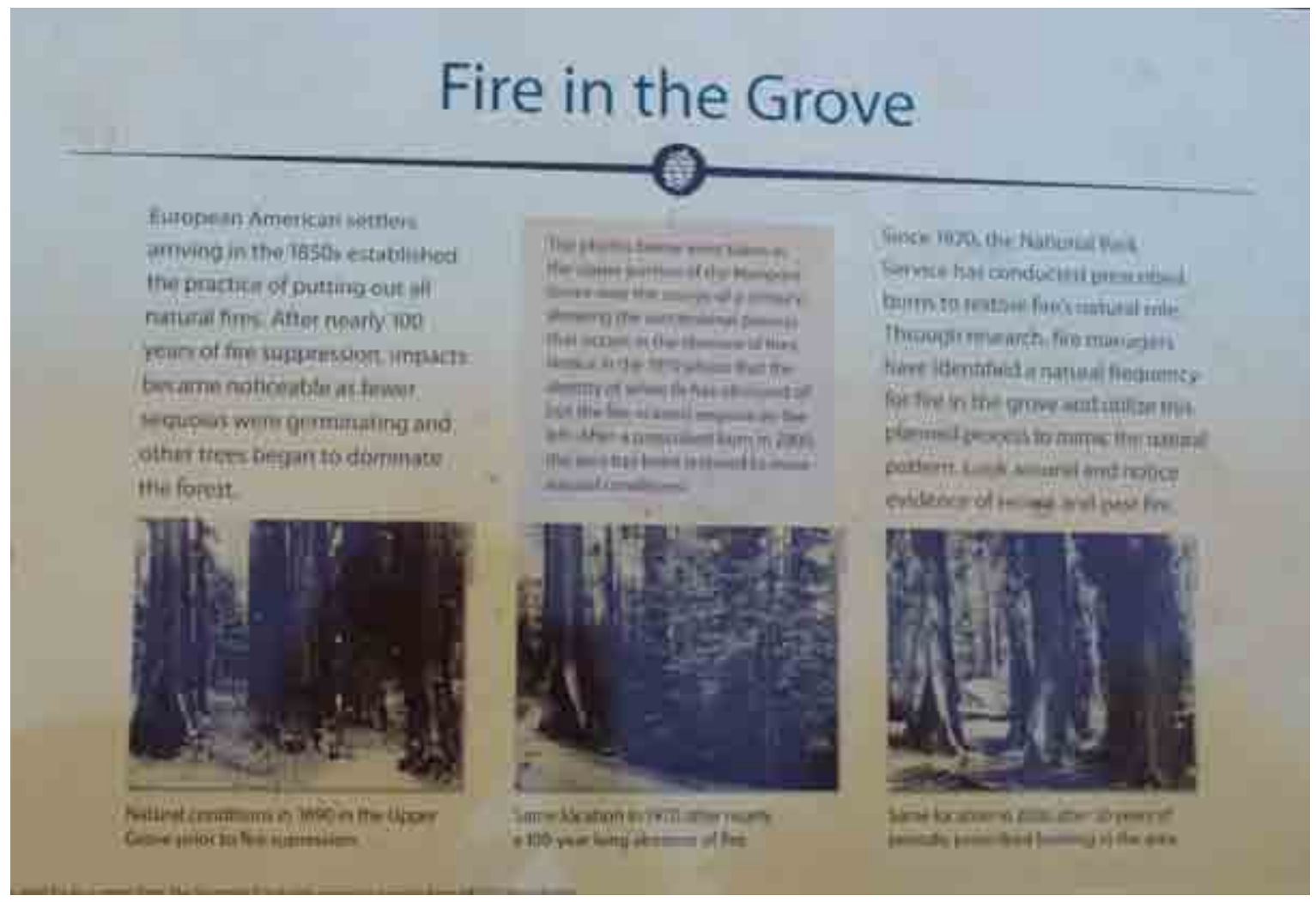

Figura 57. Cartel ubicado en el Mariposa Grove of Giant Sequoias (Parque Nacional de Yosemite, Estados Unidos). En él se ilustran los efectos ecológicos de la supresión del fuego en el bosque de secuoyas y las condiciones alcanzadas tras la aplicación de un programa de restablecimiento del papel natural del fuego por medio de quemas controladas. En él se anima al visitante a descubrir en el entorno las evidencias de fuegos recientes y pasados.

En esta perspectiva, desde luego más compleja y ambiciosa, la estética de lo natural no se busca en sí misma, ni es un subproducto de una situación o diseño que cumple los objetivos de adecuación ecológica, no sólo se centra en definir los casos en los que es posible 
Gobster, P. H. (1994). The aesthetic experience of sustainable forest ecosystems. En W. W. Covington y L. F. De Bano

(Eds.), Sustainable

Ecological Systems: Implementing an Ecological

Approach to Land Management (pp. 246-255) (General Technical Report RM247). Fort Collins, CO: USDA Forest Service, Rocky Mountain Forest and Range

Experiment Station.

Nassauer, J. I. (1995b). Messy Ecosystems, Orderly Frames. Landscape Journal, 14(2), 161-170.

Thayer, R. L. (1989).

The experience of sustainable landscapes. Landscape Journal, 8(2), 101-110.

Thayer, R. L. (1998). Landscape as an Ecologically Revealing Language [Special Issue: Exhibit Catalog. EcoRevelatory Design: Nature Contructed/Nature

Revealed]. Landscape Journal, Special Issue, 118-

aprovechar el éxito común, ni trata de embellecer una circunstancia derivada de la dinámica natural para alcanzar una mayor aceptación social. La estética ecológica atiende al grado y modo en que la ecología se muestra en el paisaje (o no se muestra) y gestiona activamente el modo en que este hecho condiciona la experiencia estética y favorece ciertas repercusiones en su funcionamiento ecológico. En último término pretende hacer atractiva esa situación mediante el cambio de la mentalidad o apelando a reacciones que no son las inmediatas.

Como se vio en el Capítulo III.4, la forma en la que el paradigma de la estética ecológica pueda alcanzar este objetivo se funda en dos estrategias. Por un lado se trataría de actuar sobre la forma que el público tiene de percibir e interpretar los valores ecológicos (intervenciones a través del conocimiento, que afectan a la componente humana), y por otro lado en definir actuaciones en el paisaje en las que se alinee una experiencia estética positiva y el sostenimiento de los procesos ecológicos (intervenciones que modifican el patrón y características del medio físico).

A nivel de diseño de paisaje existen algunas experiencias que se basan en los postulados de la estética ecológica. Algunas, como se ha visto en el Capítulo III, son de corte más genérico, como las líneas de acción propuestas por Gobster (1994) para adoptar una perspectiva de la ecología estética en la gestión sostenible de los ecosistemas forestales. Otras están basadas en una sólida y contrastada elaboración teórica sobre estética y permiten producir diseños que acomodan la interpretación cultural de lo sostenible (Nassauer, 1995b). Otras, en fin, están basadas en una estrategia de la expresión conspicua de los procesos ecológicos y la interpretación visible de la sostenibilidad del paisaje (Figura 58 y 59), caso del denominado "lenguaje de revelación de lo ecológico" ("Ecologically Revealing Language") (Thayer, 1989, 1998). Todas estas propuestas no se fundamentan exclusivamente en la estrategia de la integración visual de actuaciones en el paisaje, la imitación o el diseño inspirado en lo natural, sino en evidenciar los procesos ecológicos y proporcionar la certidumbre de que lo que se percibe es sostenible. 

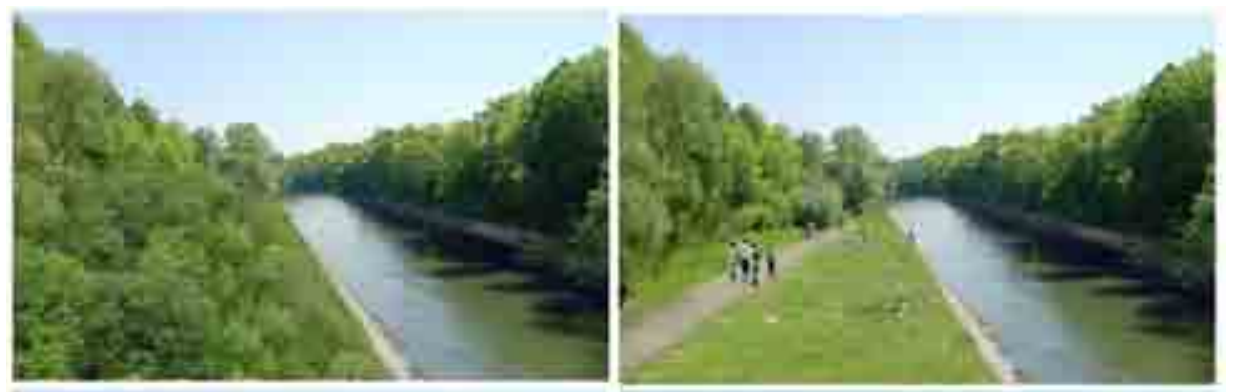

Junker, B. y Buchecker, M

(2008). Aesthetic

preferences versus

ecological objectives in river restorations. Landscape and Urban Planning, 85(3-4),

141-154.

Thayer, R. L. (1998).
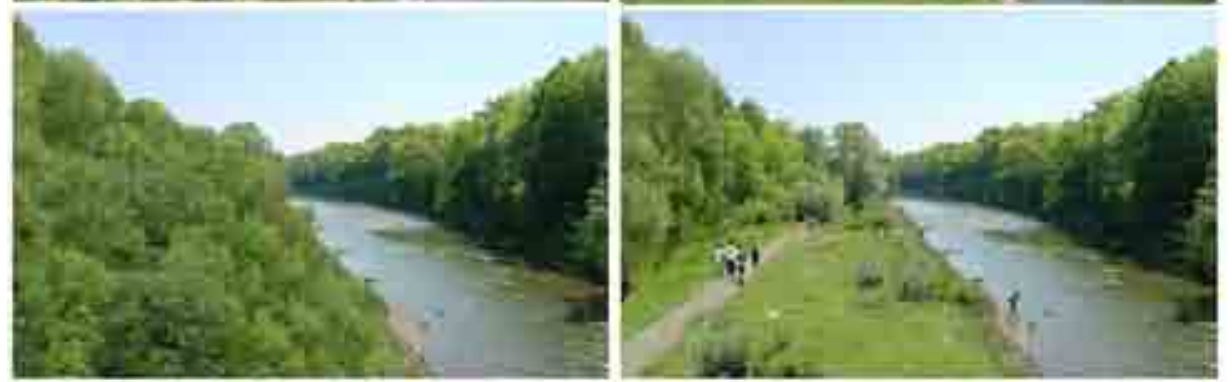

Landscape as an Ecologically Revealing Language [Special Issue: Exhibit Catalog. EcoRevelatory Design: Nature Contructed/Nature Revealed]. Landscape Journal, Special Issue, 118129
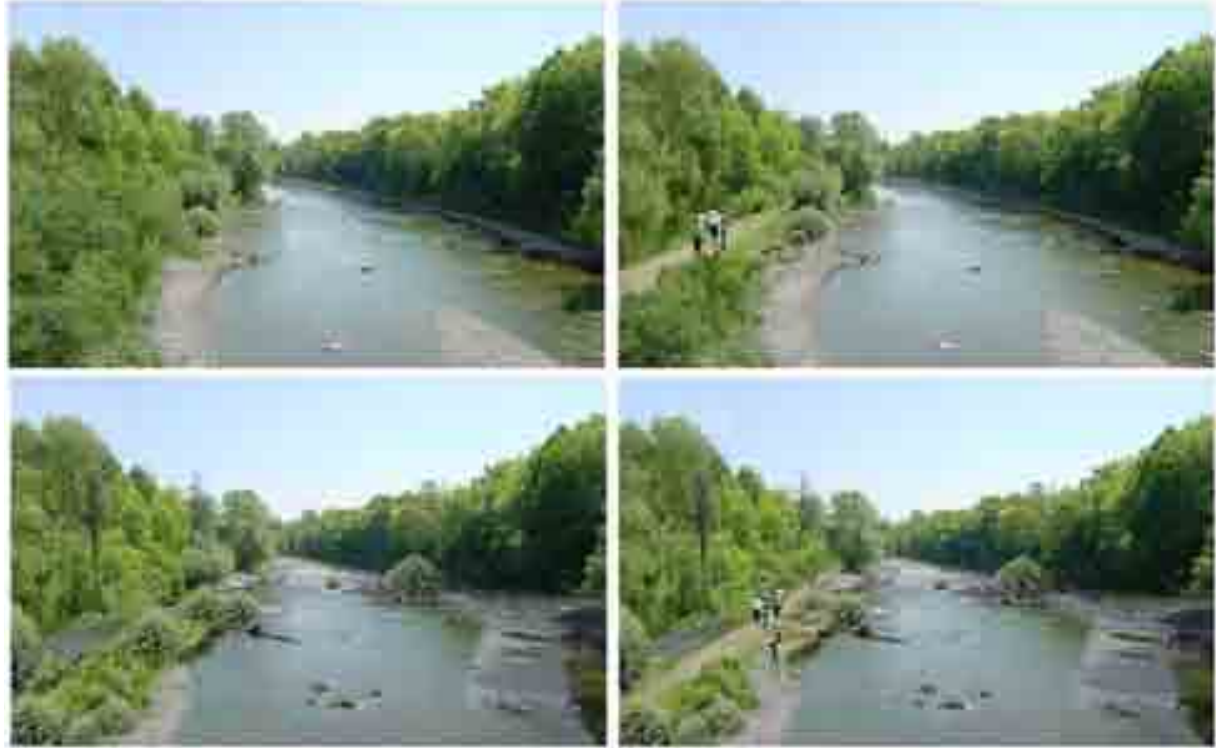

Figura 58. La serie de imágenes contenida en esta página muestra las simulaciones visuales de distintas soluciones de restauración de la morfología de un paisaje rivereño suizo, con distintos niveles de integridad ecológica o naturalidad. Basándose en la encuesta en la que se pedía evaluar cada escenario según una escala de preferencia y en términos de estética escénica, naturalidad percibida y satisfacción de las necesidades recreativas, los autores concluyen que los encuestados mostraron mayor preferencia estética por los diseños que mostraban mayor naturalidad (Junker y Buchecker, 2008). Este ejemplo ilustra la diferencia conceptual con la estrategia de investigación y actuación en el paisaje mostrada en la página siguiente, una de las propuestas presentadas en el concurso-exposición titulado "Diseño Eco-revelador: Naturaleza Construida/Naturaleza Revelada". Tal y como Thayer (1998) enuncia, estos diseños son "evidentemente antrópicos, pero deliciosamente orgánicos y expresivos de su función hidráulica y ecológica" (p. 122). 
Hill, K. (1998).

Ring Parks as diverted Dikes

[Special Issue: Exhibit

Catalog. Eco-Revelatory

Design: Nature

Contructed/Nature

Revealed]. Landscape Journal, Special Issue, 35-
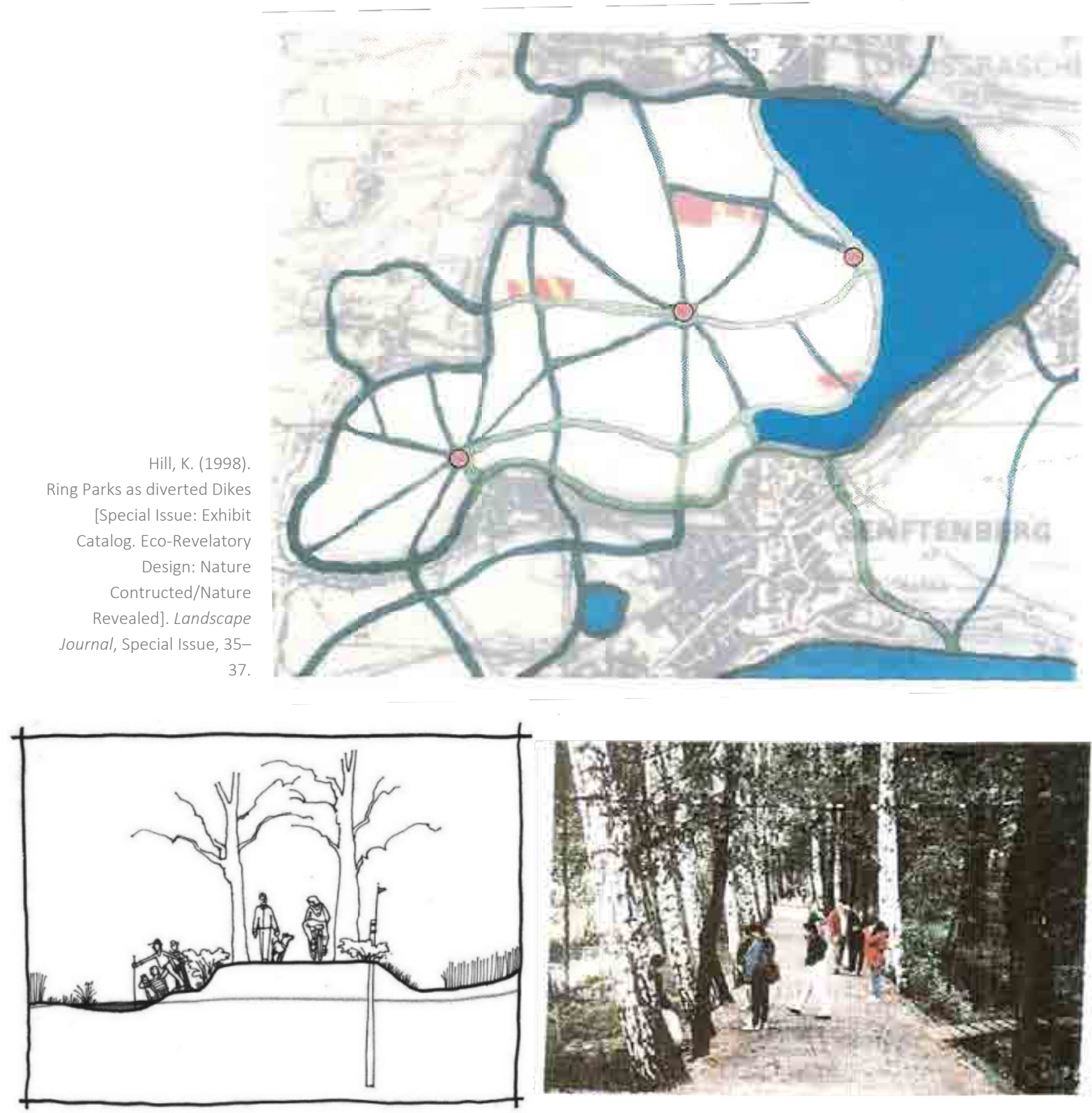

Figura 59. Imágenes extraídas de la propuesta presentada por Kristina Hill en el concurso-exposición titulado "Diseño Ecorevelador: Naturaleza Construida/Naturaleza Revelada". El diseño eco-revelador ("eco-revelatory design") se enunció en la exposición como aquel que revela e interpreta los fenómenos ecológicos. La imagen muestra el plano de los paseos arbolados y torres en una antigua zona minera, que funcionan como áreas para descubrir los procesos de regeneración ecológica que se introdujeron en la restauración. Un pozo de seguimiento muestra abiertamente los resultados de un test de calidad de agua y el estanque de la izquierda sólo se llena cuando la calidad y cantidad del agua freática adquiere un valor mínimo. En caso contrario el flujo es derivado a las zonas de tratamiento y regeneración de agua, entre otras, praderas con especies que regeneran el suelo y el agua, a modo de filtros verdes. El interés de la propuesta es que provee al público de información tangible sobre la calidad de su medio ambiente y traslada a la superficie, de forma perceptible y literal, un sistema que de otro modo permanece prácticamente invisible en el paisaje. 


\section{IV.3. CONCLUSIONES DE CARA A LA PROPUESTA METODOLÓGICA QUE SE PRESENTA}

A lo largo de la exposición de los antecedentes se ha realizado un repaso comprensivo de los diferentes enfoques que en el transcurso de la historia y en la actualidad se ha dedicado a la relación entre la dimensión ecológica y la dimensión perceptiva o estética del paisaje. Fruto de esta revisión se constata que la interfaz entre la ecología y la estética no sólo existe, sino que en ocasiones es más amplia de lo esperado en primera instancia, y que frecuentemente conjuga un vínculo tan escurridizo como significativo por su influencia en el comportamiento humano y resultado de gestión de los espacios. Como igualmente se desprende de este recorrido, el interés por la relación entre ecología y estética viene de antiguo y actualmente se contempla cada vez más como uno de los aspectos en la compleja realidad hombre-naturaleza que es conveniente considerar para alcanzar un mejor tratamiento del paisaje.

En este ámbito, el tratamiento del paisaje desde la denominada "estética ecológica", un paradigma emergente, ensancha las posibilidades contempladas hasta ahora en la consideración de las relaciones entre ecología y estética y, por ese motivo, resulta un enfoque llamado a trascender. Desde esta perspectiva, la percepción del paisaje se posiciona como un factor importante que puede dirigir nuestra atención y determinar en un sentido $u$ otro la forma de entender e impactar sobre su dimensión ecológica. De tal manera, la estética ecológica pretende servirse de la apariencia del paisaje para dirigir la evolución del mismo hacia estados más sostenibles.

Derivado de la revisión del estado de la cuestión, igualmente se evidencia que, en el plano conceptual, las formulaciones y discusiones teóricas sobre la interfaz entre la ecología y la estética ha avanzado en la últimas décadas. Sin embargo, y aunque se han llevado a cabo algunas experiencias prácticas en el campo de la evaluación de la percepción y la producción de diseños en el paisaje, estas son escasas 
y todavía se encuentran en sus inicios. Este hecho es especialmente notorio en el ámbito de la planificación del paisaje.

Sheppard, S. R. J., Harshaw, H. W., y Mc Bride, J. R. (2001). Priorities for Reconciling Sustainability and Aesthetics in Forest Landscape Management. En S. R. J. Sheppard y H. W. Harshaw (Eds.), Forests and Landscapes: Linking Ecology, Sustainability and Aesthetics (pp. 263-288). Nueva York, NY: CABI Publishing - IUFRO.
En la revisión conjunta que varios especialistas en la materia hicieron de esta cuestión, la conexión entre ecología, sostenibilidad y estética, en este caso centrada en el paisaje forestal, pero válida para otros contextos, se concluyó que la caracterización de la relación entre estética y sostenibilidad estaba aún insuficientemente investigada. A este respecto, trazaron una serie de prioridades de investigación para proveer a los gestores de criterios e indicadores que les asistieran en un tratamiento del paisaje que conectara la estética y la sostenibilidad y que siguen vigentes. Estas directrices se relacionan con 3 ámbitos:

- entender mejor cómo la gente percibe la sostenibilidad en el paisaje

- definir de forma más sólida como esta percepción se relaciona con la sostenibilidad que efectivamente se presenta en el paisaje

- encontrar modos para que dicha sostenibilidad pueda hacerse más tangible o notoria en el paisaje

La propuesta metodológica de esta tesis camina hacia esta perspectiva y pretende realizar una contribución a la planificación del paisaje que incorpore la perspectiva de la estética ecológica. Dicha contribución primero desarrolla una metodología de análisis de la percepción de la componente ecológica en términos estéticos y cómo esta define el modo de interpretarla, para posteriormente integrarla en un proceso de planificación del paisaje en el que se prescriben directrices de actuación que busquen una relación de sinergia entre ambas componentes. 
CAPÍTULO IV. PRÁCTICA EN EL TRATAMIENTO CONJUNTO DE LO ECOLÓGICO Y LO PERCIBIDO

EN EL PAISAJE 


\section{CAPÍTULO V}

ANÁLISIS DE LA PERCEPCIÓN DE LA CALIDAD ECOLÓGICAY ESTÉTICA DEL PAISAJE. CASO DE ESTUDIO DE LA PERCEPCIÓN POR PARTE DE TÉCNICOSY POBLACIÓN LOCAL EN UN PAISAJE FORESTAL:

LA CUENCA ALTA DEL RÍO IREGUA (LA RIOJA, ESPAÑA) 


\author{
V.CAPÍTULO \\ ANÁLISIS DE LA PERCEPCIÓN DE LA \\ CALIDAD ECOLÓGICA Y ESTÉTICA DEL \\ PAISAJE. CASO DE ESTUDIO DE LA \\ PERCEPCIÓN POR PARTE DE TÉCNICOS Y \\ POBLACIÓN LOCAL EN UN PAISAJE \\ FORESTAL: LA CUENCA ALTA DEL RÍO \\ IREGUA (LA RIOJA, ESPAÑA)
}

Extraído de

López-Rodríguez, A., Escribano-Bombín, R., Hernández-Jiménez, V. y Bell, S. (2018). Perceptions of ecological and aesthetic quality by natural resource professionals and local people. A qualitative exploration in a mountainous landscape (La Rioja, Spain). Landscape Research (publicado on-line el 4 de abril de 2018). DOI: 10.1080/01426397.2018.1446073

(Incluido en el Anexo I)

Gobster, P. H. (1999).

An ecological aesthetic for forest landscape management.

V.1. INTRODUCCIÓN
Parsons, R. (1995). Conflict

between ecological sustainability and environmental aesthetics:

Es claro que cuando se trata la interacción entre percepción y ecología resulta fundamental conocer la forma en la que la gente percibe, experimenta y reacciona ante el funcionamiento y dinámica natural del paisaje. Numerosos autores han Ilamado la atención sobre la necesidad de desarrollar esta cuestión, no sólo por extender nuestro conocimiento al respecto, sino también para que pueda ser aplicado tanto en el ámbito de la planificación, como en la gestión y diseño del paisaje (Gobster, 1999; Parsons, 1995; Sheppard et al., 2001). Priorities for Reconciling
Conundrum, canärd or curiosity. Landscape and Urban Planning, $32,227-244$.

Sheppard, S. R. J., Harshaw, H. W., y Mc Bride, J. R. (2001). Sustainability and Aesthetics in Forest Landscape Management. En S. R. J. Sheppard y H. W. Harshaw (Eds.), Forests and Landscapes: Linking Ecology, Sustainability and Aesthetics (pp. 263-288). Nueva York, NY: CABI Publishing - IUFRO 
García-Abril, A., Núñez, M. V., Grande, M. A., Velarde, D. Martínez-Obispo, P., y Rodríguez-Solano, R. (2013). Landscape indicators for Sustainable Forest Management. En E. MartinezFalero, S. Martin-Fernandez, y A. D. García-Abril (Eds.), Quantitative Techniques in Participatory Forest Management (pp. 263-366). Boca Ratón, NW: CRC Press,

Taylor \& Francis Group.

Zube, E. H., Sell, J. L., y Taylor, J. G. (1982).

Landscape Perception:

Research, Application and Theory. Landscape Planning, 9, 1-33.

Carlson, A. (1977). On the possibility of quantifying scenic beauty. Landscape Planning, 4, 131-172.

Carlson, A. (1993). On the theoretical vacuum in landscape assessment. Landscape Journal, 12(1), 51-56.

Tindall, D. B. (2001). Why do you think that hillside is ugly? A sociological perspective on aesthetic values and public attitudes about forest. En S. R. J.

Sheppard y H. W. Harshaw (Eds.), Forests and Landscapes: Linking Ecology, Sustainability and Aesthetics (pp. 57-70). Nueva York, NY: CABI Publishing IUFRO.
Actualmente se cuenta con una base empírica al respecto, si bien únicamente se han tratado aspectos parciales sobre la experiencia estética de la dimensión ecológica del paisaje. Además, la mayor parte de la investigación sobre el tema ha sido realizada bajo el signo del contexto recreativo y el paisaje escénico, y se ha centrado además en explicar los resultados de la interacción entre estética y ecología más que en los argumentos o valores que los sostienen y los determinan. Frecuentemente, estos estudios se han apoyado en métodos basados en el uso de encuestas en las que el público define sus preferencias ante una serie de fotografías o visualizaciones (asignado una valoración según una escala o relacionándolos con una lista de adjetivos, por ejemplo), o bien responde a cuestionarios con preguntas cerradas ("close-ended surveys") (para una revisión del tema consultar por ejemplo García-Abril et al., 2013). En general, estas aproximaciones han demostrado ser válidas, fiables y útiles dada la facilidad de tratamiento estadístico de sus resultados y porque han sido capaces de definir unos patrones de preferencias por determinados elementos o cualidades del paisaje más natural (Zube et al., 1982).

Ahora bien, preguntémonos por lo significativo de sus resultados. Su capacidad para esclarecer el fenómeno de la percepción de la dimensión ecológica y su relación con la interpretación estética es limitada, pues tratan sólo una de sus numerosas y complejas relaciones que se dan en el paisaje. Conocer qué paisajes o cualidades son apreciados y los elementos físicos que contribuyen a dicha preferencia es sólo una de las facetas en la interfaz entre ecología y estética (Carlson, 1977). Conocer de qué manera y cuáles son las razones por las que ciertos paisajes o cualidades resultan apreciados aporta mayor luz a un fenómeno tan relacionado con los valores, actitudes y contexto en el que se produce (Carlson, 1993).

En este sentido, Tindall (2001) ofrece un ejemplo esclarecedor sobre cómo la forma de mirar hacia el paisaje y los valores estéticos asociados pueden conectar con ciertas actitudes y opiniones sobre, en este caso, la gestión forestal y su impacto en el paisaje. El autor expone el caso de turistas que expresaron su disconformidad con la apariencia de laderas recientemente aprovechadas mediante cortas a hecho, al mismo tiempo que ensalzaban las cualidades visuales de lo 
que percibían como un bosque maduro sin intervención, que sin embargo se trataba de una masa aprovechada por el mismo método y cuyo desarrollo había podido integrar los signos más evidentes de la actuación. Este ejemplo ilustra cómo un determinado estado ecológico puede no mostrarse fácilmente legible y marca la importancia de distinguir entre la preferencia que provoca la impresión de belleza de un determinado paisaje y la preferencia que induce la idea u opinión que se tiene de ese paisaje. Carlson (2001) define este asunto como clave para realizar una correcta evaluación de la relación entre la ecología, la sostenibilidad y la estética, dado que no es lo mismo preguntarse sobre si a la gente le gusta la apariencia de los paisajes sostenibles (imagen) o sobre si la gente prefiere los paisajes sostenibles (idea). Consecuentemente, Carlson aboga por que los análisis no sólo estén basados en el aspecto del

Carlson, A. (2001) Aesthetic preferences for sustainable landscapes: seeing and knowing. En S. R. J. Sheppard y H. W. Harshaw (Eds.), Forests and Landscapes: Linking Ecology, Sustainablility, and Aesthetics (pp. 31-42). Nueva York, NY: CABI Publishing - IUFRO. paisaje, sino también en su capacidad de expresar su sostenibilidad a la luz de nuestro conocimiento (o creencias) y nuestro juicio sobre por qué los paisajes se muestran de la manera en que se muestran.

A este respecto, se necesita ahondar en enfoques que traten de forma más específica las conexiones entre los valores (que no reacciones) estéticos y ecológicos, que superen la simple constatación de una preferencia hacia un paisaje natural producto de una determinada dinámica ecológica y que indaguen de forma más profunda en el fenómeno, preguntándose sobre las causas y consecuencias de una determinada percepción. Este es el enfoque que adopta la investigación empírica del presente capítulo, en la que se presenta una metodología para el análisis de la percepción estética de la dimensión ecológica de un paisaje. La aportación de esta investigación es doble:

- Proponer una metodología de análisis cualitativo de la interpretación estética y la valoración que se hace de la dimensión ecológica del paisaje y verificar su validez.

- Ampliar el conocimiento existente sobre la evaluación del paisaje en clave ecológica y estética que hacen dos grupos sociales: los técnicos gestores y la población local. 
Dandy, N. y Van Der Wal, R. (2011). Shared appreciation of woodland landscapes by land management professionals and

lay people: An exploration through field-based interactive photo-elicitation. Landscape and Urban Planning, 102(1), 43-53.

Gómez-Limón, J. y de Lucio Fernández, J. V. (1999) Changes in use and landscape preferences on the agricultural-

livestock landscapes of the central Iberian Peninsula (Madrid, Spain). Landscape and Urban Planning, 44, 165-175.

Rogge, E., Nevens, F., y Gulinck, H. (2007). Perception of rural landscapes in Flanders: Looking beyond aesthetics. Landscape and Urban Planning, 82, 159-

174.
El caso de estudio analiza la percepción de dos grupos sociales de interés estratégico: los técnicos gestores y la población local. Dichos agentes ejercen una influencia significativa y directa en el paisaje por medio de sus decisiones de planificación y gestión, y de sus actividades diarias. Sin embargo, no han recibido demasiada atención por parte de los estudios empíricos o discusiones teóricas, que normalmente se orientan al público que hace uso del paisaje con fines turístico-recreativos. Este hecho es especialmente cierto en el caso de los técnicos, grupo que evidentemente modifica de forma relevante el paisaje y cuya apreciación estética ha sido muy escasamente analizada. Algunos estudios, sin embargo, han explorado la percepción de estos grupos de manera directa o indirecta, constatando diferencias en el modo en que los técnicos especializados en el ámbito del paisaje, los gestores, la población que vive en el paisaje y los visitantes o público general miran e interpretan las cualidades del paisaje y le asignan funciones (Dandy y Van Der Wal, 2011; GómezLimón y Fernández, 1999; Rogge, Nevens, y Gulinck, 2007). Estas visiones, y las causas y argumentos que las sostienen, merecen pues ser examinadas en mayor profundidad.

El caso de estudio trata específicamente la percepción de estos dos grupos en un contexto de paisaje predominantemente natural, de carácter forestal, en el que vive una población rural en declive y en el que los objetivos de conservación y de uso turístico-recreativo y educativo del paisaje son primordiales. 


\section{V.2. ÁREA DE ESTUDIO}

El área de estudio se sitúa en la parte alta del valle del río Iregua, localizado en la parte riojana del Sistema Ibérico (Sierra de Cameros). El valle incluye el Parque Natural Sierra Cebollera y los municipios circundantes, que abarcan más de $440 \mathrm{~km} 2$ : Villoslada de Cameros, Lumbreras, Ortigosa de Cameros, Villanueva de Cameros, El Rasillo de Cameros, Pinillos de Cameros, Almarza de Cameros, Nieva de Cameros y Torrecilla en Cameros (Figura 60).

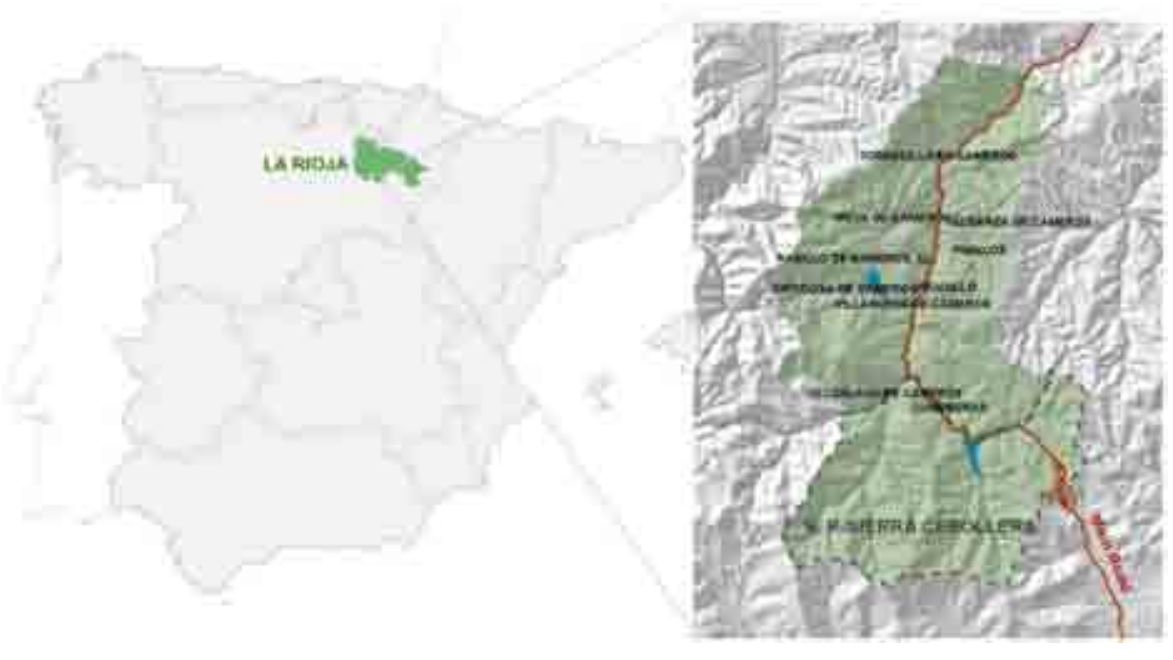

Figura 60.- Localización y límites del área de estudio.

El paisaje es montañoso, con formas redondeadas y elevaciones de más de $2.000 \mathrm{~m}$ en algunos puntos: El Castillo de Vinuesa (2.083), el Peñón de Santosonario (2.058) y el Telégrafo (2078). En la zona de cumbres existen vestigios de la actividad glaciar del Cuaternario, y aún se distinguen las formas de los circos glaciares ("hoyos"), una de las representaciones de erosión glaciar más importantes de la península.

El clima del valle es mediterráneo con influencia atlántica. En el pasado, los rebaños de ovejas trashumantes modelaron un paisaje prácticamente deforestado. Desde hace 150 años los bosques se están recuperando y hoy en día el paisaje es predominantemente boscoso. Los melojares (Quercus pyrenaica) se extienden entre los 1.000 y 1.400 metros de altitud y dan paso a los hayedos (Fagus sy/vatica) y pinares de pino silvestre (Pinus sy/vestris) a medida que la altitud aumenta. Por encima de los 1.800-1.900 m) el clima se recrudece y se extienden las comunidades de matorrales y herbazales de alta montaña (Aramburu Maqua, Escribano Bombín, López Rodríguez, Pastor Piñuela, y Rastrollo Gonzalo, 2009).

Aramburu Maqua, M.P., Escribano Bombín, R., López Rodríguez, A., Pastor Piñuela, M, Rastrollo Gonzalo, A. (2009). Diseño y Redacción de las Fichas de los Paisajes Singulares y Sobresalientes de la Comunidad de La Rioja. Logroño: Consejería de Turismo, Medio Ambiente y Política Territorial, Gobierno de La Rioja (trabajo técnico no publicado). 
Existen 9 pueblos en esta zona, con un total aproximado de 1.500 habitantes (el mayor de ellos, Torrecilla en Cameros, cuenta con 530 habitantes. Datos del Instituto Nacional de Estadística de 2017): Villoslada de Cameros, Lumbreras, Ortigosa de Cameros, Villanueva de Cameros, El Rasillo de Cameros, Pinillos de Cameros, Almarza de Cameros, Nieva de Cameros y Torrecilla en Cameros. Además, se localizan dentro del área de estudio las aldeas de San Andrés y El Horcajo.

El área está sujeta a la disminución de esa población por causa del éxodo rural. La economía local estaba, y todavía está, unida a la ganadería extensiva, silvicultura $y$, en pequeña medida, a la agricultura. Actualmente también se basa en el turismo y en actividades recreativas al aire libre. El territorio es mayoritariamente de propiedad municipal, y la planificación y gestión de los recursos naturales son dirigidas por La Oficina regional de Medio Ambiente y Conservación de la Naturaleza.

Existen 2 grandes embalses en el área: Embalse de Pajares (1995, 35 $\mathrm{hm}^{3}, 162 \mathrm{ha}$.) y Embalse de González Lacasa (1962, 33 hm³, 152 ha.)
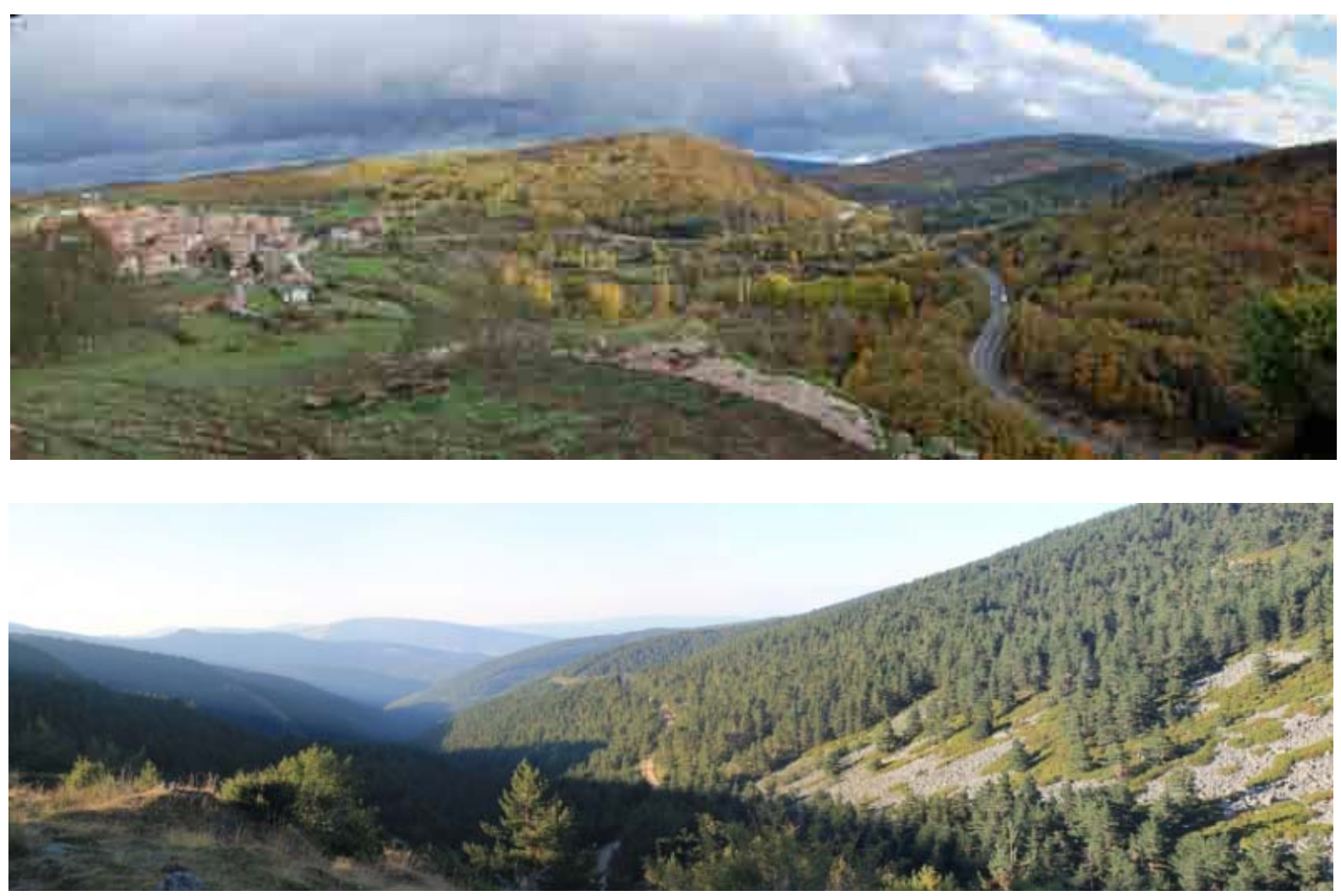

Figura 61. Imágenes representativas del área de estudio. 


\section{V.3. MATERIAL Y MÉTODOS}

\section{V.3.1. Marco conceptual de análisis}

El marco conceptual de análisis que guía esta investigación se funda en la Teoría del Lugar ("Theory of Place") desarrollada por David Canter (Canter, 1977). En la exposición de su teoría, Canter observa que para obtener información sobre un proceso esencialmente interno y subjetivo como es la relación que el individuo establece con

Canter, D. (1977).

The psychology of place. Londres, UK: Architectural Press. su entorno perceptible (véase paisaje), no es apropiado basar el análisis en el simple estímulo (esto es, por ejemplo, la respuesta directa ante una fotografía), pues esto lleva a centrarse únicamente en el objeto. El autor, en contraposición a este enfoque, defiende que para conocer en profundidad esta relación es necesario centrarse en el proceso mental (la cognición) que acompaña a la percepción y dirigir la atención hacia la noción que se tiene del entorno, entendido como lugar, hacia la manera que se tiene de "representarlo en nuestras cabezas". Es el análisis de estos sistemas conceptuales que nos llevan a reconocer, comprender, interpretar y actuar en un lugar lo que nos conduce a preguntarnos por el cómo y el por qué del fenómeno. Para ello, Canter desarrolló una teoría comprensiva del lugar de la que deriva una metodología de análisis muy adecuada para el objetivo que se pretende.

Según la Teoría del Lugar de Canter, los principales componentes que se combinan de forma inseparable para formar la esencia del lugar son (Figura 62):

- las concepciones ("conceptions"), es decir, la comprensión, expectativas y valoración que el individuo hace del lugar (paisaje)

- las actividades ("activities"), esto es, las acciones, comportamientos o funciones que se relacionan con dicho lugar

- y los atributos físicos ("physical attributes"), o sea, los elementos o propiedades físicas que se perciben en ese lugar. 
Canter, D. (1977) The psychology of place. Londres, UK: Architectural Press.

Ward Thompson, C., Aspinall, P., Bell, S., y Findlay, C. (2005). "It Gets You Away From Everyday Life": Local Woodlands and Community Use-What Makes Difference? Landscape Research 30(1), 109-146.

Ward Thompson, C., Aspinall, P. Bell, S., Findlay, C., Wherrett, J., y Travlou, P. (2004). Open space and social inclusion: Local woodland use in Central Scotland.

Report to the Forestry

Commission, Edinburgh. Edinburgh: Forestry Commission.

Bell, S. (2009). Landscape change, landscape perception and the Latvian countryside (Tesis doctoral). Eesti Maaülikoo (Universidad de Ciencias Naturales de Estonia), Tartu.

Oliveira, E. S. (2011) Immigrants and Public Open Spaces: attitudes, preferences and uses (Tesis doctoral no publicada). Universidad de Edimburgo, Edimburgo

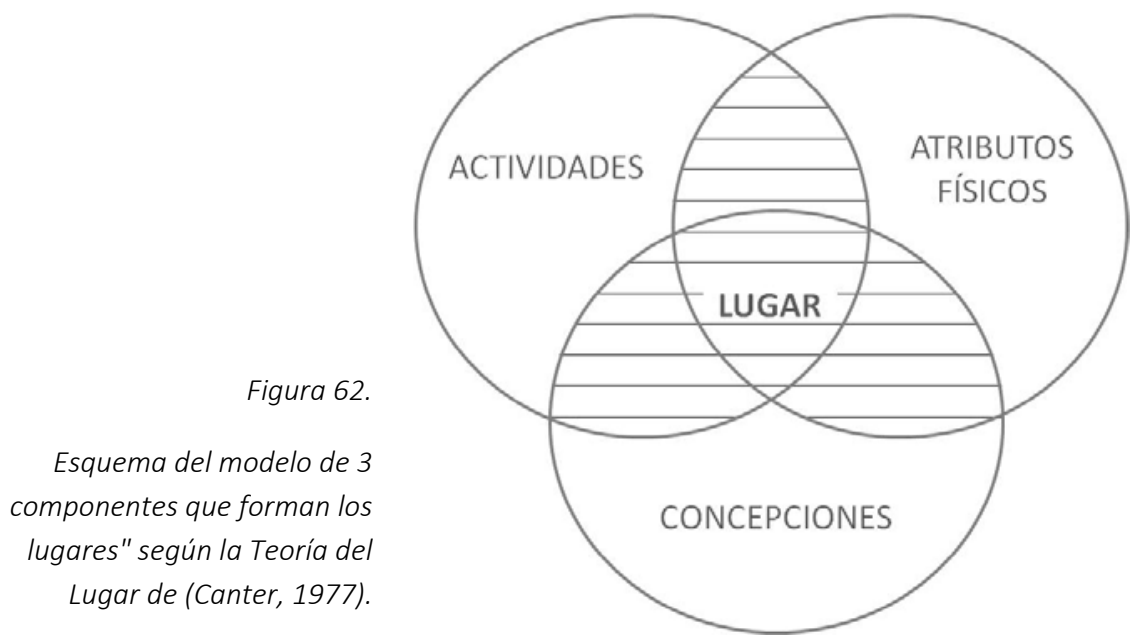

Analizando estos componentes de manera conjunta es posible conectar forma, sentido y función del paisaje y así explorar la interpretación del lugar de forma profunda. Para hacer aflorar estos 3 aspectos, Canter propone el uso de herramientas como la representación del lugar mediante el dibujo, su descripción o la observación directa del comportamiento que se tiene en él. Esta perspectiva y métodos ha sido aplicados en algunos estudios en el campo de la arquitectura del paisaje, relacionados con el uso de los espacios forestales (Ward Thompson et al., 2004; Ward Thompson, Aspinall, Bell, y Findlay, 2005), con la percepción del paisaje rural (Bell, 2009) o con la experiencia de los espacios libres urbanos (Oliveira, 2011).

\section{V.3.2. Método analítico}

\section{Diseño de la entrevista}

Dado que el objetivo es definir una metodología que permita conocer en profundidad el fenómeno de la percepción de la ecología en el paisaje y su relación con la interpretación estética, se adoptó una aproximación cualitativa basada en la realización de una serie de focus groups y de entrevistas personales. La dinámica de los focus groups y las entrevistas personales se basó en un diseño de entrevista confeccionada para poder explorar los 3 componentes del modelo analítico de Canter: concepciones, actividades y atributos físicos. De tal manera, los entrevistados localizaron en un mapa confeccionado al 
efecto (ver Anexo I) una serie de lugares que para ellos presentaran 4 cualidades diferenciadas: alta y baja calidad ecológica, y alta y baja calidad del paisaje percibido. Seguidamente se les solicitó que describieran con detalle las características del lugar y, un aspecto clave, explicaran las razones de su decisión. Por último, se les pidió que comentaran su opinión sobre la influencia que la gestión que se llevaba a cabo en el espacio tenía sobre la ecología y la estética del paisaje, la de su propia actividad y su relación con otras actividades, y por la evolución previsible del paisaje.

El formato de entrevista semiestructurada y compuesta por preguntas abiertas (open-ended questions) permitió a los entrevistados comentar en profundidad todos los temas de su interés $y$, de tal manera, hacer emerger aquellos aspectos del paisaje que ellos mismos, sin condicionamiento del investigador, definieron como significativos dentro de su concepción de la ecología y la estética del paisaje (user-led interview). El papel del investigador se limitó a exponer los objetivos y mecánica de la entrevista y a redirigir la conversación hacia los aspectos de interés. La concreción de las cualidades buscadas en un localización precisa del mapa y la descripción exhaustiva de sus características permitió ligar la dimensión física del paisaje con la interpretación de ambos aspectos.

\section{Selección de participantes}

La selección de los encuestados se condujo siguiendo la estrategia cualitativa de muestreo intencional, propositivo o de juicio (purposeful sampling). Dicha técnica es no probabilística, por lo que no persigue seleccionar una muestra amplia de casos elegidos de forma aleatoria con el afán de que sea estadísticamente representativa de la población total, sino trabajar con un número limitado de casos que ofrezcan una información rica y significativa sobre el fenómeno en estudio. Es decir, la intención no es la medición de un fenómeno, sino entender detalladamente y en toda su complejidad dicho fenómeno (Bryman, 2004). Dentro de este tipo de estrategia, se aplicó la técnica de muestreo de máxima variación (maximum variation sampling), que pretende alcanzar una comprensión del fenómeno a través de su

Bryman, A. (2004). Social research methods. Oxford, UK: Oxford University Press. 
Patton, M. Q. (2002) Qualitative research and evaluation methods ( 3 a ed.) Thousand Oaks, CA: Sage. búsqueda de una muestra de perspectivas distintas sobre el tema de estudio. De tal manera, el investigador puede llegar a conocer cómo un fenómeno es entendido por personas diferentes y detectar patrones relevantes, compartidos o divergentes a través de los casos, cuya significación deriva del hecho de surgir desde la heterogeneidad de la muestra. La clave que define la validez del análisis es por tanto la fidelidad con que las observaciones reflejen el fenómeno en estudio y la fidelidad con que el analista capte el sentido de dichas observaciones (Patton, 2002; Teddlie y Yu, 2007).

Entre octubre de 2013 y febrero de 2016, se llevaron a cabo 3 focus group, complementados con una serie de entrevistas personales en profundidad, realizadas en el área de estudio. En total se entrevistaron a 36 participantes, pertenecientes a dos grupos diferenciados según el tipo de conocimiento del medio natural y el tipo de uso o implicación en el paisaje (Tabla 4):

- Grupo de los técnicos. Representado por profesionales con formación científico-técnica en medio natural y responsabilidad en la gestión o conservación del espacio a través de la administración pública (áreas de actuación en gestión forestal, conservación de la naturaleza, planificación, calidad y educación ambiental).

- Grupo de la población local. Representado por componentes de la comunidad local que trabajaban y/o vivían en el área de estudio, con un contacto frecuente y directo con el paisaje estudiado, y una experiencia fundamentalmente empírica de las dinámicas naturales (si bien ciertos participantes poseían cierto grado de conocimiento formalizado). En este grupo se incluyeron personas dedicadas a la ganadería, a los trabajos forestales, al turismo rural, a la administración local, entre otros, todos ellos residentes en el paisaje, al menos una parte significativa del año. 
Tabla 4. Características básicas de los participantes de cada grupo.

\begin{tabular}{|c|c|c|c|c|c|c|}
\hline \multicolumn{2}{|c|}{$\begin{array}{l}\text { GRUPO/ } \\
N^{\circ} \text { DE } \\
\text { ESTREVISTAS }\end{array}$} & OCUPACIÓN & GÉNERO & EDAD & FORMACIÓN & $\begin{array}{l}\text { CONTACTO CON EL PAISAJE } \\
\text { (profesional/personal) }\end{array}$ \\
\hline \multirow{4}{*}{ 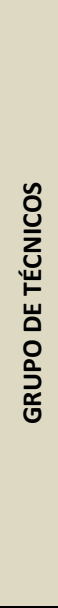 } & \multirow{4}{*}{18} & $\begin{array}{l}\text { Consejería de Agricultura, } \\
\text { Ganadería y Medio Ambiente: } \\
\text { - Gestión Forestal: } 3 \\
\text { - Conservación de la Naturaleza, } \\
\text { Planificación e Integración } \\
\text { Ambiental: } 6 \\
\text { - Educación Ambiental: } 1\end{array}$ & $\begin{array}{l}\text { Hombres: } \\
6 \\
\text { Mujeres: } \\
4\end{array}$ & $\begin{array}{c}<35: 2 \\
35-50: 3 \\
51-65: 5\end{array}$ & Universitaria & $\begin{array}{l}\text { Trabajo a nivel regional y en la zona; } \\
\text { residente parcial - conexiones- } \\
\text { personales: } 1 \\
\text { Trabajo cerca de la zona; residente } \\
\text { parcial - conexiones-personales: } 1 \\
\text { Trabajo en la zona; no residente: } 1 \\
\text { Trabajo a nivel regional; no } \\
\text { residente: } 7\end{array}$ \\
\hline & & Educación Ambiental: 5 & $\begin{array}{l}\text { Hombres: } \\
5\end{array}$ & $\begin{array}{c}<35: 2 \\
35-50: 3\end{array}$ & $\begin{array}{c}\text { Técnico } \\
\text { medio: } 3 \\
\text { Universitaria: } \\
2\end{array}$ & $\begin{array}{l}\text { Trabajo en la zona; residente: } 1 \\
\text { Trabajo en la zona; residente parcial } \\
\text { - conexiones-personales: } 2 \\
\text { Trabajo a nivel regional y en la zona; } \\
\text { no residente: } 2\end{array}$ \\
\hline & & Agente forestal: 1 & $\begin{array}{c}\text { Hombres: } \\
1 \\
\end{array}$ & $35-50$ & $\begin{array}{l}\text { Técnico } \\
\text { medio }\end{array}$ & Trabajo en la zona; residente \\
\hline & & $\begin{array}{l}\text { Consultor en temas forestales y de } \\
\text { gestión ambiental: } 2\end{array}$ & $\begin{array}{l}\text { Hombres: } \\
2 \\
\end{array}$ & $\begin{array}{c}<35 \\
50-65 \\
\end{array}$ & Universitaria & $\begin{array}{l}\text { Trabajo en la zona; no residente, sin } \\
\text { conexiones personales }\end{array}$ \\
\hline \multirow{4}{*}{ 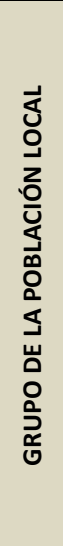 } & \multirow{4}{*}{18} & Ganaderos: 5 & $\begin{array}{l}\text { Hombres: } \\
3 \\
\text { Mujeres: } \\
2 \\
\end{array}$ & $\begin{array}{l}\text { 35-50: } 1 \\
51-65: 4\end{array}$ & $\begin{array}{l}\text { Primaria: } 3 \\
\text { Secundaria: } 1 \\
\text { Técnico } \\
\text { medio: } 1 \\
\end{array}$ & Residente \\
\hline & & $\begin{array}{c}\text { Operarios de actividades forestales: } \\
4 \\
\text { (1 también ganadero) } \\
\end{array}$ & $\begin{array}{l}\text { Hombres: } \\
4\end{array}$ & $\begin{array}{c}<35: 3 \\
35-50: 1\end{array}$ & $\begin{array}{l}\text { Primaria: } 3 \\
\text { Técnico } \\
\text { medio: } 1 \\
\end{array}$ & Residente \\
\hline & & $\begin{array}{l}\text { Administración local (actividad } \\
\text { principal no relacionada con la } \\
\text { ganadería o el sector forestal): } 3\end{array}$ & $\begin{array}{l}\text { Hombres: } \\
2 \\
\text { Mujeres: } \\
1 \\
\end{array}$ & $\begin{array}{l}\text { 50-65: } 1 \\
>65: 2\end{array}$ & $\begin{array}{l}\text { Primaria: } 1 \\
\text { Secundaria: } 2\end{array}$ & $\begin{array}{l}\text { Residente: } 2 \\
\text { Residente parcial: } 1\end{array}$ \\
\hline & & $\begin{array}{c}\text { Otros: } 6 \\
\text { (4 de ellos también propietarios de } \\
\text { casa rurales, } 1 \text { de ellos también } \\
\text { ganadero) }\end{array}$ & $\begin{array}{l}\text { Mujeres: } \\
3 \\
\text { Hombres: } \\
3\end{array}$ & $\begin{array}{c}35-50: 2 \\
51-65: 2 \\
>65: 2\end{array}$ & $\begin{array}{l}\text { Secundaria:2 } \\
\text { Técnico } \\
\text { medio: } 2 \\
\text { Universitaria: } \\
2 \\
\end{array}$ & $\begin{array}{l}\text { Residente: } 4 \\
\text { Residente parcial: } 2\end{array}$ \\
\hline
\end{tabular}

\section{Análisis de los datos}

Cada entrevista fue grabada y transcrita literalmente para su posterior análisis en gabinete utilizando la técnica de la codificación (Bryman, 2004). Mediante esta técnica, el investigador analiza el contenido de las entrevistas asignando códigos a cada parte del texto, es decir, enuncia el significado, idea o concepto que encierra cada frase o Bryman, A. (2004). Social research methods. Oxford, UK: Oxford University Press. grupo de frases del entrevistado, para posteriormente relacionarlos entre ellos y con los fundamentos teóricos de la investigación, y organizarlos en categorías que expliquen de forma integrada el fenómeno. Dichas categorías se vincularon explícitamente con los 3 componentes del modelo de análisis de Canter: concepciones (sentido), actividades (función) y atributos físicos (forma). 


\section{V.4. RESULTADOS}

El tipo de paisaje seleccionado por los participantes en cada categoría (alta y baja calidad ecológica y de paisaje percibido), así como los atributos que evaluaron como relevantes se encuentran resumidos en la Tabla 5. En el Anexo I se presenta una relación de términos ampliado sobre cada aspecto tratado. En el marco del modelo de 3 componentes de Canter (atributos físicos, concepciones y actividades), la variación entre e intragrupos y las razones que la fundamentan están descritas a continuación. 
Tabla 5.- Síntesis de los tipos de paisaje y características seleccionadas y comentadas por los participantes en las entrevistas.

\begin{tabular}{|c|c|c|c|c|c|c|}
\hline \multicolumn{7}{|c|}{ GRUPO DE LOS TÉCNICOS } \\
\hline \multicolumn{7}{|c|}{ CALIDAD ECOLÓGICA ALTA } \\
\hline 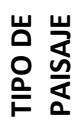 & BOSQUES & $\begin{array}{l}\text { PAISAJES DE ALTA } \\
\text { MONTAÑA }\end{array}$ & RIBERAS & DEHESAS & \multicolumn{2}{|c|}{$\begin{array}{c}\text { OTROS } \\
\text { (pedregales, } \\
\text { formaciones kársticas) }\end{array}$} \\
\hline 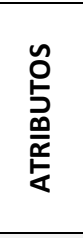 & $\begin{array}{l}\text { - Diversidad } \\
\text { - Buen estado de } \\
\text { conservación } \\
\text { - Poco impacto } \\
\text { humano/naturalidad } \\
\text { - Árboles maduros } \\
\end{array}$ & $\begin{array}{l}\text { - Poco impacto } \\
\text { humano/naturalidad } \\
\text { - Singularidad } \\
\text { - Buen estado de } \\
\text { conservación } \\
\text { - Diversidad }\end{array}$ & $\begin{array}{l}\text { - Poco impacto } \\
\text { humano/naturali } \\
\text { dad } \\
\text { - Diversidad } \\
\text { - Singularidad } \\
\text { - Calidad del agua } \\
\end{array}$ & $\begin{array}{l}\text { - Diversidad } \\
\text { - Árboles } \\
\text { maduros } \\
\text { - Buen estado de } \\
\text { conservación }\end{array}$ & & \\
\hline & \multicolumn{6}{|c|}{ CALIDAD ECOLÓGICA BAJA } \\
\hline 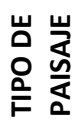 & EMBALSES & $\begin{array}{c}\text { ÁREAS SUJETAS A } \\
\text { APROVECHAMIENTO } \\
\text { GANADERO INTENSIVO }\end{array}$ & $\begin{array}{c}\text { NUEVAS } \\
\text { URBANIZACIONES }\end{array}$ & CANTERAS & BOSQUES & \\
\hline $\begin{array}{l}\frac{n}{5} \\
\frac{0}{\alpha} \\
\frac{0}{\alpha}\end{array}$ & $\begin{array}{l}\text { - Distorsión de la } \\
\text { dinámica fluvial } \\
\text { - Alto impacto } \\
\text { humano, carácter } \\
\text { artificial } \\
\text { - Degradación del } \\
\text { suelo y cobertura } \\
\text { vegetal } \\
\text { - Ocupación del área } \\
\end{array}$ & $\begin{array}{l}\text { - Uso intensivo } \\
\text { - Contaminación } \\
\text { - Degradación del } \\
\text { suelo y cobertura } \\
\text { vegetal }\end{array}$ & $\begin{array}{l}\text { - Carácter artificial, } \\
\text { falta de } \\
\text { coherencia con } \\
\text { las condiciones } \\
\text { naturales }\end{array}$ & $\begin{array}{l}\text { - Degradación } \\
\text { del suelo y } \\
\text { cobertura } \\
\text { vegetal } \\
\text { - Contaminación }\end{array}$ & $\begin{array}{l}\text { - Falta de } \\
\text { diversidad } \\
\text { - Gestión } \\
\text { inapropiada }\end{array}$ & 望 \\
\hline & \multicolumn{6}{|c|}{ CALIDAD DEL PAISAJE PERCIBIDO ALTA } \\
\hline 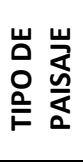 & $\begin{array}{l}\text { PAISAJES DE ALTA } \\
\text { MONTAÑA }\end{array}$ & BOSQUES & $\begin{array}{c}\text { PUEBLOS Y } \\
\text { PAISAJES } \\
\text { TRADICIONALES } \\
\text { ALREDEDOR }\end{array}$ & $\begin{array}{l}\text { RIBERAS, } \\
\text { EMBALSES }\end{array}$ & \multicolumn{2}{|c|}{ CORTADOS ROCOSOS } \\
\hline 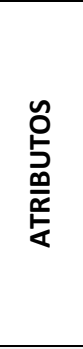 & $\begin{array}{l}\text { - Vistas panorámicas y } \\
\text { escénicas } \\
\text { - Poco impacto } \\
\text { humano/naturalidad } \\
\text { - Diversidad } \\
\text { - Singularidad } \\
\text { - Elementos culturales } \\
\text { integrados en el } \\
\text { contexto natural }\end{array}$ & $\begin{array}{l}\text { - Diversidad } \\
\text { - Árboles maduros } \\
\text { - Singularidad } \\
\text { - Poco impacto } \\
\text { humano/naturalidad }\end{array}$ & $\begin{array}{l}\text { - Carácter } \\
\text { tradicional } \\
\text { cultural, } \\
\text { Elementos } \\
\text { culturales } \\
\text { integrados en el } \\
\text { contexto natural } \\
\text { - Singularidad }\end{array}$ & $\begin{array}{l}\text { - Buen estado de } \\
\text { conservación } \\
\text { - Presencia de } \\
\text { agua }\end{array}$ & \multicolumn{2}{|l|}{ - Singularidad } \\
\hline & \multicolumn{6}{|c|}{ CALIDAD DEL PAISAJE PERCIBIDO BAJA } \\
\hline 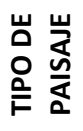 & EMBALSES & $\begin{array}{c}\text { ÁREAS SUJETAS A } \\
\text { APROVECHAMIENTO } \\
\text { GANADERO INTENSIVO }\end{array}$ & $\begin{array}{c}\text { NUEVAS } \\
\text { URBANIZACIONES }\end{array}$ & CANTERAS & BOSQUES & \multirow[b]{2}{*}{ 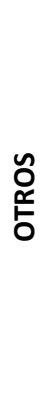 } \\
\hline 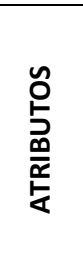 & $\begin{array}{l}\text { - Alto impacto } \\
\text { humano, carácter } \\
\text { artificial } \\
\text { - Degradación del } \\
\text { suelo y cobertura } \\
\text { vegetal }\end{array}$ & $\begin{array}{l}\text { - Degradación del } \\
\text { suelo y cobertura } \\
\text { vegetal } \\
\text { - Uso intensivo } \\
\text { - Contaminación } \\
\text { - Falta de coherencia y } \\
\text { cuidado }\end{array}$ & $\begin{array}{l}\text { - Carácter artificial, } \\
\text { falta de } \\
\text { coherencia con } \\
\text { las condiciones } \\
\text { naturales }\end{array}$ & - Impacto visual & $\begin{array}{l}\text { - Falta de } \\
\text { diversidad } \\
\text { - Gestión } \\
\text { inapropiada }\end{array}$ & \\
\hline
\end{tabular}


Tabla 5.- (Cont.)

\begin{tabular}{|c|c|c|c|c|c|}
\hline \multicolumn{6}{|c|}{ GRUPO DE LA POBLACIÓN LOCAL } \\
\hline & \multicolumn{5}{|c|}{ CALIDAD ECOLÓGICA ALTA } \\
\hline 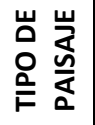 & BOSQUES & $\begin{array}{l}\text { PAISAJES DE ALTA } \\
\text { MONTAÑA }\end{array}$ & LAGUNAS & \multicolumn{2}{|c|}{$\begin{array}{c}\text { OTROS } \\
\text { (pastizales, dehesa', } \\
\text { entorno de los pueblos) }\end{array}$} \\
\hline 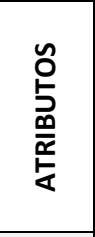 & $\begin{array}{l}\text { - Cuidado, gestión } \\
\text { activa } \\
\text { - Buen estado de } \\
\text { conservación } \\
\text { - Diversidad } \\
\text { - Árboles maduros }\end{array}$ & $\begin{array}{l}\text { - Buen estado de } \\
\text { conservación } \\
\text { - Poco impacto } \\
\text { humano/naturalidad }\end{array}$ & $\begin{array}{l}\text { - Buen estado de } \\
\text { conservación } \\
\text { - Singularidad }\end{array}$ & & \\
\hline & \multicolumn{5}{|c|}{ CALIDAD ECOLÓGICA BAJA } \\
\hline 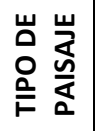 & BOSQUES & CULTIVOS Y PASTOS & $\begin{array}{l}\text { ENTORNO DE LSO } \\
\text { PUEBLOS }\end{array}$ & \multicolumn{2}{|l|}{ - } \\
\hline 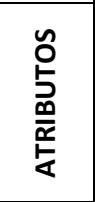 & $\begin{array}{l}\text { - Falta de gestión } \\
\text { activa } \\
\text { - Matorralización, } \\
\text { invasión del bosque } \\
\text { - Gestión inapropiada }\end{array}$ & $\begin{array}{l}\text { - Matorralización, } \\
\text { invasión del bosque }\end{array}$ & $\begin{array}{l}\text { - Gestión de residuos } \\
\text { inapropiada }\end{array}$ & - & \\
\hline & \multicolumn{5}{|c|}{ CALIDAD DEL PAISAJE PERCIBIDO ALTA } \\
\hline 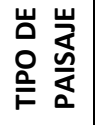 & BOSQUES & RIBERAS, EMBALSES & $\begin{array}{l}\text { PAISAJES DE ALTA } \\
\text { MONTAÑA }\end{array}$ & $\begin{array}{l}\text { PUEBLOS Y SITIOS } \\
\text { CULTURALES }\end{array}$ & \multirow{2}{*}{ 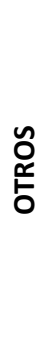 } \\
\hline 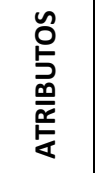 & $\begin{array}{l}\text { - Diversidad de } \\
\text { árboles, cambio } \\
\text { estacional } \\
\text { - Árboles maduros }\end{array}$ & $\begin{array}{l}\text { - Presencia de agua } \\
\text { - Singularidad }\end{array}$ & $\begin{array}{l}\text { - Panoramic/scenic } \\
\text { views } \\
\text { - Agreste } \\
\text { - Diversidad }\end{array}$ & $\begin{array}{l}\text { - Carácter tradicional } \\
\text { y significación } \\
\text { cultural }\end{array}$ & \\
\hline & \multicolumn{5}{|c|}{ CALIDAD DEL PAISAJE PERCIBIDO BAJA } \\
\hline 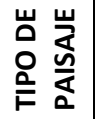 & BOSQUES & ARTIFICIAL RESERVOIRS & $\begin{array}{l}\text { NEW HOUSING } \\
\text { DEVELOPMENTS }\end{array}$ & $\begin{array}{l}\text { ÁREAS MENOS } \\
\text { ARBOLADAS }\end{array}$ & \multirow[b]{2}{*}{ 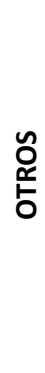 } \\
\hline 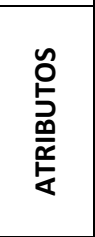 & $\begin{array}{l}\text { - Gestión inapropiada, } \\
\text { efectos negativos de } \\
\text { los trabajos } \\
\text { forestales } \\
\text { - Matorralización, } \\
\text { invasión del bosque }\end{array}$ & $\begin{array}{l}\text { - Degradación del suelo } \\
\text { y cobertura vegetal } \\
\text { - Alto impacto humano, } \\
\text { carácter artificial }\end{array}$ & $\begin{array}{l}\text { - Falta de coherencia } \\
\text { con el entorno }\end{array}$ & $\begin{array}{l}\text { - Falta de cobertura } \\
\text { arbolada }\end{array}$ & \\
\hline
\end{tabular}




\section{V.4.1. Parajes seleccionados y atributos físicos que determinaron la evaluación de la calidad del paisaje}

Los técnicos asociaron la alta calidad ecológica fundamentalmente con atributos relacionados con la naturalidad, buen estado de conservación, singularidad o madurez de los ecosistemas. Consecuentemente, tendieron a seleccionar paisajes representativos de estas cualidades: bosques maduros y poco modificados, ecosistemas de alta montaña y riberas fluviales $(39,28$ y $19 \%$ de las elecciones respectivamente). La naturalidad y la escasa influencia humana fue destacada como el factor clave que aportaba calidad al paisaje: el $67 \%$ se refirió a estas características en sus descripciones, utilizando términos como "menos intervenido", "más natural", "sin influencia del hombre", "menos visitado", "agreste y salvaje" o "menos accesible".

[TÉCNICO DEDICADO A EDUCACIÓN AMBIENTAL] (refiriéndose al área de cumbres de la Sierra Cebollera) "Es más difícil andar por ahí, es una zona más abrupta, no van los visitantes, es menos accesible. Cuando se anda por ahí es diferente la sensación, es más asalvajado, menos intervenido. [...] Tiene un poquito de lo que yo considero que es la zona menos humanizada con una alta calidad ecológica."

En la mayoría de los casos estos lugares (básicamente paisajes boscosos y de alta montaña) coincidieron con los elegidos como de alta calidad estética. Los atributos en esta dimensión fueron asociados también con la ausencia de impacto antrópico, la variedad de elementos, la madurez de la vegetación o la presencia de elementos singulares, como vistas panorámicas o escénicas. Los términos usados para describir estos paisajes ilustran estas evaluaciones: "lejos de la civilización, "más natural", "bien conservado", "paisaje agreste y solitario", "tiene de todo", "hay gran variedad de árboles y colores" y "están los circos glaciares, que son muy emblemáticos".

La mayoría de los técnicos entrevistados (el 72\%) eligieron estos tipos de paisaje tanto en las categorías de alta calidad ecológica como en la estética y muchos de ellos refirieron que para ellos sus características eran apreciadas en ambos aspectos. Incluso varios, al comentar las 
características ecológicas de estos paisajes, entremezclaron de manera fortuita los términos estéticos.

[TÉCNICO DEDICADO A LA CONSULTORÍA AMBIENTAL PARA LA ADMINISTRACIÓN] "Yo pienso que la calidad ecológica y estética es un todo. Es evidentemente para mi que la calidad del paisaje, es lo que percibe una persona en el entorno que le rodea más inmediato y lejano, que para mí le proporciona un cierto placer, bienestar o

comodidad. Por tanto para mí tiene mucho de elementos naturales y poco artificiales, que destaquen poco o que estén muy integrados dentro del paisaje. Por ejemplo, aqui puedes ver la variedad de especies y de condiciones ecológicas, desde los encinares en los pisos basales, luego los robles marcescentes e inmediatamente los pinares. Eso también es visualmente interesante, el ver esa transición."

[TÉCNICO DEDICADO A CONSULTORÍA AMBIENTAL] "Pienso que los pinos de las cumbres de Cebollera son de alta calidad ecológica. Me refiero a los que son naturales, donde tienen los troncos retorcidos. Puedes ver que no están repoblados, que crecen en condiciones más ecológicas. Son distintos a los típicos pinares densos que hay en las zonas bajas."

[TÉCNICO DEDICADO A EDUCACIÓN AMBIENTAL] "Cuando caen un montón de pinos por una tormenta yo no considero que el paisaje esté degradado... bueno, es natural, los árboles siempre están cayendo, forma parte de la dinámica forestal."

[TÉCNICO DEDICADO A GESTIÓN AMBIENTAL] "En términos de ecología quizá para mí el elemento más significativo sean las canteras, me parecen una verdadera herida en el paisaje. Esta cantera de aquí (en Torrecilla), aunque no es muy visible, es como una especie de mácula en el territorio."

Cuando los entrevistados del grupo de los técnicos comentaron la influencia positiva del hombre en el entorno natural, esta se ligó al grado de integración en el entorno natural y su carácter tradicional. A la inversa, las actuaciones humanas como construcciones pobremente integradas en el paisaje natural (presas, urbanizaciones), la ganadería intensiva o las canteras fueron asociadas a la baja calidad del paisaje. El 70\% asoció estas actividades con un impacto humano patente que causaba un efecto artificial negativo en el paisaje, una perturbación de las dinámicas ecológicas, degradación de la vegetación y contaminación de los suelos. El $80 \%$ de los técnicos igualmente percibió efectos negativos en el paisaje como "el contraste de lo artificial en el paisaje natural", "la mala impresión que provoca un área degradada por el sobrepastoreo" o "la falta de integración con las prácticas y materiales tradicionales". A continuación se muestra una conversación que ilustra esta postura: 
[FOCUS GROUP ENTRE TÉCNICOS DE LA ADMINISTRACIÓN FORESTAL Y AMBIENTAL]

"Técnico1: El primer filtro sería el tema humano, el impacto de las infraestructuras por ejemplo, ese sería un poco el primer filtro. Que no hubiera, o que estuvieran integradas

Técnico2: Claro, que si hubiera que estuvieran integradas

Técnico3: Pero eso no es la intervención humana en el sentido de... porque a veces la intervención humana da paisajes muy bonitos

Técnico1: iSi,si, claro! iPero que estén integradas!

Técnico2: La Dehesa del rebollar, yo lo he cogido como paisaje y bueno también como ecológico.

Técnico4: jEl caso más claro, por ejemplo, El Rasillo (una urbanización de nueva construcción).

Técnico1: O la cantera de Nieva. Eso sería un poco la intervención humana no integrada. Porque la intervención integrada...un pueblo paisajisticamente puede ser muy bonito.

$[\ldots]$

Técnico1: Yo creo que todos valoramos el paisaje humanizado, ¿no?, tipo dehesas, praderías. Todo el paisaje aquí está humanizado, no hay nada que no esté tocado, ¿no?

Técnico4: yo los prados de la Pineda...es uno de los paisajes que yo he elegido, y eso es intervención humana todo.

Técnico3: Claro pero no es una alteración, sino que es algo tradicional, es un uso tradicional.

Técnico2: Pero se mantiene la naturalidad de alguna manera, claro.

Técnico1: O aunque no la mantenga, o la mantenga a medias, ¿no?

Técnico3: Claro, no la mantiene porque si no hubiera humanos habría arbolado, obviamente (Técnico1: iClaro!) Pero la calidad que transmite es positiva, ver un paisaje humanizado..."

Ambos grupos hicieron la misma selección de ciertos tipos de paisajes. Así, las áreas boscosas, los paisajes de cumbres o alta montaña y las riberas o lagunas fueron catalogadas por técnicos y población local como de alta calidad ecológica y estética (más del 70\% de las elecciones en ambas categorías). Ahora bien, en su evaluación manejaron diferentes consideraciones y destacaron distintas características físicas. 
Así, el grupo de la población local en general no consideró la naturalidad (entendida como la escasa presencia humana) como el atributo que determinaba la calidad del paisaje, de hecho muy frecuentemente eligieron los montes intervenidos y con aprovechamientos forestales como los de mayor calidad (75\% de las elecciones). Paralelamente, el carácter natural del paisaje fue escasamente destacado por este grupo (11\% de veces), únicamente fue mencionado en el caso de paisajes de alta montaña. De tal manera, se aprecia como la evaluación que lo locales hicieron de las cualidades ecológicas y estéticas del paisaje natural no se apoyó tanto en la percepción de una naturaleza intocada, como en una naturaleza sensata y cuidadosamente controlada ("bien mantenida", "más trabajada", "mantenida", "bien cuidada" o "limpia").

\section{[FOCUS GROUP CON GANADEROS Y MIEMBROS DE LA ADMINISTRACIÓN LOCAL]}

"Local1: La Pineda es lo que mejor está sin duda. Invierten más recursos de la venta de madera en la gestión forestal, lo han hecho así desde hace mucho tiempo [...] Está más equilibrado, más agradable y puedes pasear por allí.

Local2: Y notas enseguida el trabajo que le hacen, es muy agradecida ese terreno.

Local1: En realidad, no hay nada que esté mal, mal en la comarca.

Local2: No, no hay sitios que se hayan dejado, que estén totalmente abandonados.

Local1: Han desbrozado los caminos, han ampliado las áreas de pastoreo y ahora hay más pastaderos para el ganado... está mejor. "

La población local destacó clara e insistentemente la falta de mantenimiento del paisaje como el mayor problema que afectaba a sus cualidades estéticas y ecológicas. Las causas de esta condición del paisaje fueron asociadas a la regresión de la actividad ganadera, que estaba conduciendo a un proceso de dinámica más natural del paisaje, proceso que fue percibido en clave negativa. La invasión del matorral en pastizales y bosques así como la reforestación espontánea fueron percibidas como las evidencias físicas de este proceso, que fue entendido como negativo por provocar la homogeneización del paisaje, la pérdida de espacios abiertos y un incremento del riesgo de incendios. Los paisajes que mostraban estas características fueron evaluados como "inestables" y fuera de control, y fueron además 
descritos como faltos de atractivo ("desordenados, "sucios", "abandonados", "degradados" o simplemente "feos").

[POBLACIÓN LOCAL, MIEMBRO DE LA ADMINISTRACIÓN LOCAL] "Cuando no hay ganado se llena de matorral, los pastos se llenan de maleza, que no sirve para nada. Esa es la peor área que yo veo. No me gusta, prefiero los pastizales con algunos árboles dispersos, no los que están todos matorralizados."

Los técnicos, por su parte, no repararon tanto en este proceso y cuando fueron preguntados expresamente al respecto, mostraron opiniones más diversas y complejas. Algunos de ellos evaluaron negativamente la dinámica menos intervenida por la ganadería, argumentando que el paisaje perdía la riqueza del mosaico de coberturas y la variedad visual, dando como resultado una simplificación del paisaje y una pérdida de algunos hábitats escasos y valiosos. Otros, consideraron que simplemente se trataba de un cambio que producía diferentes cualidades en el paisaje. De hecho, muchos de estos participantes valoraron paisajes muy antropizados, como las dehesas, los pueblos o los praderías. Otros, finalmente, determinaron que la calidad ecológica del área provenía precisamente de la reducción de la intervención humana.

\section{V.4.2. Actividades y percepción del paisaje gestionado}

\section{Ganadería}

Prácticamente ningún participante del grupo de la población local consideró que la actividad ganadera tuviera efectos negativos en el paisaje. Al contrario, el $88 \%$ de ellos definieron esta actividad, directa o indirectamente, como una forma fundamental de gestión del paisaje, para controlar el proceso de matorralización y avance del bosque, para acondicionar las masas forestales (desbroce, bajo riesgo de incendio) y para que el paisaje se mostrara mejor cuidado ("limpio", "que no parezca feo y abandonado porque no se ha desbrozado el matorral"). Estas percepciones y consideraciones reflejan cómo la población local asocia las cualidades que busca en el paisaje con la actividad de su propio grupo social. 
[POBLACIÓN LOCAL, MIEMBRO DE LA ADMINISTRACIÓN LOCAL] "Yo creo que la ganadería en estas zonas es la que mantiene el monte. Es que ha sido siempre. Además, cuando ha habido ganadería es cuando el monte ha estado más limpio, cuando se deja la ganadería es cuando el monte se llena de broza. En Torrecilla hay una zona que es la del Serradero que es donde está más la ganadería que hay, y es donde está más limpio y se ve mejor."

Los técnicos, por su parte, reconocieron los efectos positivos de la actividad ganadera sobre la dinámica ecológica del paisaje $y$, sobre todo, su importancia social. Ahora bien, destacaron frecuentemente que la actividad intensiva y concentrada en determinadas áreas provocaba impactos negativos del tipo ecológico y/o estético (39\% y $44 \%$ de los participantes respectivamente se refirieron a estos efectos). De tal manera, las críticas no se orientaron a la existencia de la actividad, sino a ciertas forma de llevarla a cabo: denotaron claramente que una gestión intensiva y poco dedicada por parte de los ganaderos derivaba en contaminación de las aguas, degradación del suelo y, finalmente, resultaba en una apariencia de degradación y descuido. Este grupo asoció un adecuado estado ecológico y estético del paisaje con una ganadería gestionada de forma extensiva, con un trabajo esmerado por parte de los ganaderos.

[TÉCNICO DEDICADO A EDUCACIÓN AMBIENTAL] "Una zona afectada por el pisoteo pues la gente lo percibe como tal y yo también. Sobre todo porque se concentra el ganado, bueno están justo al lado de granjas, el ganado no lo mueven como yo creo que debería hacerse en la zona, que es liberando un poco la zona y abriendo el ganado, dejándolo más alejado para que paste. Sino que se concentra en la entrada de la granja en este caso, San Andrés, es el sendero, es una pista que es un sendero, con lo cual más de medio metro de barro no te lo quita nadie, no puedes pasar. No es que la vaca en sí se coma el pasto, es el permanente...están siempre permanentemente en la misma zona. iAunque sean pocas! Aunque tengas 3 vacas pero si las tienes en la misma zona pues al final acaban con esa zona."

\section{Gestión forestal}

El aprovechamiento forestal fue considerado como una actividad necesaria, sin impactos ecológicos inaceptables e incluso, en ocasiones, beneficiosa para las dinámicas ecológicas del monte. Prácticamente todos los participantes argumentaron que en la zona se aplicaba un aprovechamiento sensible, poco intensivo, de carácter conservador y con una repercusión económica en los pueblos de la comarca muy valorada. De manera paralela al caso de la ganadería, los efectos ecológicos negativos del aprovechamiento forestal no fueron 
asociados a la actividad en sí, sino a la manera de llevarla a cabo: el uso de máquinas procesadoras-cosechadoras fue evaluado muy negativamente por su impacto sobre el suelo forestal y los daños que provocaba a la masa remanente.

En esta misma línea, los impactos en el plano estético fueron incluso más duramente criticados. Así, este tipo de aprovechamiento fue considerado como un sistema poco respetuoso, que resultaba en un "aspecto desordenado y sucio del monte", fundamentalmente debido a la presencia de troncos y ramas cortados que permanecen esparcidos en el monte. El efecto artificial de las pistas forestales también provocó una evaluación negativa ("parece como si alguien le hubiera pasado un peine al monte").

[POBLACIÓN LOCAL, GANADERA] "El único sitio que ves mal es en el que han estado cortando madera con máquinas. es que dejan todas la ramas y las copas cortadas tiradas. Lo ves que está destrozado y como descuidado. A mí me parece bien que corten madera, pero deberían llevarse el árbol entero. Conservan el pinar pero icómo dejan el suelo! Los árboles pueden caerse porque se mueren o porque los tira el viento, y ves los troncos caídos en el monte de vez en cuando, pero los restos que dejan cuando cortan eso es peor, es más feo."

[TÉCNICO DEDICADO A EDUCACIÓN AMBIENTAL] "Por ejemplo, un bosque con una tormenta en la que se han caído muchos pinos, yo no la entiendo como de escaso valor paisajístico, bueno, es una circunstancia, se han caído, siempre se caen, forma parte de la dinámica del bosque. [refiriéndose al aprovechamiento con procesadora] Detraen calidad de paisaje porque no se tritura lo que se queda, da un paisaje no más claro, sino mucho más sucio, de ramas, troncos que no valen y todo eso queda tirado. Digamos que visualmente no es atractivo."

Muchos de los entrevistados opinaron que los métodos tradicionales de aprovechamiento forestal, menos mecanizados (usando motosierra, skidder y saca de la madera con mulas), era una alternativa más respetuosa con el medio y una manera de que la intervención no se hiciera tan notoria y así minimizar sus efectos estéticos negativos.

[POBLACIÓN LOCAL, MIEMBRO DE LA ADMINISTRACIÓN LOCAL] "Cuando usan las procesadoras, arrasan el monte; cuando usan las maquinitas (refiriéndose a skidders), ieso es maravillosos! [...] Y mejor sería si no dejaran madera en el monte para que no se pudra y cause problemas de sanidad. Y si usaran caballos para sacar la madera, eso sería aún mejor y más bonito."

[TÉCNICO DEDICADO A GESTIÓN FORESTAL] "Para mí el impacto no es la corta en sí, se corta siempre por aclareo sucesivo, no pasamos del 100 al 0 . Es la forma de actuar. Es decir, si por ejemplo se actúa haciendo muchas calles con procesadora, las rodadas, las heridas en el desembosque... Pero para mi el peor es la artificialidad por ejemplo de las calles cada $28 \mathrm{~m}$, para mi es lo que estéticamente, paisajísticamente 
me parece más negativo. Luego, que haya restos de madera...bueno, no me gusta pero me parece que al final se pudre y ya está. Las rodadas no son buenas pero al final se terminan disimulando. [..] Pero si usas skidder y mulas, es que poco después ni te das cuenta de que se ha cortado madera alli."

[TÉCNICO, AGENTE FORESTAL] "La entresaca no me parece mal, sobre todo es la infraestructura, cuando no puede entrar la cosechadora, que no entre."

Los participantes, de ambos grupos, fueron en general muy críticos con lo que consideraron un trabajo poco cuidadoso por parte de las empresas maderistas adjudicatarias de los aprovechamientos. Estas fueron consideradas como agentes externos al territorio, con responsables poco involucrados en la conservación del paisaje y operarios poco interesados en la ejecución cuidadosa de las labores que llevan a cabo en el monte.

\author{
[FOCUS GROUP ENTRE TÉCNICOS DE LA ADMINISTRACIÓN FORESTAL Y AMBIENTAL]
}

Tecnico4: La cuestión es esa, si es un parque natural o parque nacional que el valor paisajístico y turístico tal... pues a lo mejor hay que suprimir los aprovechamientos. [...] pero ir a ver un aprovechamiento con procesadora recién acabado es que es desolador. Incluso a nosotros nos parece... Yo he tenido un aprovechamiento que después ha venido un vendaval y me ha tirado la mitad de los árboles que quedaban y entonces eso ya...

Tecnico2: y unido a lo que había dejado, que ya lo había dejado mal el maderista...

$[\ldots]$

Tecnico4: Mira los desbroce esos rectilineos que hacen (refiriéndose a las empresas contratadas), que nos ha costado tanto cambiar, y todavía siguen. Tienes un paisaje poblado de matorral, y entonces cogen y te desbrozan una zona. iPues es dificilísimo que no te los hagan cuadrados, o rectangulares, con 4 esquinas perfectas!.

Tecnico2: Y el problema no es tanto que nosotros lo entendamos, sino es que ellos...

Tecnico4: Luego el tío te lo hace, y una vez que se ha llevado la máquina pues dices... ibah!

Tecnico2: Es que tienden a la regularidad, ahí recto, y a los maquinistas les cuesta mucho buscar la naturalidad a base de la orografía.

[POBLACIÓN LOCAL, DEDICADO AL TURISMO RURAL] "Cortar árboles es beneficioso si se hace con cuidado, pero la saca arruina el monte. Bueno... al final lo que cuenta es el beneficio económico del que lo hace. Cuanto más rápido trabajen, más ganan y eso es mejor para ellos. Los maderistas no piensan ecológicamente, ellos llegan, sacan la madera y se van, y ya está. Pero las máquinas destrozan el bosque, los caminos. Te dicen que lo van a arreglar, pero tienes que controlar su trabajo." 


\section{V.5. DISCUSIÓN}

\section{V.5.1. Distinta interpretación de los significados y atributos del paisaje}

Los resultados del estudio mostraron las diferencias que existían entre ambos grupos, técnicos y población local, en el modo de percibir e interpretar los rasgos ecológicos y la estética del paisaje, diferencias reflejadas tanto en los lugares seleccionados, como en los atributos descritos y los términos usados en dicha descripción.

Dandy, N., y Van Der Wal, R.

(2011). Shared appreciation of woodland landscapes by land management professionals and

De tal forma, los técnicos tendieron a privilegiar la naturalidad y el mínimo impacto humano en su valoración del paisaje, mientras que lay people: An exploration through field-based interactive los locales prefirieron las características de un paisaje mantenido activamente por el hombre, utilizando frecuentemente el término "limpio" y expresando su preocupación por los efectos de una dinámica más natural derivada del proceso de abandono del uso local del medio. Este parece ser el resultado derivado de una manera distinta de asignar significado al paisaje, de entender el lugar del hombre en el mismo, de definir sus funciones, usos y el tipo de experiencia que se busca y, consecuentemente, los atributos que responden a estas expectativas.

photo-elicitation. Landscape and Urban Planning, 102(1), 43-53.

Natori, Y. y Chenoweth, R. (2008).

Differences in rural landscape perceptions and preferences between farmers and naturalists. Journal of Environmental Psychology, 28, 250-267.

Rogge, E., Nevens, F., y Gulinck, H. (2007). Perception of rural landscapes in Flanders: Looking beyond aesthetics. Landscape and Urban Planning, 82, 159174.

En estudios precedentes se han encontrado actitudes similares. Así, en distintos contextos paisajísticos y en comparación con otros grupos, se ha constatado una clara preferencia por la naturalidad entre los profesionales dedicados al medio natural y a la conservación (Dandy y Van Der Wal, 2011; Natori y Chenoweth, 2008; Rogge, Nevens, y Gulinck, 2007; van den Berg, Vlek, y Coeterier, 1998). Gómez-Limón y de Lucío Fernández (1999) encontraron esta pauta en su estudio sobre las preferencias ante fotografías que mostraban la evolución de una dehesa de la Sierra de Guadarrama. Los autores explican la diferencia encontrada entre los gestores y los ganaderos en la distinta concepción del modelo de intervención en el paisaje (paisaje ideal como producto de la naturaleza o de la cultura van den Berg, A. E., Vlek, C. A. J., y Coeterier, J. F. (1998). Group differences in the aesthetic evaluation of nature

development plans: A multilevel approach. Journal of Environmental Psychology, 18, 141-157.

Gómez-Limón, J. y de Lucio Fernández, J. V. (1999). Changes in use and landscape preferences on the agriculturallivestock landscapes of the central Iberian Peninsula (Madrid, Spain). Landscape and tradicional) y en la identificación por parte de los gestores del paisaje 
Carlson, A. (1977). On the possibility of quantifying scenic beauty. Landscape Planning, 4, 131-172.

Hull, R. B., Robertson, D. P., y Kendra, A. (2001). Public understandings of nature: A case study of local knowledge about 'natural' forest conditions. Society \& Natural Resources, 14(4), 325-340.

Ruiz, J. P. y Gonzalez-Bernaldez, F. (1983). Landscape perception by its traditional users: The ideal landscape of Madrid livestock raisers. Landscape Plannning, 9(3-4), 279-297.

Höchtl, F., Lehringer, S., y Konold, W. (2005). "Wilderness": What it

means when it becomes a reality - A case study fromthe southwestern Alps. Landscape and Urban Planning, 70(1-2), 85-

Hunziker, M. (1995). The spontaneous reafforestation in abandoned agricultural lands:

Perception and aesthetic assessment by locals and tourists. Landscape and Urban Planning, 31, 399-410.

Pereira, E., Queiroz, C., Pereira, H. M., y Vicente, L. (2005). Ecosystem services and human well-being: A participatory study in a mountain community in Portugal. Ecology and Society, 10(2), 14-36.

Ruskule, A., Nikodemus, O. Kasparinskis, R., Bell, S., y Urtane,

I. (2013). The perception of abandoned farmland by local people and experts: Landscape value and perspectives on future land use. Landscape and Urban Planning, 115, 49-61.

Soliva, R., Ronningen, K., Bella, I., Bezak, P., Cooper, T., Flo, B. E., Marty, P., y Potter, C. (2008). Envisioning upland futures: Stakeholder responses to scenarios for Europe's mountain landscapes. Journal of Rural Studies, 24(1), 56-71. boscoso como el paisaje en su mejor estado natural y de conservación. También se ha argumentado que el mayor conocimiento científico y comprensión del funcionamiento del medio natural induce una mayor sensibilidad hacia las cualidades de este tipo de paisaje y contribuye a una predilección por cómo se muestra (Carlson, 1977).

Por su parte, los entrevistados que pertenecían al grupo de la población local mostraron mayor preferencia por lo que Hull, Robertson y Kendra (2001) denominaron de forma muy ilustrativa la "Naturalidad cultural o culturizada" ("Cultured Naturalness"), es decir, aquellos paisajes que son predominantemente naturales pero que contienen signos que expresan la identidad local y revelan la presencia de gente que habita el paisaje y vive de la tierra. En esta misma línea, Ruiz y González-Bernáldez (1983)identificaron que, para los ganaderos tradicionales de la sierra de Guadarrama, el significado de palabras como "bonito" se encontraba siempre relacionado con características funcionales del paisaje, esto es, con signos de buena o mala utilización del medio, y por tanto siempre implicaba "mejor gestionado". Por otro lado, son varios los estudios que han comprobado que gran parte de los pobladores del paisaje creen que la biodiversidad o sostenibilidad es mayor en los paisajes más culturales en comparación con los más naturales (Höchtl, Lehringer, y Konold, 2005; Hunziker, 1995; Pereira, Queiroz, Pereira, y Vicente, 2005; Ruskule, Nikodemus, Kasparinskis, Bell, y Urtane, 2013; Soliva et al., 2008; van den Berg et al., 1998).

Este distinto patrón de valoración del paisaje se hizo sobre todo patente al tratar la percepción del proceso de "asilvestramiento" o dinámica más natural del paisaje. Estudios radicados en paisajes con características similares, es decir, área rurales de montaña en las que existe un declive poblacional, encontraron también este fenómeno, esto es, la población local tiende a valorar negativamente las consecuencias ecológicas y estéticas del proceso de abandono y evolución del paisaje hacia un estado más natural o agreste (Höchtl et al., 2005; Hunziker, 1995; Pereira et al., 2005; Ruskule et al., 2013; Soliva et al., 2008). Estas percepciones se relacionan con sentimientos de pérdida de significación cultural e identidad local que provoca la progresiva menor presencia de la comunidad local en el paisaje. Los resultados de este estudio muestran además que los técnicos no 
repararon tanto en este proceso, hecho en consonancia con la mayor atención que dedicaron a las características puramente naturales. Mostraron no obstante una diversidad de opiniones cuando reflexionaron sobre el impacto ecológico y estético del proceso, diversidad que refleja una base común de valoración del paisaje más natural pero una distinta valoración del papel del hombre como modificador del paisaje.

\section{V.5.2. La percepción del cuidado como factor determinante de la evaluación del paisaje gestionado/intervenido}

El cuidado puede definirse como la atención esmerada y diligente que se dedica a realizar un cometido de forma adecuada (Solicitud y atención para hacer bien algo, según la definición de la Real Academia de la Lengua Española). Los resultados muestran que la percepción de esta característica, el cuidado, estuvo muy presente en la evaluación que los entrevistados hicieron de los efectos de la gestión a la que estaba sujeto el paisaje. La Teoría de la Estética del Cuidado ("Theory of the Aesthetic of Care") de Nassauer establece que se tiende a percibir como paisajes valiosos y bellos aquellos que muestran estar bien cuidados, y que esta percepción contribuye a identificarlos además como paisajes en armonía con la naturaleza (Nassauer, 1995b). De hecho, la percepción del cuidado se ha perfilado como uno de los factores clave en la valoración estética del paisaje agrícola y urbano, condición que puede tener importancia también en los paisajes más naturales (Nassauer, 1992, 2011). Esto es así, puesto que el paisaje más natural frecuentemente exhibe signos de intervención humana que actúan como indicadores de las condiciones en las que se gestiona ese paisaje y no tanto de las condiciones ecológicas del ecosistema.

Nassauer, J. I. (1995b).

Messy Ecosystems, Orderly Frames. Landscape Journal, 14(2), 161-170.

Nassauer, J. I. (1992).

The appearance of ecological systems as a matter of policy. Landscape Ecology, 6(4), 239250 .

Nassauer, J. I. (2011) Care and stewardship: From home to planet. Landscape and Urban Planning, 100, 321-323.

Ahora bien, el cuidado, que se revela como una idea compartida en la búsqueda de la calidad estética del paisaje, puede ser identificada en distintos elementos y percibida de formas variadas (Nassauer, 2011). A este respecto, los resultados de este estudio constatan que todos los participantes valoraron el paisaje con apariencia de estar bien 
cuidado y que interpretaron de forma más o menos clara esa imagen como un signo de buena gestión ecológica. La divergencia no surgió entonces del objetivo de una gestión adecuada y respetuosa, sino en algunos de los rasgos físicos que a su juicio evidenciaban ese estado. Estos rasgos se encontraron fundamentalmente con los resultados de dos de las actividades con mayor influencia en el paisaje: la ganadería y la gestión forestal.

De tal manera, la población local identificó las condiciones de un paisaje bien cuidado, atractivo y con un adecuado estado ecológico con los efectos de la actividad ganadera que ejercía su propio grupo social (por ejemplo, el control de la matorralización del monte por la acción del ganado). No destacaron sin embargo rasgos que para los técnicos fueron signo evidente de una gestión ganadera inadecuada por poco esmerada. Estos percibieron como ecológica y estéticamente impactantes los efectos visibles de una ganadería más intensiva, dado que relacionaron los beneficios de la ganadería sobre el paisaje con la actividad extensiva más tradicional, entendida como más respetuosa y que exige al ganadero más dedicación. Estos resultados indican que, si bien ambos grupos consideraron como potencialmente provechosa la actividad ganadera, tanto en el plano estético como en el ecológico, difirieron en la manera en que esta debe llevarse a cabo para hacer efectivos esos beneficios.

En relación a la gestión forestal, hubo más coincidencia en las evaluaciones y el reconocimiento de los rasgos visibles asociados. Así, ambos grupos percibieron como un problema estético relevante la apariencia caótica y "sucia" de las masas sujetas a aprovechamientos forestales, así como la proliferación de caminos forestales. En este caso, la evaluación que se hizo del cuidado con que se realizaban los aprovechamientos en el monte se vinculó claramente con el comportamiento del operador a cargo de esas intervenciones. De tal manera, las consecuencia negativas en el plano ecológico y estético fueron atribuidas al método de aprovechamiento mecanizado usando procesadoras-cosechadoras forestales, y la responsabilidad fundamental se atribuyó al proceder de las empresas concesionarias del aprovechamiento. Este rechazo a la apariencia desordenada y poco natural de las operaciones forestales, así como a las evidencias de daños que provoca, ha sido reconocido por la investigación como 
uno de los que más condicionan la evaluación en términos de Gobster, P. H. (1999). conveniencia que se hace de la gestión forestal (Gobster, 1999). En An ecological aesthetic for forest landscape management. este sentido, la "Administración o Gobernanza Visible" (Theory of Visible Stewardship) de Sheppard (2001) enfatiza que la apariencia del monte tras los trabajos de aprovechamiento de madera hace que estos se presenten como actuaciones precipitadas, drásticas y con interés únicamente extractivo, es decir, no muestran las evidencias de una actividad cuidadosa, protectora y responsable por la que pueda ser más valorada. Dicha teoría establece por tanto que para que las actividades forestales puedan ser percibidas inequívocamente como buenas prácticas en el monte han de mostrar de una forma más obvia Sheppard. (2001). Beyond Visual Resource Management : Emerging Theories of an Ecological Aesthetic and Visible Stewardship. En S. R. J. Sheppard y H. W. Harshaw (Eds.), Forests and Landscapes: Linking Ecology, Sustainablility, and Aesthetics (pp. 149-173). Nueva York: CABI el compromiso de los responsables por la mejora del entorno, es decir, proyectar un respeto más patente por el medio natural y el lugar en el que se trabaja. 


\section{CAPÍTULO PROPUESTA METODOLÓGICA PARA UNA PLANIFICACIÓN DEL PAISAJE QUE INCORPORE LA INTERPRETACIÓN ESTÉTICA DE LA COMPONENTE ECOLÓGICA}


CAPÍTULO VI.- PROPUESTA METODOLÓGICA PARA UNA PLANIFICACIÓN DEL PAISAJE QUE INCORPORE LA INTERPRETACIÓN ESTÉTICA DE LA COMPONENTE ECOLÓGICA.

V.5.1.- Encuadre metodológico 185

V.5.2.- Evaluación del paisaje en términos visuales y de apreciación escénica 186

V.5.3.- Evaluación de la interpretación de los valores ecológico-estéticos del paisaje 188

VI.6.- IDENTIFICACIÓN DE ÁMBITOS DE ACTUACIÓN ECOLÓGICO-ESTÉTICA Y DELINEACIÓN DE ESTRATEGIAS DE ACTUACIÓN EN EL PAISAJE 


\section{CAPÍTULO \\ PROPUESTA METODOLÓGICA PARA UNA \\ PLANIFICACIÓN DEL PAISAJE QUE \\ INCORPORE LA INTERPRETACIÓN \\ ESTÉTICA DE LA COMPONENTE \\ ECOLÓGICA}

\section{VI.1. INTRODUCCIÓN Y OBJETIVOS}

En el presente capítulo se propone una aproximación a la práctica de la planificación del paisaje basada en la estética ecológica, que amplíe los factores perceptivos considerados y que tome en cuenta la manera en la que el fenómeno social de la apreciación estética del paisaje puede afectar a su valoración en términos ecológicos y finalmente a sus condiciones y funcionamiento.

La estética ecológica enfoca el análisis de los valores ecológicos y estéticos entendiéndolos como factores que se explican el uno al otro y se condicionan. No evalúa el valor estético de la componente ecológica, sino el condicionamiento en la valoración de lo ecológico que viene derivado de la estética. Requiere pues de metodologías que integren de manera efectiva en el proceso de planificación la forma en que lo ecológico se muestra en el paisaje, la atención que provoca, las reacciones estéticas que genera y como estas inciden en la propia valoración ecológica.

La escala de la propuesta de análisis es la de planificación del paisaje, por lo que su objeto es llegar a una evaluación que sirva como marco de referencia para actuaciones de gestión y diseño del paisaje, actuaciones que se pueden concretar en una fase posterior, pero que necesitan de la contextualización que ofrece la planificación territorial para ser identificadas y orientadas. 


\section{VI.2. MARCO METODOLÓGICO}

Se propone una metodología de evaluación del paisaje que integre la consideración de cómo la interpretación estética de la dimensión ecológica del paisaje puede reforzar o, al contrario, debilitar, su valor ecológico. La perspectiva de análisis se funda pues sobre la base de las relaciones de sinergia y conflicto que se establecen entre ambas dimensiones. Esto es, se evalúa cómo lo percibido se alinea o no con la valoración ecológica y actúa o puede llegar a actuar como un factor que consolide la conservación de dichos valores. O presentado de manera inversa, se busca resolver la discordancia de lo ecológico y lo percibido, que puede debilitar su valoración y, en último término, su conservación.

Esta perspectiva de tratamiento del paisaje se fundamenta en el fenómeno denominado como "Sostenibilidad Cultural" (Nassauer, 1997, ver Capítulo III.4.6.), que manifiesta que la permanencia de los paisajes saludables depende en gran medida de la atención que reciban por parte del hombre. Así, los paisajes con buenas condiciones ecológicas que adicionalmente disfruten de la aprobación social, tienen más probabilidad de recibir un tratamiento apropiado y sostenido en el tiempo. A la inversa, paisajes cuya valoración social no se encuentre alineada con su calidad ecológica pueden llegar a estar en riesgo. Entre los motivos que contribuyen a dicha consideración social se encuentra de forma destacada la apreciación estética, factor que transmite de manera poderosa el valor ecológico del paisaje (ver Capítulo III.4.).

El procedimiento general de la metodología (Figura 63) se funda en la evaluación, en primer lugar, de la calidad ecológica en el territorio. Dicha evaluación puede atender al todo o un aspectos de dicha calidad, para lo cual habrá que seleccionar un modelo de evaluación específico. Una vez establecido dicho valor ecológico base, se analiza el sentido y grado con el que la apreciación estética de la componente ecológica refuerza o debilita dicho valor. Este refuerzo por medio de lo percibido puede darse a través de 2 dimensiones que recogen los distintos modos de apreciación estética del medio más natural: el ámbito de apreciación del paisaje que comporta la apreciación puramente visual y escénica del paisaje; y el ámbito que atiende al modo de entender lo que se percibe, en el que se incluye la manera y las razones por las que la población percibe las dinámicas ecológicas y las juzga en términos estéticos, más allá del sentimiento de belleza. 

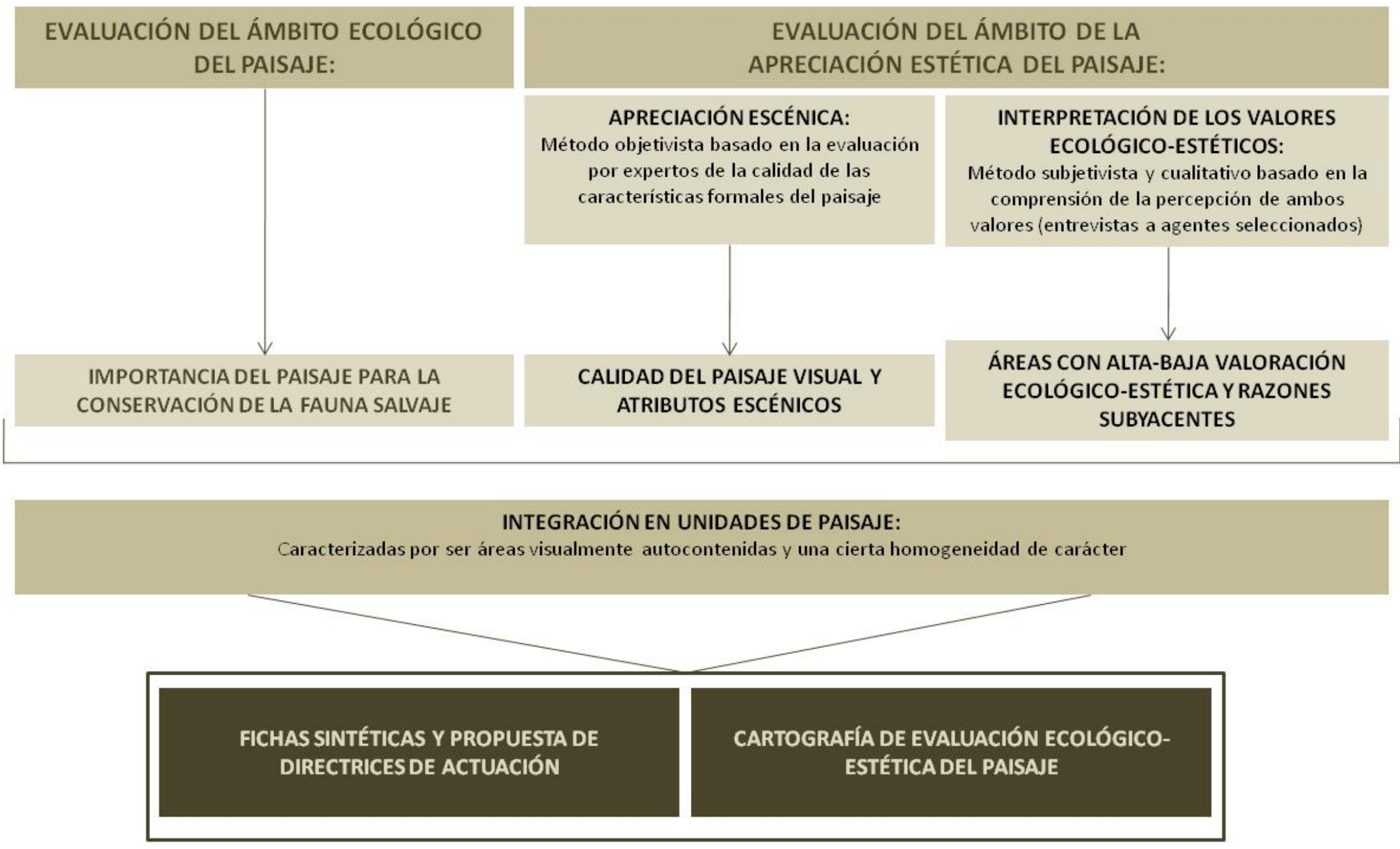

Figura 63. Esquema general de la metodología de planificación del paisaje que incorpora la estética ecológica. 


\section{VI.3. DEFINICIÓN DE UNIDADES DE PAISAJE}

En el proceso de planificación del paisaje resulta esencial que la definición de actuaciones sea referenciada en una unidad de actuación operativa. A este respecto, las unidades de paisaje definidas según la metodología expuesta en Aramburu y Escribano (2014) resulta ser una unidad de referencia muy adecuada. Las unidades así definidas contienen un espacio visual propio y un comportamiento más o menos homogéneo frente a las modificaciones. Además, al estar definidas a una escala territorial (1:50.000) presentan una superficie y nivel de detalle muy adecuados para la propuesta de objetivos planificadores.

La unidad de paisaje determinada por medio de esta metodología es una porción de territorio caracterizada por ser una zona visualmente autocontenida y por poseer una combinación propia de geología, relieve, naturaleza y forma de los materiales geológicos de superficie, las masas de agua y los usos del suelo. El primer criterio para delimitarlas es visual: se definen los cerramientos visuales de tal forma que el observador abarque con su campo de visión y desde distintos puntos de observación la mayor parte de esa porción de territorio y no la del territorio circundante (posee una cierta independencia y coherencia visual interna). El segundo criterio, que agrega o desagrega las unidades visuales, remite a la homogeneidad en el carácter general de la unidad, en cuyo caso el resultado puede coincidir bien con un relieve homogéneo, misma vegetación y usos del suelo o elementos antrópicos, bien con la combinación de dos o más de estos elementos.

El procedimiento esquemático seguido para definir las unidades de paisaje se refleja en la Figura 64.

Aramburu, M. P., y Escribano, R. (Eds.) (2014). Guía para la elaboración de estudios del medio físico. Contenido y metodología (4a ed.). Madrid: Fundación Conde del Valle de Salazar; Ministerio de Agricultura, Alimentación y Medio Ambiente. 


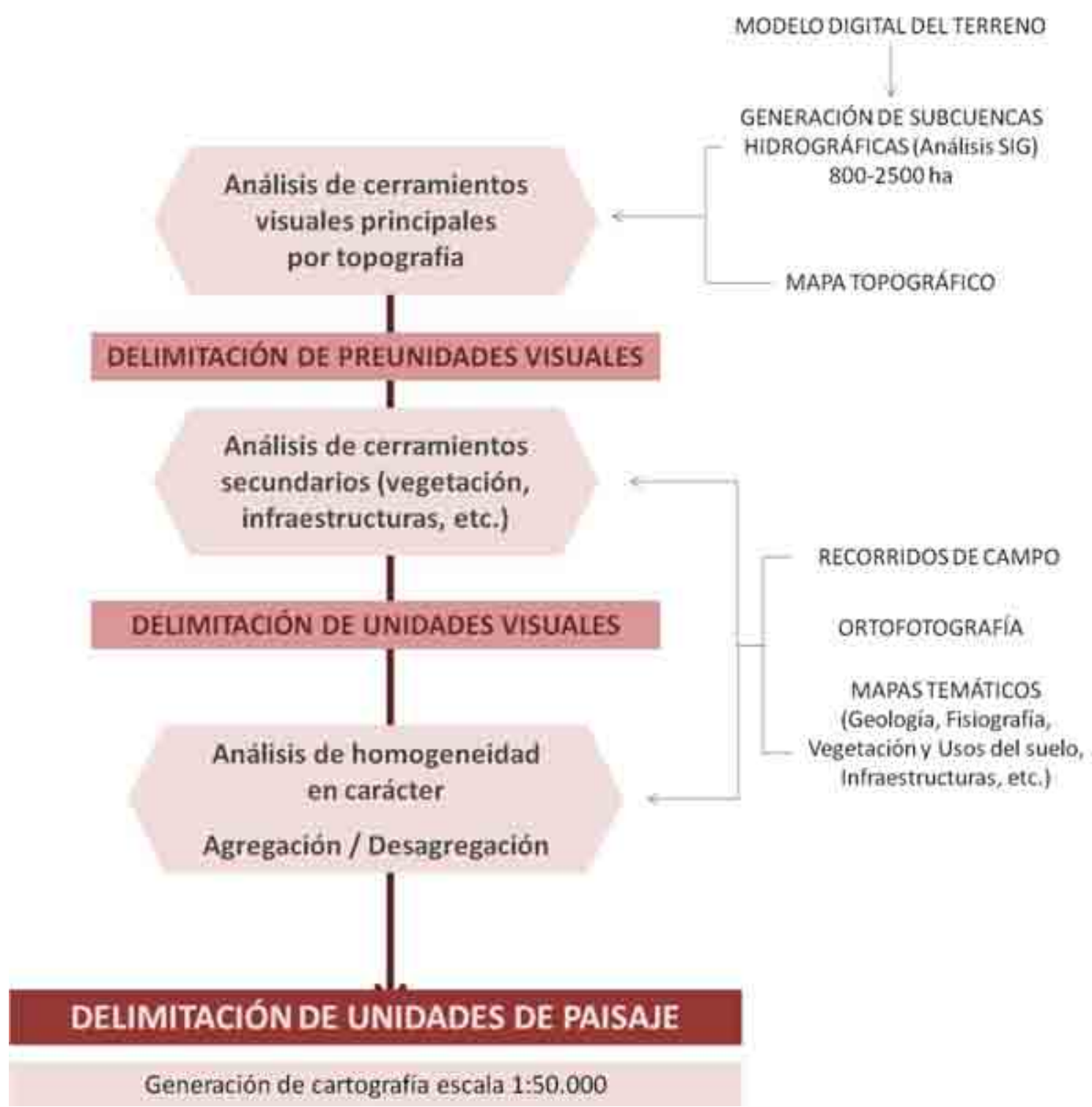

Figura 64. Esquema general del procedimiento de definición de unidades de paisaje según la metodología expuesta en Aramburu y Escribano (2014). 


\section{VI.4. EVALUACIÓN DEL ÁMBITO ECOLÓGICO}

\section{VI.4.1. Encuadre metodológico}

La planificación ecológica busca servirse de la información biofísica y sociocultural para la toma de decisiones respecto a los usos del suelo y prácticas de gestión, de manera que se alcance un uso del territorio que acomode las necesidades humanas (Steiner y Brooks, 1981). Dentro de este marco, la evaluación ecológica puede realizarse pues desde distintos puntos de vista y tomando en cuenta un conjunto definido de factores, tanto bióticos, como abióticos y/o culturales, siempre relacionados con los objetivos que se quieran alcanzar (Ndubisi, 2002).

La perspectiva que se adopta en la metodología propuesta es la de la planificación para la conservación de la biodiversidad, a través de la identificación de la importancia de los elementos del territorio como recurso para la conservación de las poblaciones de fauna. Es decir, no se analiza el paisaje como ecosistema completo, sino como hábitat, concentrando los esfuerzos en la planificación para la correcta gestión de usos del suelo que sostienen las poblaciones de fauna (Sanderson, Redford, Vedder, Coppolillo, y Ward, 2002). La ecología del paisaje ofrece una perspectiva y herramientas útiles a este propósito, pues posibilita tener en cuenta tanto la estructura de los hábitats, como el paisaje que rodea al hábitat a distintas escalas hábitat (Diaz y Apostol, 1992; Farina, 2006; Forman y Godron, 1986; Naveh y Lieberman, 1994; Sanderson et al., 2002; Turner, 1989). El paisaje puede definirse como "una superficie de terreno homogénea, compuesta por un conjunto de ecosistemas en interacción que se repiten de forma similar en ella" (Forman y Godron, 1986). Así, desde el enfoque de esta disciplina, por encima de su división en componentes, el paisaje es la relación entre ellos a través de su estructura espacial. Es esta la dimensión que aporta el interés al análisis: la consideración de la distribución espacial, es decir, conocer cómo los elementos se encuentra situados unos respecto de otros e interaccionan en consecuencia a lo largo de una cierta extensión de territorio, posibilita
Steiner, F. y Brooks, K. (1981) Ecological planning: A review. Environmental Management, 5(6), 495-505.

Ndubisi, F., 2002.

Ecological planning: a Historical and Comparative Synthesis. Baltimore, MD: John Hopkins University Press.

Sanderson, E. W., Redford, K. H. Vedder, A., Coppolillo, P. B., y Ward, S. E. (2002). A conceptual model for conservation planning based on landscape species requirements. Landscape and Urban Planning, 58(1), 41-56.

Diaz, N. y Apostol, D. (1992). Forest Landscape Analysis and Design: a process for developing and implementing land management objectives for landscape patterns (R6 ECO-TP. 043-92). Pacific Northwest Region: U.S. Forest Service Research.

Farina, A. (2006).

Principles and Methods in Landscape Ecology: Towards a Science of the Landscape. Cambridge, UK: Chapman \& Hall. Forman, R. T. T. y Godron, M. (1986). Landscape Ecology. Nueva York, NY: John Wiley \& Sons. Turner, M. (1989). Landscape Ecology: The Effect of Pattern on Process. Annual Review of Ecology and Systematics, 2, 171-197.

Naveh, Z., y Lieberman, A. S. (1994). Landscape Ecology: Theory and Application (2a ed.). Nueva York, NY: Springer-Verlag. 
Irastorza, P. (2006). Integración de la ecología de paisaje en la planificación territorial. Aplicación a la Comunidad de Madrid (Tesis doctoral no publicada) E.T.S. Ingenieros de Montes Universidad Politécnica de Madrid, Madrid.

scribano, R. (1977) El análisis de la fauna en los modelos de Planificación (Tesis doctoral no publicada). E.T.S

Ingenieros de Montes Universidad Politécnica de Madrid, Madrid.

Steinitz, C. (1990) Toward a sustainable landscape with high visual preference and high ecological integrity: the loop road in Acadia National Park, U.S.A. Landscape and Urban Planning, 19(3), 213-250. entender el funcionamiento del paisaje en su conjunto, conjunto que posee propiedades que las partes no tienen (Irastorza, 2006).

Este enfoque metodológico no aborda pues la evaluación ecológica del paisaje desde un punto de vista amplio, integrando los numerosos procesos abióticos, bióticos y culturales que en realidad definen la compleja realidad ecológica del territorio. Sirve sin embargo para ilustrar la propuesta de incorporación del fenómeno social de la interpretación estética de la componente ecológica del paisaje a la planificación.

\section{VI.4.2. Descripción del método}

El método de evaluación de la importancia para la conservación de la fauna se basa en la identificación de grupos ecológicos de especies y aplicación e integración de los denominados Modelos de Idoneidad o aptitud de Hábitat (Habitat Suitability Approach), que determinan la capacidad potencial de acogida del paisaje en función de los requerimientos cualitativos y cuantitativo de las especies presentes (Escribano, 1977; Steinitz, 1990). En consecuencia, el modelo se basa en determinar la importancia de cada área del paisaje para proveer hábitat de calidad al mayor número de especies de fauna, incorporando principios de disponibilidad de hábitat y de ecología del paisaje en el proceso de planificación y toma de decisiones.

La Figura 65 muestra el esquema general del método seguido para la evaluación ecológica del paisaje. A continuación se detalla el procedimiento detallado. 


\section{FASE 1. INVENTARIO}

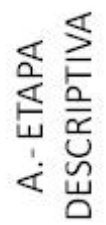

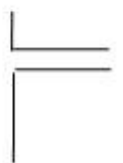

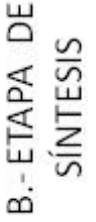

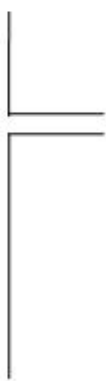

通

A.1.1 ESPECIES

Confección del listado lo más completo posible de especies de fauna salvaje presentesy su status de proteccion

A.1.3 SELECCIÓN DE ESPECIES CON SIGNIFICACIÓN AL NIVEL DE PAISAJE
A.1.2 ELEMENTOS BIOFÍSICOS DEL PAISAJE

Listado de cartografia de mayor detalle de elementos biofísicos presentes en el paisaje

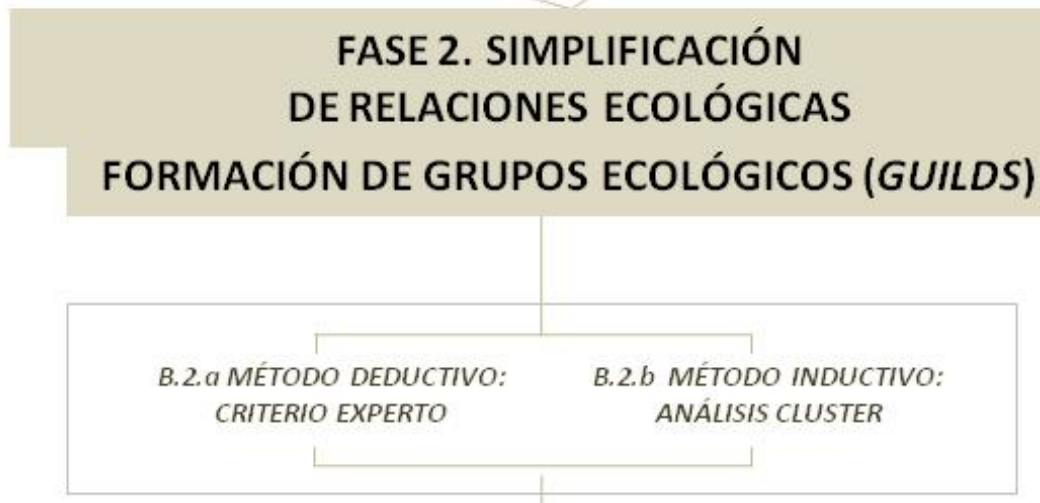

B.2.3 ENUNCIADO DE GRUPOS ECOLOGICOSY ESPECIES QUE LOS COMPONEN

FASE 3. APLICACIÓN DE MODELOS DE EVALUACIÓN DE IDONEIDAD DE HÁBITAT DE LOS GRUPOS ECOLÓGICOS (HSMGri)

Cartografia de los hábitats y evaluación de idoneidad de hábitat basado en principios del Habitat Suitability Model (HSM) y la Ecologia del Paisaje

FASE 4. INTEGRACIÓN Y EVALUACIÓN DE LA IMPORTANCIA DEL PAISAJE PARA LA CONSERVACIÓN DE LA FAUNA SALVAJE

Análisis ecológico

EVALUACIÓN DE LA IDONEIDAD DEL HÁBITAT DE CADA GRUPOECOLÓGICO

HSMGr1, HSMGr2,...,HSMGri
C.4.1. Análisis protección legal

EVALUACIÓN DEL NIVEL DE SENSIBILIDAD DE CADA GRUPOECOLÓGICO

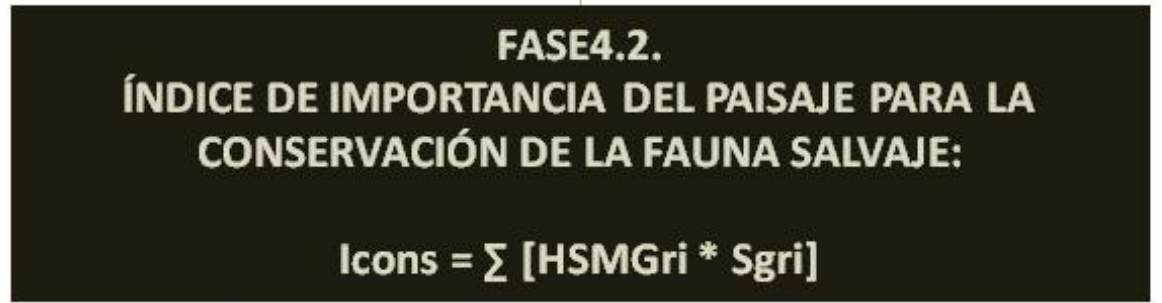

Figura 65. Esquema general de la evaluación ecológica del paisaje basada en la importancia para la conservación de la fauna. 


\section{ETAPA A.- DESCRIPTIVA - FASE 1: INVENTARIO}

La fase de inventario responde a la necesidad de conocer y registrar la información completa y de mayor detalle de la que se pueda disponer sobre especies presentes en la zona y características del medio, para poder posteriormente relacionarlas.

\section{A.1.1. - Inventario de especies de fauna presentes y status de protección}

En primer lugar, es necesario conocer el listado más completo posible de especies de fauna salvaje presentes en el lugar. Igualmente, se ha de contar con una descripción del estatus de protección de cada especie, a nivel regional, nacional e internacional, para poder evaluar la sensibilidad y el grado de amenaza de dichas especies.

Las fuentes de información han de ser fiables y completas, para lo que los inventarios y atlas oficiales suelen ser particularmente apropiados. Se pueden incluir además los resultados de estudios a nivel local cuando estos hayan sido confeccionados con suficiente rigor.

\section{A.1.2.- Inventario de los elementos biofísicos del paisaje}

Es necesario confeccionar el listado de información cartográfica que recoja la presencia y distribución de los elementos del medio biofísico con el mayor detalle posible, sin perder operatividad. El nivel de detalle que se pueda alcanzar en esta fase determinará en buena medida las estructuras asociadas que se puedan llegar a analizar, y por ende los requerimientos de las especies

Su confección se debe basar en cartografías e inventarios del medio ya elaborados, con una calidad y precisión suficiente y homogénea, y que sean fácilmente accesibles para que su tratamiento sea lo más eficaz y eficiente posible, tal y como demanda un análisis a escala de planificación.

\section{A.1.3.- Selección de especies con significación al nivel de paisaje}

De entre todas las especies presentes en el área de estudio se han de seleccionar aquellas con suficiente significación a la escala de análisis considerada y a los objetivos planteados. Es necesario, por tanto, 
seleccionar para el análisis posterior las especies con requerimientos dependientes de procesos o configuraciones a nivel de macrohábitat o paisaje (Bell y Apostol, 2008; Sanderson et al., 2002). Así, se excluirán del análisis las especies

- con dominio vital muy restringido

- con requerimientos con representación física limitada

- dependientes de estructuras muy escasas en el paisaje

- con presencia residual en el área

- difíciles de inventariar o tratar cartográficamente a escalas regionales/comarcales

Esto no quiere decir que se obvie su presencia o importancia, sino que su tratamiento requiere de otros métodos, un nivel de detalle de inventario del medio apropiado y escalas de trabajo diferentes, no abordables en el proceso de planificación considerado.

\section{B.- ETAPA DE SÍNTESIS - FASE 2: SIMPLIFICACIÓN DE RELACIONES ECOLÓGICAS: FORMACIÓN DE GRUPOS DE ESPECIES ("GUILDS")}

Frecuentemente, los gestores se encuentran con un número de especies de fauna inmanejable cuyos requerimientos individuales completos no es posible tener en cuenta en un proceso de evaluación y decisión. Un hipotético estudio completo trataría cada especie como un elemento individual, contrastando con el mayor detalle posible los requerimientos de cada una con los elementos biofísicos del paisaje. Sin embargo, esta estrategia no resulta operativa por la cantidad de información que requiere, que en muchas ocasiones no está disponible, ya que no se cuenta con un conocimiento suficiente de los requerimientos de muchas de las especies. Por otro lado, seleccionar algunas especies representativas -especies principales, especies indicadoras, especies clave, especies paraguas, especies bandera o especies social o económicamente importantes- (Bell y Apostol, 2008; Escribano, 1977) entraña el riesgo de obviar los requerimientos o el papel de algunas especies que pueden tener significación (Simberloff, 1998; Wiens, Hayward, Holthausen, y Wisdom, 2008). Una manera operativa de afrontar esta cuestión es la formación de "Grupos de especies" (Guilds, Root, 1967), entendidos como el conjunto de especies que presentan requerimientos de hábitats próximos y que usan los elementos del paisaje de forma similar. Esta estrategia aúna
Bell, S. y Apostol, D. (2008). Designing Sustainable Forest Landscapes. Londres, UK/ Nueva York, NY: Taylor \& Francis.

Sanderson, E. W., Redford, K. H., Vedder, A., Coppolillo, P. B., y Ward, S. E. (2002). A conceptual model for conservation planning based on landscape species requirements. Landscape and Urban Planning, 58(1), 41-56.

Escribano, R. (1977). El análisis de la fauna en los modelos de Planificación (Tesis doctoral no publicada). E.T.S. Ingenieros de Montes - Universidad

Politécnica de Madrid, Madrid.

Simberloff, D. (1998).

Flagships, umbrellas, and keystones: Is single-species management passé in the landscape era? Biological Conservation, 83(3), 247-257.

Wiens, J. A., Hayward, G. D., Holthausen, R. S., y Wisdom, M. J. (2008). Using surrogate species and groups for conservation planning and management. Bioscience, 58(3), 241-252. 
Bell, S. y Apostol, D. (2008). Designing Sustainable Forest Landscapes. Londres, UK/ Nueva York, NY: Taylor \& Francis.

Wiens, J. A., Hayward, G. D., Holthausen, R. S., y Wisdom, M. J. (2008). Using surrogate species and groups for conservation planning and management. Bioscience, 58(3), 241-252 la necesidad de simplificar la enorme complejidad encerrada en las relaciones especies-medio, sin perder la perspectiva global de funcionamiento del ecosistema (Bell y Apostol, 2008; Wiens et al., 2008).

La formación de estos grupos de especies se basa en el reconocimiento de que las comunidades ecológicas están compuestas por agrupamientos de organismos que potencialmente interaccionan fuertemente entre ellos pero sólo débilmente con los miembros de otros grupos. Esta asimetría de relaciones permite organizar la alta variedad presente en un número limitado de agrupaciones que aglutinen los requerimientos más afines, de tal manera que es posible tener en cuenta las necesidades de gran parte de las especies y relacionarlos con las estructuras de paisaje que requieren de forma operativa. Este proceso de formación de grupos puede llevarse a cabo mediante métodos deductivos (formulación previa de criterios de clasificación basados en el conocimiento experto o literatura consultada) o en métodos inductivos (análisis estadísticos de agrupación no supervisada: análisis clúster) (Wiens et al., 2008).

\section{B.2.a.- Método deductivo: clasificación por criterio experto}

Por medio de este método, el o los expertos definen unas normas de clasificación en distintos grupos, basadas en los requerimientos de las especies y las características del medio físico que se consideren relevantes o sean significativas para los objetivos planteados. Por ejemplo, se puede establecer el criterio inicial de matiz eurosiberiano o mediterráneo de la especies, posteriormente definir los grupos de especies típicas forestales, de espacios abiertos o ambientes antropizados, o por complejidad estructural o de estratos, establecer la distinción entre especies más propias de masas de coníferas o frondosas, etc.

La ventaja de este método reside en que es intuitivo y es posible mantener el control sobre el proceso de agrupación, que puede ser adaptado completamente a los intereses del análisis. Presentan además bastante lógica ecológica, los grupos son fácilmente interpretables y pueden componerse de forma rápida. Sin embargo, con una gran cantidad de especies puede resultar difícil realizar la clasificación $y$, en todo caso, está sujeta a un mayor grado de subjetividad. 


\section{B.2.b.- Método inductivo: análisis estadísticos de clasificación no supervisada (análisis clúster)}

El análisis clúster o de conglomerados es un método estadístico de clasificación automática de datos, que busca agrupar elementos basándose en la relación entre numerosas variables interdependientes. Para ello utiliza distintas estrategias que en general tratan de lograr la máxima homogeneidad en cada grupo y la mayor diferencia entre ellos. Así, reduce la redundancia en los datos creando grupos y evidenciando en mayor o menor grado la estructura de la relación entre los componentes (Vilà, Rubio, Berlanga, y Torrado, 2014). El principio que fundamenta el uso de la técnica clúster en ecología es que gran parte de la variabilidad de los datos ecológicos está frecuentemente concentrado en un número relativamente limitado de componentes, que usualmente están fuertemente relacionados con algún factor ecológico o ambiental (McGarigal, Cushman, y Stafford, 2000).

Se trata de una técnica exploratoria y descriptiva, útil como herramienta para desentrañar relaciones en sistemas ecológicos complejos y poder determinar grupos ecológicos de forma sistemática y ordenada, entendiendo esos grupos como conjuntos de especies con rasgos o funciones similares (Pla, Casanoves, y Di Rienzo, 2012). El resultado obtenido puede variar según la forma de aplicar el análisis (distancia seleccionada, método de agrupamiento). Sin embargo, esto no les resta validez, pues al ser una técnica exploratoria, se concibe más como una herramienta que asiste en el proceso de definición y esclarecimiento de relaciones entre datos. De hecho, la característica más importante que aporta robustez a la agrupación resultante es que pueda ser interpretada y presente un sentido conceptual sólido (McGarigal et al., 2000).

La ventaja de este método reside en que reduce la subjetividad ya que, adecuadamente aplicado, permite hacer aflorar grupos de forma inductiva, es decir desde los propios datos, con una participación mínima del operador. La subjetividad sin embargo no es inexistente, pues dependerá de las decisiones tomadas en 3 pasos fundamentales:

Vilà, R., Rubio, M. J., Berlanga, V., y Torrado, M. (2014).

Cómo aplicar un cluster jerárquico en SPSS. REIRE, 7(1).

McGarigal, K., Cushman, S., y Stafford, S. (2000). Multivariate Statistics for Wildlife and Ecology Research. Nueva York, NY: Springer.

Pla, L., Casanoves, F., y Di Rienzo, J. (2012).

Quantifying Functional Biodiversity. BMC Veterinary Research, 7, 98. 
- selección de los elementos (especies) a analizar

- selección y definición de las variables caracterizadoras

- selección de la medida de similitud utilizada para comparar casos, así como el algoritmo de agrupamiento de los conglomerados.

Además, las técnicas del tipo jerarquizados presentan una estructura

Wiens, J. A., Hayward, G. D., Holthausen, R. S., y Wisdom,

M. J. (2008) Using surrogate species and groups for conservation planning and management. Bioscience, 58(3), 241-252

Vilà, R., Rubio, M. J., Berlanga, V., y Torrado, M. (2014) Cómo aplicar un cluster jerárquico en SPSS. REIRE, 7(1). anidada de resultados que permite decidir qué nivel jerárquico es el más apropiado para establecer la clasificación, hecho muy útil si se juega con distintos niveles de detalle de la información sobre el medio o de precisión del análisis (Wiens et al., 2008). Sus principales desventajas son que pueden requerir mucho tiempo y pueden presentarse dificultades a la hora de interpretar los resultados, ya sea por la complejidad intrínseca de los datos o por una elección inadecuada de variables (Vilà et al., 2014).

El esquema general del método de análisis clúster adoptado se expone en la Figura 66 y se desgrana en apartados posteriores.

De entrada, para aplicar esta técnica no se debe cumplir ningún supuesto paramétrico, aunque hay que tener en cuenta una serie de condiciones básicas (Vilà et al., 2014) que se incorporan en los siguientes apartados que explican el procedimiento. 


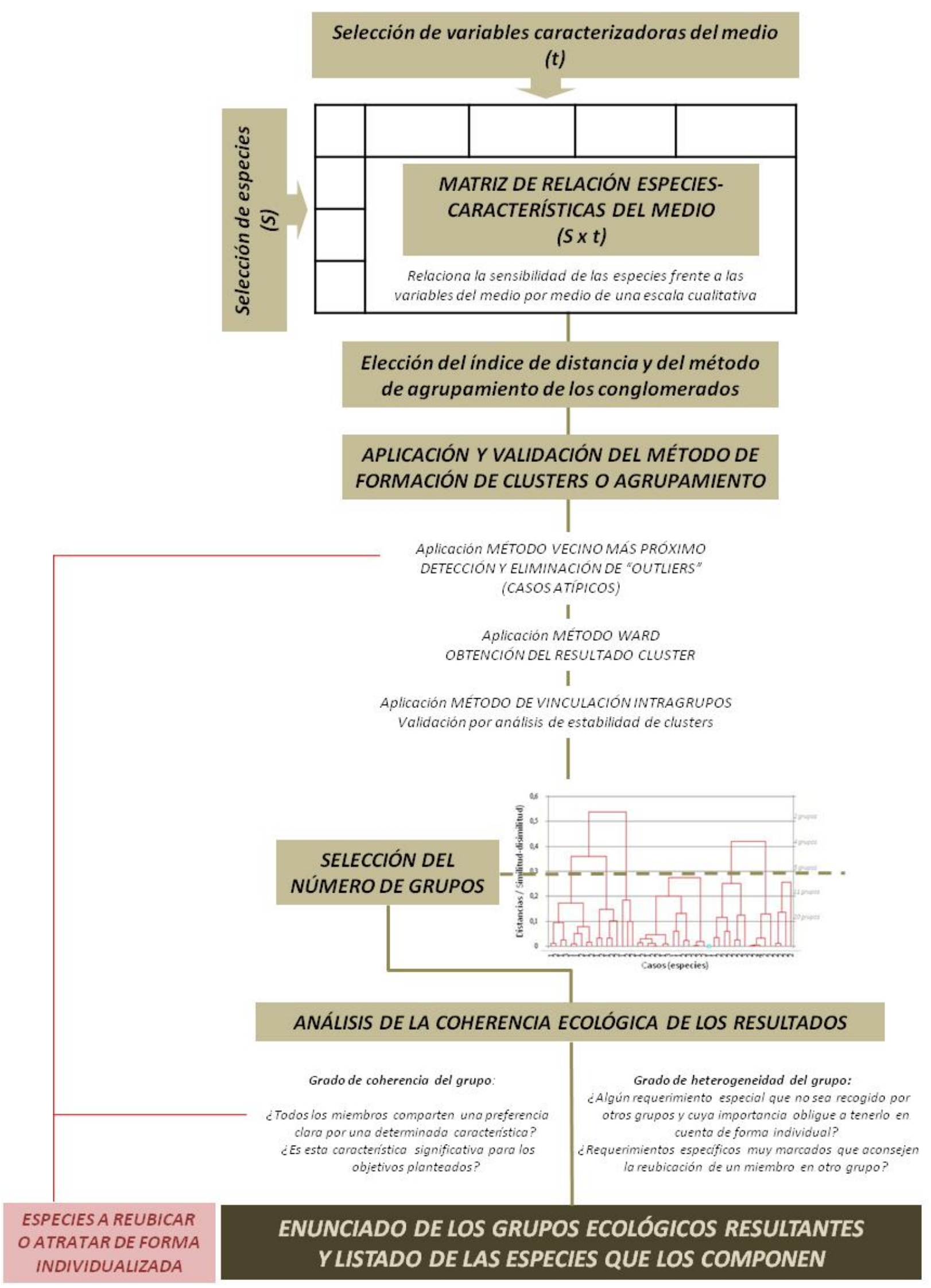

Figura 66. Metodología general de formación de Grupos ecológicos de especies de fauna. 


\section{B.2.a.1.- Selección de variables caracterizadoras del medio}

Las relaciones ecológicas dependen de un sinfín de variables físicas del medio, de entre las que habrá de elegir un número limitado que permita alcanzar los objetivos planteados. En primer lugar, dichas variables han de tener significación en cuanto a los requerimientos de las especies seleccionadas para el análisis. Dado que las objeto de análisis son especies con significación a nivel de paisaje, dichas variables biofísicas habrán de ser significativas a escala de macrohábitat. Esta escala es igualmente la relevante a efectos de percepción humana del paisaje y estética. Habrán que elegir igualmente aquellas variables que sea posible cartografiar con la información disponible en el momento y a la escala propia de la planificación que se pretende. Por ejemplo, si se determina un grupo que está condicionado por la existencia de un sotobosque abundante en las masas forestales y no es posible definir qué masas presentan esta característica, la evaluación de idoneidad del hábitat no podrá realizarse a esa escala de análisis.

\section{B.2.a.2.- Confección de la matriz de relación especies-características} del medio

La agrupación mediante la técnica clúster jerárquica se basa en una matriz de similaridad/disimilaridad que relaciona la respuesta de las especies frente a las variables caracterizadoras del medio. Se ha de confeccionar por tanto una matriz de doble entrada $\mathrm{S} x \mathrm{t}$, en la que $\mathrm{S}$ represente a cada especie y $t$ a cada variable caracterizadora del

Short, H. L. y Burnham, K. P. (1982). Technique for structuring wildlife guilds to evaluate impacts on wildlife communities (Special Scientific Report - Wildlife n. 244). Washington, D.C.: United States Department of the Interior. Fish and Wildlife Service. medio y en la que se evalúe la sensibilidad de cada especie ante cada característica. Para ello, es conveniente que las variables caracterizadoras del medio distingan entre dos ámbitos: importancia para la cría-refugio de la especie e importancia para su alimentación. Si bien esta diferenciación multiplica las variables tenidas en cuenta y complica el análisis, permite una descripción más fiel del uso del hábitat (Short y Burnham, 1982).

Las preferencias de cada especie por cada variable se estiman usando una escala cualitativa, derivada de la consulta de la literatura especializada, contrastando varias fuentes en la medida de lo posible, y adoptando las tendencias principales, más definitorias y claras. Una 
de las ventajas del enfoque cualitativo respecto al cuantitativo a la hora de evaluar la sensibilidad respecto a las variables es el pragmatismo, la capacidad de homogeneizar la información de manera más fácil y fiel a la realidad, y la optimización de informaciones imprecisas o incompletas (Fattorini, 2013).

B.2.a.3.- Elección del índice de distancia y del método de agrupamiento

En este paso es necesario seleccionar dos condicionantes que definirán en gran medida la manera en que se forman los clúster o conglomerados: la medida de distancia, que cuantifica el grado de similitud entre dos unidades de análisis, y el método de agrupamiento o clusterización, es decir, el criterio o regla para agrupar y asignar las especies a cada aglomerado.

Es importante reiterar que el resultado variará según se adopte uno u otro método. A este respecto, dado que existen multitud de métodos adecuados para realizar el análisis clúster, el factor clave para su elección es lo revelador y representativo de su resultado, atendiendo a los objetivos marcados. Según la mayoría de autores, la replicación de los patrones de agrupamiento al aplicar varios métodos es signo de un resultado significativo y coherente, pues la reiteración en las soluciones probablemente indique una estructura subyacente de los datos. Un criterio generalmente aceptado es el de aplicar los métodos más usuales, sencillos y fáciles de interpretar (distancia euclídea al cuadrado/Método del vecino más lejano, Método de promedio intergrupos, Método de Ward), y comprobar la coherencia de los resultados. En caso que no se dé esta coherencia, se pasaría a aplicar McGarigal, K., Cushman, S., Y Stafford, S. (2000). Multivariate Statistics for Wild life and Ecology Research. Nueva York, otro tipo de métodos (McGarigal et al., 2000).

Como paso previo, es muy recomendable detectar casos atípicos (outliers), ya que estos deforman las distancias y producen agrupaciones unitarias, distorsionando los resultados. Para ello, se ha de aplicar un análisis previo utilizando el índice de similitud de distancia euclídea al cuadrado y el método de agrupamiento del vecino más cercano, muy sensibles a la ocurrencia de grupos unitarios con características muy diferenciadas (Vilà et al., 2014). Estos casos Vilà, R., Rubio, M. J., Berlanga, V., y Torrado, M. (2014) Cómo aplicar un cluster serán apartados del análisis principal para su reconsideración en una jerárquico en SPSS. REIRE, 7(1). etapa posterior, una vez formados los grupos, en la que se dirimirá si se integran en uno de esos grupos o se mantiene un tratamiento 
individualizado por lo particular de los requerimientos que ostentan estas especies.

Finalmente, para realizar el agrupamiento en clústeres propiamente dicho se aplica un algoritmo de agrupación y se contrasta la estabilidad de los resultados aplicando otro método, de tal manera que dicho análisis de sensibilidad permita validar de cierta forma los grupos obtenidos. Los resultados son representados por medio de un dendrograma, que muestra los agrupamientos que se forman en cada fase y su nivel de similitud.

\section{B.2.a.4.- Selección del número de grupos y análisis de la coherencia} ecológica de los resultados

Un aspecto clave en la formación de grupos de especies es la elección del número de agrupamientos que se van a obtener finalmente y la comprobación de su lógica ecológica.

Para la elección del número de grupos a formar es necesario combinar dos criterios: nivel de detalle/escala del análisis y objetivos marcados. Así, la escala de análisis en la que nos encontremos, el detalle de la información con la que se cuente y la disponibilidad de tiempo y recursos definen absolutamente la precisión del análisis posterior que se pueda llevar a cabo y, consecuentemente, el número de grupos a manejar. Cuanta mayor precisión y recursos se pueda dedicar, el número de grupos y por tanto la precisión en las características que los diferencian aumentará (Figura 67). Los grandes grupos, más generales, sirven en escalas de planificación pequeñas en las que los macrohábitats generales y la distribución espacial prevalecen. Estos pueden ser divididos en varios grupos más reducidos cuando el análisis se realiza a escalas más finas y con la participación de un mayor número de variables ambientales. A las escalas de mayor

Wiens, J. A., Hayward, G. D., Holthausen, R. S., y Wisdom, M. J. (2008) Using surrogate species and groups for conservation planning and management. Bioscience, 58(3), 241-252

Vilà, R., Rubio, M. J., Berlanga, V., y Torrado, M. (2014). Cómo aplicar un cluster jerárquico en SPSS. REIRE, 7(1). detalle, los grupos se multiplicarán, estará representado un número pequeño de especies y será posible definir requerimientos muy concretos (Wiens et al., 2008). Resulta a este respecto especialmente útil la estructura de los resultados obtenidos por los métodos jerárquicos, dado que permite formar grupos a distintos niveles. La visualización del árbol de clasificación o dendrograma facilita enormemente esta tarea, pues permite seguir de forma gráfica el procedimiento de unión seguido, mostrando qué grupos se van uniendo, en qué nivel concreto lo hacen y con qué grado de similitud (Vilà et al., 2014). 

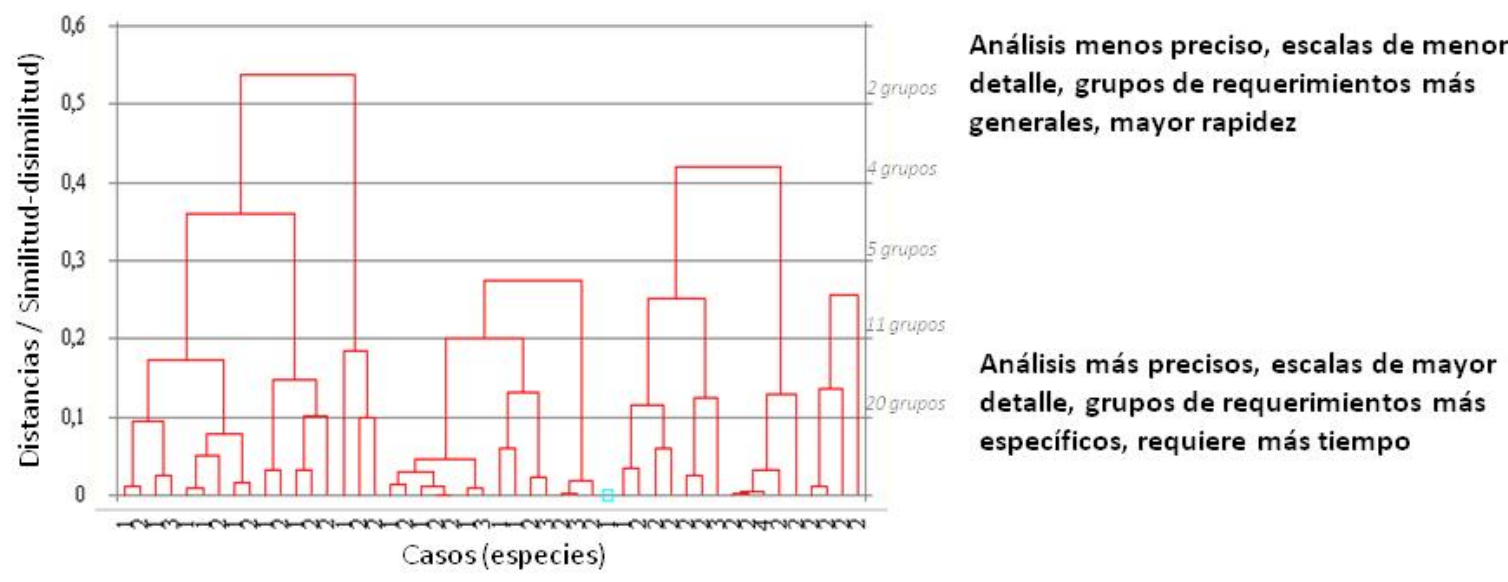

Análisis más precisos, escalas de mayor detalle, grupos de requerimientos más específicos, requiere más tiempo

Figura 67. Criterios de elección del número de grupos en un análisis clúster.

Paralelamente, es necesario considerar la significación y base ecológica de los grupos para poder validarlos, analizando lo apropiado de la pertenencia de cada especie al grupo que corresponda. Para ello, es necesario examinar 2 aspectos:

- Grado de coherencia del grupo: requerimientos o características del medio comunes a los miembros.

¿Todos los miembros comparten una preferencia clara por una determinada característica(s)?

¿Es esta característica(s) significativa para los objetivos planteados?

- Grado de heterogeneidad del grupo: requerimientos que diferencian a cada miembro.

¿Existe algún requerimiento especial que no sea recogido por otros grupos y cuya importancia obligue a tenerlo en cuenta de forma individual?

¿Existen requerimientos específicos muy marcados que aconsejen la reubicación de un miembro en otro grupo? 
Irastorza, P. (2006). Integración de la ecología del paisaje en la planificación territorial. Aplicación a la Comunidad de Madrid (Tesis doctoral no publicada). E.T.S. Ingenieros de Montes Universidad Politécnica de Madrid, Madrid.

Tras esta comprobación, puede ocurrir que algún miembro cambie de grupo o que algunas especies sean tratadas de forma independiente por lo particular de sus requerimientos. Esto resulta esencial no sólo para asegurar la relevancia de la relación interna en el grupo, sino para detectar aquellas diferencias que quedan diluidas en la generalización del agrupamiento y a cuyo examen no se debe renunciar. Este aspecto resulta especialmente importante en el caso de especies con un grado de protección (y por tanto de amenaza) elevado.

\section{B.2.3..- Enunciado de los grupos ecológicos y listado de las especies que los componen}

Finalmente, se enuncian los grupos ecológicos definitivos y las especies que lo componen, y se describen de forma general los requerimientos que comparten en cuanto a uso del medio .

\section{C.- ETAPA EVALUATIVA - FASE 3: APLICACIÓN DE MODELOS DE EVALUACIÓN DE IDONEIDAD DE HÁBITAT DE LOS GRUPOS ECOLÓGICOS}

Escribano, R. (1977) El análisis de la fauna en los modelos de Planificación (Tesis doctoral no publicada). E.T.S

Ingenieros de Montes Universidad Politécnica de Madrid, Madrid.

Steinitz, C. (1990). Toward a sustainable landscape with high visual preference and high ecological integrity: the loop road in Acadia National Park, U.S.A. Landscape and Urban Planning, 19(3), 213-250.
En esta fase, se evalúa la aptitud de cada sector del territorio para albergar a cada grupo ecológico de especies por medio de la llamada Modelización de Idoneidad o aptitud de Hábitat (Habitat Suitability Model, HSM). Mediante este método, se evalúa la calidad del hábitat de la o las especies a lo largo del área en estudio, de tal manera que se obtiene una estimación de la idoneidad o aptitud de cada área del paisaje para cubrir los requisitos de supervivencia y reproducción de las especies, esto es, una estimación de su presencia potencial en el paisaje (Escribano, 1977; Steinitz, 1990). La Figura 68 muestra el esquema general seguido. 


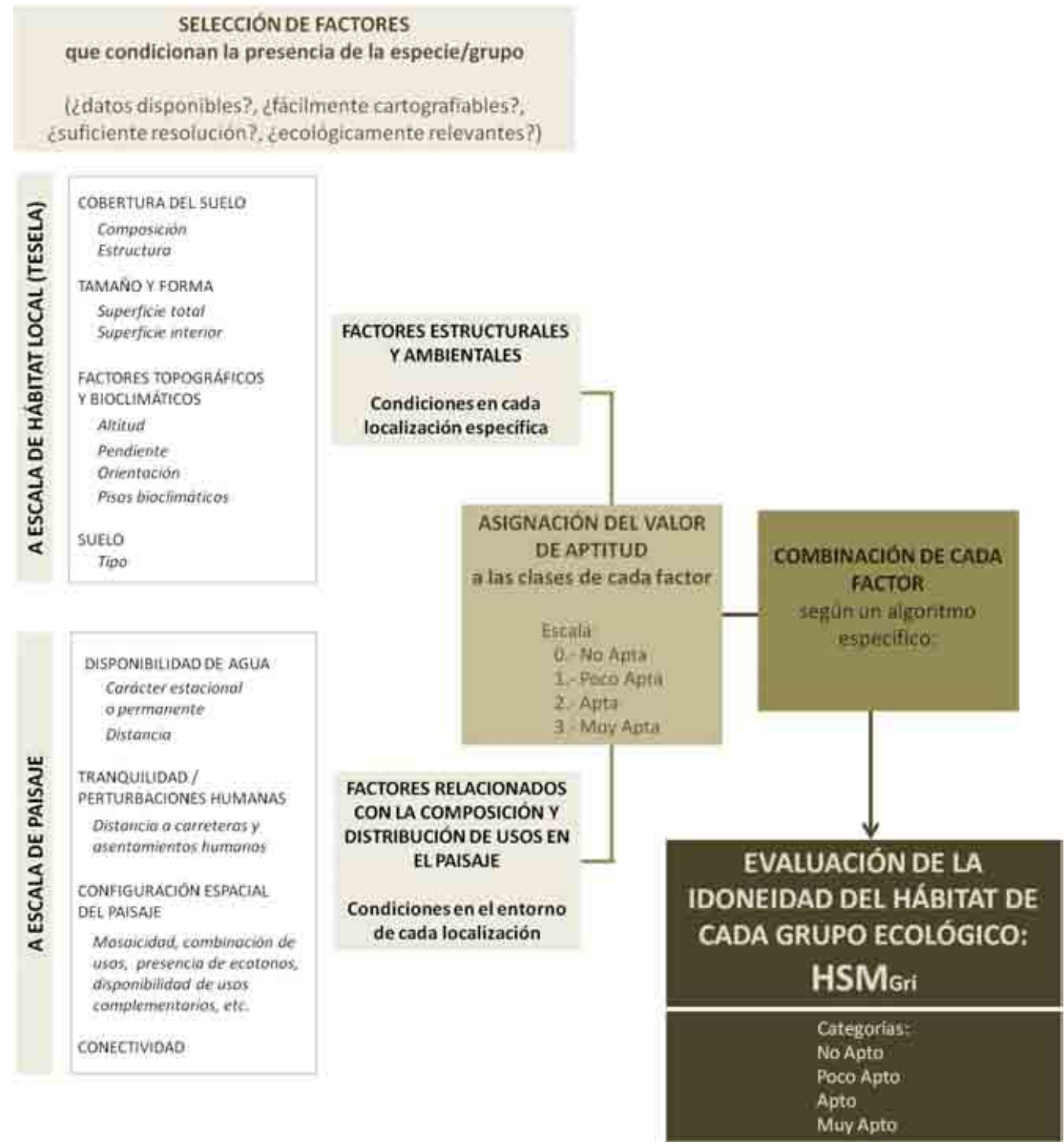

Figura 68. Esquema general de la metodología de Modelización de Idoneidad de Hábitat (Habitat Suitability Model, HSM) para cada Grupo ecológico de especies de fauna. 
En primer lugar, es necesario definir la combinación de factores que cubren los requisitos biológicos y ecológicos esenciales del grupo y que posibilitan que unas determinadas estructuras del paisaje sean más o menos preferidas o aptas. Los requisitos de las especies están fundamentalmente relacionados con la disponibilidad de alimento, agua, cobertura para poder cazar o defenderse frente a predadores, condiciones térmicas, tranquilidad y lugares de reproducción. Estos factores pueden ser de dos tipos: relacionados con el hábitat local (las condiciones que se dan en cada localización específica), o bien dependiente de las condiciones que se den alrededor del hábitat local (de la presencia y distribución de estos factores a escala de paisaje). Seguidamente, se asignan los criterios para definir el grado de aptitud (No Apto, Poco Apto, Apto, Muy Apto) de cada clase dentro de los factores, así como su combinación, basándose en la capacidad para proveer hábitat de calidad y cubrir los requerimientos del grupo.

La selección de factores, peso de cada factor y estimación de grados de aptitud se realiza basándose en los datos contenidos en la literatura especializada. Para llevarlo a cabo, es posible adoptar 2 estrategias (Wiens et al., 2008):

- Seleccionar una especie como representante del grupo.

Esta será la que presenten los requerimientos más estrictos, o bien mayor sensibilidad a cambios o amenazas en el biotopo. La ventaja de este enfoque reside en la mayor facilidad para comprender la respuesta de una sola especie a las condiciones del medio (siempre que se cuente con suficiente información sobre ella) y un seguimiento posterior será más concreto y sencillo. La desventaja es que, aunque teóricamente incluiría las necesidades de los demás miembros del grupo, se corre el riesgo de dejar de tener en cuenta ciertas necesidades de otros componentes del grupo.

- Basarlo en los requerimientos del grupo de especies.

Este enfoque se basa en adoptar los valores medios en cuanto a requerimientos del grupo. Resulta más flexible a la hora de captar la variedad de necesidades del conjunto de 
especies, aunque la representación de su respuesta no es tan directa ni clara, y su seguimiento más difícil.

Una vez definidos los criterios de idoneidad, se analizan su concurrencia en el territorio mediante el uso de Sistemas de Información Geográfica (SIG), que permiten cartografiar la distribución en el territorio de cada factor a partir de la información geográfica disponible y mediante el uso de herramientas de análisis espacial, así como combinarlos según un algoritmo específico. La evaluación de la idoneidad se realiza pues basándose en las características cartografiables del medio, según su capacidad para cubrir los requerimientos de cría, refugio-tranquilidad y alimentación de los grupos ecológicos. Se lleva a cabo en 2 ámbitos diferenciados:

- eVAluación de la idoneidad dE lOS FActores ESTRUCTURALES Y AMBIENTALES DE CADA ÁREA DEL TERRITORIO (ANÁLISIS A ESCALA DE HÁBITAT LOCAL). Se constituyen las categorías de aptitud intrínseca de cada tesela o área en función de sus características estructurales y ambientales (estructura y composición de las cobertura del suelo, tamaño y forma de las teselas de hábitat potencial, factores bioclimáticos relacionados con la termicidad y humedad, o relacionados con la productividad del suelo).

- eVALUACIÓn de la INFLUENCIA DE RECURSOS ALREDEDOR DE CADA ÁREA DEL TERRITORIO (ANÁLISIS A ESCALA DE PAISAJE). Se ajusta el nivel de idoneidad intrínseco dependiendo de la presencia y configuración espacial de recursos alrededor de cada hábitat local y que condicionan su aptitud. Este análisis se realiza teniendo en cuenta la disponibilidad de agua, presencia e intensidad de perturbaciones humanas, la configuración espacial de usos y elementos a nivel del paisaje y la conectividad potencial que se presente.

Cada una de las variables evaluadas se estandariza en una escala homogénea y se transforma al formato de datos raster (modelización del medio en una malla sistemática de celdas que contienen un valor que representa información y que cubre todo el territorio de manera continua). El tamaño de la celda ha de ser homogéneo para todas las variables y dependerá del grado de precisión más grosero de la información inventariada con la que se cuente. Las diversas capas que 
contengan la evaluación de idoneidad por cada factor se pueden así combinar de forma ponderada para dar un valor final de idoneidad o aptitud de cada área del territorio para cada grupo ecológico (HSM $\left.\mathrm{Gri}_{1}\right)$.

Finalmente, a efectos interpretativos, los valores de idoneidad de clasifican en 4 categorías según la siguiente escala:

- MUY APTA: estructuras potencialmente capaces de acoger a la gran mayoría de las especies del grupo o sostener poblaciones abundantes y estables, en razón de la preferencia de las especies más exigentes o por las condiciones óptimas que ofrece.

- APTA: estructuras capaces de acoger a gran parte de las especies pero que no responden a las exigencias más estrictas o cuyas condiciones no son óptimas, por lo que tendrán capacidad de sostener poblaciones menos abundantes y/o más inestables.

- POCO APTA: estructuras con capacidad residual para albergar a la comunidad de especies, bien porque ofrece condiciones degradadas o muy alejadas del óptimo, o por responder sólo a requerimientos secundarios de la totalidad o una parte de los componentes del grupo. Frecuentemente se tratará de hábitats que las especies no usen para criar, pero que tenga cierto papel como refugio y cría y también como hábitat apto para moverse por el paisaje.

- NO APTA: estructuras que no ofrecen condiciones para la especie/grupo, por lo que no serán utilizadas.

C.- ETAPA DE EVALUACIÓN - FASE 4: INTEGRACIÓN Y EVALUACIÓN DE LA IMPORTANCIA DEL PAISAJE PARA LA CONSERVACIÓN DE LA FAUNA SALVAJE

Mediante la combinación de la idoneidad de hábitat y la sensibilidad de las especies se obtiene el ÍNDICE DE LA IMPORTANCIA DEL PAISAJE PARA LA CONSERVACIÓN de fauna terrestre, I Icons (Figura 69). 


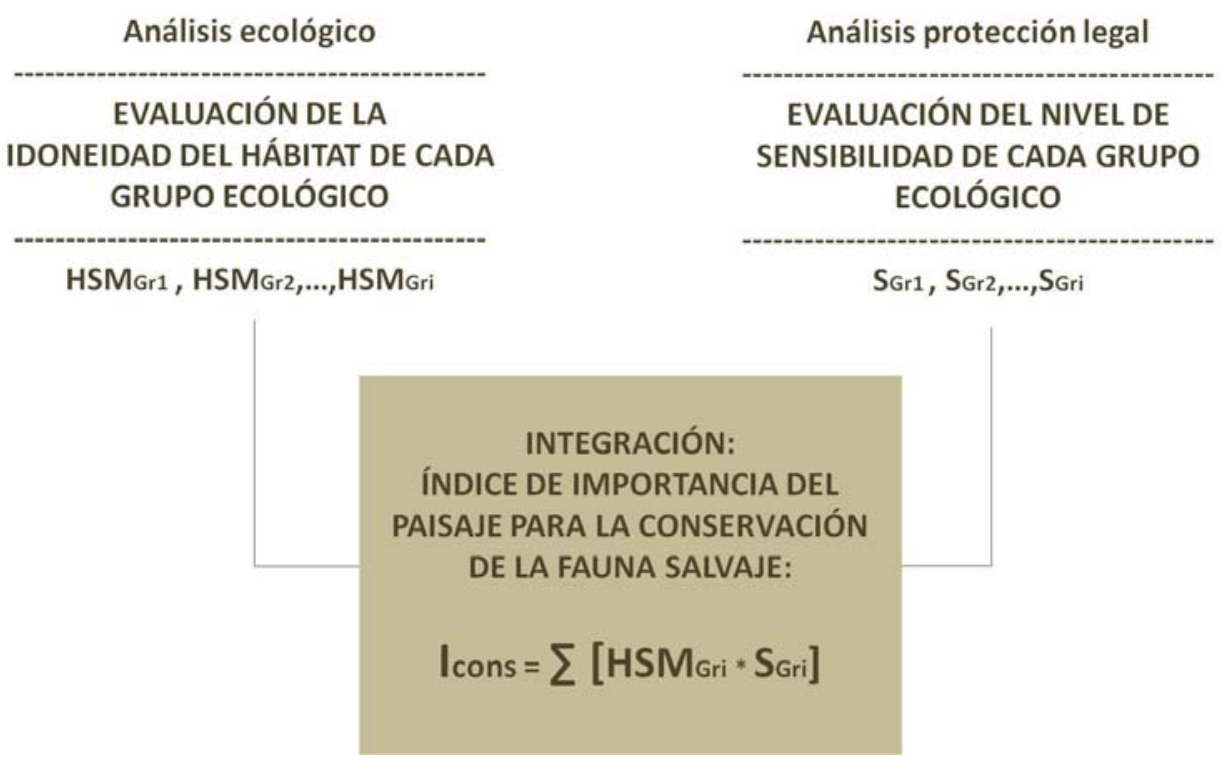

Figura 69. Esquema de integración para la obtención del índice de importancia del paisaje para la conservación de la fauna salvaje en cada punto del territorio.

En este paso, y como consecuencia de la introducción de un parámetro de sensibilidad definido en los sistemas de protección legal, el análisis puramente ecológico que hasta este punto se llevaba a cabo (aspecto meramente funcional) se transforma en un análisis de importancia para la conservación (en el que se establece un nivel de prioridad de actuación en función de su grado de amenaza de las especies reconocido legalmente). Dicho paso ostenta el interés de permitir la transición hacia aspectos prácticos, dado que el nivel de sensibilidad se relaciona con las prioridades de actuación para la conservación de la especie y su hábitat que se marcan en las políticas de planificación, ordenación y gestión del paisaje.

\section{C.4.1.- Evaluación de la sensibilidad de los Grupos ecológicos}

El parámetro de sensibilidad de los grupos ecológicos, $\mathrm{S}_{\mathrm{Gr}}$, se calcula mediante la suma de los valores de sensibilidad de cada especie que lo compone, teniendo en cuenta su inclusión en alguna de las categorías de protección emitidas a escala mundial, europeo, nacional o regional. Se considera que el nivel de protección alcanzado en razón del grado de amenaza de una especie es indicativo del nivel de sensibilidad de la especie según el criterio mostrado en la Tabla 6. 
Tabla 6. Categorías de protección para especies de fauna definidas a distintas escalas.

\begin{tabular}{|c|c|c|c|c|c|c|c|c|}
\hline \multicolumn{2}{|c|}{$\begin{array}{l}\text { ESCALA- } \\
\text { ÁMBITO }\end{array}$} & \multicolumn{2}{|c|}{ GLOBAL-NACIONAL } & EUROPEO & \multicolumn{2}{|c|}{ NACIONAL } & \multicolumn{2}{|c|}{ REGIONAL } \\
\hline & $\begin{array}{l}\text { MBLA- } \\
\text { MBITO } \\
\text { ITERIO }\end{array}$ & \multicolumn{2}{|c|}{$\begin{array}{l}\text { Criterios y categorías de la } \\
\text { UICN concretados para la } \\
\text { situación específica nacional } \\
\text { (Libro Rojo Nacional) }\end{array}$} & \multirow{3}{*}{$\begin{array}{c}\text { Directivas UE: Dir } \\
\text { 92/43/CEE } \\
\text { "Hábitats" / Dir } \\
\text { 79/409/CEE"Aves" } \\
\text { Anexo II (prioritario) } \\
\text { Anexo IV (protección } \\
\text { especial) }\end{array}$} & \multicolumn{2}{|c|}{$\begin{array}{l}\text { Listado de Especies } \\
\text { Silvestres en Régimen } \\
\text { de Protección Especial y } \\
\text { Catálogo Español de } \\
\text { Especies Amenazadas }\end{array}$} & \multicolumn{2}{|c|}{$\begin{array}{l}\text { Catálogo Regional de } \\
\text { Especies Amenazadas } \\
\text { (adopción general de } \\
\text { categorías) }\end{array}$} \\
\hline \multirow{5}{*}{ 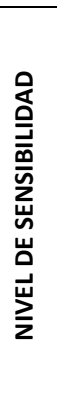 } & \multirow{2}{*}{$\begin{array}{l}\text { MUY ALTO } \\
\text { (4) }\end{array}$} & $C R$ & En peligro crítico & & & & & \\
\hline & & EN & En peligro & & EP & En peligro & PE & En peligro \\
\hline & ALTO (3) & VU & Vulnerable & Anexo II / Anexo I & VU & Vulnerable & VU & Vulnerable \\
\hline & MEDIO (2) & LR (NT) & $\begin{array}{r}\text { Bajo Riesgo } \\
\text { (Casi Amenazado) }\end{array}$ & & & & SAH & $\begin{array}{r}\text { Sensible a la } \\
\text { Alteración de su } \\
\text { Hábitat }\end{array}$ \\
\hline & BAJO (1) & LR (LC) & $\begin{array}{r}\text { Bajo Riesgo } \\
\text { (Preocupación } \\
\text { Menor) }\end{array}$ & - & Incluido & - & IE & $\begin{array}{r}\text { De Interés } \\
\text { Especial }\end{array}$ \\
\hline
\end{tabular}

NOTA. Una explicación más detallada de los criterios de inclusión en cada categoría y sus implicaciones se recoge en el Anexo II.

Los criterios para definir el nivel de sensibilidad de cada especie según la categoría alcanzada en cada escala es la siguiente:

- MUY ALTO: si está incluida en una categoría de riesgo muy alto en al menos 2 escalas.

- ALTO: si está incluida en una categoría de riesgo muy alto en alguna escala, acompañada de niveles altos en al menos otro ámbito; o bien está incluida en categoría de riesgo alto en al menos 1 escala.

- MEDIO: si está incluido en la categoría de Bajo Riesgo - Casi Amenazado (IUCN) o Sensible a la Alteración de su Hábitat (Regional).

- BAJO: incluida únicamente en categorías de riesgo bajo. 
C.4.2.- Integración de la Idoneidad de hábitat y la Sensibilidad de las especies: ÍNDICE DE LA IMPORTANCIA DEL PAISAJE PARA LA CONSERVACIÓN DE LA FAUNA SALVAJE

La integración y obtención del ÍNDICE DE LA IMPORTANCIA DEL PAISAJE PARA LA CONSERVACIÓN DE LA FAUNA SALVAJE (ICONS) se realiza mediante la siguiente expresión:

$$
\mathrm{I}_{\mathrm{CONS}}=\Sigma\left[\mathrm{HSM}_{\mathrm{Gri}} * \mathrm{~S}_{\mathrm{Gri}}\right]
$$

Siendo $I_{\text {Cons }}$ el índice que informa sobre la importancia de cada parte del paisaje para la conservación de las especies, HSM $_{\text {Gri }}$ la idoneidad o aptitud de cada parcela para proveer de hábitat potencial para el grupo ecológico i; y $\mathrm{S}_{\mathrm{Gri}}$ el grado de sensibilidad alcanzado por dicho grupo ecológico i.

Los valores de $I_{\text {cons }}$ finalmente se clasifican según una escala relativa de 5 categorías: Mínima, Menor, Media, Mayor y Máxima. Como resultado, se obtiene una cartografía en la que se detalla el índice de

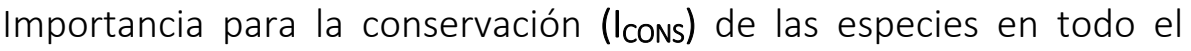
territorio de estudio y con el nivel de detalle definido por la escala de análisis (tamaño de celda raster). 


\section{VI.5. EVALUACIÓN DEL ÁMBITO DE LA APRECIACIÓN ESTÉTICA}

\section{VI.5.1. Encuadre metodológico}

El propósito de la evaluación estética de la componente ecológica del paisaje es el de esclarecer en qué entornos y aspectos, y por qué razones, la apreciación del paisaje percibido influye en la apreciación de su componente ecológica y puede determinar un refuerzo o debilitamiento de sus valores. De tal manera, el análisis del paisaje desde este punto de vista se funda en la consideración de 2 áreas de influencia de la estética sobre la ecología:

Sheppard, S. R. J., Harshaw, H. W., y Mc Bride, J. R. (2001). Priorities for Reconciling Sustainability and Aesthetics in Forest Landscape Management. En S. R. J. Sheppard y H. W. Harshaw (Eds.), Forests and Landscapes: Linking Ecology, Sustainability and Aesthetics (pp. 263-288). Nueva York, NY: CABI Publishing - IUFRO.

Bell, S. (2012). Landscape. Pattern, Perception and Process (2a ed.). Nueva York, NY: Routledge.

Aramburu, M. P., y Escribano, R. (Eds.) (2014). Guía para la elaboración de estudios del medio físico. Contenido y metodología (4a ed.). Madrid: Fundación Conde del Valle de

Salazar; Ministerio de Agricultura, Alimentación y Medio Ambiente.

Zube, E. H., Sell, J. L., y Taylor, J. G. (1982). Landscape Perception: Research, Application and Theory. Landscape Planning, 9, 1-33.
- Evaluación del paisaje en términos visuales y de apreciación escénica.

El primero de los ámbitos evalúa la forma en la que un determinado paisaje puede ver socialmente reforzado o debilitado su valor ecológico por medio del sentido de belleza que aporta su contemplación. Se trataría del refuerzo por la vía de las preferencias escénicas que puede albergar la mayoría del público, materia de gran parte de la investigación sobre percepción del paisaje y de los denominados sistemas de gestión del paisaje como recurso visual (VRM, Visual Resource Management, ver Capítulo IV.1). Tal y como advierten Sheppard, Harshaw, y Mc Bride (2001), aunque quizá la belleza escénica no haya de ser tratada como el único y más importante valor, no resulta conveniente menospreciarlo, pues determinadas representaciones ecológicas o políticas de intervención se fundan en la apreciación escénica del paisaje. Su importancia radica en que en general aquello que es percibido como bello es valorado y es lo que, en última instancia, decidimos conservar (Bell, 2012).

Para la determinación de las cualidades escénicas del paisaje se ha seleccionado uno de los enfoques de evaluación dominante en la práctica de planificación y gestión del paisaje como recurso visual: la evaluación experta por métodos indirectos basada en aspectos formales (Aramburu y Escribano (Eds.), 2014; Zube et al., 1982). En este enfoque, un grupo de profesionales con experiencia, que actúan como representantes de la sociedad, traslada los rasgos biofísicos y 
antrópicos del paisaje a una serie de parámetros relacionados con el diseño formal (línea, forma, color...) y su combinación en características visuales complejas (variedad, unidad...). Dichos atributos son tratados como indicadores de la apreciación escénica del público general y son evaluados según su grado de aportación a la calidad del paisaje, utilizando reglas derivadas de los modelos clásicos de percepción y juicio estético (Daniel, 2001).

- Evaluación de la interpretación de los valores ecológico-estéticos del paisaje

Esta componente trata de captar cómo el valor ecológico del paisaje puede verse socialmente reforzado o debilitado a través del significado de lo que se percibe, más allá del sentimiento inmediato de belleza. Se trataría del refuerzo por la vía de la interpretación estética del resultado del funcionamiento ecológico, la consideración de aquellos factores ecológicos que pueden ser percibidos a escala de paisaje y que en última instancia pueden provocar un sentimiento de placer o rechazo de diversa naturaleza (por conocimiento del medio natural y sus dinámicas, por la valoración de sus funciones, por la apreciación de una imagen de cuidado, etc.) (Gobster et al., 2007).

El enfoque de análisis en esta área ha de ser necesariamente subjetivista y cualitativo, puesto que el enfoque de interpretación requiere de perspectivas comprensivas, centradas en el entendimiento detallado del hecho interpretativo del sujeto $\mathrm{y}$, algo esencial, el conocimiento de sus razones subyacentes (Tindall, 2001). La evaluación propuesta por tanto se basa en la realización de entrevistas semiestructuradas y en profundidad, de forma individual o grupal (Focus Groups), a agentes con una opinión fundada en la experiencia del paisaje objeto de estudio.

\section{VI.5.2. Evaluación del paisaje en términos visuales y de apreciación escénica}

Entre los métodos disponibles se ha seleccionado el desarrollado por la antiguamente denominada Cátedra de Planificación y Proyectos de la Escuela de Ingenieros de Montes (Universidad Politécnica de Madrid), recogido en Aramburu y Escribano (Ed.) (2014). Este es un procedimiento de referencia en el ámbito español y ha sido aplicado en diversos espacios: Comunidad de Madrid (Aramburu Maqua, Escribano Bombín, Ramos Gonzalo, y Rubio Maroto, 2003), La Rioja (Aramburu Maqua, Escribano Bombín, López Hernández, y Sánchez
Daniel, T. C. (2001). Whither scenic beauty? Visual landscape quality assessment in the 21st century. Landscape and Urban Planning, 54(1-4), 267-281.

Gobster, P. H., Nassauer, J. I., Daniel, T. C., y Fry, G. (2007). The shared landscape: what does aesthetics have to do

with ecology? Landscape Ecology, 22(7), 959-972.

Tindall, D. B. (2001). Why do you hink that hillside is ugly? A sociological perspective on aesthetic values and public attitudes about forest. En S. R. J. Sheppard y H. W. Harshaw (Eds.), Forests and Landscapes: Linking Ecology, Sustainability and Aesthetics (pp. 57-70).

Nueva York, NY: CABI Publishing - IUFRO.

Aramburu, M. P. y Escribano, R. (Eds.) (2014). Guía para la elaboración de estudios del medio físico. Contenido y metodología (4a Edición). Madrid: Fundación Conde del Valle de Salazar; Ministerio de Agricultura, Alimentación y Medio Ambiente.

Aramburu Maqua, M. P. Escribano Bombín, R., Ramos Gonzalo, L., y Rubio Maroto, R. (2003). Cartografía del Paisaje de la Comunidad de Madrid. Madrid: Comunidad Autonoma Madrid. Dirección General de Promoción y Disciplina

Ambiental. 
Aramburu Maqua, M. P., Escribano Bombín, R., López Hernández, R., y Sánchez Ramos, P. (2004). Estudio y Cartografía del Paisaje de la Comunidad Autónoma de La Rioja. Consejería de Turismo,

Medio Ambiente y Política

Territorial, Gobierno de La Rioja (publicación electrónica).

Ibarra, P. y Escribano, R. (Coord.) (2009). Mapas de Paisaje de las Comarcas de La

Jacetania, Alto Gallego, Matarraña /Matarranya,

Maestrazgo, Gúdar-

Javalambre, La Sierra de Albarracín y Los Monegros. Zaragoza: Departamento de Política Territorial, Justicia e Interior, Gobierno de Aragón.

Cifuentes, P. (1976). La calidad visual de unidades territoriales. Aplicación al Valle del Tiétar (Tesis doctoral no publicada). E.T.S. Ingenieros de

Montes - Universidad Politécnica de Madrid, Madrid
Ramos, 2004) o Aragón (Ibarra y Escribano (Coord.), 2009), entre otros.

Dicho método define la calidad visual del paisaje como el mérito de este para ser conservado (Cifuentes, 1976), mérito que viene expresado por la combinación armónica (escénica) de la disposición de formas, volúmenes, colores, etc. Las unidades de paisaje de referencia son las unidades visualmente autocontenidas delimitadas según el método expuesto en el Capítulo IV.3.).

El modelo de calidad distingue entre calidad visual intrínseca y sus factores modificadores. La calidad visual intrínseca se corresponde con la valoración por parte de los expertos del mérito visual de las características propias de cada punto del paisaje, factores biofísicos y antrópicos tales como la fisiografía, la vegetación y usos del suelo, la presencia de agua superficial y las estructuras o elementos antrópicos con efecto artificializante. Cada componente valorada se agrega posteriormente para obtener un valor final de calidad visual intrínseca en cada unidad en que se divide el paisaje. La calidad visual intrínseca se ve modificada al alza por una serie de factores de índole visual presentes en la unidad de paisaje: la variación de altitud que se da en la unidad, la presencia de valores naturales con atractivo visual y la existencia de elementos culturales de carácter histórico. Finalmente, se evalúa la aportación a la calidad de la unidad que tienen las vistas panorámicas, es decir, la percepción desde la unidad de horizontes escénicos como elevaciones singulares o cumbres serranas. En la Figura 70 se refleja la estructura del modelo.

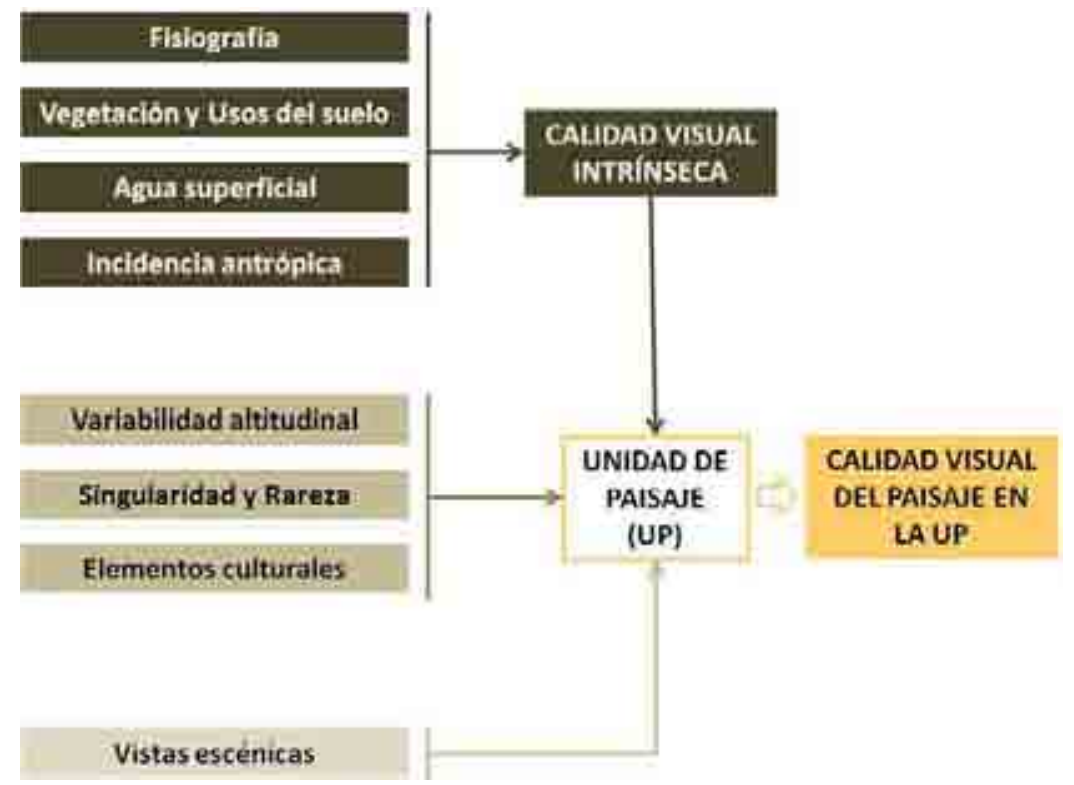

Figura 70. Esquema del los componentes del modelo para la determinación de la calidad visual del paisaje recogido en Aramburu y Escribano (Eds.) (2014). 
Derivados del proceso de evaluación se obtienen 2 tipos de resultados:

- Las clases de calidad para cada Unidad de Paisaje. Se establecen 5 clases relativas al conjunto de unidades: calidad Muy Alta, Alta, Media, Baja y Muy Baja.

- La tabla de valoración de cada componente del paisaje desagregada, en la que se recoge los criterios y valoraciones asignadas por los expertos.

Dado que la valoración se realiza de forma comparativa según los componentes presentes y en función de la distribución de valores y de las frecuencias obtenidas en el conjunto de unidades, el valor asignado no es absoluto, sino que ha de interpretarse como relativo y válido para las unidades evaluadas.

\section{VI.5.3. Evaluación de la interpretación de los valores ecológico-estéticos del paisaje}

El método adoptado se encuentra expuesto en el Capítulo $V$, por lo que únicamente se recoge aquí una síntesis y se detallan una serie de consideraciones.

\section{A.- CONTEXTUALIZACIÓN DE LA EXPERIENCIA ESTÉTICA}

A la hora de analizar cualitativamente la experiencia estética del paisaje es necesario definir el contexto en el que esta sucede, pues de él depende la naturaleza de la experiencia que se produzca (Gobster et al., 2007). Este contexto depende de dos factores: el tipo de paisaje y las circunstancias personales que afectan al observador. La definición de ambos aspectos se requiere pues como paso previo para poder orientar el análisis y entender mejor la experiencia que se examina.

En cuanto a la contextualización de la experiencia según el tipo del paisaje, es necesario identificar el carácter de este y describir propiedades como el grado de naturalidad aparente, el patrón de combinación de usos y elementos constitutivos, el poso cultural que muestre, la estructura de tenencia de tierra, el tipo de sociedad que se asienta y hace uso del territorio, etc. Todos estos rasgos influyen en el tipo de experiencia que se tenga y las acciones que se contemplan,

Gobster, P. H., Nassauer, J. I., Daniel, T. C., y Fry, G. (2007). The shared landscape: what does aesthetics have to do with ecology? Landscape Ecology, 22(7), 959-972. 
y por tanto su análisis es necesario para poder interpretar adecuadamente los resultados.

Con respecto a la contextualización de las características del observador, la definición de los factores socio-culturales y personales que afectan al observador, tales como expectativas, grado de implicación, interés o familiaridad con el paisaje, actividades que se realizan, grupo social al que pertenece, etc., es esencial para entender las circunstancias personales que influyen en la forma de mirar e interpretar el paisaje.

\section{B.- SELECCIÓN Y DESCRIPCIÓN DE PARTICIPANTES}

Dado que el objetivo es conocer de manera profunda la interpretación en términos estéticos de la componente ecológica del paisaje, el análisis se ha de centrar en la información aportada por personas con un contacto frecuente y directo con él, de forma que se asegure de manera efectiva que dichos entrevistados están próximos al paisaje y lo han experimentado suficientemente. Por otro lado, dado que se considera que la interpretación de la dimensión ecológica depende fundamentalmente del tipo de relación que se establezca con el paisaje (expectativas e intereses) y el conocimiento sobre medio natural y ciencia ecológica que se tenga, se han de seleccionar casos que sean representativos de distintas situaciones atendiendo a estas dimensiones. De tal manera, los entrevistados se seleccionaría de entre la población que vive y/o trabaja en el paisaje. El rango de variación de visiones respondería a la combinación del tipo de conocimiento sobre temas ambientales o del medio natural de los participantes, y el tipo de uso o implicación en el paisaje.

\section{C.- MÉTODO ANALÍTICO}

El marco conceptual que sirve para el diseño de la dinámica de la entrevista y el análisis e interpretación de los resultados se basa en el modelo de 3 componentes derivado de la Teoría del Lugar de Canter (Theory of Place, Canter, 1977). Dicha teoría expone que para comprender en toda su dimensión la percepción y experiencia del entorno que tiene el ser humano, es necesario identificar el comportamiento asociado al lugar, las características físicas que muestra y las concepciones que se tienen de dicho comportamiento en dicho marco físico. 
De tal manera, el método analítico se sirve de un entrevista semiestructurada cuyo diseño se basa en la selección en un mapa y descripción por parte de los participantes de lugares que respondan a una evaluación en términos de alta o baja calidad ecológica y/o estética. Adicionalmente, se pregunta por su opinión sobre la influencia sobre la ecología y la estética del paisaje de la gestión que se lleva a cabo en el paisaje, la de su propia actividad y su relación con otras actividades, y por la evolución previsible del paisaje. Los resultados derivados de este modelo de entrevista proveen de dos tipos de información: una serie de valoraciones en clave ecológica y estética ligadas a determinadas localizaciones y características físicas, y una serie de evaluaciones expuestas de manera general o no ligadas a localizaciones concretas.

El análisis cualitativo del contenido de las entrevistas se realiza por medio de un proceso de codificación de los conceptos encerrados (Bryman, 2004), basado en el modelo de los 3 componentes de la percepción de Canter. De tal manera es posible categorizar los argumentos ofrecidos y además relacionarlos con los atributos físicos percibidos, puesto que el procedimiento obliga a que las valoraciones se liguen en mayor o menor grado con localizaciones concretas o rasgos del paisaje, es decir, tienen una traducción física y son por tanto son cartografiables.

\section{D.- RESULTADOS Y ALCANCE}

Como resultado del proceso se obtiene:

- Una serie de temas y razones relevantes en cuanto a la forma de percibir, interpretar y juzgar la relación entre la ecología y la estética en el paisaje, definidos por los propios entrevistados y susceptibles de ser incorporados en las propuestas de tratamiento del paisaje.

- Una concreción geográfica de las áreas, elementos o atributos físicos cuyos valores ecológicos o estéticos han sido referidos en la consulta cualitativa en uno u otro sentido.

Bryman, A. (2004).

Social research methods. Oxford, UK: Oxford University Press. 
Es importante delimitar el alcance de los resultados de la investigación cualitativa basada en entrevistas en profundidad: dado el número limitado de entrevistas que permite llevar a cabo esta metodología, dichos resultados tienen un carácter comprensivo, más que evaluativo. Es decir, su utilidad reside en el estudio intensivo de pocos casos para poder hacer emerger los conceptos importantes para los participantes, entender como son percibidos y perfilar las razones que se encuentran tras dicha percepción. Estos conceptos o dimensiones significativas pueden no ser los únicos y sus contornos pueden no estar perfectamente definidos, pero permite construir un marco interpretativo, el armazón que sostiene un posible análisis posterior que examine en detalle y de forma intensiva ciertos fenómenos, elementos o zonas más específicas del paisaje. 


\section{VI.6. IDENTIFICACIÓN DE ÁMBITOS DE ACTUACIÓN ECOLÓGICO-ESTÉTICA Y DELINEACIÓN DE ESTRATEGIAS DE ACTUACIÓN EN EL PAISAJE}

Una vez obtenida la evaluación de la importancia para la conservación de las distintas áreas del paisaje, determinados sus valores escénicos y perfilada la forma en que los valores ecológicos son interpretados en clave estética, es necesario integrar estas dimensiones para poder definir las estrategias de actuación sobre el paisaje.

Las unidades de paisaje definidas son la base en las que se realiza un análisis que relacione los resultados en todos los ámbitos, que deriva en una definición del valor de conservación base y un diagnóstico del potencial de refuerzo de ese valor en razón de la valoración estética de su componente ecológica. Este diagnóstico se concreta en la identificación y localización, más o menos detallada según las posibilidades de cada caso, de las áreas y atributos percibidos en el paisaje que responden a esa valoración y una relación de las razones por las que dicha valoración se produce. Sobre esta base descriptiva se obtienen directrices de actuación y de gestión encaminadas a orientar un tratamiento integrado de ambos aspectos.

Así, una actitud positiva o negativa hacia el paisaje o un aspecto concreto del mismo en una unidad de paisaje puede derivar en un reforzamiento o debilitamiento de su calidad ecológica por razones sociales fundadas en criterios estrictos de belleza escénica (bonito/ feo), un atractivo derivado del conocimiento de su adecuación ecológica (bueno/malo) o por ubicarse dentro de un espacio protegido (conservado o no), la percepción de la conveniencia o el cuidado con el que se interviene en el paisaje (bien gestionado/mal gestionado), etc. La casuística puede ser muy variada. La comprensión de la naturaleza de dicha actitud orienta de manera más efectiva las directrices de actuación que se prescriban.

Este proceso de integración se facilita mediante la confección de una ficha sintética en la que se organizan y relacionan los distintos aspectos, tal y como muestra la Figura 70. 
Los resultados se concretan en:

- CARTOgRAFÍA que, tomando como base de análisis las unidades de paisaje, determine los ámbitos geográficos y/o rasgos físicos en los que la relación entre ambos tipos de evaluaciones muestran un grado mayor o menor de refuerzo o debilitamiento.

- FICHAS SINTÉTICAS en las que se reflejen los valores y atributos con importancia en cada ámbito y la relación entre ellos.

- ÁMBITOS Y DIRECTRICES DE ACTUACIÓN en el paisaje para una gestión optimizada del tratamiento ecológico-estético del paisaje. 


\begin{tabular}{|c|c|c|c|c|}
\hline \multicolumn{5}{|c|}{ CÓDIGO UNIDAD PAISAJE - NOMBRE } \\
\hline \multirow{2}{*}{\multicolumn{3}{|c|}{$\begin{array}{l}\text { EVALUACIÓN DE LA CALIDAD DEL PAISAJE VISUAL } \\
\text { CATEGORÍA ASIGNADA: MUY BAJA/BAJA/MEDIA/ALTA/MUY ALTA }\end{array}$}} & \multicolumn{2}{|c|}{ PERCEPCIÓN DEL VALOR ECOLÓGICO-ESTÉTICO (EVALUACIÓN LOCAL) } \\
\hline & & & $\begin{array}{l}\text { CONSIDERACIÓN ESTÉTICA } \\
\text { MAYOR, MEDIA, MENOR (VARIABLE) }\end{array}$ & \begin{tabular}{|c|} 
CONSIDERACIÓN ECOLÓGICA \\
MAYOR, MEDIA, MENOR (VARIABLE)
\end{tabular} \\
\hline FISIOGRAFÍA & \multicolumn{2}{|c|}{$\begin{array}{c}\text { Características en las que se basa la evaluación } \\
\text { del modelo }\end{array}$} & $\begin{array}{c}\text { Características derivadas de las entrevistas } \\
\text { En cuanto a valoración estética }\end{array}$ & $\begin{array}{c}\text { Características derivadas de las entrevistas } \\
\text { En cuanto a valoración ecológica }\end{array}$ \\
\hline VEGETACIÓN/USOS & \multicolumn{2}{|c|}{ Aportan calidad escénica } & + Características destacadas en clave positiva & + Características destacadas en clave positiva \\
\hline AGUA SUPERFICIAL & \multicolumn{2}{|c|}{ Detraen calidad escénica } & - Características destacadas en clave negativa & - Características destacadas en clave negativa \\
\hline \multicolumn{5}{|l|}{ INCIDENCIA ANTRÓPICA } \\
\hline \multicolumn{5}{|l|}{ VARIACIÓN ALTITUDINAL } \\
\hline \multicolumn{5}{|l|}{$\begin{array}{r}\text { SINGULARIDAD Y RAREZA } \\
\text { (Valores naturales con } \\
\text { atractivo visual) }\end{array}$} \\
\hline \multicolumn{5}{|l|}{$\begin{array}{r}\text { VISTAS PANORÁMICAS } \\
\text { (Fondo visual y Elevaciones } \\
\text { singulares) }\end{array}$} \\
\hline \multicolumn{5}{|c|}{ CONCLUSIONES DE LA COMPARACIÓN ECOLOGÍA-ESTÉTICA } \\
\hline \multicolumn{2}{|c|}{ IMPORTANCIA PARA LA CONSERVACIÓN } & \multicolumn{3}{|c|}{ CATEGORÍA ASIGNADA: MUY BAJA/BAJA/MEDIA/ALTA/MUY ALTA (Síntesis de características relevantes en cuanto a conservación) } \\
\hline \multicolumn{2}{|c|}{ RASGOS QUE APORTAN CALIDAD ESCÉNICA } & \multicolumn{3}{|c|}{ Síntesis de cualidades identificadas por el modelo de evaluación visual del paisaje } \\
\hline \multicolumn{2}{|c|}{ RASGOS QUE NO APORTAN CALIDAD ESCÉNICA } & \multicolumn{3}{|c|}{ Síntesis de rasgos que afcetan a la calidad escénica de la unidad } \\
\hline \multicolumn{2}{|c|}{ PERCEPCIÓN DEL VALOR ECOLÓGICO-ESTÉTICO } & \multicolumn{3}{|c|}{ Síntesis de las evaluaciones estéticas y características con incidencia en la gestión ecológica, derivadas de las entrevistas } \\
\hline & & unciado de & $\begin{array}{l}\text { DIRECTRICES DE ACTUACIÓN: } \\
\text { líneas de actuación prescritas para la u }\end{array}$ & de paisaje \\
\hline
\end{tabular}


Mapa mostrando la evaluación de la importancia del paisaje para la conservación de la fauna salvaje y registro fotográfico seleccionado

Figura 71. Ficha de análisis de la relación entre los valores ecológico-estéticos y la importancia para la conservación. 
CAPÍTULO VI. PROPUESTA METODOLÓGICA PARA UNA PLANIFICACIÓN DEL PAISAJE QUE INCORPORE LA INTERPRETACIÓN ESTÉTICA DE LA COMPONENTE ECOLÓGICA 


\section{CAPÍTULO VII APLICACIÓN A UN CASO DE ESTUDIO: PLANIFICACIÓN ECOLÓGICO-ESTÉTICA DEL PAISAJE EN LA SIERRA OESTE DE MADRID}

CAPÍTULO VII.- APLICACIÓN A UN CASO DE ESTUDIO: PLANIFICACIÓN ECOLÓGICO-ESTÉTICA DEL PAISAJE EN LA SIERRA OESTE DE MADRID

VII.1.- LOCALIZACIÓN, ÁREA DE PLANIFICACIÓN Y UNIDADES DE PAISAJE

VII.4.1.- Evaluación del paisaje en términos visuales y de apreciación escénica 229

VII.4.2.- Evaluación de la interpretación de los valores ecológico-estéticos del paisaje_231

VII.5.- IDENTIFICACIÓN DE ÁMBITOS DE ACTUACIÓN ECOLÓGICO-ESTÉTICA Y DELINEACIÓN DE ESTRATEGIAS DE ACTUACIÓN EN EL PAISAJE 
CAPITUULO VII. APLICACIÓN A UN CASO DE ESTUDIO: PLANIFICACIÓN ECOLÓGICO-ESTÉTICA

DEL PAISAJE EN LA SIERRA OESTE DE MADRID 


\section{APLICACIÓN A UN CASO DE ESTUDIO: PLANIFICACIÓN ECOLÓGICO-ESTÉTICA DEL PAISAJE EN LA SIERRA OESTE DE MADRID}

\section{VII.1. LOCALIZACIÓN, ÁREA DE PLANIFICACIÓN Y UNIDADES DE PAISAJE}

El área de estudio se localiza en la vertiente sur de la zona de transición entre la Sierra de Gredos y Guadarrama, en la cuenca del río Alberche. Administrativamente, el área pertenece fundamentalmente a la Comunidad de Madrid, aunque también integra pequeñas áreas que pertenecen a Castilla y León (provincia de Ávila) y Castilla la Mancha (provincia de Toledo). Se sitúa a unos 80 $\mathrm{km}$ de la capital madrileña, formando parte de la denominada Comarca de la Sierra Oeste, en el extremo oeste de la Comunidad de Madrid (Mapa 1, Figura 72).

El territorio del estudio de planificación comprende 28.023 hectáreas,

Aramburu Maqua, M. P., Escribano Bombín, R., Ramos Gonzalo, L., y Rubio Maroto, R. (2003). Cartografía del Paisaje de la Comunidad de Madrid. Madrid: Consejería de Medio Ambiente de la Comunidad de Madrid. Madrid: Dirección General de Promoción y Disciplina Ambiental Consejería de Medio Ambiente - Comunidad de Madrid. cuyo límite corresponde al perímetro exterior de un conjunto de unidades de paisaje tal y como son definidas en la Cartografía del Paisaje de la Comunidad de Madrid (Aramburu Maqua, Escribano Bombín, Ramos Gonzalo, y Rubio Maroto, 2003). Los límites del área objeto de estudio no están por tanto definidos administrativamente, sino que se asientan sobre una base de planificación del paisaje y se definen por una cierta homogeneidad en el carácter. En concreto, el área engloba 15 (sub)unidades de paisaje que servirán de unidad de referencia para la propuesta de actuaciones. La Tabla 7 muestra sus características básicas, que se detallan en las Fichas de análisis (página 279 y siguientes). 
Tabla 7. Características básicas de las (sub)unidades de paisaje objetos de estudio, según se encuentran definidas en Aramburu Maqua, Escribano Bombín, Ramos Gonzalo y Rubio Maroto (2003).

\begin{tabular}{|c|c|c|c|c|}
\hline CÓDIGO UNNIDAD & \multicolumn{2}{|c|}{ NOMBRE UNIDAD } & EXTENSIÓN & CARÁCTER \\
\hline Unidad A13 & \multicolumn{2}{|l|}{ OLLA GRANDE } & 1.649 ha & Forestal-ganadero \\
\hline Unidad A14 & \multicolumn{2}{|c|}{ ARROYO DE VALDEZATE } & 2.905 ha & Forestal-ganadero \\
\hline Subunidad A15a & \multirow{3}{*}{ 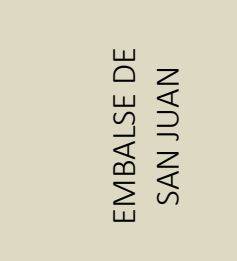 } & COSTA DE MADRID & 1.973 ha & $\begin{array}{l}\text { Forestal-ganadero / } \\
\text { Turístico }\end{array}$ \\
\hline Subunidad A15b & & $\begin{array}{l}\text { PICO DE LA } \\
\text { CABRERA ALTA }\end{array}$ & 667 ha & Forestal-ganadero \\
\hline Subunidad A15c & & CERRO DEL YELMO & 861 ha & Forestal-ganadero \\
\hline Subunidad A16a & \multirow{2}{*}{ 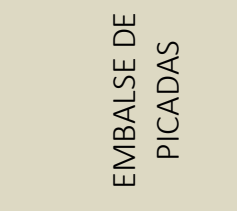 } & CUERDA DE LA VIÑA & 885 ha & Forestal-ganadero \\
\hline Subunidad A16b & & $\begin{array}{l}\text { CORTADOS DEL } \\
\text { EMBALSE }\end{array}$ & 678 ha & Forestal-ganadero \\
\hline Subunidad A17b & NAVAS DEL REY & -EL MORRO & 1.160 ha & Forestal-ganadero \\
\hline Subunidad A22a & \multirow{2}{*}{ 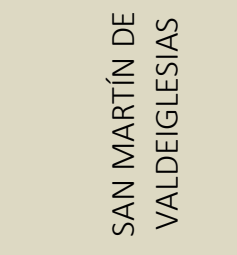 } & TRASIERRA & 1.478 ha & $\begin{array}{l}\text { Agrícola / Forestal- } \\
\text { ganadero }\end{array}$ \\
\hline Subunidad A22b & & $\begin{array}{l}\text { SAN MARTÍN DE } \\
\text { VALDEIGLESIAS }\end{array}$ & 5.529 ha & $\begin{array}{l}\text { Agrícola / Forestal- } \\
\text { ganadero }\end{array}$ \\
\hline Unidad A23 & \multicolumn{2}{|c|}{ PEÑA DE CADALSO } & 1.549 ha & Forestal-ganadero \\
\hline Subunidad A24a & \multirow{2}{*}{ 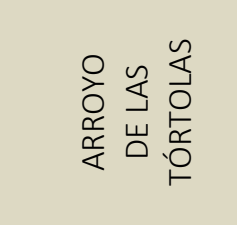 } & $\begin{array}{l}\text { ARROYO DE LAS } \\
\text { TÓRTOLAS }\end{array}$ & 1.556 ha & $\begin{array}{l}\text { Forestal-ganadero / } \\
\text { Agrícola }\end{array}$ \\
\hline Subunidad A24b & & $\begin{array}{l}\text { PUENTE DE LA } \\
\text { AVELLANEDA }\end{array}$ & 1.637 ha & $\begin{array}{l}\text { Forestal-ganadero / } \\
\text { Agrícola }\end{array}$ \\
\hline $\begin{array}{l}\text { Unidad de Paisaje } \\
\text { UP A25 }\end{array}$ & \multicolumn{2}{|c|}{ ROZAS DE PUERTO REAL } & 4.861 ha & Forestal-ganadero \\
\hline $\begin{array}{l}\text { Unidad de Paisaje } \\
\text { UP A26 }\end{array}$ & \multicolumn{2}{|c|}{ CADALSO DE LOS VIDRIOS } & 2.284 ha & $\begin{array}{l}\text { Forestal-ganadero / } \\
\text { Agrícola }\end{array}$ \\
\hline
\end{tabular}


El área de análisis varía sin embargo según la naturaleza de este, por lo que se distinguen (Mapa 1, Figura 72).

- Área de análisis de la percepción del paisaje.

El análisis del paisaje percibido se ajusta a los límites definidos para el área de planificación, determinado por las 15 (sub)unidades de planificación del paisaje.

- Área de análisis ecológico del paisaje.

Con el fin de buscar una coherencia en la caracterización ecológica, los límites en los que se aplica dicho análisis no se ajustan exactamente a los límites definidos por el área de planificación, sino que buscan una cierta homogeneidad biofísica en divisorias del relieve, cuencas hidrológicas y tipo de ecosistema, cuyos límites pueden o no coincidir con los límites de las unidades de paisaje de Madrid definidas por criterios visuales. Además, para tener en cuenta las relaciones con áreas adyacentes y minimizar en lo posible el efecto borde, se ha extendido el límite de análisis en una banda de 1 kilómetro alrededor del perímetro del área delimitada (Buffer). 


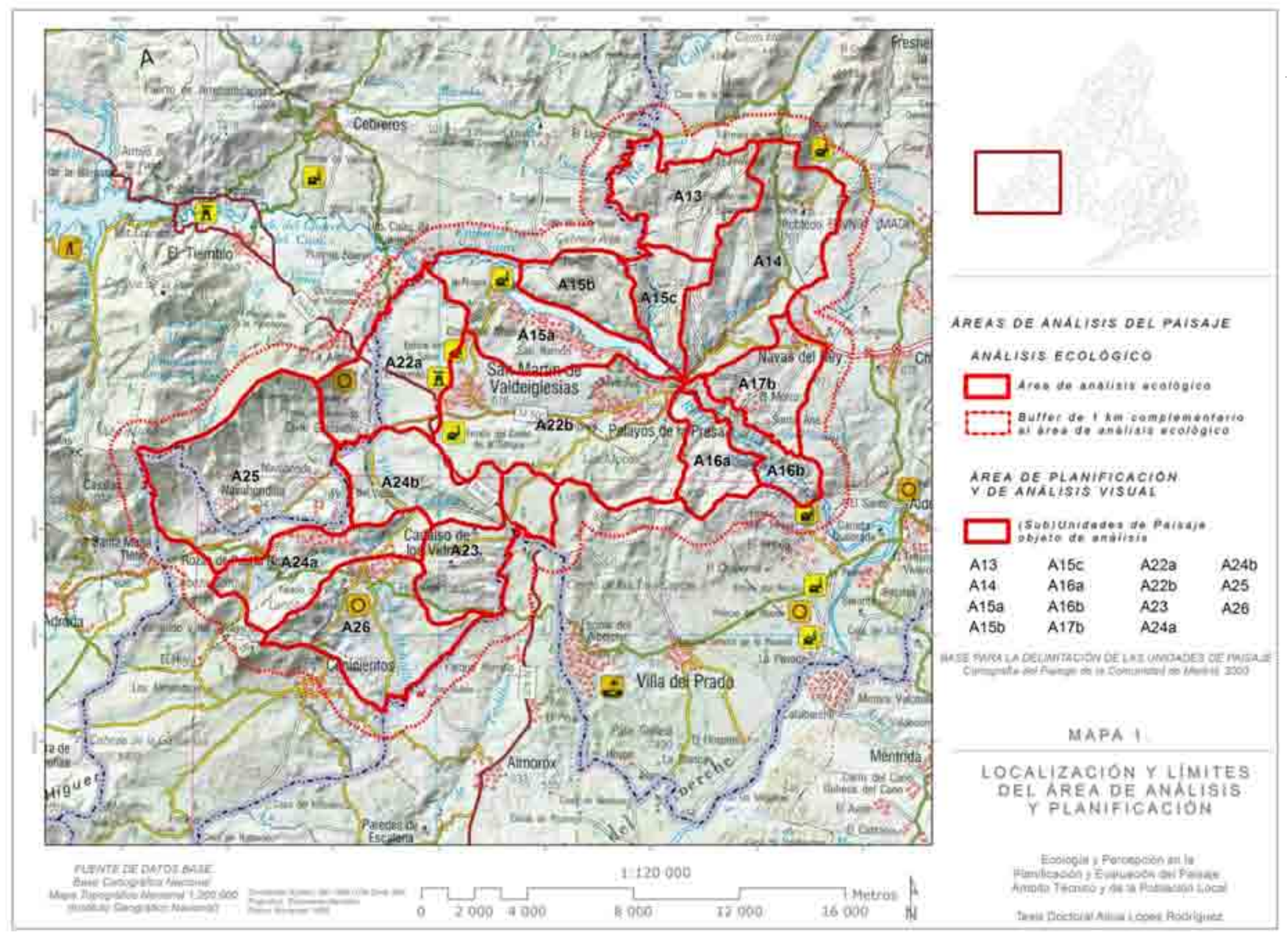

Figura 72. Localización y límites del área de análisis. 


\section{VII.2. DESCRIPCIÓN GENERAL DEL PAISAJE}

Administrativamente, el área de estudio comprende los términos municipales madrileños de San Martín de Valdeiglesias, Pelayos de la Presa y Cadalso de los Vidrios, y parte de los municipios de Navas del Rey, Robledo de Chavela, Las Rozas de Puerto Real y Cenicientos, además de parte de los municipios abulenses de Navahondilla y Cebreros. Comprende los núcleos de población de San Martín de Valdeiglesias (7.840 habitantes, datos de 2007 del Instituto Nacional de Estadística), Cadalso de los Vidrios (2.823 hab.), Las Rozas de Puerto Real (432 hab.) y Pelayos de la Presa (2.468 hab.), Navahondilla (165 hab.) y Navahonda (29 hab.). Además, existen numerosas urbanizaciones, fundamentalmente de segunda residencia, repartidas por el área: Entrepinos (285 hab.), El Morro (208 hab.), Costa de Madrid (163 hab.), Javacruz (163 hab.), San Ramón (132 hab.), San Juan (46 hab.), Santa Ana (45 hab.) y Navapark (34 hab.) (Mapa 1, Figura 72).

Está conectada con la capital por la carretera principal M-501, que continúa hasta Plasencia. La N-403 que conecta Ávila con Toledo atraviesa el área de norte a sur pasando por San Martín. El resto de carreteras son secundarias.

\section{Geomorfología y geología}

Aramburu Maqua, M. P. Escribano Bombín, R., Ramos Gonzalo, L., y Rubio Maroto, R. (2003). Cartografía del Paisaje de la Comunidad de Madrid. Madrid: Consejería de Medio Ambiente de la Comunidad de Madrid. Madrid: Dirección General de Promoción y Disciplina Ambiental Consejería de Medio Ambiente - Comunidad de Madrid.
Geomorfológicamente, la zona de estudio se ubica en un área de transición entre la Sierra de Gredos, la Sierra de Guadarrama y la depresión del Tajo. Así, se pueden encontrar dos grandes unidades fisiográficas: el Eje serrano-fosa del Alberche y la Rampa serrana (Aramburu Maqua, Escribano Bombín, Ramos Gonzalo, y Rubio Maroto, 2003).

EI EJE SERRANO-FOSA DEL ALBERCHE se despliega de forma oblicua, en dirección SO-NE. Comprende en su parte SO las estribaciones orientales de la sierra de Gredos (Alto del Mirlo - Cuerda de Pedro Duermes - Pico Guisando), y en su parte NE los relieves residuales del inicio de la Sierra de Guadarrama (Las Cabreras, sierra de La Almenara). Está fundamentalmente compuestas por materiales silíceos graníticos (granitos y gneises), y alcanzan altitudes de hasta 1.768 metros (Alto del Mirlo). Entre ambas cadenas de elevaciones graníticas se interpone el valle del Alberche, que forma un relieve del 
tipo depresión-corredor que conecta ambas mesetas (fosa tectónica de Cebreros-Valdeiglesias).

Las laderas de la sierra de solana dan paso de forma brusca a los piedemontes tipo rampa, que anteceden a las Ilanuras aluviales del Tajo. En la RAMPA SERRANA se despliega el lehm granítico, originado por el proceso de "arenización" del roquedo granítico de las elevaciones de la sierra. Esta rampa se encuentra disectada por la red fluvial, que en determinadas zonas forma fosas secundarias, como la del Arroyo de Tórtolas o la anegada por el Embalse de Picadas. Sobre ella sobresalen diversas elevaciones de formas más o menos abruptas, en forma de alineaciones y formas aisladas: la sierra de la HigueraCenicientos-Lancharrasa enlaza, a través de una sucesión de elevaciones de cierta altitud en dirección SO-NE (Alto la Mira, 1036; Loma de la Fuente Fría, 964; Cerro de Valdenoches, 902 m.), con la Cuerda de la Parada y Verduguera $(963,1038$ m.) y la sierra de la Almenara (1.259 m.), que inicia ya el ascenso hacia la sierra del Guadarrama en dirección algo más al norte. La Peña Cenicientos (1.252 m.) y la Peña de Cadalso (1.044 m.), de morfología tipo monteisla, se erigen como un elemento geomorfológico de referencia en la zona.

\section{Climatología}

La zona, climatológicamente, se encuadra bajo un régimen mediterráneo templado y seco de interior, con veranos secos y cálidos, inviernos suaves y lluvias que se concentran en primavera y verano. Las temperaturas de media varían entre los 13-15 C. La amplitud térmica es alta, alrededor de 20oC: el mes más frío (Enero) oscila entre 4 ㅇ y $60 \mathrm{C}$, y el mes más caluroso (Julio) entre $23 \circ$ y $25 \circ \mathrm{C}$. La pluviosidad media anual se encuentra entre 600 y 800 mm., debido a la cercanía de la sierra. Los meses secos son julio y agosto y el máximo pluviométrico se registra entre noviembre y diciembre, con otro máximo en marzo (Encinas, 2000; Sancho García, 2003).

Es necesario sin embargo hacer una distinción en sectores: el sector occidental (municipios de Rozas de Puerto Real Cenicientos y Cadalso de los Vidrios) constituye el área climatológicamente más Iluviosa y fresca, evolucionando hacia el este a condiciones de mayor termicidad y sequía (San Martín de Valdeiglesias y Pelayos de la Presa). Esto es debido a que el aire de influencia atlántica cargado de humedad topa contra el último obstáculo que representan las elevaciones de las estribaciones de Gredos, desvaneciéndose antes de llegar a las elevaciones alrededor del embalse de San Juan, que presentan además menor altitud.

Encinas, A. (2000). Propuesta de una metodología de análisis del paisaje para la integración visual de actuaciones forestales (Tesis doctoral no publicada). E.T.S. Ingenieros de Montes Universidad Politécnica de Madrid, Madrid.

Sancho García, I. (2003). Estudio del paisaje en la cuenca del río Alberche a su paso por la Comunidad de Madrid (Tesis doctoral no publicada). Fitoclimatología y dinámica vegetal. Universidad Autónoma de Madrid, Madrid. 


\section{Hidrografía}

La totalidad de la zona de estudio pertenece a la cuenca hidrográfica del Tajo. El río principal en torno al cual se articula la red hidrográfica de la zona es el Alberche, que atraviesa la fosa tectónica de CebrerosValdeiglesias, "rompiendo" la continuidad serrana y transitando hacia la Ilanura toledana, para encontrarse con el Tajo. En su recorrido dentro del área de estudio es embalsado en el Embalse de San Juan (año 1955, capacidad 162 hm³ , lámina de 650 ha) y el Embalse de Picadas (año 1952, capacidad 15 hm³ , lámina de 92 ha) (datos del Ministerio de Fomento). Ambos se utiliza fundamentalmente para riego, para aprovechamiento energético y para abastecimiento de agua en poblaciones de la periferia del Área Metropolitana de Madrid.

El tributario más importante del Alberche es el río Cofio, que se une a aquel por la margen izquierda del embalse de San Juan. Su caudal, aunque irregular, se mantiene durante todo el año. Desde la margen derecha del Alberche, los ríos más importantes, en razón de su caudal y su constancia, son el Arroyo de Las Tórtolas y su tributario el Avellaneda, y el Arroyo del Molino de la Presa. El resto de cursos de agua son arroyos de caudal irregular y escaso desarrollo.

\section{Biogeografía, vegetación y usos del suelo}

Sancho García, I. (2003) Estudio del paisaje en la cuenca del río Alberche a su paso por la Comunidad de Madrid (Tesis doctoral no publicada) Fitoclimatología y dinámica vegetal. Universidad Autónoma de Madrid, Madrid.
Desde el punto de vista biogeográfico, la vegetación se distribuye según la existencia de 2 zonas: la zona basal perteneciente al dominio fitoclimático mesomediterráneo (400-800 m. de altitud) y las elevaciones, que llegan a tener un fitoclima supramediterráneo (800$1.500 \mathrm{~m}$ ), que aparece sobre todo en el sector más occidental Sancho García, 2003).

EI DOMINIO MESOMEDITERRÁNEO es la zona naturalmente ocupada por los pinares, encinares y cultivos.

El pinar de pino piñonero (Pinus pinea) es la cubierta vegetal que se presenta en grandes extensiones en el piedemontes y lomas bajas, formando una de las mayores manifestaciones del centro peninsular. El pino piñonero ocupa prioritariamente exposiciones de solana, dando paso al pino resinero (Pinus pinaster) en exposiciones menos expuestas y en cotas más altas. Su presencia ha sido favorecida por el hombre desde antiguo por el interés de la producción de piñón, y por influencia antrópica presenta menores densidades y árboles con copas altas y ahuecadas para activar la producción de fruto. Ocupa los cerros graníticos y también parte de los relieves ondulados que por condiciones naturales corresponderían a la encina (Quercus ilex), con el que se mezcla en ocasiones dando lugar a un pinar desarrollado con 
un subpiso de encinar. El sotobosque está compuesto fundamentalmente por retama (Retama sphaerocarpa), jara pringosa (Cistus ladanifer) y cantueso (Lavandula stoechas).

La presencia de encinares también se ha visto reducida dado que los cultivos han ocupado históricamente las tierras más aptas de la zona llana. De tal manera, la encina ocupa fundamentalmente retazos entremezclados con los cultivos, en forma primordialmente arbustiva o poco desarrollada. Restan escasas manchas extensas, y en general poco desarrolladas, en suelos de menor interés agrícola. En este piso a la encina le acompaña frecuentemente el enebro (Juniperus oxycedrus). También la cornicabra (Pistacia terebinthus) aparece dispersa en laderas secas y pedregosas. La jara pringosa (Cistus ladanifer), retamas o escobas (Retama sphaerocarpa, Cytisus multiflorus), cantuesos (Lavandula stoechas), tomillos (Thymus masttichina, T. zygis) y el bercial (Stipa gigantea) completan la cohorte de matorral. Los melojos (Quercus pyrenaica) aparecen dispersos entre el encinar en los terrenos más frescos con suelos más profundos y entonces el sotobosque se enriquece con la presencia de la jara estepa (Cistus laurifolius) y la retama negra (Cytisus scoparia).

Localmente se pueden encontrar bosquetes de alcornoques o algún pie disperso, más frecuentes hacia el oeste por la mayor humedad que aporta la influencia atlántica.

Los cultivos se extienden en las zonas más llanas y con mejores suelos, fundamentalmente formando tres conjuntos bien diferenciados: la zona agrícola alrededor de San Martín, el mosaico agrícola-forestal de la subcuenca del arroyo Tordillos y los prados con setos del fondo del valle del Avellaneda. La base de cultivo son las viñas y olivares, en estructura minifundista muchas veces creando un mosaico agroforestal al combinarse con retazos de vegetación seminatural o pequeñas elevaciones con roca aflorante. Existe un estado de abandono general del campo, con numerosas parcelas con viñas arrancadas o invadidas por el pastizal-matorral. En el fondo del valle del arroyo Avellaneda la humedad edáfica es mayor, por lo que los prados y pastizales más o menos higrófilos se extienden, en ocasiones albergando setos arbolados y fresnedas trasmochadas que actúan como continuación de la vegetación de ribera.

En general las orlas de los cursos de agua representan una banda bastante más estrecha de lo que cabría esperar por la ocupación de cultivos y prados en las vegas y en numerosas ocasiones se ve interrumpida su continuidad. El aliso (Alnus glutinosa), junto con sauces (Salix sp.), fresnos (Fraxinus angustifolia), chopos (Populus 
alba, P. nigra) y algunos olmos (Ulmus minor) forman el estrato arbolado de las riberas.

EI DOMINIO SUPRAMEDITERRÁNEO se encuentra fundamentalmente en la parte más occidental del área. En las localizaciones más frescas, con mayor humedad y menor temperatura, la encina y el pino piñonero dan paso al melojo (Quercus pyrenaica) y al pino resinero (Pinus pinaster). El cortejo acompañante también varía en consecuencia, y aparecen la retama negra (Cytisus scoparius) y la jara estepa (Cistus laurifolius). El melojo forma masas boscosas submediterráneas fundamentalmente en la ladera sur del Cordal de Pedro Duermes, Cerro de Guisando y umbrías de la Peña Cenicientos, dada la mayor aportación de humedad que reciben de las nubes cargadas de humedad que provienen de la fachada atlántica. En la misma ladera, en su extremo occidental, se encuentra el castañar de Rozas de Puerto Real, relevante por formar una masa extensa y desarrollada, singularidad en el contexto de la Comunidad de Madrid. Coronando el Cordel de Pedro Duermes, se presentan retazos del pinar de pino resinero que domina en la ladera norte y que en la exposición sur sustituye al melojo únicamente en altura y en suelos más raquíticos o en pendiente mayor.

Existe un pequeño enclave por encima de los $1.400 \mathrm{~m}$, el Alto del Mirlo (1.768 m.), en el que los rigores del clima imponen una cobertura de matorral almohadillado y pastizal de gramíneas (Festuca indigesta, Nardus stricta en zona con encharcamiento). El piornal se forma fundamentalmente por piorno serrano (Cytisus oromediterraneus) y el cambrión (Echinospartum barnadesii), endemismo grediense, acompañados en algunos puntos de cambroños (Adenocarpus hispanicus).

\section{Incendios y repoblaciones forestales}

Decreto 59/2017, de 6 de junio, por el que se aprueba el Plan Especial de Protección Civil de Emergencia por Incendios Forestales en la Comunidad de Madrid (INFOMA). Boletín Oficial de la Comunidad de Madrid núm. 136 de 9 de junio de 2017 , p. 10 a 79.
El área de estudio es una zona castigada por los incendios forestales. Está catalogada como de alto riesgo a nivel nacional en razón de la ocurrencia de incendios y conatos en el último decenio (Decreto 59/2017) y, en el contexto de la Comunidad de Madrid, es una de las zonas más problemáticas en este aspecto. Se trata de una zona de monte mediterráneo en el que las condiciones climáticas y la dinámica natural incluyen la ocurrencia de incendios. A esto se une la acción distorsionadora antrópica, que provoca que la frecuencia y magnitud de los incendios forestales sean mayores: presencia elevada de interfaz urbano-forestal, uso recreativo del monte muy intenso en algunas áreas, extensas masas forestales, unido a un aprovechamiento menos intensivo del monte y un proceso de abandono de parcelas agrícolas que ha derivado en unas condiciones 
de las masas forestales inadecuadas (densidades muy elevadas, mayor densidad de matorral y madera muerta en el monte, mayor continuidad horizontal y vertical del combustible).

Como consecuencia de la incidencia de incendios, se han llevado a cabo campañas y repoblaciones puntuales en la zona desde hace décadas por parte de los servicios responsables de la Comunidad de Madrid y localizadas fundamentalmente en los montes de utilidad pública (Manuel Valdés, 1996).

Manuel Valdés, C. (1996). Tierras y montes públicos en la Sierra de Madrid (sectores central y meridional). Serie Estudios. Madrid: Ministerio de Agricultura, Pesca y Alimentación, Secretaría General Técnica.

\section{Medio socioeconómico}

En épocas pretéritas la presión humana determinó una profunda modificación del paisaje vegetal. Hoy día dicho paisaje se encuentra en transición debido al efecto contrario, despoblación, que ha caracterizado la mayor parte de los territorios de la meseta interior ibérica en los últimos 40 años. Históricamente la población se ha ocupado en labores agrícolas y los montes han estado sujetos a pastoreo, aprovechamiento maderero, de leñas, de piña, carboneo y algo de resinación. Todas estas actividades están en declive, y en muchas ocasiones se realizan únicamente como complemento a otras actividades del sector terciario y la construcción. La denominación de origen "Vinos de Madrid" ha impulsado la industria local asociada y en los últimos años se han expandido o han aparecido nuevas bodegas.

La actividad extractiva alcanza importancia localmente: en el ámbito de Cadalso de los Vidrios existe una larga tradición de cantería y al este de la peña de Cadalso, alrededor del arroyo de las Culebras, se extiende un paraje en el que la roca granítica aflora superficialmente y hasta 3 grandes canteras ocupan un espacio de más de 100 hectáreas.

La urbe madrileña, situada a unos $80 \mathrm{~km}$, ejerce una poderosa influencia sobre la zona por el uso turístico intensivo del Embalse de San Juan y la ocupación de segundas viviendas en las urbanizaciones. En el embalse de San Juan, concebido desde su construcción como polo de atracción turística a nivel nacional, la navegación a motor está permitida, y cuenta con un pequeño embarcadero y establecimientos hosteleros que atrae a una gran masa de visitantes en los meses estivales. La construcción de viviendas de segunda residencia ha supuesto un notable crecimiento urbanístico en la comarca, en ocasiones sin respeto por la planificación y legalidad vigente (Encinas, 2000; Sancho García, 2003).

Encinas, A. (2000). Propuesta de una metodología de análisis del paisaje para la integración visual de actuaciones forestales (Tesis doctoral no publicada). E.T.S. Ingenieros de Montes Universidad Politécnica de Madrid, Madrid.

Sancho García, I., 2003. Estudio del paisaje en la cuenca del río Alberche a su paso por la Comunidad de Madrid (Tesis doctoral no publicada). Fitoclimatología y dinámica vegetal. Universidad Autónoma de Madrid, Madrid. 

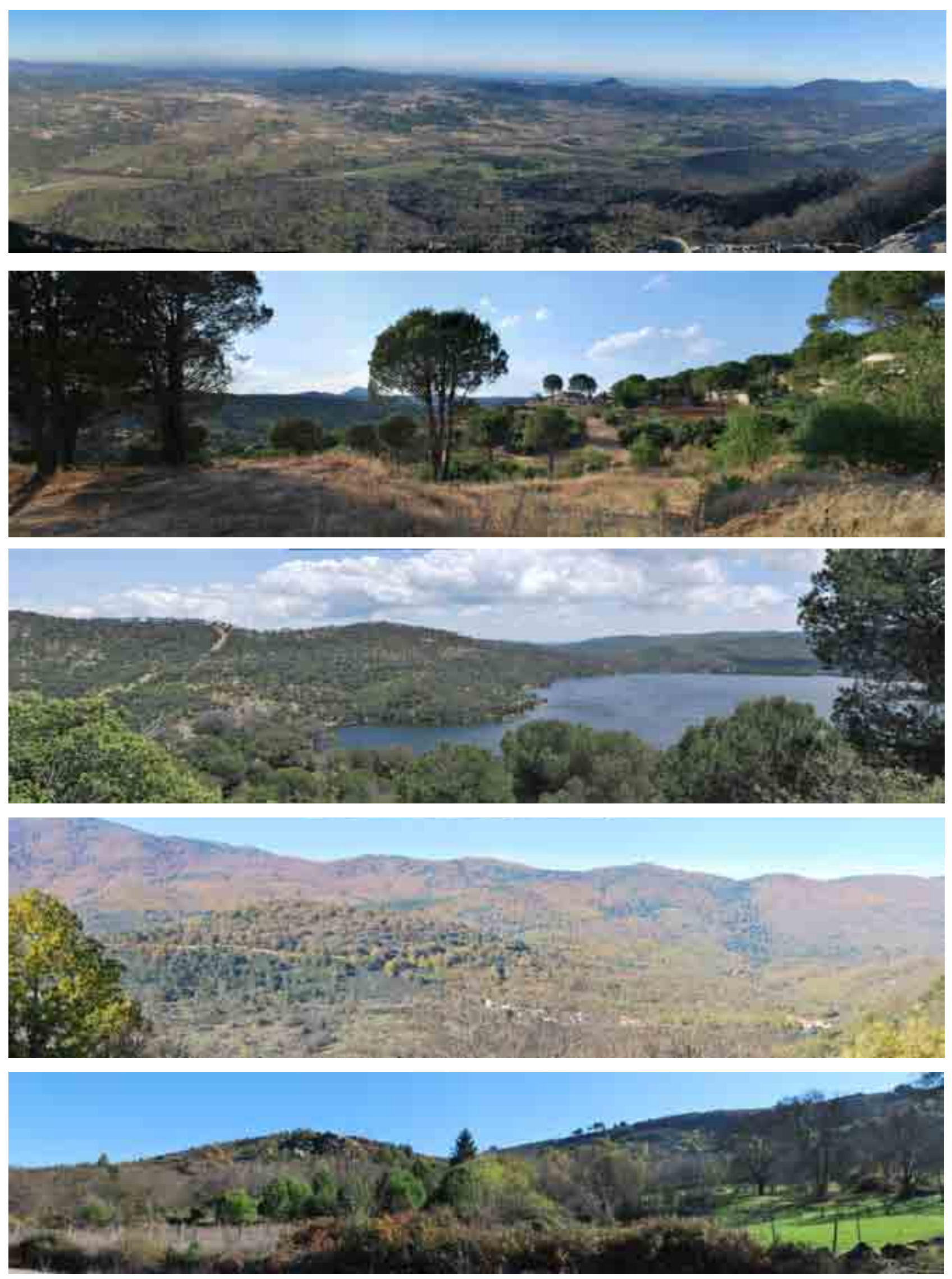

Figura 73. Vistas representativas del área de estudio. 


\section{Estructura de propiedad de la tierra y áreas protegidas}

En el área de estudio se encuentran fundamentalmente 3 tipos de estructura de tenencia de tierra: las grandes extensiones de montes forestados de propiedad pública (Montes de Utilidad Pública), las parcelas minifundistas agrícolas, de pequeña extensión y numerosos propietarios locales, y las grandes fincas de propiedad privada pertenecientes a grandes terratenientes que, en general, no viven en la zona.

En canto a las áreas protegidas, es de destacar que casi toda la zona está incluida dentro del LIC/ZEPA ES3110007 Cuencas de los ríos Alberche y Cofio, y una pequeña parte en el LIC/ZEPA ES4110113 Cerro de Guisando (Directiva 92/43/CEE y Directiva 2009/147/CE). Existen igualmente una gran extensión de espacios forestales catalogados como Montes de Utilidad Pública (Mapa 2, Figura 74).

Directiva 92/43/CEE del Consejo, de 21 de mayo de 1992, relativa a la conservación de los hábitats naturales y de la fauna y flora silvestres. Boletín Oficial del Estado núm. 206 de 22 de julio de 1992, p. 7 a 50.

\section{Directiva 2009/147/CE del} Parlamento Europeo y del Consejo, de 30 de noviembre de 2009, relativa a la conservación de las aves silvestres. Boletín Oficial del Estado núm. 20 de 26 de enero de 2010, p. 7 a 25.

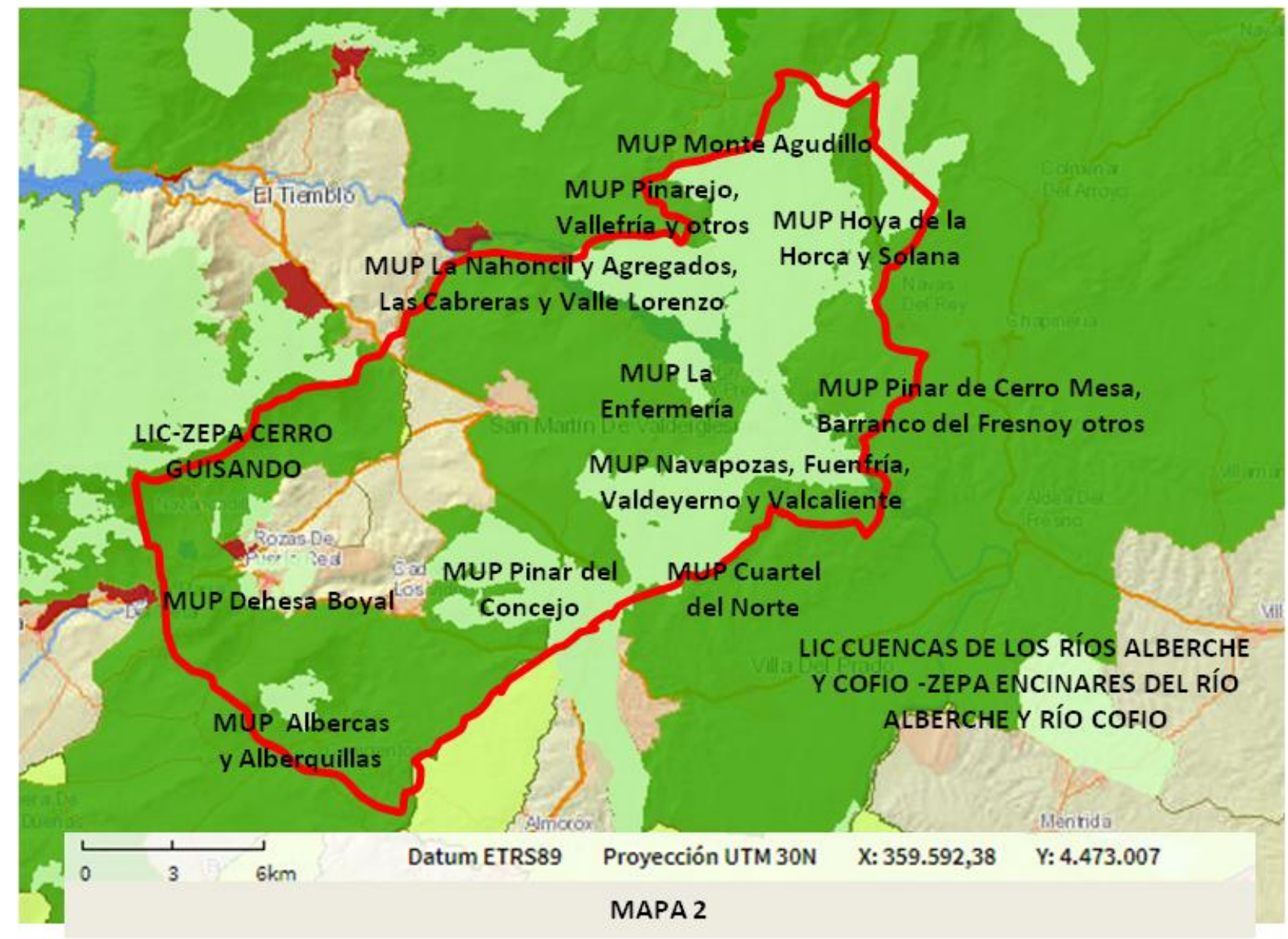

Figura 74. Áreas protegidas en la zona de estudio. 


\section{VII.3. EVALUACIÓN DEL ÁMBITO ECOLÓGICO}

\section{A.- ETAPA DESCRIPTIVA - FASE 1: INVENTARIO}

\section{A.1.1.- Inventario de especies de fauna presentes y status de protección}

Ministerio de Agricultura, Pesca y Alimentación y del Medio Ambiente (2018). Inventario Español de Especies Terrestres (IEET) [formato shapefile] Madrid: Ministerio de

Agricultura, Pesca y Alimentación y del Medio Ambiente. Recuperado de https://www.miteco.gob.es/es/ biodiversidad/temas/inventario s-nacionales/inventarioespecies-terrestres/
La identificación de las especies de fauna presentes en la zona se basó en el Inventario Español de Especies Terrestres (IEET, año 2018). Se han tenido en cuenta las cuadrículas del IEET de $10 \times 10 \mathrm{~km}$ que incluyen una parte significativa del área de estudio, esto es, al menos un $20 \%$ de la cuadricula comprendida en la zona: 30TUK77, 30TUK76, 30TUK87, 30TUK86, 30TUK85, 30TUK97, 30 TUK96 (Figura 75).

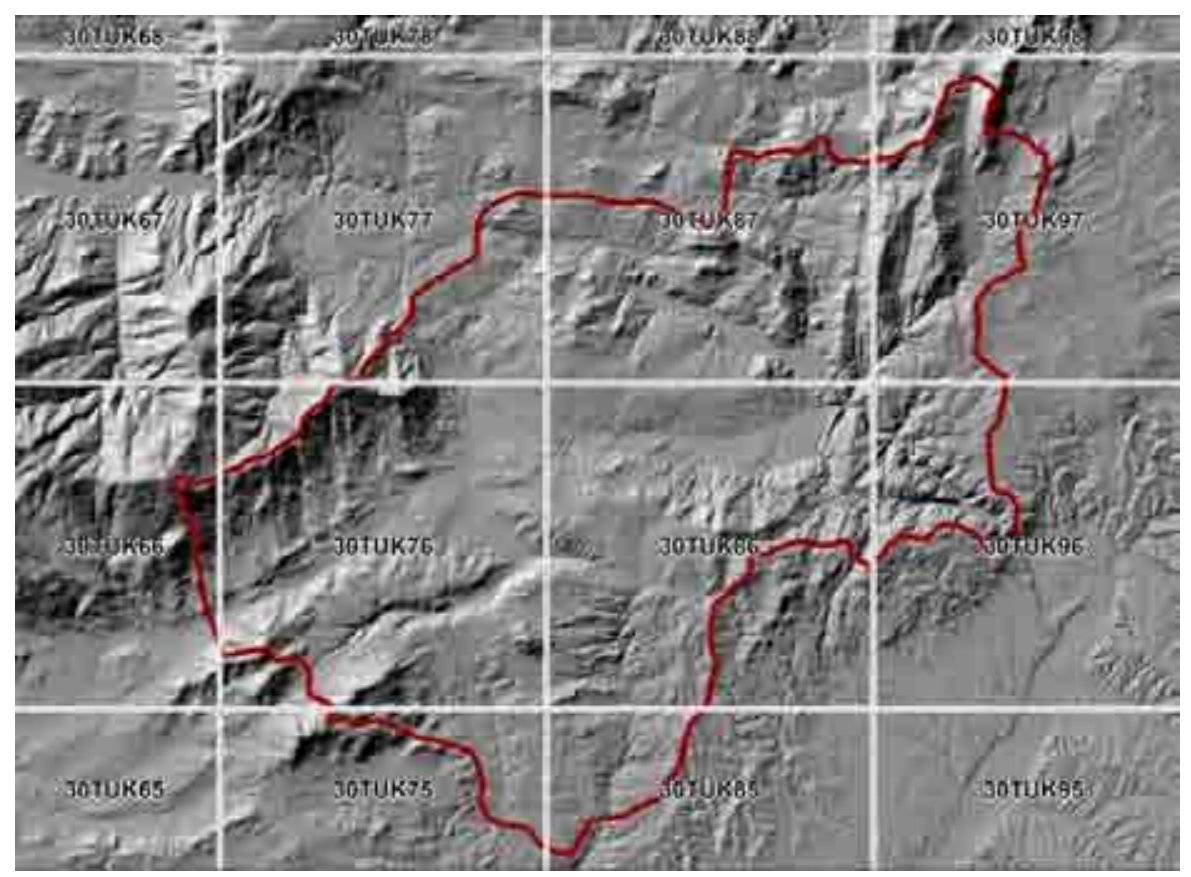

Figura 75. Distribución de la malla 10x10km del Inventario Español de Especies Terrestres (IEET) con respecto a la zona de estudio.

El IEET presenta como ventaja el hecho de ser un listado institucional de ámbito nacional, llevado a cabo por expertos, siguiendo criterios científicos suficientemente homogéneos y sistematizados en todo el 
territorio. Ofrece por tanto información fiable y contrastada, derivada de un sistema estable, actualizado y fácilmente accesible, y a un nivel de detalle adecuado si se pretende realizar un análisis a nivel regional/comarcal.

A partir del Inventario Español de Especies Terrestres (IEET) se identificaron como presentes en la zona un total de 241 especies de fauna, repartidas entre mamíferos (50), aves (127), reptiles (24), anfibios (14), peces (15) e invertebrados (11). El listado completo y los detalles de su designación como especie protegida a nivel mundial, europeo, nacional y regional se recogen en el Anexo II.

\section{A.1.3.- Selección de las especies con significación a nivel de paisaje}

Tomando como base el listado de del IEET, se ha realizó una selección de las especies de fauna presentes en el área que a priori tuvieran suficiente relevancia a la escala considerada, esto es, a escala paisaje, y para los objetivos planteados en el análisis. Por tanto, de las 241 especies presentes, las no preseleccionadas se listan a continuación:

- Invertebrados (11): con dominios vitales muy restringidos y/o muy dependientes de una planta o grupo de plantas huésped, por lo que tienen poca significación en cuanto a conservación a escala del paisaje, sino más bien están vinculados a la conservación de sitios muy localizados y derivados de un inventario de gran detalle.

- Anfibios (14): son especies con escasa movilidad y dependientes de cursos y puntos de agua con condiciones muy particulares, no detectables en la escala y tipo de análisis definido.

- Reptiles (24): al igual que en el caso anterior, su difícil tratamiento cartográfico y significación a la escala de paisaje considerada hace que su análisis específico sea más conveniente.

- Peces y aves/mamíferos estrictamente acuáticos $(15+10)$ : dado que la calidad y cantidad de agua dependen de procesos muy particulares, muy dependientes en el área 
considerada de la gestión hídrica humana y de difícil inventario, su tratamiento se deja como un análisis específico de distinta naturaleza.

- Aves aerófagas (5) y quirópteros (17): su relativa independencia de los usos del suelo por sus costumbres aerófagas y vinculación con lugares muy específicos de refugio y reproducción (hábitos cavernícolas/fisurícolas o huecos de árboles) los posiciona como un grupo singular cuyo tratamiento merece un análisis diferente.

- Mamíferos con dominio vital restringido (14): se excluyen del análisis las especies de mamíferos de pequeño tamaño que presentan dominios vitales de varias decenas o pocas centenas de metros. Dada la escala de análisis, su inclusión no supondría un condicionamiento significativo.

- Especies exóticas invasoras o introducidas con fines económico-cinegéticos o ganaderos y que dependen exclusivamente del manejo humano (4). En este grupo se encuentran las especies cuyo efecto ecológico es negativo o cuyas poblaciones están completamente supeditadas a la intervención humana.

- Otras (6). Cabra montés (Capra pyrenaica), con presencia residual, y aves esteparias, propias de ambientes localizados más al sur del ámbito de estudio.

Finalmente, las especies preseleccionadas fueron 121, correspondientes al grupo de los mamíferos terrestres de mediano y gran tamaño (14) y de las aves (107) (ver Tabla en Anexo II).

\section{A.1.2.- Inventario de los elementos biofísicos del paisaje}

La Tabla 8 muestra de manera sintética las variables del medio relevantes para el análisis especies-hábitats, indicando la escala o resolución de la información, el grado de actualización y la fuente de origen de los datos. 
Tabla 8. Listado de variables del medio relevantes para el análisis ecológico.

\begin{tabular}{|c|c|c|c|}
\hline TEMA & INFORMACIÓN & ESCALA/Resolución & AÑO ACTUALIZACIÓN / FUENTE DE DATOS \\
\hline LOCALIZACIÓN Y LÍMITES & $\begin{array}{l}\text { Límites de la zona de estudio sobre Base } \\
\text { Cartográfica Nacional }\end{array}$ & $1: 50.000$ & $\begin{array}{l}\text { Actualización continua / Base Cartográfica Nacional (Instituto Geográfico } \\
\text { Nacional, 2015) }\end{array}$ \\
\hline CLIMA/BIOCLIMA & $\begin{array}{l}\text { Temperatura media anual } \\
\text { Precipitación media anual } \\
\text { Clasificación bioclimática }\end{array}$ & $\begin{array}{l}\text { Resolución } 50 \mathrm{~m} \\
\text { (interpolación a partir de los } \\
\text { datos de las estaciones } \\
\text { meteorológicas de la AEMET) }\end{array}$ & $\begin{array}{l}\text { Comunidad de Madrid, 2007. Atlas. El medio ambiente en la Comunidad de } \\
\text { Madrid. } \\
\text { (Rivas-Martínez (Coord.), 2007) }\end{array}$ \\
\hline GEOLOGÍA Y LITOLOGÍA & Tipos litológicos & $1: 50.000$ & $\begin{array}{l}\text { Mapa Geológico España } \\
\text { (Instituto Geológico y Minero de España) }\end{array}$ \\
\hline GEOMORFOLOGÍA & $\begin{array}{l}\text { Dominios y Elementos fisiográficos } \\
\text { Pendientes y Orientaciones }\end{array}$ & $\begin{array}{l}1: 500.000 \text { y } 1: 50.000 \\
5 \mathrm{~m}\end{array}$ & $\begin{array}{l}\text { (Pedraza, Martín Duque, y Carrasco, 1998) } \\
\text { Modelo Digital del Terreno (IGN) }\end{array}$ \\
\hline HIDROGRAFÍA & $\begin{array}{l}\text { Red de cursos de agua, embalses, lagunas y } \\
\text { charcas }\end{array}$ & $\begin{array}{l}1: 50.000 \text { y } \\
1: 25.000\end{array}$ & $\begin{array}{l}\text { Base Cartográfica Nacional } \\
\text { (IGN) }\end{array}$ \\
\hline SUELOS & $\begin{array}{l}\text { Clasificación de tipos de suelo según la sistemática } \\
\text { de la FAO }\end{array}$ & $1: 200.000$ & $\begin{array}{l}\text { Comunidad de Madrid, 2007. Atlas. El medio ambiente en la Comunidad de } \\
\text { Madrid. }\end{array}$ \\
\hline VEGETACIÓN Y USOS DEL SUELO & $\begin{array}{l}\text { Categorías de Vegetación y Usos según Tipo, } \\
\text { Composición, Densidad, desarrollo }\end{array}$ & $\begin{array}{l}1: 50.000 \\
1: 25.000\end{array}$ & $\begin{array}{l}\text { Fusión del MFE50 y SIOSE2011 con actualización mediante interpretación de } \\
\text { ortofoto de máxima actualidad 2014/ Mapa Forestal Nacional - MFE50) } \\
2011 \text { / Cartografía de Ocupación del Suelo de España - SIOSE2011 (IGN) }\end{array}$ \\
\hline ORTOFOTO & Ortofotografías aéreas digitales & Resolución $25 \mathrm{~cm}$ & 2016 / Plan Nacional de Ortofotografía Aérea -PNOA IGN) \\
\hline
\end{tabular}




\section{B.- ETAPA DE SÍNTESIS - FASE 2: SIMPLIFICACIÓN DE RELACIONES ECOLÓGICAS: FORMACIÓN DE GRUPOS DE ESPECIES ("GUILDS")}

Para la formación de los grupos de especies se optó por un tratamiento diferenciado de los mamíferos terrestres y las aves, dadas las diferencias en los hábitos y condiciones de movilidad de ambos grupos. Esta distinción permite formar grupos más coherentes y facilitará el tratamiento posterior en clave de evaluación de idoneidad de hábitat.

\section{B.2.a.- Determinación de los grupos de mamíferos (Método deductivo)}

En el caso de los mamíferos terrestres, dado el reducido número de especies objeto de análisis, se consideró como más operativa la agrupación basada en el criterio experto. Para ello, se recopiló información en la literatura especializada sobre los requerimientos de hábitats de las 14 especies seleccionadas y se agruparon basándose fundamentalmente en las preferencias por ciertas coberturas del suelo y la combinación y configuración espacial de estas (Tabla 9). 
Tabla 9. Grupos de mamíferos terrestres en el área de estudio: listado de especies asociadas, breve descripción del biotopo.

\begin{tabular}{|c|c|c|}
\hline \multicolumn{3}{|c|}{ GRUPOS DE ESPECIES DE MAMÍFEROS TERRESTRES } \\
\hline NOMBRE-TIPO DE GRUPO & ESPECIES INCLUIDAS & DESCRIPCIÓN \\
\hline M_A.- ESPECIES DE ÁMBITO FORESTAL & $\begin{array}{l}\text { - Ardilla (Sciurus vulgaris) } \\
\text { - Corzo (Capreolus capreolus) } \\
\text { - Garduña (Martes foina) } \\
\text { - Gineta (Genetta genetta) }\end{array}$ & $\begin{array}{l}\text { Especies que ocupan áreas boscosas, en las que encuentran cobijo y alimento. El desarrollo } \\
\text { de gran parte de su actividad y la consecución de su ciclo vital depende de la existencia de } \\
\text { estas masas }\end{array}$ \\
\hline $\begin{array}{l}\text { M_B.- ESPECIES GENERALISTAS QUE } \\
\text { REQUIEREN CIERTA COBERTURA FORESTAL }\end{array}$ & $\begin{array}{l}\text { - Lirón careto (Eliomys quercinus) } \\
\text { - Jabalí (Sus scrofa) } \\
\text { - Zorro (Vulpes vulpes) } \\
\text { - Turón (Mustela putorius) } \\
\text { - Comadreja (Mustela nivalis) }\end{array}$ & $\begin{array}{l}\text { Especies que pueden completar su ciclo biológico en el medio forestal, pero que pueden } \\
\text { explotar una gran variedad de hábitats y recursos. } \\
\text { Les favorece la diversidad de usos del suelo, que les provee de mayor variedad de recursos } \\
\text { alimenticios a lo largo del año debido a su capacidad para explotarlos, siempre que les } \\
\text { proporcionen una mínima cobertura vegetal para refugio-cría. }\end{array}$ \\
\hline $\begin{array}{l}\text { M_C.- ESPECIES QUE PREFIEREN PAISAJES EN } \\
\text { MOSAICO }\end{array}$ & $\begin{array}{l}\text { - Tejón (Meles meles) } \\
\text { - Gato montés (Felis silvestris) }\end{array}$ & $\begin{array}{l}\text { Especies que necesitan cierto grado de cobertura leñosa como lugar para refugio y cría, } \\
\text { pero cuya presencia también precisa de medios heterogéneos que combinen de forma } \\
\text { equilibrada estos espacios con áreas abiertas para la caza y búsqueda de alimento. } \\
\text { Requieren por tanto una estructura del paisaje en mosaico y evitan las áreas homogéneas, } \\
\text { tanto si se trata de bosques continuos, como si se trata de áreas abiertas extensas. }\end{array}$ \\
\hline $\begin{array}{l}\text { M_D.- ESPECIES DE ÁREAS DE TRANSICIÓN } \\
\text { ENTRE MEDIOS CON COBERTURA CERRADA Y } \\
\text { MEDIOS ABIERTOS }\end{array}$ & $\begin{array}{l}\text { Dominio vital pequeño } \\
\text { - Conejo (Oryctolagus cuniculus) } \\
\text { - Liebre (Lepus granatensis) } \\
\text { Dominio vital extenso } \\
\text { - Ciervo (Cervus elaphus) }\end{array}$ & $\begin{array}{l}\text { Especies que ocupan la zona de transición entre dos medios y usan estos de forma } \\
\text { diferenciada a lo largo del día. Precisan de una combinación de zonas con cobertura leñosa } \\
\text { para protegerse (bosques y matorrales altos) anexas a áreas abiertas en las que } \\
\text { alimentarse (herbazales, matorral bajo, cultivos). }\end{array}$ \\
\hline
\end{tabular}




\section{B.2.b.- Determinación de los grupos de aves (Análisis clúster)}

En el caso de las aves, dado el elevado número de especies presentes (106), un tratamiento más sistemático de sus requerimientos y un método de agrupamiento más objetivable se estimó más adecuado, por lo que se optó por un análisis clúster del tipo jerárquico aglomerativo. Además, la jerarquía de agrupación que establece este método resulta muy útil a la hora de elegir el número de grupos.

\section{B.2.b.1.- Selección de variables caracterizadoras del medio}

Se seleccionaron una serie de variables relacionadas con aspectos de tipología, composición y estructura de las coberturas del suelo asociados a los potenciales requerimientos de las especies a tratar. Dichas variables fueron seleccionadas por su significación para los objetivos del estudio (la planificación basada en los elementos del paisaje con expresión física y espacial), por ser cartografiables y, por supuesto, por ser relevantes en cuanto a los requerimientos de las especies tratadas. La Tabla 10 recoge las variables seleccionadas.

Tabla 10. Listado de variables que caracterizan la cobertura del suelo incluidas en el análisis.

\begin{tabular}{|c|c|}
\hline \multirow{14}{*}{ TIPO COBERTURA } & Pinares \\
\hline & Encinares \\
\hline & Melojares \\
\hline & Castañares \\
\hline & Riberas \\
\hline & Humedales \\
\hline & Matorrales \\
\hline & Herbazales \\
\hline & Cultivos herbáceos de secano \\
\hline & Cultivos leñosos \\
\hline & Cultivos con arbolado disperso \\
\hline & Mosaico de cultivos y retazos de vegetación semi-natural \\
\hline & Afloramientos rocosos \\
\hline & Cortados rocosos \\
\hline \multirow{5}{*}{$\begin{array}{l}\text { CARACTERÍSTICAS } \\
\text { ESTRUCTURALES }\end{array}$} & Repoblaciones \\
\hline & Masa arbolada madura \\
\hline & Masa arbolada joven \\
\hline & Masa arbolada densa \\
\hline & Masa arbolada clara \\
\hline \multirow{2}{*}{ POSICIÓN } & Borde \\
\hline & Interior \\
\hline
\end{tabular}


NOTA. Aunque la presencia de sotobosque puede ser una variable importante a tener en cuenta, la imposibilidad de cartografiarla impide que entre a formar parte del listado.

\section{B.2.b.2.- Confección de la matriz de relación especies-características del medio}

Para definir las preferencias de cada especie en el uso del medio, se construyó una matriz en la que viene indicada la mayor o menor afinidad de cada una de ellas por cada variable del medio seleccionada. Dichas preferencias se distinguen en dos ámbitos: importancia para la cría-refugio de la especie, e importancia para su alimentación. Si bien la diferenciación entre cría-refugio y alimentación multiplica las variables tenidas en cuenta y complica el análisis, permite una descripción más fiel del uso del hábitat (Short y Burnham, 1982). En el caso del análisis pretendido, resulta esencial por ejemplo para poder tener en cuenta adecuadamente los requerimientos de las especies que combinan varios medios dependiendo de la actividad que lleven a cabo en cada uno.

Short, H. L. y Burnham, K. P. (1982). Technique for structuring wildlife guilds to evaluate impacts on wildlife communities (Special Scientific Report - Wild life n. 244). Washington, D.C.: United States Department of the Interior. Fish and Wildlife Service.

El índice seleccionado para representar las preferencias fue del tipo cualitativo ordinal:

- Valor 0 --> la especie no usa nunca o casi nunca el hábitat con dicha característica o incluso lo rehúye.

- Valor 1 --> la especie puede usar el hábitat con esa característica, entre otros, o lo ocupa de forma secundaria.

- Valor 2 --> la especie tienen una especial preferencia por ese hábitat o esa característica, o bien es el único que ocupa.

La asignación de valores del índice de preferencias se derivó de la información extraída de la literatura especializada. El Anexo II recoge la asignación detallada de este índice por cada especie y variable considerada. Puesto que la escala de evaluación es homogénea para todas las variables, no fue necesario normalizarlas para el análisis. 
B.2.b.3.- Elección del índice de distancia y del método de agrupamiento

Previo al análisis de agrupamiento propiamente dicho, se aplicó un análisis de detección de casos atípicos (outliers), es decir, especies con preferencias que el método no ajusta bien en ningún grupo. Para ello, se aplicó la medida de similitud basada en la distancia euclídea al cuadrado y el método de agrupamiento por el vecino más cercano. Dicho método produce grupos encadenados muy sensibles a la existencia de este tipo de casos. En este caso, los casos atípicos correspondieron al Búho real (Bubo bubo), la Cigüeña negra (Ciconia nigra), Cigüeña blanca (Ciconia ciconia), Cuervo (Corvus corax) y Estornino negro (Sturnus vulgaris). Estas especies se fueron analizadas de forma específica en una fase posterior.

El análisis clúster se aplicó utilizando el índice de similitud de distancia euclídea al cuadrado y mediante el método de agrupamiento por enlace promedio entre grupos. Para comprobar la estabilidad de los resultados, se realizó el análisis también por el método de Ward. Ambos métodos son comúnmente utilizados y arrojaron resultados con tendencias y con una lógica ecológica similares (el Anexo II) recoge los detalles del análisis clúster para el caso de las aves).

\section{B.2.b.4.- Selección del número de grupos y análisis de la coherencia ecológica de los resultados}

Los resultados se presentan en forma de dendrograma, en el que aparece la distancia de corte que determina el número de grupos seleccionados (Figura 75). Los resultados detallados se recogen en el Anexo II).

Para la elección del número de grupos se tuvo en cuenta el modo y distancia de agrupamiento de las especies, combinado con la significación ecológica y la necesaria operatividad que impone el contexto de planificación. Igualmente se reasignaron las especies que se apartaron del análisis por su efecto distorsionador a un grupo con preferencias suficientemente afines, o bien, se posicionaron como especies merecedoras de un análisis específico: 
Búho real (Bubo bubo) y Cuervo (Corvus corax) --> ESPECIES ASOCIADAS A ROQUEDOS

Estornino negro (Sturnus vulgaris) --> ESPECIES DE ÁREAS ABIERTAS CON MATORRALES Y ARBOLADO DISPERSO

Cigüeña negra (Ciconia nigra) --> TRATAMIENTO ESPECÍFICO

Cigüeña blanca (Ciconia ciconia) --> TRATAMIENTO ESPECÍFICO

El enunciado de los grupos de aves definitivos y el listado de las especies que lo componen se recogen en la Tabla 11. 


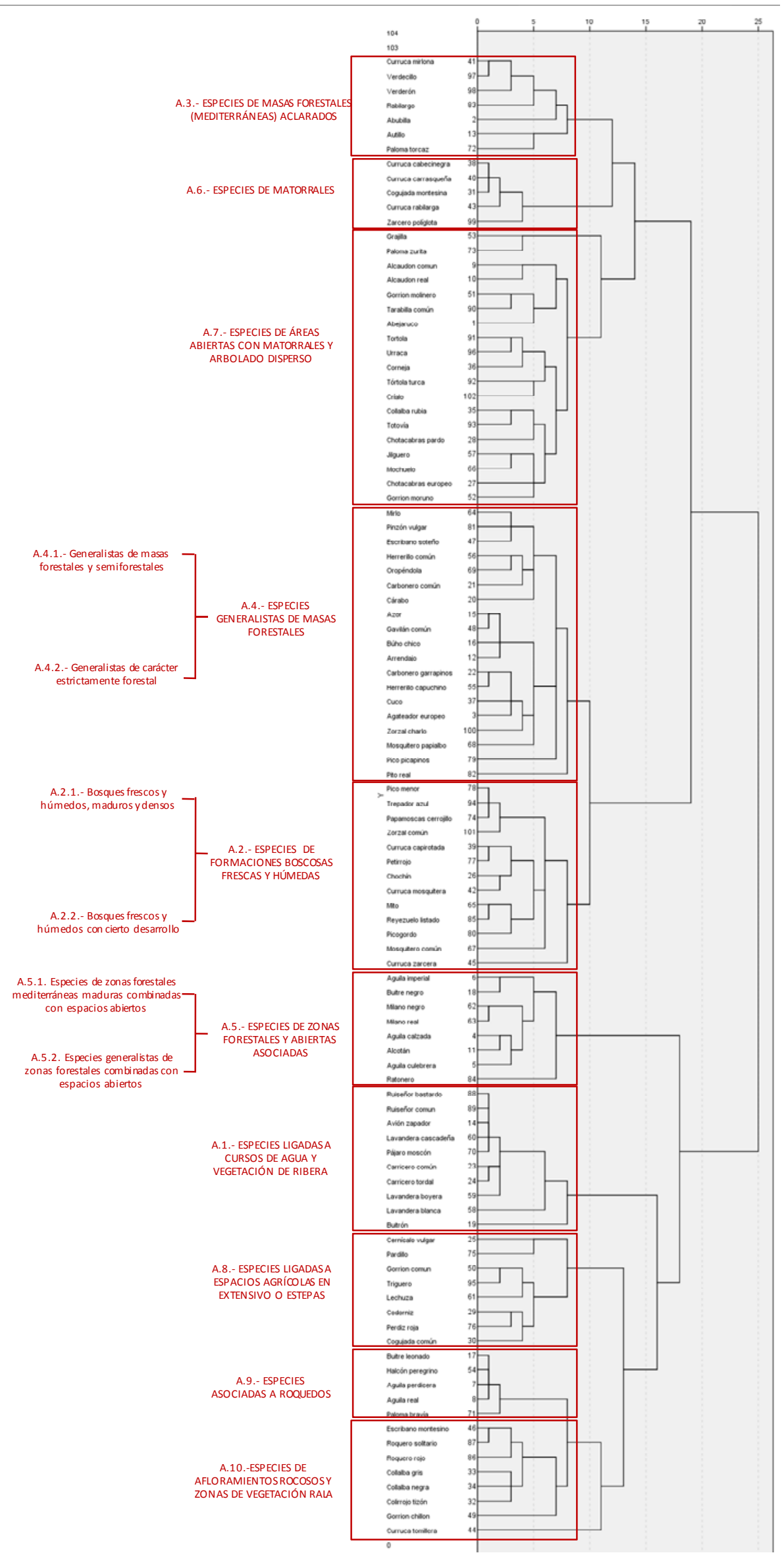

Figura 75. Dendrograma resultado del análisis clúster para las aves y definición de grupos. 
Tabla 11. Grupos de aves en el área de estudio: listado de especies asociadas, breve descripción del medio utilizado.

\begin{tabular}{|c|c|c|}
\hline \multicolumn{3}{|c|}{ GREMIOS ECOLÓGICOS DE AVES } \\
\hline NOMBRE-TIPO DE GREMIO & ESPECIES INCLUIDAS & DESCRIPCIÓN - FUENTES DE INFORMACIÓN \\
\hline $\begin{array}{l}\text { A.1.- ESPECIES LIGADAS A CURSOS DE AGUA Y } \\
\text { VEGETACIÓN DE RIBERA }\end{array}$ & $\begin{array}{l}\text { Avión zapador (Riparia riparia) } \\
\text { Carricero común (Acrocephalus scirpaceus) } \\
\text { Carricero tordal (Acrocephalus arundinaceus) } \\
\text { Lavandera boyera (Motacilla flava)** } \\
\text { Lavandera cascadeña (Motacilla cinerea)** } \\
\text { Lavandera blanca (Motacilla alba) } \\
\text { Pájaro moscón (Remiz pendulinus) } \\
\text { Ruiseñor bastardo (Cettiacetti) } \\
\text { Ruiseñor común (Luscinia megarhynchos) } \\
\text { Buitrón (Cisticola juncidis) }\end{array}$ & $\begin{array}{l}\text { Especies completamente ligadas a la existencia de cursos o masas de agua y dependientes en gran } \\
\text { medida de la vegetación de ribera bien conservada en las orillas. Completan su ciclo reproductivo } \\
\qquad \text { en este hábitat. } \\
\text { Pueden ocupar secundariamente herbazales o formaciones vegetales húmedas en las } \\
\text { proximidades (prados húmedos, prados con setos, bosques y malezas con mayor humedad } \\
\text { edáfica), especialmente si se localizan cerca de las riberas. }\end{array}$ \\
\hline $\begin{array}{l}\text { A.2.- FORMACIONES BOSCOSAS FRESCAS Y } \\
\text { HÚMEDAS }\end{array}$ & \multicolumn{2}{|c|}{$\begin{array}{l}\text { Especies de carácter eminentemente forestal que presentan una marcada predilección por los bosques frescos y húmedos con un mínimo de } \\
\text { madurez. Son especies con un mayor o menor matiz eurosiberiano, que se ligan a bosques de caducifolios (castañares), a las masas de frondosas } \\
\text { submediterráneas (formaciones de Quercus pyrenaica) o formaciones de ámbito mediterráneo con mayor grado de humedad y frescor (formaciones } \\
\text { de ribera en ámbito mediterráneo, encinares o pinares húmedos y en umbría). } \\
\text { Todas gustan de ocupar las formaciones arbóreas de ribera y varias de ellas utilizan los bosques de galería para penetrar en los ámbitos más } \\
\text { mediterráneos, por lo que es importante tenerlos en cuenta como hábitats de cría y refugio en este ámbito y por su función como conectores. }\end{array}$} \\
\hline $\begin{array}{r}\text { A.2.1. Bosques frescos y húmedos } \\
\text { con cierto desarrollo }\end{array}$ & $\begin{array}{l}\text { Chochín (Troglodytes troglodytes) } \\
\text { Curruca mosquitera (Sylvia borin) } \\
\text { Curruca capirotada (Sylvia atricapilla) } \\
\text { Curruca zarcera (Sylvia communis) } \\
\text { Mosquitero común (Phylloscopus collybita) } \\
\text { Mito (Aegithalos caudatus) } \\
\text { Petirrojo (Erithacus rubecula) } \\
\text { Picogordo (Coccothraustes coccothraustes) } \\
\text { Reyezuelo listado (Regulus ignicapilla) }\end{array}$ & $\begin{array}{l}\text { Es el grupo de especies con requerimientos más generalistas dentro del tipo descrito. Ocupan } \\
\text { cualquier tipo de bosque fresco y húmedo. }\end{array}$ \\
\hline $\begin{array}{r}\text { A.2.2. Bosques frescos y húmedos, } \\
\text { maduros y densos }\end{array}$ & $\begin{array}{l}\text { Papamoscas cerrojillo (Ficedula hypoleuca) } \\
\text { Pico menor (Dendrocopos minor) } \\
\text { Trepador azul (Sitta europaea) } \\
\text { Zorzal común (Turdus philomelos) }\end{array}$ & $\begin{array}{l}\text { Presentan unos requerimientos algo más estrictos que el grupo anterior: además de un } \\
\text { ambiente fresco y húmedo, necesitan la presencia de arbolado viejo para ubicar sus nidos } \\
\text { (por sus hábitos trogloditas) y también una cobertura arbórea densa. }\end{array}$ \\
\hline
\end{tabular}




\begin{tabular}{|c|c|c|}
\hline Tabla 11 (Cont.) & \multicolumn{2}{|c|}{ GREMIOS ECOLÓGICOS DE AVES } \\
\hline NOMBRE-TIPO DE GREMIO & ESPECIES INCLUIDAS & DESCRIPCIÓN - FUENTES DE INFORMACIÓN \\
\hline $\begin{array}{l}\text { A.3. MASAS FORESTALES (MEDITERRÁNEAS) } \\
\text { ACLARADAS }\end{array}$ & $\begin{array}{l}\text { Abubilla (Upupa epops) } \\
\text { Autillo (Otus scops) } \\
\text { Curruca mirlona (Sylvia hortensis) } \\
\text { Paloma torcaz (Columba palumbus) } \\
\text { Rabilargo (Cyanopica cyana) } \\
\text { Verdecillo (Serinus serinus) } \\
\text { Verderón (Carduelis chloris) }\end{array}$ & $\begin{array}{l}\text { Especies con matiz mediterráneo, con una acusada preferencia o incluso dependencia de } \\
\text { masas desarrolladas con una estructura arbolada aclarada. En la zona se asocian claramente } \\
\text { con las formaciones mediterráneas de pinares y encinares abiertos, y ocupan muchas veces } \\
\text { los cultivos arbóreos (olivares, almendrales). }\end{array}$ \\
\hline A.4.- GENERALISTAS DE MASAS FORESTALES & \multicolumn{2}{|c|}{$\begin{array}{l}\text { Especies típicamente forestales, que son capaces de explotar un amplio rango de masa arboladas. Aunque muchas muestran una cierta preferencia } \\
\text { en cuanto a composición, desarrollo o estructura de ciertas masas, son especies forestales muy plásticas. }\end{array}$} \\
\hline $\begin{array}{l}\text { A.4.1. Generalistas de masas } \\
\text { forestales y semiforestales }\end{array}$ & $\begin{array}{l}\text { Cárabo (Strix aluco) } \\
\text { Carbonero común (Parus major) } \\
\text { Herrerillo común (Parus caeruleus) } \\
\text { Oropéndola (Oriolus oriolus) } \\
\text { Pinzón vulgar (Fringilla coelebs) } \\
\text { Mirlo (Turdus merula) } \\
\text { Escribano soteño (Emberiza cirlus) }\end{array}$ & $\begin{array}{c}\text { Especies muy adaptables, en general con bastante capacidad para ocupar cualquier tipo de } \\
\text { masa arbolada, ya sea de composición, desarrollo o estructura, en cualquier ambiente. Son } \\
\text { capaces incluso de ocupar hábitats semiforestales, o espacios abiertos con árboles dispersos, } \\
\text { matorrales altos e incluso cultivos leñosos arbóreos. }\end{array}$ \\
\hline $\begin{array}{l}\text { A.4.2. Generalistas de carácter } \\
\text { estrictamente forestal }\end{array}$ & $\begin{array}{l}\text { Agateador europeo (Certhia brachydactyla) } \\
\text { Arrendajo (Garrulus glandarius) } \\
\text { Azor (Accipiter gentilis) } \\
\text { Búho chico (Asio otus) } \\
\text { Carbonero garrapinos (Parus ater) } \\
\text { Cuco (Cuculus canorus) } \\
\text { Gavilán común (Accipiter nisus) } \\
\text { Mosquitero papialbo (Phylloscopus bonelli) } \\
\text { Pico picapinos (Dendrocopos major) } \\
\text { Pito real (Picus viridis) } \\
\text { Herrerillo capuchino (Parus cristatus) } \\
\text { Zorzal charlo (Turdus viscivorus) }\end{array}$ & $\begin{array}{l}\text { Son especies con marcado carácter forestal, capaces de ocupar cualquier tipo de bosque, pero no } \\
\text { suelen ocupar ambientes semiarbolados. } \\
\text { Presentan ciertas preferencias o limitaciones: por sus hábitos trogloditas o costumbres de caza } \\
\text { prefieren bosques desarrollados o con arbolado maduro (Agateador, Pico picapinos) o bien son } \\
\text { más abundantes en ciertos tipos de bosques (el Carbonero garrapinos, Herrerillo capuchino y } \\
\text { Reyezuelo listado muestran preferencia por las masas de coníferas). } \\
\text { Algunas tienen problemas para ocupar fragmentos pequeños de bosque. }\end{array}$ \\
\hline
\end{tabular}




\begin{tabular}{|c|c|c|}
\hline Tabla 11 (Cont.) & \multicolumn{2}{|c|}{ GREMIOS ECOLÓGICOS DE AVES } \\
\hline NOMBRE-TIPO DE GREMIO & ESPECIES INCLUIDAS & DESCRIPCIÓN - FUENTES DE INFORMACIÓN \\
\hline $\begin{array}{l}\text { A.5.- ESPECIES DE ZONAS FORESTALES Y } \\
\text { ABIERTAS ASOCIADAS }\end{array}$ & \multicolumn{2}{|c|}{ Especies que nidifican en masas forestales y dependen de los espacios abiertos (cultivos, herbazales, matorral...) para su alimentación. } \\
\hline $\begin{array}{r}\text { A.5.1. Especies de zonas forestales } \\
\text { mediterráneas maduras } \\
\text { combinadas con espacios abiertos }\end{array}$ & $\begin{array}{l}\text { Águila imperial ibérica (Aquila adalberti) } \\
\text { Buitre negro (Aegypius monachus) }\end{array}$ & $\begin{array}{l}\text { Especies que requieren de masas forestales maduras, del ámbito mediterráneo (pinares y } \\
\text { encinares) con arbolado de grandes dimensiones para ubicar el nido y espacios abiertos o en } \\
\text { mosaico cercanos para cazar. Se trata de rapaces de gran tamaño muy sensibles a las molestias } \\
\text { humanas, por lo que escogen las zonas con menor grado de transitabilidad para ubicar sus nidos. }\end{array}$ \\
\hline $\begin{array}{r}\text { A.5.2. Especies generalistas de } \\
\text { zonas forestales combinadas con } \\
\text { espacios abiertos }\end{array}$ & $\begin{array}{l}\text { Águila calzada (Hieraaetus pennatus) } \\
\text { Águila culebrera (Circaetus gallicus) } \\
\text { Alcotán (Falco subbuteo) } \\
\text { Milano real (Milvus milvus) } \\
\text { Milano negro (Milvus migrans) } \\
\text { Ratonero europeo (Buteo buteo) } \\
\end{array}$ & $\begin{array}{l}\text { Especies capaces de ocupar gran variedad de masas forestales, con tal de que tengan cierta } \\
\text { madurez y formen un mosaico con espacios abiertos cercanos para cazar. En general, la } \\
\text { heterogeneidad bosque-zonas despejada les favorece. }\end{array}$ \\
\hline A.6.-ESPECIES DE MATORRALES & $\begin{array}{l}\text { Cogujada montesina (Galerida theklae) } \\
\text { Curruca carrasqueña (Sylvia cantillans) } \\
\text { Curruca cabecinegra (Sylvia melanocephala) } \\
\text { Curruca rabilarga (Sylvia undata) } \\
\text { Zarcero políglota (Hippolais polyglotta) }\end{array}$ & $\begin{array}{l}\text { Especies propias de formaciones de matorral, con preferencia por el ámbito mediterráneo. Su } \\
\text { presencia depende de la existencia de ese matorral en el que nidifican y encuentran el alimento, } \\
\text { en formaciones puras o como orla forestal, pero también como sotobosque de formaciones } \\
\text { arboladas abiertas, o en mosaico con cultivos y pastizales. }\end{array}$ \\
\hline $\begin{array}{l}\text { A.7.- ESPECIES DE ÁREAS ABIERTAS CON } \\
\text { MATORRALES Y ARBOLADO DISPERSO }\end{array}$ & $\begin{array}{l}\text { Abejaruco (Merops apiaster) } \\
\text { Alcaudón común (Lanius senator) } \\
\text { Alcaudón real (Lanius excubitor) } \\
\text { Críalo (Clamator glandarius) } \\
\text { Chotacabras europeo (Caprimulgus europaeus) } \\
\text { Chotacabras pardo (Caprimulgus ruficollis) } \\
\text { Collalba rubia (Oenanthe hispanica) } \\
\text { Corneja (Corvus corone) } \\
\text { Gorrión molinero (Passer montanus) } \\
\text { Gorrión moruno (Passer hispaniolensis) } \\
\text { Jilguero (Carduelis carduelis) } \\
\text { Mochuelo (Athene noctua) } \\
\text { Paloma zurita (Columba oenas) } \\
\text { Tarabilla común (Saxicola torquatus) } \\
\text { Tórtola común (Streptopelia turtur) } \\
\text { Tórtola turca (Streptopelia decaocto) } \\
\text { Totovía (Lullula arborea) Urraca (Pica pica) }\end{array}$ & $\begin{array}{l}\text { Especies que explotan zonas abiertas con matorrales, arbolado y/o bosquetes dispersos (tales } \\
\text { como campiñas y pastizales con arbolado o matorral, sotos en áreas agrícolas o cultivos leñosos). } \\
\text { También en bosques mediterráneos aclarados y dehesas, aunque no se trata de especies } \\
\text { estrictamente de masas forestales abiertas, sino de especies que pueden ocupar estos hábitats } \\
\text { dado que son dependientes de la estructura que combine los matorrales y árboles para nidificar o } \\
\text { como posaderos para cazar, en los espacios abiertos extensos con herbáceas para encontrar su } \\
\text { alimento. } \\
\text { Rehúyen las áreas muy forestales, especialmente los bosques densos, y tienen, al menos, un } \\
\text { matiz de preferencia mediterránea }\end{array}$ \\
\hline
\end{tabular}


Tabla 11 (Cont.)

\begin{tabular}{|c|c|c|}
\hline \multicolumn{3}{|c|}{ GREMIOS ECOLOGICOS DE AVES } \\
\hline NOMBRE-TIPO DE GREMIO & ESPECIES INCLUIDAS & DESCRIPCIÓN - FUENTES DE INFORMACIÓN \\
\hline $\begin{array}{l}\text { A.8.- ESPECIES LIGADAS A ESPACIOS } \\
\text { AGRÍCOLAS EN EXTENSIVO O ESTEPAS }\end{array}$ & $\begin{array}{l}\text { Cernícalo vulgar (Falco tinnunculus) } \\
\text { Codorniz (Coturnix coturnix) } \\
\text { Cogujada común (Galerida cristata) } \\
\text { Gorrión común (Passer domesticus) } \\
\text { Lechuza (Tyto alba) } \\
\text { Pardillo común (Carduelis cannabina) } \\
\text { Perdiz roja (Alectoris rufa) } \\
\text { Triguero (Emberiza calandra) }\end{array}$ & $\begin{array}{l}\text { Aves especializadas en espacios abiertos llanos/ondulados provistos de vegetación herbácea, } \\
\text { dedicados por tanto a pastizales o cultivos herbáceos, en régimen extensivo. Les favorece en } \\
\text { mayor o menor medida el paisaje heterogéneo, con parcelario pequeño, presencia de linderos y } \\
\text { barbechos/eriales. } \\
\text { También pueden ocupar, en menor medida, medios agrícolas escasamente arbolados, dehesas o } \\
\text { cultivos arbóreos. } \\
\text { No se tienen en cuenta las aves de carácter más estepario, pues pertenecen a los cultivos } \\
\text { cerealistas extensos de alrededor de la zona estudiada y no encuentran en el área tratada hábitat } \\
\text { adecuado, precisamente por la presencia mayoritaria de cultivos leñosos (de hecho son } \\
\text { únicamente detectadas en cuadrículas periféricas). Únicamente se tienen en cuenta aquellas que } \\
\text { prefiriendo los medios llanos y cultivados de menor tamaño, son además capaces de colonizar } \\
\text { áreas con cultivos leñosos y han sido detectadas en buena parte de las cuadrículas centrales del } \\
\text { área analizada. }\end{array}$ \\
\hline A.9.- ESPECIES ASOCIADAS A ROQUEDOS & $\begin{array}{l}\text { Águila real (Aquila chrysaetos) } \\
\text { Águila perdicera (Hieraaetus fasciatus) } \\
\text { Buitre leonado (Gyps fulvus) } \\
\text { Halcón peregrino (Falco peregrinus) } \\
\text { Paloma bravía (Columba livia/domestica) }\end{array}$ & $\begin{array}{l}\text { Especies que anidan en cortados rocosos y se alimentan en espacios abiertos. El grupo está } \\
\text { formado fundamentalmente por rapaces rupícolas, aves de presa muy territoriales, con áreas de } \\
\text { campeo extensas y que necesitan la combinación de diferentes usos del suelo. } \\
\text { Todas las especies necesitan cortados o paredes rocosas para instalar su nido, y se alimentan } \\
\text { de presas pequeñas-medianas que capturan fundamentalmente cerniéndose sobre sus } \\
\text { presas en el suelo o en vuelo, preferentemente en espacios abiertos. Algunas de ellas incluso } \\
\text { establecen relaciones de competencia por los lugares de cría (Águila real y perdicera). }\end{array}$ \\
\hline $\begin{array}{l}\text { A.10.- ESPECIES DE AFLORAMIENTOS ROCOSOS } \\
\text { Y ZONAS DE VEGETACIÓN RALA }\end{array}$ & $\begin{array}{l}\text { Collalba gris (Oenanthe oenanthe) } \\
\text { Collalba negra (Oenanthe leucura) } \\
\text { Colirrojo tizón (Phoenicurus ochruros) } \\
\text { Curruca tomillera (Sylvia conspicillata) } \\
\text { Escribano montesino (Emberiza cia) } \\
\text { Gorrión chillón (Petronia petronia) } \\
\text { Roquero rojo (Monticola saxatilis) } \\
\text { Roquero solitario (Monticola solitarius) }\end{array}$ & $\begin{array}{l}\text { Especies que ocupan afloramientos rocosos, zonas escarpadas y rocosas, en combinación con } \\
\text { áreas de vegetación herbácea, rala o matorrales dispersos. Pueden encontrarse también si } \\
\text { existe una cobertura arbórea clara. Les favorece la presencia de muros de piedra y } \\
\text { construcciones. }\end{array}$ \\
\hline
\end{tabular}




\section{C.- ETAPA EVALUATIVA - FASE 3: APLICACIÓN DE MODELOS DE EVALUACIÓN DE IDONEIDAD DE HÁBITAT DE LOS GRUPOS ECOLÓGICOS}

Se aplicó un modelo de Idoneidad o aptitud de hábitat específico para cada grupo de especies, que dio como resultado la serie cartográfica que recoge el grado de idoneidad de cada parcela del territorio de $2500 \mathrm{~m}^{2}$ (celdas de 50×50m).

El Anexo II presenta la ficha de análisis, esquema metodológico con los criterios de combinación y asignación de valores de cada factor y cartografía resultante para cada grupo considerado.

\section{C.- ETAPA EVALUATIVA - FASE 4: INTEGRACIÓN Y EVALUACIÓN DE LA IMPORTANCIA DEL PAISAJE PARA LA CONSERVACIÓN DE LA FAUNA SALVAJE}

La importancia del paisaje para la conservación de la fauna terrestre (mamíferos y aves) se evaluó mediante el índice Icons, obtenido en cada parcela de terreno de $50 \times 50 \mathrm{~m}$ por la integración de los resultados del Modelo de evaluación de Idoneidad de Hábitat correspondiente a cada grupo de especies, ponderado por la sensibilidad de cada gremio según la siguiente expresión:

$$
\mathrm{I}_{\mathrm{CONS}}=\sum\left[\mathrm{HSM}_{\mathrm{Gri}} * \mathrm{~S}_{\mathrm{Gri}}\right]
$$

Siendo $I_{\text {cons }}$ el índice que informa sobre la importancia del paisaje para la conservación de las especies, HSM Gri la idoneidad o aptitud para proveer de hábitat potencial para el gremio ecológico i; y $\mathrm{S}_{\mathrm{Gri}}$ el grado de sensibilidad alcanzado por dicho gremio i.

En el Anexo II se muestra en detalle el resultado de la asignación de sensibilidad a cada gremio ecológico, y se presenta en cartografía el resultado del índice $I_{\text {cons }}$ para cada parcela $50 \times 50 \mathrm{~m}$ del paisaje (Mapa 3, Figura 76) y el valor medio correspondiente a cada unidad del paisaje (Mapa 4, Figura 77). 


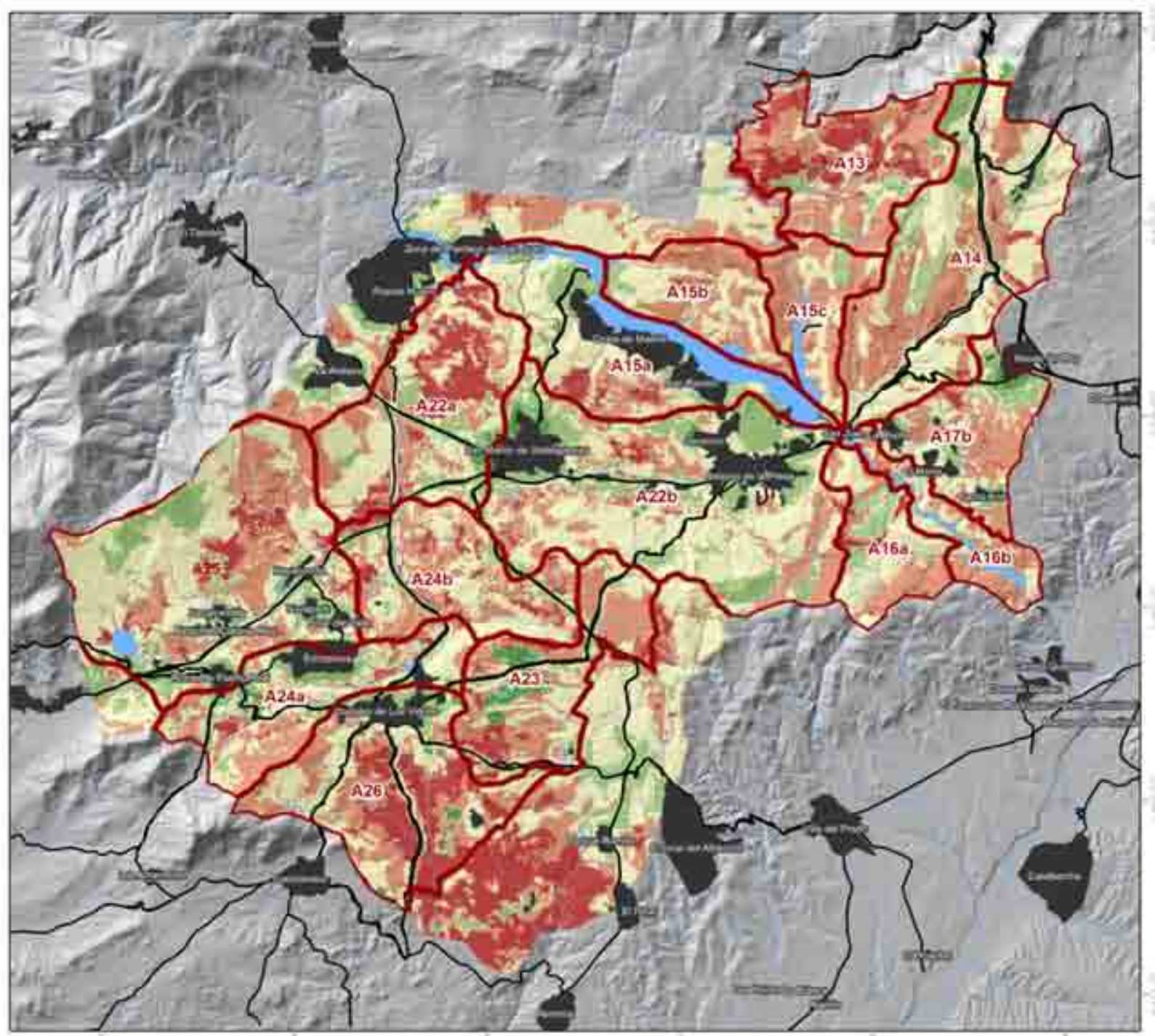

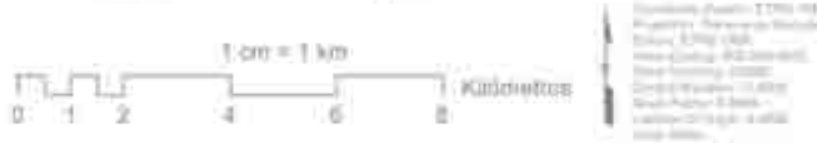

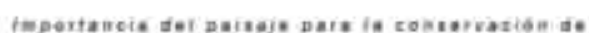

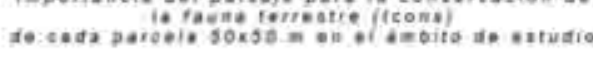

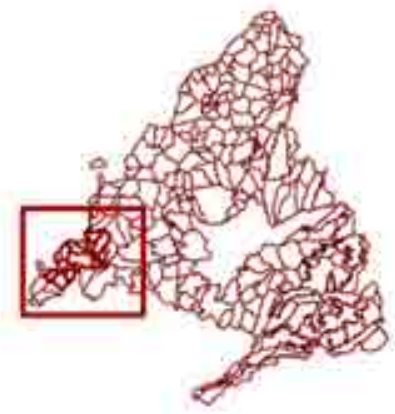

(Sub)unidodes de paisule

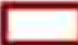

Grados de importancia conservacion (ifeonst MINIMA $(1,6-90.8]$ MENOR $190.8 \cdot 170$ MEDIA $(170 \cdot 226.21$ MAYOR (228.2 - 285.6) MAXXIMA (285.6 - 421]

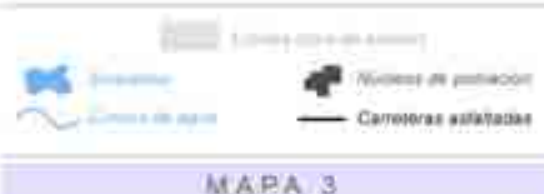

IMPORTANCIA DEL PAISAJE PARA LA CONSERVACION DE FAUNA TERRESTRE

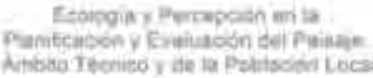

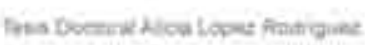

Figura 76. Cartografía de la Importancia del paisaje para la conservación de la fauna terrestre en cada parte del territorio. 

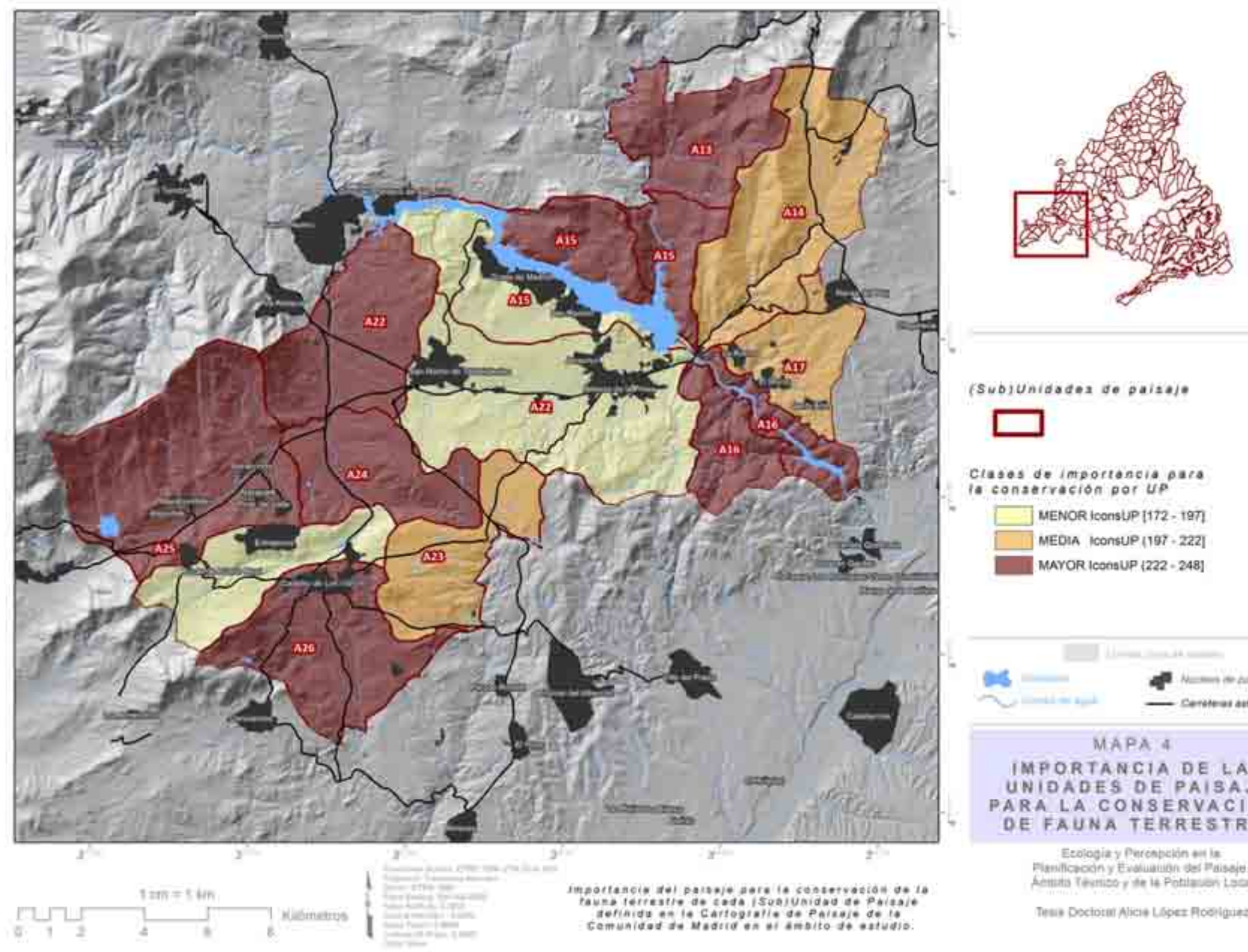

(sub)unidodes de paisele

clases do importancia para

la conservacion oor UP

MENOR ICONSLP I1172, 1 in

$\square$ MEDIA ICONSUP $1197 \cdot 222]$

[ MAYOR ICOCAUP $\{222-248\}$

Figura 77. Cartografía de la Importancia del paisaje para la conservación de la fauna terrestre referenciado en las unidades de paisaje.

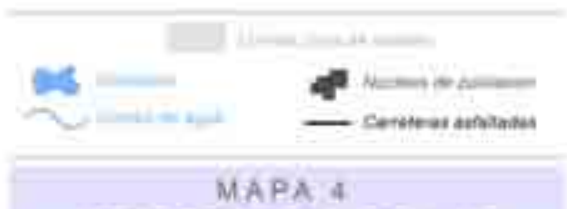

IMPORTANCIA DE LAS UNIDADES DE PAISAJE PARA LA CONSERVACION DE FAUNA TERRESTRE

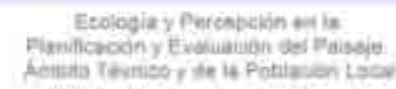

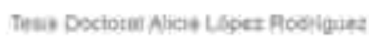




\section{VII.4. EVALUACIÓN DEL ÁMBITO DE LA APRECIACIÓN ESTÉTICA}

Aramburu Maqua, M. P. Escribano Bombín, R., Ramos Gonzalo, L. y Rubio Maroto, R. (2003). Cartografía del Paisaje de la Comunidad de Madrid. Madrid: Comunidad Autonoma Madrid. Dirección General de Promoción y Disciplina Ambiental.
La valoración escénica del paisaje para cada Unidad de Paisaje se deriva del trabajo de Aramburu Maqua et al. (2003), que cartografía, describe y valora en términos de calidad y fragilidad visual las unidades de paisaje en el territorio de la Comunidad de Madrid.

El área de estudio consta de 15 Unidades/Subunidades de Paisaje que, dentro del contexto de la Comunidad de Madrid, muestran una calidad del paisaje visual evaluada como Media a Alta (Mapa 5, Figura 78). Ahora bien, más que en este resultado del grado de calidad del paisaje, interesa conocer cuáles son los rasgos o componentes del paisaje que aportan o detraen calidad a la unidad según el criterio aplicado por los expertos. A este respecto, las características generales del paisaje de cada unidad que determinan la evaluación de la calidad visual se especifican para cada (sub)unidad de paisaje considerada en las Fichas de análisis (página 279). 


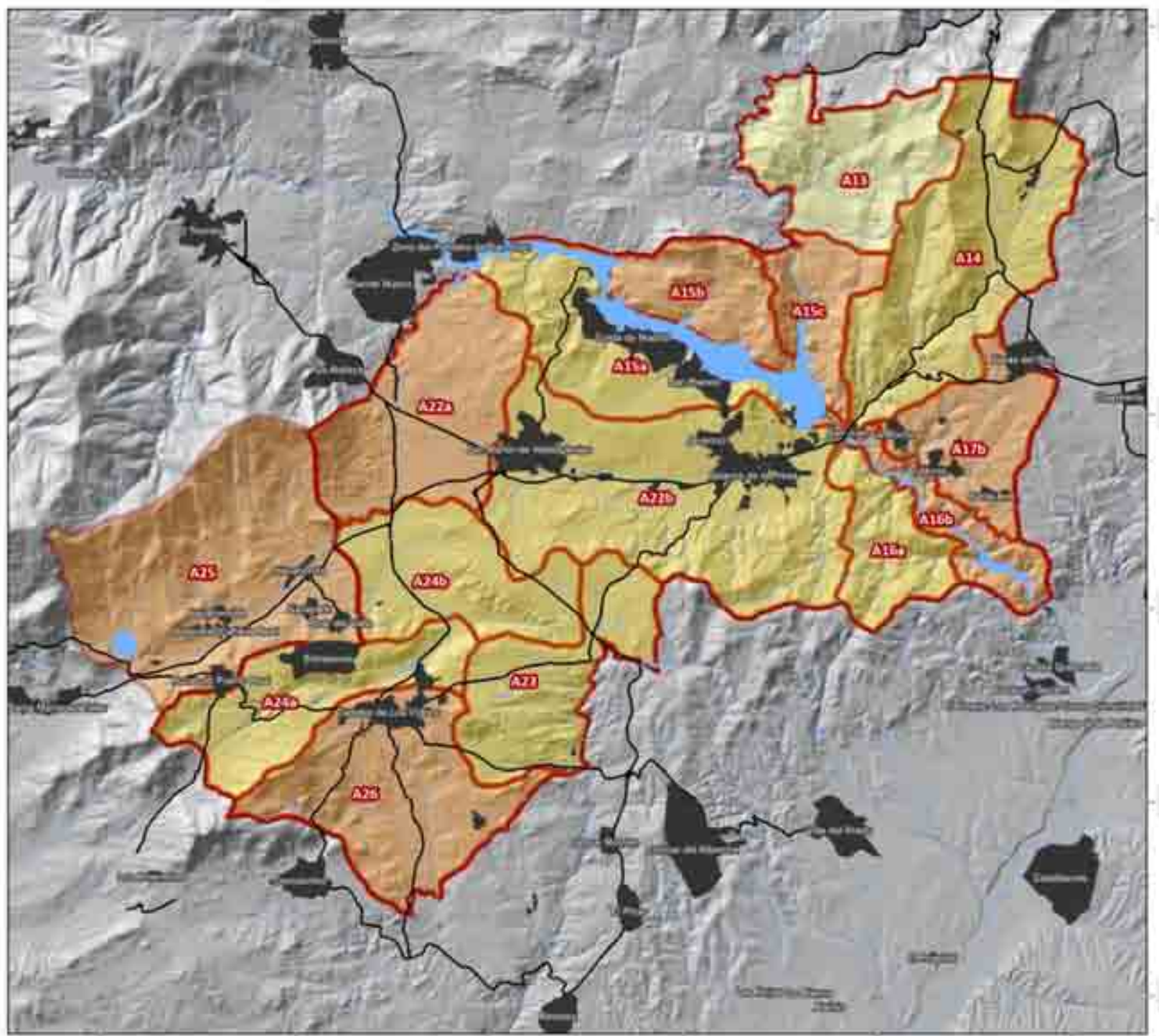

17.

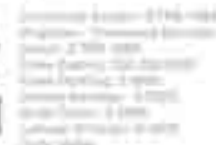

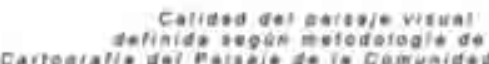

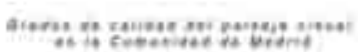

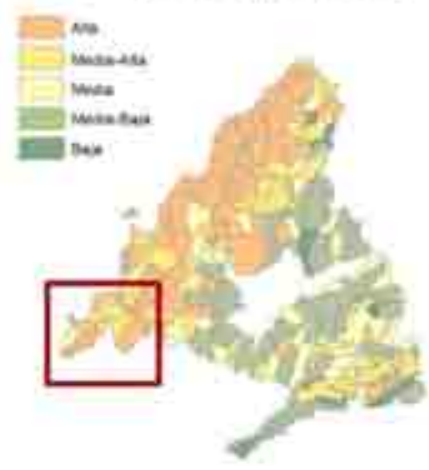

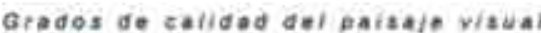

ALTA

MEDIA.ALTA

MEDIA

(Sub) Unitados do paisait

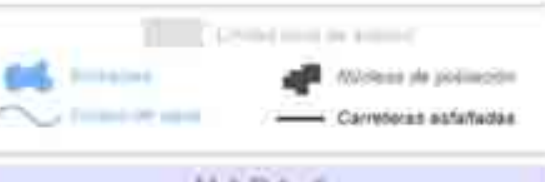

MAPA S

CALIDAD DEL

PAISAJE VISUAL EN LAS UNIDADES DE PAISAJE DEL AREA DE ESTUDIO Ecologia y Nertopón mi iz

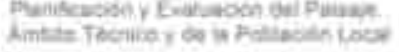

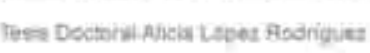

Figura 78. Cartografía de la calidad del paisaje en las unidades del área de estudio. 


\section{VII.4.2. Evaluación de la interpretación de los valores ecológico-estéticos del paisaje}

La evaluación tiene lugar mediante la participación de una serie de personas involucradas en el territorio.

\section{A.- SELECCIÓN Y DESCRIPCIÓN DE LAS CARACTERÍSTICAS DE LOS PARTICIPANTES}

La selección de los encuestados se condujo siguiendo la estrategia cualitativa de muestreo intencional, propositivo o de juicio (Purposeful sampling) (Bryman, 2004). En total se realizaron entrevistas a 30 participantes, cuyas características se exponen en la Tabla 12. En primer lugar, se realizó un Focus Group (abril de 2014, 5 participantes, duración 3 horas) en el que se contó con una representación diversa de distintos contextos situacionales: concejal de medio ambiente de un municipio de la zona, técnico municipal de medio ambiente, agente forestal, agricultor y consultor especializado en educación ambiental, todos residentes en la zona. Tras esta primera experiencia, se realizaron una serie de entrevistas personales a 25 agentes que respondían a las características buscadas (mayo-julio de 2015, duración 45-75 minutos cada entrevista).

La selección de los encuestados se basó en la búsqueda de distintas situaciones personales dentro de dos dimensiones de variación:

- La primera dimensión caracteriza el contexto de los participantes según el TIPO DE CONOCIMIENTO DEL MEDIO NATURAL que tengan, y se reparte en las siguientes categorías:

- CONOCIMIENTO NO FORMAL: conocimiento proveniente de la experiencia práctica de trabajar en el aprovechamiento agrícola y/o forestal o de la simple observación y contacto con el paisaje de la comarca.

- CONOCIMIENTO FORMAL: formación técnico-científica reglada en ciencias del medio natural (formación relacionada con la biología, ciencias forestales, ambientales o agronómicas) 
- La segunda dimensión caracteriza el contexto de los entrevistados en función del TIPO DE EXPERIENCIA E IMPLICACIÓN EN EL PAISAJE DE LA COMARCA, basada en una ocupación o modo de vida centrado o no en el medio natural:

- RESIDENTES CON UNA OCUPACIÓN NO RELACIONADA CON LA GESTIÓN DEL TERRITORIO O DEL MEDIO NATURAL DE LA COMARCA. En este grupo se encuadran aquellos participantes con formación relacionada o no con las ciencias naturales, más o menos sensibilizados con el tema, cuyo medio de vida no se basa en la gestión o aprovechamiento de los recursos naturales.

- MODO DE VIDA RELACIONADO CON EL APROVECHAMIENTO AGROFORESTAL EN LA COMARCA. En este grupo se incluyen todos aquellos participantes residentes en la comarca que total o parcialmente se dedican al trabajo del campo o al aprovechamiento de los recursos naturales del medio.

- ocupación RELACIONAdA cON la gestión DEL TERRITORIO DE LA COMARCA (no específicamente medio natural). Categoría de entrevistados asociados directamente a la gestión del territorio no centrada en el manejo de los aspectos ecológicos o del medio natural.

- OCUPACIÓN RELACIONADA CON LA GESTIÓN DEL MEDIO NATURAL DE LA COMARCA. Participantes implicados de manera directa en la administración y gestión ecológica del medio natural de la comarca.

- OCUPACIÓN RELACIONADA CON LA EDUCACIÓN AMBIENTAL/TURISMO NATURAL EN LA COMARCA. Grupo de participantes cuya ocupación se relaciona con las actividades de educación y sensibilización ambiental y/o con la organización de actividades que busquen el conocimiento y disfrute del medio natural de la zona. 
Tabla 12. Características de los entrevistados.

\begin{tabular}{|c|c|c|c|c|c|}
\hline & & $\begin{array}{c}\text { TIPO DE CONOCIMIENTO D } \\
\text { NO FORMAL } \\
\text { (conocimiento por medio de la } \\
\text { experiencia práctica y observación) }\end{array}$ & $\begin{array}{l}\text { AMBIENTALES O DEL MEDIO NATURAL } \\
\text { FORMAL } \\
\text { (formación técnico-científica reglada) }\end{array}$ & & \\
\hline \multirow{5}{*}{ 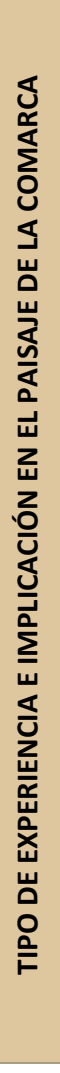 } & $\begin{array}{l}\text { RESIDENTES CON UNA OCUPACIÓN NO } \\
\text { RELACIONADA CON LA GESTIÓN DEL } \\
\text { TERRITORIO O DEL MEDIO NATURAL DE } \\
\text { LA COMARCA }\end{array}$ & $\begin{array}{l}2 \text { Miembros organización ecologista } \\
\text { (administrativo y educador) } \\
1 \text { intereses naturalistas } \\
\text { (ocupaciones no ambientales) }\end{array}$ & $\begin{array}{c}1 \text { Educador (Biología) } \\
1 \text { Consultor ambiental (Biología) } \\
1 \text { Agente medioambiental (otra comarca) Miembro } \\
\text { organización ecologista }\end{array}$ & 6 & entrevistados \\
\hline & $\begin{array}{l}\text { MODO DE VIDA RELACIONADO CON EL } \\
\text { APROVECHAMIENTO AGROFORESTAL } \\
\text { EN LA COMARCA }\end{array}$ & $\begin{array}{c}1 \text { Agricultor } \\
3 \text { Bodegueros/Agricultores } \\
3 \text { Ganaderos } \\
1 \text { Ocupado en sector construcción } \\
\text { (piñero) }\end{array}$ & 1 Guarda de caza & 10 & entrevistados \\
\hline & $\begin{array}{l}\text { OCUPACIÓN RELACIONADA CON LA } \\
\text { GESTIÓN DEL TERRITORIO DE LA } \\
\text { COMARCA } \\
\text { (no específicamente medio natural) }\end{array}$ & $\begin{array}{l}2 \text { Agentes de desarrollo rural } \\
\text { (formación no ambiental) }\end{array}$ & $\begin{array}{c}1 \text { Agente de desarrollo rural } \\
\text { (C. agronómica) } \\
1 \text { Técnico ordenación/gestión agrícola } \\
\text { (C. forestal) }\end{array}$ & 4 & entrevistados \\
\hline & $\begin{array}{l}\text { OCUPACIÓN RELACIONADA CON LA } \\
\text { GESTIÓN DEL MEDIO NATURAL DE LA } \\
\text { COMARCA }\end{array}$ & 1 Concejal medio ambiente & $\begin{array}{c}\text { 3 Agentes medioambientales } \\
1 \text { Técnico ambiental municipal } \\
\text { (CC. ambientales) } \\
\text { 2 Técnico proyecto conservación fauna (Biología, } \\
\text { zoología) }\end{array}$ & 7 & entrevistados \\
\hline & $\begin{array}{l}\text { OCUPACIÓN RELACIONADA CON LA } \\
\text { EDUCACIÓN AMBIENTAL/TURISMO } \\
\text { NATURAL EN LA COMARCA }\end{array}$ & - & $\begin{array}{l}2 \text { Técnicos centro de educación ambiental } \\
\text { (C. forestal, CC. ambientales) } \\
1 \text { Técnico centro de fauna } \\
\text { (Biología) }\end{array}$ & 3 & entrevistados \\
\hline & & 14 entrevistados & 16 entrevistados & 30 & $\begin{array}{c}\text { TOTAL } \\
\text { ENTREVISTADOS }\end{array}$ \\
\hline
\end{tabular}




\section{B.-RESULTADOS}

Las localizaciones escogidas por los participantes en cada una de las categorías se muestran de forma sintética en las Tablas 13, 14, 15 y 16, agrupadas por tipologías de paisaje. Acompaña a esta información la relación de atributos o características que explican la valoración de los participantes, derivada de la descripción y comentarios hechos. Además, se incluye una cuantificación básica del número de entrevistados y/o frecuencia con que se hizo referencia a cada sitio o atributo. Esta cuantificación únicamente pretende dar una idea de la importancia o la redundancia con que ciertos ítems fueron puestos de relieve por los participantes, y por tanto no tiene significación estadística.

A continuación, se expone la serie de temas surgidos en las entrevistas con significación en la percepción y valoración de la relación entre estética y ecología, con la explicación comprensiva de los valores y causas que los encuadran. Una serie de citas extraídas de las entrevistas jalonan la explicación e ilustran las percepciones y valoraciones de los participantes sintetizadas en el texto.

Finalmente, se incluye la cartografía que, tomando como base de análisis las unidades de paisaje definidas, presenta una síntesis de las conclusiones derivadas de los resultados de la investigación sobre la percepción social, esto es, una referencia geográfica de los patrones de interpretación estética de la componente ecológica, asociada a cada unidad de paisaje que contenga características que induzcan dicha percepción (Mapa 6, Figura 79). 
Tabla 13. Tipos de paisaje seleccionados, características comentadas por los entrevistados y frecuencia de selección: categoría Alta Calidad Ecológica.

\begin{tabular}{|c|c|c|c|c|c|}
\hline \multicolumn{6}{|c|}{ EVALUACIÓN ECOLÓGICA ALTA } \\
\hline $\begin{array}{c}\text { № DE PARTICIPANTES QUE SELECCIONA EL } \\
\text { TIPO DE PAISAJE/ No TOTAL DE } \\
\text { PARTICIPANTES .- PORCENTAJE QUE } \\
\text { REPRESENTA }\end{array}$ & TIPO PAISAJE & \multicolumn{2}{|c|}{$\begin{array}{l}\text { NNo DE PARTICIPANTES QUE SELECCIONA EL } \\
\text { TIPO DE PAISAJE / NOMBRE DEL PARAJE } \\
\text { SELECCIONADO }\end{array}$} & \multicolumn{2}{|r|}{ № VECES SELECCIONADO / CARACTERÍSTICA DESTACADA } \\
\hline \multirow{19}{*}{ 21/30 PART. - 70\% } & \multirow{19}{*}{$\begin{array}{l}\text { PAISAJE FORESTAL, } \\
\text { MONTE }\end{array}$} & \multirow{6}{*}{13} & \multirow{6}{*}{$\begin{array}{l}\text { MONTE DE UTILIDAD PÚBLICA M.U.P. } 54 \\
\text { "LAS CABRERAS" }\end{array}$} & 7 & PRESENCIA FAUNA PROTEGIDA \\
\hline & & & & 5 & BIODIVERSIDAD \\
\hline & & & & 5 & BUEN ESTADO DE CONSERVACIÓN \\
\hline & & & & 5 & NATURALIDAD, POCA PRESENCIA HUMANA \\
\hline & & & & 3 & BOSQUE DESARROLLADO, ARBOLADO MADURO \\
\hline & & & & 2 & FIGURA PROTECCIÓN \\
\hline & & \multirow{4}{*}{5} & \multirow{4}{*}{ MONTE AL ESTE DE CADALSO } & 2 & BOSQUE DESARROLLADO, ARBOLADO MADURO \\
\hline & & & & 2 & NATURALIDAD, POCA PRESENCIA HUMANA \\
\hline & & & & 2 & CUIDADO, MANTENIMIENTO, APROVECHAMIENTO \\
\hline & & & & 1 & BIODIVERSIDAD \\
\hline & & \multirow{3}{*}{3} & \multirow{3}{*}{$\begin{array}{l}\text { M.U.P. } 55 \text { "NAVAPOZAS, FUENFRÍA, } \\
\text { VALDEYERNO Y VALCALIENTE" }\end{array}$} & 2 & BIODIVERSIDAD \\
\hline & & & & 1 & PRESENCIA FAUNA PROTEGIDA \\
\hline & & & & 1 & POCA PRESENCIA HUMANA \\
\hline & & \multirow{2}{*}{1} & \multirow{2}{*}{ PARAJE "CANTO EL GUARRO" } & 1 & BIODIVERSIDAD \\
\hline & & & & 1 & FIGURA PROTECCIÓN \\
\hline & & 2 & $\begin{array}{l}\text { MONTE "LIMPIO", CON PRESENCIA DE } \\
\text { GANADO } \\
\end{array}$ & 2 & CUIDADO, MANTENIMIENTO, APROVECHAMIENTO \\
\hline & & 1 & PEÑ CFNUCIENTOS M & 1 & BIODIVERSIDAD \\
\hline & & 2 & 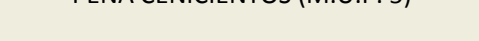 & 1 & PRODUCTIVIDAD, VIGOR \\
\hline & & 1 & OTROS (Monte Almenara) & 1 & BIODIVERSIDAD \\
\hline \multirow{18}{*}{ 15/30 PART. - $50 \%$} & \multirow{18}{*}{$\begin{array}{l}\text { GRANDES FINCAS } \\
\text { PRIVADAS }\end{array}$} & \multirow{5}{*}{5} & & 3 & BIODIVERSIDAD \\
\hline & & & & 2 & BUEN ESTADO DE CONSERVACIÓN \\
\hline & & & $\begin{array}{l}\text { CERRO GUISAINDU (cuerda de Pedro } \\
\text { Duermes) }\end{array}$ & 2 & CUIDADO, BUENA GESTIÓN \\
\hline & & & & 1 & NATURALIDAD \\
\hline & & & & 1 & PRODUCTIVIDAD, VIGOR \\
\hline & & & & 3 & PRESENCIA FAUNA PROTEGIDA \\
\hline & & 5 & FINCA "EL RINCÓN DE LOS CANCHOS" & 3 & POCA PRESENCIA HUMANA \\
\hline & & & & 1 & BIODIVERSIDAD \\
\hline & & & & 2 & POCA PRESENCIA HUMANA \\
\hline & & 3 & FINCA "EL SANTO" & 1 & PRESENCIA FAUNA PROTEGIDA \\
\hline & & & & 1 & BIODIVERSIDAD \\
\hline & & & & 3 & CUIDADO, MANTENIMIENTO, APROVECHAMIENTO \\
\hline & & 4 & GRANDES FINCAS (en general) & 1 & POCA PRESENCIA HUMANA \\
\hline & & & & 1 & PRESENCIA FAUNA PROTEGIDA \\
\hline & & & & 1 & BUEN ESTADO DE CONSERVACIÓN \\
\hline & & 1 & FINCA "SANTA IFONOR" & 1 & BIODIVERSIDAD \\
\hline & & & & 1 & PRESENCIA FAUNA PROTEGIDA \\
\hline & & 1 & OTROS (Dehesa Hospital) & 1 & BUEN ESTADO DE CONSERVACIÓN \\
\hline & & & & 3 & SINGULARIDAD \\
\hline & & & & 2 & BUEN ESTADO DE CONSERVACIÓN \\
\hline & & 7 & CASTAÑAR IASROZAS & 2 & BIODIVERSIDAD \\
\hline & & r & 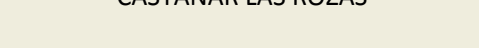 & 1 & ARBOLADO DESARROLLADO \\
\hline & & & & 1 & PRESENCIA FAUNA PROTEGIDA \\
\hline $9 / 30$ PART - $30 \%$ & PAISAJE FORESTAL - & & & 1 & NATURALIDAD \\
\hline 年 & BOSQUE & 1 & PINARES (en general) & 1 & BOSQUE DESARROLLADO, ARBOLADO MADURO \\
\hline & & 1 & 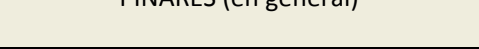 & 1 & PRESENCIA FAUNA PROTEGIDA \\
\hline & & 1 & DINAP CAPRETEP $\triangle 1-511$ & 1 & BUEN ESTADO DE CONSERVACIÓN \\
\hline & & & & 1 & GESTIÓN ADECUADA \\
\hline & & 1 & ENCINAP DEIA PAPRA & 1 & NATURALIDAD \\
\hline & & 1 & LIVCINAR DE LA TANRA & 1 & BIODIVERSIDAD \\
\hline & & 2 & EMPAICE DE DICADAC & 2 & BIODIVERSIDAD \\
\hline & & ك & 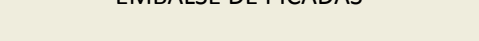 & 2 & POCA PRESENCIA HUMANA, TRANQUILIDAD \\
\hline & & & & 2 & EQUILIBRIO \\
\hline & & 2 & 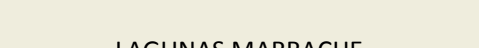 & 1 & BIODIVERSIDAD \\
\hline 6/30 PART. - $20 \%$ & CUINAS CUIN PKESEINCIA & J & 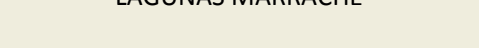 & 1 & FIGURA PROTECCIÓN \\
\hline & & & & 1 & PRESENCIA FAUNA PROTEGIDA \\
\hline & & & & 1 & BIODIVERSIDAD \\
\hline & & 2 & RÍO ALBERCHE & 1 & BUEN ESTADO DE CONSERVACIÓN \\
\hline & & & & 1 & CUIDADO Y CONTROL \\
\hline
\end{tabular}


Tabla 14. Tipos de paisaje seleccionados, características comentadas por los entrevistados y frecuencia de selección: categoría Alta Calidad Estética.

\begin{tabular}{|c|c|c|c|c|c|}
\hline \multicolumn{6}{|c|}{ EVALUACIÓN ESTÉTICA PAISAJE ALTA } \\
\hline $\begin{array}{l}\text { № DE PARTICIPANTES QUE SELECCIONA EL } \\
\text { TIPO DE PAISAJE/ No TOTAL DE PARTICIPANTES } \\
\text {.- PORCENTAJE QUE REPRESENTA }\end{array}$ & TIPO PAISAJE & № D & $\begin{array}{l}\text { RTICIPANTES QUE SELECCIONA EL } \\
\text { PAISAJE / NOMBRE DEL PARAJE } \\
\text { SELECCIONADO }\end{array}$ & & $\begin{array}{c}\text { ECES SELECCIONADO / CARACTERÍSTICA } \\
\text { DESTACADA }\end{array}$ \\
\hline \multirow{10}{*}{ 14/30 PART. - $47 \%$} & \multirow{10}{*}{$\begin{array}{l}\text { PAISAJE FORESTAL, } \\
\text { MONTE }\end{array}$} & \multirow{5}{*}{14} & \multirow{5}{*}{ MONTE DE "LAS CABRERAS" } & 8 & BELLEZA ESCÉNICA \\
\hline & & & & 5 & BUEN ESTADO DE CONSERVACIÓN Y LIMPIEZA \\
\hline & & & & 3 & NATURALIDAD \\
\hline & & & & 3 & BIODIVERSIDAD \\
\hline & & & & 1 & PRESENCIA FAUNA SINGULAR \\
\hline & & \multirow{3}{*}{1} & \multirow{3}{*}{ LOS MORALES } & 1 & FRESCOR/HUMEDAD \\
\hline & & & & 1 & PRESENCIA FAUNA SINGULAR \\
\hline & & & & 1 & BELLEZA ESCÉNICA \\
\hline & & \multirow{2}{*}{1} & \multirow{2}{*}{ ZONA OESTE } & 1 & BIODIVERSIDAD \\
\hline & & & & 1 & PRODUCTIVIDAD/VIGOR \\
\hline \multirow{9}{*}{ 13/30 PART. - $43 \%$} & \multirow{9}{*}{$\begin{array}{l}\text { ELEVACIONES } \\
\text { SINGULARES }\end{array}$} & \multirow{2}{*}{6} & \multirow{2}{*}{ PEÑA CENICIENTOS } & 4 & PRESENCIA VEGETACIÓN \\
\hline & & & & 2 & BELLEZA ESCÉNICA \\
\hline & & 4 & PEÑA CADALSO & 1 & PRESENCIA RISCOS \\
\hline & & & \multirow{3}{*}{ CERRO GUISANDO } & 3 & BELLEZA ESCÉNICA, PANORÁMICA \\
\hline & & 3 & & 1 & CARÁCTER SALVAJE \\
\hline & & & & 1 & VARIEDAD \\
\hline & & 2 & CHAPINERÍA & 2 & PANORÁMICA \\
\hline & & 1 & DEHESA ENTREPINOS & 1 & PANORÁMICA \\
\hline & & 1 & OTROS (Cerro Santisteban, El Guijo) & 1 & PANORÁMICA \\
\hline \multirow{8}{*}{ 11/30 PART. - $37 \%$} & \multirow{8}{*}{$\begin{array}{l}\text { PAISAJE FORESTAL - } \\
\text { BOSQUE }\end{array}$} & \multirow{5}{*}{11} & \multirow{5}{*}{ CASTAÑAR LAS ROZAS } & 6 & SENSACIÓN FRESCOR/HUMEDAD \\
\hline & & & & 3 & COLORIDO \\
\hline & & & & 2 & VARIEDAD \\
\hline & & & & 1 & BELLEZA ESCÉNICA \\
\hline & & & & 1 & BUEN ESTADO DE CONSERVACIÓN \\
\hline & & \multirow{2}{*}{4} & \multirow{2}{*}{ PINARES MADUROS (general) } & 4 & BOSQUE DESARROLLADO, ARBOLADO MADURO \\
\hline & & & & 1 & ACCESIBILIDAD \\
\hline & & 2 & PINAR CARRETERA M-541 & 3 & BELLEZA ESCÉNICA \\
\hline \multirow{8}{*}{ 7/30 PART. - $23 \%$} & \multirow{8}{*}{$\begin{array}{c}\text { ESPACIO } \\
\text { AGROGANADERO, } \\
\text { CAMPO }\end{array}$} & 2 & PIEDRA ESCRITA Y EL JUNCAL & 2 & PRODUCTIVIDAD \\
\hline & & \multirow[t]{2}{*}{2} & VALLE NAVAHONDILLA & 2 & $\begin{array}{l}\text { CUIDADO, MANTENIMIENTO, } \\
\text { APROVECHAMIENTO }\end{array}$ \\
\hline & & & & 1 & VARIEDAD \\
\hline & & 1 & VALLE DEL TORTOLAS & 1 & BELLEZA ESCÉNICA \\
\hline & & 1 & VIÑAS DEHESA SAN MARTIN & 1 & BELLEZA ESCÉNICA \\
\hline & & 1 & VIÑAS (GENERAL) & 1 & COLORIDO \\
\hline & & 1 & CAMPO CUIDADO (en general) & 1 & $\begin{array}{l}\text { CUIDADO, MANTENIMIENTO, } \\
\text { APROVECHAMIENTO }\end{array}$ \\
\hline & & 1 & CANTORREDONDO & 1 & \\
\hline & & 5 & EMBLASE DE PICADAS & 4 & BELLEZA ESCÉNICA, PANORÁMICA \\
\hline & & & & 2 & TRANQUILIDAD \\
\hline 8/30 PART - $27 \%$ & ZONAS CON PRESENCIA & 1 & COLA EMBALSE S. JUAN & 1 & BELLEZA ESCÉNICA \\
\hline O/SU PAKI. - $21 \%$ & DE AGUA & & & 1 & VARIEDAD \\
\hline & & 1 & RIBERAS (en general) & 1 & ACCESIBILIDAD \\
\hline & & & & 1 & BIODIVERSIDAD \\
\hline & & & & 1 & POCA PRESENCIA HUMANA \\
\hline 2/30 PART. - $6 \%$ & OTROS & 2 & $\begin{array}{l}\text { FINCA SANTA LEONOR, TOROS } \\
\text { GUISANDO }\end{array}$ & 1 & PRESENCIA FAUNA SINGULAR \\
\hline & & & & 1 & BELLEZA ESCÉNICA \\
\hline
\end{tabular}


Tabla 15. Tipos de paisaje seleccionados, características comentadas por los entrevistados y frecuencia de selección: categoría Baja Calidad Ecológica

\begin{tabular}{|c|c|c|c|c|c|}
\hline \multicolumn{6}{|c|}{ EVALUACIÓN ECOLÓGICA BAJA } \\
\hline $\begin{array}{c}\text { № DE PARTICIPANTES QUE SELECCIONA EL TIPO } \\
\text { DE PAISAJE/ No TOTAL DE PARTICIPANTES .- } \\
\text { PORCENTAJE QUE REPRESENTA }\end{array}$ & TIPO PAISAJE & \multicolumn{2}{|c|}{$\begin{array}{l}\text { № DE PARTICIPANTES QUE SELECCIONA EL } \\
\text { TIPO DE PAISAJE / NOMBRE DEL PARAJE } \\
\text { SELECCIONADO }\end{array}$} & \multicolumn{2}{|r|}{ № VECES SELECCIONADO / CARACTERÍSTICA } \\
\hline \multirow{5}{*}{ 15/30 PART. - $50 \%$} & \multirow{5}{*}{$\begin{array}{l}\text { ÁREAS SUJETAS A USO } \\
\text { TURÍSTICO INTENSIVO }\end{array}$} & \multirow{3}{*}{15} & \multirow{3}{*}{ ZONA BAÑO EMBALSE DE SAN JUAN } & 10 & USO INTENSIVO \\
\hline & & & & 6 & FALTA DE CUIDADO \\
\hline & & & & 5 & PRESENCIA BASURA Y CONTAMINACION \\
\hline & & 2 & ZONA BAÑO EMBALSE DE PICADAS & 2 & PRESENCIA BASURA Y CONTAMINACION \\
\hline & & 1 & MONTE (en general) & 1 & USOS IRRESPETUOSOS \\
\hline \multirow{7}{*}{ 13/30PART. - $43 \%$} & \multirow{7}{*}{$\begin{array}{l}\text { ESPACIO } \\
\text { AGROGANADERO, } \\
\text { CAMPO }\end{array}$} & 5 & CAMPO ABANDONADO (en general) & 5 & FALTA DE MANTENIMIENTO \\
\hline & & 3 & $\begin{array}{l}\text { CULTIVOS TRATADOS CON HERBICIDAS } \\
\text { (en general) }\end{array}$ & 3 & MALAS PRÁCTICAS/GESTIÓN \\
\hline & & 3 & ÁREA AGRÍCOLA (general) & 3 & $\begin{array}{c}\text { PRESENCIA DE CONSTRUCCIONES POCO CUIDADAS Y } \\
\text { ESCOMBROS: "CHABOLISMO" }\end{array}$ \\
\hline & & 2 & PRADO LA MATA & 2 & MALAS PRÁCTICAS/GESTIÓN \\
\hline & & \multirow{2}{*}{1} & \multirow{2}{*}{ CAMPO ABANDONADO NORTE M-501 } & 1 & FALTA DE MANTENIMIENTO \\
\hline & & & & 1 & BAJA DIVERSIDAD \\
\hline & & 1 & CHARCAS GANADO & 1 & PROBLEMAS SANIDAD ANIMAL \\
\hline \multirow{3}{*}{ 10/30 PART. - $33 \%$} & \multirow{3}{*}{ ESPACIO CONSTRUIDO } & 9 & URBANIZACIONES & 9 & IMPACTO EN EL ECOSISTEMA, ARTIFICIALIDAD \\
\hline & & 1 & NÚCLEOS URBANOS & 1 & PRESENCIA BASURAS \\
\hline & & 2 & DESDOBLAMIENTO CARRETERA & 2 & IMPACTO EN EL ECOSISTEMA \\
\hline \multirow{6}{*}{ 8/30 PART. - $27 \%$} & \multirow{6}{*}{$\begin{array}{l}\text { PAISAJE FORESTAL, } \\
\text { MONTE }\end{array}$} & 2 & \multirow{2}{*}{$\begin{array}{c}\text { ÁREAS AFECTADAS POR INCENDIOS } \\
\text { FORESTALES - LADERAS VALLE } \\
\text { VALDEZATE }\end{array}$} & 2 & PÉRDIDA DE VIGOR \\
\hline & & 2 & & 1 & PÉRDIDA DE VEGETACIÓN \\
\hline & & \multirow{2}{*}{3} & \multirow{2}{*}{ MONTE DESCUIDADO EN GENERAL } & 2 & MATORRALIZACIÓN \\
\hline & & & & 1 & FALTA DE CUIDADO Y CONTROL \\
\hline & & 2 & PINAREJA NAVAS & 2 & ESTADO SANITARIO DEFICIENTE \\
\hline & & 1 & MONOCULTIVO DE PINO & 1 & RIESGO INCENDIOS \\
\hline \multirow{3}{*}{ 7/30 PART. - $23 \%$} & \multirow{3}{*}{$\begin{array}{l}\text { ÁREAS SUJETAS A } \\
\text { EXPLOTACIÓN MINERA }\end{array}$} & \multirow{3}{*}{7} & \multirow{3}{*}{ CANTERAS CADALSO } & 7 & AFECCIÓN AL ECOSISTEMA \\
\hline & & & & 2 & IMPACTO SONORO \\
\hline & & & & 1 & FALTA DE RESTAURACIÓN \\
\hline \multirow{2}{*}{ 3/30 PART. - $10 \%$} & \multirow{2}{*}{$\begin{array}{l}\text { MONTE - GRANDES } \\
\text { FINCAS PRIVADAS }\end{array}$} & \multirow{2}{*}{3} & \multirow{2}{*}{ FINCAS CINEGÉTICAS } & 3 & MALAS PRÁCTICAS/GESTIÓN (cinegética) \\
\hline & & & & 1 & FALSA NATURALIDAD \\
\hline \multirow{2}{*}{ 2/30 PART. - $6 \%$} & \multirow{2}{*}{$\begin{array}{c}\text { ZONAS CON PRESENCIA } \\
\text { DE AGUA }\end{array}$} & 1 & EMBALSES & 1 & BAJA DIVERSIDAD \\
\hline & & 1 & RIBERAS CON ÁRBOLES PODRIDOS & 1 & FALTA DE GESTIÓN \\
\hline
\end{tabular}


Tabla 16. Tipos de paisaje seleccionados, características comentadas por los entrevistados y frecuencia de selección: categoría Baja Calidad Estética.

\begin{tabular}{|c|c|c|c|c|c|}
\hline \multicolumn{6}{|c|}{ EVALUACIÓN ESTÉTICA PAISAJE BAJA } \\
\hline $\begin{array}{l}\text { № DE PARTICIPANTES QUE SELECCIONA EL TIPO DE } \\
\text { PAISAJE/ No TOTAL DE PARTICIPANTES .- } \\
\text { PORCENTAJE OUE REPRESENTA }\end{array}$ & TIPO PAISAJE & $\begin{array}{l}\text { № DE } \\
\text { PAIS }\end{array}$ & $\begin{array}{l}\text { TICIPANTES QUE SELECCIONA EL TIPO DE } \\
\text { NOMBRE DEL PARAJE SELECCIONADO }\end{array}$ & & № VECES SELECCIONADO / CARACTERÍSTICA \\
\hline \multirow{6}{*}{ 13/30 PART. - $43 \%$} & \multirow{6}{*}{$\begin{array}{l}\text { ESPACIO } \\
\text { AGROGANADERO, } \\
\text { CAMPO }\end{array}$} & 3 & ÁREA CULTIVADA (en general) & 3 & ASPECTO DE ABANDONO Y DETERIORO \\
\hline & & \multirow{2}{*}{4} & \multirow{2}{*}{ ALREDEDOR NAVAS } & 4 & FATA ARBOLADO \\
\hline & & & & 1 & RELIEVE PLANO \\
\hline & & 4 & ÁREA AGRÍCOLA (general) & 4 & $\begin{array}{l}\text { PRESENCIA DE CONSTRUCCIONES POCO CUIDADAS Y } \\
\text { ESCOMBROS: "CHABOLISMO" }\end{array}$ \\
\hline & & 3 & CULTIVOS ALREDEDOR M-501 & 3 & ASPECTO DE ABANDONO Y DETERIORO \\
\hline & & 2 & CULTIVOS ALREDEDOR N-403 & 2 & ASPECTO DE ABANDONO Y DETERIORO \\
\hline \multirow{2}{*}{ 10/30 PART. - $33 \%$} & \multirow{2}{*}{$\begin{array}{l}\text { ÁREAS SUJETAS A } \\
\text { USO TURÍSTICO } \\
\text { INTENSIVO }\end{array}$} & \multirow{2}{*}{10} & \multirow{2}{*}{$\begin{array}{c}\text { ZONA DE BAÑO DE EL EMBALSE SAN } \\
\text { JUAN }\end{array}$} & 10 & USO INTENSIVO \\
\hline & & & & 4 & USOS IRRESPETUOSOS \\
\hline \multirow{5}{*}{ 10/30 PART. - $30 \%$} & \multirow{5}{*}{$\begin{array}{c}\text { ESPACIO } \\
\text { CONSTRUIDO }\end{array}$} & 7 & \multirow{2}{*}{ URBANIZACIONES } & 7 & ARTIFICIALIDAD \\
\hline & & & & 3 & ESTÉTICA POCO CUIDADA \\
\hline & & 3 & NÚCLEO URBANO DE SAN MARTÍN & 3 & ARTIFICIALIDAD \\
\hline & & 2 & DISPERSIÓN URBANA & 2 & SENSACIÓN DE DESORDEN Y DESCONTROL \\
\hline & & 1 & MUCHA INFRAESTRUCTURA & 1 & ARTIFICIALIDAD \\
\hline \multirow{7}{*}{ 8/30 PART. - $27 \%$} & \multirow{7}{*}{$\begin{array}{l}\text { PAISAJE FORESTAL, } \\
\text { MONTE }\end{array}$} & \multirow{3}{*}{5} & \multirow{2}{*}{$\begin{array}{c}\text { ÁREAS AFECTADAS POR INCENDIOS } \\
\text { FORESTALES - LADERAS VALLE } \\
\text { VALDEZATE } \\
\end{array}$} & 3 & PÉRDIDA DE VIGOR \\
\hline & & & & 1 & PÉRDIDA DE VEGETACIÓN Y RIESGO DE INCENDIO \\
\hline & & & $\begin{array}{l}\text { ÁREAS AFECTADAS POR INCENDIOS } \\
\text { FORESTALES - MONTE DE SAN MARTÍN A } \\
\text { PANTANO }\end{array}$ & 1 & FALTA DE VIGOR, MALA DINÁMICA \\
\hline & & 2 & MONTES CON CORTAFUEGOS & 2 & IMPACTO VISUAL \\
\hline & & \multirow{2}{*}{2} & \multirow{2}{*}{ CANTO EL GUARRO } & 1 & MATORRALIZACIÓN, DENSIDAD EXCESIVA \\
\hline & & & & 1 & FALTA VIGOR/PRODUCTIVIDAD \\
\hline & & 2 & EFECTOS SEQUÍA & 2 & FALTA VIGOR/PRODUCTIVIDAD \\
\hline \multirow[b]{2}{*}{ 6/30 PART. - $20 \%$} & \multirow{2}{*}{$\begin{array}{l}\text { ÁREAS SUJETAS A } \\
\text { EXPLOTACIÓN } \\
\text { MINERA }\end{array}$} & \multirow[b]{2}{*}{6} & \multirow[b]{2}{*}{ CANTERAS CADALSO } & 5 & IMPACTO VISUAL \\
\hline & & & & 3 & IMPACTO SONORO \\
\hline 3/30 PART. - $10 \%$ & OTROS & 3 & $\begin{array}{l}\text { ANTENAS, TORRES DE ELEVACIÓN, } \\
\text { VERTEDERO }\end{array}$ & 3 & IMPACTO VISUAL \\
\hline
\end{tabular}




\section{B.1.- Percepción de valores en cada tipo de paisaje}

\section{B.1.1.- Paisaje forestal}

Los valores ecológicos y estéticos estuvieron fundamentalmente asociados al paisaje forestal. La mayoría de los entrevistados optaron en alguna de sus selecciones por destacar dichos valores en el paisaje forestal tipo "monte" o tipo "bosque". De hecho, una parte significativa de los encuestados eligieron los mismos paisajes forestales en ambas categorías e incluso específicamente reconocieron que para ellos ambos aspectos iban de la mano. La característica buscada en esta clase de paisaje correspondió con zonas cubiertas por una masa arbolada desarrollada y suficientemente extensa, es decir, la clave para la valoración del paisaje forestal recayó en la presencia de un ecosistema arbolado maduro.

Los valores ecológicos asociados se relacionaron con la biodiversidad presente (en ocasiones con referencia explícita a la fauna singular protegida), el buen estado de conservación (a veces expresado de esa manera, a veces expresado a través del reconocimiento de una gestión adecuada, o por encontrarse bajo una figura de protección), y, finalmente, por un alto grado de naturalidad o escasa influencia humana patente.

En cuanto a la estética de estos lugares, la percepción estuvo muy relacionada con características escénicas habituales (variedad, bosque maduro, presencia de riscos o roquedos singulares, colorido), aunque también se recalcaron atributos como la sensación de frescor, la percepción del vigor del ecosistema o el buen estado de conservación de algunos lugares.

Dos espacios fueron distinguidos de manera muy especial en ambos aspectos: el Monte de Utilidad Pública de Las Cabreras (M.U.P. no 54); y el Castañar de Las Rozas de Puerto Real. Ambos parajes actuaron por tanto como espacios singulares que encarnaba el ideal buscado. 


\section{B.1.2.--- Grandes fincas privadas}

Otro tipo de paraje muy comentado, aunque exclusivamente por sus valores ecológicos, fue el de las grandes fincas privadas. En el área es frecuente este tipo de tenencia de la tierra: grandes superficies agroforestales gestionadas para aprovechamiento ganadero $y$ cinegético (a veces con algunas pequeñas parcelas dedicadas al cultivo de viña). Tal y como enunció de forma muy expresiva uno de los participantes: "A esta zona la llaman la pequeña Andalucía".

Estos espacios recibieron en general un reconocimiento destacado sobre su valor ecológico, fundamentado en la biodiversidad que albergan (especial referencia hecha a la fauna singular protegida que acogen), su buen estado de conservación, y la poca presencia humana. Estéticamente sin embargo no fueron objeto de demasiados comentarios, dado que al ser espacios cerrados al acceso público las ocasiones de percepción de su paisaje no son frecuentes ni generalizadas.

\section{B.1.3.-.- Paisaje agrícola/agroforestal}

El valor ecológico o estético del espacio agrícola apenas fue puesto de relieve por los entrevistados. Únicamente los participantes con una actividad más ligada a la agricultura o ganadería subrayaron de forma espontánea el atractivo del paisaje cultivado y a su vez pusieron de relieve las disfunciones ecológicas y productivas que provocaba el abandono del campo.

[AGRICULTOR] "No debemos olvidar que tenemos una agricultura muy bonita aquí, aunque se nos está acabando..."

[GANADERO] (valorando la calidad estética del paisaje) "La parte por encima del pueblo, como hacia Costa de Madrid (urbanización a orillas del embalse de San Juan). Es un terreno llanito, muy poco trabajoso, hay también muchas encinas. Se ve muy igual todo, mucho campo, mucha oliva, muchas viñas. Aunque la mayoría estén perdidas pero todavía se ve... Por esa zona puede ser por donde haya más campo más cuidado, que haya más gente que tenga el campo más cuidado. Por otros sitios se ve más perdido."

Para el resto de participantes, en general los valores del espacio agrícola pasaron desapercibidos hasta que no se preguntó específicamente por ello. En estos casos se juzgó como un espacio 
poseedor de cualidades comparativamente no destacables (por ejemplo comparado con el espacio forestado o paisajes sobresalientes como el del monte de Las Cabreras); o bien poseedor de valor ecológico o estético fundamentalmente al aparecer combinado en mosaico con el espacio forestal.

\footnotetext{
[AGENTE MEDIOAMBIENTAL, MIEMBRO ORgANIZACIÓN ECOLOGISTA] "Por ejemplo de Navas a El Morro yo veía cultivos tanto mantenidos como abandonados. Y me gustaba, porque veía un mosaico de... aquí hay un arroyito con su vegetación de ribera, sus zarzas, sus arbustos espinosos... más allá un olivar que está cuidado, y más allá un olivar abandonado que ya tiene pino piñonero, encina y tal. Y luego hay una zona más asi de rastrojo, de pasto... a mí me parece un "collage cojonudo", y además a los chavales se lo hago ver: mirad para que tengamos al águila imperial en el bosque mediterráneo necesitamos una zona donde tenga para comer, y entonces necesitamos que esa zona tenga conejo, liebre, perdices... de día la ves así, y al caer la tarde ves al búho, al águila imperial por ahí dando vueltas... lo que pasa es que tenemos tanto para elegir que te vas a Las Cabreras, porque ies una cosa tan evidente!"
}

[TÉCNICO PROYECTO CONSERVACIÓN FAUNA, BIÓLOGO] "A mí no me...por ejemplo en esta zona son mucho en mosaico y es cierto que en términos de paisaje y de la biodiversidad va a ser incluso enriquecedor, por fuerza. Siempre que se respete ese mosaico, que tengas aquí un prado, y luego una viña, y luego una viña más pequeña o más grande...que no sea un monocultivo. A mí no me causa ningún problema, es más, lo veo muy bien. Siempre que no sea un sistema en espaldera, que eso es destructor, lo va a prohibir la Unión Europea. Eso es un matadero de bichos, aparte de que es horrible."

Ahora bien, la percepción del mantenimiento y prácticas de manejo adecuadas del área cultivada entró a formar parte destacada de las evaluaciones negativas hechas en ambas dimensiones, independientemente del grupo social al que perteneciera el entrevistado. Esta evaluación expresada en términos negativos estuvo fundamentalmente relacionada con la pérdida de la funcionalidad y el encanto de base de un espacio minifundista y cultivado tradicionalmente que, a causa del abandono y el mal uso, se convierte en un espacio degradado, poco respetado, desordenado, incoherente, con aspecto descuidado y con repercusiones negativas en la ecología de la zona.

[GANADERO] "El campo está perdido aquí, las viñas y eso están perdidas"

[CONCEJAL ENCARGADO DE MEDIO AMBIENTE LOCAL] "Luego en cuanto a calidad ecológica baja, para mí el prado de La Mata, que es una zona situada en un triángulo entre la 403, la 501 y la AV-502. Es una zona muy peculiar, explotada por agricultores desde tiempos remotos, desde el siglo XIX, y bueno es una zona que 
tiene una riqueza muy grande porque hay alli unos grandes manantiales [...] Y claro yo lo que veo es que eso tiene unos manantiales divinos, que yo creo que eso tiene una carga ecológica buenísima. Sin embargo está muy deteriorado por prácticas... porque allí cada uno cultiva lo que le da la gana, ipufff!, tan pronto meten ganadería como agricultura, la agricultura cada uno siempre lo que le da la gana... es una zona un poco caótica." / "Como calidad de paisaje baja aquí lo tengo muy claro, son los dos los márgenes de las carreteras [...] Todo el margen me parece deplorable, no sólo por la falta de mantenimiento de la carretera, la falta de mantenimiento de las fincas, aquí no hay gusto por tener la finca bonita, aquí nos construimos la casa, el chalé y lo demás. Otro es el margen de la carretera 403: igual, es exactamente lo mismo [...] Hasta que empieza todo este paisaje de pinar hacia Castilla la Mancha me parece precioso todo eso, sin embargo antes, pues está un poco descuidado. Precisamente por eso, no cuidamos... parece mentira, porque luego tenemos viñas bonitas y ... pero con unos simples detalles yo creo que quedaría bastante mejor."

[AGENTE DESARROLLO RURAL, INGENIERO AGRÓNOMO] "No creo que sea especialmente rico, pero no es desdeñable. Si miras la media de edad, ellos no están pensando en el futuro de la viña, están pensando en que ya poco hay que hacer. Además la media de edad es muy alta. Y como además no hay relevo generacional, fijate. Relevo al final es eso, que muchas empresas han visto un nicho de mercado, que lo que están haciendo es recuperar tierras que están... no mal cuidadas.. bueno sí, quizá sí, pero ya no quizá con ese mimo de que es tu sustento, sino ya como algo complementario, como algo accesorio que te da ya un poco más igual. Porque como no lo conservas mirando hacia adelante. Es casi como una obligación."

\section{Llama especialmente la atención las opiniones tan encendidas y vehementes que se dedicaron al denominado fenómeno del "chabolismo", es decir, la aparición desordenada y sin control de construcciones de baja calidad y elementos incoherentes en el espacio agrícola.}

[BODEGUERO-AGRICULTOR] "Aquí se han hecho casas en cualquier sitio, sin permiso, de cualquier manera... lo que llamamos aquí el 'chabolismo', eso de llegar y hacer una casita en medio del campo sin permiso ninguno. Toda esta zona está infectada de chabolistas."

[AGENTE MEDIOAMBIENTAL] "Es un fenómeno que se da sobre todo en Cadalso, y es la cantidad de 'chabolismo' en todo el término. Es que además es chabolismo, no son casas, es cha-bo-lis-mo. Es repugnante, no te puedes imaginar la gente donde tienen la sensibilidad, eso degrada, degrada completamente. Aparte es que el hombre que entra en esos lugares, de respeto por la naturaleza nada de nada: ni se integran en ella, ni sacan provecho de lo que tienen que sacar. Porque ellos van: iOye, qué sitio más bonito! Pues se agradece, ipero dale algo de ti!...no, nada. Eso está muy degradado, muy degradado."

Otro de los factores que se presentaron frecuentemente en la evaluación del espacio agrícola fue el de las malas prácticas a la hora 
de aplicar herbicidas y pesticidas. En este caso se ponen de relieve los efectos negativos de la toxicidad sobre el ecosistema.

[GANADERO] "La gente ya no quiere trabajar en el campo. Antes trabajaban en el campo, sacaban, se mantenía. Ahora van y echan insecticidas, que debería estar prohibido, insecticidas para las hierbas. iLo mata todo! Es veneno que quema las hierbas, imagínate, entra un conejo, come y... Cae cerca de un arroyo y es como un aceite. Eso no puede ser bueno. Y luego a los 10 días a lo mejor no pasa nada, pero solo los 10 días primeros. Eso debería estar prohibido, eso es veneno puro. Este año la Comunidad (gobierno de la Comunidad de Madrid) curó todas las cunetas. Ahí es mejor poner un caminero, que no curar en furgoneta iQué bonito, regando ahí todas las cunetas en el mes de mayor calor! Yo no sé, eso vienen de la Comunidad. Eso es veneno puro. Dicen que está prohibido y siguen echando..."

[BODEGUERO-AGRICULTOR] "Desde hace algunos años se está abusando de los herbicidas y eso está deteriorando bastante el paisaje. Y es que últimamente lo están echando hasta los ayuntamientos en las cunetas para evitar incendios, que lo que hacen es lo contrario, porque lo que hacen es dejar la hierba alta y seca y es más peligroso. Pero no sólo es peligroso por los incendios, yo creo que echar un herbicida es más peligroso para la ecología y el paisaje."

[EDUCADOR, BIÓLOGO] "El espacio agrícola, dentro de lo que son los espacios agrícolas, no me parece lo más horroroso que se pueda ver, sobre todo si lo comparo con las canteras. Además yo creo que es completamente compatible una agricultura

un poquito más respetuosa con el medio ambiente de la que se practica aquí. Acostumbrado a los paisajes castellanos que son kilómetros y kilómetros de cereal, ique también tienen su encanto en determinadas épocas, eh!. Lo que me fastidia sobre todo es que están afectando a la fauna, lo único que le ocurre es que utilizan muchísimos pesticidas y herbicidas, y además sin control."

\section{B.2.- Impactos antrópicos sobre el paisaje}

Los principales impactos que los participantes consideraron de forma consistente que detraía calidad en ambas dimensiones se identificaron con los efectos de las urbanizaciones e infraestructura, y con las áreas sujetas a explotación minera (canteras de granito). La evaluación negativa fue fundamentalmente puesta de relieve por los participantes con formación en el ámbito ambiental y de gestión de recursos naturales.

Así, la ocupación del suelo por el espacio construido e infraestructuras, el efecto de distorsión sobre las dinámicas de los ecosistemas y la artificialidad que inducen fueron destacados como efectos negativos sobre la ecología de la zona. La artificialidad fue igualmente puesta de relieve como un impacto en la calidad de un paisaje percibido como "orgánico", aunque la impresión de falta de 
respeto por el medio a la hora de planificar y ejecutar estos espacios y una apariencia de construcción de baja calidad, desordenada e incoherente tuvo también peso en las valoraciones.

[TÉCNICO DE EDUCACIÓN AMBIENTAL, INGENIERA FORESTAL] "Es una zona natural urbanizada, una construcción dentro del monte supuestamente respetándolo. A mí la urbanización Entrepinos... paisajísticamente no me parece mal, no me parece mal que se haga una urbanización y que se quiten unos árboles determinados para meter los chalecitos, porque pienso que se integra en el paisaje. Hombre porque está en un alto, pero si está en una zona más baja, no te llama tanto la atención. Pero de ahía que hayan respetado la ecología de la zona...pues creo que no sinceramente."

[TÉCNICO ORDENACIÓN/GESTIÓN AGRÍCOLA, INGENIERO FORESTAL] “Han metido urbanizaciones como esta, entre medias de todo. Si, hay muchos pinos entre medias, pero crean un problema serio."

[AGENTE MEDIOAMBIENTAL, MIEMBRO ORGANIZACIÓN ECOLOGISTA] "SOn mordiscos aquí y allá que hacen difícil la conexión entre ecosistemas [...] Son construcciones cutres, lleno de mierda, están fuera de lugar. "

[TÉCNICO PROYECTO CONSERVACIÓN FAUNA, ZOÓLOGO] "Hay mucha infraestructura, pantanos, casas de labores, carreteras, tendidos eléctricos. Es parte del paisaje, pero rompen el encanto."

[AGENTE DE DESARROLLO RURAL, INGENIERO AGRÓNOMO] "Hay un caos urbanístico, no hay ningún tipo de planificación...ya no sabes si está en rural o urbano, distinta tipología de edificios...se han ido haciendo según se han ido poniendo. No está ordenado."

[PROPIETARIO-GESTOR FINCA, INGENIERO DE MONTES] (valoración ecológica) "Algunas urbanizaciones tiene impacto ecológico. No me gusta caer en el cliché de que las urbanizaciones y las canteras son de calidad ecológica baja porque tienen que estar, y Cadalso es Cadalso gracias a lo que le generan las canteras también, pero...." / (valoración estética) "Creo que las urbanizaciones siempre y cuando no sea demasiada cantidad y no gasten demasiada agua son buenas, y si son razonables en la zona las que hay. A mi me horrorizaba lo que querían hacer en Navahonda hacia arriba, sobre todo por los campos de golf, alli donde hay un problema de agua muy gordo, no creo que sea lo más adecuado. Pero bueno, La Atalaya es fea... pues la Atalaya tiene chalets feos pero porque la gente que los compró no tenía dinero para

hacerse un chalet superguay, entre otras cosas. Que a lo mejor en algunas urbanizaciones las administraciones de los pueblos de alrededor deberían haber tenido unas normas urbanísticas más claras respecto a la estética."

En cuanto a las canteras, las afecciones ecológicas se ligaron al impacto de ocupación del suelo, falta de restauración y molestias a la fauna a causa del ruido, destacando que estos efectos se producían además en zonas sensibles con alto valor natural. Paisajísticamente, 
fundamentalmente se destacó el impacto visual de una actividad incoherente con el contexto "natural" y, también, el impacto sonoro.

[GUARDA DE CAZA] "Visualmente es muy impactante, y muy fea, es horroroso... Io que era un pinar ahora es un boquete. Y es que tienen una extracción de piedra exagerada."

[EDUCADOR, BIÓLOGO] "Producen unos impactos visuales pavorosos y acústicos tremendos, aunque digan que no, y están además en zonas muy sensibles, no me gustan nada."

\section{B.3.- Percepción de las dinámicas y procesos ecológicos}

B.3.1.- Incendios forestales

La ocurrencia de incendios forestales fue uno de los procesos evaluados con incidencia en el paisaje más relevante, referencia frecuente en selecciones y comentarios. El impacto tanto ecológico como estético de los incendios forestales fue ponderado por los participantes atendiendo a dos dimensiones: la percepción de sus efectos y la consideración del riesgo de que se produjeran. Además, el papel de los cortafuegos fue también frecuentemente valorado en relación a este tema.

- Efectos de los incendios forestales

Las zonas afectadas por incendios forestales fueron claramente evaluadas como una de las de menor calidad, tanto en el plano ecológico, como en el estético. Esa percepción estuvo presente en el discurso de prácticamente todos los participantes, en mayor o menor medida, de forma directa o indirecta.

La pérdida de la cobertura arbórea a consecuencia de los incendios ocurridos se identificó como el principal impacto percibido en el paisaje en ambas facetas. Además, varios participantes hicieron igualmente referencia a los efectos negativos que producían los incendios forestales en cuanto a pérdida de fertilidad, que derivaba finalmente en una falta de vigor y riqueza del ecosistema.

[CONSULTOR AMBIENTAL, BIÓLOGO] "Por el tema de los incendios y la regeneración, toda la zona del embalse hasta el pueblo (San Martín)... pues hasta los vecinos lo entienden, simplemente se dan un paseo y dicen ¿aquí qué pasa? 
¿que aquí empiezan a verse caer pinos, y cada vez más pinos y más pinos, no se ve una regeneración del bosque?. Por los incendios hay cada vez hay más pinos secos, menos regeneración, y luego también ves escolítidos, perforadores..."

[MIEMBRO DE UN GRUPO ECOLOGISTA, ADMINISTRATIVA] "La zona que va a Robledo con los incendios que ha habido es ya desolador ir a verlo, ya no tiene ningún encanto, no sé si habrá fauna ya, pero poca, porque no tienen ya ningún refugio natural. Eso fue en el 2003, han pasado ya 12 años y nada de recuperación. Y como se han ido quemando las zonas pegadas pues realmente está afectando mucho, se ha convertido en una mancha desprotegida totalmente, de perímetro muy grande y no sé cuánto tardará, pero vamos... Mi percepción desde luego es que se han ido restringiendo estas zonas, claramente. Desde el Alto de La Granjilla tienes una visual a esta zona y, en invierno, no, porque está verde el pasto, pero en verano es dantesco ver cómo ha ido avanzando el desierto, ipero de una forma espectacular!"

\section{- Riesgo de ocurrencia de incendios forestales}

La percepción de signos que revelan un alto riesgo de incendio en las áreas forestales fue interpretada no solo como un problema ecológico, sino también estético. Esta condición se asoció fundamentalmente con masas arboladas muy densas y/o que presentaban un estrato continuo y abundante de matorral de sotobosque, a las que se calificó como "sucias" e inaccesibles.

[PROPIETARIO-GESTOR FINCA, INGENIERO DE MONTES] "Destacaría los incendios que ha habido en Navas del Rey. Subir por la antigua carretera de Navas, que tenía el pinar tan precioso y ahora ver que hay...bueno, al final va a acabar saliendo un continuo de encina-jara que no es negativo, pero que lo que va a hacer es que haya otro incendio y se pierda incluso el continuo encina-jaral."

[TÉCNICO PROYECTO CONSERVACIÓN FAUNA, ZOÓLOGO] "Es que es un monocultivo de pino, prácticamente. Hay un profesor que nos enseñó que 'pino plantado, pino quemado', y más tarde o más temprano está pasando. Y tenía razón, que toda esta parte se quemó, esta se quemó, los incendios de hace dos años... y todos los años pasa algo. También es cierto que también se queman los robledales de Galicia, ¿no? Pero es lo que menos. Y lo que menos se quema en esta zona son las encinas."

La impresión que provocaba era negativa no sólo por la percepción de la amenaza que suponía, sino que era estéticamente poco valorado dado que se erigía como el signo notorio de la falta de gestión o cuidado del monte.

[GANADERO] (comentando la calidad ecológica de la zona) "Debe estar un poco más limpio el monte, mondar más los pinos, cortar las jaras, los pinos más limpios..mejor. Lo hacen nada más que en la carretera y los cortafuegos, pero luego cuando te metes por dentro las jaras están a 2 metros, los pinos uno seco y caído, otro sin remondar. Han de limpiar más el monte [...] Es que está muy sucio. 
Pero el monte está bien, nada más que habría que limpiarlo un poco. Para los fuegos y todo sería bueno, porque el pino no se quema: hay un fuego, y si no tiene jara debajo, el pino no se quema Se quemará un poco el pasto, pero la llama no sube y el pino no se quema. Ahora, si tiene mucho forraje eso arde por abajo y arriba el pino. Si estuviera más limpio habría menos fuegos y todo."

[TÉCNICO CENTRO DE FAUNA, BIÓLOGO] "Realmente yo creo que para gestionar bien un monte lo primero que tienes que tener es un grupo de gente destinada a mantener ese monte, es decir, o bien mantener un grupo de cuadrillas limpiando el monte, para evitar incendios en verano, o bien tener subvenciones y fomentar la ganadería, que es como antiguamente como se hacía, pastoreo por el monte, ovejas cabras, etc. que se comieran todo para evitar que hubiese ese tipo de problemas a la hora de incendios forestales"

- Consideración del efecto de los cortafuegos

A la hora de evaluar el efecto sobre el paisaje de los cortafuegos, el juicio sobre su eficacia se perfiló como el factor decisivo. De tal manera, se expresaron dos posiciones:

Posición A.- Consideración de los cortafuegos como un elemento eficaz para la lucha contraincendios, cuyo impacto visual y ecológico podía ser consecuentemente aceptado: presencia admitida como "un mal menor". Esta percepción estuvo asociada fundamentalmente a los participantes cuyo modo de vida derivaba de la explotación agroforestal en la comarca.

[GANADERO] "Hombre, creo que está bien, donde los hacen, para cortar los fuegos. El impacto ecológico que tienen es los árboles que destruyen, que arrancan. La vegetación que matan. Pero no está mal, porque también si no haces los cortafuegos... Aquí el mejor cortafuegos es el ganado, que es el mejor cortafuegos que hay."

[PROPIETARIO-GESTOR FINCA, INGENIERO DE MONTES] "Para mí un cortafuegos me parece bien que visualmente esté un poquito más camuflado, pero para mí eso no es lo importante, lo importante es que haga su función. Si tiene que haber

27 que no sean muy monos, los prefiero. Y creo que hay demasiada poca cantidad de cortafuegos"

Posición B.- Duda o no reconocimiento de la eficacia de los cortafuegos: "no hace su función". Esta percepción estuvo asociada mayoritariamente a participantes con formación técnica sobre medio natural, que consideraron a los cortafuegos como un elemento susceptible de una mejor planificación o diseño; o bien como un elemento más o menos superfluo del cual es posible, e 
incluso conveniente, prescindir por su impacto sobre la ecología y el paisaje de la zona. Las dudas sobre su eficacia se basaron en la consideración de la incapacidad en general de los cortafuegos para detener o ralentizar el avance del incendio o, en una posición más matizada, la de considerar que sólo algunos cortafuegos no cumplían adecuadamente con su función a causa de una planificación, diseño o mantenimiento inadecuado. En algunos casos incluso se denotó una desconfianza ante la sensibilidad y grado de conocimiento técnico del personal a cargo.

\section{[AGENTE MEDIOAMBIENTAL, MIEMBRO ORGANIZACIÓN ECOLOGISTA] "La} pregunta es ¿cuáles son efectivos y cuáles no?. Habría que estudiar, y eso me lo dijo el técnico: ¿cuales son efectivos por el tema de vientos dominantes, pendientes etc. y cuáles no tienen ningún sentido?. Las áreas cortafuegos visualmente son un impacto brutal, y de hecho en otras zonas de Madrid no lo hay. Del ancho que son aquí, que son 2 o 3 palas de bulldozer, es una barbaridad. Y también provocan erosión, porque no dejas de remover la tierra cada año. Y visualmente son llamativos, o sea, hace daño. Pero si a mí alguien me asegura que no va a haber incendios, pues me parece un mal menor. Me gustaría que el monte estuviera tratado de tal manera que no hubiera necesidad de tener áreas cortafuegos porque no hay combustible. Pues eso implica iniciativa pública o privada, y darle valor. Mi propuesta sería hacer fajas auxiliares alrededor de todas las carreteras de la Comunidad de Madrid. [...] Aquí hemos visto incendios pasar el embalse de Picadas. Entonces, claro, cortafuegos de 8, 10, 15 m, 20... y los hemos visto pasar un embalse... pues lo mismo es que es una figura obsoleta."

[AGENTE MEDIOAMBIENTAL] "iAh! y una cosa también paisajísticamente muy negativa son los cortafuegos, que hay también en esa zona. Eso es cosa de los ingenieros, que son cerriles. Paisajísticamente es una brecha, es como si fuese una agresión, ahí ver pasar un bulldozer arriba y abajo por el monte pues...es doloroso, puede ser doloroso para el que entienda o para el que no entienda,

independientemente del conocimiento que tenga. Pero luego, si tienes conocimiento... Yo creo que esos cortafuegos están mal planeados, que provocan muchos procesos erosivos graves, colmatan algunas charcas y algunos arroyos, con graves consecuencias ecológicas. Y luego a la hora de la verdad no sirven para nada algunos, algunos sí otros no, pero hay algunos que no sirven para nada en cuestión de incendios. Habría que evitar cortafuegos en pendientes pronunciadas, en terrenos llanos mejor, pero esas pendientes tan grandes deberían evitarse. Se debería sustituir por áreas cortafuegos (sic), creo yo. Hay un cortafuegos que separa el monte 55 del 56 que es absurdo, eso es una pista para motos. En los dos lados está superespeso de vegetación y hay algún punto en que casi se tocan las copas de los árboles. Sin embargo siguen pasando bulldozer todos los años y arrastrando un montón de tierra al arroyo. Ese es quizá el peor ejemplo de todos."

[AGENTE MEDIOAMBIENTAL] "Se buscaba el sitio idóneo, pero yo tengo una polémica muy grande con el servicio de bomberos. En esta zona existen dos tipos de cortafuegos: el cortafuegos, cortafuego, que lo hizo el servicio de incendios, y el cortafuegos de deslinde. Y ellos [refiriéndose a Protección Ciudadana] no entienden que esos cortafuegos no sirven de cortafuegos. ¿De qué me sirve un cortafuegos en el fondo de un barranco, si en cuanto haya un fuego de copas se te va? A los primeros ingenieros el impacto en el paisaje les preocupaba y 
dejaban pinos en medio del cortafuegos por el tema visual. Ahora como ha pasado de Medio Ambiente a Protección Ciudadana, si hay un arbolito, estorba a la máquina.

Sea como fuere, y tal y como se desprende de los comentarios, en ambos casos se consideró como mejor alternativa o como complemento necesario a la presencia del cortafuegos la ejecución de fajas cortafuegos o fajas auxiliares en las carreteras y caminos, y muy especialmente, la prevención de incendios mediante el control del combustible presente en el monte (por medio del aprovechamiento de los recursos del monte o por trabajos selvícolas). Esta última consideración está vinculada con la valoración del proceso de abandono del medio que se analiza a continuación.

\section{B.3.2.- Proceso de abandono o falta de mantenimiento del paisaje}

Otro de los procesos más comentados, que conecta claramente la evaluación del estado ecológico y la estética, fue el del progresivo abandono del paisaje debido a la cada vez menor presencia del tradicional interventor $\mathrm{y} / \mathrm{o}$ a la insuficiente gestión de la administración. Dicha percepción se evidenció tanto en el caso del espacio agrícola como en el forestal.

Así, el mantenimiento del espacio cultivado y de los usos tradicionales del monte (ganadería, recogida de leña y piñas...) fue considerado como clave para el buen funcionamiento ecológico del paisaje. La constatación de la desaparición de estas actividades sugiere un estado ecológico deficitario, vinculado además a una imagen de abandono y desaliño. Por otro lado, en general se considera que la gestión forestal pública es insuficiente en la zona y no consigue contrarrestar los efectos negativos que acarrea la disminución de la intervención local.

[GANADERO] "Hay mucho campo perdido. Yo como ganadero en parte me beneficia, para comer las ovejas, pero está el campo muy perdido ya, muy mal."

[PROPIETARIO-GESTOR FINCA, INGENIERO DE MONTES] "A nivel de aprovechamientos, la gestión forestal está bien, es correcta, pero debería de poder cuidarse más el campo en general, el monte. Pero para eso tendría que generar valor, porque en caso contrario lo que haría sería multiplicar los costes de la administración por 1000. Es una pena el abandono de viñas, una pena gorda. Ahora están recuperando pequeñas viñas para las bodegas, para hacer un vino un poco más selecto. Pero hay mucha zona de viñedo que se abandonó, se quitaron las cepas y ahora mismo está prácticamente como pasto para ganado y poco más. Me gusta 
mucho el viñedo en otoño, y las zonas de olivar también me gustan bastante. Ecológicamente se pierde un uso de suelo durante muchísimas generaciones, es posible que luego colonicen otras especies, que a lo mejor...no creo que sean muy endémicas las que colonicen, porque al final, terreno abandonado hay muchísimo,

hay demasiado, entonces no creo que aporte un valor mayor ecológico al estar abandonado por mucho que haya 4 especies que la colonicen. Porque me dirás: un viñedo ecológico tiene solamente la vid, porque todo lo demás se ara, se corta. Pero es un terreno utilizado, y mucho, sostenible durante muchísimos siglos, ha dado dinero a la zona, hace que el monte esté más cuidado. Y ese es el problema, el abandono, y es porque la gente no vive, ni en la comarca [...] Es difícil, ¿no? pero yo creo que si tu quieres arreglar una comarca, lo cual es muy complicado, dale salida económica, y todo lo demás, incluso el paisaje, irá detrás."

[AGENTE DE DESARROLLO RURAL, INGENIERO AGRÓNOMO] "Yo creo que hay muy poca gestión, incluida la forestal. Y no hay mantenimiento de las actividades, lo cual genera problemáticas. La cabaña ganadera ha disminuido un montón en extensivo y no hay una gestión que asegure un buen estado del monte. [...] A mí me desafora mucho el abandono de los cultivos, aunque también tienes esa percepción de que es un mundo que muere y otro que viene. Depende de cómo se produzcan las cosas, porque por otro lado piensas que donde no hay un interés económico muy grande las zonas naturalizadas van ganando su espacio."

Los signos visibles de este proceso se identificaron con el avance del monte en el espacio agrícola, la matorralización de las masas forestales y una homogeneización del paisaje. Las consecuencias ecológicas previstas consistieron en un aumento del riesgo e intensidad de los incendios forestales. En cuanto a la imagen que estos espacios proyectan, la evaluación fue negativa, pues sugería un espacio desatendido y mal cuidado, inaccesible e inestable.

[GANADERO] (refiriéndose a zonas con calidad de paisaje baja) "Por ejemplo, en Canto el Guarro, que hay mucho pino, tendrían que hacer alguna limpieza o algo, hay mucho. Antiguamente no había tantos, cuentan que no había tanto. Siempre ha habido ganado allí metido. Antes había viñas entre medias, pero ahora ya se lo ha comido todo el pino, la gente lo ha dejado abandonado y son pinos grandes."

[AGENTE MEDIOAMBIENTAL] "Cuando yo vine aquí, todos los campos alrededor de San Martín eran viñas, era un mar de viñas. Ahora me doy una vuelta por ahí y se me cae el alma a los pies. Si te pones a analizar la causa, ves una viña muy bonita, muy buena, y resulta que el dueño tiene otro trabajo principal o está jubilado. Pero el agricultor de base no lo tienes ya."

La constatación de una intervención humana menos intensiva en el territorio fue interpretada también en clave positiva, pues algunos participantes advirtieron determinados procesos que interpretaron como signos de recuperación de riqueza ecológica.

[BODEGUERO] "Cuanto más monte haya, menos caza menor y hay más caza mayor. Al haber más monte, hay más caza mayor y se comen los cultivos. De hecho esta 
primavera en la zona de Tabalón, Mariano se dio de frente con unos lobos [...] Aquí se están empezando a ver animales que hace años dejaron de verse. Por ejemplo el gato montés, que yo lo he visto. Antes había, desaparecieron, y otra vez han vuelto.

Pero es por lo mismo, es por el monte, que está avanzando, están volviendo a su hábitat. (Ganadero en conversación) Claro, las piedras, iles hacían un agujero para poner una cepa!. Y como todo eso se va perdiendo, el monte va recuperando lo que era suyo y los animales que había están regresando también."

[CONSULTOR AMBIENTAL, BIÓLOGO] "Llevo 40 años aquí, y ya he visto, iceh?! Y lo que si he visto desde hace 10-15 años es que a nivel de avifauna se están introduciendo especies que estuvieron en su tiempo, se fueron, y han vuelto. El rabilargo por ejemplo, las oropéndolas. Ya empieza a ser una clave, es un síntoma también de calidad ambiental. Tienes las collalba, los carboneros, las abubillas...es muy sintomático. Incluso con la evolución y el propio envejecimiento del monte sigues viendo unos valores ecológicos que se van manteniendo y que evidentemente siguen ahi."

[CONCEJAL ENCARGADO DE MEDIO AMBIENTE LOCAL] "Yo lo que he visto lo voy a explicar como el que no tiene ni idea de campo. Cuando llegué hace 10 años aquí de vuelta, cuando yo iba con mi padre al campo a echar una mano, lo veía y me lo decía un amigo: es que no hay bichos aquí. O sea, tu ibas a una viña y es verdad que no te molestaban las hormigas, los saltamontes. Yo me acuerdo de pequeño que estabas harto de que te picara todo, que siempre te tenías que quitar algo de encima. Y es verdad que hace 10 años ibas por un camino y no te salían ni saltamontes. Y sin embargo ahora vas y es verdad que cuando vendimio dejo las ventanas del coche

abiertas y luego tengo eso una semana como un terrario. Yo creo que está cambiando el ecosistema. [Agricultor en conversación] ¿Sabes lo que pasa? Que antes se curaba para todo, y ahora que no se trabajan las viñas pues no curan."

\section{B.4.- Percepción de la gestión y uso del paisaje}

La evaluación del resultado de las intervenciones en el paisaje por distintos agentes fue un aspecto omnipresente en los comentarios expresados. La atribución de la responsabilidad de la gestión del paisaje se centró en 3 administradores, que por tanto se identificaron como los principales generadores de determinadas cualidades 0 deficiencias en algunos paisajes:

- La administración autonómica (Servicios forestales-Medio Ambiente de la Comunidad de Madrid), como responsable principal del estado del paisaje forestal de uso público.

- Los propietarios-terratenientes, como responsables del estado de las grandes fincas, que ocupan un espacio considerable en la comarca.

- La población local, como responsable principal del espacio agrícola y construido, y partícipe del estado del terreno forestal público. 
Por otro lado, los visitantes fueron identificados como usuarios relevantes del paisaje que, provenientes fundamentalmente de la ciudad de Madrid, pasan el día en la zona atraídos fundamentalmente por sus valores naturales y, muy especialmente, por el área recreativa entorno al pantano de San Juan

\section{B.4.1.- Percepción de la gestión por parte de la administración}

En la gran mayoría de los casos la actuación de la administración a cargo de la gestión pública del medio biofísico fue evaluada en términos negativos. De los comentarios vertidos se destila la existencia de una crisis de confianza en la legitimidad de su actuación, motivada por la evidencia de que la gestión llevada a cabo no es ni activa, ni razonable, ni bienintencionada. La combinación de estos 3 factores estuvo presente en la percepción expresada por todos los grupos sociales representados en las entrevistas.

- Falta de gestión/intervención en el paisaje forestal

Los entrevistados percibieron una clara falta de gestión activa, atenta y responsable de las masas forestales por parte de la administración pública, y consideraron que este hecho repercutía negativamente en el estado ecológico y en la estética del paisaje. Mayoritariamente entendieron que el origen fundamental de esta situación se encontraba en la falta de interés o compromiso de la administración, que era percibida como un ente abstracto, genérico e inconcreto que no se preocupaba suficientemente por alcanzar unas condiciones del paisaje adecuadas. Prácticamente la totalidad de los entrevistados argumentó que percibía la gestión forestal pública como insuficiente e incluso inexistente a efectos prácticos, y que este hecho daba como resultado unas masas forestales desatendidas, con un potencial de aprovechamiento infravalorado e infrautilizado, con dinámicas ecológicas inadecuadas y en riesgo evidente de sufrir un incendio forestal catastrófico. 
preventivo, que lo hacen los bomberos. Y el servicio forestal de la Comunidad de Madrid brilla por su ausencia. Lo que aprecio es que no está coordinado."

[TÉCNICO CENTRO DE FAUNA, BIÓLOGO] “La sensación es que yo creo que no se hace, o se hace muy poca gestión forestal"

[AGENTE DE DESARROLLO RURAL, INGENIERO. AGRÓNOMO] "Al final toda esta zona lo que hay es muchos intereses económicos, al final las zonas mejor cuidadas, o gestionadas, son las que pertenecen a manos privadas y se gestionan. Y lo otro sigue como su suerte, entre comillas."

Por tanto, en el caso de este paisaje no existe un problema asociado a la visibilidad de actuaciones forestales que potencialmente pueden presentar problemas de aceptación pública o que afecten a la belleza del paisaje. Al contrario, existe un problema de falta de evidencia de actuación o, formulado a la inversa, se perciben signos en el paisaje que evidencian una degradación paulatina del mismo dado que no se están realizando las actuaciones pertinentes por parte del gestor a cargo.

- Actuaciones inapropiadas

A la percepción generalizada de una actuación insuficiente de la administración se unió la evidencia encontrada por buena parte de los entrevistados de que el diseño y ejecución de ciertas actuaciones del gestor público afectaban al correcto funcionamiento ecológico y a la estética del paisaje. Esta percepción derivaba en general en una crisis de confianza en lo acertado, conveniente o coherente de la actuación de la administración, motivada por la evidencia que se tiene de que la gestión llevada a cabo no está suficientemente meditada ni es, en ocasiones, bienintencionada. La inadecuación de las actuaciones se percibió como motivada por 3 factores:

- Actuaciones sin verdadero calado: "No hay una gestión de verdad del monte"

[AGENTE DE DESARROLLO RURAL, INGENIERO AGRÓNOMO] "Muchas veces me planteo que se gestiona para cubrir el expediente: hay tanto dinero, pues este año da para esto y ya está, se acabó. No hay una gestión de verdad del monte. Pero es que además incluso en los más "valioso", que la administración tiene la obligación de cuidar, tampoco es que la gestión sea extraordinaria. Y de 
hecho la sensación que te da, y que te hace ligar un concepto que yo creo que es erróneo, es que las zonas privadas están mejor cuidadas que las zonas que no. [...] Te alimenta las sensaciones de lo que se hace no está bien hecho en el fondo, es una cuestión de asignación de recursos, como no es importante, pues no se le destina. Bueno, es más bien: como la gente no manifiesta la importancia de eso, bueno, el dinero lo pongo en lo que es visible [...] Ecológicamente es lo que es, me pregunto la funcionalidad última, si alguien ha valorado alguna vez si sirve o no sirve en la zona. O sea, yo entiendo que hacen

eso y que no piensan cuando lo hacen y lo hacen como churros. [...] Mi experiencia más cercana, es con la repoblación de Valdemaqueda después del incendio y es como decir ¿de verdad hay técnicos detrás de esto? ¿A quién se le ha ocurrido esto? La sensación es marciana. Lo dejan como una superficie lunar y con mis ojos nada más que veo suelo que se pierde, suelo que se pierde, suelo que se pierde..."

[PIÑERO] "El monte se recupera [después de un incendio], tarda, pero se recupera. Se recupera mejor solo, y no es ir en contra de nadie. Por ejemplo, aqui en la Fuenfría se quemó un año. Pues el ICONA fue a restaurar y ¿para qué ponen muchos tiestos si luego no los riegan? Se van a secar. Es lo que hicieron allí. O sea, ellos repueblan, ponen muchos pinos, y luego los abandonan. iNi uno salió!. Arrancan los que han salido solos, de un piñón."

- Actuaciones sin fundamento debido a una falta de conocimiento práctico de las dinámicas y necesidades de la zona: "Se gestiona desde la oficina"

Para explicar este hecho resulta particularmente interesante perfilar la imagen que se tenía de la figura del técnico responsable de la administración forestal, de la guardería y de los retenes.

Tanto la guardería como los retenes se percibían como una figura presente en el paisaje y cercana, al margen de que los efectos de su labor reciba tanto críticas como reconocimiento. El técnico, sin embargo, no era percibido de esta manera. No se le reconocía suficiente vinculación y contacto directo con el paisaje (sobre todo desde el grupo de los agentes dedicados al aprovechamiento de los recursos naturales), por lo que en numerosas ocasiones fue juzgado como un interventor alejado de la realidad y sin un conocimiento suficiente del funcionamiento y necesidades del medio.

[PIÑERO] "El problema es que no saben lo que es el monte. O sea, que para ser ingeniero de cualquier cosa tienes que saber de lo que se trata. Sí saben lo que es un tomillo, pero luego van al monte y no saben lo que es, no saben lo que es un romero, un ciprés. Son de oficina." 
[BODEGUERO-AGRICULTOR] "Pero hay técnicos que están siempre en oficina y no saben lo que es el campo. El campo hay que vivirlo para saber lo que es [...] El agricultor, sin tener conocimientos técnicos, sabe mejor como conservar el campo, porque lo ha hecho toda la vida y come del campo. El ingeniero lo que tiene que enseñarle es a plantar una gramínea de última generación, ecológica y tal, pero no le enseñes a plantar una gramínea de toda la vida."

- Decisiones no vinculadas al criterio puramente técnico: "Intervenciones de cara a la galería", "Decisiones políticas"

Por último, en ocasiones los entrevistados dudaron de la honestidad de algunas actuaciones de la administración, que juzgaron como ineficientes o incluso motivadas por intereses de cariz político o económico, más que por la previsión de beneficios ecológicos o estéticos del propio paisaje.

[BODEGUERO-AGRICULTOR] "La gestión forestal es mala, no por los ingenieros, por la administración. Si a los ingenieros los dejaran creo que la mayoría lo haría bien. Pero la de la administración es mala, porque hace años se empezó con una cosa que es una tontería, que es gastar dinero para quedar bien."

[MIEMBRO DE UN GRUPO ECOLOGISTA, ADMINISTRATIVA] “Cuando se anuncian las grandes reforestaciones, solo me quedo en los carteles de la Comunidad de Madrid con cifras astronómicas, ipero astronómicas! y luego te paseas por la zona teóricamente repoblada y solo ves los canutillos de plástico, y no me salen las cuentas. Al contrario, está peor que el terreno colindante que se quemó igual y con el mismo suelo y qué bien está, lo ves guapo. Esas actuaciones la experiencia me ha demostrado que son un fiasco [...] Cuando ha habido problemas de plagas no hemos visto un verdadero interés por solucionarlo, ni trabajos serios. Entonces parece que la intervención forestal es de cara a la galería, a ver qué se puede hacer para sacar una foto pero no un trabajo en continuidad y que sobre todo tenga un sentido."

\section{Focus Group:}

[CONSULTOR AMBIENTAL, BIÓLOGO] "Esa zona la resaltaría porque, a diferencia de otras zonas donde fundamentalmente hay pinar, se ha trabajado más y se aprecia una mejor conservación del monte

[AGENTE MEDIOAMBIENTAL] Pero eso tiene truco

[CONSULTOR AMBIENTAL, BIÓLOGO] iClaro que tiene truco!

[AGENTE MEDIOAMBIENTAL] El tema de los retenes ahora lo gestiona Protección Ciudadana, que quiere que la gente vea que hay retenes. Entonces solo te permiten trabajar en los límites de carreteras, de pistas o de vías pecuarias. No te deja trabajar en el centro del monte, todos los proyectos orientados alli, te los tiran. Y es lo que dice él, todo el mundo lo ve. Tú vas con el coche y piensas: estupendo [...] Desde que hay cargos políticos en cargos técnicos, esto no funciona. Y últimamente en la Comunidad de Madrid pasa [...] 
No es como antes, que venía el ingeniero de montes y sabía igual que tú o más que tú algunas veces. Y ahora no, eso se ha olvidado".

\section{B.4.2.- Percepción de la gestión de propietarios de grandes fincas}

Buena parte de las evaluaciones relacionadas con la faceta ecológica del paisaje se dedicaron alas grandes fincas sujetas a la gestión de un terrateniente, propietarios privados de grandes extensiones que fueron identificados como otro de los agentes clave en la gestión ecológica del paisaje. De los comentarios referidos se desprende que las evaluaciones se realizaron basándose en dos condiciones: el acceso restringido al espacio y su estado de conservación dependiente de la responsabilidad o sensibilidad del propietario.

\section{- Acceso restringido}

La accesibilidad limitada en estos espacios se entendió mayoritariamente como el factor que definía la calidad ecológica diferenciada en las grandes fincas, pues se entendió que las molestias y agresiones humanas se minimizan. En este sentido, la presencia de especies protegidas singulares fue utilizada como argumento $\mathrm{O}$ indicador de la calidad ecológica de estos espacios, que fueron considerados como una especie de reserva.

\section{[AGENTE MEDIOAMBIENTAL, MIEMBRO ORGANIZACIÓN ECOLOGISTA] “En esta} parte está la Finca de EI Santo. La propiedad privada es lo que tiene, que nos impide acceder, para lo bueno y para lo malo. Si los que llevan las fincas son consecuentes, pues alli han tenido en el mismo año cigüeña negra y águila imperial ibérica"

[TÉCNICO ORDENACIÓN/GESTIÓN AGRÍCOLA, INGENIERO FORESTAL] "LOS alrededores del embalse de San Juan están fatal, salvo la zona del río Cofio, que vuelven a ser grandes fincas. Las fincas particulares grandes es cierto que se protegen, vamos, como no tiene acceso la gente, pues es donde se refugian más las especies protegidas. No hacen explotaciones forestales casi, sólo aprovechamiento de piña. Algunos tienen algo de viña. Por ejemplo, aquí está la finca de [nombre del titular omitido] que tiene poca viña, con lo cual no produce vino. Esto lo tiene aquí para vivirlo, para su bodega, para disfrutarlo y poco más."

- Responsabilidad/sensibilidad del propietario

Por otro lado, el grado de implicación del dueño en la conservación de la finca y los intereses que mueven su gestión fue juzgado como el 
condicionante que posibilitaba el desarrollo del alto potencial ecológico que se le atribuye a dichos terrenos.

Así, al igual que los entrevistados apreciaron el estado ecológico de las fincas con aprovechamiento y actuaciones de mantenimiento, criticaron las malas prácticas de gestión, fundamentalmente asociadas a la falta de actuaciones selvícolas para prevención de incendios y, sobre todo, a una gestión cinegética intensiva que excedía la carga admitida por el terreno.

\section{Focus Group:}

[comentando el valor ecológico]

[BODEGUERO] "Hay alguna finca, que la limpian."

[GANADERO] "Hay alguna finca... El Encinar de la Parra. El Hoyo, que es una finca grandísima de olivos."

[BODEGUERO] "El Hoyo también está bien."

[GANADERO] "Es de [nombre del titular omitido], y la otra de (nombre del titular omitido).Son las dos fincas mejores que hay en el pueblo."

[BODEGUERO] "A parte de eso, hacen aprovechamiento de la finca. Este año no hicieron cacería, pero venden leña."

[GANADERO] "El jabalí, ciervo...y lo van limpiando."

[Comentando el valor paisajístico]

[GANADERO] "El Juncal también es una finca bonita. Está muy limpia, tiene muy buena pradera... y es para ganadería, para vaca avileña ecológica."

[BODEGUERO] "Limpia...porque también se dedican al ganado. Habiendo ganado, te lo tienen siempre limpio."

[GANADERO] "Si, pero aparte de eso es que no le han dejado echar encina, no tienes apenas encinas, es casi todo pradera. Es particular. Tipo dehesa para ganado."

[MIEMBRO DE UN GRUPO ECOLOGISTA, ADMINISTRATIVA] "Según sea el propietario de turno está bien cuidada o es un polvorín. Hay propietarios, nuevos propietarios, que están haciendo un buen cuidado de las áreas que puedan ser sensibles a un incendio, tratando el sotobosque; y hay otros que sinceramente... Hay un propietario histórico en la comarca, él no compró esto, y el otro día estuve por alli y me quedé acojonada. Se juntaban pinos alli en los que las ramas salían del suelo, todo cerrado, en una zona que hace mucho viento y pensé ilo que hay aquí!. Es una herencia de su familia y su política es: a los cazadores no les interesa que su coto se queme, entonces se lo cedo gratuitamente para evitar esa cerilla malintencionada. Pero desde luego limpieza, mantenimiento, conservación, un mínimo de prevención... hay cero. Y pone los pelos de punta, porque para nosotros los veranos son catastróficos" 
[TÉCNICO PROYECTO CONSERVACIÓN FAUNA, ZOÓLOGO] (comentando ecología baja) "Cada vez hay menos explotaciones ganaderas y todo son fincas cinegéticas, que tienen sus pros y sus contras: no pasa nadie, y entonces está todo más tranquilo, pero también es un poco contraproducente, porque que sean sólo dedicadas a la explotación cinegética... no sé qué porcentaje tendrá, pero muy alto. Y que al final son granjas y tienen sus cebaderos. Te dicen, he visto un jabalí, iy eso no es un jabali, están cebados! Pues dices que está tan manipulado todo que lo que te crees que es natural pues no es tan natural. Ves ciervos y en realidad... o muflones, que no deberían estar alli, o gamos, tampoco. La visión más romántica que puedes tener pues se rompe un poco al ver realmente lo que hacen con el medio. Claro, al final es tan antrópico todo que...está todo manipulado. Pero bueno, te vuelvo a decir, teniendo biodiversidad, aunque sea un poco artificial..."

[EDUCADOR, BIÓLOGO] "Aquí las fincas privadas, no todas, hay excepciones, pero algunas son campos de tiro al animal, o sea, les da exactamente igual. O tienen tanta densidad de ciervos en algunas zonas que han acabado con todo, porque se lo comen todo."

\section{B.4.3.- Percepción de la acción de la población local}

Como ya se ha comentado, uno de los factores que se identificaron como importantes para el correcto funcionamiento e imagen del paisaje fue el de su uso y aprovechamiento por parte de la población local (agricultura, ganadería, aprovechamiento de leñas, de piñas...). La falta de la acción local en el monte se refleja en un estado de abandono del paisaje interpretado en clave negativa. La evaluación en ese sentido estuvo más presente en los comentarios de los entrevistados cuyo medio de vida se vincula al trabajo de campo, que identificaron claramente al agricultor $y$ ganadero como el gestor preocupado y juicioso, que mantiene, conserva y asegura la estabilidad del paisaje. Sin embargo, también el resto de participantes lo pusieron de relieve.

[GANADERO] "Hay sitios en los que la máquina no entra. El animal se mete por todos lados y te limpia. Muchas veces haces un favor, porque perjudica pero beneficia mucho. Hay gente que cree que esto de las cabras hace mucho daño, que secas árboles y secas de todo...y sí, puedes secar un pino, pero estás repoblando otros 5. Eso la gente no se da cuenta."

[BODEGUERO-AGRICULTOR] "Creo que la mejor manera de mantener es como toda la vida, es con los campos con ganado [...] En la vida ha habido problemas con la agricultura, llevamos miles de años y el campo se ha mantenido precisamente por la agricultura y hemos heredado unos campos maravillosos que es ahora cuando se están contaminando y no precisamente por el agricultor. iPero si el agricultor y el ganadero son los menos interesados en que el campo se hunda, si es de lo que vive!" 
la extensión y la continuidad, y que un uso a través de los años, que es el aprovechamiento de piña, ha llevado a que se conserve el bosque tal y como estaba, entre comillas 'limpio' pero que mantiene mucha biodiversidad. [¿A qué te refieres

con limpio?] A mi no me gusta la palabra limpio, porque a mí los montes con vegetación y que son más salvajes me gustan más. No me refiero al término que se suele utilizar forestalmente, sino que un monte que tiene una producción y estás sacando recursos de él, te interesa que siga para adelante. O sea, yo veo un monte lleno de jara y me encanta, pero también veo un monte que les sacas rendimiento y estás haciendo que muchas familias vivan de él, y me gusta más. El hecho social de que un monte sea productivo es positivo, porque se mantiene."

Los entrevistados encontraron las causas de la disminución de la influencia de ese gestor en el paisaje en la escasa rentabilidad de los aprovechamientos forestales y agrícolas, que acaba conduciendo al abandono de la actividad. Igualmente, el gestor local percibía que la administración ejerce un control excesivo e innecesario sobre su actividad, al mismo tiempo que adolece de una falta de reconocimiento e impulso de la misma. Esta percepción deriva en la sensación de pérdida de acción y control sobre el entorno, que puede conducir a la pérdida de la responsabilidad del local sobre el paisaje.

[PIÑERO] "Si hablamos de la zona de cepas, está de pena, se está dejando perder. No se labran porque no valen. Aquí no hay cooperativas, funciona bastante mal. El fruto no vale, así que la gente no labra, simple y llanamente. [...] Pero bueno, siempre hay... yo tengo lo de mis padres, pues trato de cuidarlo, trato de cuidarlo, trato de cuidarlo... pero llega un punto en que te das cuenta que, después de picar, el dinero está saliendo de tu bolsillo...pues lo siento mucho por mis padres, pero esto se queda así. Y el monte por las mismas, igual, porque verdaderamente no se cuida. La gente ve el paisaje más bien como un decorado, porque no hay expectativas de que el monte valga para nada."

[BODEGUERO] "Yo soy de los que piensan que los incendios se apagan en invierno. Hay muchos montes que a los ganaderos no les dejan entrar con el ganado porque dicen que se comen los brotes jóvenes. Cuando siempre ha convivido el ganado en el monte, el monte estaba limpio y no había incendios en verano. Alli se columpian un poquito bastante. Si entras con el ganado te denuncian. A lo largo de todo el año. Cuando se equivocan. Mira, hace 12 años hubo un incendio en San Martín yo estaba en el retén de Cadalso, de hecho lo vimos nosotros, fuimos los primeros en acudir después del retén de San Martín. Ese incendio fue culpa de los forestales. Ese año prohibieron al cabrero meter las cabras en el pinar y esa prohibición supuso que se quemaran más de 4000 hectáreas de terreno. Y nada más empezar el fuego era de copas, había pasto de más de 2 metros de altura. Y al año siguiente, cuando se recuperó un poco el monte, ya volvieron a permitir la entrada a los cabreros. iSi siempre han convivido! Los pinos sueltan las piñas y hay ranchos de 15 o 20 pinitos y los animales se van a comer 5 ó 6, es una selección natural, el más fuerte es el que va a tirar para arriba."

[AGENTE DE DESARROLLO RURAL, GEÓGRAFA] "Aquí casi todo el monte lo gestiona la Comunidad de Madrid, no puedes hacer nada. [...] ¿Problemas medio ambientales? La falta de uso, los espacios que se están abandonando, básicamente. La limpieza del monte a través de contratas que crean un desapego del habitante del 
monte, que siempre ha sido suyo, siempre lo ha conservado. El sistema de los aprovechamientos por subasta pública son cosas que te alejan del ciudadano. Y no creo que una contrata externa sirva para cuidar el monte mejor [...] Casi todo pasa por la Comunidad de Madrid, o sea, ipara cortar un pino! Hay que pedir permiso para todo. Entonces hay una lejanía muy grande. Imagino que el objetivo es proteger el medio ambiente lo más posible, y la idea es buena, evitar que cada uno haga de su

capa un sayo, pero ha resultado en exactamente lo contrario. El campo ya no pertenece a la gente del municipio y así lo viven. Es el otro el que viene a cuidarlo y otro el que viene a disfrutarlo, los famosos visitantes."

\section{B.4.4.-Percepción del uso turístico-recreativo}

El uso turístico-recreativo intensivo y poco respetuoso con el medio fue posicionado por los entrevistados como una de las actividades más perturbadoras del funcionamiento ecológico del espacio y que más impactaba en el atractivo del paisaje.

Así, la zona de baño del embalse de San Juan-Picadas fue destacada por una mayoría de entrevistados, en ocasiones de forma muy visceral, como uno de los entornos de menor calidad. La causa se encontró precisamente en el efecto de perturbación y degeneración que provoca la masificación turística, la utilización poco considerada del espacio y la presencia de basuras.

[TÉCNICO AMBIENTAL MUNICIPAL, CC. AMBIENTALES] "La zona del embalse de San Juan, la conocida como El Muro, me coincide (en valoración negativa en cuanto a ecología y atractivo). Es una zona muy antropizada debido al uso turístico y de ocio, que en muchas ocasiones produce cierta degradación ecológica de la zona. Y la gran afluencia de público produce que en muchos casos la percepción de la zona sea de baja calidad."

[AGENTE DE DESARROLLO RURAL, CC. POLÍTICAS] "Toda la zona del pantano, todas las urbanizaciones que hay, es donde mayor impacto ecológico hay. Siempre ha habido muchísimo turismo, pero no es un turismo de calidad. Esta zona de Pelayos es una zona muy conflictiva, donde está el embarcadero y el club náutico, luego el agua baja y pasa por Villa del Prado. En verano eso se llena, y la gente está acostumbrada a dejar la bolsita de basura, y lo dejan clavada en un árbol, que siempre me ha llamado la atención. Y el agua de San Martín es potable pero huele a insecticida, a lejía." / (valorando la estética) "A mí la zona de San Juan no me gusta, es horrible, en verano es una invasión. Yo he visto fregar una paellera con Fairy en el pantano."

Dicha percepción fue generalizada en aquellas áreas en las que el uso turístico se concentra pero también se evidenció en otras zonas.

[AGENTE MEDIOAMBIENTAL] "Ejemplo de degradación, esto: internet. Ahora está muy de moda, hay gente que con esto de la aventura nos creemos superhéroes. 
Viene uno, se mete sin pedirle permiso a nadie por donde le da la gana, sea finca privada, sea lo que sea, te hace una ruta con su aparatito, lo cuelga en internet y eso se convierte en la nueva religión, eso es palabra de Dios. Entonces muchas veces serán rutas que marcan que no producen daño, pero otras..."

[PIÑERO] "Aquí en San Martín, yo creo que ninguno. Y te digo, hay zonas protegidas, por ejemplo Las Cabreras, que es un monte público, que está digamos cerrado al

público. Pero no se cuida, realmente el monte no se cuida. A partir de cierta temporada se olvidan de que está ahí. Entonces, se destroza mucho que hay basura por todos lados, por todos lados. Van los que van a hacer alpinismo, montañismo, senderismo y todos llegan por todos lados y está hecho una pena."

Finalmente, hay que hacer notar la valoración que los participantes hicieron del potencial del paisaje de la zona para atraer turismo y generar actividad económica. Numerosos participantes aseguraron que la zona poseía valores suficientes, tanto ecológicos como estéticos, si bien algunos otros expresaron sus dudas sobre si dichos valores eran destacados si se comparaban con los de otras zonas de la comunidad de Madrid. Preguntados sobre si pensaban que la población de la comarca reconocía ese potencial en el paisaje, la mayoría de entrevistados adujeron que existía una falta de reconocimiento de esos valores por parte institucional y de la población local, e igualmente señalaron que la falta de impulso por ambas partes limitaba su aprovechamiento.

[GUARDA DE CAZA] "Esto no lo valoran, en general. Yo estuve en reuniones con la Consejería de Medio Ambiente, hace años, cuando entonces era guardia, para tratar de valorar más esta zona, darle un... y entonces en la Consejería dijeron que no era de su interés, que estaban valorando más la zona norte de Madrid. No sé si porque

es más rica naturalmente... pero digamos que ellos siempre las actuaciones de subvenciones y demás se han ido hacia el norte. Y para la población va en perjuicio, porque si que la valoración de Medio Ambiente no te sitúa..."

[MIEMBRO DE UN GRUPO ECOLOGISTA, ADMINISTRATIVA] "Falta orgullo de lo que tienen. La gente no solo no está orgullosa de su entorno, sino que lo sienten como una losa. No han sido capaces de ver que el atractivo de esto es el medio natural."

[AGENTE DE DESARROLLO RURAL, GEÓGRAFA] "La gente no percibe que el valor ecológico y de paisaje de su comarca puede ser una alternativa de desarrollo. No, porque no es rentable. Al menos como lo ha hecho toda la vida la gente, ese es el drama de los agricultores y los ganaderos. Y el tema del turismo yo creo que es una mentira que les han metido para tenerlos entretenidos, lo siento. Yo llevo muchos años aquí y pienso que el tipo de viene aquí porque tiene una segunda residencia, con los amigos y tal, muy bien. ¿Para competir con otras zonas? Es que llevan tanta delantera y aquí tenemos tan poquito que ofrecer. Ya hay algunas casas rurales que malviven, no es una forma de vida. Puede ser complementaria, pero ¿complementaria a qué? Este pueblo tiene un entorno bonito pero como puede serlo Miraflores de la Sierra. Y el pueblo en sí no es bonito, no se ha cuidado. No sirve para vivir, en cuanto encuentran un trabajo fijo pues lo dejan o se queda como segunda opción. No es singular, está 
claro. Aqui la única singularidad que podía competir con otros vecinos de la comunidad era el embalse navegable. Y de ahi el desarrollo de San Martín. El resto no tiene esa capacidad de atracción. Y se han intentado 1000 cosas, en medio ambiente sobre todo. Yo no sé si por la idiosincrasia de la gente, porque no se ponen de acuerdo, pero nunca se ha conseguido vender el conjunto de la comarca como un destino claro, que la gente diga ¿dónde vas? ¡Pues a la Sierra Oeste!."

\section{B.5.- Evaluación de la fauna singular protegida}

La presencia de fauna singular protegida en el entorno fue reconocida, directa o indirectamente, por una parte significativa de los entrevistados y referida para argumentar el valor ecológico de ciertas zonas. En este sentido, la fauna emblemática protegida se erige como el elemento tangible que evidencia la calidad ecológica y el buen estado de conservación de ciertos espacios (Las Cabreras, Embalse de Picadas, Cuerda de Pedro Duermes, monte de Cadalso, grandes fincas privadas). Igualmente, su presencia actuó en ciertos entrevistados como un factor estético, como un componente que aportaba atractivo a ciertos paisajes. Se puso pues de manifiesto que el hecho de conocer la presencia de ciertas especies singulares o tener la posibilidad de verlas en ciertos sitios, o incluso meditar sobre su presencia pasada o futura, sugiere una calidad ecológica diferenciada, se evalúa como importante y aporta una mayor trascendencia al espacio.

[GUARDA DE CAZA] "La ecología es lo que más me atrae, porque es fundamental para sobrevivir en donde estamos, en esta zona ZEPA. Entonces me parece un caso superior, vamos. Hombre, una zona de protección de aves, que la han catalogado así, en la cual bueno hay especies protegidas que se sirven a la vez del medio protegido que hay, que está totalmente catalogado como tal. Entonces, si la base fundamental de que esas especies protegidas cacen aqui es porque debemos de cuidar, como se está haciendo, la caza. En este caso muchas veces la caza menor es uno de los fundamentales alimentos del águila imperial ibérica, del búho, etc. Y por eso se trata de hacerlo bien."

[TÉCNICO PROYECTO CONSERVACIÓN FAUNA, BIÓLOGO] (Describiendo un paisaje de calidad) "Que sea arbolado, que tenga verde, que no esté desprovisto de vegetación, que tenga también montañas, riscos donde puedan habitar distintas especies de aves. Cuanto más agreste, cuanto más irregular, cuanto más heterogéneo, más agradable para mí. Por ejemplo El Cofio, la zona de Las Cabreras, toda la zona de Valdemaqueda, Santa Catalina, aunque se quemó, pero bueno. Está el monte y quedaban unos reductos de cigüeña negra. Son zonas que tienen mucha vegetación, las conozco bastante bien, tienen una gran biodiversidad de paisaje y sé que habitan especies protegidas, que habita el águila imperial ibérica, cigüeña negra, águila perdicera. Y eso es también síntoma de un alto índice de calidad 
ecológica, porque si no fuese así no podrían vivir alli, si hubiese muchas molestias, si no hubiese alimento, si hubiera aguas sucias... son bioindicadores."

[AGENTE MEDIOAMBIENTAL] "A mi la fauna me parece un elemento importante del paisaje, pues mirar al monte y aunque no los veas, saber que hay lobos, o que había osos en el siglo tal, o corzos o ciervos. Sobre todo las especies más emblemáticas, porque son una parte muy atractiva del paisaje."

\section{Ahora bien, algunos participantes describieron conflictos a nivel local con este tipo de especies, debido fundamentalmente a las limitaciones de uso que se imponen por la presencia de una especie con alto grado de protección.}

[AGENTE MEDIOAMBIENTAL] "¿Qué vale la madera hoy en día? ¿Para el presupuesto de un pueblo? Sin embargo, hay que fomentar, y ahí sí que tienen que ser la administración, el turismo ecológico de calidad, o sea natural, ornitológico. Ahí hay un nido, ¿qué pasa, que hay que esconderle? A unas distancias reglamentarias se puede ver, iclaro que sí! iclaro que sí! Y es mejor publicarlo y decir que está aquí. Y ya los paisanos si ven que tienen unos ingresos ya se encargarán de que no le pase nada al nido. Ellos no pueden ver una posibilidad en eso cuando hay políticos que culpan al águila de que el pueblo no crezca, eso era muy popular: 'La culpa la tiene el águila', textualmente. Bien, el águila es una especie protegida en peligro de extinción, pero la figura de ZEPA no venía dada precisamente por el águila, y la ZEPA es Cenicientos, Cadalso...y unos pueblos han crecido y otros no. El odio que hay hacia el águila, de que es la culpable, ha calado. [...] Hay que fomentar el turismo de calidad. Los ingleses son más ornitológicos, ipero vienen por el conjunto de ecosistemas que tenemos aquí! iHay un biodiversidad!"

[BODEGUERO] "Aquí, en esta zona no puedes hacer prácticamente nada. El pueblo no puede crecer porque es zona ZEPA. Intentaron hacer un desguace y como es zona ZEPA se lo denegaron, la Comunidad de Madrid, directamente se lo rechazó. Es que es lo que tiene. Vamos a ver, yo personalmente lo de la ZEPA lo considero un tanto absurdo. Ahi la verdad es que los forestales se pasan de castaño oscuro. Se ponen a cerrar caminos para que la gente no pase por si se molesta al águila imperial. Si tu pasas y no le haces nada, ya pueden pasar 20000 personas que el águila va a seguir. Yo lo considero un absurdo. [...] O sea, si el animal quiere procrear, va a procrear, estés o no estés. Evidentemente nadie se va a subir a un pino a tirar el nido abajo,

eso no cabe en cabeza. Aquí el 95\% de la gente que viene son senderistas. La escalada no sé si está todavía permitida. Por eso lo de la ZEPA está bien hasta cierto punto. Al pueblo no le deja crecer. [¿¿ué beneficios crees que tiene?]Para el pueblo ninguno." 
CAPÍTULO VII. APLICACIÓN A UN CASO DE ESTUDIO: PLANIFICACIÓN ECOLÓGICO-ESTÉTICA DEL PAISAJE EN LA SIERRA OESTE DE MADRID 

forestales

UPA15a - COSTA DE MADRID

Se reconocen los EFECTOS ECOLÓGICOS YESTÉTICOS conservacion, variedad de elementos y naturalida

\begin{tabular}{|c|c|}
\hline $\begin{array}{c}\text { UP } 25 \text { - CERRO GUISANDO, CUERDA } \\
\text { PEDRO DUERMES }\end{array}$ & \\
\hline $\begin{array}{l}\text { ESPACIO AGRICCLA MÁS VALORADO por la } \\
\text { percepción de MAYOR MANTENIMIENTO, CUIDADO } \\
\text { YVIG OR (clima más húmedo) }\end{array}$ & \\
\hline 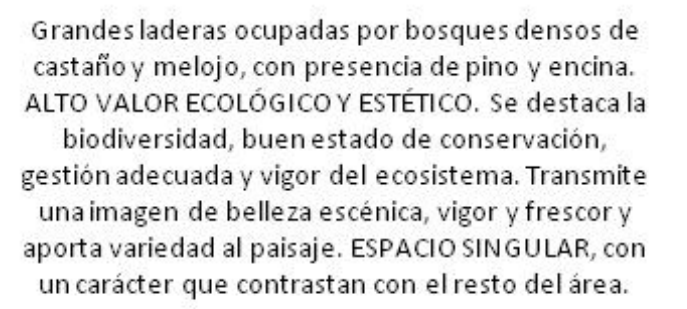 & \\
\hline UP A24b -PUENTE DE LA AVELLANEDA & \\
\hline $\begin{array}{l}\text { Componente agricola que proyecta una IMAGEN } \\
\text { DE ABANDONO }\end{array}$ & \\
\hline UPA24a - ARROYO DE LAS TORTOLAS & \\
\hline $\begin{array}{l}\text { Componente agricola que proyecta una IMAGEN } \\
\text { DE ABANDONO. }\end{array}$ & \\
\hline $\begin{array}{l}\text { Componente forestal afectada por LA PRESENCIA } \\
\text { DEURBANIZACIONES que impactan } \\
\text { negativamente en ambos aspectos }\end{array}$ & \\
\hline UPA26 - CADALSO DE LOS VIDRIOS & \\
\hline $\begin{array}{l}\text { PAISAJEDE MOSAICO agricola, parcelas abandonadas } \\
\text { retazos de vegetación semi-natural. RELATIVAMENTE } \\
\text { VALORADECCOLOGGCAMENTE por algunos } \\
\text { participantes, si bien, su estado de ABANDONO Y } \\
\text { presencia de construcciones incoherentes } \\
\text { (CHABOLISMO) le resta en general atractivo y } \\
\text { reconocimiento }\end{array}$ & \\
\hline $\begin{array}{l}\text { LADERAS FORESTADAS de la umbría de Peña } \\
\text { Cenicientos: VALOR ECOLÓGICO Y ESTÉTICO }\end{array}$ & \\
\hline
\end{tabular}

UPA15b - PICO DE LA CABRERA ALT

$\frac{\text { UP A15C - CERRO DEL YELMO }}{\text { Becertas }}$

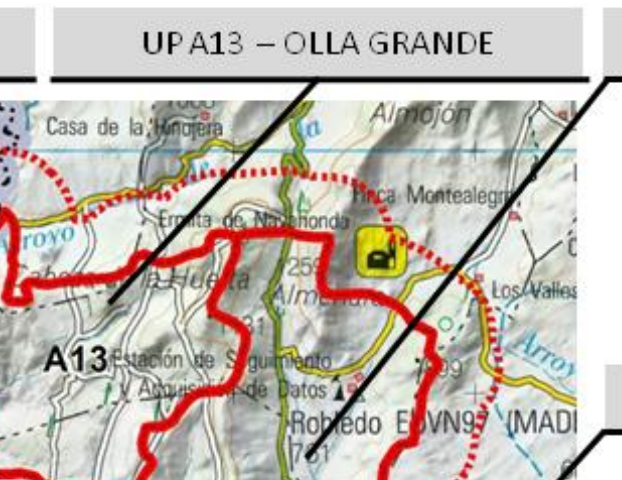

UPA14 - ARROYO DE VALDEZATE

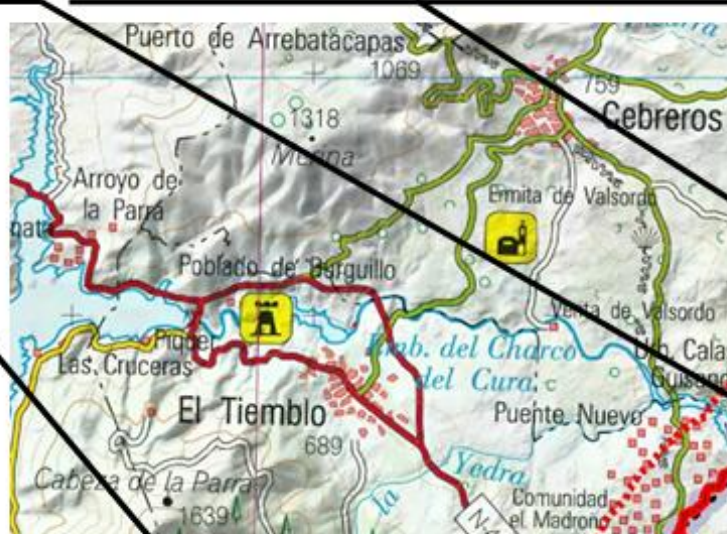

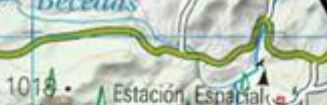

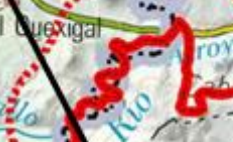

\section{更}

- ARROYO DE VALDEZATE Cenicientos: VALOR ECOLÓGICO Y ESTÉIICO
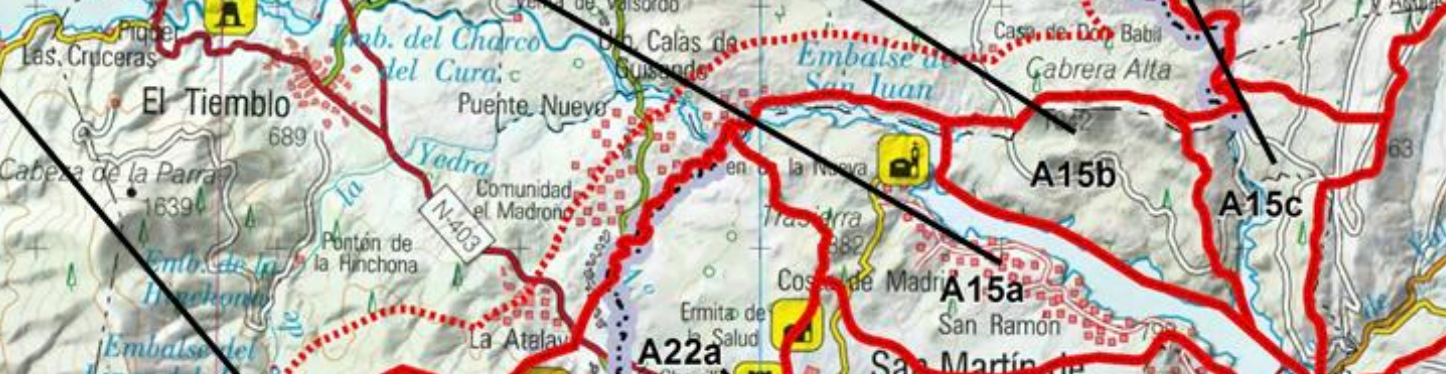

UPA17b - ELMORRO

Sestacan las AFECCIONES DE LAS URBANIZACIONES.

MOSAICO AGRICOLA relativamente valorado

imagen de ABANDONO

UPA16b - CORTADOS DEL EMBALSE

Unidad evaluada como SIN GULAR, ALTO VALOR

Aunque se distingue un emplazamiento degradado por el despacio esperibido comano uepuradora), elresto

(afluencia del público controlada)

Valor por FAUNA SINGULAR PROTEGIDA

FINCA PRIVADA "EI Santo", evaluada con ALTO VALOR

ECOLÓGICOY YSTADO DE CONSERVACIÓN

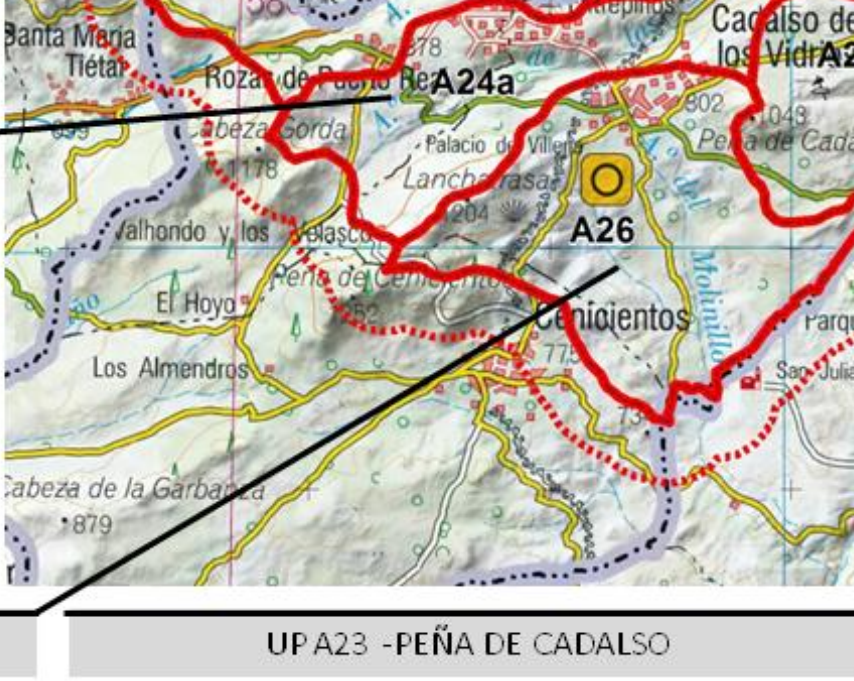
Paisaje forestal con estética asociada a un pinar maduro
bien gestionado, se le reconoce ALTO VALOR ECOLÓGICO ESTÉtico por esa razón

Valor por FAUNA SINGULARPROTEGIDA

ELEVACIÓN SIN GULAR muy valorada paisajisticamente: Peña de Cadalso

El GRAN IMPACTO DE LAS CANTERAS hace que la calidad de ciertos sitios contraste con la evaluación positiva general

Figura 79. Sintesis de la evaluación ecológico-estética derivada de las entrevistas para cada (sub)Unidad de paisaje.
UPA16a -CUERDA DE LA VIÑA

Parte de la unidad pertenece al M.U.P. 55 , PARAJE

AFECTADO POR INCENDIOS FORESTALES

zona sur perteneciente a la FINCA PRIVADA "EI Rincón de

, Evaluada CON ALTOVALOR ECON
ESTADO CONSERVACION

Pógina 265

\section{UPA22a-TRASIERRA Pasa desapercibido, excepto finca del Monte} Paisaje agricola ABANDONADO con zon
forestal AFECTADA POR INCENDIO

UP A22b -SAN MARTIN DE VALDEIGLESIAS

Laderas forestadas (Canto el Guarro, Monte 55) con EvaLUACIÓN VARIABLE: ecologia positiva por tratarse de un PINAR MADURO, LA FALTA 促

Espacio agricola-urbano VALORADO NEG ATIVAMENTEEN AMBAS DIMENSIONES: ASPECTO DE ABANDONO, FALTA DE CUIDADO Y SENSACION DEDESORDEN ( “CHABOLISMO"). También por la
ARTIFICIALIDAD que induce el espacio construido y las infraestructuras 
CAPÍTULO VII. APLICACIÓN A UN CASO DE ESTUDIO: PLANIFICACIÓN ECOLÓGICO-ESTÉTICA DEL PAISAJE EN LA SIERRA OESTE DE MADRID 


\section{VII.5. IDENTIFICACIÓN DE ÁMBITOS DE ACTUACIÓN ECOLÓGICO-ESTÉTICA Y DELINEACIÓN DE ESTRATEGIAS DE ACTUACIÓN EN EL PAISAJE}

A continuación se muestran las estrategias de actuación para, en la zona de análisis, realizar un tratamiento dirigido a integrar la estética y la ecología en el contexto de planificación del paisaje.

Los resultados se concretan en:

- Definición de ÁMBITOS Y DIRECTRICES DE ACTUACIÓN para una gestión optimizada del tratamiento ecológico-estético del paisaje.

- FICHAS SINTÉTICAS en las que se reflejen los valores y atributos con importancia en cada ámbito, la relación entre ellos y las directrices de actuación para cada unidad de paisaje.

\section{ESTRATEGIAS DE ACTUACIÓN EN EL PAISAJE}

\section{ÁMBITO A.- USO Y GESTIÓN DEL PAISAJE}

El contexto paisajístico del caso de estudio se encuadra dentro del tipo agroforestal sujeto a una intervención humana intensa y patente, tanto en el pasado como en el presente. Dicho contexto explica que la evaluación del paisaje realizada por los participantes no se asentara en la búsqueda de la naturalidad o ausencia de modificación humana, sino en la constatación de una intervención o gestión adecuada.

Para extraer las conclusiones sobre la contribución de la evaluación hecha sobre la adecuación de la actuación gestora, a continuación se derivan las conclusiones centradas en los 3 agentes que fueron identificados como gestores con mayor influencia en el paisaje: la administración pública (a cargo fundamentalmente del ámbito forestal), la población local (sobre todo ligada al ámbito agrícola y 
ganadero, aunque también con influencia en el forestal) y los propietarios de grandes fincas.

\section{Subámbito A.1.- Gestión pública del medio natural: la gestión insuficiente, ineficaz y no legitimada}

Al margen de que la gestión pública del medio natural efectivamente fuera más o menos activa, es claro que los participantes tenían una impresión muy negativa sobre ella, pues expresaron frecuente y consistentemente su percepción de una degradación paulatina del paisaje debido a que no se estaban realizando las actuaciones pertinentes por parte del gestor público a cargo. De tal manera, se constata que existe una crisis de confianza en la misma. Paralelamente, dicha intervención en el paisaje se juzga como esencial para la consecución de un correcto funcionamiento ecológico, para el buen estado de conservación del medio, y para que el paisaje se muestre con todo su atractivo (especialmente la gestión forestal, que afecta a las condiciones del tipo de paisaje más valorado en ambos aspectos).

En este caso, el paisaje no presenta pues un problema asociado a la visibilidad de actuaciones en el medio natural que potencialmente pueden presentar problemas de aceptación pública o que afecten a su atractivo, sino más bien una falta de evidencia de actuación, lo que la Teoría de la Administración Visible (Visible Stewardship, Sheppard, 2001) enuncia como la carencia de signos evidentes de que el gestor aprecie y respete el paisaje y se preocupe suficientemente por su protección y buen funcionamiento. Resulta ser este un factor con importancia evidente en la manera en que se evalúa el estado ecológico y los valores estéticos del paisaje y en consecuencia su incorporación en el tratamiento ecológico-estético del paisaje se revela como trascendente.

A este respecto, en primer lugar sería necesario analizar si verdaderamente la percepción está fundada en la realidad, es decir, identificar si la actuación de la administración es todo lo activa, razonable y bienintencionada que cabría esperar. Derivado de este análisis se podrían identificar 2 situaciones de gestión:

Sheppard, S.R.J. (2001) Beyond Visual Resource Management : Emerging Theories of an Ecological Aesthetic and Visible Stewardship. En S. R. J. Sheppard y H. W. Harshaw (Eds.), Forests and Landscapes: Linking Ecology Sustainablility, and Aesthetics (pp. 149-173). Nueva York, NY: CABI Publishing - IUFRO. 
Gobster, P. H., Nassauer, J. I., Daniel, T. C., y Fry, G. (2007). The shared landscape: what does aesthetics have to do with ecology? Landscape Ecology, 22(7), 959-972.

- Paisajes sujetos a una gestión insuficiente o inadecuada y que efectivamente muestren esta condición: en este caso el primer paso sería ajustar dicha gestión a lo conveniente.

- Paisajes sujetos a una gestión suficiente y adecuada pero que no muestran dicha condición. Este caso necesitaría de estrategias de actuación que hicieran más patente que dicha gestión existe y que visibilizara la bondad de sus efectos. Tal y como recogen Gobster et al. (2007), dicho objetivo puede conseguirse mediante el diseño del paisaje o mediante la provisión de información que esclarezca el impacto real que tienen las actuaciones.

Algunos de estos paisajes podrían gestionarse de tal manera que se erigieran en lo que se denomina "Paisajes Demostrativos

- Gestión como "Paisajes Demostrativos": espacios en los que se aplicara una intervención adecuada y que contuvieran signos notorios de esta intervención, de tal manera que proyectaran una imagen positiva sobre la actuación del gestor público.

Subámbito A.2.- Gestión de la población local y su repercusión en el

Cheng, A. S., Kruger, L. E., y Daniels, S. E. (2003) "Place" as an integrating concept in natural resource politics: Propositions for a social science research agenda. Society \& Natural Resources, 16, 87-104.

Hunziker, M., Buchecker, M., y Hartig, T. (2007). Space and Place - Two Aspects of the Human-landscape Relationship. En F. Kienast, O. Wildi, y S. Ghosh (Eds.), A Changing World. Challenges for Landscape Research (pp. 4762). Dordrecht: Springer.

Ward Thompson, C., Aspinall, P., Bell, S., Findlay, C., Wherrett, J., y Travlou, P. (2004). Open space and social inclusion: Local woodland use in Central Scotland. Report to the Forestry Commission, Edinburgh. Edinburgh: Forestry Commission. proceso de abandono y cuidado del paisaje

En cuanto a la percepción y evaluación de la acción del otro gran gestor del paisaje, la población local, el factor clave fue la constatación del proceso de abandono generalizado de las actividades de aprovechamiento de los recursos del medio. Dicha percepción se sustanció en la evaluación negativa de bosques con densidad excesiva de árboles y estrato arbustivo profuso, o áreas cultivadas que se han dejado de mantener y están siendo invadidas por la vegetación. La constatación de este hecho puede tener implicaciones profundas en la forma de entender el paisaje, relacionadas con la forma de experimentar el apego al lugar (place attachment) y la continuidad cultural en el paisaje. Ambas dimensiones se erigen como componentes importantes en la manera que tiene la población local de experimentar el paisaje, de valorarlo y protegerlo, pues normalmente se traducen en un poderoso sentido de responsabilidad y compromiso hacia el lugar, que se correlaciona con sentimientos de cuidado y dedicación a las prácticas gestoras (Cheng, Kruger, y Daniels, 2003; Hunziker, Buchecker, y Hartig, 2007; Ward Thompson 
et al., 2004) La percepción de la progresiva pérdida de influencia en el paisaje del local, del gestor tradicional, puede por tanto derivar en la sensación de falta de capacidad de acción y control sobre el entorno, que finalmente conduzca a la pérdida de la responsabilidad sobre el paisaje y a repercusiones negativas en su estado. Es pues este un aspecto importante a tener en cuenta en la propuesta de tratamiento ecológico-estético del paisaje.

El abandono de las actividades agropecuarias en el territorio rural, dinámica que se extiende por toda Europa, es sin embargo difícil de revertir, dado que se origina por procesos socioeconómicos que trascienden el ámbito de la planificación del paisaje y la escala localcomarcal (Garrote García, 2009). La pregunta capital sobre este asunto, desde la perspectiva que se trata, gira en torno a la conveniencia o inconveniencia de sus efectos ecológicos. Este es un tema de discusión frecuente en el ámbito de la investigación y la gestión (Gobster, 2014), que en general se concreta en dos perspectivas: la que defiende la promoción de políticas de conservación de los paisajes tradicionales (Angoletti, 2014); y la que apuesta por una regeneración natural o "renaturalización" del paisaje europeo (Schnitzler, 2014). En cuanto a este último enfoque, y a efectos del tema que subyace en este análisis, es necesario tener en cuenta que dicho proceso ha sido objeto de investigaciones específicas que han determinado que, como en el caso que nos ocupa, genera impresiones negativas y sugiere pérdida de valores ecológicos, fundamentalmente en la población local (Höchtl, Lehringer, y Konold, 2005; Hunziker, 1995; Pereira, Queiroz, Pereira, y Vicente, 2005; Ruskule et al., 2013).

De tal manera, en el área de análisis, la decisión se debe encaminar en cada zona concreta hacia una de las 2 estrategias, dependiendo de la importancia de los valores ecológico-estéticos que alberguen y también teniendo en cuenta la posibilidad de éxito:

- Estrategia de mantenimiento de la actividad local, y por tanto la gestión del paisaje a través del aprovechamiento agropecuario y forestal. En este sentido, es clave la búsqueda e implantación en el territorio de aprovechamientos viables y de valor añadido que permitan conservar el atractivo del paisaje y que por supuesto
Garrote García, F. (2009). La transformación del paisaje y las políticas de desarrollo de la Unión Europea. Caso de estudio: Sierra Norte de Madrid (1980-1999) (Tesis doctoral no publicada). E.T.S. Ingenieros de Montes - Universidad Politécnica de Madrid, Madrid.

Gobster, P. H. (2014)

Re-wilding Europe's traditional agricultural landscapes: Values and

the link between science and practice. Landscape and Urban Planning, 126, 65

Angoletti, M. (2014).

Rural landscape, nature conservation and culture: Some notes on research trends and management approaches from a (southern) European perspective. Landscape and Urban Planning, 126, 66-73.

Schnitzler, A. (2014). Towards a new European wilderness: Embracing unmanaged forest growth and the decolonisation of nature. Landscape and Urban Planning, 126, 74-80.

Höchtl, F., Lehringer, S., y Konold, W. (2005). "Wilderness": what it means when it becomes a reality - a case study from the southwestern Alps Landscape and Urban Planning, 70(1-2), 85-95.

Hunziker, M. (1995). The spontaneous reafforestation in abandoned agricultural lands: perception and aesthetic assessment by locals and tourists. Landscape and Urban Planning, 31, 399-410

Pereira, E., Queiroz, C., Pereira, H. M., y Vicente, L. (2005). Ecosystem services and human well-being: A participatory study in a mountain community in Portugal. Ecology and Society, 10(2).

Ruskule, A., Nikodemus, O.

Kasparinskis, R., Bell, S., y Urtane, I. (2013). The perception of

abandoned farmland by local people and experts: Landscape value and perspectives on future land use. Landscape and Urban Planning, 115, 49-61. 
respeten sus valores ecológicos (por ejemplo el aprovechamiento del piñón y la producción de vino y aceite de calidad).

- Estrategia de acompañamiento al proceso de abandono de estas prácticas y regeneración natural del paisaje, de tal manera que se dirija en la medida de lo posible la dinámica de cambio para minimizar los efectos negativos ecológicos y estéticos (por ejemplo, los efectos producidos por los incendios forestales).

\section{Subámbito A.3.- Percepción del cuidado en el paisaje agrícola}

El cuidado, el esmero con el que se trabaja y mantiene la finca cultivada formó parte destacada de la evaluación del paisaje agrícola. Más allá de la actitud que provocaba la visión de las parcelas antiguamente cultivadas y actualmente abandonadas, la falta de cuidado también se percibió en 2 componentes del paisaje: la presencia de elementos como las viviendas aisladas de baja factura (calificadas como "chabolas") o los somieres formando parte del vallado de las fincas; y el uso indiscriminado de herbicidas y plaguicidas. Estas características determinaron una aparente dejadez y falta de sensibilidad del propietario, con repercusiones en el plano ecológico, pues se relacionó con una falta de respeto por los valores

Nassauer, J. I. (1995b) Messy Ecosystems, Orderly Frames. Landscape Journal, $14(2), 161-170$

Nassauer, J. I. (1988) The aesthetics of horticulture: neatness as a form of care. HortScience, 23(6), 973-977

Nassauer, J. I., Wang, Z., y Dayrell, E. (2009). What will the neighbors think? Cultural norms and ecological design. Landscape and Urban Planning, 92(3-4), 282-292 naturales, y por tanto con un potencial impacto en la ecología del área. Además, se produjo una resonancia en el plano estético, pues estos espacios fueron percibidos como feos, degradados $y$, en palabras de los propios entrevistados, "cutres". Tal y como determina la Teoría de la Estética del Cuidado (Aesthetic of Care, Nassauer, 1995b), el paisaje es un espacio abierto a la vista de todos y concebido esencialmente como público, y por tanto está sujeto al juicio del observador en función de una serie de normas culturales, que relacionan el estado del paisaje con el modo de ser de las persona a cargo de su cuidado (Nassauer, 1988; Nassauer, Wang, y Dayrell, 2009).

Las estrategias encaminadas a neutralizar este fenómeno y aprovechar las oportunidades que ofrece incluirían: 
- Programa de control de construcciones no legales

- Normativa que limite el uso de ciertos materiales en construcciones e instalaciones rurales. Esta medida habría de ser acompañada de un programa de ayudas económicas.

\section{Subámbito A.4.- Gestión de las grandes fincas de titularidad privada}

Las grandes fincas fueron consideradas como áreas de reserva con una importante aportación a los valores ecológicos de la comarca. La evaluación realizada relacionó en positivo un aprovechamiento activo y una gestión cinegética sostenible con un estado de conservación del paisaje destacado y con la protección de especies singulares, hecho este último con gran trascendencia por la inclusión de la zona en un espacio de la Red Natura2000 (LIC "Cuencas de los ríos Alberche y Cofio" y ZEPA "Encinares del río Alberche y río Cofio, Decreto 26/2017).

Ahora bien, el despliegue de todo el potencial de valores de estas fincas estuvo sometido a la reflexión sobre la responsabilidad o sensibilidad del propietario a la hora de llevar a cabo la gestión del terreno. En aquellos casos en los que se apreció un aprovechamiento activo y adecuado la evaluación fue muy positiva. Las apreciaciones negativas se fundamentaron en las afecciones en ambas dimensiones que provoca la intensificación y artificialización de la producción cinegética ("granjas de producción cinegética") y la falta de tratamiento selvícola de las masas forestales (fundamentalmente por el riesgo percibido de incendio forestal).

- Consolidación de su papel como reserva y espacios clave para la conservación por medio de ayudas dirigidas a tratamientos selvícolas y una gestión cinegética gestionada con criterios de sostenibilidad.

Decreto 26/2017, de 14 de marzo, por el que se declara la zona especial de conservación "Cuencas de los ríos Alberche y Cofio" y se aprueban su plan de gestión y el de la zona de especial protección para las aves "Encinares del río Alberche y río Cofio". Boletín Oficial de la Comunidad de Madrid núm. 65 de 17 de marzo de 2017, p. 64 a 280. 


\section{Subámbito A.5.- Uso turístico-recreativo del paisaje}

El uso turístico-recreativo intensivo fue claramente evaluado como una de las actividades de mayor impacto en la zona. Mientras que el proceso de abandono del campo y la falta de gestión pública del paisaje forestal fueron percibidos como fenómenos que afectaban de forma generalizada a todo el paisaje, los efectos negativos de la actividad turística fueron referidos sobre todo en zonas y épocas muy concretas: la gran concentración de visitantes de un día que se produce en torno a los embalses, y sus comportamientos poco respetuosos con los valores del entorno produjeron un rechazo muy importante y las afecciones en el plano ecológico y estético estuvieron vinculadas.

Por otro lado, el resto del espacio fue juzgado como infrautilizado en este aspecto. Los resultados apuntan hacia la posible existencia de una cierta falta de reconocimiento de valores ecológicos y estéticos en el paisaje por parte de las instituciones y la población local, que condiciona que el uso recreativo pueda posicionarse como una actividad económica relevante. Esta circunstancia, sin embargo, necesita de análisis complementarios para su constatación.

Teniendo en cuenta estas condiciones, las medidas propuestas serían:

- Programa de regulación y ordenación del uso turístico que redistribuya la presión en todo el espacio y reoriente el tipo de uso y las prácticas que impactan, tanto ecológica como estéticamente, en determinados espacios.

- Fomento del uso turístico de calidad del espacio basado en sus valores naturales. Esta medida acompañaría al anterior programa y potencialmente podría contrarrestar la idea que se alberga de una zona con valor comparativamente menor. A este respecto, la presencia de fauna singular puede posicionarse como un valor natural estratégico en el proceso. 


\section{ÁMBITO B.- RIESGO E INCIDENCIA DE LOS INCENDIOS FORESTALES}

El proceso con mayor impacto en la forma en la que los entrevistados evaluaron ecológica y estéticamente el paisaje correspondió al riesgo y efectos derivados de los incendios forestales. Efectivamente, el área de estudio está catalogada como una de las de mayor riesgo por incendios naturales, la incidencia de estos es recurrente, afecta a grandes extensiones y el fenómeno tiene una importante resonancia social. Todos los municipios de la zona han estado históricamente catalogados por los sucesivos Planes Especiales de Protección Civil de Emergencia por Incendios Forestales en la Comunidad de Madrid (INFOMA) como Zonas de Alto Riesgo por Incendios, es decir, áreas en las que la frecuencia o virulencia de los incendios forestales y la importancia de los valores amenazados hace necesaria la toma de medidas especiales de protección (Decreto 59/2017).

La falta de cubierta arbolada y la percepción de pérdida de vigor de los ecosistemas afectados actuaron como signos patentes de la afección ecológica en el paisaje y como una de las causas de disminución de su valor estético. Por otro lado, las masas forestales no sujetas a aprovechamiento o actuaciones selvícolas de mantenimiento (con densidad excesiva, estrato abundante de matorral o falta de poda) fueron calificadas como faltas de cuidado y sucias, como zonas en riesgo asociadas a un estado ecológico pobre e inestable, antesala de la pérdida catastrófica de valores, afecciones ya percibidas en las áreas ya afectadas por el fuego.

En este sentido, la gestión para reducir el combustible y la consecución de una estructura de las masas forestales resistente al fuego fue reconocida de manera general como clave para alcanzar unas condiciones ecológicas más convenientes, un ecosistema más estable, y una imagen que proyectase esta idea. Esta preferencia por las actuaciones preventivas en la gestión del fuego en el monte y por sus resultados patentes ha sido puesta de relieve en estudios anteriores en los que se ha analizado la opinión de expertos en la materia (González, Kolehmainen, y Pukkala, 2007; Raftoyannis et al., 2014) y en público en general (Soliva et al., 2008). Además, existe la constatación de que, en ciertas zonas, las estrategias de gestión de riesgos en el paisaje son mejor aceptadas cuando las condiciones que

Decreto 59/2017, de 6 de junio, por el que se aprueba el Plan Especial de Protección Civil de Emergencia por Incendios Forestales en la Comunidad de Madrid (INFOMA). Boletín Oficial de la Comunidad de Madrid núm. 136 de 9 de junio de 2017, p. 10 a 79.

González, J., Kolehmainen, O. Y Pukkala, T. (2007). Using expert knowledge to model forest stands vulnerability to fire. Computers and Electronics in Agriculture, 55, 107-114.

Raftoyannis, Y., Nocentini, S., Marchi, E., Sainz, R. C., Guemes, C. G., Pilas, I., Peric, S., Paulo, J.A., MoreiraMarcelino, A.C., CostaFerreira, M., Kakouris, E., y Lindner, M. (2014). Perceptions of forest experts on climate change and fire management in European Mediterranean forests. IForest, 7(1), 33-41..

Soliva, R., Rønningen, K., Bella, I., Bezak, P., Cooper, T., Flø B.F., Marty, P., y Potter, C. (2008). Envisioning upland futures: Stakeholder responses to scenarios for Europe's mountain landscapes. Journal of Rural Studies, 24(1), 56-71 
Eriksson, L., Björkman, C., y Klapwijk, M. J. (2017). General Public Acceptance of Forest Risk Management Strategies in Sweden: Comparing Three Approaches to Acceptability. Environment and Behavior, 50(159-186).

Ribe, R. G. (2006). Perceptions of forestry alternatives in the US Pacific Northwest: Information effects and acceptability distribution analysis. Journal of Environmental Psychology, 26(2), 100-115.

Cheng, A. S., Kruger, L. E., Y Daniels, S. E. (2003). "Place" as

an integrating concept in natural resource politics: Propositions for a social science research agenda. Society \& Natural Resources, 16, 87-104.

Brunson, M. (1993). "Socially acceptable" forestry: what does it imply for ecosystem management. Western Journal of Applied Forestry, 8(4), 116-119. producen se corresponden con el tipo de bosque que el público prefiere o con los valores ecológicos que se esperan (Eriksson, Björkman, y Klapwijk, 2017; Ribe, 2006). A este respecto, en la zona existe claramente la percepción en todos los grupos sociales entrevistados de que la acción ejercida por la actividad ganadera extensiva en el monte es una vía necesaria y conveniente para gestionar adecuadamente la incidencia del fuego. La incorporación del agente local en la gestión de su propio paisaje ha sido insistentemente identificado como un estrategia clave para alcanzar la sostenibilidad del paisaje, estrategia que aprovecha el potencial que ofrece el saber local y la implicación en el paisaje como lugar, y aumenta el conocimiento y aceptación de las políticas de gestión en el paisaje (Cheng et al., 2003)

En cuanto a la evaluación de la presencia de cortafuegos, esta fue controvertida, pues se fundó en la percepción dispar de lo efectivo de su función protectora. Tal y como establece Brunson (1993), la aceptabilidad de una intervención en el territorio depende en gran medida del propósito que la impulsa y el grado con que las alternativas que se contemplen sea consideradas como factibles, deseables y justas o equitativas. En este caso, los participantes críticos con los efectos de los cortafuegos no sólo dudaron de la legitimidad de la intervención, sino que consideraron alternativas de diseño con mejores resultados en cuanto a impacto ecológico e integración paisajística (áreas cortafuegos, tratamiento de bordes de los cortafuegos). En todo caso, y como ya se ha expuesto, la alternativa expuesta como más conveniente por la generalidad de entrevistados fue la gestión preventiva.

Derivados de estas conclusiones se pueden definir cuatro líneas de actuación con repercusión clara en ambas dimensiones:

- Programa de restauración de ecosistemas afectados por el fuego, e intervenciones para la mejora sanitaria y vigor de las masas afectadas. Los espacios sujetos a estas actuaciones podría además erigirse como "Paisajes demostrativos", es decir, espacios en los que se aplicara una intervención adecuada y que contuvieran signos notorios de esta intervención, de tal manera que proyectaran una imagen positiva sobre la actuación del gestor público. 
- Programa de tratamiento selvícola preventivo de las masas forestales, con objeto de reducir el riesgo de incendios y aumentar su resistencia al fuego. Un cuidadoso diseño de las actuaciones para la gestión del combustible puede generar una dinámica de sinergia entre la consecución de un paisaje más resistente a los incendios forestales y su efecto estético (en el plano escénico y en el plano de interpretación de una gestión adecuada).

- Programa para la incorporación del aprovechamiento ganadero extensivo en la gestión del combustible. Una política que se valga de este agente promocionaría la implicación local en la gestión del paisaje y una mayor responsabilidad hacia su estado y apariencia.

- Programa de revisión de la planificación, diseño y gestión de los cortafuegos con el objetivo de, en caso que se considere, modificarlo para maximizar su eficacia y minimizar sus afecciones ecológicas $e$ impacto visual negativo. En el ámbito del paisaje, cada territorio requiere un diseño de cortafuegos específico y ajustado a sus características ecológicas y estéticas. En su caso, esta línea de actuación ha de ir acompañada por un programa de información que potencie el reconocimiento de su función de defensa.

\section{ÁMBITO C.- EL VALOR DE LA FAUNA SINGULAR PROTEGIDA}

La zona estudiada, perteneciente al LIC y ZEPA "Encinares del río Alberche y río Cofio", resulta ser un área muy rica en especies con alto nivel de protección legal, muy especialmente las pertenecientes al grupo de las aves. Así, especies como el águila imperial ibérica (Aquila adalberti), el buitre negro (Aegypius monachus), el águila real (Aquila chrysaetos) o la cigüeña negra (Ciconia nigra), por citar algunas, anidan y campean por el espacio (Decreto 26/2017).

Para muchos participantes estas especies emblemáticas, con un status de protección alto y muy reconocido, resultaban un valor importante de la zona, un indicador de riqueza y buen estado ecológico, además de un componente que aportaba atractivo y significación al paisaje. Reconocieron pues el status de las especies emblemáticas como lo que Callicott (1983), basándose en el pensamiento de Aldo Leopold, denominó "especies estéticas indicadoras" ("aesthetic indicator

Decreto 26/2017, de 14 de marzo, por el que se declara la zona especial de conservación "Cuencas de los ríos Alberche y Cofio" y se aprueban su plan de gestión y el de la zona de especial protección para las aves "Encinares del río Alberche y río Cofio". Boletín Oficial de la Comunidad de Madrid núm. 65 de 17 de marzo de 2017, p. 64 a 280.

Callicott, J. B. (1983). The Land Aesthetic [Special Issue: A Cumulative Index to the First Seven Years of Environmental Review]. Environmental Review, 7 (4), 345-358. 
species"), especies que tienen un papel primordial en el atractivo del paisaje, no sólo por la belleza que posean en sí mismas, sino por la dimensión simbólica que ostentan y que dota de significados profundos al paisaje, pues se erigen como representantes de las dinámicas existentes y su esencia ecológica.

Ahora bien, es necesario tener en cuenta que, mientras que ciertos participantes, al igual que puede ocurrir con el público en general, reconocieron la importancia de dichas especies en el paisaje, otros tantos refirieron que para la población local existía un conflicto con su presencia, fundamentalmente asociado con las restricciones de uso que imponen. Es este un fenómeno social antiguo y bien documentado.

Se presenta aquí un valor no reconocido por igual, y por tanto falto de consolidación, que muestra un potencial grande para la gestión

Sergio, F., Newton, I., Marchesi, L., y Pedrini, P. (2006). Ecologically justified charisma: preservation of top predators delivers biodiversity conservation. Journal of Applied Ecology, 43(6), 10491055. conjunta de lo ecológico y lo estético. En efecto, a este tipo de especies se les dedica un esfuerzo de conservación especial, que normalmente va acompañado de medidas restrictivas, pero también de fondos económicos para actuaciones de adecuación de su hábitat, por lo que inducen una determinada condición del paisaje (Sergio et al., 2006).

Teniendo en cuenta lo expuesto, se proponen estas líneas de actuación para reforzar su consideración:

- Racionalización y estudio detallado de las limitaciones de uso que impone en el territorio la presencia de especies protegidas, con el objetivo de compatibilizar su conservación con la consecución del desarrollo económico y social en la zona.

- En el diseño de medidas en el paisaje relacionadas con su conservación, consideración de soluciones que muestren de manera notoria el efecto beneficioso de su presencia, no sólo en cuanto a funcionamiento ecológico, sino también en cuanto a estética del paisaje, lo cual pasa no sólo por conseguir una imagen apreciada por su belleza, sino también por el reconocimiento de una estructura del medio natural con utilidad social. Por ejemplo, una actuación de desbroce que tenga como objetivo la mejora del hábitat de una especie protegida puede también percibirse como una actuación 
para disminuir el riesgo de incendio forestal, con un beneficio para actividades de aprovechamiento ganadero aportado gracias a la presencia de dicha especie.

ÁMBITO D.- IMPACTOS MUY NOTORIOS EN EL PAISAJE: URBANIZACIÓN Y MINERÍA

La urbanización desordenada y las grandes canteras de granito instaladas en la zona fueron uno de los impactos que aparecieron como más patentes en el paisaje, dada su dimensión y su grado de visibilidad. En cuanto a la connotación de su apariencia, los entrevistados las juzgaron como actuaciones poco sensibles con el medio, poco planificadas y ejecutadas de manera poco cuidadosa.

- Control de la construcción de urbanizaciones en sitios importantes para la conservación y de alta calidad escénica (Revisión de los planes urbanisticos de los términos municipales).

- Por parte del sector público responsable de esta actuación, definición de un protocolo de restauración de canteras más exigente y que pueda albergar diseños que demuestren de manera patente el funcionamiento ecológico y la recuperación del ecosistema. 
FICHAS SINTÉTICAS EN LAS QUE SE REFLEJEN LOS VALORES Y ATRIBUTOS CON IMPORTANCIA EN CADA ÁMBITO, LA RELACIÓN ENTRE ELLOS Y LAS DIRECTRICES DE ACTUACIÓN PARA CADA UNIDAD DE PAISAJE.

Se recogen a continuación las Fichas específicas de cada unidad del paisaje en la que se reflejan las características que aportan calidad ecológica, visual-escénica y ecológico-estética (para una explicación del formato de ficha, ver Apartado IV.6, página 194). 


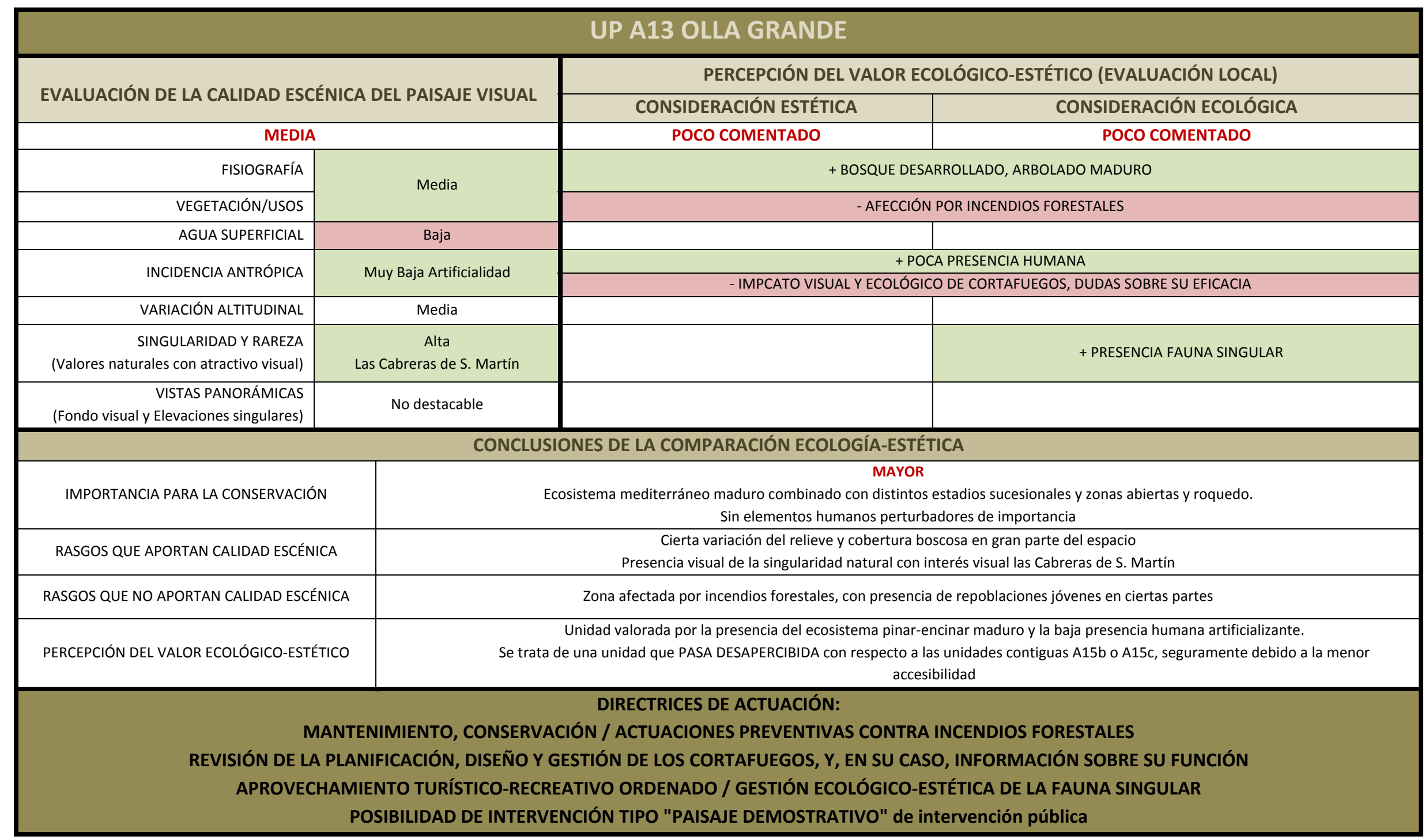




\section{UP A13 OLLA GRANDE (Cont.)}

Vista de la zona oeste de la unidad, M.U.P. Monteagudillo
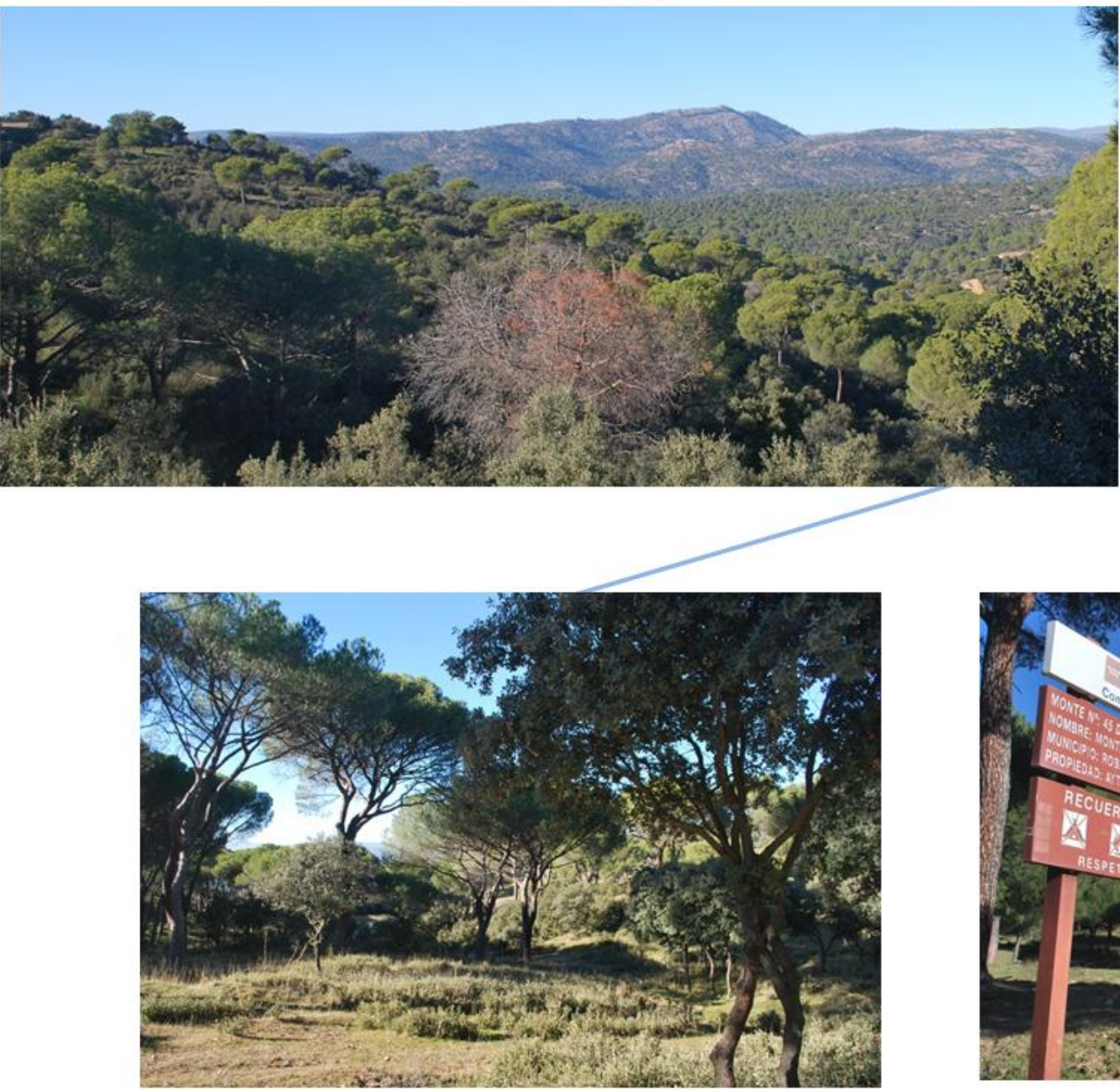

Vista típica de la masa forestal de pino piñonero y encina
Importancia ecológica en la UP
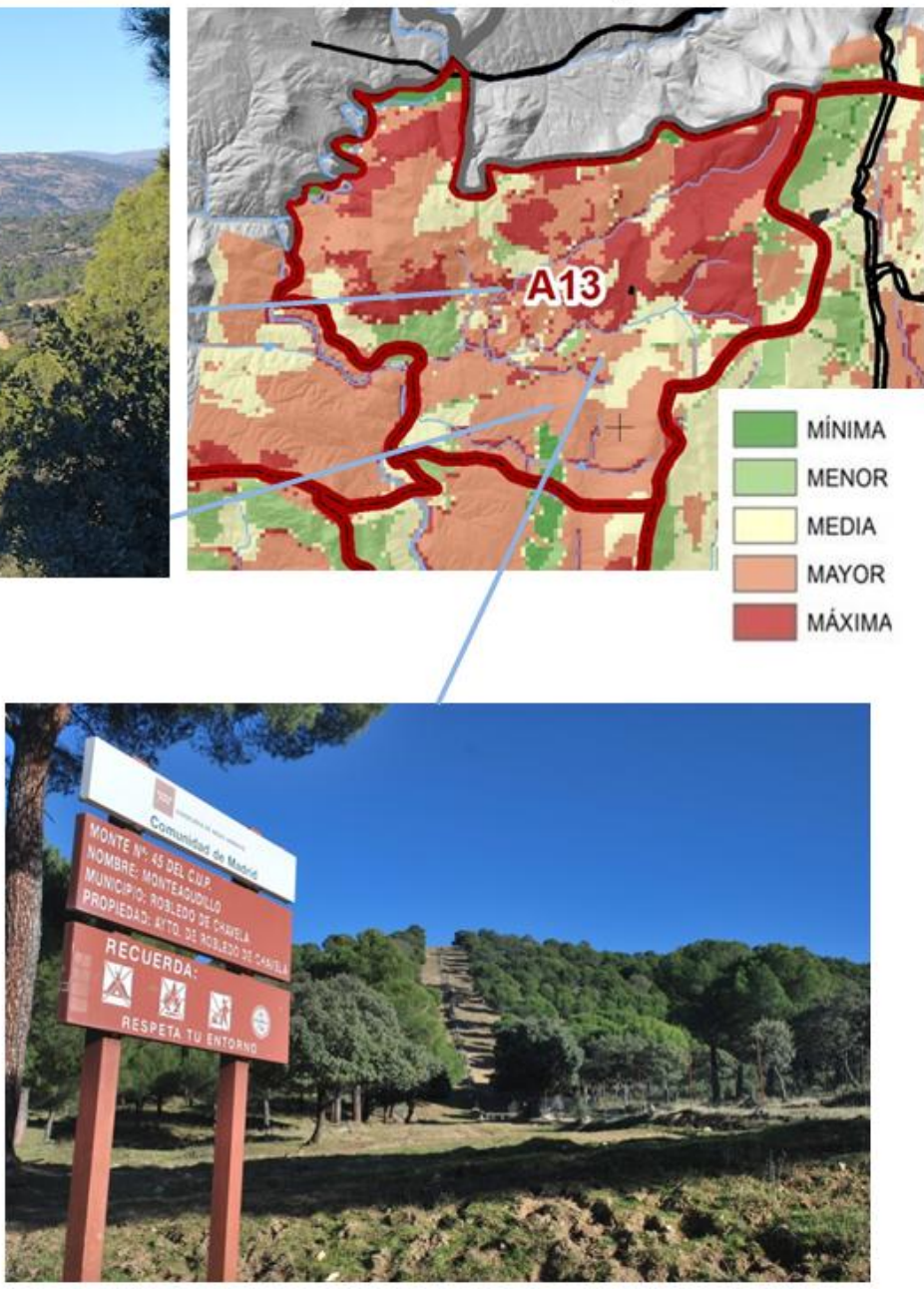

Vista de uno de los numerosos cortafuegos de la unidad Con repoblación joven 


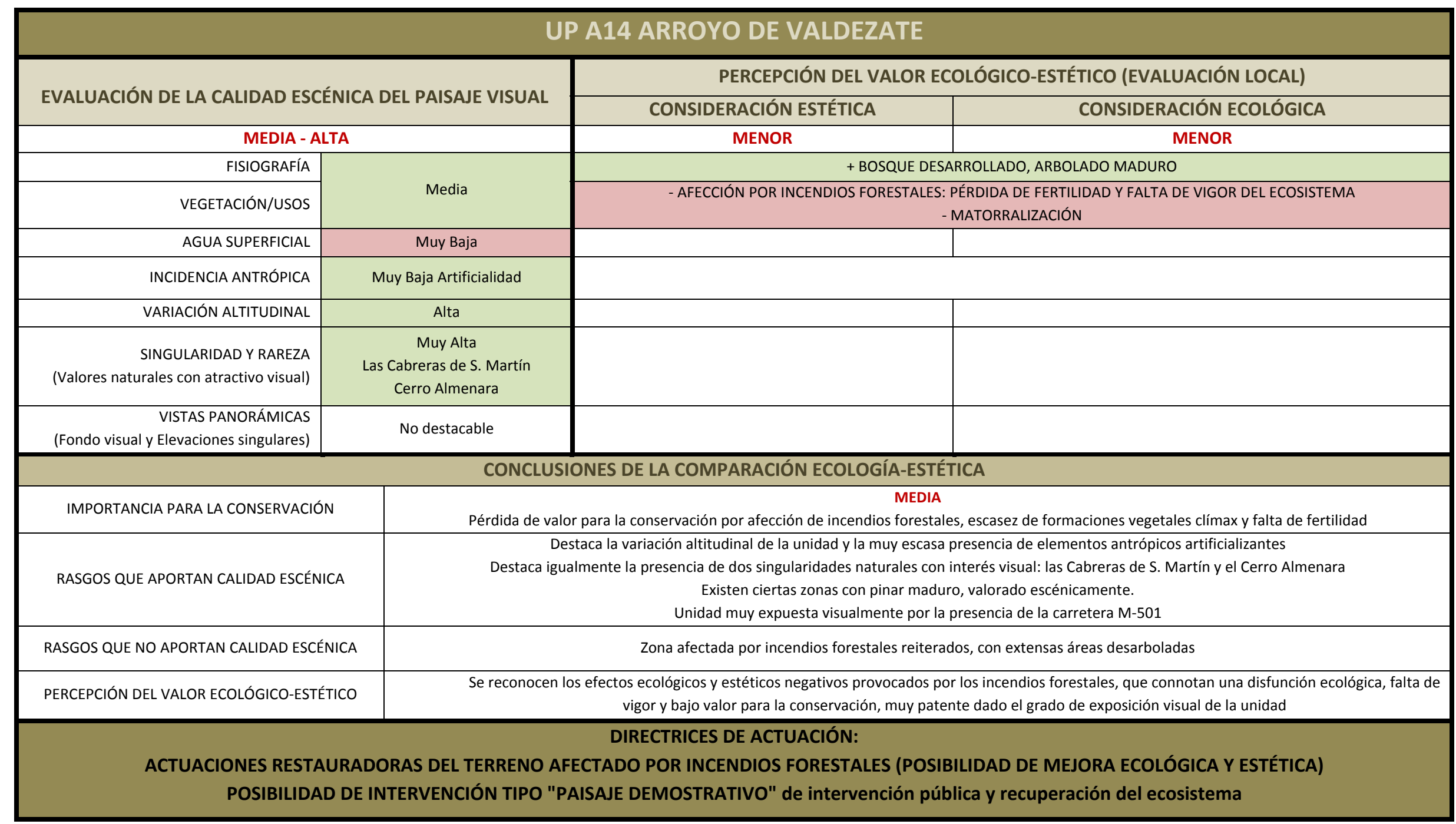


UP A14 ARROYO DE VALDEZATE (Cont.)

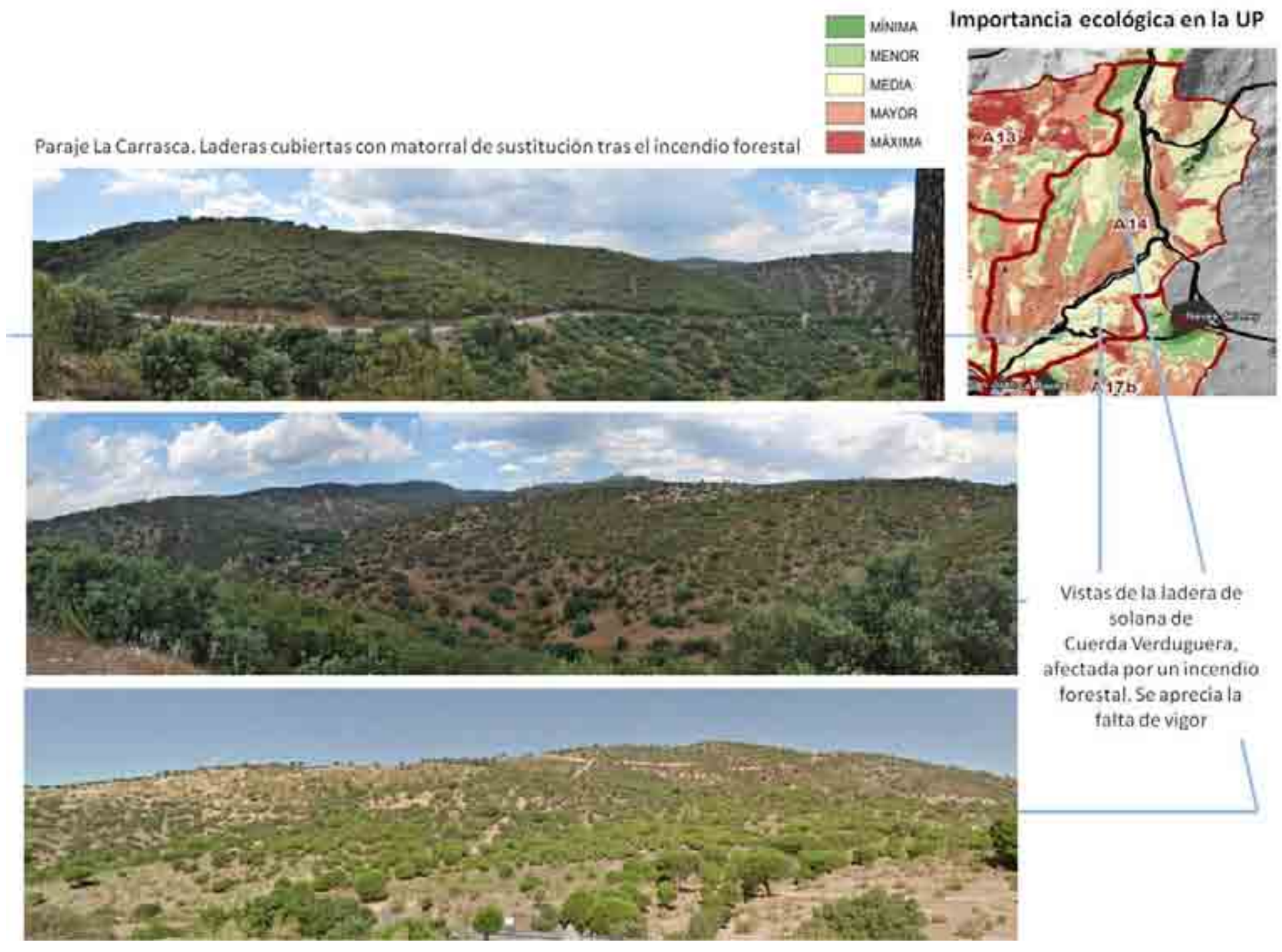




\begin{tabular}{|c|c|c|c|c|}
\hline \multirow{2}{*}{\multicolumn{3}{|c|}{ EVALUACIÓN DE LA CALIDAD ESCÉNICA DEL PAISAJE VISUAL }} & \multicolumn{2}{|c|}{ PERCEPCIÓN DEL VALOR ECOLÓGICO-ESTÉTICO (EVALUACIÓN LOCAL) } \\
\hline & & & CONSIDERACIÓN ESTÉTICA & CONSIDERACIÓN ECOLÓGICA \\
\hline \multicolumn{3}{|c|}{ MEDIA-ALTA } & MENOR & MENOR \\
\hline \multicolumn{3}{|c|}{\begin{tabular}{l|l} 
FISIOGRAFÍA &
\end{tabular}} & & +2 \\
\hline VEGETACIÓN/USOS & \multicolumn{2}{|r|}{ Alta } & \multicolumn{2}{|c|}{$\begin{array}{c}\text { (Pinares) } \\
\text { - FALTA DE VIGOR, MALA DINÁMICA }\end{array}$} \\
\hline AGUA SUPERFICIAL & \multicolumn{2}{|r|}{ Alta } & \multicolumn{2}{|c|}{ - USO RECREATIVO INTENSIVO E IRRESPETUOSO } \\
\hline INCIDENCIA ANTRÓPICA & \multicolumn{2}{|r|}{ Artificialidad Media } & $\begin{array}{l}\text { - FALTA DE CUIDADO, PRESENCIA BASURA Y } \\
\text { CONTAMINACION } \\
\text { (Urbanizaciones) } \\
\text { - ARTIFICIALIDAD, ESTÉTICA POCO CUIDADA }\end{array}$ & $\begin{array}{l}\text { - USOS IRRESPETUOSOS QUE IMPACTAN EN EL ECOSISTEMA } \\
\text { (Urbanizaciones) } \\
\text { - IMPACTO EN EL ECOSISTEMA DE LAS URBANIZACIONES }\end{array}$ \\
\hline VARIACIÓN ALTITUDINAL & & No destacable & & \\
\hline $\begin{array}{r}\text { SINGULARIDAD Y RAREZA } \\
\text { (Valores naturales con atractivo visual) }\end{array}$ & & $\begin{array}{c}\text { Alta } \\
\text { s Cabreras de S. Martín }\end{array}$ & \multicolumn{2}{|c|}{ + ÁREA DE LAS CABRERAS, VISIBLE DESDE LA UNIDAD, MUY VALORADA POR SU ECOLOGÍA Y ESTÉTICA (ver ficha A15b) } \\
\hline $\begin{array}{r}\text { VISTAS PANORÁMICAS } \\
\text { (Fondo visual y Elevaciones singulares) } \\
\end{array}$ & \multicolumn{2}{|r|}{ No destacable } & & \\
\hline \multicolumn{5}{|c|}{ CONCLUSIONES DE LA COMPARACIÓN ECOLOGÍA-ESTÉTICA } \\
\hline \multicolumn{2}{|l|}{ IMPORTANCIA PARA LA CONSERVACIÓN } & La prese & $\begin{array}{l}\text { Combinación de usos y vegetació } \\
\text { un uso intensivo de los recursos del embalse }\end{array}$ & $\begin{array}{l}\text { or para la conservación. } \\
\text { in de urbanizaciones le restan valor de conservación }\end{array}$ \\
\hline RASGOS QUE APORTAN CALIDAD ESCÉN & & \multicolumn{3}{|c|}{ Variedad de usos y vegetación. Presencia de lámina de agua del embalse de San Juan } \\
\hline RASGOS QUE NO APORTAN CALIDAD ESCE & & & acto visual del embalse en épocas de estiaje/U & presentes con un efecto artificializante \\
\hline \multicolumn{2}{|c|}{ PERCEPCIÓN DEL VALOR ECOLÓGICO-ESTÉTICO } & \multicolumn{3}{|c|}{$\begin{array}{l}\text { Una de las unidades peor valoradas en ambos aspectos: se reconoce un valor de base, pero se percibe como DEGENERADA ECOLÓGICA Y PAISAJÍSTICAMENTE, } \\
\text { a causa del USO TURÍSTICO-RECREATIVO INTENSIVO Y DESCONTROLADO y, en menor medida, por la presencia de grandes urbanizaciones } \\
\text { Gran contraste con la valoración de la unidad anexa (A15b Embalse de San Juan- Las Cabreras), presente en el espacio visual } \\
\text { Se percibe cierto decaimiento en los pinares de la zona noroeste que sugiere una MALA DINÁMICA ECOLÓGICA Y UNA FALTA DE ATRACTIVO }\end{array}$} \\
\hline $\begin{array}{r}\text { PROGR } \\
\text { TRATAMIENTO SANITA }\end{array}$ & $\begin{array}{l}\mathrm{AA} \\
\mathrm{Y}\end{array}$ & $\begin{array}{r}\text { E REGULACIÓN Y ORL } \\
\text { E MEJORA DE VIGOR } \\
\text { POSIBILIDA }\end{array}$ & $\begin{array}{l}\text { DIRECTRICES DE ACTUACIÓN: } \\
\text { CIÓN DEL USO TURÍSTICO Y URBANIZ } \\
\text { MASA DE PINAR, PRIORITARIO EN L } \\
\text { INTERVENCIÓN TIPO "PAISAJE DEMC }\end{array}$ & $\begin{array}{l}\text { PARA SEGUNDA VIVIENDA } \\
\text { DE ALTO VALOR PARA LA CONSERVACIÓN } \\
\text { " }\end{array}$ \\
\hline
\end{tabular}




\section{UP A15a EMBALSE DE SAN JUAN - COSTA DE MADRID (Cont.)}

Pinares en la carretera M-957 Virgen dela Nueva, valor para la conservación. percepción de falta de vigor

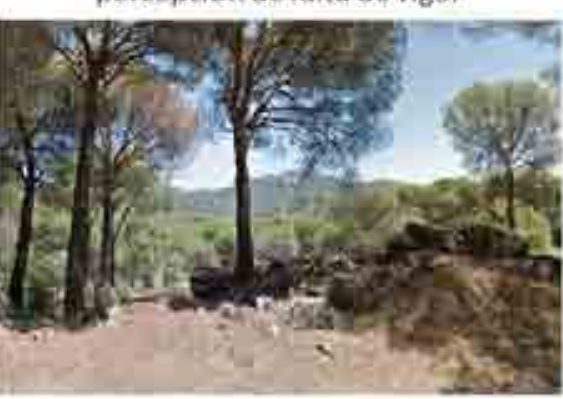
conocida como "El Muro"

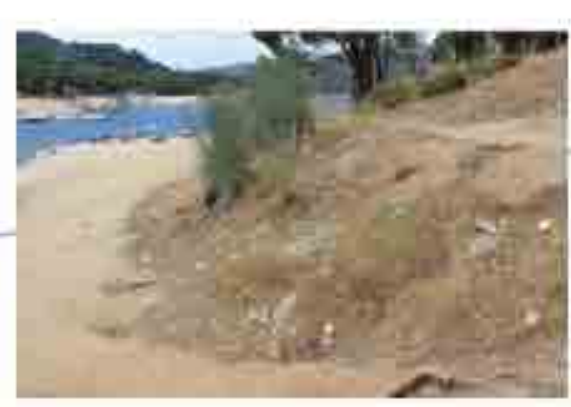

Zona de baño del embalse de San Juan en temporada alta.
Importancia ecológica en la UP

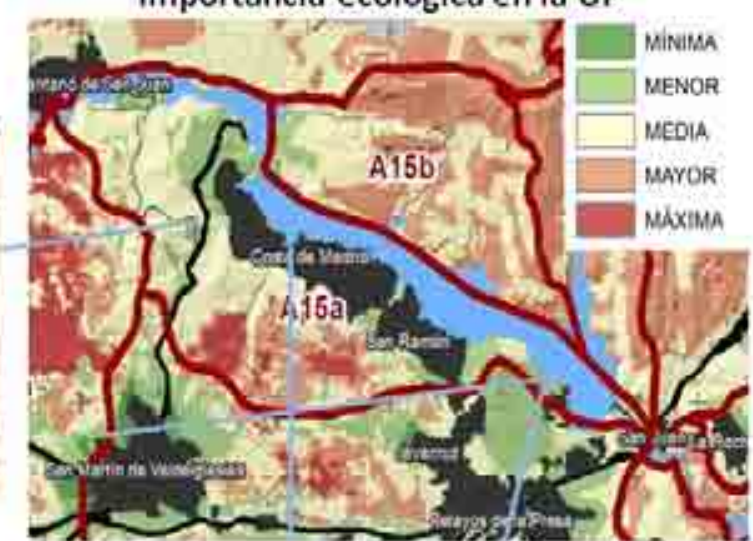

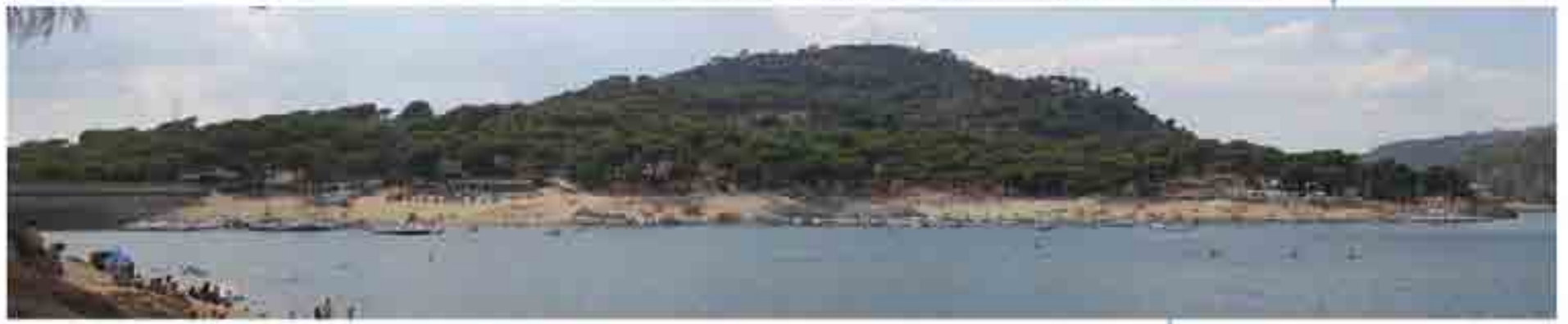

Vista de la margen opuesta desde la orilla de la Urbanización Costa de Madrid. Se aprecia el pinar maduro de pino pinoneroy la elevacion singular de "La Cabrera Alta"

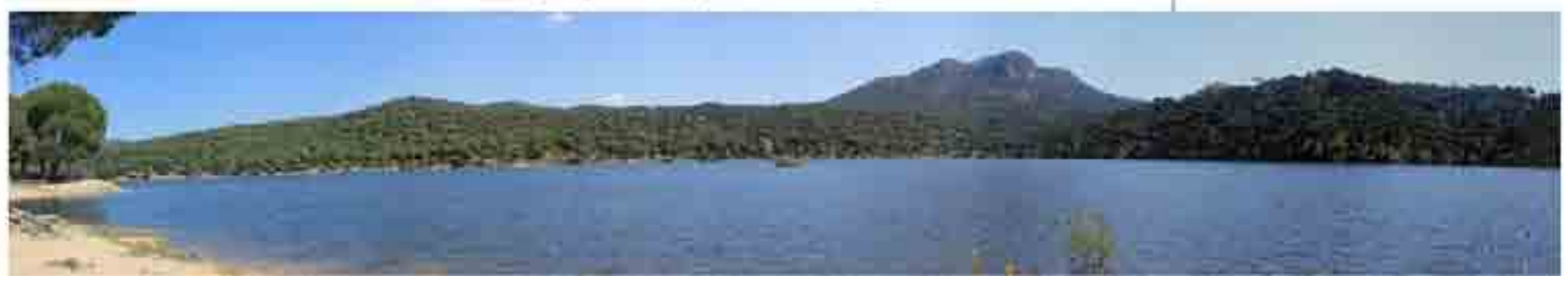




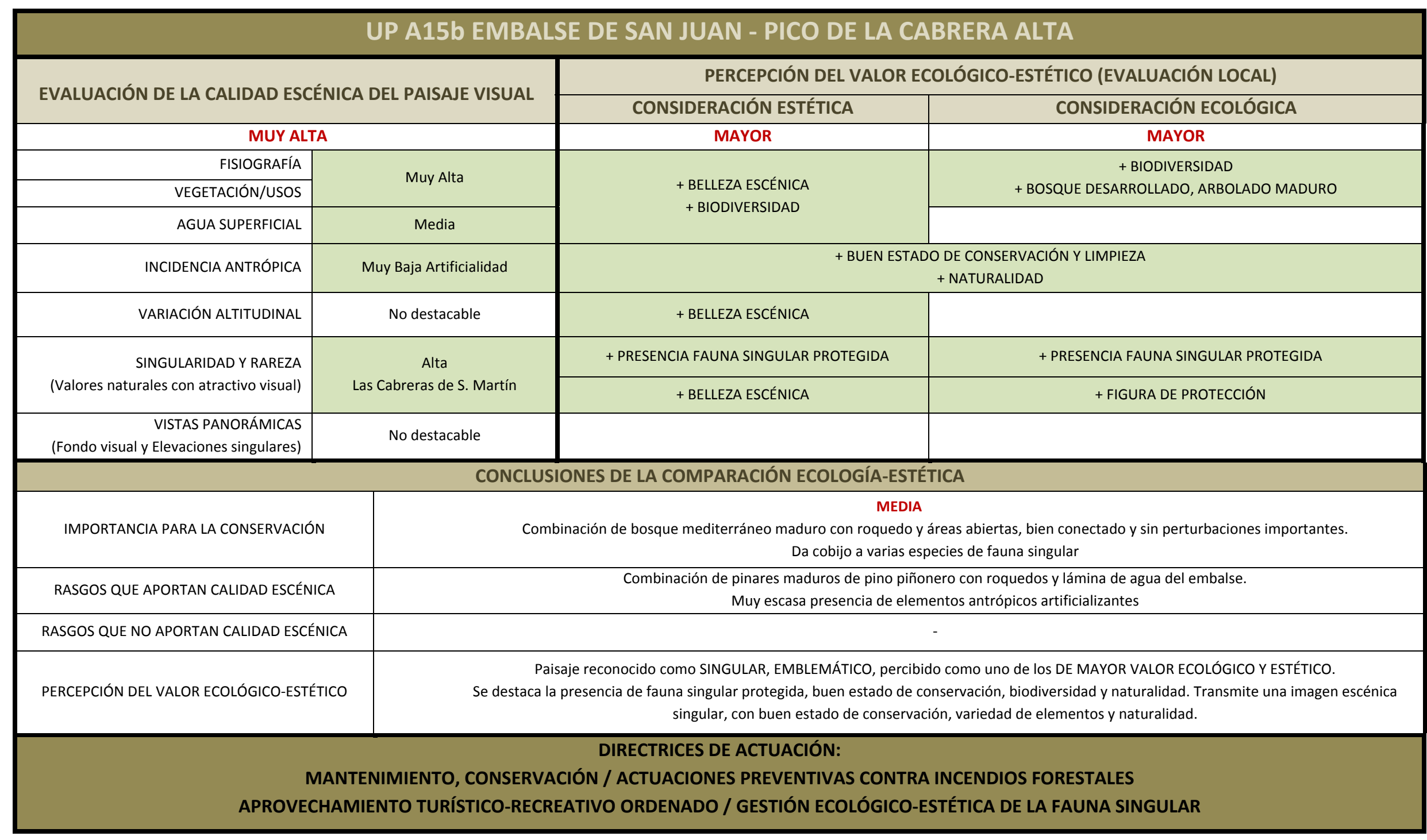


UP A15b EMBALSE DE SAN JUAN - PICO DE LA CABRERA ALTA (Cont.)

Paraje de "La Dehesa de La Cabrera", confa formación rocosa "Cabrera Baja" al fondo

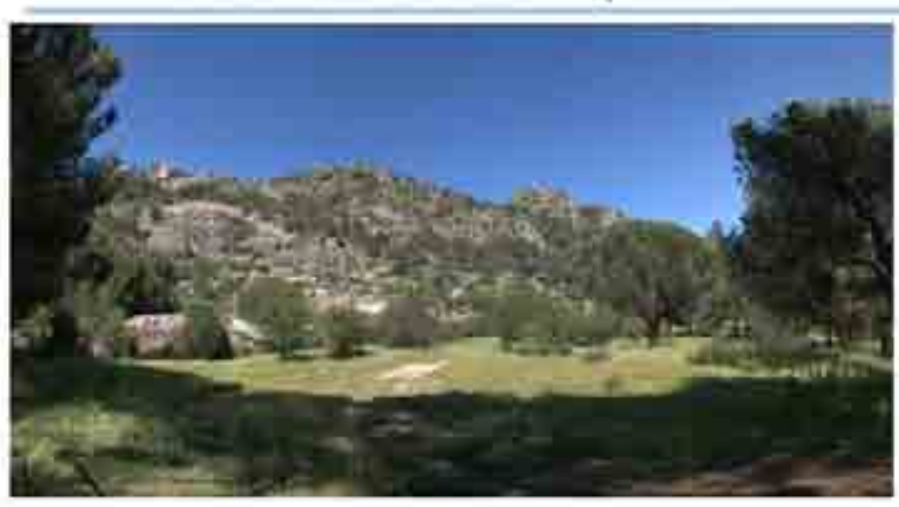

Vista del embalse de San Juan desde el Monte de "Las Cabreras"

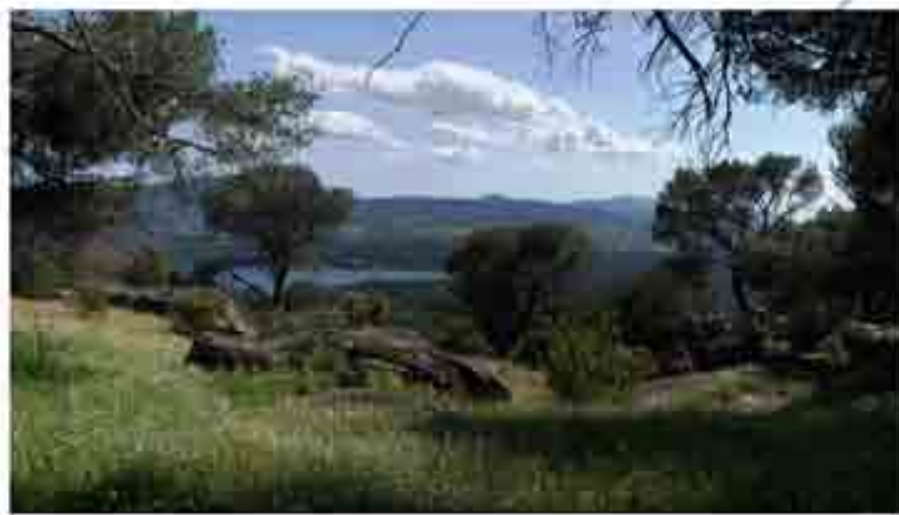

importancia ecologica en la UP
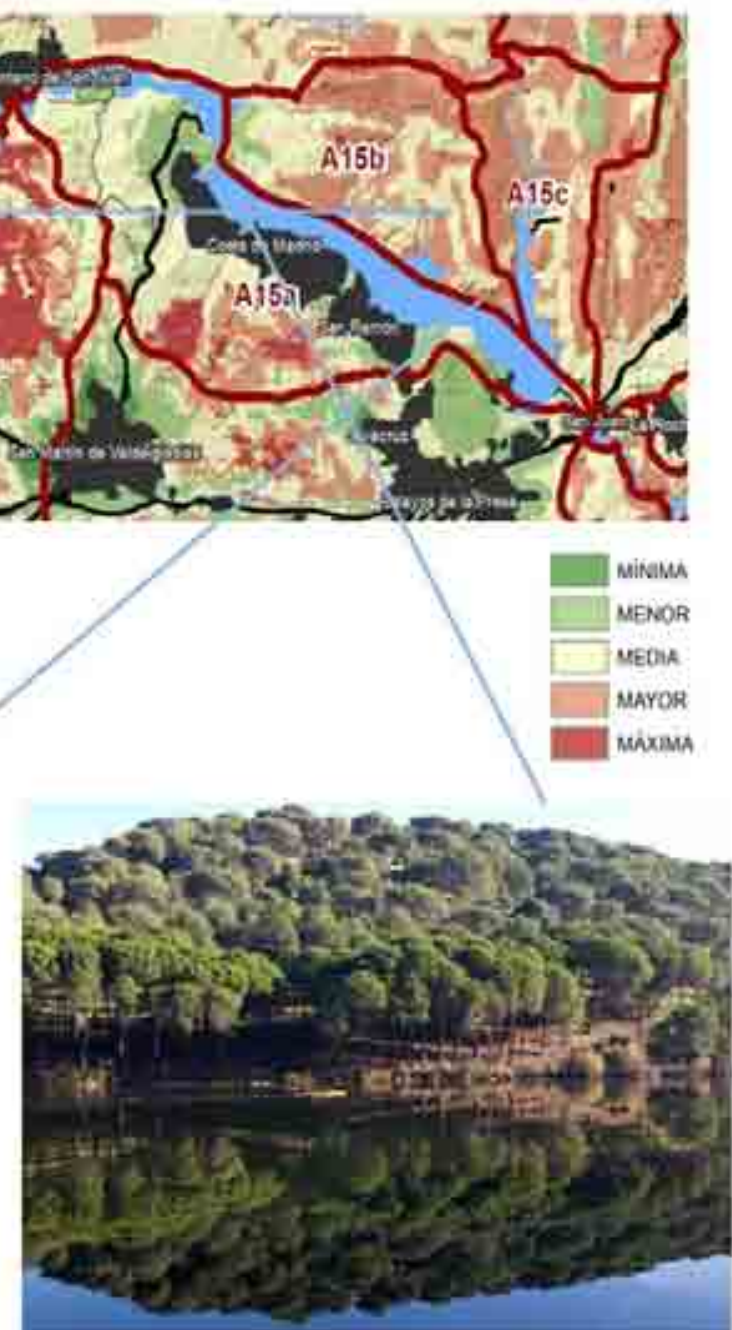

Vistas de "Las Cabreras" desde la parte opuesta del embalse 


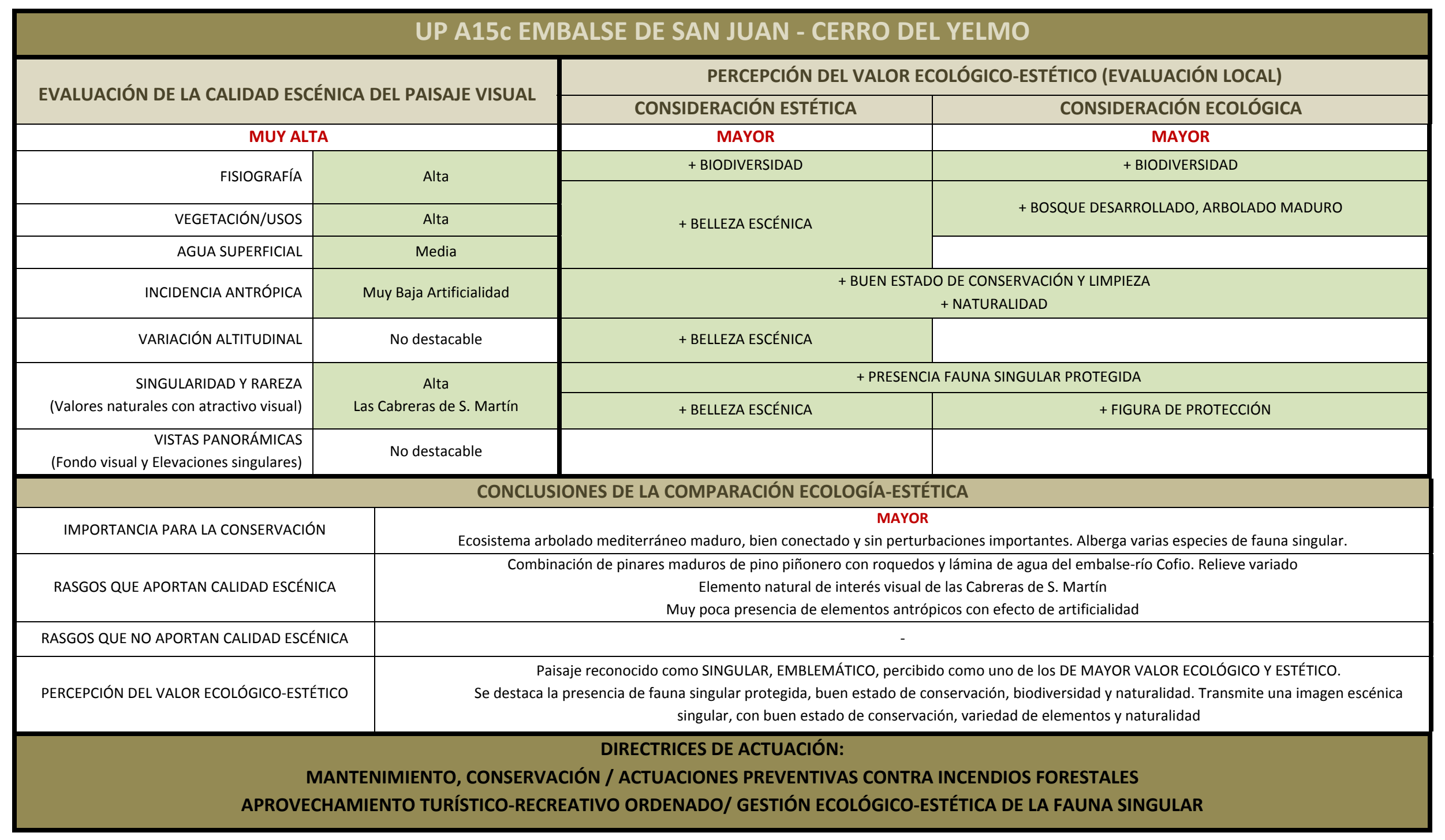




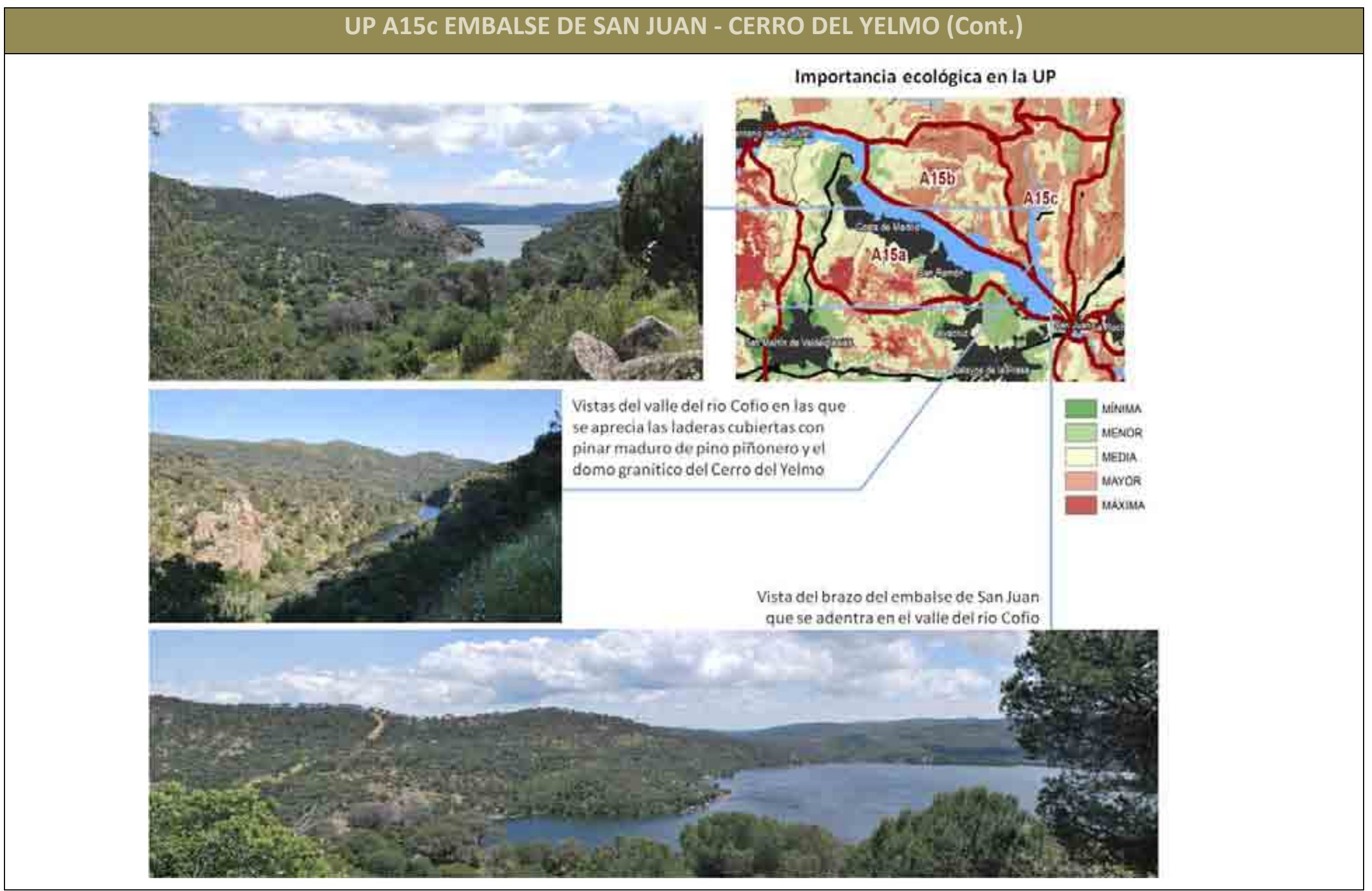




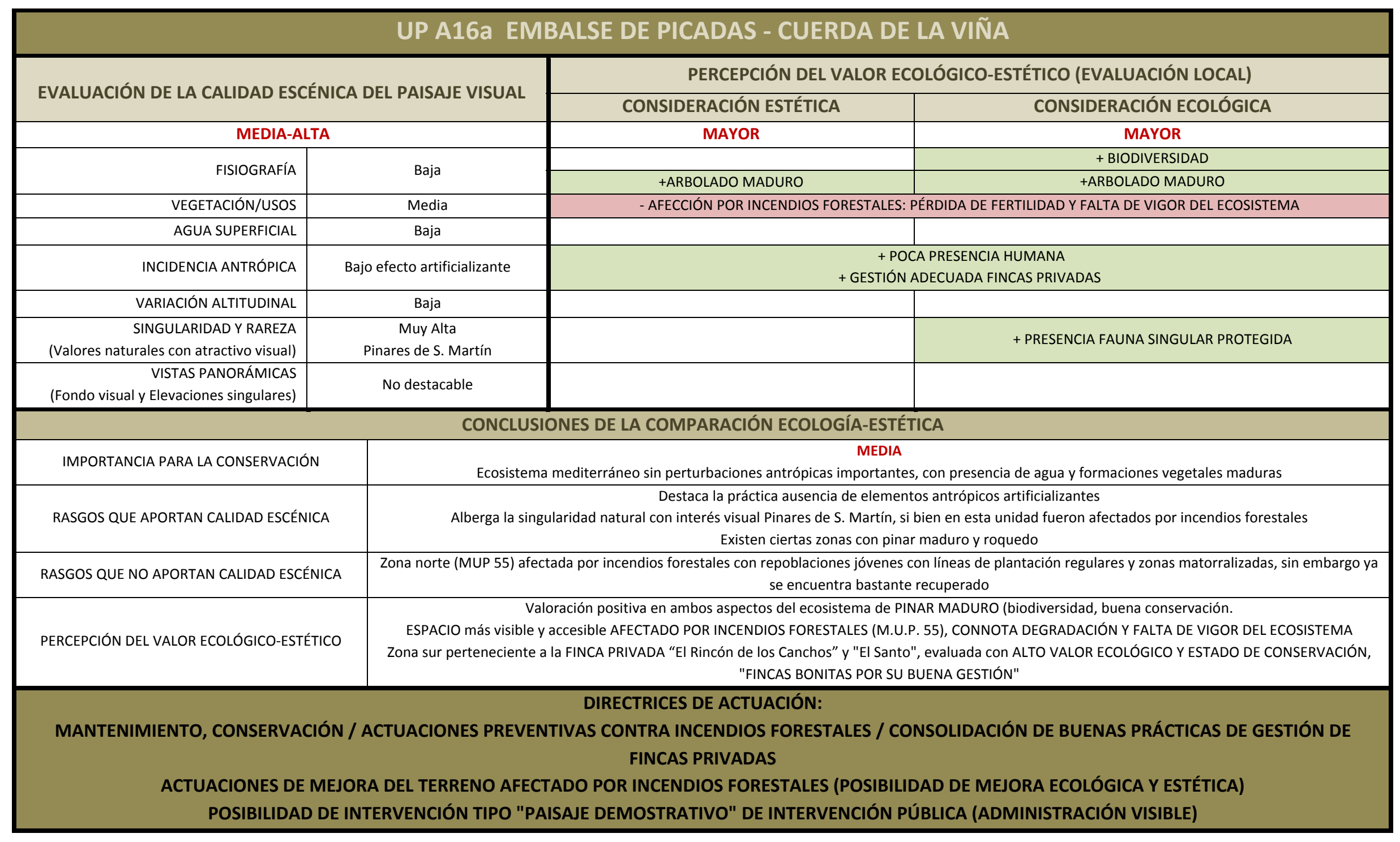




\section{UP A16a EMBALSE DE PICADAS - CUERDA DE LA VIÑA (Cont.)}

Zonas afectadas por incendio forestal hace unos 30 años, con repoblaciones de pino y encina en terrazas
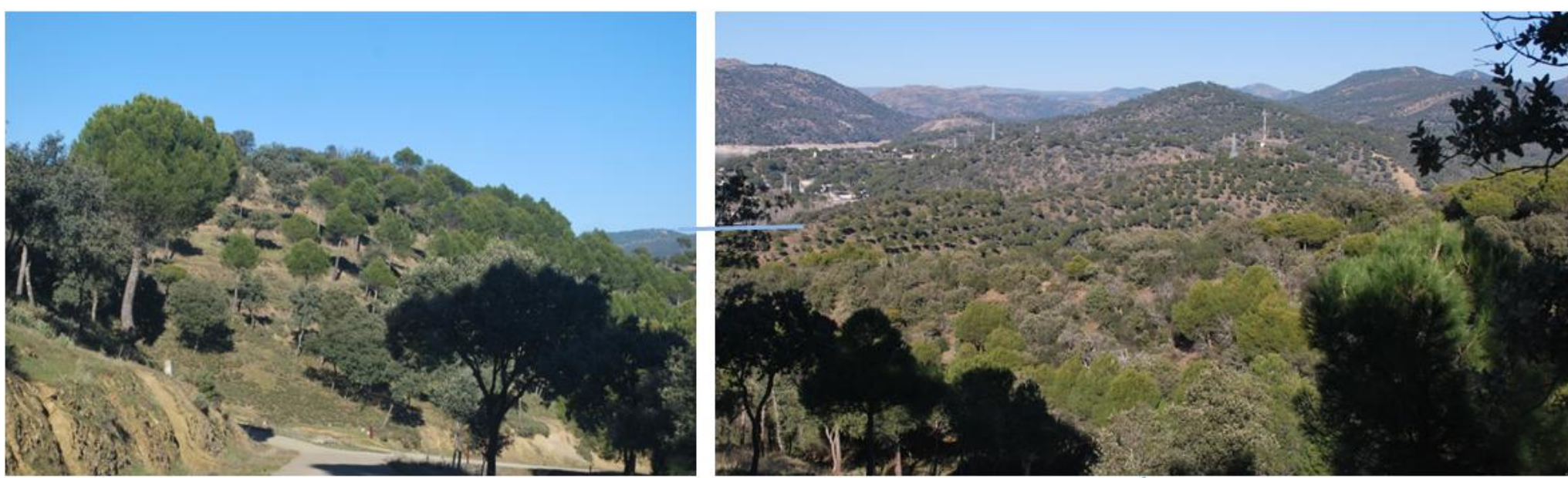

Vista del Barranco del Pocito Importancia ecológica en la UP

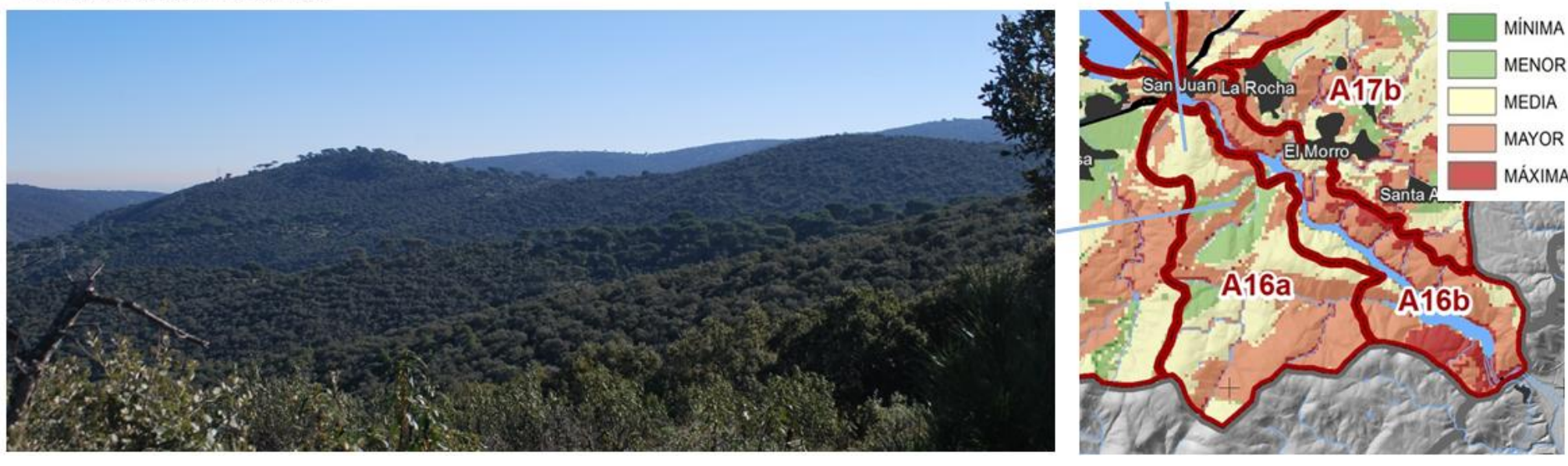




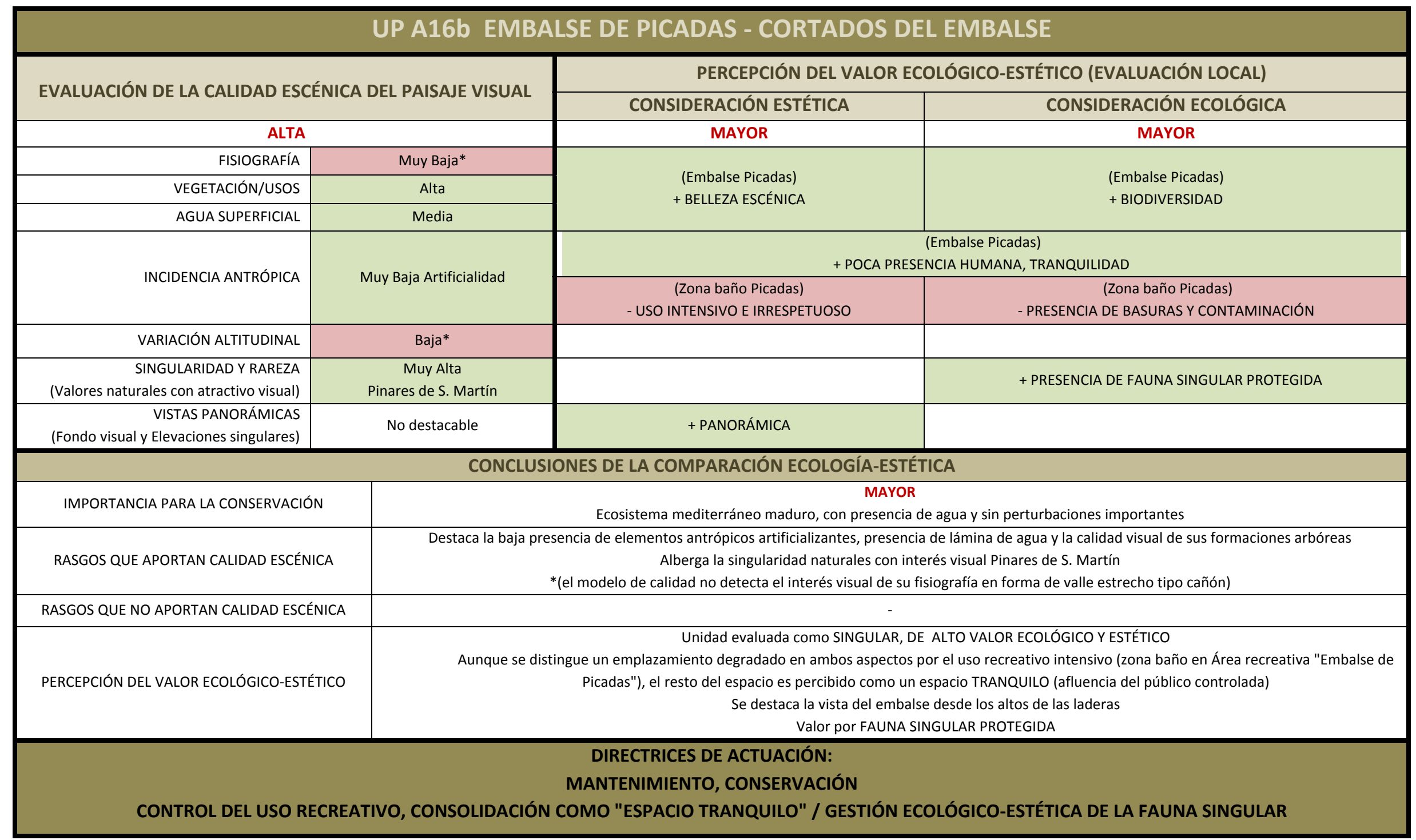




\section{UP A16b EMBALSE DE PICADAS - CORTADOS DEL EMBALSE (Cont.)}

Vista de la garganta que ocupa el embalse de Picadas desde la Vía Verde

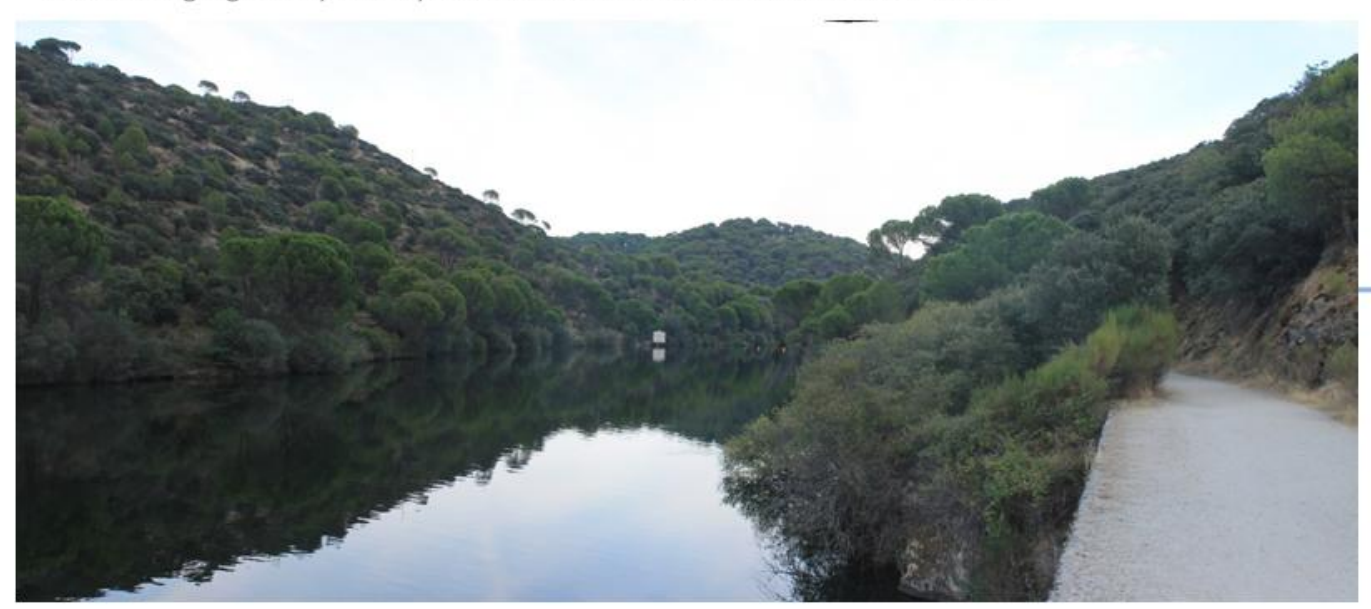

Importancia ecológica en la UP

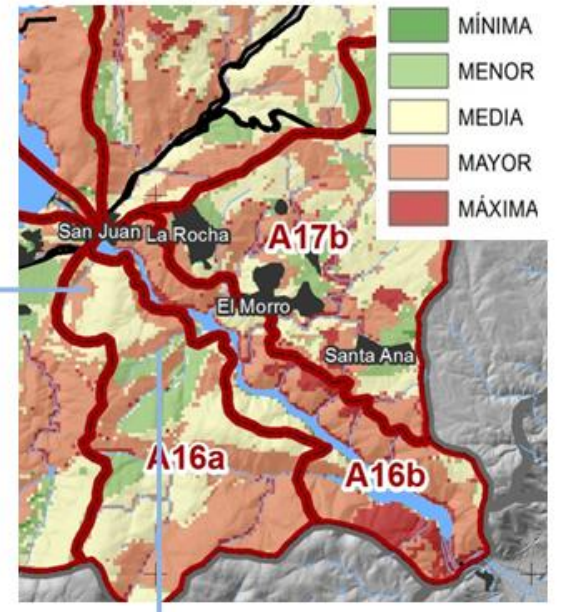

Laderas cubiertas de encinar y pinar de la garganta Picadas

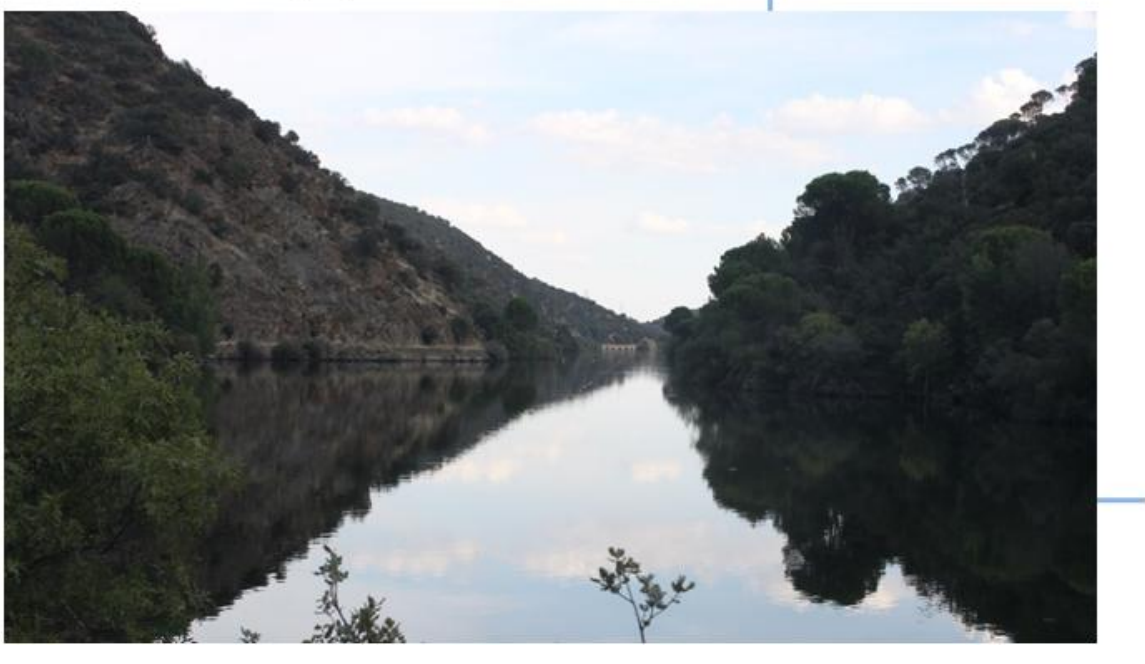




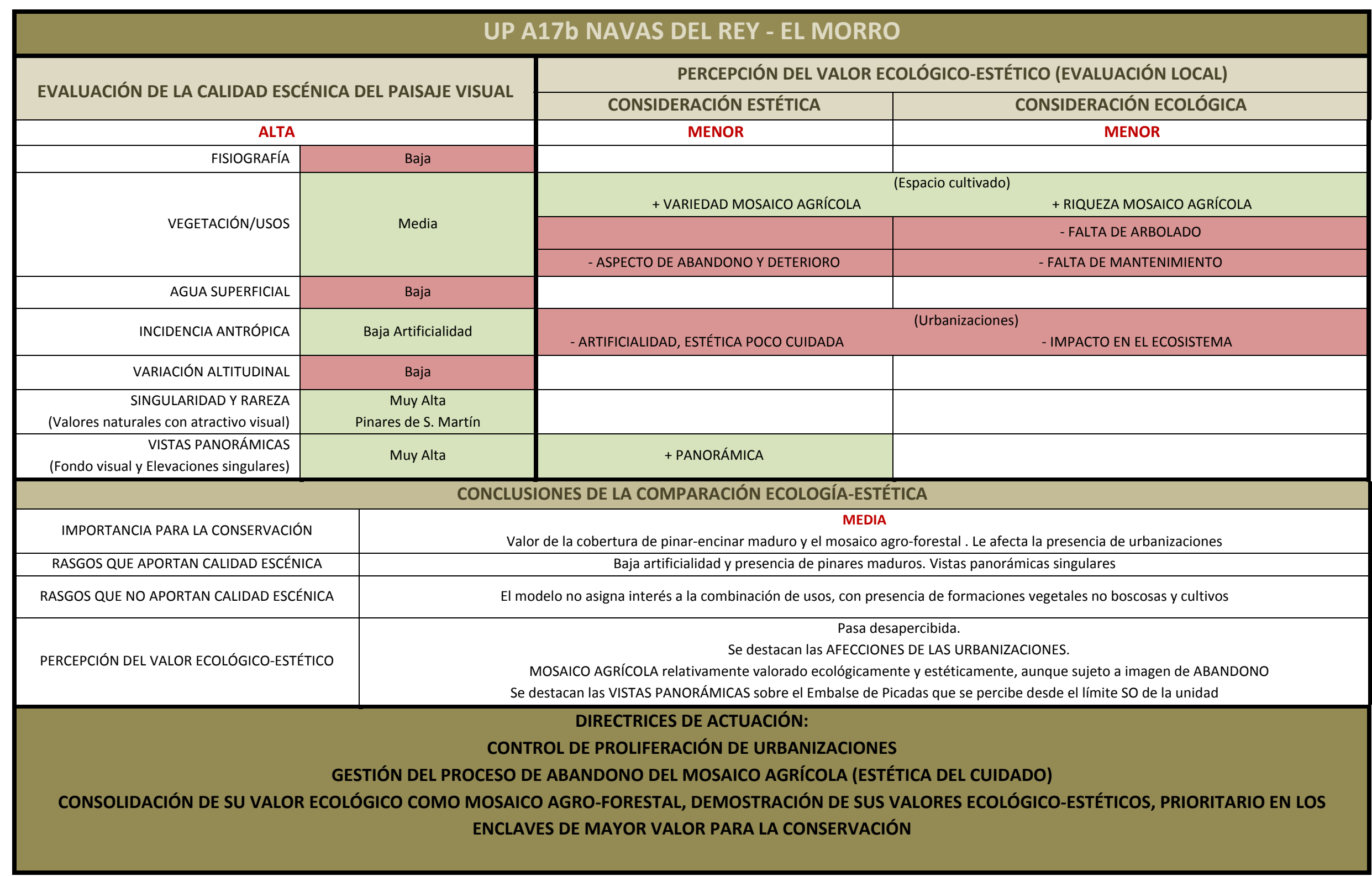


UP A17b NAVAS DEL REY - EL MORRO (Cont.)

Encinares arboreo arbustivos en el entorno de la urbanizacion La Rocha. Al fondo, las primeras elevaciones de la Sierra de Gredos (Cerro Guisando, Cuerda de Pedro Duermes, Alto el Mirlo)

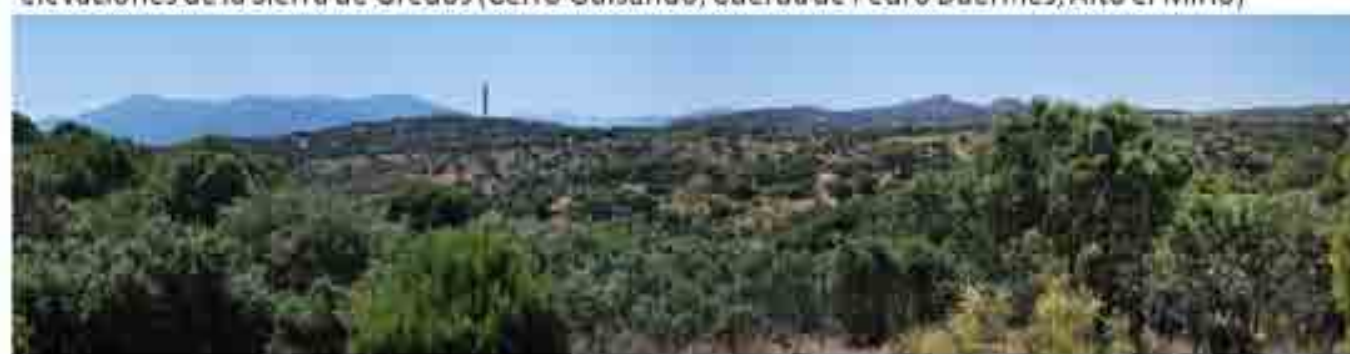

Pinares maduros de pino piñonero en las rampas que inician su descenso al valle del embalse de Picadas
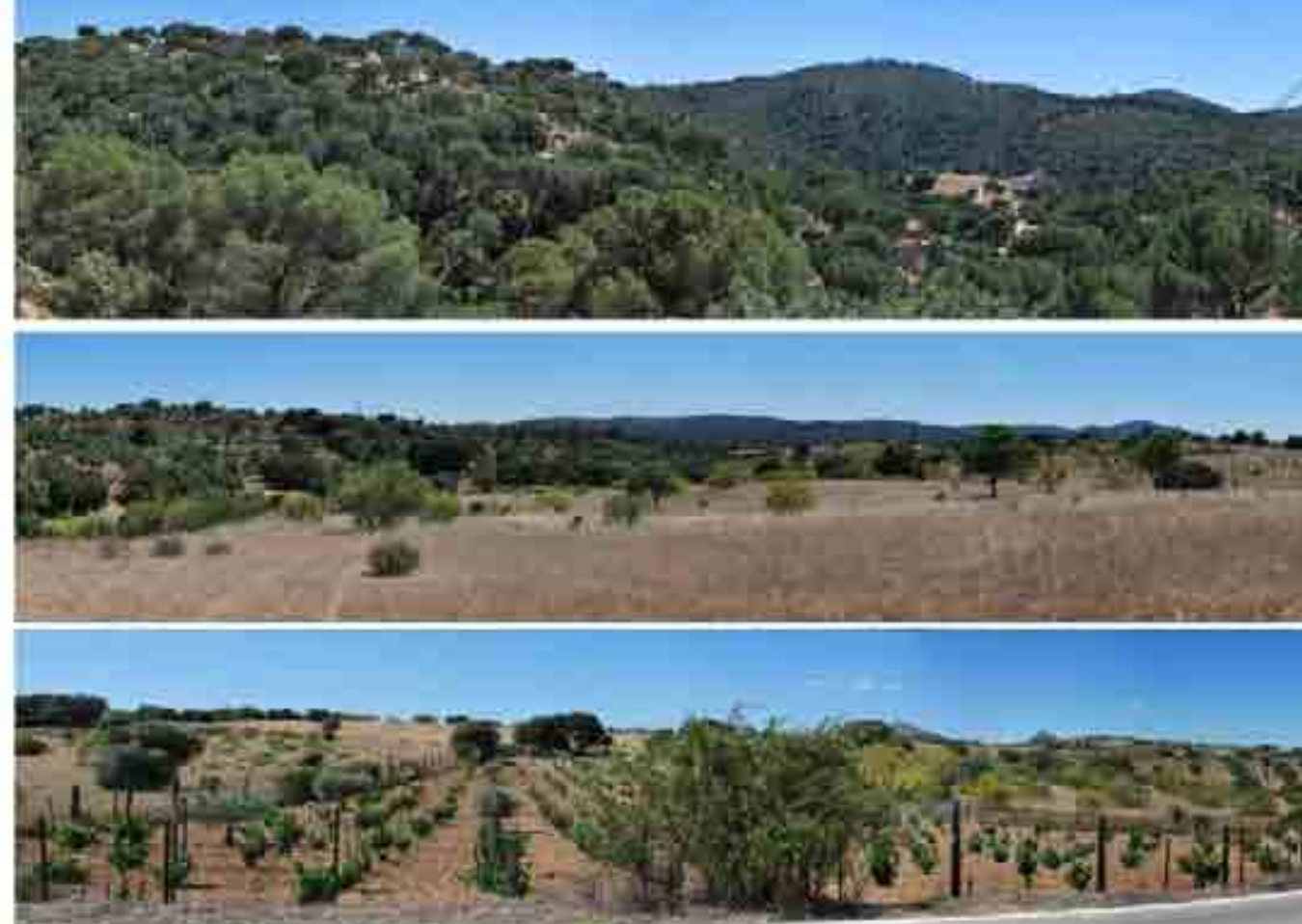

Importancia ecológica en la UP

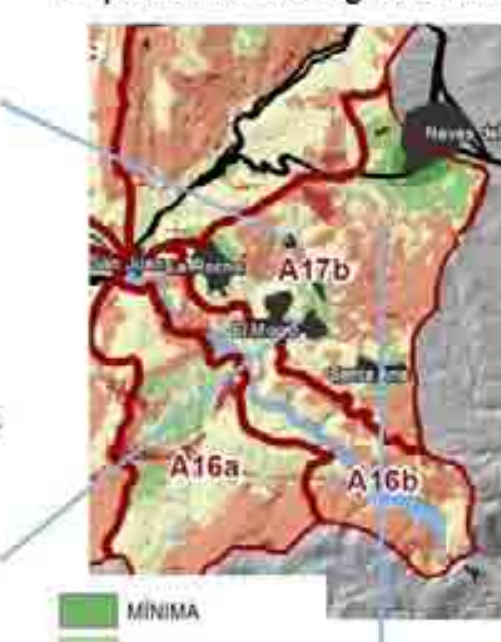

I Minima

MENOR

MEDUA

MAYOR

mixima

Pastizalesymatorralen el paraje "El Valle"

Mosaico de parcelas cultivadasy sin uso en los alrededores de Navás del Rey 


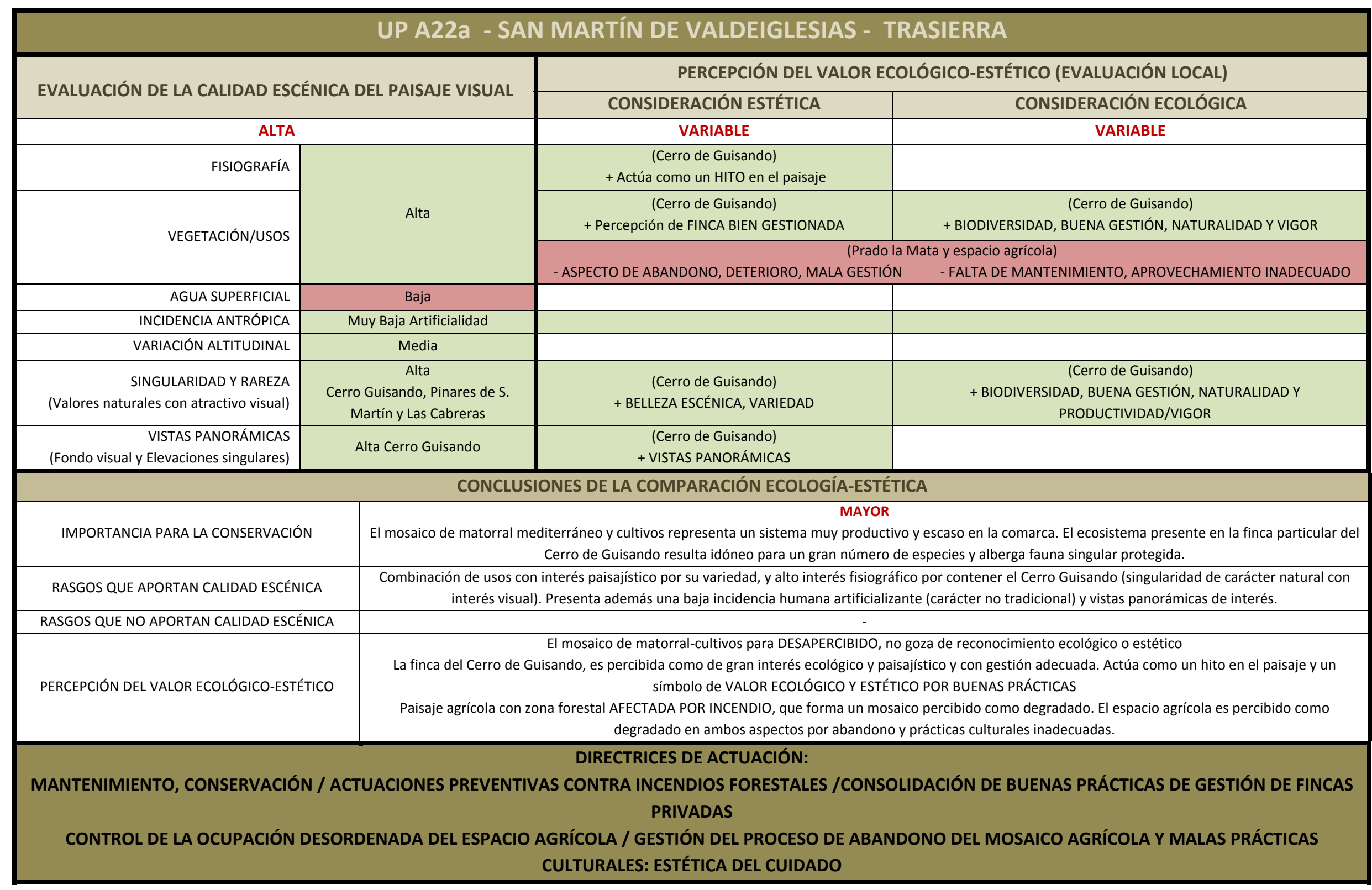




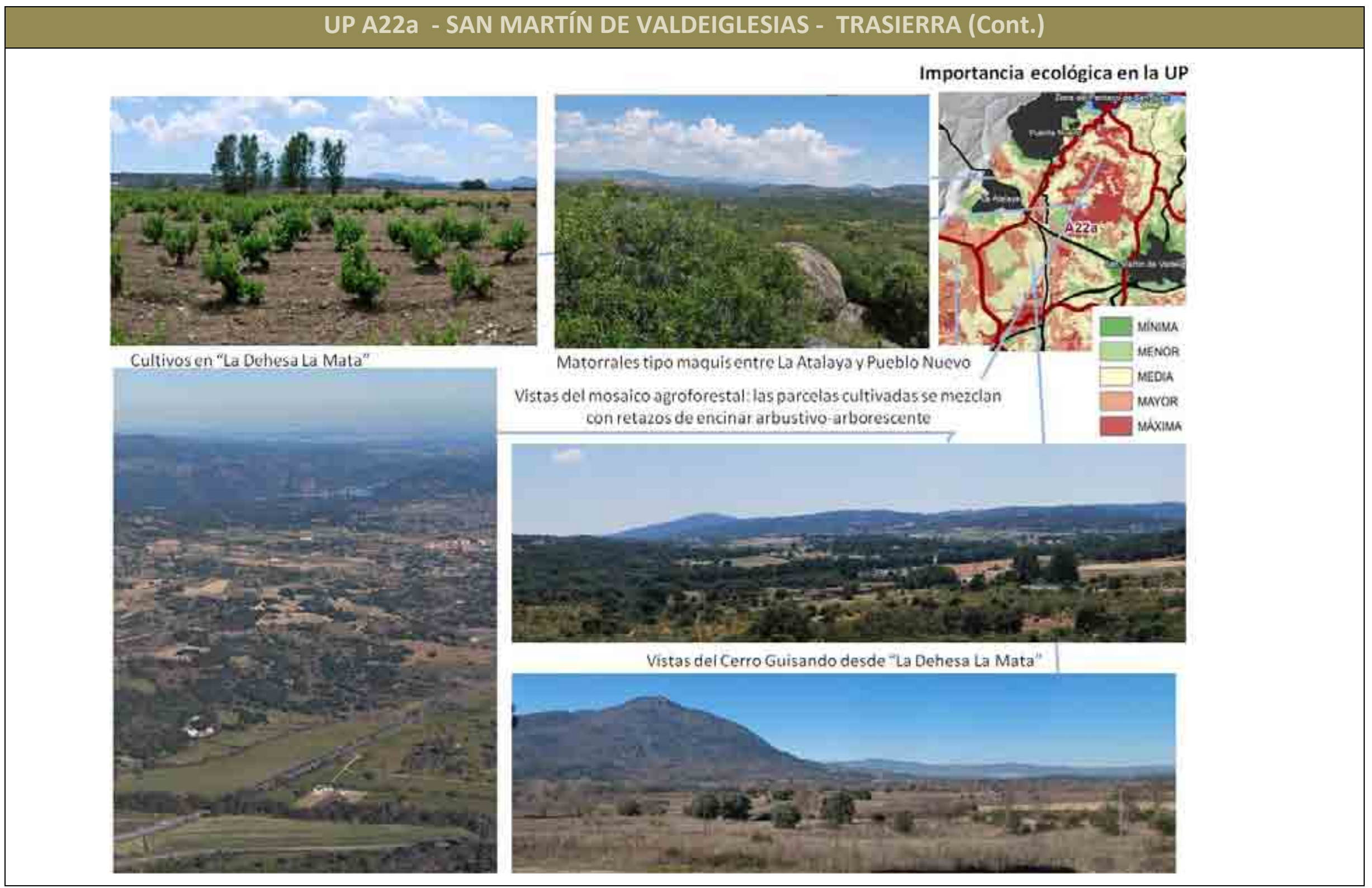




\begin{tabular}{|c|c|c|c|}
\hline \multirow{2}{*}{\multicolumn{2}{|c|}{$\begin{array}{l}\text { EVALUACIÓN DE LA CALIDAD DEL PAISAJE VISUAL } \\
\text { (EVALUACIÓN EXPERTA) }\end{array}$}} & \multicolumn{2}{|c|}{ PERCEPCIÓN DEL VALOR ECOLÓGICO-ESTÉTICO (EVALUACIÓN LOCAL) } \\
\hline & & CONSIDERACIÓN ESTÉTICA & CONSIDERACIÓN ECOLÓGICA \\
\hline \multicolumn{2}{|c|}{ MEDIA- ALTA } & VARIABLE & VARIABLE \\
\hline \multirow{3}{*}{ FISIOGRAFÍA } & \multirow{8}{*}{ Media- Alta } & & $\begin{array}{l}\text { (Laderas forestadas: Canto el Guarro, MUP 55) } \\
\text { + BIODIVERSIDAD }\end{array}$ \\
\hline & & \multicolumn{2}{|c|}{ + BOSQUE DESAROLLADO, ARBOLADO MADURO } \\
\hline & & \multicolumn{2}{|c|}{ - FALTA DE CUIDADO/GESTIÓN: MATORRALIZACIÓN Y DENSIDAD EXCESIVA, RIESGO DE INCENDIOS } \\
\hline \multirow{5}{*}{ VEGETACIÓN/USOS } & & \multicolumn{2}{|c|}{$\begin{array}{c}\text { (Pinares alrededor M-541) } \\
+ \text { CUIDADO, MANTENIMIENTO, BUENA GESTIÓN (forestal) }\end{array}$} \\
\hline & & \multicolumn{2}{|c|}{ (Espacio cultivado) } \\
\hline & & + VARIEDAD MOSAICO AGRÍCOLA & + RIQUEZA MOSAICO AGRÍCOLA \\
\hline & & +COLOR ESTACIONAL VIÑA, CARÁCTER TRADICIONAL MINIFUNDISTA & - BAJA BIODIVERSIDAD \\
\hline & & - ASPECTO DE ABANDONO Y DETERIORO & - FALTA DE MANTENIMIENTO \\
\hline AGUA SUPERFICIAL & Baja & & $\begin{array}{l}\text { (Lagunas Marrache) } \\
+ \text { EQUILIBRIO, BIODIVERSIDAD }\end{array}$ \\
\hline \multirow[t]{2}{*}{ INCIDENCIA ANTRÓPICA } & \multirow[t]{2}{*}{ Baja Artificialidad* } & \multicolumn{2}{|c|}{$\begin{array}{l}\text { - ARTIFICIALIDAD, ESTÉTICA POCO CUIDADA } \\
\text { - SENSACIÓN DE DESORDEN Y DESCONTROL } \\
\text { - PRESENCIA DE CONSTRUCCIONES POCO CUIDADAS Y ESCOMBROS: "CHABOLISMO" }\end{array}$} \\
\hline & & 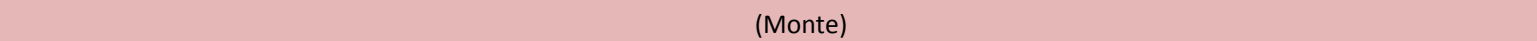 & PACTO EN ECOSISTEMA DE CORTAFUEGOS \\
\hline VARIACIÓN ALTITUDINAL & Media & & \\
\hline \multirow{3}{*}{$\begin{array}{r}\text { SINGULARIDAD Y RAREZA } \\
\text { (Valores naturales con } \\
\text { atractivo visual) }\end{array}$} & \multirow{3}{*}{$\begin{array}{l}\text { Alta } \\
\text { Pinares de S. Martín y Las Cabreras }\end{array}$} & \multicolumn{2}{|c|}{ + BOSQUE DESAROLLADO, ARBOLADO MADURO } \\
\hline & & & + PRESENCIA DE FAUNA PROTEGIDA \\
\hline & & \multicolumn{2}{|c|}{ - FALTA DE CUIDADO/GESTIÓN: MATORRALIZACIÓN Y DENSIDAD EXCESIVA, RIESGO DE INCENDIOS } \\
\hline $\begin{array}{r}\text { VISTAS PANORÁMICAS } \\
\text { (Fondo visual y Elevaciones } \\
\text { singulares) }\end{array}$ & Baja & & \\
\hline
\end{tabular}




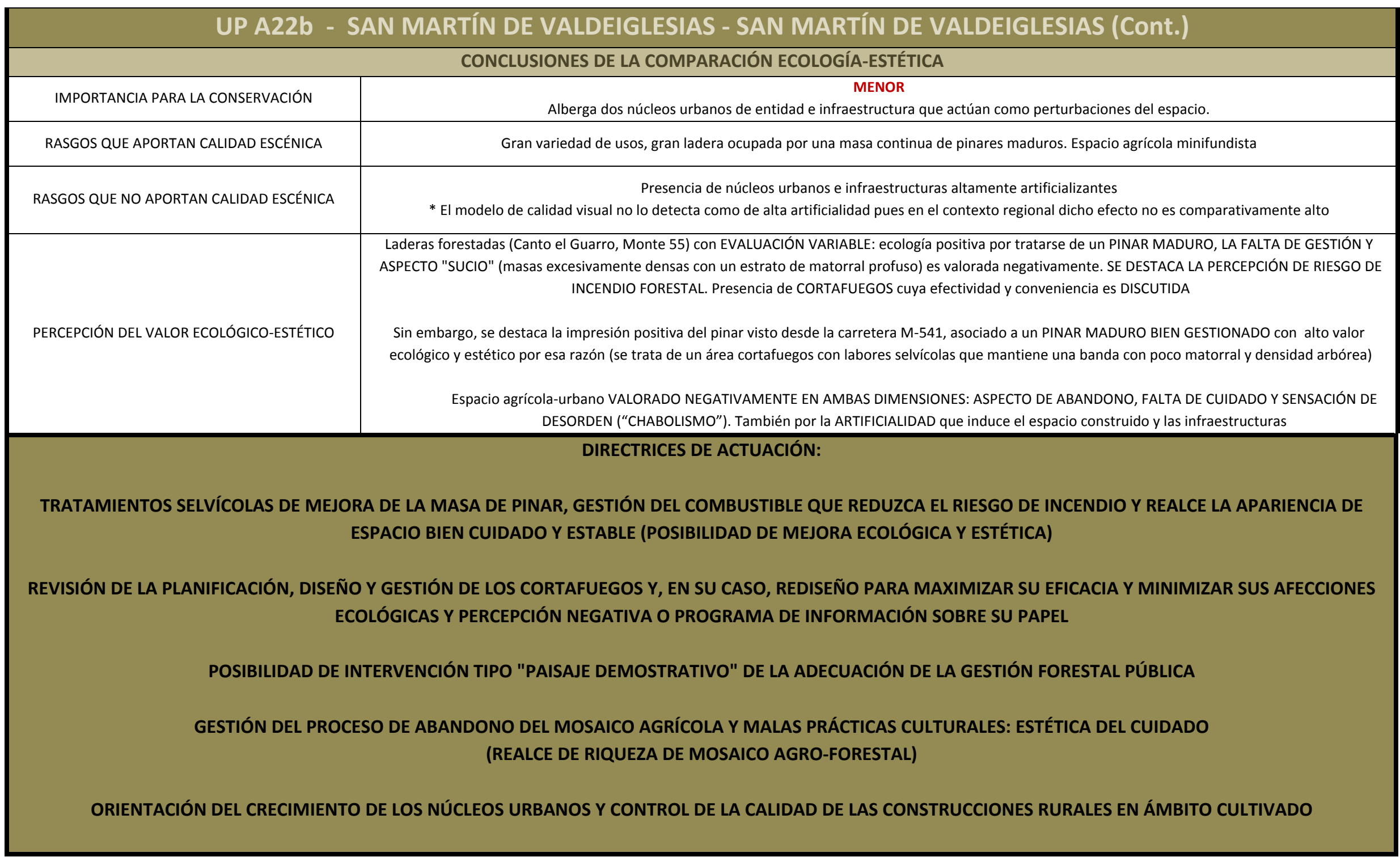


UPA22b - SAN MARTÍN DE VALDEIGLESIAS - SAN MARTÍN DE VALDEIGLESIAS(Cont.)

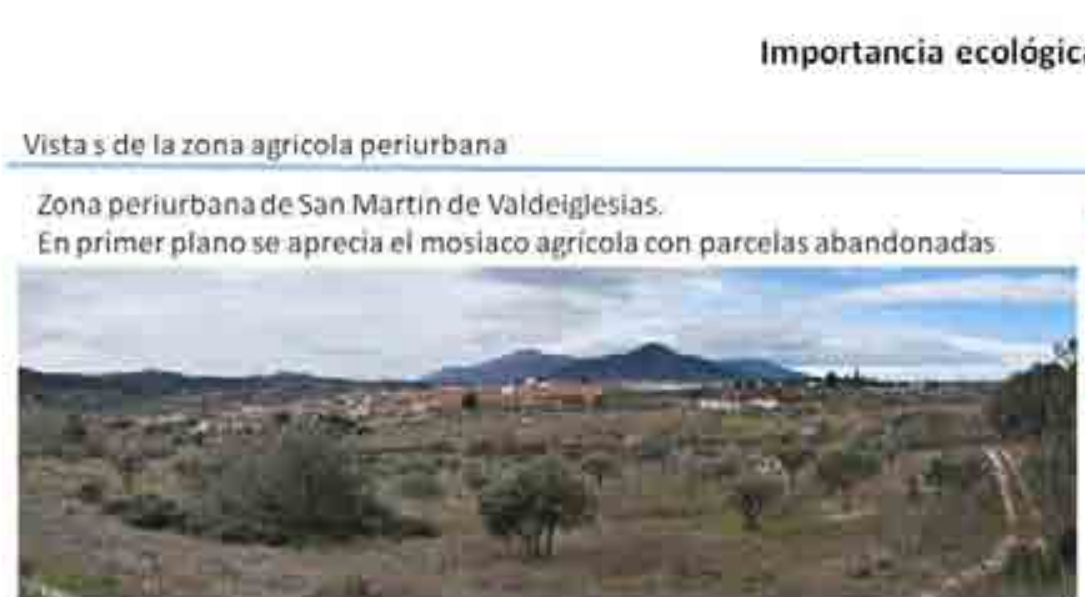

Ejemplo de finca con construcción desordenada y aspecto pococuidado
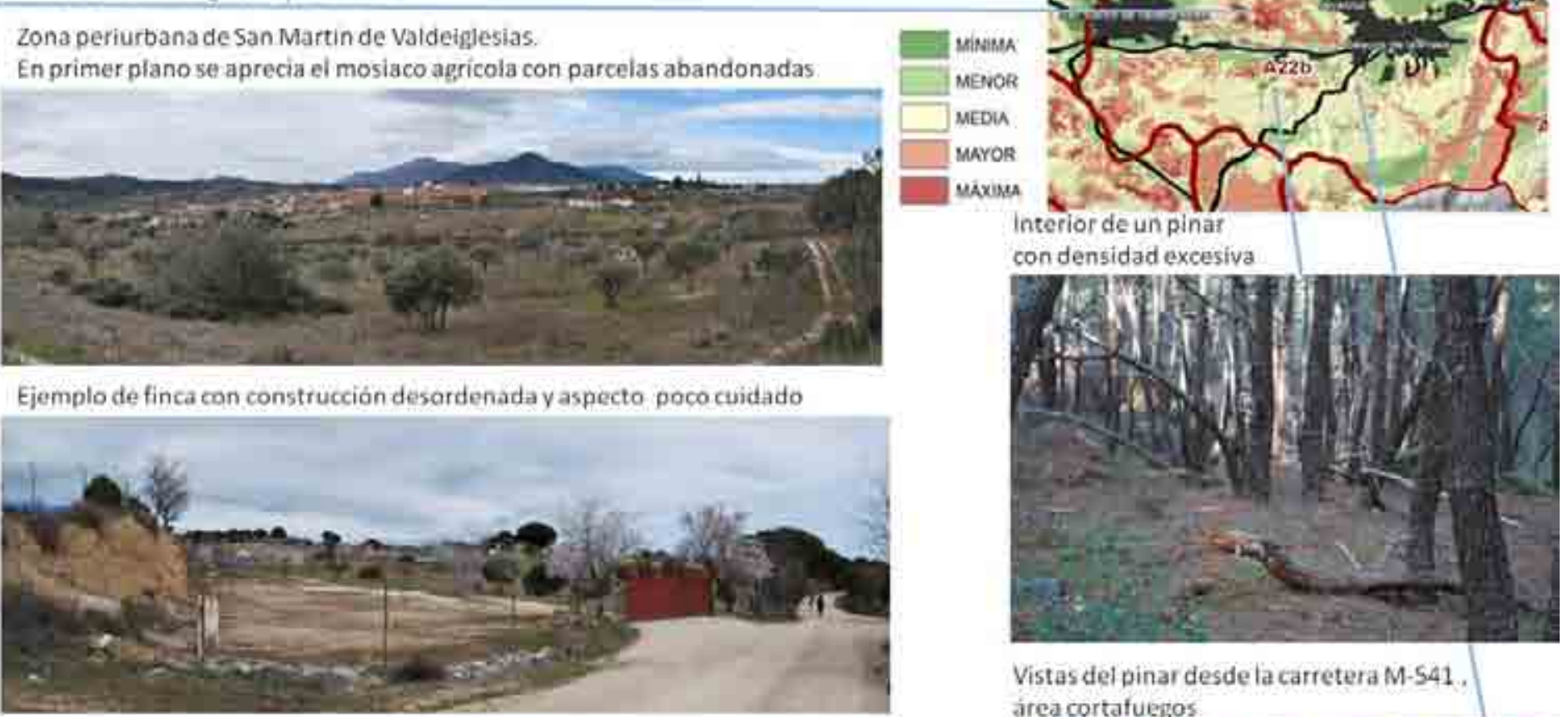

Vista de las laderas de pinar de umbria aen fa zonasur del MUP 55

En primer plano se aprecia el mosiaco agricola con parcelas abandonadas.
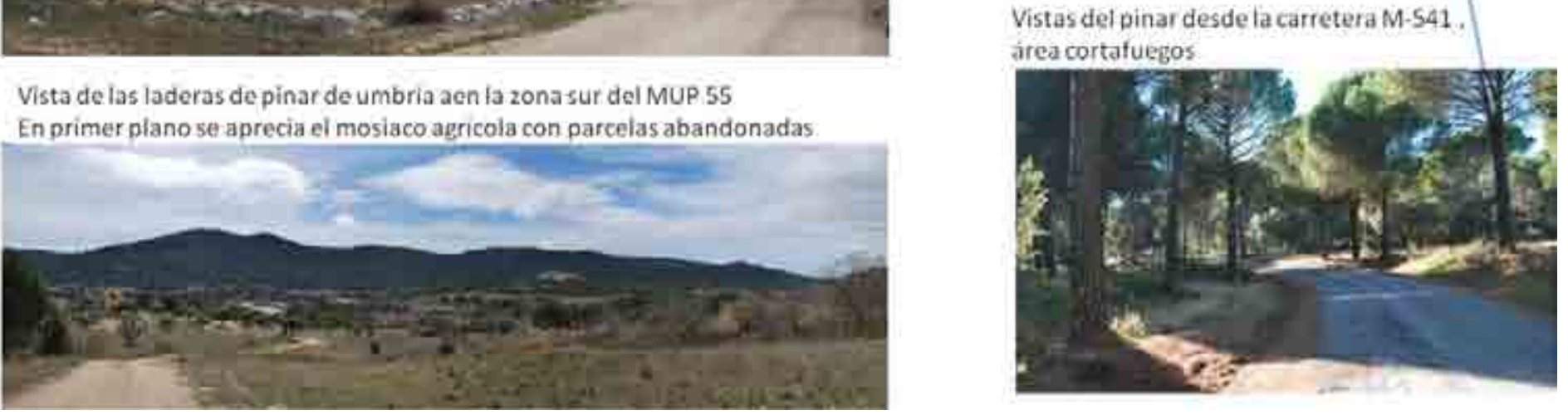


\begin{tabular}{|c|c|c|c|c|}
\hline \multicolumn{5}{|c|}{ UP A23 - PEÑA DE CADALSO } \\
\hline \multirow{2}{*}{\multicolumn{3}{|c|}{ EVALUACIÓN DE LA CALIDAD DEL PAISAJE VISUAL }} & \multicolumn{2}{|c|}{ PERCEPCIÓN DEL VALOR ECOLÓGICO-ESTÉTICO (EVALUACIÓN LOCAL) } \\
\hline & & & CONSIDERACIÓN ESTÉTICA & CONSIDERACIÓN ECOLÓGICA \\
\hline \multicolumn{3}{|c|}{ MEDIA-ALTA } & ALTA & ALTA \\
\hline FISIOGRAFÍA & \multicolumn{2}{|c|}{ Bajo } & \multirow{2}{*}{\multicolumn{2}{|c|}{$\begin{array}{l}\text { (Pinares) + BOSQUE DESARROLLADO, ARBOLADO MADURO } \\
+ \text { + CUIDADO, MANTENIMIENTO, GESTIÓN ADECUADA, BUEN ESTADO DE CONSERVACIÓN } \\
+ \text { BELLEZA ESCÉNICA }\end{array}$}} \\
\hline VEGETACIÓN/USOS & \multicolumn{2}{|c|}{ Alto } & & \\
\hline AGUA SUPERFICIAL & \multicolumn{2}{|c|}{ Bajo } & & \\
\hline \multirow[b]{2}{*}{ INCIDENCIA ANTRÓPICA } & \multirow{2}{*}{\multicolumn{2}{|c|}{ Baja artificialidad* }} & & (Pinares) + NATURALIDAD, POCA PRESENCIA HUMANA \\
\hline & & & (Canteras) - IMPACTO VISUAL Y SONORO & $\begin{array}{l}\text { - AFECCIÓN AL ECOSISTEMA, IMPACTO SONORO } \\
\text { - FALTA DE RESTAURACIÓN }\end{array}$ \\
\hline VARIACIÓN ALTITUDINAL & \multicolumn{2}{|c|}{ No destacable } & & \\
\hline $\begin{array}{r}\text { SINGULARIDAD Y RAREZA } \\
\text { (Valores naturales con } \\
\text { atractivo visual) }\end{array}$ & \multicolumn{2}{|c|}{$\begin{array}{c}\text { Alto } \\
\text { Peñas y Pinares de Cadalso }\end{array}$} & $\begin{array}{l}+ \text { COMBINACIÓN ARBOLADO Y RISCOS } \\
\text { (Peña de Cadalso) }\end{array}$ & \\
\hline $\begin{array}{r}\text { VISTAS PANORÁMICAS } \\
\text { (Fondo visual y Elevaciones } \\
\text { singulares) }\end{array}$ & \multicolumn{2}{|c|}{ No destacable } & + PANORÁMICA (Peña de Cadalso) & \\
\hline \multicolumn{5}{|c|}{ CONCLUSIONES DE LA COMPARACIÓN ECOLOGÍA-ESTÉTICA } \\
\hline \multicolumn{2}{|c|}{ IMPORTANCIA PARA LA CONSERVACIÓN } & \multicolumn{3}{|c|}{$\begin{array}{c}\text { MEDIO } \\
\text { presencia de bosque mediterráneo maduro y mosaico agro-forestal rico. Determinados lugares son idóneos para especies singulares protegidas }\end{array}$} \\
\hline \multicolumn{2}{|c|}{ RASGOS QUE APORTAN CALIDAD ESCÉNICA } & \multicolumn{3}{|c|}{$\begin{array}{l}\text { Variedad de vegetación y usos. Presencia de la singularidad de Peña de Cadalso, hito geomorfológico, } \\
\text { y los PInares de Cadalso (Pinares maduros de pino piñonero en zonas con roquedo aflorante). }\end{array}$} \\
\hline \multicolumn{2}{|c|}{ RASGOS QUE NO APORTAN CALIDAD ESCÉNICA } & \multicolumn{3}{|c|}{$\begin{array}{l}\text { Presencia de grandes canteras de granito *(el modelo o detecta su efecto artificializante y alto impacto) } \\
\text { Pérdida de la cubierta arbórea de una extensa área debido a un incendio forestal }\end{array}$} \\
\hline \multicolumn{2}{|c|}{$\begin{array}{l}\text { PERCEPCIÓN DEL VALOR ECOLÓGICO- } \\
\text { ESTÉTICO }\end{array}$} & \multicolumn{3}{|c|}{$\begin{array}{l}\text { con estética asociada a un pinar maduro bien gestionado, se le reconoce ALTO VALOR ECOLÓGICO Y ESTÉTICO por esa razón } \\
\text { ca la impresión positiva desde la carretera M-541, sujeta a labores selvícolas para prevención de incendios forestales) } \\
\text { or presencia de FAUNA SINGULAR PROTEGIDA y ELEVACIÓN SINGULAR valorada paisajísticamente: Peña de Cadalso } \\
\text { EI GRAN IMPACTO DE LAS CANTERAS hace que la calidad de ciertos sitios contraste con la evaluación positiva general }\end{array}$} \\
\hline \multicolumn{5}{|c|}{$\begin{array}{l}\text { UNIDAD CUYA IMAGEN MANIFIESTA UNA GESTIÓN FORESTAL ADECUADA: "PAISAJE DEMOSTRATIVO" GESTIÓN PÚBLICA } \\
\text { ACIÓN LABORES SELVÍCOLAS MÁS ALLÁ DE LA BANDA DE LA CARRETERA, GESTIÓN SELVíCOLA DEL RIESGO DE INCENDIO FORESTAL } \\
\text { ADORA DE CANTERAS que muestre de manera patente la recuperación del ecosistema / GESTIÓN ECOLÓGICO-ESTÉTICA DE LA FAUNA SINGULAF } \\
\text { OPORTUNIDAD de servirse de la panorámica desde Peña Cadalso para revelar la dinámica ecológica a escala de paisaje }\end{array}$} \\
\hline
\end{tabular}




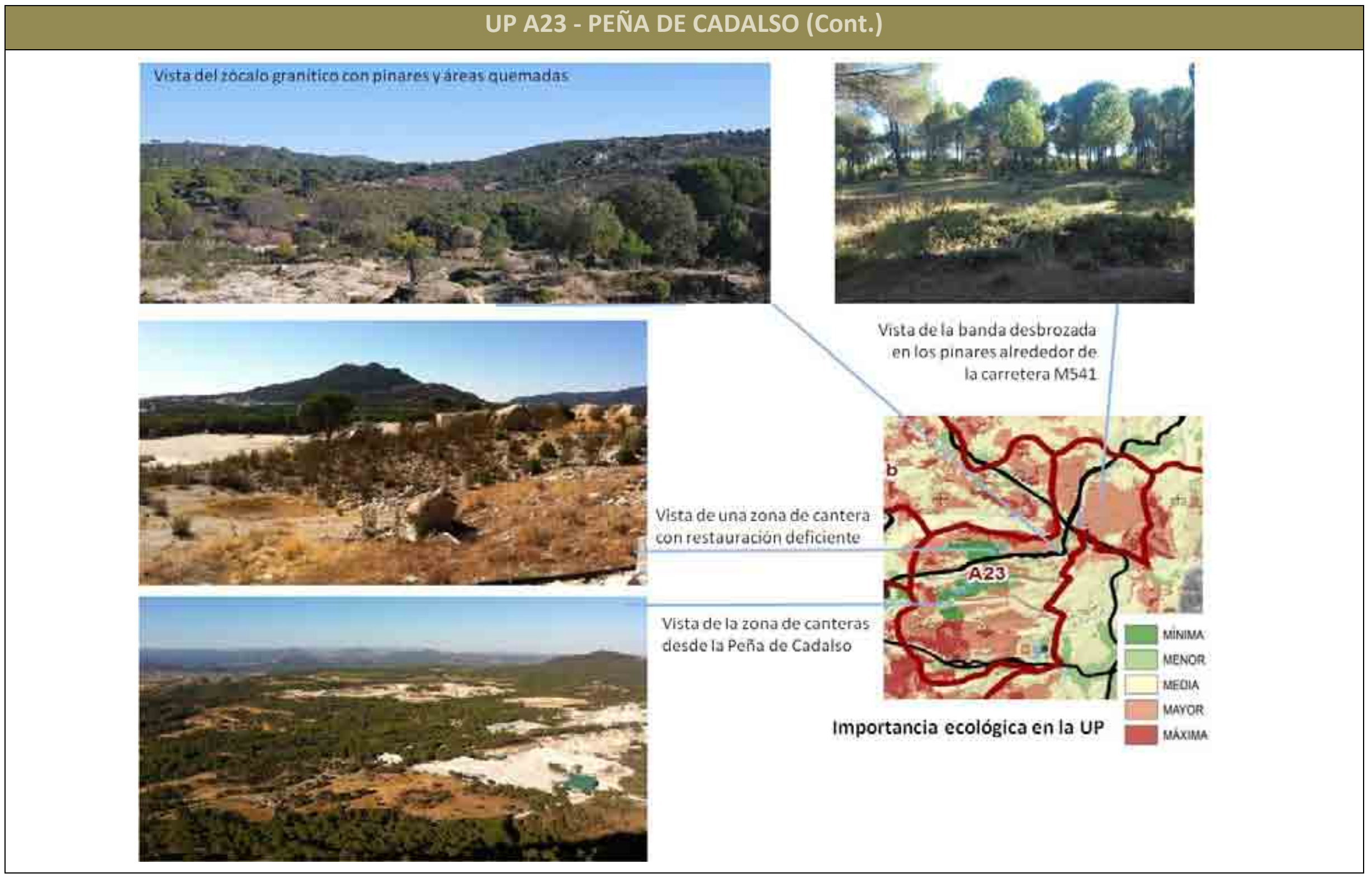




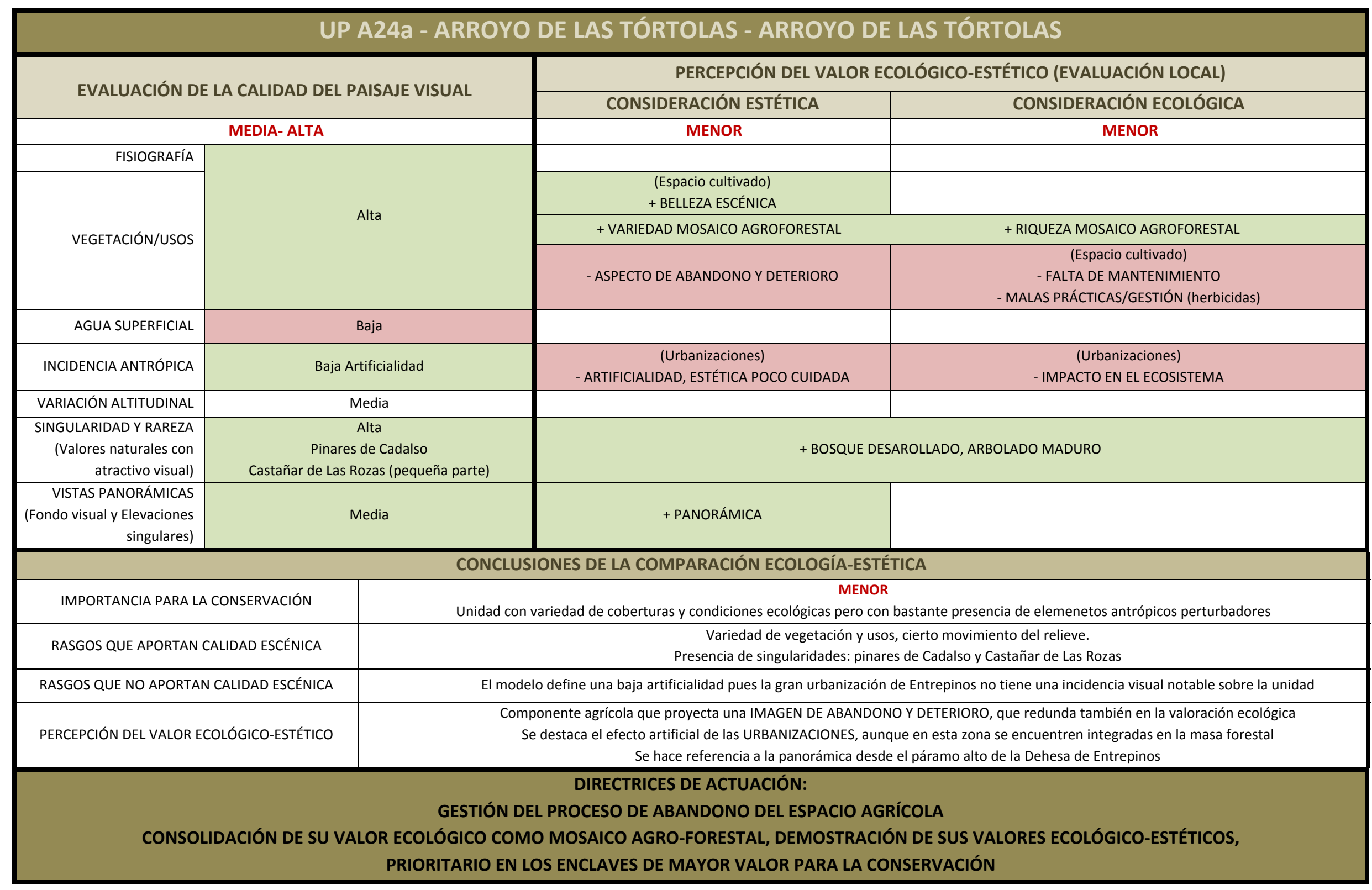




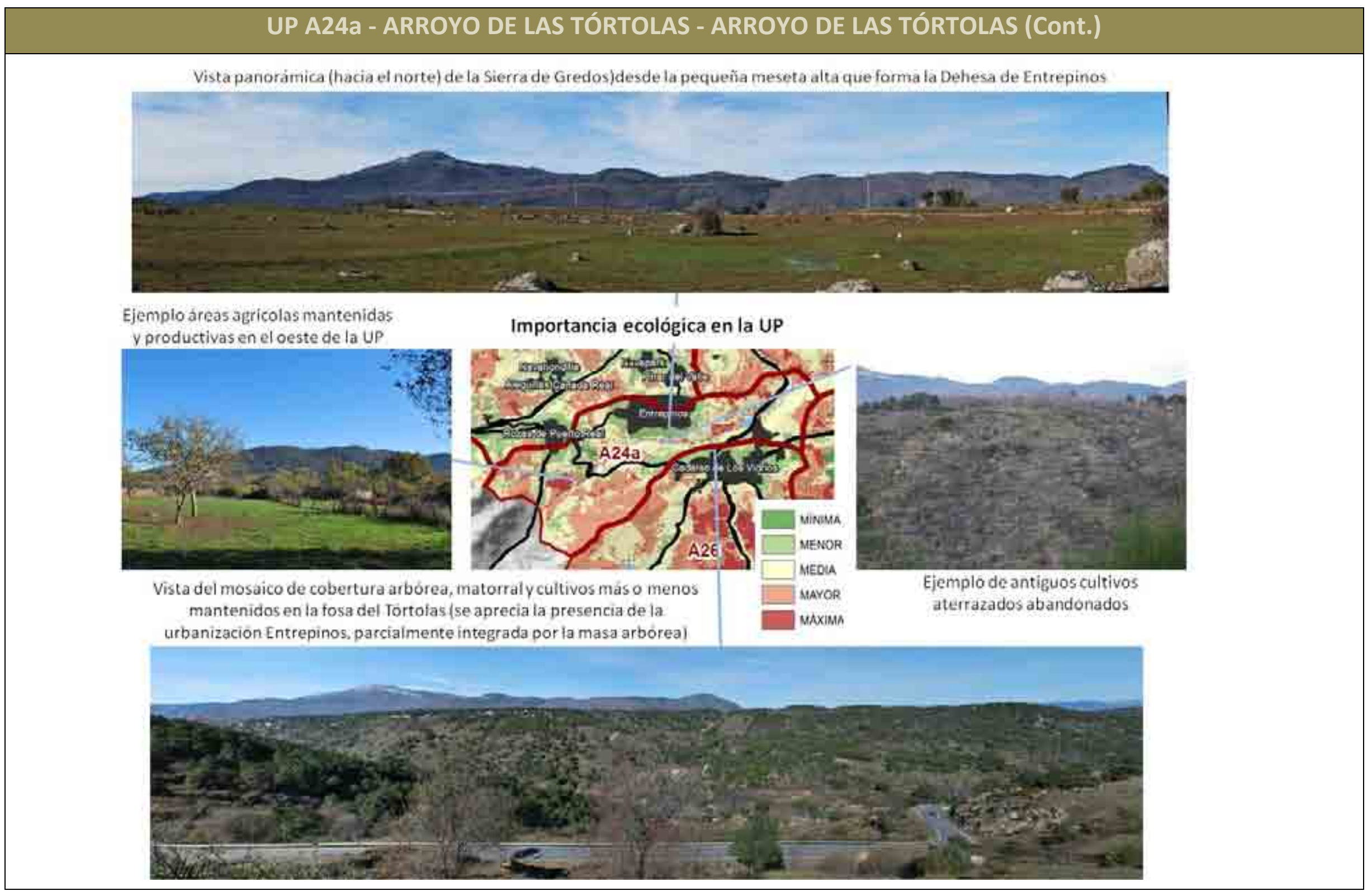




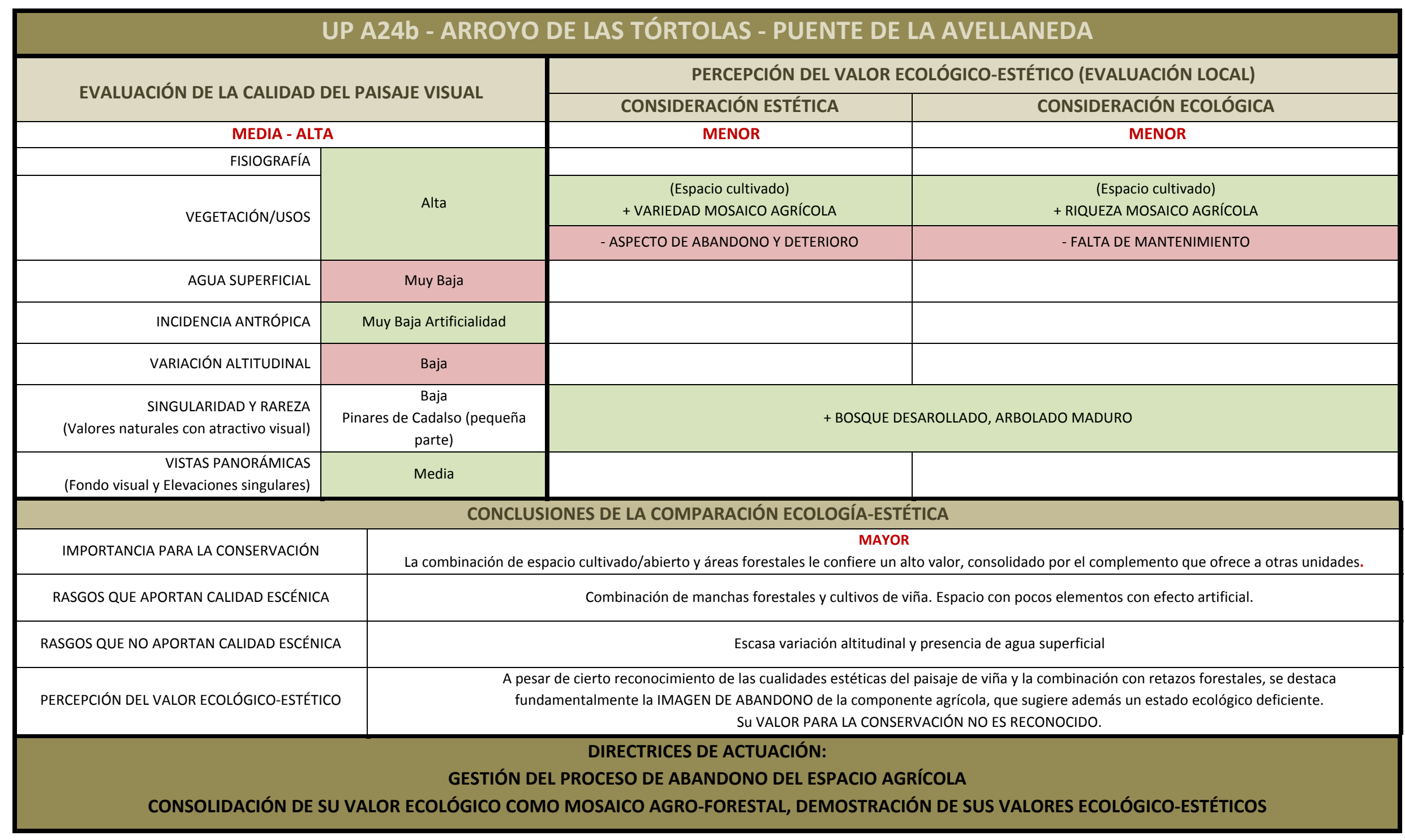


UP A24b - ARROYO DE LAS TÓRTOLAS - PUENTE DE LA AVELLANEDA (Cont.)

Vista del mosaico agricola retazos de bosque. Al fondo, el cerramiento visual delacuerda de la sierra de Gredos (UP2S)

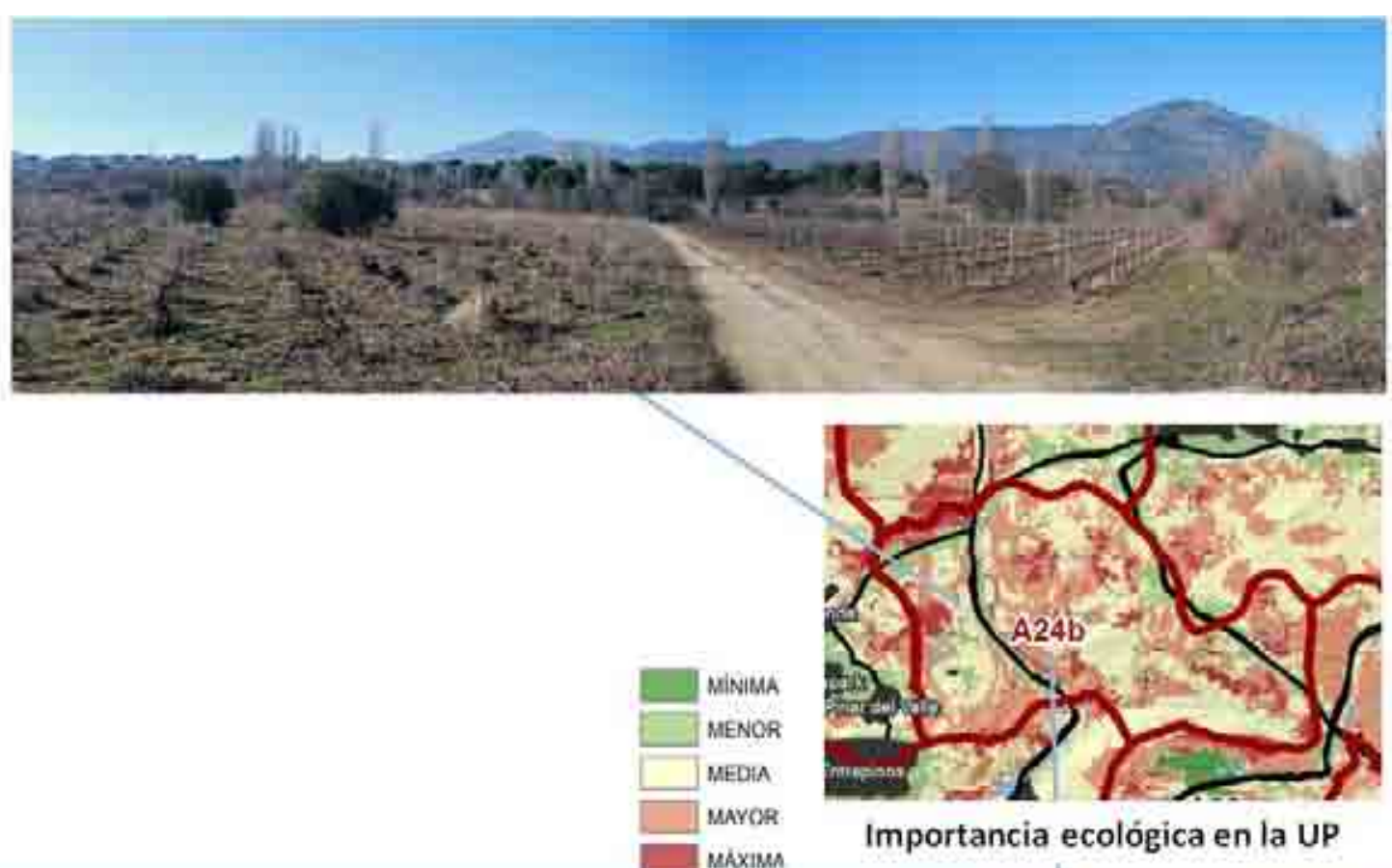

Vista representativa de cultivos

maxime

Importancia ecológica en la uP

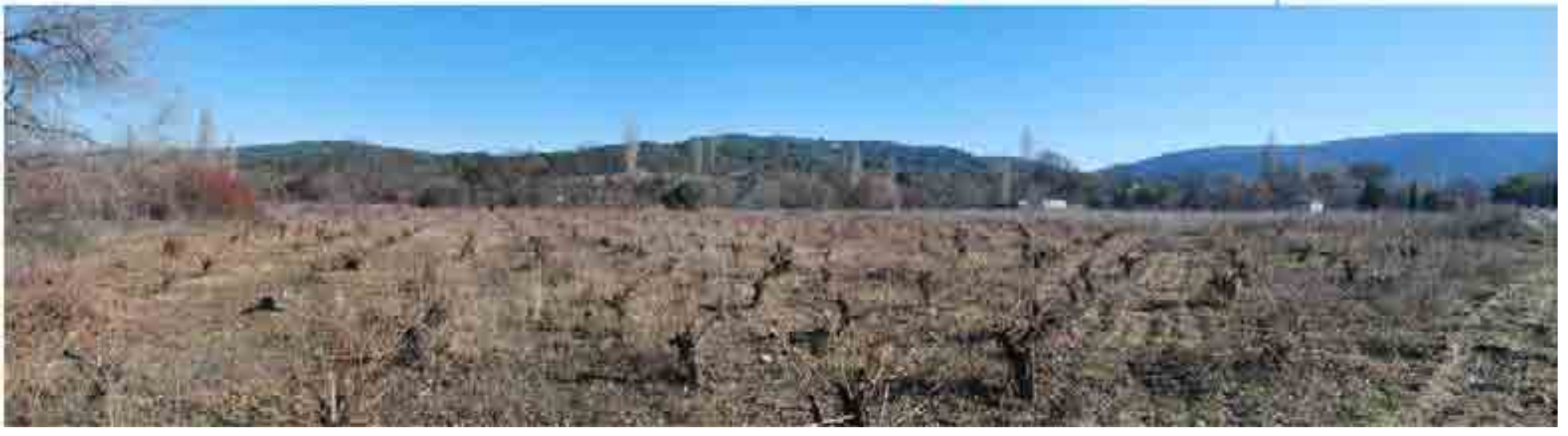




\begin{tabular}{|c|c|c|c|}
\hline \multicolumn{4}{|c|}{ UP A25 - ROZAS DE PUERTO REAL } \\
\hline \multirow{2}{*}{\multicolumn{2}{|c|}{ EVALUACIÓN DE LA CALIDAD DEL PAISAJE VISUAL }} & \multicolumn{2}{|c|}{ PERCEPCIÓN DEL VALOR ECOLÓGICO-ESTÉTICO (EVALUACIÓN LOCAL) } \\
\hline & & CONSIDERACIÓN ESTÉTICA & CONSIDERACIÓN ECOLÓGICA \\
\hline \multicolumn{2}{|c|}{ MUY ALTA } & MAYOR & \multirow{3}{*}{$\begin{array}{c}\text { MAYOR } \\
\text { +BIODIVERSIDAD, SINGULARIDAD } \\
\text { +CUIDADO, BUENA GESTIÓN, BUEN ESTADO DE } \\
\text { CONSERVACIÓN }\end{array}$} \\
\hline FISIOGRAFÍA & \multirow[b]{2}{*}{ Ito - Muy alto } & \multirow{2}{*}{$\begin{array}{l}\text { +VARIEDAD, SINGULARIDAD } \\
\text { +BELLEZA ESCÉNICA }\end{array}$} & \\
\hline VEGETACIÓN/USOS & & & \\
\hline AGUA SUPERFICIAL & Bajo & $\begin{array}{l}\text { +SENSACIÓN DE FRESCOR/HUMEDAD } \\
\text { +PRODUCTIVIDAD/VIGOR (asociado a humedad) }\end{array}$ & $\begin{array}{l}\text { +PRODUCTIVIDAD/VIGOR } \\
\text { (asociado a humedad) }\end{array}$ \\
\hline INCIDENCIA ANTRÓPICA & a artificialidad & +CARÁCTER AGRESTE & +NATURALIDAD \\
\hline VARIACIÓN ALTITUDINAL & \multicolumn{3}{|l|}{ Alto } \\
\hline $\begin{array}{r}\text { SINGULARIDAD Y RAREZA } \\
\text { (Valores naturales con } \\
\text { atractivo visual) }\end{array}$ & $\begin{array}{l}\text { Alto } \\
\text { iar de Las Rozas }\end{array}$ & $\begin{array}{c}\text { +COLORIDO, VARIEDAD, SINGULARIDAD } \\
\text { +BELLEZA ESCÉNICA } \\
\text { +BUEN ESTADO DE CONSERVACIÓN }\end{array}$ & $\begin{array}{c}\text { +BIODIVERSIDAD, SINGULARIDAD } \\
\text { +NATURALIDAD, ARBOLADO DESARROLLADO } \\
\text { +BUEN ESTADO CONSERVACIÓN, FAUNA PROTEGIDA }\end{array}$ \\
\hline $\begin{array}{r}\text { VISTAS PANORÁMICAS } \\
\text { (Fondo visual y Elevaciones } \\
\text { singulares) }\end{array}$ & Medio & + PANORÁMICA & \\
\hline \multicolumn{4}{|c|}{ CONCLUSIONES DE LA COMPARACIÓN ECOLOGÍA-ESTÉTICA } \\
\hline IMPORTANCIA PARA LA CONSERVACIÓN & \multicolumn{3}{|c|}{$\begin{array}{l}\text { Bosque submediterráneo maduro y continuo combinado con ecosistema de cumbre y fondo de valle con mosaico extensivo de cultivos y prados. Bosque de } \\
\text { ribera. Unidad con pocas perturbaciones humanas. Algunos enclave ostentan un valor ecológico máximo y albergan especies de fauna singular }\end{array}$} \\
\hline RASGOS QUE APORTAN CALIDAD ESCÉNICA & \multicolumn{3}{|c|}{$\begin{array}{l}\text { Fondo de valle con pastos mesofíticos y laderas ocupadas por bosques densos de castaños y melojos, que culminan en cumbres y presencia de escarpes } \\
\text { La cubierta boscosa recibe una valoración especialmente alta por su continuidad y la cualidad de cambio estacional del color del follaje ( Castañar de Las Rozas) }\end{array}$} \\
\hline RASGOS QUE NO APORTAN CALIDAD ESCÉNICA & \multicolumn{3}{|c|}{ 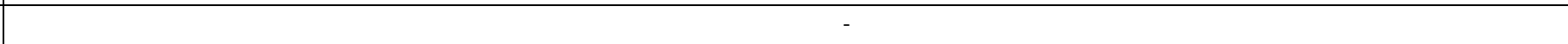 } \\
\hline PERCEPCIÓN DEL VALOR EC & \multicolumn{3}{|c|}{$\begin{array}{l}\text { Los valores ecológicos y estéticos se perciben como asociados: se valora como un espacio de GRAN VALOR EN AMBOS ASPECTO, SINGULAR por su carácter } \\
\text { que contrasta con el resto del área } \\
\text { El carácter más húmedo y un mayor aprovechamiento/mantenimiento lleva a la percepción de un PAISAJE CUIDADO, DE CARÁCTER TRADICIONAL, BIEN } \\
\text { GESTIONADO Y CON VIGOR. El espacio forestal se percibe como rico ecológicamente y bien gestionado } \\
\text { Destacan las áreas del Castañar de Rozas y laderas de Pedro Duermes (Sierra Gredos) } \\
\text { Ecológicamente se destaca la BIODIVERSIDAD, BUEN ESTADO DE CONSERVACIÓN, GESTIÓN ADECUADA Y VIGOR DEL ECOSISTEMA } \\
\text { Transmite una imagen de BELLEZA ESCÉNICA, un área variada y bien conservada/mantenida, con vigor, un espacio que aporta frescor y variedad al paisaje }\end{array}$} \\
\hline \multicolumn{4}{|c|}{$\begin{array}{l}\text { DIRECTRICES DE ACTUACIÓN: } \\
\text { CONSERVACIÓN/MANTENIMIENTO: mantenimiento del aprovechamiento actual (ESTÉTICA DEL CUIDADO) /GESTIÓN ECOLÓGICO-ESTÉTICA DE LA FAUNA SINGULAR } \\
\text { Especial atención a proliferación de urbanizaciones que afectarían mucho a sus cualidades }\end{array}$} \\
\hline
\end{tabular}




\section{UP A25 - ROZAS DE PUERTO REAL (Cont.)}
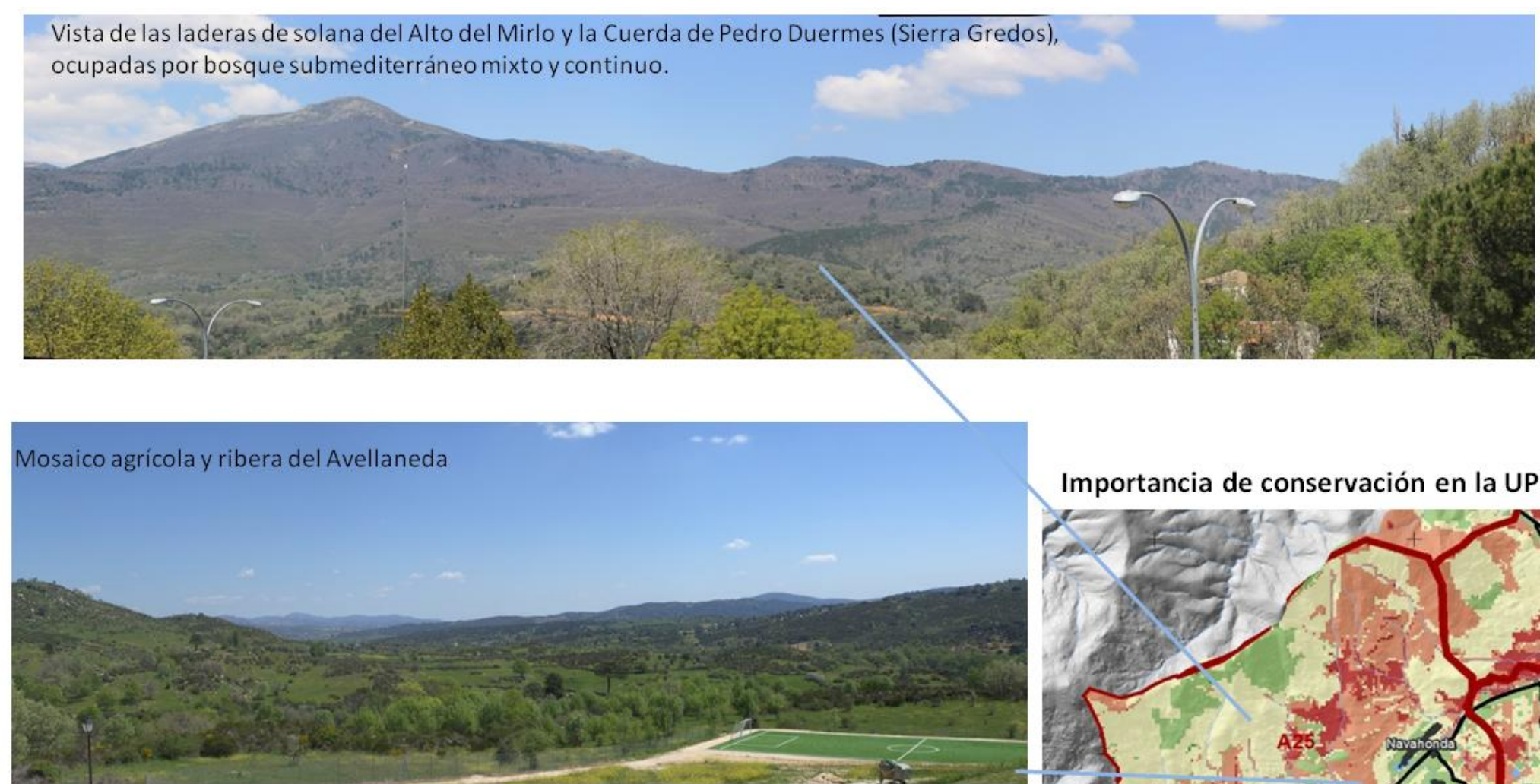

Importancia de conservación en la UP
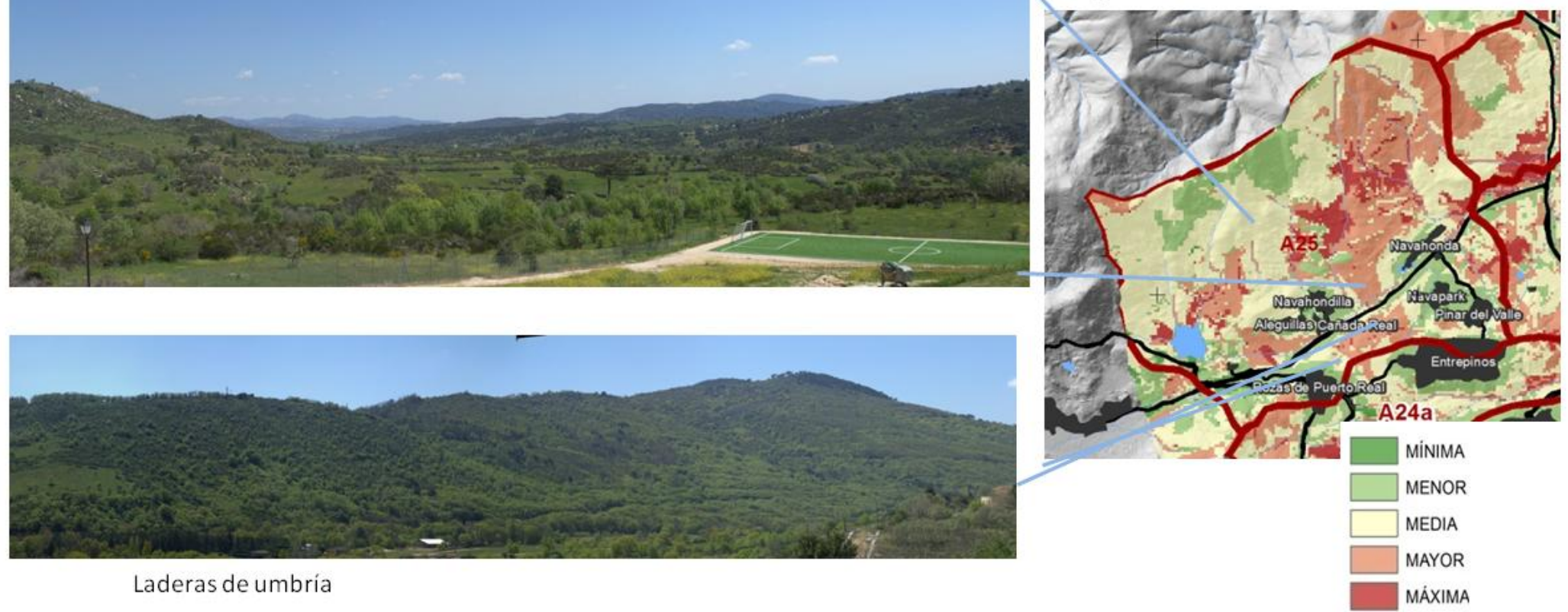

Laderas de umbría 


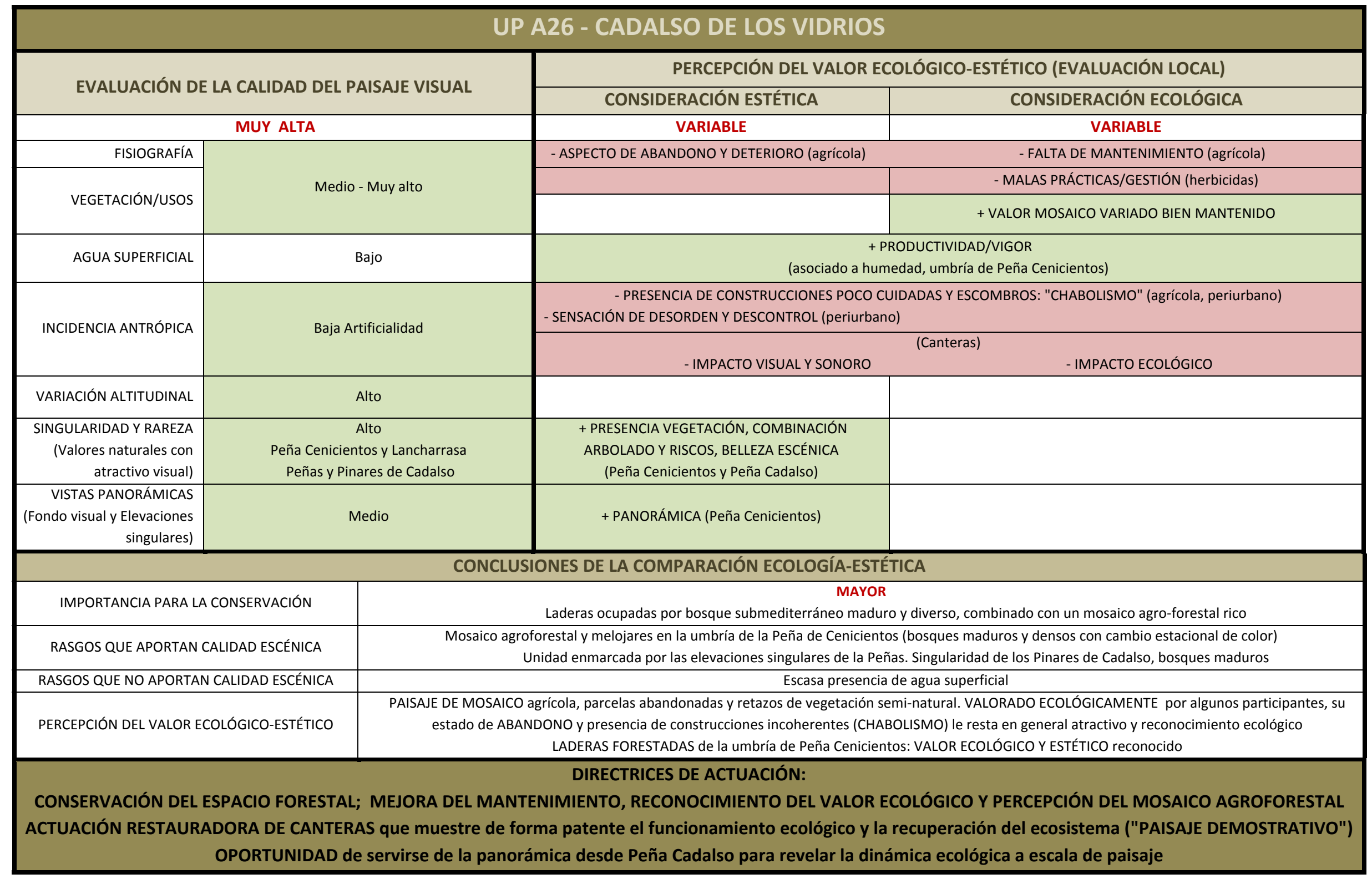


UP A26 - CADALSO DE LOS VIDRIOS (Cont.)

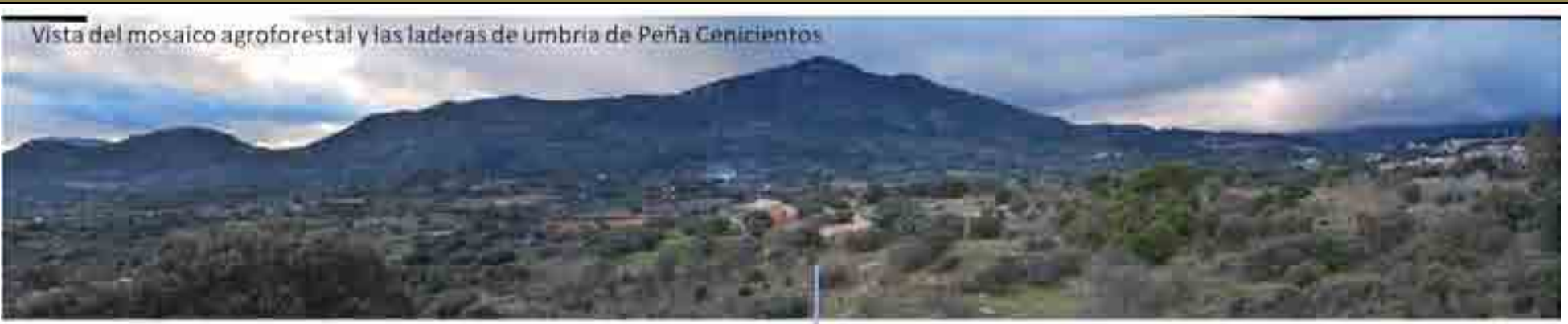

Ejemplo áreas agricolas no mantenidas

Importancia ecológica en la UP
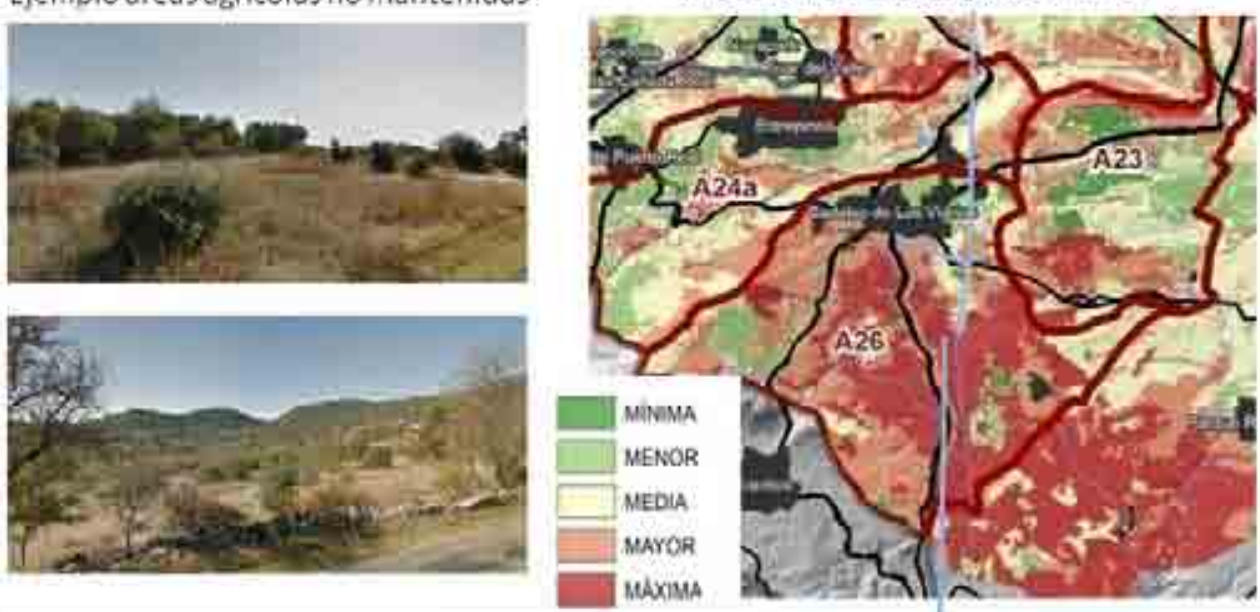

Elemplo de instalacionesque sugieren falta de cuidado
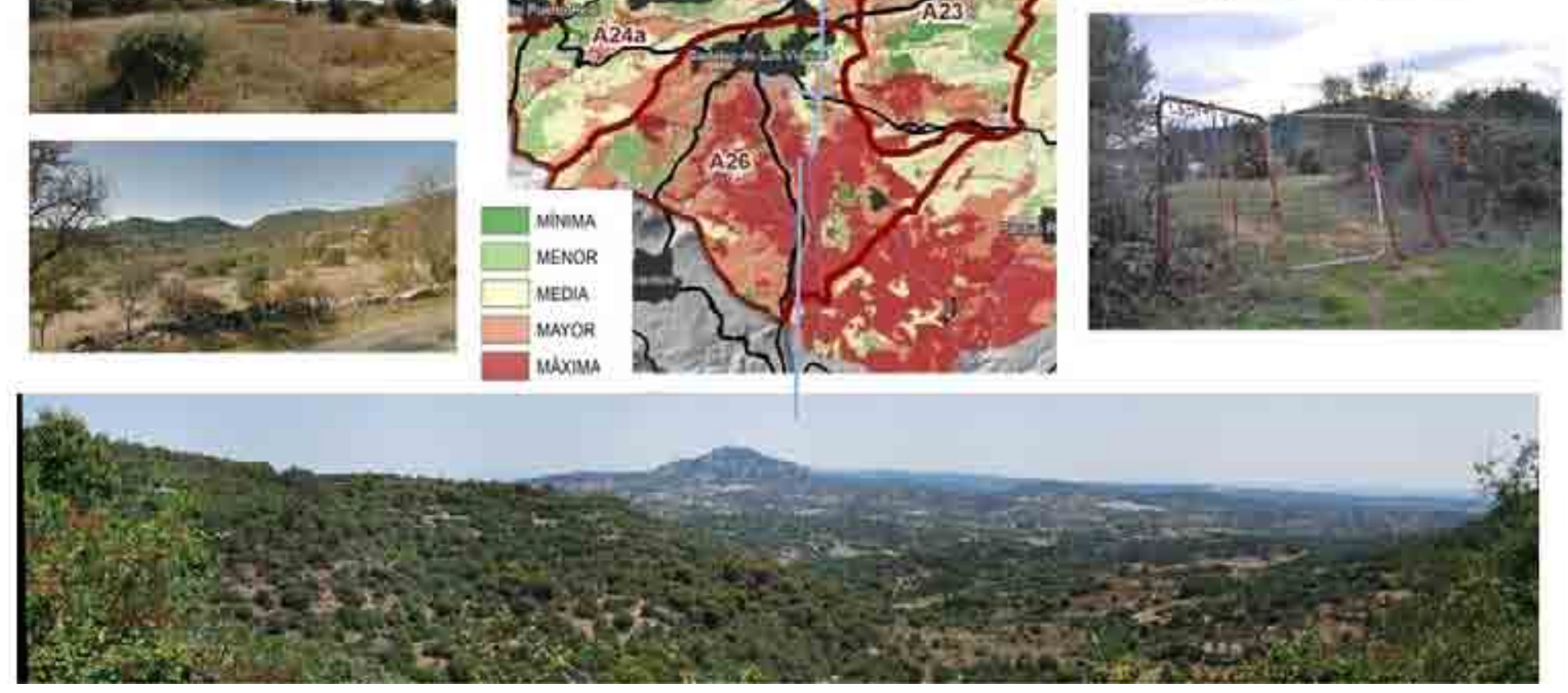
CAPÍTULO VII. APLICACIÓN A UN CASO DE ESTUDIO: PLANIFICACIÓN ECOLÓGICO-ESTÉTICA DEL PAISAJE EN LA SIERRA OESTE DE MADRID 


\section{CAPÍTULO VIII. DISCUSIÓN GENERAL}




\section{CAPÍTULO DISCUSIÓN GENERAL}

Derivado de la revisión de los antecedentes en el tratamiento de la componente ecológica y estética del paisaje surge la constatación de dos hechos: que el enfoque de la denominada "estética ecológica" resulta un paradigma relevante que ofrece la oportunidad de alcanzar un mejor tratamiento del paisaje, y que existe una insuficiencia a la hora de incorporar sus postulados en la investigación y la práctica.

La denominada "estética ecológica" surgió como una corriente que recoge la preocupación ante la manera en la que la apreciación dominante de lo natural puede afectar al funcionamiento ecológico del paisaje y se funda sobre una estrategia que se sirve de la estética del paisaje para dirigir la evolución del mismo. Atiende así la necesidad de ampliar el alcance y posibilidades de la estética del paisaje para incorporar de forma efectiva ideas o mensajes sobre los procesos ecológicos. El argumento base de esta tesis recorre este camino. De tal manera, la perspectiva de exploración de la relación entre ecología y estética en el paisaje se hace desde el punto de vista de valores que están interrelacionados, esto es, se centra en el hecho interpretativo estético que deriva de la percepción de las características ecológicas que se dan en el paisaje, que condiciona la manera de percibir y valorar la misma dimensión ecológica y, finalmente, puede llegar a determinar la misma condición ecológica del paisaje. Tal y como se pone de manifiesto en la revisión de los antecedentes, esta perspectiva todavía no está bien desarrollada, fundamentalmente en lo referente a la práctica de planificación y gestión del paisaje a escala territorial.

El principal valor de esta tesis reside pues en la lógica que encierra su indagación sobre la relación entre ecología y estética. No se trata de evaluar ambas dimensiones de forma independiente, comparar los resultados derivados de la aplicación de modelos más o menos sofisticados, y llegar a un tratamiento del paisaje que compatibilice ambos valores. Se trata de indagar y comprender las razones profundas que definen una determinada forma de percibir y valorar la realidad ecológica de un paisaje e incorporarlo a la manera de intervenir en él para mejorar esa dimensión ecológica. Lo buscado es el reforzamiento del valor ecológico a través de la sinergia que puede establecerse a partir de su interpretación estética. 
Los resultados alcanzados se refieren fundamentalmente a dos ámbitos del tratamiento de la relación entre ecología, percepción y estética en el paisaje:

- Investigación de los mecanismos que rigen la percepción humana de las características y procesos ecológicos que se dan en el paisaje.

- Desarrollo metodológico para la consecución de un modelo de planificación del paisaje que incorpore este tipo de percepción y trate de forma más específica las conexiones entre los valores estéticos y ecológicos.

INVESTIGACIÓN DE LOS MECANISMOS QUE RIGEN LA PERCEPCIÓN HUMANA DE LAS CARACTERÍSTICAS Y PROCESOS ECOLÓGICOS QUE SE DAN EN EL PAISAJE

Con respecto al primero de los ámbitos de investigación, la contribución de la tesis incluye tanto el aspecto procedimental, como el de ampliación del conocimiento sobre como es interpretado estéticamente el factor ecológico del paisaje.

\section{Metodología de análisis de las percepciones ecológico-estéticas}

El enfoque de análisis de las percepciones propuesto contribuye al desarrollo metodológico para poder captar de forma más relevante la interpretación estética de la componente ecológica. La propuesta metodológica posee una serie de fortalezas que la posicionan como un método robusto y eficaz para llegar a comprender la interacción de estos valores y perfilar las percepciones y actitudes del ser humano ante el paisaje, hecho constatado en los resultados de las 2 aplicaciones prácticas en distintos contextos paisajísticos: caso de la Cuenca Alta del río Iregua-Sierra Cebollera (La Rioja) y de la Sierra Oeste (Madrid).

Así, el método cualitativo basado en entrevistas en profundidad, propio de la investigación social, ha sido aplicado para analizar la percepción ante el paisaje (ver Capítulo V.1). De estos análisis frecuentemente se han derivado conclusiones sobre la interacción entre ecología y estética, aunque en general ha correspondido más a una cuestión complementaria o a una indagación parcial. La propuesta de análisis de la percepción, propuesta en el Capítulo V y aplicada también en el Capítulo VII, enfoca sin embargo de manera específica dicha relación entre estética y ecología, y lo hace además 
adoptando como objeto central de atención la interdependencia y condicionamiento entre ambos valores. Los resultados muestran que el diseño de la investigación cualitativa que atiende exclusivamente a la dimensión estética y ecológica permite conocer y comprender con detalle el mismo. Es este el primer paso para poder proponer actuaciones de calado.

Se constata de igual manera que la incorporación de la perspectiva de la Teoría del Lugar de Canter en el marco teórico y procedimental resulta clave para alcanzar los resultados requeridos. La estructuración de la consulta y análisis alrededor del modelo de los 3 componentes que entran a formar parte fundamental de la percepción del paisaje (concepciones-sentido, actividades-función y atributos físicos-forma) permitió dirigir la indagación específicamente hacia el ámbito de la interacción ecología-estética, hacer aflorar la interpretación del entrevistado de ambos aspectos y poder ligar los sistemas conceptuales albergados con el entorno físico. En este sentido, el uso de un mapa en el que el entrevistado debía hacer el esfuerzo de buscar y concretar geográficamente su discusión resultó igualmente esencial para reforzar esa vinculación entre la idea y la realidad física del paisaje. Esta última cuestión es de vital importancia y gran utilidad, pues las características físicas y el patrón del paisaje son la materia fundamental que trata la planificación y que modifica la gestión y diseño del paisaje dirigidos por aquella (Fry et al., 2009). De tal manera, la metodología aplicada en el Capítulo V y VII.4.3 permite llegar a unos resultados que, a la vez que constatan la existencia de una cierta relación o condicionamiento entre ambas dimensiones, informan o describen cómo es esa relación, y además lo hace de tal forma que pueden ser aplicables a un contexto de decisión sobre el paisaje.

Otra fortaleza del método reside en que permite realizar un análisis en profundidad del fenómeno en estudio, de tal manera que habilita para examinar en profundidad las causas y circunstancias que rodean al hecho interpretativo. Es posible así captar una amplia gama de matices y relaciones entre ambas dimensiones. Este es un objetivo de gran interés cuando se trata de comprender un fenómeno subjetivo tan complejo. Los resultados obtenidos así lo evidencian. Por otro lado, el enfoque de entrevista abierta y conducida por el entrevistado (user-led interview) permite escapar del condicionamiento impuesto por una selección a priori por parte del investigador de los temas o características a tratar y hacerlos emerger de forma inductiva de los propios entrevistados.

Existe a este respecto una variable no introducida en el análisis que se revela como significativa a la hora de tomar decisiones sobre el paisaje y que tiene que ver con el diagnóstico de la escala de valores

Canter, D. (1977). The psychology of place. Londres, UK: Architectural Press.
Fry, G., Tveit, M. S., Ode, A., y Velarde, M. D. (2009). The ecology of visual landscapes: Exploring the conceptual common ground of visual and ecological landscape indicators. Ecological Indicators, 9(5), 933947. 
Daniel, T. C. y Vining, J. (1983) Methodological Issues in the Assessment of Landscape Quality. En I. Altman y J. F. Wohlwil (Eds.), Behavior and the Natura Environment (pp. 39-84). Nueva York, NY: Springer US

Carlson, A. (1977) On the possibility of quantifying scenic beauty. Landscape Planning, 4, 131-172 del entrevistado. Efectivamente, los entrevistados identifican una serie de cuestiones que son relevantes en su evaluación de la relación entre estética y ecología, pero cabría preguntarse por la importancia que atribuyen a esas cuestiones con respecto a otros valores o necesidades, y la prevalencia que asignan al valor ecológico frente al estético y viceversa. Por ejemplo, un entrevistado está hablando a través de su escala de valores cuando afirma "Para mí el tema de los incendios forestales es importantísimo. Si tiene que haber muchos cortafuegos que no sean muy monos, pero si con eso logramos parar el fuego, lo prefiero". Esta cuestión se encuentra insuficientemente dirimida en el desarrollo metodológico y los resultados presentados. Dado que los recursos económicos para actuar en el paisaje son escasos, la introducción de este diagnóstico se revela esencial.

La principal limitación del método emana de la misma naturaleza del procedimiento cualitativo y estriba en la representatividad de sus resultados. Es decir, y aplicado al caso concreto que se trata, dado que el método se basa en la realización de entrevistas en profundidad para el análisis en detalle del fenómeno, el número de entrevistados no puede ser alto, por lo que, en aras de conseguir una mayor validez, sensibilidad y utilidad de los resultados, características señaladas por Daniel y Vining (1983) como esenciales para que la evaluación del paisaje sea adecuada y efectiva, se resiente la representatividad. El resultado derivado de esta perspectiva no puede por tanto entenderse como un resultado final, sino más bien como un punto de partida, oportuno precisamente porque su validez, sensibilidad y utilidad están aseguradas. El objetivo que se pretendía con el enfoque metodológico adoptado era el de obtener una información rica y significativa sobre el fenómeno de la interpretación estética de la componente ecológica del paisaje, que pudiera asistir en la comprensión profunda del mismo. En este sentido, los resultados son consistentes, pues permiten identificar los ámbitos principales en los que se produce esa relación entre ecología y estética, ámbitos relevantes y que son examinados concienzudamente para delimitar sus matices. Dichos ámbitos de partida pueden ser examinados posteriormente en busca de la representatividad aplicando otro tipo de métodos. Estos métodos pueden ser de naturaleza cuantitativa, por ejemplo, realizando una encuesta masiva basada en la evaluación de los aspectos surgidos, utilizando preguntas más cerradas o un listado de opciones. O bien pueden servir como punto de partida en un proceso participativo con agentes clave, de manera que se confronten las percepciones. En este proceso, resulta conveniente introducir la figura de un experto que, a modo de intermediario o "facilitador" -el "environmental critic" enunciado por Carlson (1977)-, relacione los agentes participantes en la transformación del paisaje y guíe de manera informada y sensible el proceso de definición de actuaciones de gestión y transformación del paisaje. 


\section{Resultados obtenidos de la investigación empírica}

En lo que tiene que ver con los resultados concretos obtenidos en las dos investigaciones empíricas sobre percepción llevadas a cabo, las conclusiones derivadas permiten avanzar en la comprensión de cómo el ser humano (un determinado grupo social) percibe, aprecia e interpreta estéticamente la componente ecológica del paisaje, cómo relaciona ambas dimensiones y cómo dicho proceso determina una actitud ante lo percibido que indica la conveniencia de ciertas estrategias de actuación en el paisaje.

En realidad, muchos de los resultados derivados de ambas investigaciones analizadas de manera independiente no presenta un carácter estrictamente novedoso, sino que validan percepciones ya identificadas en estudios empíricos precedentes, o estructuradas y descritas en teorías anteriormente desarrolladas. Aún así, el hecho de identificar este tipo de percepciones como presentes en un caso de estudio y definir las motivaciones y circunstancias que subyacen bajo esa percepción es ya de por sí una aportación valiosa. Sin embargo, el potencial exploratorio de los resultados reside sobre todo en la posibilidad que ofrecen de entender cómo el contexto en el que se dan determinadas percepciones define el tipo de relación entre ecología y estética, asunto clave para avanzar en la investigación sobre la estética ecológica. El referido contexto incluye tanto la situación personal del observador, como el tipo de paisaje en el que se produce el proceso, es decir, las características socio-culturales e intereses que rodean al individuo, y el carácter y cualidades específicas del paisaje en el que está inmerso (Gobster et al., 2007).

Gobster, P. H., Nassauer, J. I., Daniel, T. C., y Fry, G. (2007). The shared landscape: what does aesthetics have to do with ecology? Landscape Ecology, 22(7), 959-972.

La investigación se concentró en dos grupos sociales con características y circunstancias diferentes: la población que vive y aprovecha los recursos del paisaje, y los técnicos que poseen un conocimiento formal sobre medio natural y toman decisiones sobre su gestión. Ambos grupos tienen una importancia estratégica con respecto a la planificación del paisaje, pues son dos de los agentes que más directa y mayor incidencia ejercen sobre él. En ambos casos, pero sobre todo en el de los técnicos, no han sido sin embargo el objeto de estudio preferente de la investigación sobre percepción del paisaje. Los resultados obtenidos permiten constatar la existencia de ciertas tendencias estéticas en ambos grupos, con un potencial efecto sobre el paisaje ecológico.

Especial relevancia revierte el haber examinado la percepción de estos agentes en dos tipos de paisaje diferenciados: un paisaje montañoso y forestal, con carácter fundamentalmente natural, sujeto a un proceso de despoblación y gestionado con un objetivo primordial de conservación (Cuenca alta del Iregua-Sierra Cebollera, La Rioja); y otro 
paisaje de carácter agroforestal, con efectivos poblacionales más numerosos y más estables, sujeto por tanto a mayor presión humana, y con un enfoque de gestión diferente (Sierra Oeste, Madrid). La discusión sobre los resultados obtenidos arroja una serie de conclusiones respecto a la correspondencia y divergencia entre ambas dimensiones, la ecológica y la estética, y respecto a los efectos del contexto paisajístico y situacional en el proceso. Dichas conclusiones contribuyen a esclarecer el debate sobre la relación de la estética, la ecología y la sostenibilidad en el paisaje.

En este sentido, la investigación muestra cómo los técnicos o participantes con conocimiento formal sobre medio natural $y$ experiencia en su gestión comparten determinadas percepciones y actitudes con la población local que no cuenta con ese tipo de conocimiento, al igual que albergan determinadas diferencias. Según sugieren los resultados en ambas investigaciones empíricas, el patrón de coherencias y divergencias viene definido, o al menos matizado, según el tipo de paisaje de que se trate.

Así, en el caso de estudio de Sierra Cebollera (La Rioja), un paisaje de carácter predominantemente forestal y natural, la consideración de la naturalidad, su percepción en el paisaje y su vinculación a los valores ecológicos fue claramente destacada por los técnicos y diferenciada entre ambos grupos. Mientras que la población local interpretó las cualidades del paisaje desde la perspectiva de su continuidad cultural en el mismo, los técnicos la interpretaron predominantemente en términos de valor natural y de conservación. Dicha interpretación se funda en una distinta concepción o expectativas sobre la función y usos del paisaje (paisaje como reserva natural/paisaje como escenario y medio de vida), que conduce a cada grupo a percibir diferentes cualidades ecológicas y estéticas (naturalidad/rasgos sociales en el paisaje natural).

Este papel de la naturalidad percibida no siguió el mismo patrón en el caso del paisaje de la comarca de Sierra Oeste de Madrid. Dicho paisaje, de carácter agroforestal, en el que la acción humana es mucho más patente y es entendida como una parte consustancial al mismo, la naturalidad no fue tan evidenciada, y la percepción de los técnicos y no técnicos se aproximó, poniendo de relieve fundamentalmente la conveniencia de la continuidad del uso y modificación (sostenible) del paisaje, conveniencia que redunda en ambos aspectos, el estético y el ecológico. La constatación en el paisaje del proceso de abandono de usos y aprovechamientos agroforestales, la percepción de las consecuencias de la pérdida de la incidencia del gestor tradicional, fue de hecho una de las condiciones del paisaje más patentes en el caso del paisaje de la Sierra Oeste, 
mientras que en el paisaje de carácter más natural de la Sierra Cebollera riojana este proceso fue menos reconocido por los técnicos.

Una de las percepciones compartidas entre grupos sociales y contextos paisajístico fue la relacionada con lo notorio del cuidado del paisaje y la correspondiente interpretación en clave de atractivo y adecuación de las condiciones ecológicas. La expectativa de encontrar un paisaje activa y cuidadosamente gestionado/intervenido, y de que esa condición fuera manifiesta, fue generalmente compartida, si bien en ocasiones los atributos que connotaban dicho cuidado del paisaje correspondieron a distintas situaciones, características o causas. Es decir, los participantes compartían el objetivo final de gestión cuidadosa del paisaje, pero no tanto la identificación de rasgos que proyectaran esa idea, ni la forma para su consecución. Este resultado es especialmente relevante, pues confirma cómo la estrategia de gestión e intervención en el paisaje fundada en la expresión del cuidado (Teoría de la Estética del Cuidado - Aesthetic of care, Nassauer, 1995a) presenta un gran potencial y solidez por su reconocimiento social. Es necesario, sin embargo, investigar con mayor profundidad en qué elementos concretos se percibe y a qué causas se atribuye para poder formular una propuesta de intervención en el paisaje más detallada.

Con respecto a este tema, un resultado interesante es el de la constatación de que la percepción de la intervención cuidadosa fue relevante incluso en un paisaje predominantemente natural como el riojano. En los modelos de planificación, la experiencia estética en este tipo de contextos se relaciona primordialmente con sus propiedades escénicas y grado de naturalidad, mientras que se tiende a asociar la percepción del cuidado con paisajes que muestran una influencia humana más obvia (Gobster et al., 2007; Nassauer, 1992). La investigación llevada a cabo en la Sierra Cebollera sugiere que este factor puede tener también una repercusión importante en la manera en que los paisajes más naturales son percibidos y experimentados y que, por tanto, el papel de los rasgos físicos que revelan esta condición merecen consideración en la planificación ecológicopaisajística de estos espacios. Este fenómeno resulta, además, un ámbito de investigación poco explorado a la vez que prometedor por su potencial repercusión práctica.

En todo caso, la evaluación de la intención y buen hacer del gestor a cargo del paisaje formó parte fundamental en la manera de interpretar la ecología y la estética en ambos paisajes. De tal manera, los resultados obtenidos constatan la hipótesis lanzada por la Teoría de la Administración Visible (Visible Stewardship, Sheppard, 2001), es decir, los usuarios de un paisaje esperan percibir signos evidentes de que el gestor aprecia y respeta el mismo, se preocupa por que
Nassauer, J. I. (1995a). Culture and changing landscape structure. Landscape Ecology, 10(4), 229-237.
Gobster, P. H., Nassauer, J. I., Daniel, T. C., y Fry, G. (2007) The shared landscape: what does aesthetics have to do with ecology? Landscape Ecology, 22(7), 959-972

Nassauer, J. I. (1992).

The appearance of ecological systems as a matter of policy. Landscape Ecology, 6(4), 239250.

Sheppard. (2001)

Beyond Visual Resource

Management : Emerging Theories of an Ecological Aesthetic and Visible Stewardship. En S. R. J. Sheppard y H. W. Harshaw (Eds.), Forests and Landscapes: Linking Ecology, Sustainablility, and Aesthetics (pp. 149-173). New York: CABI Publishing - IUFRO. 
conserve sus valores y actúa en consecuencia. Esta expectativa hace que el atractivo y estado ecológico del mismo sea juzgado en términos de cómo actúa el gestor. Este fenómeno, relacionado con la percepción del cuidado y que se presenta, de la misma manera que aquel, tanto en el tipo de paisaje más intervenido como en el más natural, se erige igualmente como una estrategia de planificación e intervención relevante.

Es importante destacar que los resultados en ambas investigaciones muestran la prevalencia de la evaluación hecha sobre la actuación de la administración pública, erigida de esta manera como uno de los agentes con mayor importancia y más sujeto al escrutinio del observador del paisaje. En este caso, las diferencias entre contextos paisajísticos son considerables y tienen mucha significación en la práctica. En el caso de la Sierra Oeste madrileña, la percepción de degradación del paisaje no se orientó tanto a la percepción de actuaciones impactantes, sino a la falta de evidencia de la actuación del gestor público, juzgado como ausente, no interesado y no bienintencionado. En el caso de la Sierra Cebollera riojana, el interés del gestor público no fue reprobado por parte de la población local, si bien se evaluó negativamente el destino y condiciones hacia las que las decisiones técnico-políticas conducían al paisaje, pues se entendía que el espacio se valoraba más como una reserva ecológica y escenográfica que como un paisaje habitado.

Este hecho pone de relieve la oportunidad que ofrecen las divergencias y convergencias detectadas en el estudio sobre la interpretación estética de la ecología en el paisaje. La conservación y gestión de los valores de un paisaje es, o debería ser, una responsabilidad compartida entre la población local y las instituciones públicas, entre otros. Consecuentemente, para alcanzar una mejora en las condiciones ecológico-estéticas del paisaje, las decisiones de intervención deberían aprovechar la oportunidad que les ofrece las sinergias que se establecen entre la percepción de ambos agentes y tratar de resolver los conflictos surgidos.

Por último, resulta relevante destacar una percepción muy específica y con mucha repercusión en el paisaje agroforestal de la Sierra de Madrid: la relacionada con la incidencia de los incendios forestales. Sus efectos (pérdida de cubierta arbórea y falta de vigor del ecosistema), y también la apariencia del paisaje que proyecta un estado de alto riesgo de sufrir un incendio (masas forestales continuas, densas, con presencia de mucho matorral, faltas de intervenciones selvícolas) tuvo mucha repercusión en la evaluación negativa del paisaje de la comarca, tanto en el plano ecológico, como en el estético. Dicha condición del paisaje se muestra efectivamente muy patente y resultó muy notoria para los entrevistados. Se erigió 
pues como un ámbito de actuación preferente para gestionar el paisaje de manera que se pueda establecer una sinergia entre las condiciones ecológicas y su interpretación estética.

PROPUESTA METODOLÓGICA DE UN MODELO DE PLANIFICACIÓN DEL PAISAJE QUE INCORPORE DE FORMA MÁS ESPECÍFICA LAS CONEXIONES ENTRE LOS VALORES ESTÉTICOS Y ECOLÓGICOS.

La propuesta metodológica de planificación ecológico-estética del paisaje no sigue la lógica de aplicación de dos modelos independientes, uno ecológico y otro visual, de cuya comparación surgen directrices de tratamiento del paisaje. Este ámbito ya ha sido explorado anteriormente y se han definido modelos eficaces en este sentido (ver Capítulo IV). El modelo de planificación del paisaje planteado resulta innovador en el sentido de que busca decantar sobre el proceso de toma de decisiones el fenómeno subjetivo de la interpretación estética de la dimensión ecológica que se percibe en el paisaje. La oportunidad de esta perspectiva reside en incorporar la escala de percepción y dar como resultado un diagnóstico que tiene en cuenta un proceso social que, aunque indirecta y sutilmente, influye en el estado ecológico del paisaje y en su conservación a través de la interpretación estética. Permite pues diagnosticar de manera más relevante las dinámicas a las que está sometido el paisaje y proponer directrices de tratamiento ecológico y visual del paisaje más efectivas, que pueden concebirse para que tengan un efecto más allá de la impresión de belleza o la estética formal.

Los resultados derivados de la aplicación del modelo al caso de estudio del paisaje agro-forestal de la Sierra Oeste de Madrid (Capítulo VII) poseen una utilidad clara para indicar deficiencias de tratamiento del territorio tanto en un ámbito como en otro (orientar acciones de conservación sensibles con su resultado estético o, recíprocamente, orientar actuaciones de tratamiento del paisaje que redunden en un mayor beneficio ecológico), servir como una referencia en procesos de evaluación de impacto ambiental, marcar pautas o aspectos a incorporar en las soluciones de diseño en el paisaje o, en fin, contribuir al desarrollo ordenado y sostenible del territorio.

La metodología, sin embargo, presenta una serie de ámbitos de mejora que se indican a continuación:

- Mejora del modelo de evaluación ecológica de manera que sea más integral y sus resultados se liguen más a los ámbitos de apreciación estética de la ecología identificados. 
Coppolillo, P., Gomez, H., Maisels,

F., y Wallace, R. (2004)

Selection criteria for suites of landscape species as a basis for site-based conservation. Biological Conservation, 115(3), $419-430$
El modelo considera únicamente uno de los aspectos del complejo sistema de relaciones que se da en el paisaje (la importancia del paisaje para la conservación de la fauna salvaje), y por tanto representa un análisis parcial de la importancia ecológica de sus componentes. A efectos demostrativos resulta efectivo para ilustrar la manera en la que la apreciación estética del paisaje puede reforzar o debilitar un valor ecológico. Las evaluaciones del paisaje para la conservación deben atender a dos cuestiones fundamentales: dónde aplicar las medidas de conservación y cómo hacerlo (Coppolillo, Gomez, Maisels, y Wallace, 2004). Es precisamente en el cómo hacerlo donde la metodología incorpora el factor de la estética del paisaje. Ahora bien, para que el diagnóstico del impacto ecológico de la interpretación estética resultara más relevante, sería necesario obtener una evaluación más completa y significativa del funcionamiento ecológico del paisaje. Dicha evaluación habría de considerar específicamente cada uno de los procesos o componentes puestos de relieve por el modelo de evaluación de la percepción (Capítulo VII.5) y delimitar su peso y papel en el ecosistema analizado de forma integral, evaluando su importancia o significación en el conjunto.

Por otro lado, una de las variables no incluidas en el modelo de planificación es el de considerar la notoriedad de los procesos y cualidades ecológicas. El modelo identifica una serie de cuestiones percibidas, pero ¿qué pasa con aquellas características ecológicas existentes que no fueron advertidas? Si un determinado valor o desajuste ecológico pasa desapercibido cabría preguntarse si esto ocurre porque esa característica no se muestra especialmente perceptible en el paisaje, o sí se muestra pero no se repara en ella. La estrategia de actuación cambia si nos encontramos en una u otra situación.

- Reforzar la representatividad de los resultados del estudio de percepción.

Como ya se ha comentado, si bien la información derivada del modelo de indagación sobre la percepción es efectiva en indicar los ámbitos en los que la interacción entre ecología y estética posibilita prescribir intervenciones para un reforzamiento de valores, sería conveniente asegurar la representatividad de sus resultados y definir con más detalle el patrón de percepción. Este objetivo pasaría por realizar una segunda fase en la que dicha representatividad se alcanzara por métodos cuantitativos. 
- Alcanzar una mayor definición geográfica de las características físicas del paisaje y detalle de las actuaciones.

La planificación es una actividad centrada en la relación entre el saber científico y técnico, y la acción. No cabe planificación sin acción territorial, práctica (Puig i Baguer, 1995, Ndubisi, 2002). Una de las causas por las que en numerosas ocasiones se han desdeñado los resultados prescriptivos del proceso planificador se debe a su falta de concreción y medidas explícitas, más allá de meras recomendaciones o directrices (Makhzoumi y Pungetti, 1999; Termorshuizen, Opdam, y van den Brink, 2007). En este sentido, el modelo de planificación propuesto habría de mejorar el nivel de concreción de las medidas propuestas para que alcancen un nivel operativo. Para ello, resultaría fundamental que los valores y atributos implicados sean suficientemente detallados física y geográficamente, pues dicha concreción permitiría orientar de forma más eficaz las propuestas y servirá como catalizador del proceso posterior de definición de soluciones de diseño (Encinas, 2000).

En todo caso, y poniendo en perspectiva el proceso de planificación del paisaje en un contexto práctico, la utilidad de una metodología de planificación reside en último término en la cantidad de recursos que demande (tiempo, recursos materiales e información), que en ningún caso puede rebasar la disponibilidad con la que se cuenta. De tal manera, el esfuerzo de concreción habrá de ser siempre relativizado con respecto a la economía de recursos.

En resumen, los resultados expuestos en esta tesis muestran la importancia y posibilidades de incorporar el fenómeno subjetivo de la interpretación estética de la componente ecológica en la planificación del paisaje. El interés de esta incorporación no es sólo el poder llegar a actuar de manera que se refuerce la conservación de los procesos y valores ecológicos, sino la consecución de un paisaje más apreciado estéticamente y con significados ecológicos más profundos. Este factor, la percepción e interpretación estética de la componente ecológica, quizá no sea el primordial o se encuentre entre los más decisorios en algunos casos o contextos, pero la investigación llevada a cabo constata que es un elemento condicionante en grado y naturaleza variable, y que es posible adquirir mayor sostenibilidad del paisaje si se incorpora entre el rango de variables tenidas en cuenta en el proceso de toma de decisiones.

Puig i Baguer, J. (1995). Planificación del Paisaje (Landscape Planning): una herramienta para armonizar las relaciones del hombre en su entorno territorial (Según Landscape Planning y otras fuentes) (Tesis doctoral no publicada), E.T.S. Ingenieros de Montes - Universidad Politécnica de Madrid, Madrid.

Ndubisi, F., 2002. Ecological planning: a Historical and Comparative Synthesis. Baltimore, MD: John Hopkins University Press.

Makhzoumi, J. y Pungetti, G. (1999). Ecological Landscape Design and Planning: The

Mediterranean Contex. Londres, UK: E\&FN Spon.

Termorshuizen, J. W., Opdam, P., y van den Brink, A. (2007). Incorporating ecological sustainability into landscape planning. Landscape and Urban Planning, 79(3-4), 374384.

Encinas, A. (2000). Propuesta de una metodología de análisis del paisaje para la integración visual de actuaciones forestales (Tesis doctoral no publicada). E.T.S. Ingenieros de Montes Universidad Politécnica de Madrid, Madrid. 


\section{CAPÍTULO IX. CONCLUSIONES}




\section{CAPÍTULO \\ CONCLUSIONES}

\section{Diagnóstico de situación actual y oportunidades en la planificación ecológico-estética del paisaje}

- Se ha realizado un diagnóstico de las propuestas de planificación vigentes en la actualidad que ha permitido delimitar los contornos que definen el planteamiento de la relación entre ecología y estética que hace cada una $y$, consecuentemente, el alcance de sus resultados en este ámbito. De tal manera, se han distinguido tres enfoques:

- ECOLOGÍA Y ESTÉTICA. Enfoque que trata de manejar los aspectos en cuestión como valores separados: la percepción o la estética del paisaje es tratada desde el punto de vista exclusivamente visual o escénico, sin explorar u ocuparse de su conexión con lo ecológico.

- ECOLOgÍA ESTÉTICA. Enfoque que se basa en aprovechar los casos en que la apreciación de ecología y estética es coincidente, o bien en embellecer la solución ecológica.

- ESTÉTICA ECOLÓGICA. Enfoque que considera la estética como un factor de oportunidad del que el gestor puede servirse no sólo para hacer más aceptable un paisaje, sino para evidenciar las condiciones ecológicas, su adecuación, su conveniencia y la belleza que encierra. Esta perspectiva atiende más a lo deseable que a lo deseado, y su actuación se basa en proporcionar la certidumbre de que lo que se percibe es sostenible.

- De la revisión comprensiva de antecedentes se desprende que la estética ecológica se perfila como un nuevo paradigma llamado a trascender en el proceder de la planificación, gestión y diseño del paisaje, dado que ofrece un marco de análisis que viene a cubrir una insuficiencia: el del aprovechamiento de los efectos de la interpretación estética en la componente ecológica.

- Existe por tanto la oportunidad de incorporar este fenómeno al rango de variables manejadas en la planificación del paisaje, al mismo tiempo que se necesita desarrollar metodologías de planificación que incorporen de manera efectiva los postulados de la estética ecológica. 
- Para poder comprender en toda su magnitud la interrelación que se establece entre las características ecológicas de un paisaje, su percepción y su apreciación estética, es necesario no sólo identificar los aspectos en los que ambas dimensiones se alinean, sino también conocer y entender las razones y causas que animan a interpretar una determinada condición ecológica de una u otra manera. Es decir, no solo se trata de conocer el qué, sino el cómo y el por qué. El tratamiento del paisaje que basa su proceder no sólo en el resultado final, sino que también explora sus fundamentos da como resultado una gestión del paisaje más relevante y un paisaje con mayor significación estética.

- La tesis contiene resultados que contribuyen a avanzar en este sentido, ocupándose del desarrollo de tipo procedimental (metodología de evaluación de la percepción y su integración en el proceso de planificación ecológico-estética del paisaje), así como del desarrollo de la comprensión de los mecanismos que rigen la percepción humana de las características y procesos ecológicos que se dan en el paisaje.

\section{Metodología de investigación empírica sobre la percepción ecológico- estética}

- Se ha propuesto y validado una metodología de análisis de las percepciones estéticas relacionadas con la dimensión ecológica del paisaje que ha dado resultados satisfactorios.

- El enfoque cualitativo basado en entrevistas en profundidad permite comprender en gran detalle este fenómeno complejo. Este enfoque atiende de manera exclusiva a estas dos dimensiones, indaga específicamente en su relación y lo hace desde la perspectiva de valores que se condicionan el uno al otro,

- Dado que se utiliza un enfoque de investigación conducida por el entrevistado ("user-led research"), la metodología propuesta posibilita identificar los ámbitos de relación entre ecología y estética que son relevantes para los entrevistados. Se escapa así del condicionamiento o sesgo que impone la preselección por parte del investigador de las características a tratar.

- La concreción geográfica de las percepciones y evaluaciones resultó un asunto clave para alcanzar operatividad planificadora. A este respecto, la estructuración del análisis de la percepción a partir de los 3 componentes de la Teoría del Lugar de Canter (concepción, actividades y atributos físicos), el uso de la descripción detallada del sitio evaluado y su localización por parte del entrevistado en un 
mapa resultó ser un método muy adecuado para ligar el sistema conceptual del entrevistado y la realidad física del paisaje.

- La metodología se muestra efectiva en la identificación de los ámbitos en los que hay que es posible planificar tomando en cuenta el condicionamiento estético de la componente ecológica, si bien este resultado ha de ser tomado como un principio, valido, sensible y útil, pero que necesita ratificar su representatividad.

- La estructura metodológica propuesta se muestra como extrapolable a otros casos y aplicable a cualquier contexto paisajístico.

\section{Resultados sobre la percepción ecológico-estética del paisaje en los casos de estudio}

- La investigación empírica sobre la consideración ecológico-estética del paisaje se centró en dos de los agentes principales del paisaje, los técnicos especializados en el tratamiento del medio natural y la población local. Los resultados alcanzados adquieren así una gran relevancia, puesto que la percepción de estos grupos puede precipitar en intervenciones de calado en el paisaje y por tanto influir de forma importante y patente en su estado.

- Los resultados concretos de las investigaciones empíricas muestran que la consideración estética de la componente ecológica no está exclusivamente ligada a la estética formal o la simple belleza, sino que también se vincula con los significados y funciones atribuidos al paisaje, que determina su evaluación, el modo de percibirlo y los rasgos físicos en los que se repara.

- Se identificaron una serie de coherencias y divergencias en la interpretación estética de la componente ecológica entre los grupos objeto de estudio con una potencial significación en el proceder planificador, al igual que distintos patrones y matices de percepción atribuibles al contexto paisajístico.

- La naturalidad percibida y su significación ecológica fue una de las características del paisaje más valorada por los técnicos gestores consultados. La población local, sin embargo, tendió a fijar su atención en los rasgos culturales presentes en el medio natural y evaluó la sostenibilidad social del paisaje como un componente imprescindible para su buen funcionamiento e imagen. Esta percepción diferencial se relaciona tanto con el tipo de conocimiento sobre el medio que tienen ambos grupos, como con la actividad que se lleva a cabo, el uso que se hace del paisaje y la función que se considera conveniente o preeminente. 
- El factor de la naturalidad del paisaje, en todo caso, no siguió un patrón de valoración equivalente en los dos contextos paisajísticos examinados. En el paisaje agroforestal, más intervenido y con una huella humana más patente que el más natural, el valor de la naturalidad fue menos destacado, su importancia en el paisaje relativizada y, muy importante, su consideración se mostró más próxima entre técnicos y no técnicos.

- El proceso de abandono de las actividades tradicionales de aprovechamiento y la consiguiente dinámica más natural del paisaje fue otra de las percepciones de calado en la evaluación ecológica y estética de los participantes. La percepción negativa de sus consecuencias en el plano ecológico y estético fue sobre todo reconocida por la población local, que ligó de forma ineludible el buen estado del paisaje con la acción ejercida por su propio grupo.

- La expresión del cuidado o gestión atenta y dedicada del paisaje se posicionó como un factor clave en la evaluación del paisaje intervenido y se perfiló como una estrategia de evaluación y diseño ecológico-estético del paisaje efectiva. El objetivo de alcanzar una gestión atenta y sensible con las cualidades ecológico-estéticas del paisaje fue compartido por los participantes, si bien las características del paisaje que denotan dicha condición y la estrategia de gestión para alcanzarla fueron variables según el grupo social considerado y el contexto paisajístico.

- La expresión del cuidado fue una característica buscada en el paisaje más modificado, pero también se reveló como un factor manejado en la forma de percibir y evaluar el paisaje más natural. Más allá de la naturalidad percibida, el tratamiento de los rasgos físicos que revelan una gestión y aprovechamiento cuidadoso merece por tanto mayor estudio y consideración en este tipo de paisaje.

- La interpretación estética de las condiciones ecológicas del paisaje estuvo muy ligada al escrutinio del proceder de los gestores que intervienen en el paisaje. En este sentido, se constata que la estrategia de hacer evidente en el paisaje percibido que el gestor actúa con esmero, implicación y responsabilidad hacia sus valores ecológicos y estéticos -"Administración o Gobernanza Visible" (Visible Stewardship)-, resulta prometedora.

- La percepción en el paisaje del riesgo de sufrir un incendio forestal y la constatación de sus consecuencias estuvo muy presente en las consideraciones ecológico-estéticas en el ámbito de estudio del paisaje agroforestal de Madrid. Dado que actualmente es un proceso con gran incidencia en el contexto territorial español, al que cada vez más se destinan recursos y esfuerzos, su tratamiento ecológico- 
estético resulta un ámbito que ofrece un margen de actuación amplio, de gran recorrido y aun insuficientemente explorado. Los resultados muestran patrones de percepción de esta condición útiles en este sentido.

- La conservación y gestión de los valores de un paisaje es, o debería ser, una responsabilidad compartida entre la población local y los técnicos e instituciones públicas, entre otros. La existencia de convergencias y divergencias en la interpretación estética de la ecología en el paisaje pone de relieve la posibilidad de que surjan conflictos en la definición y ejecución de acciones en el paisaje. Las mismas convergencias y divergencias ofrecen la oportunidad de encontrar un camino para aprovechar las sinergias que se puedan establecer entre ambas dimensiones y minimizar los desencuentros entre ambos agentes. De tal manera, es posible prescribir determinadas estrategias de tratamiento del paisaje para lograr una mejora reforzada en las condiciones ecológico-estéticas del paisaje

\section{Modelo de planificación ecológico-estética del paisaje}

- El modelo de planificación del paisaje planteado resulta innovador en el sentido de que busca decantar sobre el proceso de toma de decisiones los efectos de la interpretación estética de la dimensión ecológica que se percibe en el paisaje. Permite pues diagnosticar de manera más relevante las dinámicas a las que está sometido el paisaje y proponer directrices de tratamiento ecológico y visual o estéticas más efectivas, que pueden concebirse para que tengan un efecto más allá de la impresión de belleza o la estética formal.

- Aplicando la metodología de análisis al modelo de planificación fue posible definir una serie de ámbitos en los que actuar para reforzar el valor ecológico por medio de su consideración estética, referenciarlos geográficamente a grandes rasgos y definir en términos generales la estrategia de actuación. Esta metodología sirve como marco para el posterior desarrollo en detalle de las actuaciones y su mayor concreción geográfica.

- Los resultados derivados del modelo de planificación propuesto poseen una utilidad clara para indicar las deficiencias de tratamiento del paisaje tanto en un ámbito como en otro (orientar acciones de conservación o restauración sensibles con su resultado estético o, recíprocamente, orientar actuaciones de tratamiento del paisaje que redunden en un mayor beneficio ecológico). Sirven igualmente como una referencia en procesos de evaluación de impacto ambiental, para marcar pautas o aspectos a incorporar en las soluciones de diseño en el paisaje o, en fin, contribuir al desarrollo ordenado y sostenible del territorio. 


\section{CHAPTER \\ CONCLUSIONS}

Diagnosis of the current situation and opportunities in ecologicalaesthetic landscape planning

- A diagnosis has been made of planning proposals currently in force. The study has allowed the definition of an outline, delineating the approach of each planning proposal to the ecology-aesthetics relationship and, consequently, the significance of their results in these fields. Therefore, three approaches have been identified:

- ECOLOGY AND AESTHETICS. An approach that handles both aspects as separate values: the perception, or aesthetics, of the landscape is treated exclusively from a visual or scenic point of view, without exploring or considering its ecological connections.

- AESTHETIC ECOLOGY. An approach that can either be based on exploiting those cases in which the ecological and aesthetical appreciation coincide, or on embellishing the ecological solution.

- eCOLOGICAL AESTHETICS. An approach that considers aesthetics as an opportunity which the agent can use not only to make a landscape more acceptable, but also to show the ecological conditions, the suitability, the convenience, and the beauty of the landscape. This perspective serves more towards the desirable than the desired, and its application is based on providing the certainty in what is perceived as sustainable.

- From a comprehensive background review, it is clear that ecological aesthetics is emerging as a new paradigm for the planning, management, and design of landscapes; in fact, it offers a framework analysis that covers the effects of aesthetic interpretation in the ecological component."

- The opportunity thus exists to incorporate this subjective phenomenon into the range of variables used in landscape planning. At the same time, it is necessary to develop new planning methodologies that could effectively incorporate the postulates of ecological aesthetics.

- In order to fully understand the interrelations existing between the ecological characteristics of a landscape, its perception and its aesthetic appreciation, we must identify the aspects in which both 
dimensions are aligned, while understanding the reasons and causes that encourage the interpretation of a certain ecological condition in different ways. In other words, it is necessary to know not only what is happening, but also how and why. The treatment of a landscape that bases its procedure not only on the final result, but also on exploring its foundations, results in a more relevant landscape management and in a landscape with greater aesthetic significance.

- The results of this thesis contribute to the advancement of landscape treatment from this point of view, dealing with the development of a procedure (methodology of perception evaluation and its integration with the process of landscape ecological-aesthetic planning), as well as with the understanding of the mechanisms which govern the human perception of ecological characteristics and of the processes that occur in the landscape.

Methodology of the empirical research on the ecological-aesthetic perception

- A methodology for the analysis of the aesthetic perceptions related to the ecological landscape dimension, which has given satisfactory results, has been proposed and validated.

- The qualitative approach based on in-depth interviews, which deals exclusively with these two dimensions, specifically investigates their relationship and consider them as values which condition each another; this approach allows us to understand this complex phenomenon in great detail.

- Given that a research approach conducted by the interviewee ("userled research") is used, the proposed methodology allows the identification of those areas of the ecology-aesthetics relationship that are relevant for the interviewees. Hence, the conditioning, or bias, imposed by the researcher's pre-selection of characteristics can be avoided.

- The geographical precision of the perceptions and evaluations was a key issue in achieving operational planning. In this regard, structuring the perception analysis following the three components of Canter's Theory of Place (design, activities and physical attributes), as well as describing in detail the evaluated site and its localization by the interviewee in a map, were very suitable methods to link the interviewee's conceptual system with the physical reality of the landscape. 
- The methodology is effective in identifying the areas in which one can act, taking into account the aesthetic conditioning of the ecological component, while achieving a real and accurate knowledge of the phenomenon. These results, which are valid, appreciable, and useful, must be considered as a general framework for the understanding of perception; nevertheless, their representativeness needs to be ratified in order to reach full significance and operability.

- The proposed methodological structure has been shown to be sound for the two different landscape contexts to which it has been applied. Given its open and flexible structure, it can be used by other territorial agents and it is applicable to any landscape context.

Results of the empirical research on the ecological-aesthetic perception of the landscape

- The empirical research on the ecological-aesthetic consideration of the landscape focused on two of the main agents of the landscape: the professionals on environmental issues and the local population. Hence, the obtained results become extremely relevant: the perception of these groups can lead to significant interventions on the landscape and visibly influence it.

- The empirical research was applied to two landscape contexts (La Rioja, a forested and more natural landscape, and Madrid, an agroforestry landscape which underwent more interventions). The results show that the aesthetic consideration of the ecological component is not exclusively linked to its formal aesthetics or simple beauty; it is also linked to the meanings and functions attributed to the landscape, which determine its evaluation, the way it is perceived, and the physical features in which it is noticed.

- A series of coherences and divergences were identified in the aesthetic interpretation of the ecological component between the groups under study, which can be potentially significant in the planning procedure, as well as different patterns and nuances in perception attributable to the landscape context.

- The perceived naturalness and its ecological significance was attributed to be one of the most valued landscape characteristics by the interviewed technical agents. The local population, however, tended to focus on the cultural features present in the natural environment, and evaluated the social sustainability of the landscape as an essential component for its proper functioning and image. These 
different perceptions are related to the type of environmental knowledge that the groups have, as well as to the activities that these groups perform, the way they use the landscape, and the functions that they consider convenient or preeminent.

- The naturalness factor of the landscape, however, was not evaluated in the same way in the two landscape contexts. In the agroforestry landscape(which underwent more intervention and presented a more obvious human footprint) the value of naturalness was less prominent. Its importance in the landscape was minimised and, more importantly, its level of consideration among technicians and non-technicians was similar.

- The process of abandoning traditional exploitation procedures and the consequent re-naturalisation of the landscape was another of the most important perceptions in the participants' ecological and aesthetic evaluations. The ecological and aesthetic consequences of these processes were recognised and perceived as negative especially by the inhabitants, who considered the good state of the landscape and the actions taken by their own social group as inevitably linked. In the case of the agroforestry landscape, the significance of this perception was greater for technicians.

- The expression of care, or attentive and dedicated landscape management, was a key factor in the evaluation of the intervened landscape; also, it was found to be an effective strategy for the evaluation and the ecological-aesthetic design of the landscape. The objective of achieving a careful and appreciable management for the ecological-aesthetic qualities of the landscape was shared by the participants. Still, the characteristics of the landscape that denoted this condition, as well as the management strategy chosen to achieve the objective varied depending on the social group and on the landscape context.

- The expression of care was a characteristic sought in the most intervened landscapes, but it was also a factor used to perceive and evaluate the most natural landscapes. Beyond the perceived naturalness, the treatment of the physical features, which reveal a careful management and exploitation, deserves to be studied in detail and should be considered with more attention for this type of landscapes.

- The aesthetic interpretation of the landscape's ecological conditions was closely linked to the scrutiny of the agents who intervene on the landscape. In this sense, we note that the strategy of highlighting, in the perceived landscape, that the agent acts with care, involvement and responsibility towards his or her ecological and aesthetic values 
("Administration or Visible Governance"- Visible Stewardship"), is promising.

- The perceived risk of the landscape suffering a forest fire and the verification of its consequences were very much present in the ecological-aesthetic considerations included in the study of the agroforestry landscape of Madrid. Because this process is impacting heavily the Spanish territory, in which increasingly more resources and efforts are allocated, its ecological-aesthetic treatment offers a wide margin of action, has a big potential and is still insufficiently explored. In this sense, the results provide useful perception patterns of this condition.

\section{Ecological-aesthetic landscape planning model}

- The proposed landscape-planning model is innovative: it seeks to integrate into the decision-making process the effects of the aesthetic interpretation of the ecological dimension perceived in the landscape.

- By applying the analysis methodology to the planning model, it was possible to define a series of areas on which to act, in order to reinforce the ecological value through its aesthetic consideration, referencing them geographically in broad strokes and defining the action strategy in general terms. This methodology serves as a framework for a subsequent detailed development of the actions and a greater geographical precision (at project level).

- The proposed planning model therefore allows a more relevant diagnosis of the dynamics to which the landscape is subjected as well as the proposal of more effective ecological-visual or aesthetic treatment guidelines, which can be designed to be effective beyond the impression of beauty or formal aesthetics.

- The results derived from the planning model are clearly useful in indicating the deficiencies of landscape treatment in different areas (pointing toward appreciable conservation or restoration actions with their aesthetic result or, reciprocally, pointing toward landscape treatments that can result in a greater ecological benefit). They are also used as a reference in environmental impact assessment processes, to mark guidelines or aspects to incorporate into the landscape design solutions or, in short, to contribute to an organized and sustainable development of the territory. 


\section{CAPÍTULOXI ÁREAS DE INVESTIGACIÓN FUTURA}




\section{CAPÍTULO \\ ÁREAS DE INVESTIGACIÓN FUTURA}

Derivados de los resultados de esta tesis se abren varias líneas que requieren mayor investigación para seguir avanzando en el tratamiento del paisaje desde el enfoque de la estética ecológica.

Las necesidades más obvias de investigación se enmarcan en los dos ámbitos principales de exploración del presente trabajo: la investigación sobre la interpretación estética de la componente ecológica y el desarrollo de un modelo de planificación que incorpore de manera efectiva dicha percepción.

De tal manera, es necesario seguir avanzando en la exploración de las percepciones que los diversos grupos sociales albergan sobre la componente ecológica y los condicionamientos estéticos existentes. En este sentido, parece relevante aplicar la metodología de análisis de la percepción a otros grupos sociales y en otros contextos paisajísticos para seguir generando una comprensión más completa del fenómeno.

Por otro lado, es necesario seguir desarrollando la metodología de planificación para acabar de decantar los efectos de la interpretación estética de lo ecológico en el proceso de decisiones sobre paisaje. A este respecto, la concreción de las estrategias y la conexión del proceso planificador y el diseño del paisaje se revela como un proceso clave que es imprescindible definir para alcanzar verdadera operatividad.

Además, relacionado con la operatividad del modelo, sería necesario analizar la factibilidad de integrar las estrategias y actuaciones sugeridas en las políticas de tratamiento del territorio o paisaje establecidas, y concretar y diseñar la manera de hacerlo. Este análisis sería por tanto de naturaleza político-administrativa y buscaría perfilar un asunto tan esencial como conocer las posibilidades de hacer realidad aquello que está prescrito en el modelo de planificación.

Por último, una línea de investigación iniciada en la tesis y cuya profundización resulta muy conveniente es la relacionada con el estudio de la percepción ecológico-estética de los técnicos y las implicaciones que tiene en su proceder. Esta tesis ha iniciado la exploración de la percepción de los técnicos/profesionales que toman decisiones sobre el tratamiento ecológico y paisajístico del territorio. Es este un asunto poco tratado y con especial trascendencia, pues sus tendencias estéticas pueden llegar a tener una resonancia significativa 
en sus decisiones y modo de actuar sobre el paisaje. Ahora bien, cabría preguntarse si esta tendencia tiene verdadero efecto en su quehacer, asunto que se podría dirimir a través de una análisis retrospectivo de sus decisiones ya tomadas. Existen a este respecto dos áreas de actuación en el paisaje de este grupo que sería necesario investigar, en función de en que componente del binomio hombrepaisaje se ponga el acento:

- La definición de propuestas de ordenación, gestión y diseño con traducción física en el paisaje.

- La transmisión de sus cualidades, tanto en su dimensión ecológica, como estética (entre otras).

La exploración de la primera de las áreas puede enfocarse por medio de una evaluación de los documentos de planificación y gestión aprobados, en clave del enfoque ecológico-estético que denoten. También por medio de un inventario exhaustivo y análisis de la manera en la que se han sustanciado en el paisaje. De tal manera, se adquiriría una idea de cómo estos aspectos operan en la concepción y en la ejecución de las actuaciones en el paisaje por parte de los profesionales a cargo.

Con respecto a la segunda área de influencia en el paisaje, sería necesario evaluar cómo la interpretación ecológico-estética del propio técnico se decanta en la educación ambiental, vía preferente a través de la cual se produce la transmisión de las cualidades observadas y valoradas por el técnico hacia el gran público. Es además la vía a través de la cual el técnico puede dirigir la atención hacia ciertos procesos o circunstancias ecológicas, e inducir un determinado modo de mirar y experimentar el paisaje. Resulta por tanto un área significativa a la hora de diagnosticar el grado de reforzamiento o debilitamiento que presentan determinados valores ecológicoestéticos. Dicho diagnóstico se podría llevar a cabo realizando un análisis de contenido de los materiales de difusión puestos a disposición del público y de las actividades de educación ambiental.

En definitiva, la línea de investigación contenida en el presente trabajo y las futuras líneas sugeridas en los párrafos anteriores deben tratar de aclarar todos los aspectos contenidos en un proceso completo de planificación del paisaje realizado desde el punto de vista de la estética ecológica: identificar los procesos ecológicos existentes y su importancia, definir la capacidad que tienen de mostrarse perceptibles, la disposición que tiene el agente en cuestión de captar su existencia, la evaluación que realiza y sus causas, diagnosticar los efectos que tiene la interpretación estética de dicha cualidad ecológica, definir la vía y la estrategia de reforzamiento de esa 
González Alonso, S. (2010). Planificación del paisaje y política territorial. De los postulados a su aplicación en España. Madrid: Fundación Conde del Valle de Salazar. valoración (sea esta por medio de las actuaciones sobre el paisaje o por medio de la educación ambiental) y, finalmente, evaluar la capacidad de actuación que se tiene para conseguir ese objetivo.

Faltaría sin embargo un último ámbito de para completar el proceso, que tiene que ver con el seguimiento o constatación de la conveniencia de los resultados planificados. A la planificación del paisaje tradicionalmente se le pide que alcance dos objetivos fundamentales: el poder de predicción y el de prescripción. Es decir, que sea capaz de adelantarse a los hechos y de formular soluciones que optimicen la gestión del paisaje a la luz de esa evolución prevista. Evidentes como son estos requisitos, lo es también el hecho de que la planificación del paisaje no se enfrenta tanto a un "déficit de saber", sino de voluntad para aplicar sus propuestas y así poder validar sus resultados (González Alonso, 2010). 


\section{REFERENCIAS BIBLIOGRÁFICAS}


Angoletti, M. (2014). Rural landscape, nature conservation and culture: Some notes on research trends and management approaches from a (southern) European perspective. Landscape and Urban Planning, 126, 66-73.

Antrop, M. (2005). Why landscapes of the past are important for the future. Landscape and Urban Planning, 70, 21-34.

Appleton, J. (1975). The Experience of Landscape. Londres, UK: Wiley \& Sons.

Appleton, J. (1984). Prospects and Refuges Re-Visited. Landscape Journal, 3(2), 91-103.

Aramburu, M. P. y Escribano, R. (Eds.) (2014). Guía para la elaboración de estudios del medio físico. Contenido y metodología (4a ed.). Madrid: Fundación Conde del Valle de Salazar; Ministerio de Agricultura, Alimentación y Medio Ambiente.

Aramburu Maqua, M. P., Escribano Bombín, R., López Hernández, R., y Sánchez Ramos, P. (2004). Estudio y Cartografía del Paisaje de la Comunidad Autónoma de La Rioja. Logroño: Consejería de Turismo, Medio Ambiente y Política Territorial, Gobierno de La Rioja (publicación electrónica). Recuperado de: https://www.larioja.org/territorio/es/ordenacion-territoriourbanismo/paisaje/estudio-cartografia-paisaje

Aramburu Maqua, M. P., Escribano Bombín, R., López Rodríguez, A., Pastor Piñuela, M, Rastrollo Gonzalo, A. (2009). Diseño y Redacción de las Fichas de los Paisajes Singulares y Sobresalientes de la Comunidad de La Rioja. Logroño: Consejería de Turismo, Medio Ambiente y Política Territorial, Gobierno de La Rioja (trabajo técnico no publicado).

Aramburu Maqua, M. P., Escribano Bombín, R., Ramos Gonzalo, L., y Rubio Maroto, R. (2003). Cartografía del Paisaje de la Comunidad de Madrid. Madrid: Consejería de Medio Ambiente de la Comunidad de Madrid. Madrid: Dirección General de Promoción y Disciplina Ambiental Consejería de Medio Ambiente - Comunidad de Madrid.

Bell, S. (1993). Elements of visual Design in the landscape (1 1 ed.). Londres, UK: Spon Press. 
Bell, S. (2009). Landscape change, landscape perception and the Latvian countryside (Tesis doctoral). Eesti Maaülikool (Universidad de Ciencias Naturales de Estonia), Tartu.

Bell, S. (2012). Landscape. Pattern, Perception and Process (2 2 ed.). Nueva York, NY: Routledge.

Bell, S. y Apostol, D. (2008). Designing Sustainable Forest Landscapes. Londres, UK/Nueva York, NY: Taylor \& Francis.

Berleant, A. (1992). The Aesthetics of Environment. Filadelfia, PA: Temple University Press.

Bernaldo de Quirós, C. (1915). Cómo fue descubierta y explorada la Pedriza de Manzanares. Peñalara, 21, 129-134.

Boada, J. M. (1929). Poesía de Montaña: “No lo sé". Peñalara, 184, 102.

Botkin, D. B. (2001). An Ecologist's Ideas About Landscape Beauty: Beauty in Art and Scenery as Influenced by Science and Ideology. En S. R. J. Sheppard y H. W. Harshaw (Eds.), Forests and Landscapes: Linking Ecology, Sustainability and Aesthetics (pp. 111-123). Nueva York, NY: CABI Publishing -IUFRO.

Botkin, D. B. (2001b). No Man's Garden. Thoreau and a new vision for civilization and nature. Washington, D.C.: Island Press \& Shearwater Books.

Bourassa, S. C. (1991). The aesthetics of landscape. Londres: Belhaven Press.

Brown, T. (1994). Conceptualizing smoothness and density as landscape elements in visual resource management. Landscape and Urban Planning, 30(1-2), 49-58.

Brunson, M. (1993)."Socially acceptable" forestry: what does it imply for ecosystem management. Western Journal of Applied Forestry, 8(4), 116-119.

Bryman, A. (2004). Social research methods. Oxford, UK: Oxford University Press.

Burke, E. (1757). A Philosophical Inquiry into the Origin of Our Ideas of the Sublime and Beautiful. Londres, UK: Dodsley. 
Callicott, J. B. (1983). The Land Aesthetic [Special Issue: A Cumulative Index to the First Seven Years of Environmental Review]. Environmental Review, 7 (4), 345-358.

Callicott, J. B. y Flader, S. L. (1992). The River of the Mother of God: and other Essays by Aldo Leopold. Madison, WI: University of Wisconsin Press.

Canter, D. (1977). The psychology of place. Londres, UK: Architectural Press.

Carandell, J. (1922). Velázquez y la Pedriza de Manzanares. Peñalara, 100, 71-73.

Carlson, A. (1977). On the possibility of quantifying scenic beauty. Landscape Planning, 4, 131-172.

Carlson, A. (1979). Appreciation and the natural environment. The Journal of Aesthetics and Art Criticism, 37(3), 267-275.

Carlson, A. (1993). On the theoretical vacuum in landscape assessment. Landscape Journal, 12(1), 51-56.

Carlson, A. (2001). Aesthetic preferences for sustainable landscapes: seeing and knowing. En S. R. J. Sheppard y H. W. Harshaw (Eds.), Forests and Landscapes: Linking Ecology, Sustainability and Aesthetics (pp. 31-42). Nueva York, NY: CABI Publishing - IUFRO.

Carlson, A. (2009). The Development and Nature of Environmental Aesthetics. En A. Carlson (Ed.), Nature and Landscape: An Introduction to Environmental Aesthetics (pp. 1-21). Nueva York, NY: Columbia University Press.

Carroll, N. (1993). On Being Moved by Nature: Between Religion and Natural History. En S. Kernall y I. Gaskell (Eds.), Landscape, Natural Beauty and the Arts (pp. 89-107). Cambridge, UK: Cambridge University Press.

Cheng, A. S., Kruger, L. E., y Daniels, S. E. (2003). "Place" as an integrating concept in natural resource politics: Propositions for a social science research agenda. Society \& Natural Resources, 16, 87-104.

Cifuentes, P. (1976). La calidad visual de unidades territoriales. Aplicación al Valle del Tiétar (Tesis doctoral no publicada). E.T.S. Ingenieros de Montes - Universidad Politécnica de Madrid, Madrid. 
Comunidad de Madrid, 2007. Atlas. El medio ambiente en la Comunidad de Madrid. Madrid: Consejería de Medio Ambiente y Ordenación del Territorio de la Comunidad de Madrid- Secretaría General Técnica.

Consejo de Europa (2000). Convenio Europeo del Paisaje (ETS No.176). Florencia: Consejo de Europa.

Coppolillo, P., Gomez, H., Maisels, F., y Wallace, R. (2004). Selection criteria for suites of landscape species as a basis for site-based conservation. Biological Conservation, 115(3), 419-430.

Cortina, A. y Queralt, A. (Ed.) (2007). Convenio Europeo del Paisaje. Textos y comentarios. Madrid: Ministerio de Medio Ambiente.

Dakin, S. (2003). There's more to landscape than meets the eye: towards inclusive landscape assessment in resource and environmental management. The Canadian Geographer/Le Géographe Canadien, 47(2), 185-200.

Dandy, N. y Van Der Wal, R. (2011). Shared appreciation of woodland landscapes by land management professionals and lay people: An exploration through field-based interactive photo-elicitation. Landscape and Urban Planning, 102(1), 43-53.

Daniel, T. C. (1990). Measuring the quality of the human environment: a phsychophysical approach. American Psychologist, 45, 633-637.

Daniel, T. C. (2001). Whither scenic beauty? Visual landscape quality assessment in the 21st century. Landscape and Urban Planning, 54(14), 267-281.

Daniel, T. C. y Vining, J. (1983).Methodological Issues in the Assessment of Landscape Quality. En I. Altman y J. F. Wohlwill (Eds.), Behavior and the Natural Environment (pp. 39-84). Nueva York, NY: Springer US.

Decreto 485/1962, de 22 de febrero, por que se aprueba el Reglamento de Montes. Boletín Oficial del Estado núm. 61 de 12 de marzo de 1962, p. 3399 a 3417.

Decreto 90/2014, de 3 de junio, sobre protección, gestión y ordenación del paisaje en la ordenación del territorio de la Comunidad Autónoma del País Vasco. Euskal Herriko Agintaritzaren Aldizkaria (Boletín Oficial del País Vasco), núm. 112 de 16 de junio de 2014. 
Decreto 26/2017, de 14 de marzo, por el que se declara la zona especial de conservación "Cuencas de los ríos Alberche y Cofio" y se aprueban su plan de gestión y el de la zona de especial protección para las aves "Encinares del río Alberche y río Cofio". Boletín Oficial de la Comunidad de Madrid núm. 65 de 17 de marzo de 2017, p. 64 a 280.

Decreto 59/2017, de 6 de junio, por el que se aprueba el Plan Especial de Protección Civil de Emergencia por Incendios Forestales en la Comunidad de Madrid (INFOMA). Boletín Oficial de la Comunidad de Madrid núm. 136 de 9 de junio de 2017, p. 10 a 79.

Diaz, N. y Apostol, D. (1992). Forest Landscape Analysis and Design: a process for developing and implementing land management objectives for landscape patterns (R6 ECO-TP-043-92). Pacific Northwest Region: U.S. Forest Service Research.

Directiva 92/43/CEE del Consejo, de 21 de mayo de 1992, relativa a la conservación de los hábitats naturales y de la fauna y flora silvestres. Boletín Oficial del Estado núm. 206 de 22 de julio de 1992, p. 7 a 50.

Directiva 2009/147/CE del Parlamento Europeo y del Consejo, de 30 de noviembre de 2009, relativa a la conservación de las aves silvestres. Boletín Oficial del Estado núm. 20 de 26 de enero de 2010, p. 7 a 25.

Encinas, A. (2000). Propuesta de una metodología de análisis del paisaje para la integración visual de actuaciones forestales (Tesis doctoral no publicada). E.T.S. Ingenieros de Montes - Universidad Politécnica de Madrid, Madrid.

Eriksson, L., Björkman, C., y Klapwijk, M. J. (2017). General Public Acceptance of Forest Risk Management Strategies in Sweden: Comparing Three Approaches to Acceptability. Environment and Behavior, 50(159-186).

Escribano, R. (1977). El análisis de la fauna en los modelos de Planificación (Tesis doctoral no publicada). E.T.S. Ingenieros de Montes Universidad Politécnica de Madrid, Madrid.

Escribano, R. y Aramburu, M. P. (2000). El paisaje: diversidad de enfoques. Boletín de la Real Sociedad Española de Historia Natural, 96, 89-97.

Farina, A. (2006). Principles and Methods in Landscape Ecology: Towards a Science of the Landscape. Cambridge, UK: Chapman \& Hall. 
Fattorini, S. (2013). Species ecological preferences predict extinction risk in urban tenebrionid beetle guilds. Animal Biology, 63(1), 93-106.

Fernández OSA, A. (1929). La fauna de nuestras montañas. Mariposas de altura. Peñalara, 181, 1-4.

Forman, R. T. T. y Godron, M. (1986). Landscape Ecology. Nueva York, NY: John Wiley \& Sons.

Frolova, M., Menor Toribio, J., y Cancer Pomar, L. (2003). El paisaje en las políticas públicas de Francia y España: desde la protección del monumento a la gestión del espacio. Estudios Geográficos, 253, 605622.

Fry, G., Tveit, M. S., Ode, A., y Velarde, M. D. (2009). The ecology of visual landscapes: Exploring the conceptual common ground of visual and ecological landscape indicators. Ecological Indicators, 9(5), 933-947.

García-Abril, A., Núñez, M. V., Grande, M. A., Velarde, D., Martínez-Obispo, P., y Rodríguez-Solano, R. (2013). Landscape indicators for Sustainable Forest Management. En E. Martinez-Falero, S. Martin-Fernandez, y A. D. García-Abril (Eds.), Quantitative Techniques in Participatory Forest Management (pp. 263-366). Boca Ratón, NW: CRC Press, Taylor y Francis Group.

Garrote García, F. (2009). La transformación del paisaje y las políticas de desarrollo de la Unión Europea. Caso de estudio: Sierra Norte de Madrid (1980-1999) (Tesis doctoral no publicada). E.T.S. Ingenieros de Montes - Universidad Politécnica de Madrid, Madrid.

Gilpin, W. (1789).Observations on several parts of England, particularly the mountains and lakes of Cumberland and Westmoreland: relative chiefly to picturesque beauty. Londres, UK: Blamire, R.

Giner de los Ríos, F. (1915). Paisaje. Peñalara, 15, 36-44 (publicado por primera vez en 1886).

Gobster, P. H. (1994). The aesthetic experience of sustainable forest ecosystems. En W. W. Covington y L. F. De Bano (Eds.), Sustainable Ecological Systems: Implementing an Ecological Approach to Land Management (pp. 246-255) (General Technical Report RM247). Fort Collins, CO: USDA Forest Service, Rocky Mountain Forest and Range Experiment Station. 
Gobster, P. H. (1995). Aldo Leopold's ecological esthetic: integrating esthetic and biodiversity values. Journal of Forestry, 93, 6-10.

Gobster, P. H. (1996). Forest aesthetics, biodiversity, and the perceived appropriateness of ecosystem management practices. En M. W. Brunson, L. E. Kruger, C. B. Tyler y S. A. Schroeder (Eds.), Defining Social Acceptability of Forests and Forestry Practices: a workshop proceedings (pp.77-97). Kelso, Washington Seattle, WA: U.S. Department of Agriculture, Forest Service, Pacific Northwest Research Station.

Gobster, P. H. (1999). An ecological aesthetic for forest landscape management. Landscape Journal, 18(1), 54-64.

Gobster, P. H. (2007).Urban Park Restoration and the "Museumification" of Nature. Nature and Culture, 2(2), 95-114.

Gobster, P. H. (2008). Yellowstone Hotspot Reflections on Scenic Beauty, Ecology, and the Aesthetic Experience of Landscape. Landscape Journal, 27, 2-8.

Gobster, P. H. (2014). Re-wilding Europe's traditional agricultural landscapes: Values and the link between science and practice. Landscape and Urban Planning, 126, 65.

Gobster, P. H., Nassauer, J. I., Daniel, T. C., y Fry, G. (2007). The shared landscape: what does aesthetics have to do with ecology? Landscape Ecology, 22(7), 959-972.

Gómez Mendoza, J. (2002). Paisajes forestales e ingeniería de montes. En F. Zoido Naranjo (Ed.), Paisaje y ordenación del territorio (pp. 237254). Sevilla: Junta de Andalucía y Fundación Duques de Soria.

Gómez Mendoza, J. (2008). La mirada del geógrafo sobre el paisaje: del conocimiento a la gestión. En J. Maderuelo (Ed.), Paisaje y Territorio (pp. 11-56). Madrid: Fundación Beulas, CDAN (Centro de Arte y Naturaleza), Abada Editores.

Gómez Mendoza, J. (2013). Del patrimonio paisaje a los paisajes del patrimonio. Documents D'anàlisi Geogràfica, 59(1), 5-20.

Gómez Zotano, J. y Riesco Chueca, P. (Eds.) (2010). Marco conceptual y metodológico para los paisajes españoles. Aplicación a tres escalas 
espaciales. Sevilla: Junta de Andalucía. Consejería de Obras Públicas y Vivienda - Centro de Estudios Paisaje y Territorio.

Gómez-Limón J. y de Lucio Fernández, J. V. (1999). Changes in use and landscape preferences on the agricultural-livestock landscapes of the central Iberian Peninsula (Madrid, Spain). Landscape and Urban Planning, 44, 165-175.

González, J., Kolehmainen, O., y Pukkala, T. (2007). Using expert knowledge to model forest stands vulnerability to fire. Computers and Electronics in Agriculture, 55, 107-114.

González Alonso, S. (2010). Planificación del paisaje y política territorial. De los postulados a su aplicación en España. Madrid: Fundación Conde del Valle de Salazar.

González Bernáldez, F. (1981). Ecología y Paisaje. Madrid: Blume.

González Bernáldez, F. (1985). Invitación a la ecología humana. La adaptación afectiva al entorno. Madrid: Tecnos S. A.

González Bernáldez, F. (1988). El paisaje natural. En J.R MartínezRodríguez (Ed.), Elementos básicos para Educación ambiental (pp. 97112). Madrid: Ayuntamiento de Madrid.

González Bernáldez, F. (2011). Invitación a la ecología humana. La adaptación afectiva al entorno. Madrid: Fundación Fernando González Bernáldez y Red Eléctrica de España (publicación original en 1985).

González Bernáldez, F., Ruiz, M., y Ruiz Sanz, J. P. (1985). La percepción del paisaje por los protagonistas de su creación y mantenimiento. Pirineos, 125, 5-29.

Hagan, J. M. (1996). Clearcutting in Maine: would somebody please ask the right question? Maine Policy Review, 5(2), 7-19.

Hepburn, R. (1966). Contemporary Aesthetics and the Neglect of Natural Beauty. En B. Williams y A. Montefiore (Eds.), British Analytical Phylosophy (pp. 285-310). Londres, UK: Routledge \& Kegan Paul.

Hernández Pacheco, E. (Dir.) (1933). Guías de los Sitios Naturales de Interés Nacional (número 3). La Comisaría de Parques Nacionales y la Protección de la Naturaleza en España. Madrid: Ministerio de Agricultura. Comisaría de Parques Nacionales. 
Hervás Más, J. (2009). Ordenación del Territorio, Urbanismo y Protección del Paisaje. Barcelona: Editorial Bosch.

Hill, K. (1998). Ring Parks as diverted Dikes [Special Issue: Exhibit Catalog. Eco-Revelatory Design: Nature Contructed/Nature Revealed]. Landscape Journal, Special Issue, 35-37.

Höchtl, F., Lehringer, S., y Konold, W. (2005). "Wilderness": What it means when it becomes a reality-A case study from the southwestern Alps. Landscape and Urban Planning, 70(1-2), 85-95.

Hull, R. B., Ashton, S. F., Visser, R. M., y Monroe, M. C. (2011). Forest Management in the Interface: Practicing Visible Cues-to-Care. Journal of Forestry, 177, 1-4.

Hull, R. B., Robertson, D. P., Buhyoff, G. J., y Kendra, A. (2000). What are we hiding behind the visual buffer strip? Forest aesthetics reconsidered. Journal of Forestry, 98(7), 34-38.

Hull, R. B., Robertson, D. P., y Kendra, A. (2001). Public Understandings of Nature: A Case Study of Local Knowledge About "Natural" Forest Conditions. Society \& Natural Resources, 14, 325-340.

Hunziker, M. (1995). The spontaneous reafforestation in abandoned agricultural lands: Perception and aesthetic assessment by locals and tourists. Landscape and Urban Planning, 31, 399-410.

Hunziker, M., Buchecker, M., y Hartig, T. (2007). Space and Place - Two aspects of the human-landscape relationship. En F. Kienast, O. Wildi y S. Ghosh (Eds.), A Changing World. Challenges for Landscape Research (pp. 47-62). Dordrecht: Springer.

Ibarra, P. y Escribano, R. (Coord.) (2009). Mapas de Paisaje de las Comarcas de La Jacetania, Alto Gallego, Matarraña /Matarranya, Maestrazgo, Gúdar-Javalambre, La Sierra de Albarracín y Los Monegros. Zaragoza: Departamento de Política Territorial, Justicia e Interior, Gobierno de Aragón.

Instituto Geográfico Nacional (España) (2011). Sistema de Información sobre Ocupación del Suelo de España 1:25.000 [mapa digital]. SIOSE2011. 1:25.000 Madrid: Instituto Geográfico Nacional. Recuperado de http://www.siose.es/. 
Instituto Geográfico Nacional (España) (2015). Mapa Topográfico Nacional de España 1:50.000 [mapa digital]. MTN50. 1:50.000 Madrid: Instituto Geográfico Nacional. Recuperado de http://centrodedescargas.cnig.es/CentroDescargas/index.jsp.

Instituto Geográfico Nacional (España) (2016). Modelo Digital de Elevaciones [formato raster]. MDE IGN. Madrid: Instituto Geográfico Nacional. Recuperado de http://centrodedescargas.cnig.es/CentroDescargas/index.jsp.

Instituto Geográfico Nacional (España) (2016). Plan de Ortofotografía Aérea [formato raster]. PNOA IGN. Madrid: Instituto Geográfico Nacional. Recuperado de http://centrodedescargas.cnig.es/CentroDescargas/index.jsp.

Instituto Geológico y Minero de España (1973-2003). Mapa Geológico de España 1:50.000 [formato shapefile]. MAGNA50. Hojas 556, 557, 579 y 580. 1:50.000 Madrid: Instituto Geográfico Nacional. Recuperado de http://info.igme.es/cartografiadigital.

Instituto Nacional para la Conservación de la Naturaleza, 1977. Inventario Nacional de Paisajes Sobresalientes II. Serie Monografías 6. Madrid: Servicio de Publicaciones Agrarias, Ministerio de Agricultura.

Irastorza, P. (2006). Integración de la ecología del paisaje en la planificación territorial. Aplicación a la Comunidad de Madrid (Tesis doctoral no publicada). E.T.S. Ingenieros de Montes - Universidad Politécnica de Madrid, Madrid.

Junker, B. y Buchecker, M. (2008). Aesthetic preferences versus ecological objectives in river restorations. Landscape and Urban Planning, 85(34), 141-154.

Kant, E. (2003). Crítica del juicio seguida de las observaciones sobre el asentimiento de lo bello y lo sublime. (A. García Moreno y J. Ruvira (Trad.)). Madrid: Nueva Biblioteca Filosófica (Trabajo original publicado en 1790).

Kaplan, S. y Kaplan, R. (1982). Cognition and environment: Functioning in an Uncertain World. Nueva York, NY: Praeger.

Kellert, S. R. (1985). Social and Perceptual Factors in Endangered Species Management. The Journal of Wildlife Management, 49(2), 528. 
Kellert, S. R. (1993). The Biological Basis for Human Values of Nature. En S. R. Kellert y E. D. Wilson (Eds.), The biophilia hypothesis (pp. 42-69). Washington, DC: Island Press.

Kimmins, J. P. (1997). The Peter Pan principle in renewable resource conflicts. En J.P. Kimmins (Ed.), Balancing Act: Environmental Issues in Forestry (2 $\underline{a}$ ed.)(pp. 6-13). Vancouver: UBC Press.

Kimmins, J. P. (2001). Visible and Non-Visible Indicators of Forest Sustainability. En S. R. J. Sheppard y H. W. Harshaw (Eds.), Forests and Landscapes: Linking Ecology, Sustainability and Aesthetics (pp. 43-56). Nueva York, NY: CABI Publishing - IUFRO.

Kovacs, Z. I., Leroy, C. J., Fischer, D. G., y Lubarsky, S. (2006). How do Aesthetics Affect our Ecology? Journal of Ecological Anthropology, 10, 61-65.

Leopold, A. (1949). A Sand County Almanac with Sketches Here and There. Nueva York, NY: Oxford University Press.

Ley de 7 de diciembre de 1916, de Parques Nacionales de España. Gaceta de Madrid, núm. 343 de 8 de diciembre de 1916, p. 575.

Ley 15/1975, de 2 de mayo, de espacios naturales protegidos. Boletín Oficial del Estado núm. 107 de 5 de mayo de 1975, pp. 9419 a 9421.

Ley 4/1989, de 27 de marzo, de Conservación de los Espacios Naturales y de la Flora y Fauna Silvestres. Boletín Oficial del Estado núm. 74, de 28 de marzo de 1989, pp. 8262 a 8269.

Ley $8 / 2005$, de 8 de junio, de Protección, Gestión y Ordenación del Paisaje.de la Comunidad Autónoma de Cataluña. Diari Oficial de la Generalitat de Catalunya, núm. 4407, de 8 de junio de 2005.

Ley 42/2007, de 13 de diciembre, del Patrimonio Natural y de la Biodiversidad. Boletín Oficial del Estado núm. 299, de 14 de diciembre de 2007, pp. 51275 a 51327.

Ley $7 / 2008$, de 7 de julio, de protección del paisaje de Galicia. Diario Oficial de Galicia, núm. 139, de 18 de julio de 2008.

Ley 5/2014, de 25 de julio, de Ordenación del Territorio, Urbanismo y Paisaje, de la Comunitat Valenciana. Diari Oficial de la Generalitat Valenciana núm. 7329, de 31 de julio de 2014. 
Litton, R. B. (1972). Aesthetic Dimensions of the Landscape.En V. Krutilia (Ed.), Natural environments (pp. 262-291). Washington, D.C.: Resources for the Future.

López Lillo, A. y Ramos, A. (2010). Valoración del paisaje natural. Madrid: ABADA.

López Silvestre, F. y Zusman, P. (2008). Las normas sobre el paisaje como mirada de época. Del proteccionismo esteticista al derecho universal en España y Argentina. Quintana, 7, 137-155.

Lothian, A. (1999). Landscape and the philosophy of aesthetics: is landscape quality inherent in the landscape or in the eye of the beholder? Landscape and Urban Planning, 44(4), 177-198.

Lucas, O. W. R. (1991). The design of Forest Landscapes. Oxford, UK: Oxford University Press.

Lucio del Valle, J.V. (2002). Paisaje y ecología del paisaje. En C. Montes, C. Levassor, A. Cuenca y S. Casado, (Eds.), Figura con paisajes. Homenaje a Fernando González Bernáldez. Madrid: Fundación Interuniversitaria Fernando González Bernáldez.

Lumsden, C. J. y Wilson, E. O. (1981). Genes, mind, and culture. Cambridge, MA: Harvard University Press.

Makhzoumi, J. y Pungetti, G. (1999). Ecological Landscape Design and Planning: The Mediterranean Contex. Londres: E\&FN Spon.

Manuel Valdés, C. (1996). Tierras y montes públicos en la Sierra de Madrid (sectores central y meridional). Serie Estudios. Madrid: Ministerio de Agricultura, Pesca y Alimentación, Secretaría General Técnica.

Martínez de Pisón, E. (1998). Imagen del paisaje. La generación del 98 y Ortega y Gasset. Madrid: Caja de Madrid, Obra social.

Mata Olmo, R. (2000). Los orígenes de la conservación de la naturaleza en España. En E. Martínez de Pisón (Ed.), Estudios Sobre el Paisaje (pp. 259-280). Madrid: Fundación Duques de Soria - Ediciones de la UAM.

Mata Olmo, R. y Sanz Herráiz, C. (Dir.) (2004). Atlas del Paisaje de España. Madrid: Ministerio de Medio Ambiente.

McGarigal, K., Cushman, S., y Stafford, S. (2000). Multivariate Statistics for Wildlife and Ecology Research. Nueva York, NY: Springer. 
Meinig, D. W. (1979). The beholding eye: Ten versions of the same scene. En D. W. Meinig y J. B. Jackson (Eds.), The interpretation of ordinary landscapes: Geographical Essays (pp. 1-9). Nueva York, NY: Oxford University Press.

Mill, J. S. (1874). Nature, the utility of religion, and Theism (2 $\mathrm{a}$ ed.). Londres, UK: Longmans, Green, Reader and Dyer.

Ministerio de Agricultura, Pesca y Alimentación y del Medio Ambiente (1997-2007). Mapa Forestal de España a escala 1:50.000. [formato shapefile]. MFE50. Madrid: Ministerio de Agricultura, Pesca y Alimentación y del Medio Ambiente.

Ministerio de Agricultura, Pesca y Alimentación y del Medio Ambiente (2018). Inventario Español de Especies Terrestres (IEET) [formato shapefile]. Madrid: Ministerio de Agricultura, Pesca y Alimentación y del Medio Ambiente. Recuperado de https://www.miteco.gob.es/es/biodiversidad/temas/inventariosnacionales/inventario-especies-terrestres/

Mollá Ruiz-Gómez, M. (2009). "El Grupo de los alemanes" y el paisaje de la Sierra de Guadarrama. Boletín de la Asociación de Geógrafos Españoles, 51, 51-64.

Montes, C., Levassor, C., Cuenca, A., y Casado, S. (Eds.) (2002). Figura con paisajes. Homenaje a Fernando González Bernáldez. Madrid: Fundación Interuniversitaria Fernando González Bernáldez.

Muir, J. (1901). Our National Parks. Boston y Nueva York, NY: Houghton, Mifflin, and Co.

Mulero Mendigorri, A. (2013). Significado y tratamiento del paisaje en las políticas de protección de espacios naturales en España. Boletín de la Asociación de Geógrafos Españoles, 62, 129-14.

Nash, R. (1969). The cultural significance of the American wilderness. En M. E. McCloskey y J. P. Gilligan (Eds.), Wilderness and the quality of life (pp. 66-73). San Francisco, CA: Sierra Club.

Nassauer, J. I. (1988). The aesthetics of horticulture: neatness as a form of care. HortScience, 23(6), 973-977.

Nassauer, J. I. (1992).The appearance of ecological systems as a matter of policy. Landscape Ecology, 6(4), 239-250. 
Nassauer, J. I. (1995a). Culture and changing landscape structure. Landscape Ecology, 10(4), 229-237.

Nassauer, J. I. (1995b). Messy Ecosystems, Orderly Frames. Landscape Journal, 14(2), 161-170.

Nassauer, J. I. (1997). Cultural Sustainability: Aligning aesthetics and Ecology. En J. I. Nassauer (Ed.), Placing nature: culture and landscape ecology (pp. 65-83). Washington, DC: Island Press.

Nassauer, J. I. (2011). Care and stewardship: From home to planet. Landscape and Urban Planning, 100, 321-323.

Nassauer, J. I., Wang, Z., y Dayrell, E. (2009). What will the neighbors think? Cultural norms and ecological design. Landscape and Urban Planning, 92(3-4), 282-292.

National Environmental Policy Act of 1969 (NEPA). Public Law 91-190, 1 de enero de 1970, pp. 852-856.

National Forest Management Act of 1976 (NFMA). Public Law 94-588, 22 de octubre de 1976, pp. 2949-2963.

Natori, Y. y Chenoweth, R. (2008). Differences in rural landscape perceptions and preferences between farmers and naturalists. Journal of Environmental Psychology, 28, 250-267.

Naveh, Z., y Lieberman, A. S. (1994). Landscape Ecology: Theory and Application (2a ed.). Nueva York, NY: Springer-Verlag.

Ndubisi, F., 2002. Ecological planning: a Historical and Comparative Synthesis. Baltimore, MD: John Hopkins University Press.

Nogué, J. (2011). El paisaje en la ordenación del territorio. La experiencia del Observatorio del Paisaje de Cataluña. Estudios Geográficos, 71(269), 415-448.

Nogué, J., Sala, P., y Grau, J. (2016). Els catàlegs de paisatge de Catalunya. metodologia. Olot/Barcelona: Observatorio del Paisatge de Catalunya/ATLL.

Observatorio de la Sostenibilidad en España (2009). Patrimonio Natural, Cultural y Paisajístico. Madrid: Observatorio de la Sostenibilidad en España, Ministerio de Medio Ambiente y Medio Rural y Marino, 
Fundación Biodiversidad, Fundación General de la Universidad de Alcalá.

Oliveira, E. S. De. (2011). Immigrants and Public Open Spaces: attitudes, preferences and uses (Tesis doctoral no publicada). Universidad de Edimburgo, Edimburgo.

Orians, G. H. (1980). Habitat selection: general theory and applications to human behavior. En J. S. Lockard (Ed.), The Evolution of Human Social Behaviour (pp. 44-66). Nueva York, NY: Elsevier.

Orians, G. H. (1986). An Ecological and Evolutionary Approach to Landscape Aesthetics. En E. C. Penning-Rowsell y D. Lowenthal (Eds.), Landscape Meanings and Values (pp. 3-25). Londres, UK: Allen and Unwing.

Ortega Cantero, N. (2003). La imagen literaria del paisaje de España. En R. Mata Olmos y C. Sanz Herráiz (Eds.), Atlas de los Paisajes de España (pp. 29-52). Madrid: Ministerio de Medio Ambiente.

Ortega Cantero, N. (2014). Montañismo y valoración del paisaje: la Real Sociedad Española de Alpinismo Peñalara (1913-1936). Ería, 95, 253279.

Ortega Cantero, N. (2015). Francisco Giner y el descubrimiento moderno del paisaje de España. Anales, 27, 23-44.

Parsons, G. (2008). Aesthetics \& Nature. Londres, UK: Continuum.

Parsons, R. (1995). Conflict between ecological sustainability and environmental aesthetics: Conundrum, canärd or curiosity. Landscape and Urban Planning, 32, 227-244.

Parsons, R. y Daniel, T. C. (2002). Good looking: in defense of scenic landscape aesthetics. Landscape and Urban Planning, 60(1), 43-56.

Patton, M. Q. (2002). Qualitative research and evaluation methods (3a ed.). Thousand Oaks, CA: Sage.

Pedraza, J., Martín Duque, J. F., y Carrasco, R. M. (1998). Mapa fisiográfico de la Comunidad de Madrid. Escala 1:50.000. Madrid: Departamento de Geobotánica de la Facultad de Ciencias Geológicas de la Universidad Complutense de Madrid - Consejería de Medio Ambiente de la Comunidad de Madrid. 
Pereira, E., Queiroz, C., Pereira, H. M., y Vicente, L. (2005). Ecosystem services and human well-being: A participatory study in a mountain community in Portugal. Ecology and Society, 10(2), 14-36.

Pla, L., Casanoves, F., y Di Rienzo, J. (2012). Quantifying Functional Biodiversity. BMC Veterinary Research, 7, 98.

Porteous, J. D. (1996). Environmental Aesthetics: Ideas, Politics and Planning. Londres y Nueva York, NY: Routledge.

Priestley, T. (1983). The Field of Visual Analysis and Resource Management: A Bibliographic Analysis and Perspective. Landscape Journal, 2(1), 52-59.

Puig i Baguer, J. (1995). Planificación del Paisaje (Landscape Planning): una herramienta para armonizar las relaciones del hombre en su entorno territorial (Según Landscape Planning y otras fuentes) (Tesis doctoral no publicada), E.T.S. Ingenieros de Montes - Universidad Politécnica de Madrid, Madrid.

Raftoyannis, Y., Nocentini, S., Marchi, E., Sainz, R. C., Guemes, C. G., Pilas, I., Peric, S., Paulo, J.A., Moreira-Marcelino, A.C., Costa-Ferreira, M., Kakouris, E., y Lindner, M. (2014). Perceptions of forest experts on climate change and fire management in European Mediterranean forests. IForest, 7(1), 33-41.

Ramos, A. y Mantilla, P. (1976). Natural landscapes in Spain. II. Ideas and real concern for landscape planning. Landscape Planning, 3, 25-33.

Ramos, A. y Pinedo, A. (1989). Modelos numéricos en evaluación del paisaje y E.I.A. Arbor, 518-519, 179-189.

Real Orden de 15 de julio de 1927, de Sitios y Monumentos Naturales de Interés Nacional. Gaceta de Madrid, núm. 203 de 22 de julio de 1927, p. 451.

Rees, R. (1975). The Scenery Cult: Changing Landscape Tastes over Three Centuries. Landscape, 19(3), 39-47.

Ribe, R. G. (1989). The aesthetics of forestry: What has empirical preference research taught us? Environmental Management, 13(1), $55-74$. 
Ribe, R. G. (1999). Regeneration harvests versus clearcuts: public views of the acceptability and aesthetics of Northwest Forest Plan harvests (Special Issue). Northwest Science, 73, 102-117.

Ribe, R. G. (2006). Perceptions of forestry alternatives in the US Pacific Northwest: Information effects and acceptability distribution analysis. Journal of Environmental Psychology, 26(2), 100-115.

Ribe, R. G., Armstrong, E. T., y Gobster, P. H. (2002). Scenic Vistas and the Changing Policy Landscape: Visualizing and Testing the Role of Visual Resources in Ecosystem Management. Landscape Journal, 21(1), 4266.

Ribe, R. G. y Matteson, M. (2002). Views of Old Forestry and New Among Reference Groups in the Pacific Northwest. Western Journal of Applied Forestry, 17(4), 173-182.

Rivas-Martínez, S. (Coord.) (2007). Mapa de series, geoseries y geopermaseries de vegetación de España [Memoria del mapa de vegetación potencial de España]. Parte I. Itinera Geobotanica, 17, 5436.

Rogge, E., Nevens, F., y Gulinck, H. (2007). Perception of rural landscapes in Flanders: Looking beyond aesthetics. Landscape and Urban Planning, 82, 159-174.

Root, R. B. (1967). The Niche Exploitation Pattern of the Blue-Gray Gnatcatcher. Ecological Monographs, 37(4),317-350.

Ruiz, J. P. y González-Bernáldez, F. (1983). Landscape perception by its traditional users: the ideal landscape of Madrid livestock raisers. Landscape Planning, 9(3-4), 279-297.

Ruskule, A., Nikodemus, O., Kasparinskis, R., Bell, S., y Urtane, I. (2013). The perception of abandoned farmland by local people and experts: Landscape value and perspectives on future land use. Landscape and Urban Planning, 115, 49-61.

Saito, Y. (1998). The aesthetics of unscenic nature. The Journal of Aesthetics and Art Criticism, 56(2), 101-111.

Sánchez Vigil, L. M., Salvador Benítez, A., y Olivera Zaldua, M. (Eds.) (2017). Portugal Inédito. Fotografías de Eduardo Hernández-Pacheco. Madrid: 
Facultad de Ciencias de la Documentación Universidad Complutense de Madrid.

Sancho García, I., 2003. Estudio del paisaje en la cuenca del río Alberche a su paso por la Comunidad de Madrid (Tesis doctoral no publicada). Fitoclimatología y dinámica vegetal. Universidad Autónoma de Madrid, Madrid.

Sanderson, E. W., Redford, K. H., Vedder, A., Coppolillo, P. B., y Ward, S. E. (2002). A conceptual model for conservation planning based on landscape species requirements. Landscape and Urban Planning, 58(1), 41-56.

Santayana, G. (1961). The Sense of Beauty: Being the Outline of an Aesthetic Theory. Nueva York, NY: Collier (publicado por primera vez en 1896).

Sanz Herráiz, C. (2008). Los científicos de la Tierra y la evolución de los estudios sobre el paisaje en España. En F. Mateu Bellés y M. Nieto Salvatierra (Eds.), Retorno al paisaje. El saber filosófico, cultural y científico del paisaje en España (pp. 389-474). Valencia: EVREN.

Schnitzler, A. (2014). Towards a new European wilderness: Embracing unmanaged forest growth and the decolonisation of nature. Landscape and Urban Planning, 126, 74-80.

Sergio, F., Newton, I., Marchesi, L., y Pedrini, P. (2006). Ecologically justified charisma: preservation of top predators delivers biodiversity conservation. Journal of Applied Ecology, 43(6), 1049-1055.

Sheppard. (2001). Beyond Visual Resource Management: Emerging Theories of an Ecological Aesthetic and Visible Stewardship. En S. R. J. Sheppard y H. W. Harshaw (Eds.), Forests and Landscapes: Linking Ecology, Sustainability and Aesthetics (pp. 149-173). Nueva York, NY: CABI Publishing - IUFRO.

Sheppard, S. R. J., Harshaw, H. W., y Mc Bride, J. R. (2001). Priorities for Reconciling Sustainability and Aesthetics in Forest Landscape Management. En S. R. J. Sheppard y H. W. Harshaw (Eds.), Forests and Landscapes: Linking Ecology, Sustainability and Aesthetics (pp. 263288). Nueva York, NY: CABI Publishing - IUFRO.

Short, H. L. y Burnham, K. P. (1982).Technique for structuring wildlife guilds to evaluate impacts on wildlife communities. Special Scientific Report. 
United States Department of the Interior. Fish and Wildlife Service, Washington, D.C.

Simberloff, D. (1998). Flagships, umbrellas, and keystones: Is single-species management passé in the landscape era? Biological Conservation, 83(3), 247-257.

Smardon, R.C., Palmer, J.E., y Felleman, J.P. (Eds.) (1986). Foundations for Visual Projects Analysis. Nueva York, NY: John Wiley \& Sons.

Snow, D. A. y Benford, R. D. (1988). Ideology, frame resonance, and participant mobilization. En B. Klandermans, H. Kriesi y S. Tarrow (Eds.), From Structure to Action (pp. 197-218). Greenwich: JAI Press.

Snow, D. A., Rochford, E. B., Worden, S. K., y Benford, R. D. (1986). Frame Alignment Processes, Micromobilization, and Movement Participation. American Sociological Review, 51, 464-481.

Soliva, R., Ronningen, K., Bella, I., Bezak, P., Cooper, T., Flo, B. E., Marty, P., y Potter, C. (2008). Envisioning upland futures: Stakeholder responses to scenarios for Europe's mountain landscapes. Journal of Rural Studies, 24(1), 56-71.

Steiner, F. y Brooks, K. (1981). Ecological planning: A review. Environmental Management, 5(6), 495-505.

Steinitz, C. (1990). Toward a sustainable landscape with high visual preference and high ecological integrity: the loop road in Acadia National Park, U.S.A. Landscape and Urban Planning, 19(3), 213-250.

Swanwick, C. (2009). L'avaluació del caràcter del paisatge al RegneUnit. En J. Nogué, L. Puigberty G. Bretcha (Eds.), Ordenació i gestió del paisatge a Europa (pp. 130-151). Olot: ObservatoridelPaisatge.

Swanwick, C. y Land Use Consultants (2002). Landscape Character Assessment: Guidance for England and Scotland (Vol. 1). The Countryside Agency - Scottish Natural Heritage.

Tarroja, À. (2006). Un concepto de paisaje para la gestión sostenible del territorio. En R. Mata Olmo y À. Tarroja (Eds.), El paisaje y la gestión del territorio. Criterios paisajísticos en la ordenación del territorio y el urbanismo (pp.41-50). Barcelona: Diputació de Barcelona / CUIMP.

Taylor, J. G., Zube, E. H., y Sell, J. L. (1987). Landscape assessment and perception research methods. En R. Bechtel, R. Marans, y W. 
Michelson (Eds.), Methods in Environment Behavior Research (pp. 363-393). Nueva York, NY: Van Nostrand Reinhold.

Teddlie, C. y Yu, F. (2007). Mixed Methods Sampling: A Typology With Examples. Journal of Mixed Methods Research, 1, 77-100.

Termorshuizen, J. W., Opdam, P., y van den Brink, A. (2007). Incorporating ecological sustainability into landscape planning. Landscape and Urban Planning, 79(3-4), 374-384.

Thayer, R. L. (1989). The experience of sustainable landscapes. Landscape Journal, 8(2), 101-110.

Thayer, R. L. (1998). Landscape as an Ecologically Revealing Language [Special Issue: Exhibit Catalog. Eco-Revelatory Design: Nature Contructed/Nature Revealed]. Landscape Journal, Special Issue, 118129.

Thorne, J. F. y Huang, C.-S. (1991). Toward a landscape ecological aesthetic: methodologies for designers and planners [Special Issue: Landscape Ecology]. Landscape and Urban Planning, 21(1-2), 61-79.

Tindall, D. B. (2001). Why do you think that hillside is ugly? A sociological perspective on aesthetic values and public attitudes about forest. En S. R. J. Sheppard y H. W. Harshaw (Eds.), Forests and Landscapes: Linking Ecology, Sustainability and Aesthetics (pp. 57-70). Nueva York, NY: CABI Publishing - IUFRO.

Tuan, Y. F. (1989). Surface Phenomena and Aesthetic Experience. Annals of the Association of American Geographers, 79, 233-241.

Tuan, Y. F. (1974). Topophilia: A Study of Environmental Perception, Attitudes and Values. Nueva Jersey, NY: Prentice-Hall.

Turner, M. (1989). Landscape Ecology: The Effect of Pattern on Process. Annual Review of Ecology and Systematics, 2, 171-197.

USDA Forest Service (1995). Landscape aesthetics. A handbook for Scenery Management (Agriculture Handbook No. 701). Washington, D.C.: U.S. Dept. of Agriculture, Forest Service.

van den Berg, A. E., Vlek, C. A. J., y Coeterier, J. F. (1998). Group differences in the aesthetic evaluation of nature development plans: $A$ multilevel approach. Journal of Environmental Psychology, 18, 141157. 
Velarde Catolfi-Salvoni, M. D. (1997). La Consideración del Paisaje en la Gestión Forestal: análisis de tendencias y propuesta de líneas de actuación (Tesis doctoral no publicada). E.T.S. Ingenieros de Montes Universidad Politécnica de Madrid, Madrid.

Vilà, R., Rubio, M. J., Berlanga, V., y Torrado, M. (2014). Cómo aplicar un cluster jerárquico en SPSS. REIRE, 7(1).

Ward Thompson, C., Aspinall, P., Bell, S., y Findlay, C. (2005). "It Gets You Away From Everyday Life": Local Woodlands and Community UseWhat Makes a Difference? Landscape Research, 30(1), 109-146.

Ward Thompson, C., Aspinall, P., Bell, S., Findlay, C., Wherrett, J., y Travlou, P. (2004). Open space and social inclusion: Local woodland use in Central Scotland. Report to the Forestry Commission, Edinburgh. Edinburgh: Forestry Commission.

Wascher, D. M. (Ed.) (2005). European Landscape Character Areas Typologies, Cartography and Indicators for the Assessment of Sustainable Landscapes. Final Project Report as deliverable from the EU's Accompanying Measure project European Landscape Character Assessment Initiative (ELCAI), funded under the 5th Framework Programme on Energy, Environment and Sustainable Development (Alterra Report No. 1254). Wageningen: Landscape Europe, ELCAI.

Wiens, J. A., Hayward, G. D., Holthausen, R. S., y Wisdom, M. J. (2008). Using surrogate species and groups for conservation planning and management. Bioscience, 58(3), 241-252.

Wilde, O. 2008. The Decay of Lying - An Observation. Richmond, UK: Alma Books Ltd. (publicado por primera vez en 1891).

Williams, D. R. (2000). Personal and Social Meanings of Wilderness: Constructing and Contesting Places in a Global Village. En A. E. Watson, G. H. Aplet y J. C. Hendee (Eds.), Personal, societal, and ecological values of wilderness: Sixth World Wilderness Congress proceedings on research, management, and allocation, Volume II (pp. 77-82). Ogden, UT: U.S. Department of Agriculture, Forest Service, Rocky Mountain Research Station.

Williams, D. R. y Kaltellbom, B. P. (1999). Leisure places and modernity: The use and meaning of recreational cottages in Norway and the USA. En D. Crouch (Ed.), Leisure practices and geographic knowledge (pp. 214-230). Londres: Routledge. 
Wilson, E. O. (1984). Biophilia: The human bond with other species. Cambridge, MA: Harvard University Press.

Wilson, E. O. (1993). Biophilia and the Conservation Ethic. En S. Kellerty E. O. Wilson (Eds.), The Biophilia Hypothesis (pp. 31-40). Washington, DC: Shearwater Books.

Wood, D. (1988). Unnatural illusions: some words about visual resource management. Landscape Journal, 192-205.

Zárate Martín, A. (1992). Pintura de paisaje e imagen de España: un instrumento de análisis geográfico. Espacio, Tiempo y Forma, Serie VI, Geografía, 5, 41-66.

Zoido Naranjo, F. (2012). El paisaje: un concepto útil para relacionar estética, ética y política. Scripta Nova. Revista Electrónica de Geografía y Ciencias Sociales [on line], 16 (407). Recuperado de: http://www.ub.edu/geocrit/sn/sn-407.htm

Zonneveld, I. S. (1995). Land ecology: an introduction to landscape ecology as a base for land evaluation, land management and conservation. Amsterdam: SPB Academic Publishing.

Zube, E. H., Sell, J. L., y Taylor, J. G. (1982). Landscape Perception: Research, Application and Theory. Landscape Planning, 9, 1-33. 


\section{Anexo I}

Artículo publicado en la revista Landscape Research

Materiales adicionales: términos y mapas

Materiales empleados en las entrevistas

\section{Anexo II}

Listado de especies de fauna presentes en el área de estudio

Matriz de relaciones entre las variables caracterizadoras del medio y los

requerimientos de las especies de aves y resultados del análisis clúster

Esquema metodológico y resultados de la evaluación de la adecuación o idoneidad de hábitat para los grupos ecológicos

Resultados de asignación de sensibilidad a los grupos ecológicos 
